\title{
Neue Biofilminhibitoren mittels Metagenom-Strategie und \\ marine Streptomyceten, neue Naturstoffe, Synthesen und Biosynthesen
}

\author{
Dissertation \\ zur Erlangung des Doktorgrades \\ der Mathematisch-Naturwissenschaftlichen Fakultäten \\ der Georg-August-Universität zu Göttingen
}

vorgelegt von

Melanie Quitschau

aus Bad Segeberg

Göttingen 2009 
D 7

Referent: Prof. Dr. S. Grond

Korreferent: Jun.-Prof. Dr. C. Ducho

Tag der mündlichen Prüfung: 23. Oktober 2009 
Die vorliegende Arbeit wurde im Institut für Organische und Biomolekulare Chemie der Georg-August-Universität Göttingen in der Zeit von November 2006 bis September 2009 unter Anleitung von Prof. Dr. A. Zeeck und Prof. Dr. S. Grond durchgeführt.

Frau Prof. Dr. Stephanie Grond und Herrn Prof. Dr. Axel Zeeck danke ich für die interessante Themenstellung, das stete Interesse und viele wertvolle Diskussionen, die den Weg zu der vorliegenden Arbeit begleitet haben. 



\section{INHALTSVERZEICHNIS}

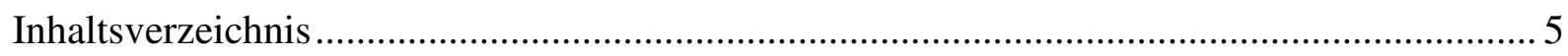

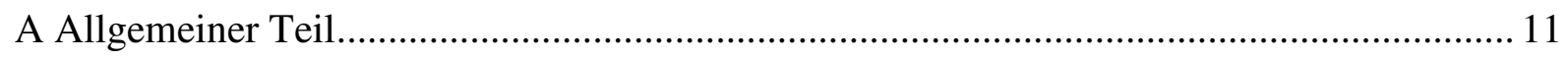

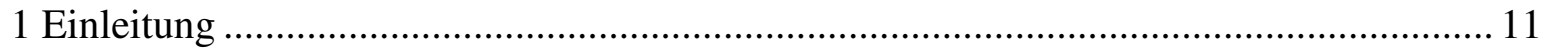

1.1 Die Naturstoff-Forschung im Kampf gegen resistente Bakterien ............................. 11

1.2 Quellen zur Erschließung neuer Naturstoffe .......................................................... 15

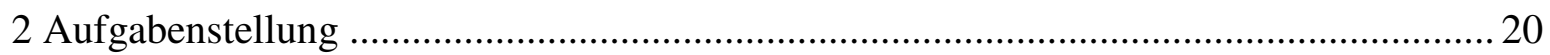

3 BMBF-Verbundprojekt „Neue Anti-Biofilmstrategien aus dem Metagenom“ ................ 22

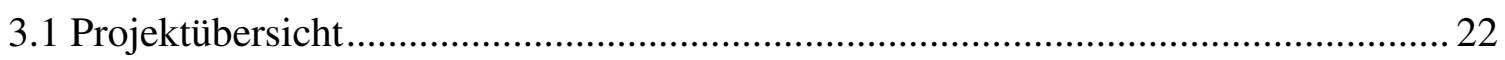

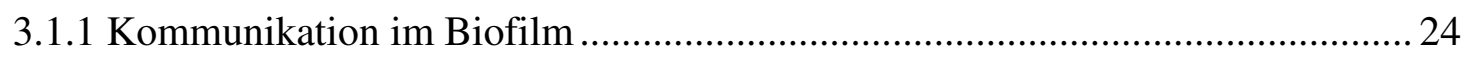

3.2 Screening und Charakterisierung von Anti-Quorum-Sensing ................................ 27

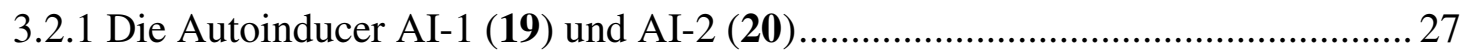

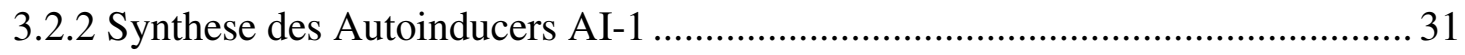

3.2.3 Reinigung des enzymatisch hergestellten Autoinducers AI-2 (20)..................... 35

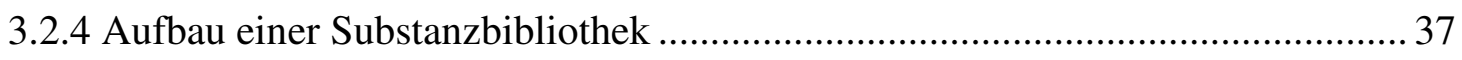

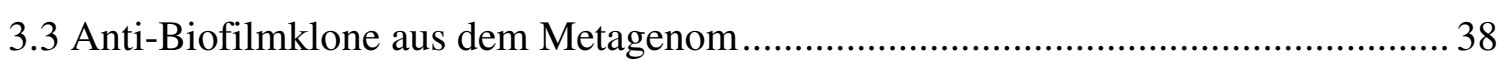

3.3.1 Enzymatischer Abbau von $N$-Acylhomoserinlactonen .................................. 40

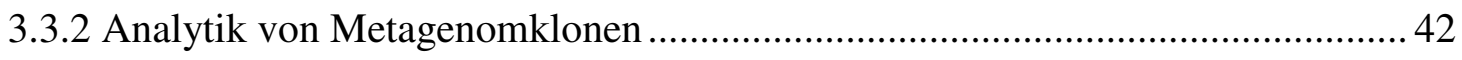

3.4 Screening von Quorum-Sensing-Inhibitoren aus dem Metagenom .......................... 51

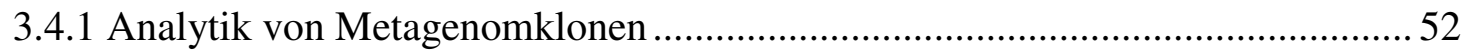

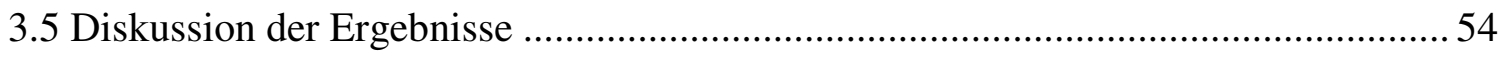

4 Assoziierte Streptomyceten von marinen Invertebraten ............................................. 57

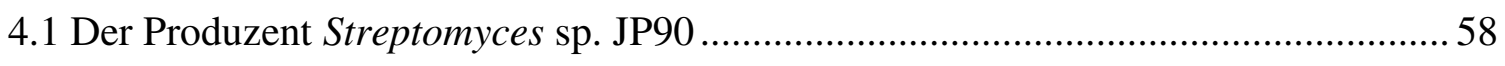

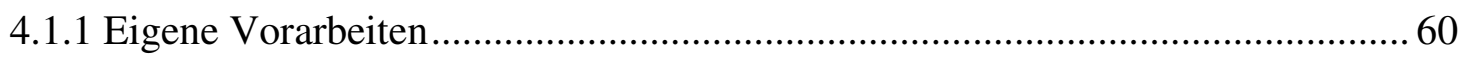

4.1.2 Synthetische Arbeiten zum Cinnamoylphosphoramid (21) und seinem

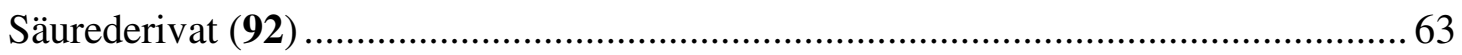

4.1.3 Fermentation und Isolierung der Metaboliten ............................................. 70

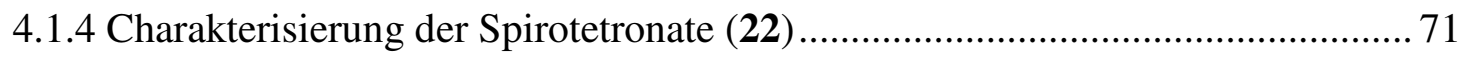

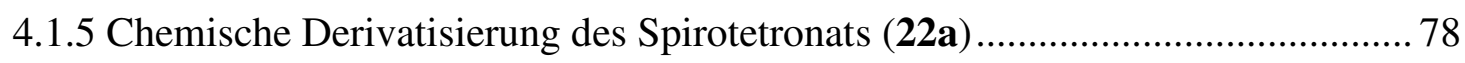

4.1.6 Die absolute Konfiguration des Rosiridols (23)............................................. 81

4.1.7 Studien zur Biosynthese ausgewählter Metaboliten....................................... 83

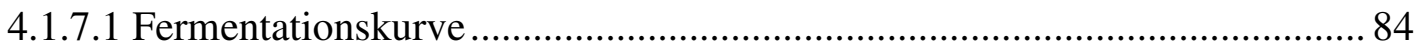

4.1.7.2 Fütterungsexperimente mit ${ }^{13} \mathrm{C}$-markierten Vorläufern .............................. 86 
4.1.7.3 Fütterungsexperimente mit potentiellen Biosynthesevorläufern................ 110

4.1.8 Diskussion und Ergebnisse der Biosynthesestudien ........................................ 113

4.1.9 Zur biologischen Aktivität ausgewählter Metaboliten .................................... 116

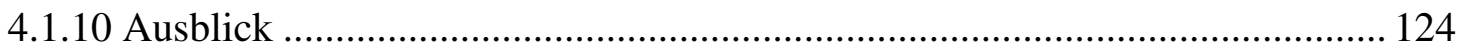

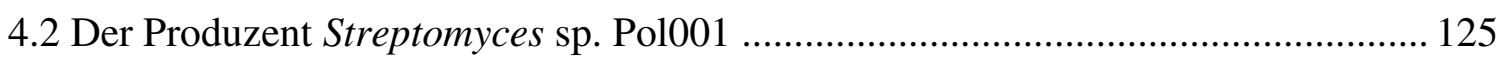

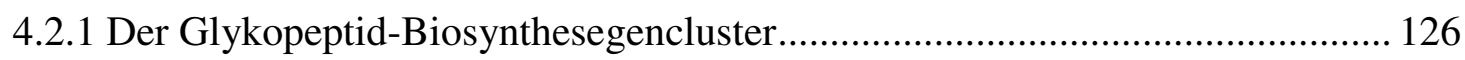

4.2.2 Analyse des Metabolitenspektrums auf Glykopeptide ..................................... 133

4.2.3 Detaillierte Analytik des gesuchten Metaboliten ............................................ 152

4.2.4 Versuche zur enzymatischen und chemischen Derivatisierung ........................ 153

4.2.5 Diskussion der Ergebnisse und Ausblick .......................................................... 155

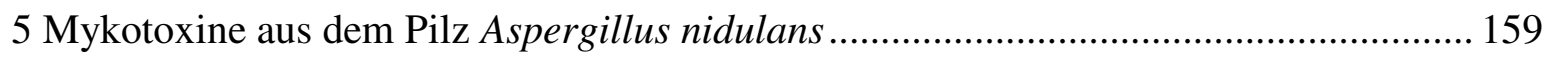

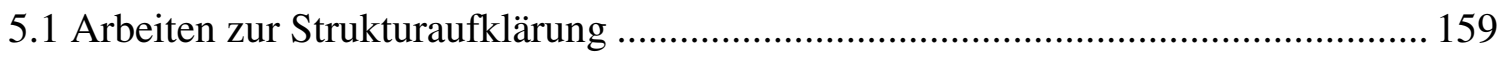

5.1.1 Verifizierung des neuen Derivats Cycloisoemericellinol (156) ........................ 166

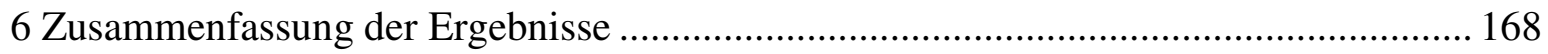

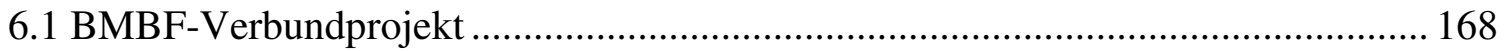

6.2 Assoziierte Streptomyceten aus marinen Invertebraten .......................................... 170

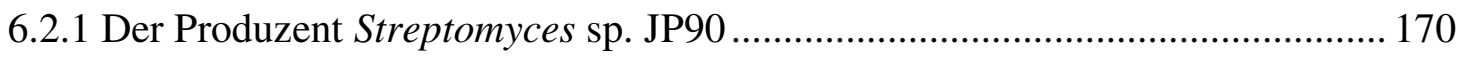

6.2.2 Der Produzent Streptomyces sp. Pol001 …................................................. 172

6.3 Mykotoxine aus Aspergillus nidulans .............................................................. 173

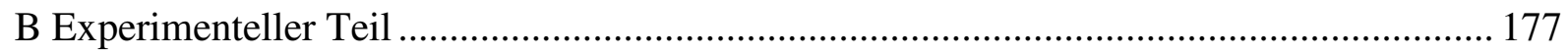

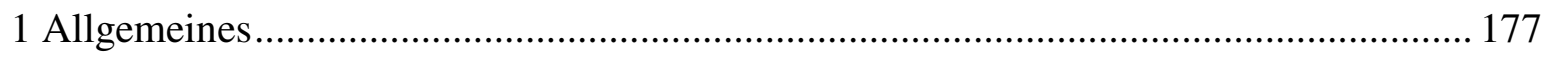

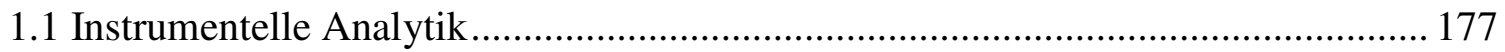

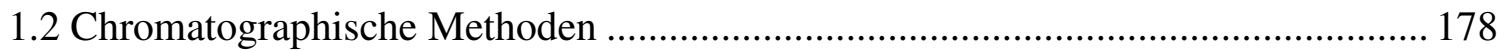

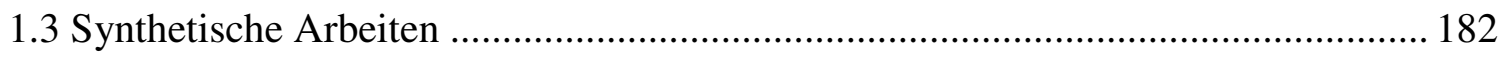

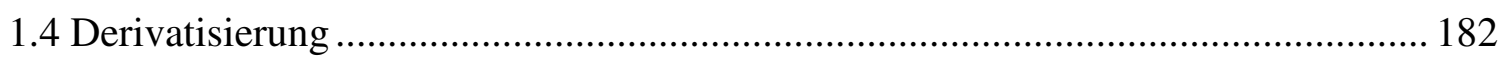

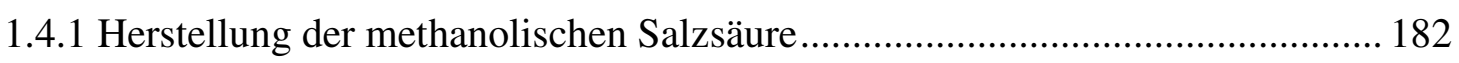

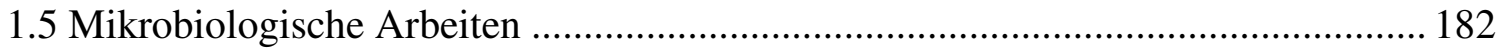

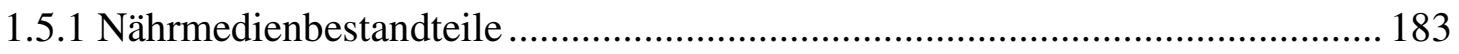

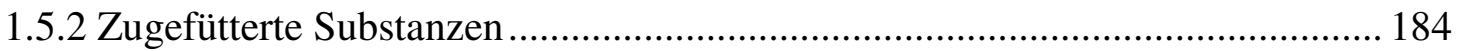

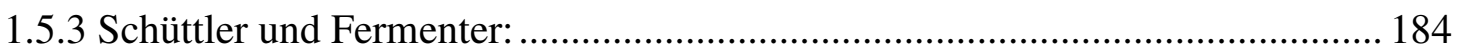

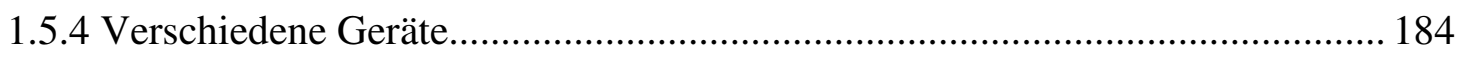

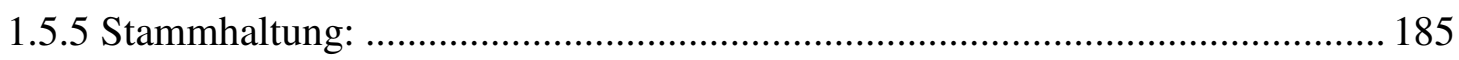

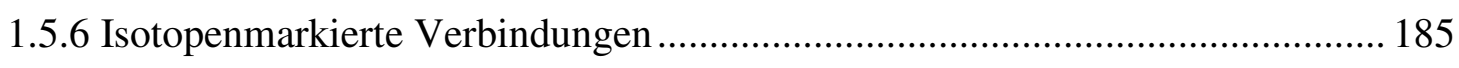

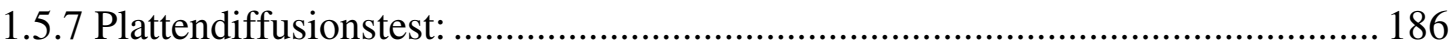


2 Neue Biofilm-Inhibitoren aus dem Metagenom.......................................................... 187

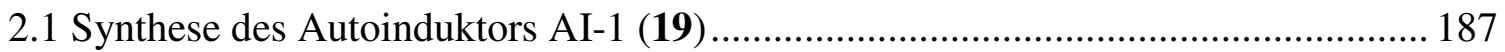

2.1.1 (3R)-3-(tert-Butyldimethylsilyloxy)butansäure (162)................................... 187

2.1.2 N-[(3R)-3-(tert-Butyldimethylsilyloxy)butyryl]-L-homoserinlacton (163) ...... 188

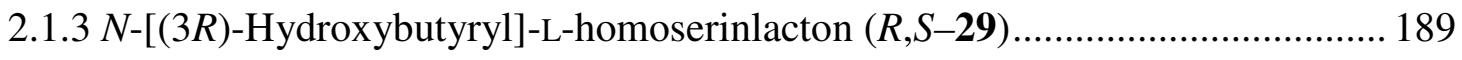

2.1.4 (3S)-3-(tert-Butyldimethylsilyloxy)butansäure (164) ..................................... 190

2.1.5 N-[(3S)-3-(tert-Butyldimethylsilyloxy)butyryl]-L-homoserinlacton (165) ........ 191

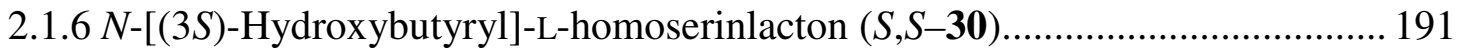

2.1.7 N-(Hydroxybutyryl)-L-homoserinmethylester (54) ........................................ 192

2.1.8 N-(Hydroxybutyryl)-L-homoserinbutylester (53) ........................................... 193

2.2 Reinigung des enzymatisch hergestellten Autoinducers AI-2 (20).......................... 193

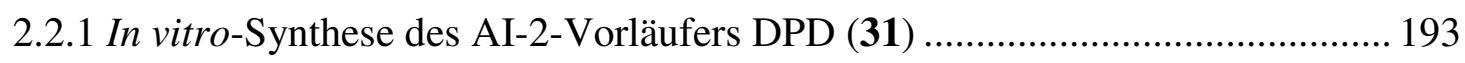

2.2.2 Affinitätschromatographie an Boronsäure-Gel ............................................. 195

2.3 Chemische Hydrolyse von $N$-Acyl-Homoserinlactonen ......................................... 195

2.3.1 Charakterisierung der $N$-Acyl-Homoserinlactone und Hydrolyseprodukte...... 196

2.4 HPLC-ESI-MS-Analytik von Metagenomklonen ................................................... 198

2.5 Vorversuche zur Analytik von Metagenomklonen .............................................. 200

2.5.1 Verifizierung Quorum-Sensing inhibierender Metagenomklone...................... 200

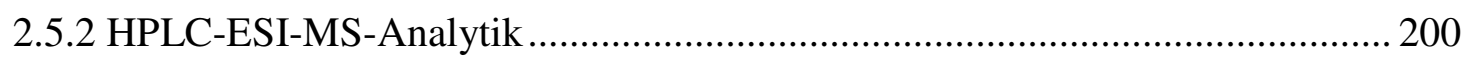

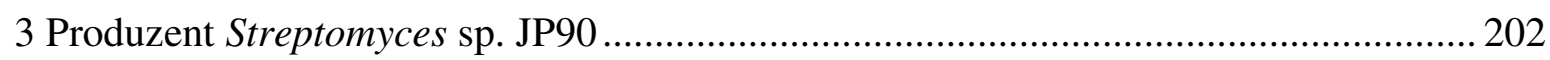

3.1 Optimierung der Synthese des rac-Cinnamoylphosphoramids (21) ........................ 202

3.1.1 3-(p-Hydroxyphenyl)acrylsäuremethylester (82) ............................................ 202

3.1.2 (E)-3-(p-Chlormethoxyphosphoryloxyphenyl)acrylsäuremethylester (86) ...... 203

3.1.3 (E)-3-(p-Aminomethoxyphosphoryloxyphenyl)acrylsäuremethylester (21) .... 203

3.2 Vorversuche zur enzymatischen Hydrolyse des Cinnamoylphosphoramids (21).... 204

3.2.1 Enzymatische Hydrolyse des Zimtsäuremethylesters (93) .............................. 204

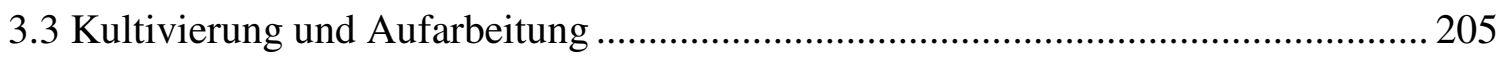

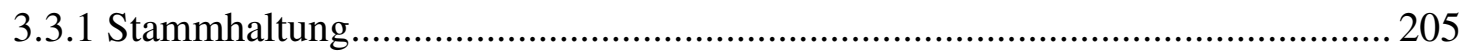

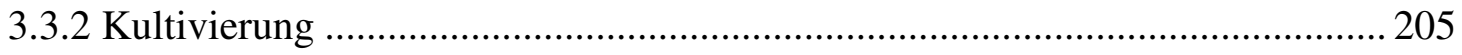

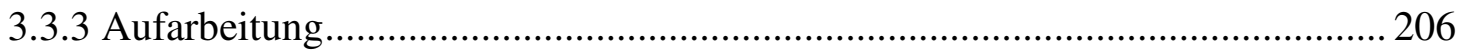

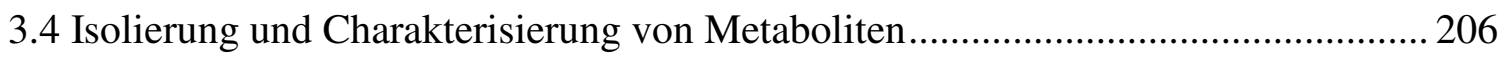

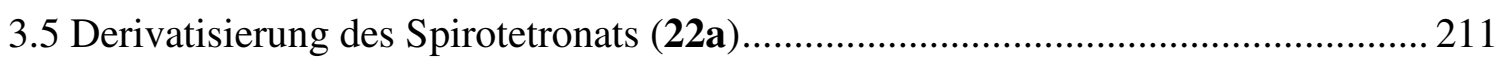

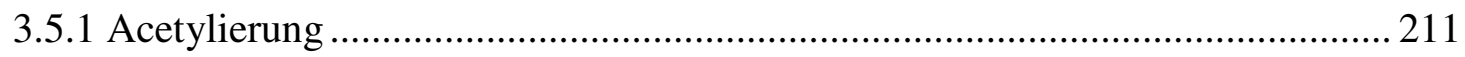

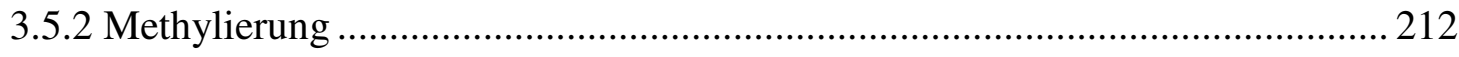




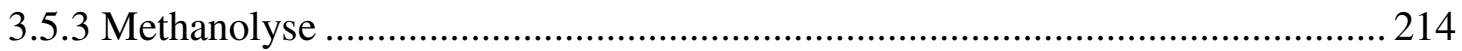

3.6 Studien zur Biosynthese ausgewählter Metaboliten.............................................. 217

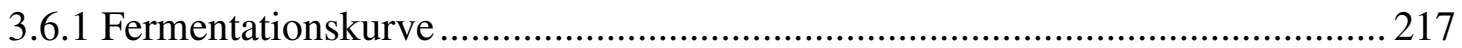

3.6.2 Fütterungsexperimente mit Natrium-[1,2- $\left.{ }^{13} \mathrm{C}_{2}\right]$ acetat und $\left[\mathrm{U}_{-}{ }^{13} \mathrm{C}_{3}\right]$ Glycerin.... 218

3.6.3 Fütterungsexperimente mit potentiellen Biosynthesevorläufern....................... 218

3.6.4 Isolierung und Charakterisierung des Metaboliten (123)................................ 219

3.7 Die absolute Konfiguration des Rosiridols (23)................................................... 220

3.7.1 Vergleichende HPLC-Analyse von nativen und totalsynthetischen Rosiridols an

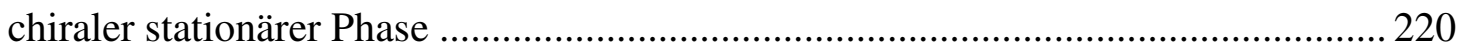

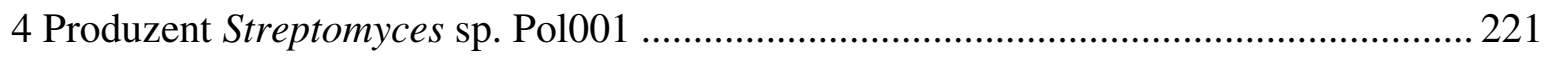

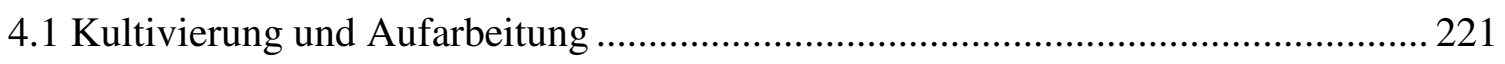

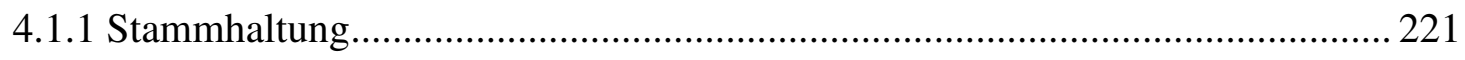

4.1.2 Variationen der Kultivierungsbedingungen ................................................. 221

4.1.3 Fütterung potentieller Vorläufer und anderer Zusätze .................................... 222

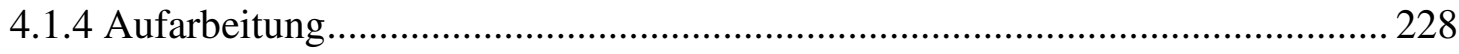

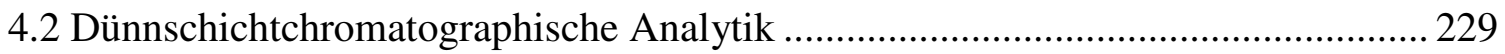

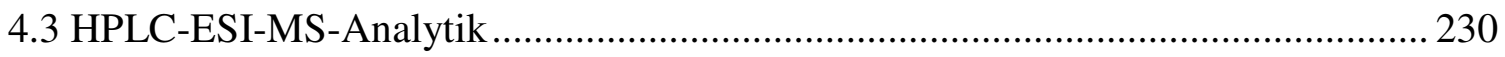

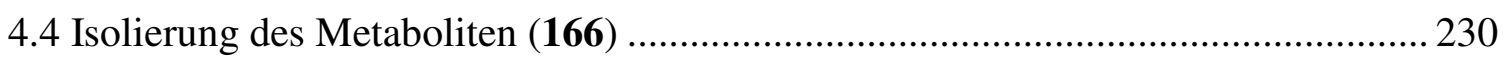

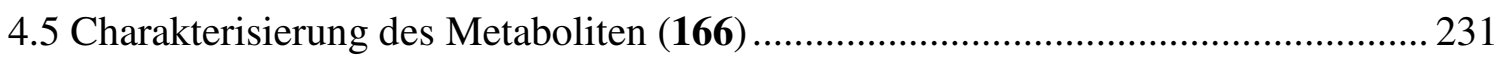

4.6 Versuche zur enzymatischen und chemischen Derivatisierung ............................. 231

4.6.1 Enzymatische Untersuchungen mit einer Sulfatase ....................................... 231

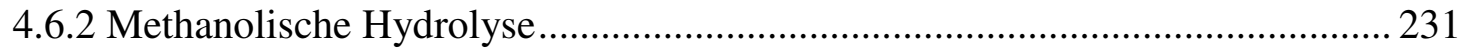

5 Charakterisierung von Metaboliten aus dem Pilz Aspergillus nidulans......................... 233

5.1 Charakterisierung der Metaboliten .................................................................... 233

5.2 Verifizierung des neuen Cycloisoemericellinols (156) ......................................... 236

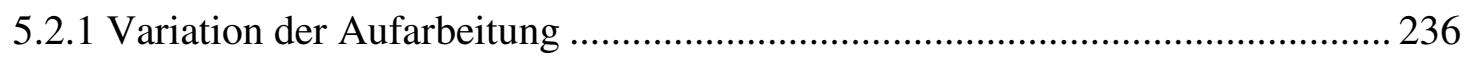

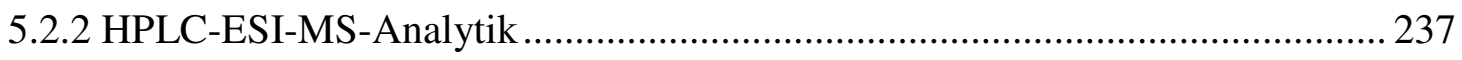

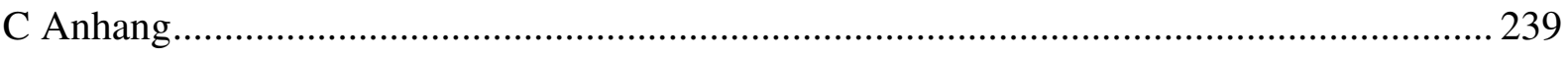

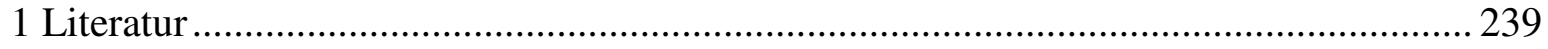

2 Veröffentlichungen und Posterpräsentationen ........................................................ 250

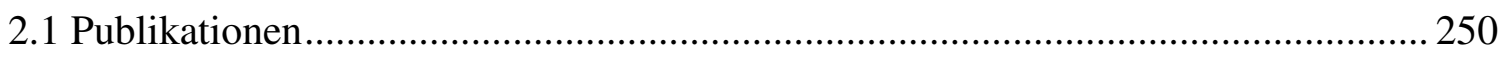

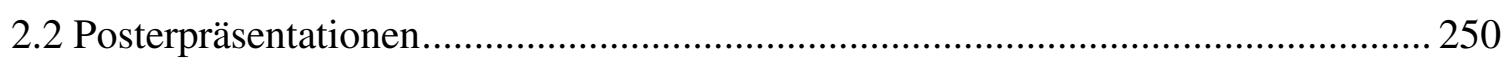

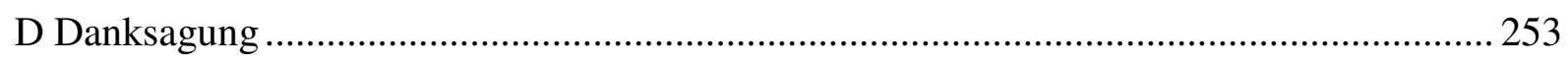

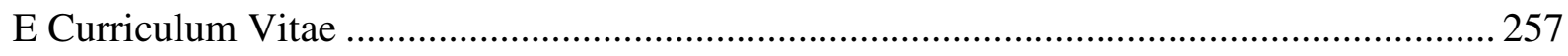





\section{A AllGEMEINER TEIL}

\section{Einleitung}

\subsection{Die Naturstoff-Forschung im Kampf gegen resistente Bakterien}

Immer häufiger können bakterielle Infektionskrankheiten aufgrund der zunehmenden Resistenzentwicklung und der steigenden Anzahl multiresistenter Krankheitserreger mit herkömmlichen Antibiotika nicht mehr behandelt werden. Ehemalige Reserveantibiotika wie z.B. das Glykopeptid Vancomycin (1, s. Abbildung 1) werden zur Ersttherapie multiresistenter Gram-positiver Erreger verwendet, versagen jedoch aufgrund von Resistenzen immer öfter. ${ }^{1}$ Studien zeigen, dass Infektionskrankheiten die zweithäufigste Todesursache weltweit und die dritthäufigste Todesursache in Industrienationen darstellen. ${ }^{2}$ Jährlich sterben allein in Deutschland mindestens 40000 Menschen infolge einer Infektion mit multiresistenten

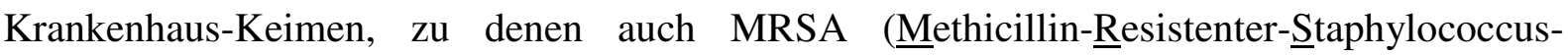
Aureus) gehört. In den USA übersteigen die Sterbezahlen für MRSA-Infektionen bereits deutlich die Zahl der HIV-assoziierten Todesfälle.,

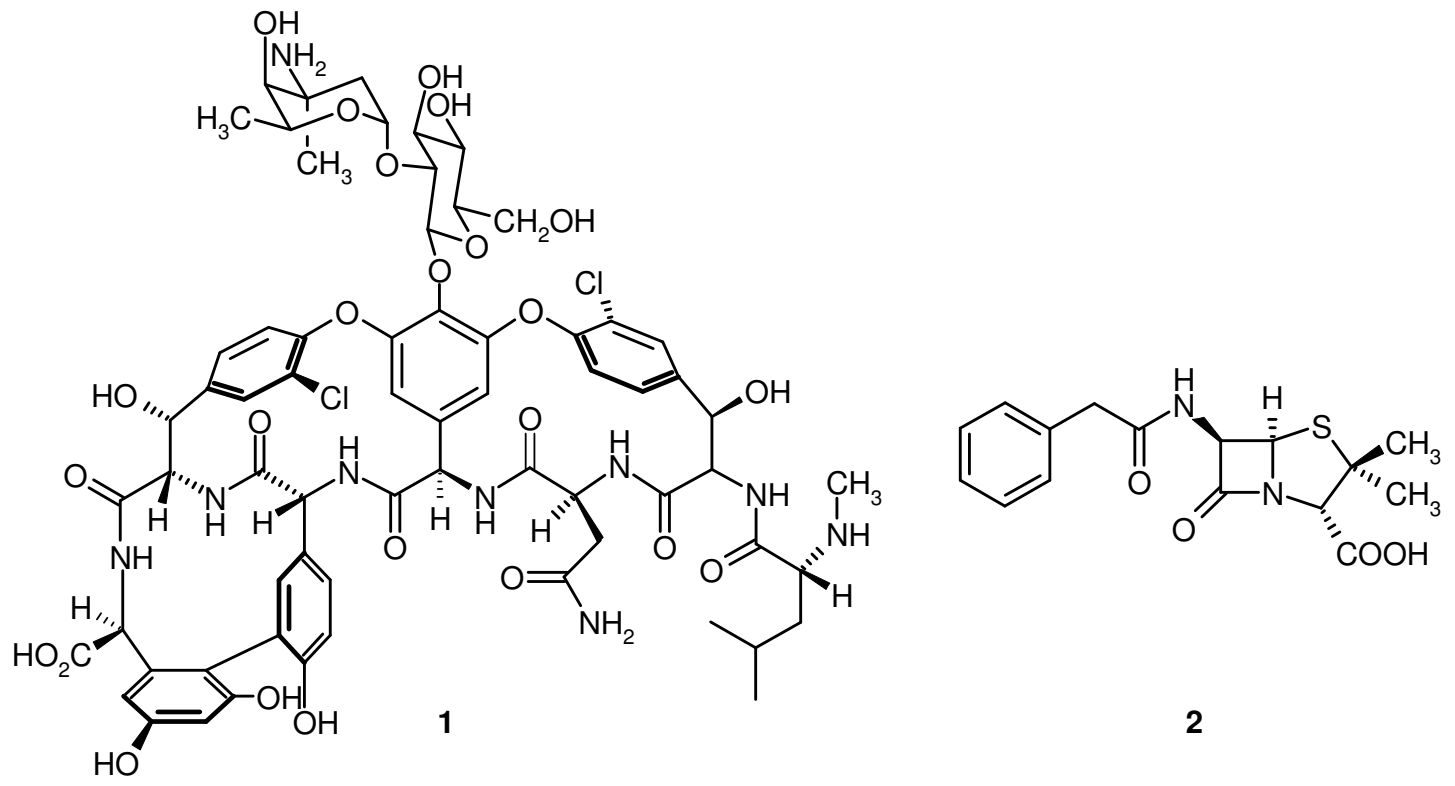

Abbildung 1. Strukturen von Vancomycin (1) und Penicillin G (2).

Tuberkulose, am häufigsten durch den Erreger Mycobacterium tuberculosis verursacht, führt die weltweite Statistik tödlicher Infektionskrankheiten an. 2006 starben nach Schätzung der Weltgesundheitsorganisation (WHO) etwa 1,5 Millionen Menschen, etwa zwei Milliarden Menschen tragen den latenten Erreger in sich. ${ }^{5}$ Nicht nur in den Entwicklungsländern, 
sondern zunehmend auch in den Industrieländern erkranken die Menschen an Tuberkulose, weil ihr Immunsystem durch Immunsupressiva, Drogenkonsum oder HIV geschwächt ist. ${ }^{4}$ Auch hier kann eine bedrohliche Resistenzentwicklung multiresistenter Erreger beobachtet werden, denen dringend neue und effektive Medikamente entgegen zu setzen sind. Allerdings lautet auch beim Einsatz von Antibiotika mit neuen Wirkmechanismen die Frage nicht, ob eine Resistenz entsteht, sondern wann sie zuerst auftritt. Je öfter Antibiotika verwendet werden, desto schneller breitet sich die Resistenz aus. ${ }^{6}$ Selbst die korrekte Anwendung von Antibiotika kann diesen natürlichen Prozess nicht verhindern, sondern nur verlangsamen.

Mit der Entdeckung des Penicillins G (2, s. Abbildung 1) 1928 durch A. Fleming nahm die Antibiotika-Entwicklung ihren Anfang und die 50er und 60er Jahre werden als Sternstunden der Arzneimittelentwicklung bezeichnet. Fast alle gegen Infektionskrankheiten einsetzbaren antibakteriellen Wirkstoffe sind vor 1970 entdeckt worden. Bakterielle Infektionen erschienen damals auf einmal beherrschbar, so dass kaum noch neue Antibiotika aus der Natur gesucht wurden, sondern der Fokus z. B auf Wirkstoffe zur Tumorbehandlung, zur Bekämpfung von Hypercholesterinämie und Bluthochdruck oder zur Anwendung in der Schmerztherapie lagen. ${ }^{1}$ Lediglich bereits vorhandene antibakterielle Substanzen wurden chemisch modifiziert, um neue Derivate herzustellen. Als Beispiel hierfür sind die Gruppe der $\beta$-Lactame zu nennen, deren Weiterentwicklung zu einer Vielzahl an Substanzen geführt hat, die immer wieder neu auftauchende Resistenzen überwinden konnten. ${ }^{7}$ In den letzten Jahrzehnten gab es nur zwei Vertreter neuer Naturstoffklassen, das synthetisch hergestellte Oxazolidinon Linezolid $(\mathbf{3}, 2000)^{8}$ und das aus Streptomyceten isolierte Lipopeptid Daptomycin (4, 2003) die beide für die antibakterielle Therapie bei multiresistenten Gram-positiven Bakterien eingesetzt werden (s. Abbildung 2). Aber auch hier sind schon erste resistente Erreger bekannt. ${ }^{1}$

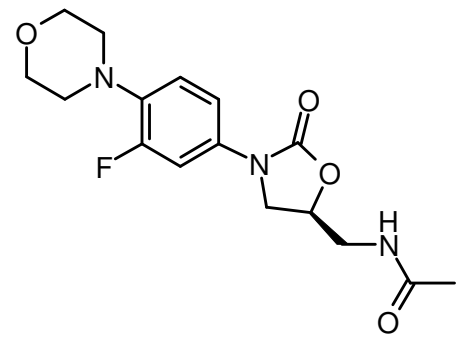

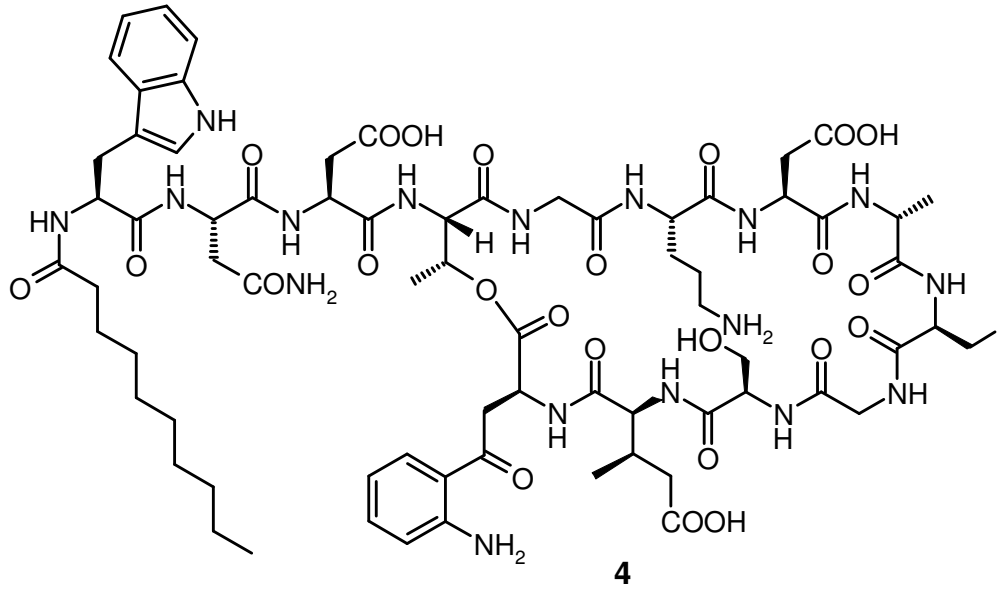

Abbildung 2. Strukturen von Linezolid (3) und Daptomycin (4). 
2006 berichteten Wissenschaftler von Merck-Laboratorien in New Jersey von Platensimycin $(\mathbf{5})^{10}$, einem ersten Vertreter einer neuen Naturstoffklasse, den sie im Rahmen eines Naturstoff-Screenings mittels eines Ganzzelltestsystems mit „Antisense-Silencing“-Technologie aus Streptomyces platensis isolierten. Bei dieser molekular-biologischen Technologie wird antisense-RNA (einzelsträngige komplementäre RNA) eingesetzt, die durch Basenpaarung an die mRNA (messenger-RNA) bindet, worüber die jeweilige Genexpression reduziert oder völlig unterbunden wird. Über die resultierende Veränderung des Phänotyps kann auf die Funktion des Gens geschlossen werden. ${ }^{11} 5$ gehört zu den wenigen Wirkstoffen, die die bakterielle Fettsäure-Synthese hemmen. ${ }^{12}$ Aus dem Stamm Streptomyces platensis konnte ein weiterer Vertreter dieser neuen Naturstoffklasse isoliert werden, das Platencin (6). ${ }^{13} \mathrm{Im}$ Gegensatz zum Platensimycin (5), welches einen selektiven Enzyminhibitor darstellt, hemmt Platencin (6) gleich zwei Enzyme in der Fettsäurebiosynthese, so dass die synergistische Wirkung zu einer starken antibiotischen Wirkung führt. ${ }^{14}$ Beide Substanzen zeigen eine breite antibakterielle Wirkung gegenüber Gram-positiven Bakterien, darunter auch multiresistente Erreger (s. Abbildung 3). Die Entdeckung dieser neuartigen potentiellen Wirkstoffe ist ein Beispiel dafür, dass auch heute noch mit Hilfe neuer Screeningsysteme neue AntibiotikaKlassen gefunden werden können. ${ }^{12}$

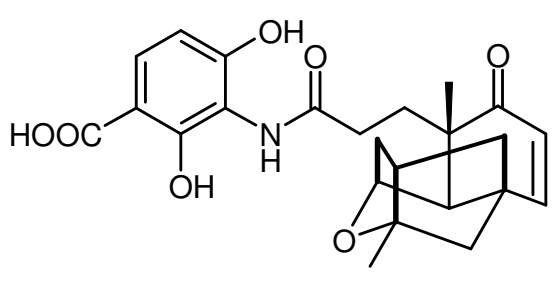

5

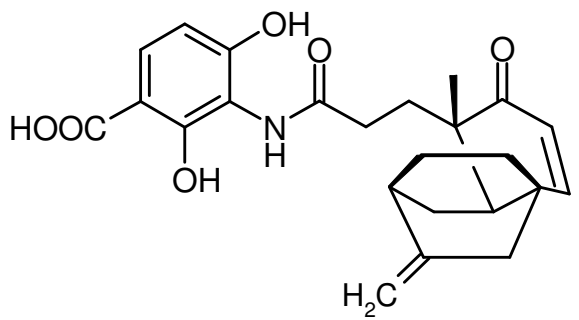

6

Abbildung 3. Strukturen einer neuen antibakteriellen Wirkstoffklasse aus Streptomyces platensis.

Neueste Erkenntnisse über den genauen Mechanismus der Inhibition bakterieller RNAPolymerasen (RNAP) durch das natürliche $\alpha$-Pyron-Antibiotikum Myxopyronin A (7) aus dem Myxobakterium Myxococcus fulvus zeigen, dass ein grundlegendes Verständnis der Wirkungsweise von Antibiotika auf molekularer Ebene die Möglichkeit bietet, neue Therapien im Kampf gegen Resistenzen aufzubauen (s. Abbildung 4). 


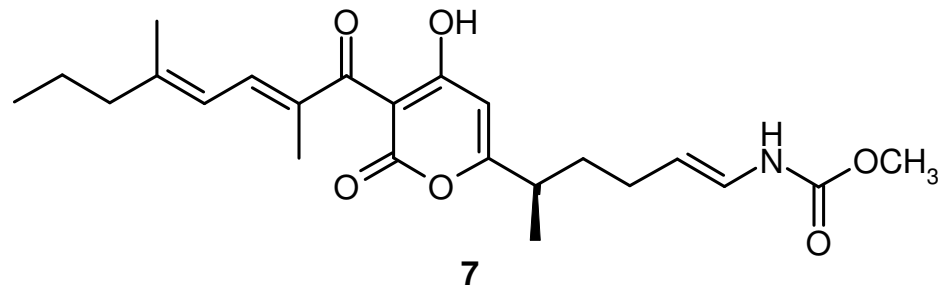

Abbildung 4. Struktur des $\alpha$-Pyron-Antibiotikum Myxopyronin A (7).

RNA-Polymerasen sind in der Behandlung von Tuberkulose ein wichtiges Target. RifamycinAntibiotika (8) stellen eine Hauptkomponente der empfohlenen Therapie dar (s. Abbildung 5). Hierbei findet das semisynthetische Rifampicin (9) Verwendung in einer festgelegten Wirkstoffkombination. ${ }^{4}$

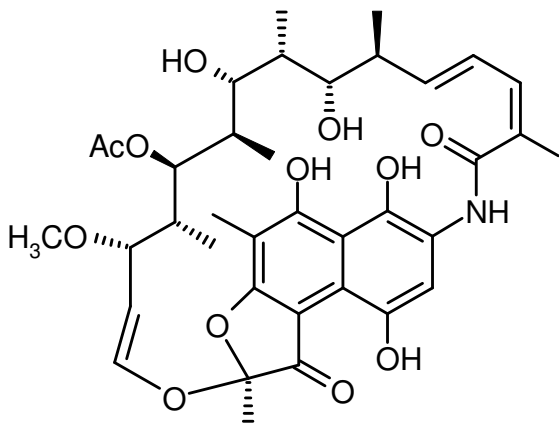

8

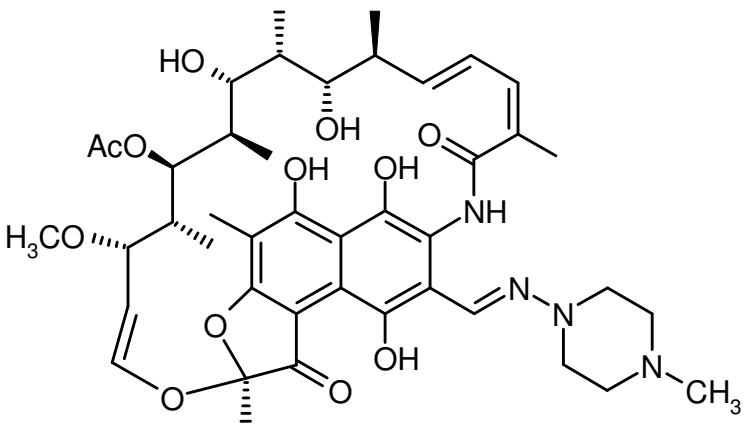

9

Abbildung 5. Strukturen des natürlichen Rifamycin (8) und des semisynthetischen Derivats Rifampicin (9).

Rifamycine binden selektiv an RNAP von Bakterien und blockieren so deren Transkription. ${ }^{4}$ Neben den Rifamycinen gibt es bisher als zugelassenes Antituberkulotikum keine weiteren Inhibitoren der bakteriellen RNAP. Aufgrund der zunehmenden Zahl Rifamycin-resistenter Mycobakterienstämme und mittlerweile auch multiresistenter Mycobakterien gegen Reserveantibiotika sind neue und effektive Therapeutika erforderlich.

Zwei weitere myxobakterielle Sekundärmetaboliten hemmen die RNAP nach demselben Prinzip: das $\alpha$-Pyron-Antibiotikum Corallopyronin A (10) ${ }^{15}$ aus Corallococcus coralloides und das 14-gliedrige Makrolacton Ripostatin A (11) ${ }^{16}$ aus Sorangium cellulosum. Die Struktur der RNAP weist eine „Krabbenscheren“-ähnliche Form auf. Die offene Form kann DNA im aktiven Zentrum binden, nach Schließen der „Zange“ beginnt die Transkription der DNA. Die $\alpha$-Pyron-Antibiotika und das Makrolacton besetzen eine hydrophobe Tasche außerhalb des aktiven Zentrums der RNAP und arretieren so eine „Zange“, wodurch die Transkription der DNA verhindert wird. Die Strukturen dieser drei Antibiotika sind viel versprechende Ausgangspunkte für die Entwicklung geeigneter Wirkstoffe, welche zur Behandlung multiresistenter Tuberkulose-Stämme in Zukunft eingesetzt werden könnten (s. Abbildung 6). ${ }^{4}$ 
<smiles>C/C=C/C/C=C(/C)C(O)CC/C(C)=C/C=C(\C)C(=O)c1c(O)cc([C@@H](C)CC/C=C/NC(=O)OC)oc1=O</smiles><smiles>C/C(=C\C(=O)OC(CC(=O)CC/C(C)=C/Cc1ccccc1)C[C@H](O)CC(=O)O)C/C=C/C/C=C(\C)CC(=O)O</smiles>

11

Abbildung 6. Myxobakterielle Sekundärstoffe als Leitstrukturen für neue RNAP-Inhibitoren.

\subsection{Quellen zur Erschließung neuer Naturstoffe}

Die rasche Ausbildung von Resistenzen beschränkt sich nicht nur auf Krankheitserreger, sondern tritt auch bei Krebszellen auf und erfordert einen kontinuierlichen Nachschub an neuen Wirkstoffen. ${ }^{7}$ Mehr als $50 \%$ aller neu zugelassenen Medikamente sind niedermolekulare Naturstoffe oder von Naturstoffen abgeleitete Wirkstoffe. ${ }^{17}$ Niedermolekulare Naturstoffe besitzen im Allgemeinen eine größere strukturelle Vielfalt und Komplexität als durch klassische oder kombinatorische Synthese erreicht werden kann. Jedoch ist die Suche nach einem viel versprechendem Naturstoff für die Behandlung kostenaufwendig und schwierig, so dass viele pharmazeutische Unternehmen in der Wirkstoffentwicklung ausschließlich auf synthetische Substanzen setzen. ${ }^{18}$ Zudem stehen dem dringenden Bedarf an neuen Wirkstoffen derzeit hohe Wiederfindungsraten beim Naturstoff-Screening gegenüber. Dies hat mehrere Gründe: Es wird vermutet, dass das immense Potential neuer Quellen heute noch längst nicht erschlossen ist, sondern weniger als $1 \%$ aller Mikroorganismen überhaupt unter heute routinemäßig verwendeten, normalen Laborbedingungen kultivierbar sind. Die Erschließung dieses gewaltigen Potentials neuer Gattungen und Arten erfordert neuartige kultivierungsunabhängige Techniken, verbesserte Methoden zur schnellen Wiedererkennung bekannter Substanzen, die Weiterentwicklung von Substanz-Datenbanken und automatisierter Verfahren zur Strukturaufklärung. ${ }^{7}$ 


\section{Totalsynthese und Semisynthese}

Die Bereitstellung von ausreichenden Substanzmengen für die Entwicklung neuer Wirkstoffe ist ein großes Problem, da auch schon im Bereich der medizinischen Forschung Substanzmengen im Gramm-Maßstab benötigt werden, um die isolierten Wirkstoffe bis zu ihrem Einsatz als Arzneimittel ausgiebig zu untersuchen. Viele Naturstoffe, die für die medizinische Entwicklung Erfolg versprechend sind, weisen sehr komplexe Strukturen auf, deren vielstufige Synthesen sehr teuer und zeitaufwendig sind. Nur in einigen Fällen bietet die Totalsynthese bzw. Partialsynthese eine Möglichkeit, ausreichende Mengen für biologische Testreihen bereitzustellen und Voraussetzungen für großtechnische Produktionen $\mathrm{zu}$ schaffen. Besonders auf dem Gebiet der marinen Naturstoffe spielt die Substanzbeschaffung eine wichtige Rolle, da die entsprechenden Wirkstoffe aus marinen Invertebraten oft nur in sehr geringem Ausmaß, manchmal sogar nur in Mengen von weniger als $10^{-6} \%$ des Feuchtgewichts, gewonnen werden können. ${ }^{19}$ Es ist klar, dass der marine Wirkstoff unter diesen Umständen niemals das spätere Arzneimittel werden kann, solange das Problem der Gewinnung nicht gelöst wird. Aber auch bei Wirkstoffen aus Pflanzen kann eine nachhaltige Substanzbeschaffung problematisch sein. Ein Beispiel hierfür ist das Antitumormittel Paclitaxel (12, Taxol $\left.{ }^{\circledR}\right)$, das aus der Rinde einer speziellen Eiben-Art isoliert wurde. Erst ein semisynthetischer Zugang ausgehend vom Vorläufer 10-Deacetylbaccatin III (13) oder Baccatin III selbst, welche aus rasch nachwachsenden Nadeln einer gut kultivierbaren EibenArt gewonnen werden können, ermöglichten die Entwicklung und Markteinführung des Krebstherapeutikums 12 (s. Abbildung 7). ${ }^{20}$

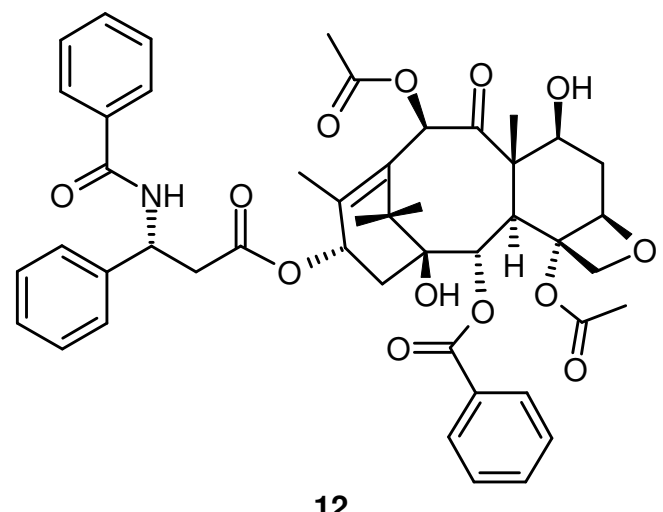

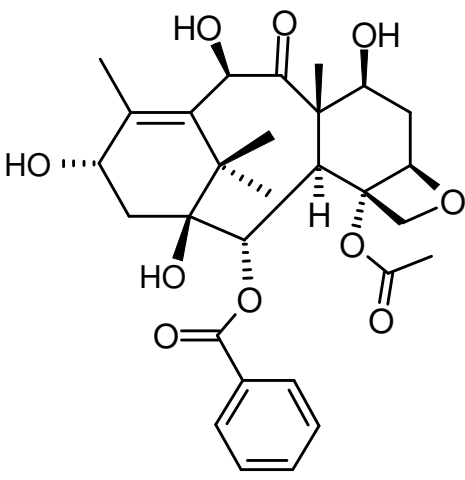

13

Abbildung 7. Strukturen von Paclitaxel (12) und dem Vorläufer 10-Desacetylbaccatin III (13).

Oftmals ist die Fermentation mit nachfolgender semisynthetischer Derivatisierung der einzig praktikable Weg zur Herstellung ausreichender Mengen neuer Naturstoffderivate für klinische Studien. ${ }^{1}$ Ein Beispiel sind hierfür die Glykopeptid-Antibiotika, zu denen das Vancomycin (1, s. Abbildung 1) gehört. Die sich derzeit in der klinischen Entwicklung befindlichen Glyko- 
peptide der zweiten Generation sind semisynthetische Derivate wie Oritavancin (LY-333328, 14) und Telavancin (TD-6424, 15), die verbesserte pharmakologische Eigenschaften und vor allem eine Wirksamkeit gegen resistente Bakterien aufweisen. ${ }^{1}$

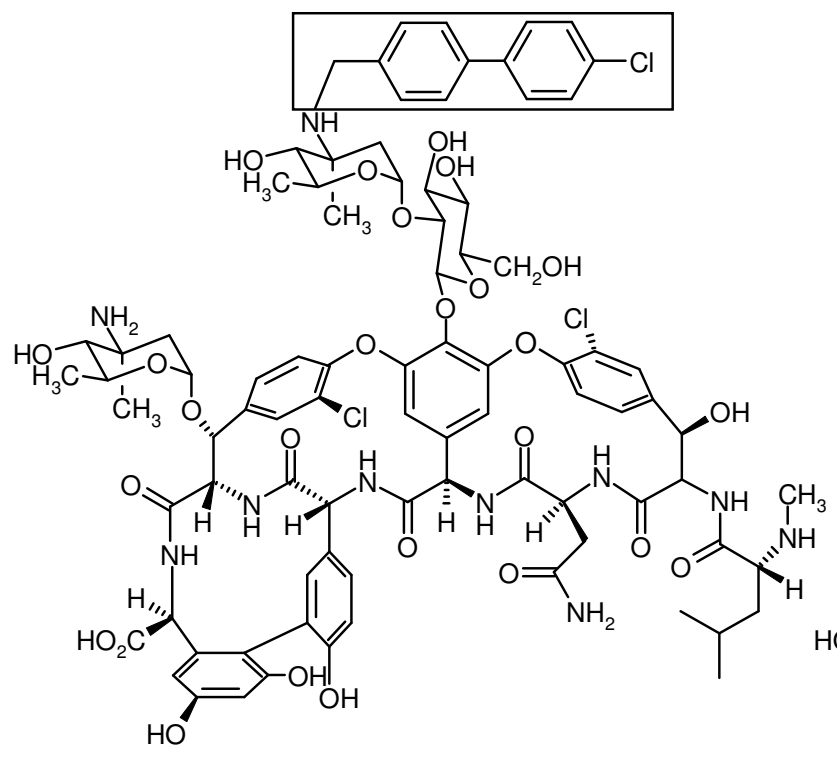

14
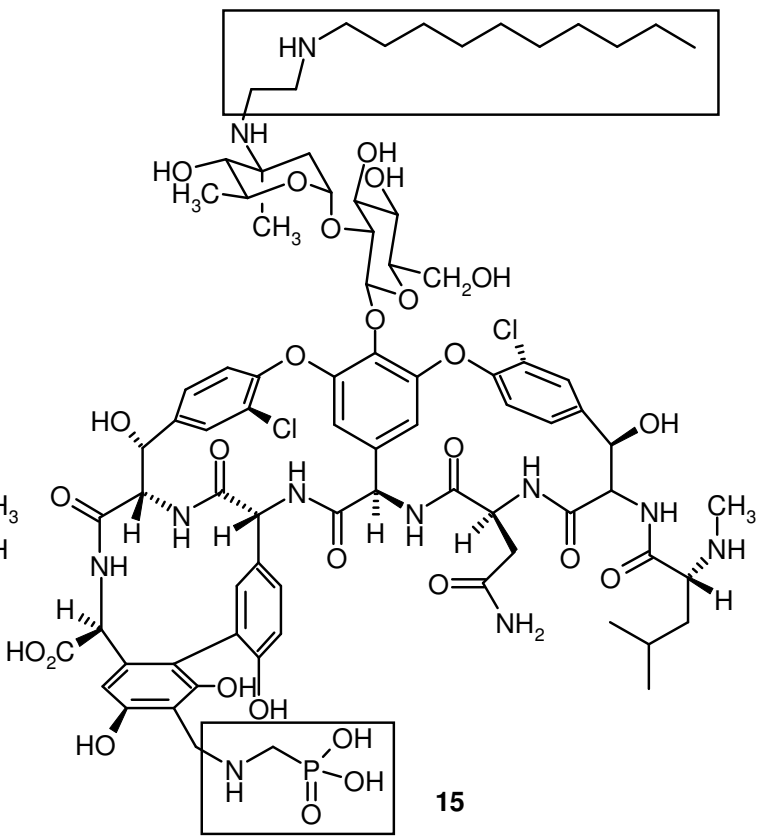

Abbildung 8. Semisynthetische Glykopeptide der 2. Generation.

\section{Kombinatorische Biosynthese}

Ein anderer Zugang neuartige, unnatürliche Naturstoffe zu gewinnen, stellt die so genannte Kombinatorische Biosynthese dar. Die strukturelle Vielfalt der Sekundärstoffe wird nicht nur durch die Variation der Grundstrukturen, sondern vielmehr durch unterschiedliche Kombinationen dieser Elemente miteinander und durch Modifikationen der Grundstrukturen mit Hilfe von Methylasen, Oxygenasen, Halogenasen, Glykosyltransferasen und anderen Enzymen erzeugt. ${ }^{21}$ Mit molekularbiologischen Techniken wird versucht, Biosynthesegene miteinander zu kombinieren oder zu verändern, um so zu neu kombinierten Naturstoffen mit verbesserten pharmakologischen Eigenschaften zu gelangen. Die unnatürlichen Erythromycinderivate $^{22} 16$ und 17 und das unnatürliche Epothilonderivat ${ }^{23} 18$ sind Beispiele für einen solchen erfolgreichen Ansatz (s. Abbildung 9). Allerdings stehen diesen erfolgreichen Ansätzen weit mehr unveröffentlichte Ansätze gegenüber, bei denen die gewünschten Ergebnisse ausblieben. ${ }^{18}$ Dennoch ist diese Technologie zum Aufbau von wertvollen Substanz-Bibliotheken mit Naturstoffanaloga für die industrielle Wirkstoffsuche ein lohnendes Ziel in der Zukunft. 


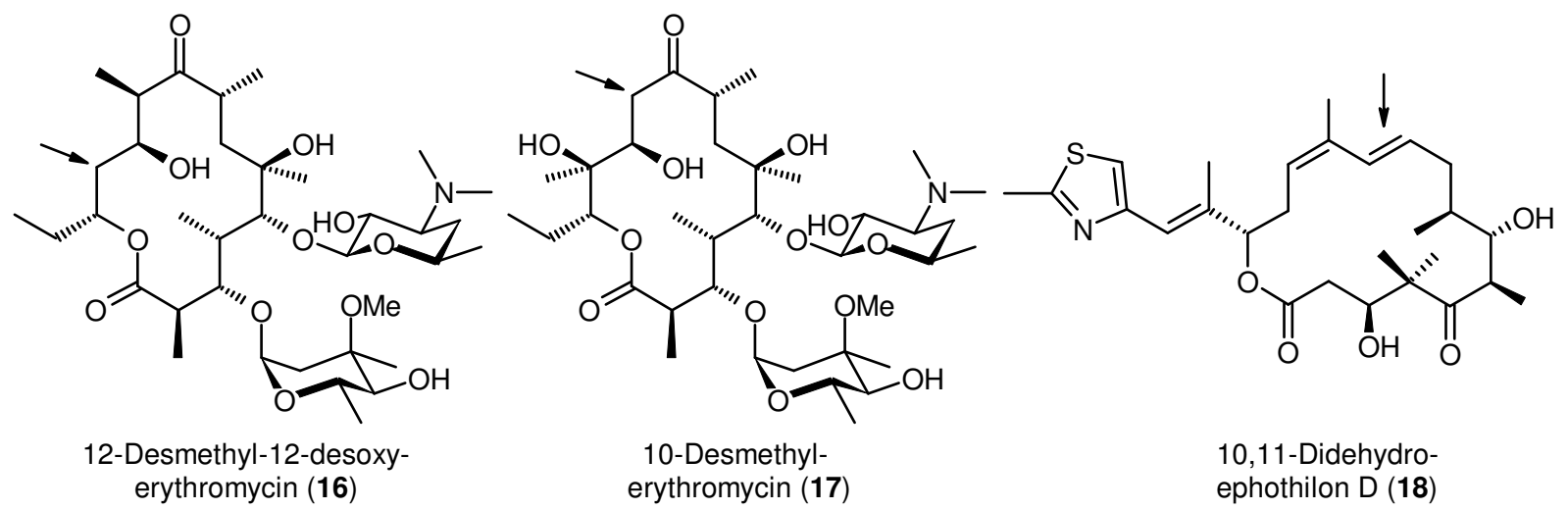

Abbildung 9. Neue Derivate aus der kombinatorischen Biosynthese.

\section{Das Metagenom}

Als Metagenom wird die Gesamtheit des genetischen Materials von Organismen aus terrestrischen oder marinen Habitaten bezeichnet, die oft nicht in Kultur gebracht werden können. Marine Organismen wie Schwämme, Manteltiere, Moos- oder andere Weichtiere produzieren eine faszinierende Vielfalt an strukturell einzigartigen Sekundärmetaboliten, deren biologische Aktivitäten sich über eine Bandbreite von antibakteriellen, antifungalen, antitumoralen, insektiziden und besonderen Enzym-inhibierenden Wirkungen erstrecken und ein großes Potential für neue Wirkstoffe zu bieten scheinen. ${ }^{24}$ Allerdings können die für eine Medikamenten-Entwicklung notwendigen Substanzmengen nur durch ein zerstörerisches Abernten der natürlichen Standorte erreicht werden, was ökologisch nicht vertretbar ist. In vielen Fällen wird vermutet, dass die tatsächlichen Produzenten dieser Substanzen bislang nicht kultivierbare Bakterien sind. Ein Beispiel für eine Beteiligung bakterieller Symbionten an der Naturstoff-Produktion ist der Schwamm Theonella swinhoei (s. Abschnitt 4 ). ${ }^{25}$ Eine gezielte Klonierung dieser Biosynthesegene und ihre Expression in einem kultivierbaren Bakterium als regenerative Quelle sollte eine Produktion der Wirkstoffe in ausreichenden Mengen ermöglichen. Doch nicht nur marine Habitate sondern auch terrestrische Habitate bergen möglicherweise ungeahnte Potentiale, die es zu erschließen gilt. Mit Hilfe von Metagenom-Strategien können Mikroorganismen unabhängig von ihrer Kultivierbarkeit identifiziert werden. ${ }^{26,27}$ Hierzu werden zunächst Metagenom-Bibliotheken (Sammlung von Klonen) angelegt, die jeweils unterschiedliche Abschnitte des Metagenoms (Gesamt-DNA) aus einer Umweltprobe enthalten. Leistungsstarke Vektorsysteme können bis zu $100 \mathrm{~kb}$ und mehr Basen stabil aufnehmen (Fosmide). Zur Identifizierung der Klone können unterschiedliche Auswahlverfahren oder Screenings herangezogen werden. Beim Screening wird zwischen einem funktionsbasiertem und sequenzbasiertem Screening unterschieden. Über 
funktionsbasierte Screenings können z. B. Antibiotika gefunden werden, wobei die bisher isolierten Substanzen strukturell einfach aufgebaut sind, da sie nur in sehr kurzen Biosynthese-Sequenzen gebildet werden. Dies ist u. a. darauf zurückzuführen, dass meistens als Expressionswirt E. coli verwendet wird. E. coli ist gentechnisch am leichtesten zu handhaben und am besten charakterisiert, ist aber für die Biosynthese von pharmakologisch interessanten Naturstoffen wie Polyketide und nichtribosomale Peptide weniger „begabt“. Zudem ist bisher die maximale Größe der Umwelt-DNA-Fragmente bisher auf ca. $80 \mathrm{~kb}$ beschränkt. Biosynthesegencluster strukturell hochkomplexer Wirkstoffe sind aber größer. Damit bedarf es in Zukunft neuartiger Verfahren zur Isolierung, Klonierung und stabiler Expression hochmolekularer Umwelt-DNA, um neue Wirkstoffe in ausreichenden Mengen produzieren zu können. ${ }^{27}$

Beim sequenzbasiertem Screening werden Metagenom-Bibliotheken auf Sequenzhomologien zu Enzymen durchmustert. Bei der Biosynthese des Großteils der bakteriellen Naturstoffe sind nur wenige unterschiedliche Enzymfamilien beteiligt. Damit können Enzyme wie z. B. spezifische Halogenasen oder Polyketidsynthasen genutzt werden, um gezielt potentielle Wirkstoffgene zu identifizieren. ${ }^{27}$ Auch erlaubt dieser Ansatz Rückschlüsse darauf, ob die isolierten Biosynthesegene einen bekannten, verwandten oder neuen Vertreter einer Naturstoffklasse kodieren. Für die Suche nach neuen Enzymfamilien ist diese Screeningmethode allerdings ungeeignet, da nur nach bekannten Genen gesucht werden kann. ${ }^{26}$ Hierfür eignen sich eher funktionsbasierte Testsysteme.

Damit wird deutlich, dass für die Gesundheit der Menschen eine konzentrierte Forschung nach neuen Wirkstoffen heute, ganz aktuell zwingend geboten ist. Positiv ist zu sehen, dass es mehrere moderne Ansätze für die Suche nach neuen Naturstoffen gibt, die eine Erschließung neuer Quellen ermöglichen. Dennoch müssen für erfolgreiche Anwendungen und Methoden noch viele Probleme angegangen werden, um die Entwicklung von neuen Medikamenten und vor allem deren kontinuierlichen Nachschub überhaupt zu gewährleisten. 


\section{Aufgabenstellung}

Im Rahmen des vom BMBF-geförderten Netzwerks „Neue Anti-Biofilmstrategien aus dem Metagenom“ geht es in der vorliegenden Arbeit um das Teilprojekt „Synthese und Chemische Analyse neuer Biofilminhibitoren“. Durch Totalsynthese und Reinigung sollen die Quorum-Sensing-Moleküle Autoinducer 1 (AI-1, 19) und Autoinducer 2 (AI-2, 20) in ausreichenden Mengen für den Projektpartner K. Jung (Universität München) hergestellt werden. Erst der Einsatz definierter Mengen der Autoinducer AI-1 (19) und AI-2 (20) gewährleistet eine hohe Reproduzierbarkeit des Autoinducer-basierten Testsystems, welches bei der Analyse von Anti-Quorum-Sensing-Klonen in München eingesetzt werden sollte. Außerdem sollten in Kooperation mit den Arbeitsgruppen W. Streit (Universität Hamburg) und R. Schmitz-Streit (Universität Kiel) die Reaktionsprodukte von Biofilm-inhibierenden Metagenom-Klonen mit Hilfe von HPLC-ESI-MS-Analysen detektiert und charakterisiert werden.

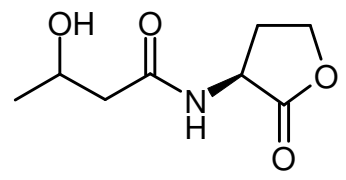

Al1 (19)<smiles>C[C@]12OC[C@@H](O)[C@]1(O)O[B-](O)(O)O2</smiles>

Al-2 (20)

Der marine Streptomycet JP90 ist ein begabter Naturstoffproduzent und Gegenstand des zweiten Teils. Ziel war zunächst die Reinigung des Rohprodukts vom synthetischen Cinnamoylphosphoramid (21) sowie die Synthese eines wasserlöslichen Analogons. Damit sollten ausreichende Mengen für biologische Testungen, die biochemische Charakterisierung und Zufütterung erhalten werden und die biologische Aktivität des potentiellen Acetylcholinesterase-Hemmers näher untersucht werden. Dieser für mikrobielle Naturstoffe ungewöhnliche Metabolit 21, dessen Struktur dem Grundgerüst von Organophosphaten entspricht, wurde von T.Schuhmann ${ }^{28}$ im Rahmen eines physikochemischen Screenings aus dem marinen Stamm Streptomyces sp. JP90 isoliert. In der eigenen Diplomarbeit ${ }^{29}$ konnte mit Hilfe der Totalsynthese von 21 die Struktur des Cinnamoylphosphoramids (21) in der absoluten Konfiguration aufgeklärt werden. Ein bisher unbekannter Sekundärmetabolit aus dem Stamm JP90 sollte im Rahmen der vorliegenden Arbeit strukturaufgeklärt werden.

Weiterhin sollten Untersuchungen zur Biosynthese der mikrobiellen Spirotetronate (22) und Rosiridol (23) aus Streptomyces sp. JP90 mit ${ }^{13}$ C-markierten Vorläufern durchgeführt werden. 


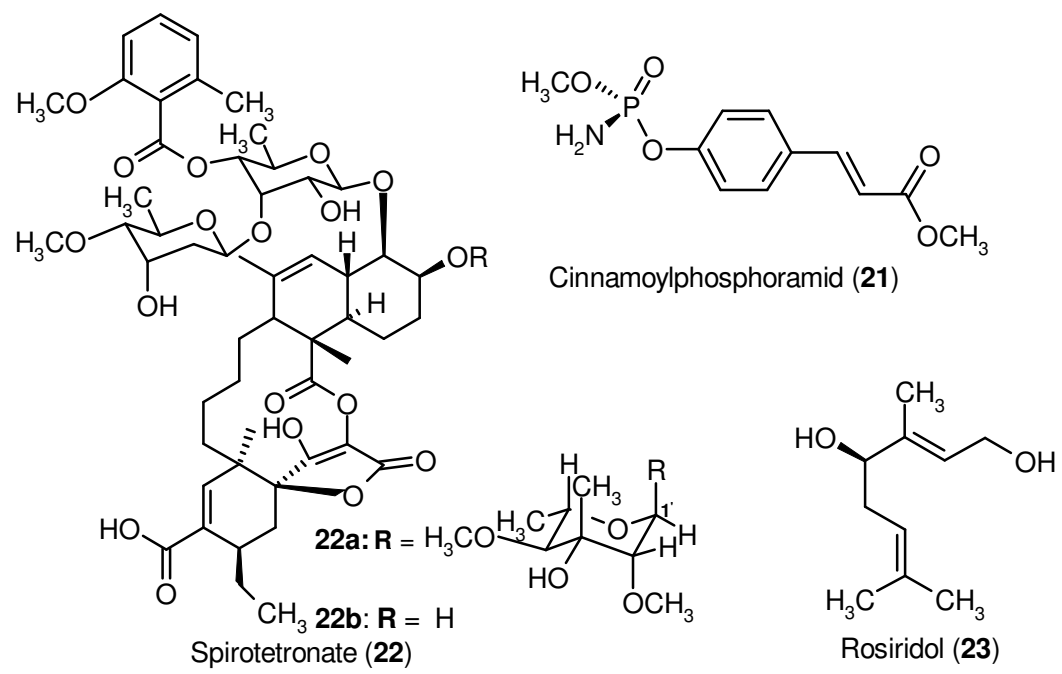

Hiervon war neben dem biosynthetischen Aufbau der Tetronsäure-, trans-Decalin- und Cyclohexen-Einheiten in den Spirotetronaten (22) auch der Biosyntheseweg von Interesse, über den der Stamm JP90 das Monoterpen Rosiridol (23) aufbaut.

In einem weiteren Teil dieser Arbeit sollte in Kooperation mit der Arbeitsgruppe Prof. $U$. Hentschel (Universität Würzburg) das Metabolitenspektrum des Stammes Streptomyces sp. Pol001 auf die Produktion eines neuen Glykopeptids (24) untersucht werden. Die Struktur des gesuchten Glykopeptids (24), bei dem es sich um das erste Glykopeptid des VancomycinTyps mit mindestens einem Sulfatsubstituenten handeln würde, wurde aus dem von M. Scheuermayer ${ }^{30}$ identifizierten Biosynthesegencluster abgeleitet.

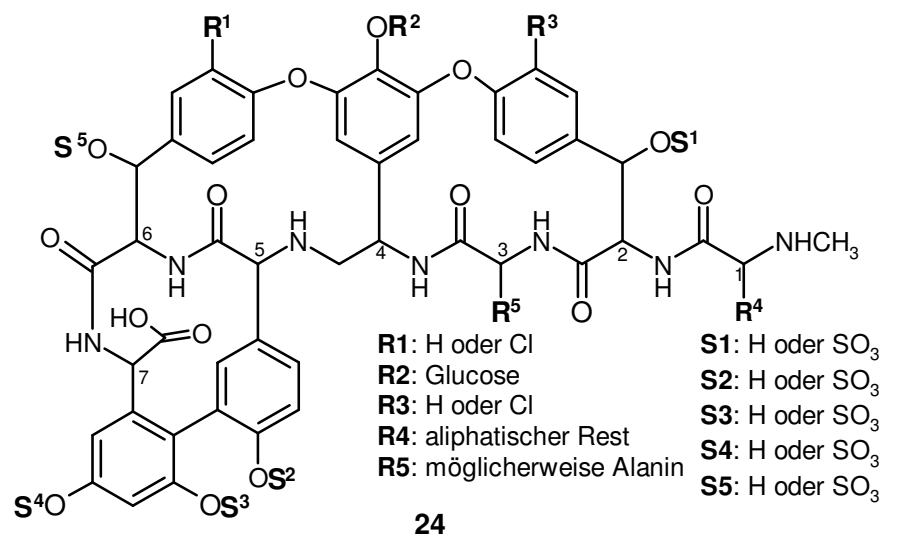

Ziel dieser Arbeit war es, für den Produzenten Pol001 optimierte Kultivierungsbedingungen bezüglich einer hohen Produktion von $\mathbf{2 4}$ zu finden und einen effizienten Zugang für die Gewinnung des neuen Glykopeptids (24) zu erreichen. Ferner sollte die Struktur des neuen Glykopeptids (24) mittels spektrometrischer und spektroskopischer Methoden aufgeklärt werden. Weitere Aufgaben zur Strukturaufklärung isolierter Sekundärstoffe wurden von C. Handrich aus der Arbeitsgruppe M. Müller (Arbeitsmedizin, Universität Göttingen) gestellt; die Identifizierung teratogener Stoffe aus dem Pilz Aspergillus nidulans war das Ziel. 


\section{BMBF-Verbundprojekt „Neue Anti-Biofilmstrategien aus dem Metagenom“}

\subsection{Projektübersicht}

Im Rahmen des vom Bundesministerium für Bildung und Forschung (BMBF) geförderten GenoMik-Plus-Programms wurde das Projekt „Neue Anti-Biofilmstrategien aus dem Metagenom“ im Zeitraum vom 01.06.2006 bis 31.05.09 gefördert und erhielt bis Ende des Jahres 2009 eine Verlängerung (FZK 03137651A). Ziel dieses Projektes war die Identifizierung von neuen Biofilminhibitoren zur Hemmung der Biofilmbildung mit Hilfe der Metagenom-Strategie, so dass das Potential bisher nicht-kultivierter Organismen genutzt werden könnte. Hierzu sollten zunächst mittels der Metagenomtechnologie MetagenomBibliotheken mit E. coli und P. aeruginosa als Wirtsstämme aus marinen und terrestrischen Habitaten erstellt werden. Diese sollten mit zuvor entwickelten Screeningsystemen auf AntiQuorum-Sensing-Klone durchmustert werden. Die so gefundenen Anti-Quorum-SensingKlone sollten mit Hilfe molekularbiologischer, biochemischer und chemisch-organischer Methoden untersucht und analysiert werden. Der Einsatz solcher Biofilminhibitoren zur wirksamen Therapie und Vermeidung von Biofilmen, in beispielsweise industriellen Prozessen, soll ferner in Kooperation mit der Industrie erforscht werden. Am BMBF-Verbundprojekt waren vier Projektpartner beteiligt (s. Abbildung 10).

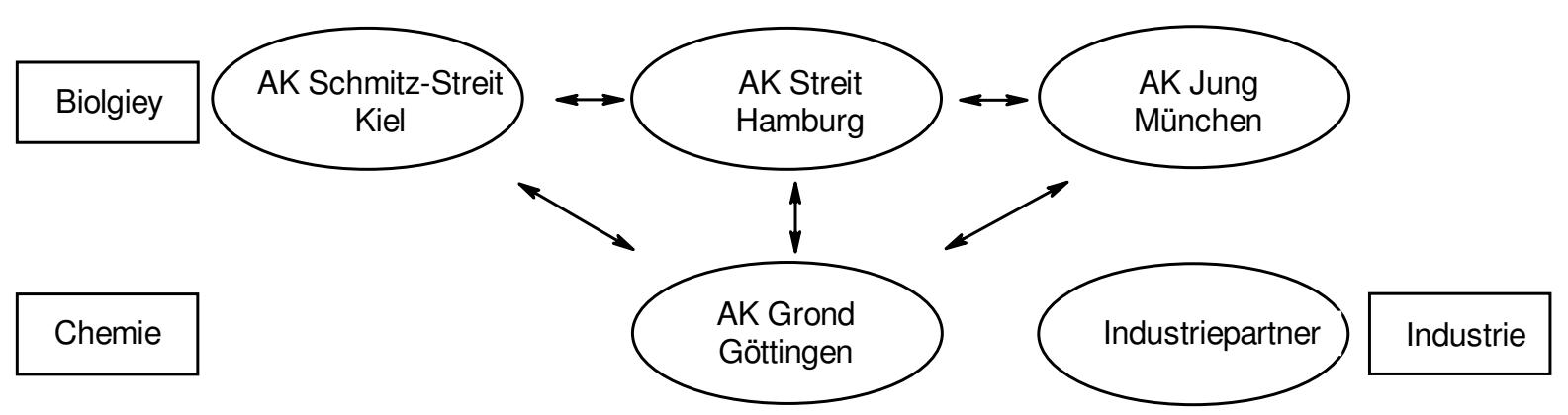

Abbildung 10. Vernetzung der Arbeitskreise im Verbundprojekt.

\section{Universität Hamburg}

(Arbeitskreis Prof. W. Streit, Abteilung für Mikrobiologie und Biotechnologie, Biozentrum Klein Flottbek)

In diesem Arbeitskreis wurden zunächst Metagenom-Bibliotheken aus terrestrischen Habitaten erstellt. Diese wurden in einem neu entwickelten Screeningsystem auf kleine und 
stabile Enzyme durchmustert, die unterschiedliche $\mathrm{N}$-Acylhomoserinlactone als Signalmoleküle der Mikroorganismen abbauen. Ferner sollen diese Enzyme auf Oberflächen immobilisiert werden, um so zur Bekämpfung von Biofilmen verwendet werden zu können. Hierzu wurde ein neuartiges Testsystem entwickelt, das es ermöglicht, diese Enzyme auf ihre Biofilm-inhibierende Wirkung zu überprüfen. Außerdem erforscht die Gruppe bessere Techniken, um die Suche nach neuen Anti-Quorum-Sensing-Molekülen zu vereinfachen und schneller durchführen.

\section{Universität Kiel}

(Arbeitsgruppe Prof. R. Schmitz-Streit, Institut für Allgemeine Mikrobiologie, Biologiezentrum)

In diesem Arbeitskreis wurden zunächst Metagenom-Bibliotheken aus marinen Habitaten erstellt. Mit Hilfe eines neu entwickelten Screeningsystems wurden diese Metagenombanken auf Anti-Quorum-Sensing-Klone hin untersucht, die die Bildung von Biofilmen durch Abbau, Inaktivierung oder Hemmung der Signalmoleküle verhindern. Hierbei wurde ein Testsystem aufgebaut, das ermöglicht, Anti-Quorum-Sensing-Klone zu detektieren, die mit Signalmolekülen des AI-2-Typs interferieren.

\section{LMU München}

(Arbeitskreis Prof. K. Jung, Departement Mikrobiologie I, Abteilung für Mikrobiologie)

In diesem Arbeitskreis wurden Testsysteme mit den Reporterstämmen Vibrio harveyi MM77 und Photorhabdus luminescens etabliert. Hiermit können Anti-Quorum-Sensing-Klone anhand ihres inhibitorischen Effektes auf die QS-kontrollierte Biolumineszenz identifiziert werden. Weiterhin wurde ein Einzelzelltestsystem mit Vibrio harveyi entwickelt, das zur Verifizierung der neuen Quorum-Sensing-, und Anti-Quorum-Sensing-Moleküle eingesetzt werden kann. Außerdem konnte in der Arbeitsgruppe bereits ein Testsystem aufgebaut werden, mit dessen Hilfe Anti-Quorum-Sensing-Aktivitäten von Metagenomklonen oder Naturstoffen biochemisch analysiert und charakterisiert werden sollen.

\section{Universität Göttingen}

(Arbeitskreis PD Dr. S. Grond, Institut für Organische und Biomolekulare Chemie)

In diesem Teilprojekt „Synthese und Chemische Analyse von neuen Biofilminhibitoren“ wurden für den Aufbau der Testsysteme der Kooperationspartner Quorum-Sensing-Moleküle durch Totalsynthese oder Reinigung ausgewählter Signalmoleküle bereitgestellt. Des Weiteren wurden für massenspektrometrische Untersuchungen eine HPLC-ESI-MS-Methode 
etabliert, mit deren Hilfe positiv getestete metagenomische Klone aus dem biologischen Screening auf ihre Quorum-Quenching-Aktivität untersucht wurden. Weiterhin wurde der Aufbau einer Substanzbibliothek begonnen, die auf Quorum-Sensing- und Anti-QuorumSensing-Aktivität in Kooperation mit der Arbeitsgruppe Jung getestet wurde.

\subsubsection{Kommunikation im Biofilm}

\section{Was ist Biofilm?}

Mikrobielle Biofilme sind Aufwüchse auf Oberflächen, die den Mikroorganismen als typischer Lebensraum dienen. Durch einen zähen Film aus Polysacchariden sind die im Biofilm lebenden Organismen vor mechanischen Kräften, gegenüber extremen pH- und Temperaturschwankungen, aber auch gegen Biozide, Antibiotika und Desinfektionsmittel oder Immunabwehrmechanismen des Wirtsorganismus bei Infektionen geschützt. In Biofilmen erfolgt ein Informationsaustausch in Form von Gentransfer oder mittels niedermolekularer Signalmoleküle. In Laboruntersuchungen von Reinkulturen wurde festgestellt, dass Signalmoleküle an der Entwicklung der dreidimensionalen Struktur von Biofilmen sowie beim Aufrechterhalten der ungestörten Funktionsweise beteiligt sind. ${ }^{31}$ Biofilme sind nicht nur in der freien Natur ubiquitär. In klinischen Bereichen sind mikrobielle Kontaminationen und Besiedlung von medizinischen Instrumenten, Kathetern und Implantaten insbesondere durch pathogene Erreger gefährlich. ${ }^{32}$ Aber auch bei industriellen Prozessen haben Biofilme durch Biokorrosion oder Biofouling unerwünschte und schädliche Auswirkungen, die zu großen finanziellen Verlusten führen. ${ }^{33}$ In den letzten Jahren wurden viele neue Ansätze entwickelt, die mikrobielle Anheftung und Biofilmbildung vermeiden sollen. Hierzu gehören die Entwicklung von veränderten Oberflächenstrukturen und Materialien, sowie mechanische und elektrochemische Verfahren zur Bekämpfung von Biofilmen. Eine andere Möglichkeit, die Bildung von Biofilmen zu verhindern oder deren Ablösung zu erwirken, besteht darin, die Kommunikation der Bakterien zu stören.

\section{Quorum-Sensing}

Die Kommunikation zwischen Bakterienzellen wird als Quorum-Sensing (QS) bezeichnet und basiert auf der Produktion und Wahrnehmung niedermolekularer Signalmoleküle, so genannter Autoinducer (AI). ${ }^{34}$ Es wird dabei angenommen, dass bestimmte Prozesse, wie z. B. die Biolumineszenz, die bereits beschriebene Ausbildung von Biofilmen, oder die Produktion von Virulenzfaktoren erst dann ausgeführt werden, wenn eine entsprechend hohe Anzahl an Bakterienzellen vorliegt. Bereits in den 70er Jahren wurde das Phänomen ursprünglich in den marinen Leuchtbakterium Vibrio fisheri, einem Symbionten aus marinen Vertebraten ent- 
deckt. Hierbei wurde beobachtet, dass die Bakterienzellen erst bei einer entsprechenden Zelldichte innerhalb der Organe des Wirts Biolumineszenz zeigen. ${ }^{35}$ Die bakterielle Kommunikation in Gram-negativen und Gram-positiven Mikroorganismen bedient sich strukturell unterschiedlicher Moleküle. In Gram-negativen Bakterien stellen die $N$-Acylhomoserinlactone (AHL, 25) die am weitesten verbreitete Gruppe an Signalmolekülen dar, deren Produktion bei mehr als 50 Bakterienarten nachgewiesen werden konnte. ${ }^{36}$ Als weitere bekannte Gruppen von Signalmolekülen sind Furanone des AI-2-Typs oder Quinolon-Derivate zu nennen, wobei vermutet wird, dass Autoinducer 2 (AI-2, 20) an der Kommunikation zwischen verschiedenen Arten von Bakterien beteiligt sind. Gram-positive Mikroorganismen setzen eher kleine Peptide als Signale ein (s. Abbildung 11).<smiles>[R]C(=O)[NH2+][C@@H]1CCOC1=O</smiles><smiles>[R]C(=O)CC(=O)[NH2+][C@H]1CCOC1=O</smiles>

$N$-Acylhomoserinlactone (HSL oder $\mathrm{AHL}$ )

(25)

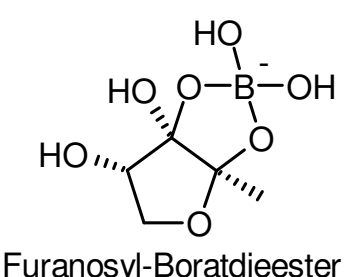

(Al-2, 20)<smiles></smiles>

4-Quinolon-Derivate (PQS)<smiles></smiles>

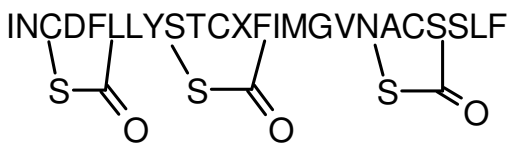

Peptide (AIP):

Cyclische Lactone und Thiolactone

Abbildung 11. Strukturen ausgewählter Signalmolekülgruppen aus Gram-negativen und Gram-positiven Mikroorganismen.

Bis heute ist das Phänomen Quorum Sensing eine Hypothese, die experimentell noch nicht im Detail bewiesen werden konnte. In der Literatur werden als mögliche Funktion für dieses Phänomen noch weitere Konzepte debattiert. Ein Beispiel ist hierfür das von Redfield et al. ${ }^{37}$ diskutierte „Diffusion Sensing“, bei dem mit Hilfe der Signalmoleküle der Massentransfer, also die Diffusion im Medium, bestimmt werden kann und Quorum Sensing nur als Nebeneffekt auftritt. 2007 wurde eine Hypothese publiziert, in der versucht wird, die umstrittenen Konzepte als „Efficiency Sensing“ zu vereinigen. ${ }^{38}$ Hierbei wird angenommen, dass die Zellen zunächst diffusionsfähige kleine Moleküle produzieren, deren Synthese energetisch nicht aufwendig ist, um sie gezielt in die Umgebung freisetzen. Mit Hilfe dieser Signalmoleküle sollen die Zellen herausfinden können, ob die Notwendigkeit besteht, energetisch aufwendigere extrazelluläre Effektoren zu synthetisieren. 


\section{Strategien der Kommunikationsstörung}

Bereits Ende der 90er Jahre konnte für einige Bakterien nachgewiesen werden, dass QS-Systeme für die Entwicklung von Biofilmen essentiell sind. ${ }^{31,34}$ Die Störung solcher QS-Systeme, die auch als Anti-Quorum-Sensing (AQS) bezeichnet wird, gilt als aussichtsreiche Strategie im Kampf gegen die zunehmende Resistenzentwicklung bei Mikroorganismen gegenüber bakteriziden Wirkstoffen. Diese Systeme üben keinen Selektionsdruck auf die Bakterien aus, sondern hemmen die Funktion, pathogene Eigenschaften auszuführen. ${ }^{39}$ In der Literatur wird zwischen zwei Prozessen unterschieden, die QS-Systeme stören ${ }^{40}$ :

1. Bei Quorum-Quenching (QQ) wird QS gestört, indem das Signalmolekül durch enzymatischen Abbau oder Modifikation inaktiviert wird.

2. Bei Quorum-Sensing-Inhibierung (QSI) erfolgt ein Eingriff innerhalb der Signal-Transduktions-Kaskade, worüber QS inhibiert wird, das kann Blockierung von Rezeptoren oder fehlende Biosynthese anderer Komponenten des Signalweges sein.

Zurzeit ist die Blockade des Signalmolekül-Rezeptorproteins eine sehr viel versprechende Strategie zur Störung der mikrobiellen Kommunikation. Ein gut untersuchtes Beispiel für die Blockade des AHL-regulierenden Prozesses sind halogenierte Furanone (26) aus der Rotalge Delisea pulchra. Dabei wird nicht direkt der Rezeptor blockiert, sondern durch deren Eingriff innerhalb der Signal-Transduktions-Kaskade diese gehemmt. ${ }^{41}$ Allerdings sind die bisher untersuchten Furanone (26) aufgrund ihrer Cytotoxizität für eine praktische Anwendung nur bedingt einsetzbar. Ein weiteres Beispiel für QS-Inhibitoren aus der Natur sind die aus dem Pilz Penicillium isolierten Sekundärmetaboliten Penicillinsäure (27) und Patulin (28) (s. Abbildung 12). ${ }^{42}$ Bisherige Bemühungen Struktur-Analoga solcher natürlichen QSInhibtoren zu synthetisieren, resultierten allerdings in Derivaten, die lediglich eine geringere Aktivität im Vergleich zu den Leitstrukturen aufwiesen. ${ }^{39}$

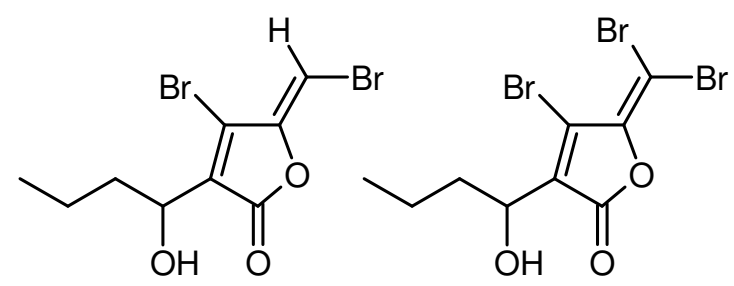

Halogenierte Furanone aus D. pulchra (26)

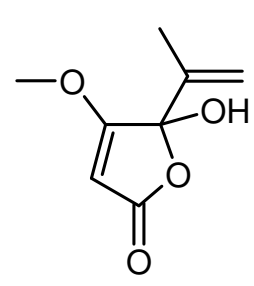

Penicillinsäure

(27)

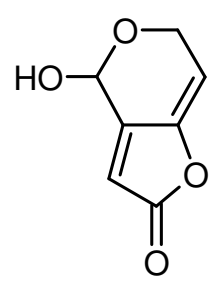

Patulin (28)

Abbildung 12. Quorum-Sensing-Inhibitoren aus natürlichen Quellen.

Eine weitere aussichtsreiche Strategie stellen enzymatische Abbaureaktionen oder Modifikationen von Signalmolekülen dar. Hierbei werden Enzyme gesucht, die die Signalmoleküle 
chemisch so verändern, dass deren Aktivität die des Autoinducers einschränkt oder sogar ganz unterbindet. Beispiele für solche Enzyme werden im Folgenden beschrieben.

\section{Denkbare Chemie-Innovation des Biofilm-Projektes}

Im Rahmen dieses Verbundprojektes gehören zu den Aufgaben des Naturstoffchemikers zum einen Untersuchungen von Signalmolekülen und deren Derivaten aus enzymatischen Abbauoder Modifikationsreaktionen und Quantifizierung dieser Enzymumsätze, um die enzymatischen Aktivitäten mit Hilfe chemischer Analysenmethoden $\mathrm{zu}$ verifizieren und möglicherweise bisher noch unbekannte enzymatische Abbauprodukte neuer Enzymklassen nachzuweisen. Zum anderen ist natürlich die Isolierung von Naturstoffen mit Anti-Quorum-SensingAktivität (AQS) und deren Strukturaufklärung mittels spektrometrischer und spektroskopischer Methoden von besonderem Interesse. Bisher können mit Hilfe der Metagenomtechnologie nur kleine, strukturell einfach aufgebaute Naturstoffe isoliert werden, da diese in sehr kurzen Biosynthesegensequenzen gebildet werden können (s. Abschnitt 1.2 ). Für einen Sekundärstoff liegt die Größe des Inserts (Abschnitt der Umwelt-DNA) mindestens zwischen 30-40 kb, damit das Vorliegen einer kleinen Polyketidsynthase (PKS) oder nichtribosomale Peptidsynthase (NRPS) überhaupt möglich ist. Zudem können aber auch neue BiomolekülDerivate, d.h. leicht veränderte Primärstoffwechsel-Intermediate wie z. B. nitrierte oder halogenierte Aromaten von Aminosäuren an QSI beteiligt sein, die es zu isolieren gilt. Für eine ferne industrielle Nutzung bieten diese strukturell einfach aufgebauten Naturstoffe ein großes Potential in der Bekämpfung von Biofilmen.

\subsection{Screening und Charakterisierung von Anti-Quorum-Sensing}

Im Arbeitskreis K. Jung (LMU München) wurde ein Testsystem mit dem Reporterstamm Vibrio harveyi MM77 etabliert, mit dessen Hilfe über inhibitorische Effekte auf die QSkontrollierte Biolumineszenz potentielle Anti-Quorum-Sensing-Klone identifiziert werden können.

\subsubsection{Die Autoinducer AI-1 (19) und AI-2 (20)}

Die QS-kontrollierte Biolumineszenz in dem Gram-negativen Bakterium der Spezies $V$. harveyi wird durch drei Autoinduktoren gesteuert, die Autoinducer AI-1 (19) und AI-2 (20) und CAI-1, dessen Struktur noch unbekannt ist. ${ }^{43}$ Der Einfluss der Autoinducer AI-1 (19) und AI-2 (20) auf die Biolumineszenz wird eingehend erforscht. Jung et al. konnten zeigen, dass die Autoinduktoren synergistisch auf die Induktion von Biolumineszenz wirken und mit 
Hilfe eines entwickelten Testsytems die zellulären Mechanismen des jeweiligen Signalmoleküls biochemisch analysieren. ${ }^{44}$

\section{Der Autoinducer AI-1(19)}

Der Autoinducer AI-1 (19) gehört zur Klasse der N-Acylhomoserinlactone (AHLs), die von Gram-negativen Bakterien als QS-Signal genutzt werden. Erstmalig wurde das $\mathrm{N}$-(3Hydroxybutyryl)homoserinlacton als Signalmolekül aus $V$. fisheri Anfang der 80er Jahre von Eberhard et al. identifiziert und seine Struktur aufgeklärt. ${ }^{45} \mathrm{Da}$ es der erste identifizierte Autoinducer aus V. fisheri ist, wird er als AI-1 (19) bezeichnet. Für die biologische Aktivität von $\mathrm{N}$-Acylhomoserinlactonen ist die $S$-Konfiguration (L-Konfiguration) des Lactonringes essentiell. Synthetische $R$-Isomere zeigten im Vergleich keine biologische Aktivität. ${ }^{46}$ Die Konfiguration der Hydroxyfunktion an C-3 der Acylkette von AI-1 (19) ist $R$-konfiguriert. Das $R$-Hydroxybutyrat stammt von $R$ - $\beta$-Hydroxybutyryl-ACP aus der Fettsäurebiosynthese, welches aus zwei Molekülen Acetyl-CoA über Acetoacetyl-CoA und anschließender stereospezifischer Reduktion der Ketofunktion an C-3 aufgebaut wird. ${ }^{47}$ Die $S$-Form würde im Gegensatz dazu aus der $\beta$-Oxidation von Fettsäuren erhalten werden. Um die Annahme des biosynthetischen Ursprungs $\mathrm{zu}$ belegen, wurde als Inhibitor der Fettsäurebiosynthese Cerulenin eingesetzt. Dieses hemmt die $\beta$-Ketoacyl-ACP-Synthase, so dass der Aufbau der Fettsäure nicht erfolgen kann. Hiermit wurde eindeutig die Annahme bestätigt, dass die aktive Form des AI-1, das ( $R, S)$-AI-1 (29) ist (s. Abbildung 13).

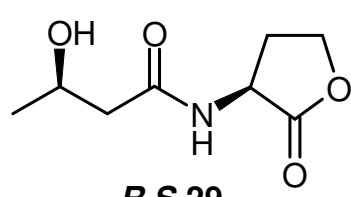

$R, S-29$

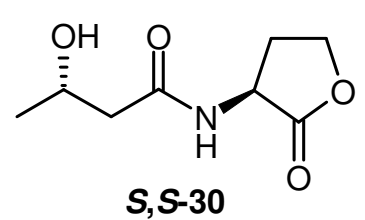

S,S-30

Abbildung 13. Strukturen von $(R, S)$-AI-1 (29) und $(S, S)$-AI-1 (30).

Für Untersuchungen inhibitorischer Effekte auf die Induktion der Biolumineszenz in $V$. harveyi wurden $(S, S)$-AI-1 (30) und $(R, S)$-AI-1 (29) als Epimerengemisch und als reine Diastereomere eingesetzt. Hierbei zeigte sich, dass $(R, S)$-AI-1 (29) zehnmal aktiver ist als $(S, S)$-AI-1 (30), das aber auch keine hemmenden Einflüsse auf die Aktivität des $(R, S)$-AI-1 (29) ausübt. Molekulare Modellstudien ergaben für die Orientierung der Hydroxyfunktion der Acylkette am Wirkort völlig verschiedene Ausrichtungen, wodurch vermutlich eine andere Anordnung in der Enzymtasche des Rezeptors resultiert und zu dem beobachteten Aktivitätsunterschied führen könnte. ${ }^{47}$ 


\section{Der Autoinducer AI-2}

Der Autoinducer AI-2 (20), ein Furanosyl-borat-diester, wurde als erstes im marinen Bakterium V. harveyi identifiziert, mittlerweile konnte dieser Autoinducer in vielen Gramnegativen und Gram-positiven Bakterien beobachtet werden (s. Abbildung 15). Des Weiteren konnten das für die Biosynthese des AI-2-Vorläufers DPD (4,5-Dihydroxy-2,3-pentandion, 31) erforderliche Enzym $\operatorname{LuxS}$ in vielen sequenzierten bakteriellen Genomen gefunden werden. Aufgrund dieser Beobachtungen wird angenommen, dass es sich bei AI-2 (20) um ein ubiquitäres Signalmolekül handelt, über das die Kommunikation zwischen Bakterienarten erfolgt. AI-2 (20) entsteht in Gegenwart von Bor aus dem offenkettigen Vorläufer DPD (31), das aufgrund seiner Struktur sofort in wässriger Lösung zum Ketal cyclisiert. Die Biosynthese des DPDs (31) erfolgt ausgehend von $S$-Adenosylmethionin (SAM, 32), das in der Zelle als Methyldonor fungiert (s. Abbildung 14). ${ }^{49}$ Bei der Übertragung der Methylgruppe auf ein Substrat entsteht aus SAM (32) das toxische $S$-Adenosylhomocystein ( $\mathrm{SAH}, \mathbf{3 3}$ ), welches zu Adenosin und Homocystein (34) verstoffwechselt werden kann. In Gegenwart des Genprodukts LuxS allerdings erfolgt eine durch das Enzym $P f s$ katalysierte Umwandlung des SAH (33) zu S-Ribosylhomocystein (SRH, 35) und Adenin. Das hierbei gebildete SRH (35) wird durch das Enzym LuxS zu stöchiometrischen Mengen an DPD (31) und dem für Zellen toxischen Homocystein (34) umgesetzt. In der Literatur wird außerdem die Möglichkeit einer LuxS-unabhängigen Bildung von DPD (31) beschrieben, die von einer spontanen Umwandlung von Ribulose-5-phosphat ausgeht. ${ }^{48}$ Hiermit wird versucht zu erklären, warum AI-2Aktivitäten in Bakterien beobachtet werden, die nicht über das Genprodukt LuxS verfügen.

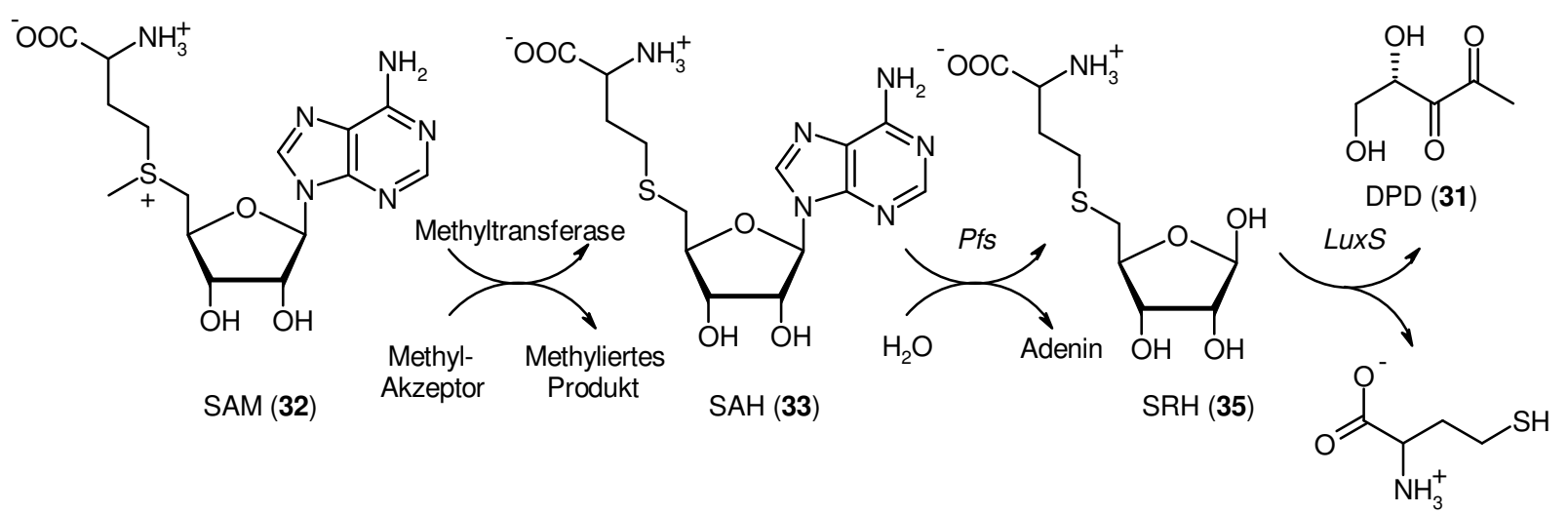

(34)

Abbildung 14. Metabolischer Weg zur Bildung des Vorläufers DPD (31).

Das offenkettige DPD (31) steht im wässrigen Medium mit drei möglichen Signalmolekülen in einem thermodynamischen Gleichgewicht: (2S,4S)-2-Methyl-2,3,3,4-tetrahydroxytetra- 
hydrofuran ( $S$-THMF, 37), (2R,4S)-2-Methyl-2,3,3,4-tetrahydroxytetrahydrofuran ( $R$-THMF, 38) und 4-Hydroxy-5-methyl-3(2H)-furanon (MHF, 39), die in der Literatur gerne als Signalmoleküle des AI-2-Typs zusammengefasst werden (s. Abbildung 15). ${ }^{49}$

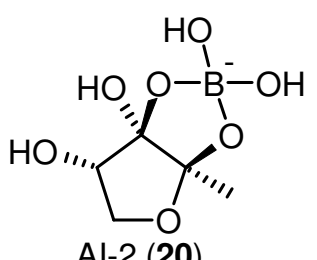

$\mathrm{Al}-2(20)$<smiles>C[C@]1(O)OC[C@@H](O)C1(O)O</smiles>

S-THMF (37)<smiles>CC1(O)OC[C@@H](O)C1(O)O</smiles>

$R$-THMF (38)<smiles>CC1=C(O)C(=O)CO1</smiles>

MHF (39)

Abbildung 15. Die vier Signalmoleküle des AI-2-Typs.

In Gegenwart von Bor bildet sich aus S-THMF (37) der Furanosyl-borat-diester AI-2 (20). Mit Hilfe von Kristallstrukturen konnte gezeigt werde, dass AI-2 (20) in V. harveyi an den Rezeptor LuxP bindet, während R-THMF (38) in E. coli und S. typhimurium an den Rezeptor LsrB bindet. ${ }^{50}$ Es konnte experimentell gezeigt werden, dass die Signalmoleküle $S$-THMF (37) und $R$-THMF (38) über die offenkettige Form miteinander im Gleichgewicht stehen (s. Abbildung 16). Nur in Gegenwart von Borsäure konnte das enzymatisch synthetisierte DPD (31) Biolumineszenz bei $V$. harveyi induzieren oder das am Rezeptor LsrB-gebundene $R$ THMF (38) freigesetzt werden. Das freigesetzte $R$-THMF (38) wandelt sich über die offenkettige Form zum Furanosyl-borat-diester (20) um und kann in V. harveyi Biolumineszenz erzeugen. Somit ist das Vorliegen von Borsäure notwendig für die Stimulation von Biolumineszenz in $V$. harveyi, und tatsächlich lebt das marine Bakterium $V$. harveyi in Meerwasserregionen, die hohe Konzentrationen an Borsäure aufweisen. ${ }^{51}$

Ein weiteres Molekül, das zum AI-2-Typ gehört, ist das MHF (39, s. Abbildung 16). Dieses kann aus dem Intermediat $R$-DHMF (41) über Keto-Enol-Tautomerie und Abspaltung von Wasser gebildet werden und steht damit auch in Beziehung zum DPD (31). In der Literatur wurden Extrakte aus der enzymatischen Synthese mit LuxS durch GC-MS-Analyse auf ein Produkt des AI-2-Typs hin untersucht. Hierbei konnte MHF (39) durch Vergleich der Retentionszeiten und des Fragmentierungsmusters mit synthetischem Material identifiziert werden, das Vorliegen eines weiteren Signalmoleküls des AI-2-Typs konnte nicht verifiziert werden. ${ }^{52}$ Aufgrund dieser Beobachtung wird vermutet, dass MHF (39) das Hauptprodukt der LuxSReaktion ist, während nur ein geringer Anteil der offenkettigen Form zu AI-2 (20) oder $R$ THMF (38) cyclisiert, der nicht mittels GC-MS detektiert werden kann. Im Gegensatz zu AI-2 (20) weist das MHF (39) eine um den Faktor 1000 geringere Aktivität auf, da vermutlich die Rückreaktion von MHF (39) über $R$-DHMF (41) zu DPD (31) nur zu sehr geringen Anteilen abläuft. Das thermodynamische Gleichgewicht scheint eindeutig auf der Seite des MHF 
(39) zu liegen, das aufgrund der Wasserabspaltung aus entropischen Gründen auch zu erwarten ist. Mit der Lage des chemischen Gleichgewichts auf Seiten des MHF (39) könnte auch dessen Bildung als mutmaßliches Hauptprodukt begründet werden.

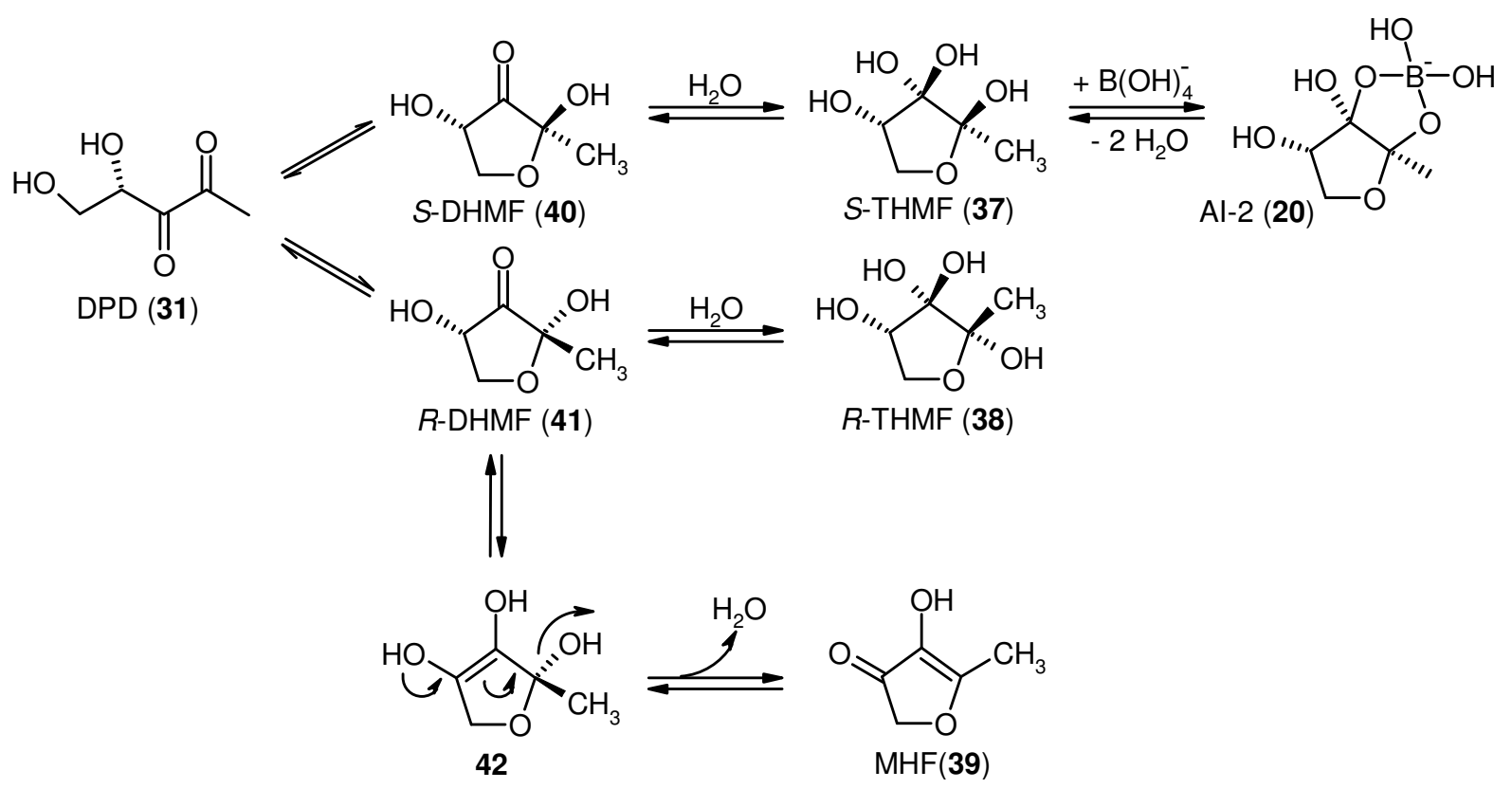

Abbildung 16. Chemisches Gleichgewicht des offenkettigen Vorläufers DPD (31) und seine vier Signalmoleküle: AI-2 (20), $S$-THMF (37), $R$-THMF (38) und MHF (39).

\subsubsection{Synthese des Autoinducers AI-1}

Für die Analyse von Anti-Quorum-Sensing-Klonen in der Arbeitsgruppe K. Jung (LMU München) sollte ein Autoinducer-basiertes Testsystem mit Vibrio harveyi etabliert werden. Um eine hohe Reproduzierbarkeit des Bioassays gewährleisten zu können, sollten definierte Mengen von enantiomerenreinem Autoinducer AI-1 (19) und AI-2 (20) eingesetzt werden. Aus diesem Grund sollte im Rahmen der vorliegenden Arbeit AI-1 (19) synthetisiert werden. Dazu sollten ein Epimerengemisch und beide enantiomerenreinen Epimere chemisch dargestellt werden, um den Einfluss der absoluten Konfiguration bei der Induktion von Biolumineszenz in $V$. harveyi im Vergleich mit Literaturdaten zu untersuchen. Zusätzlich sollte eine Reinigungsmethode für den enzymatisch hergestellten Autoinduktor AI-2 (20) etabliert werden, da das bei der enzymatischen Synthese anfallende Nebenprodukt toxisch auf Testzellen wirkt. Bis zu diesem Zeitpunkt konnte das enzymatisch hergestellte AI-2 (20) aufgrund dieser Toxizität für geplante Langzeitmessungen nicht eingesetzt werden. 


\section{Bekanntes zur Synthese von AI-1 (19)}

Für Untersuchungen der Induktion von Biolumineszenz in V. harveyi durch Zugabe des Autoinducers AI-1 (19), dessen Funktion als Autoinducer so experimentell verifiziert werden sollte, führte Eberhard et al. 1981 erstmalig die Synthese des $N$-(3-Hydroxybutyryl)homoserinlactons (19) ausgehend vom Natriumsalz des 3-Hydroxybutyrats (43) und $\alpha$-Amino- $\gamma$ butyrolactonhydrobromid (44) durch EDC.HCl-vermittelte Kupplung in Wasser bei Raumtemperatur durch (s. Schema 1). ${ }^{45}$ Nach 24 h Rühren bei Raumtemperatur wurde die wässrige Phase mit Chloroform extrahiert. Nach säulenchromatographischer Reinigung an Kieselgel $\left(\mathrm{CHCl}_{3} / \mathrm{MeOH}\right.$ 98:2) wurde die Zielverbindung in einer Ausbeute von $7 \%$ erhalten. Für diese niedrige Ausbeute ist das ungeeignete Lösungsmittel Wasser verantwortlich zu machen, da es die intermediäre gemischte Anhydridspezies hydrolytisch abfängt. Der Einsatz von Wasser als Lösungsmittel ist unsinnig.<smiles>CC(O)CC(=O)[O-]</smiles>

43<smiles>O=C1OCC[C@H]1NBr</smiles>

44

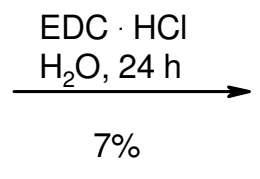

Schema 1. Erste chemische Synthese des Autoinducers AI-1 (19) gemäß Eberhard et al. ${ }^{45}$.

In der Literatur wird für die Synthese von längerkettigen 3-Hydroxy-Derivaten der N-Acylhomoserinlactone von Eberhard et al. ein Syntheseansatz beschrieben, bei dem zunächst die Synthese des 3-Hydroxyesters (45) über eine Reformatsky-Reaktion erfolgte. ${ }^{53}$ Die sekundäre Hydroxyfunktion des 3-Hydroxyesters (45) wurde THP geschützt, der Ester alkalisch hydrolysiert und anschließend mit $\alpha$-Amino- $\gamma$-butyrolactonhydrobromid (44) durch eine EDC.HCl-vermittelte Kupplung in Wasser in das entsprechende THP-geschützte $N$-3Hydroxyhomoserinlacton (47) überführt und nach säurekatalysierter Entschützung die Zielverbindung (48) in Ausbeuten von $10 \%$ erhalten (s. Schema 2). Die Verwendung von Wasser verringerte die mögliche Gesamtausbeute sicher auch in diesem Fall.

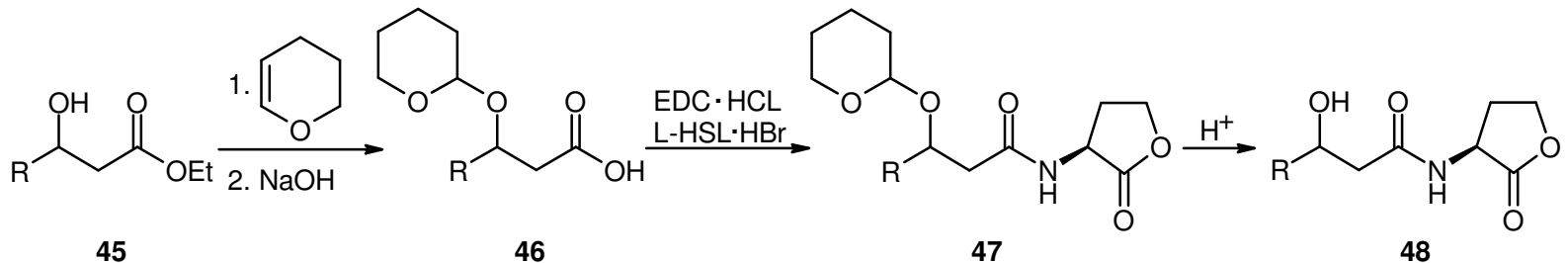

Schema 2. Synthese längerkettiger 3-Hydroxyhomoserinlacton-Derivate (48) gemäß Eberhard et al. ${ }^{53}$. 
Eigene Arbeiten zur Synthese von AI-1 (19) und seinen enantiomerenreinen Epimeren

Im Rahmen der eigenen Arbeiten wurde für die Synthese des AI-1 (19) eine Synthesesequenz bestehend aus Schützung des sekundären Alkohols, EDC.HCl-vermittelte Kupplung und Entschützung gewählt, die auch die chemische Darstellung der enantiomerenreinen Epimere erlauben sollte. Als Schutzgruppe für den sekundären Alkohol wurde nicht die THP-Schutzgruppe eingesetzt, da diese ein zusätzliches Stereozentrum einführt. Dieses zusätzliche Stereozentrum ist mit zwei Nachteilen verbunden. Zum einen führt es zu komplexen NMRSpektren, und zum anderen ist eine Induktion der relativ großen Schutzgruppe in folgenden Reaktionen nicht auszuschließen. Aus diesen Gründen wurde als Schutzgruppe für den sekundären Alkohol die alternative TBS-Schutzgruppe gewählt, die stabil bei den eher basischen Reaktionsbedingungen sein würde und in der Synthese die THP-Gruppe weitgehend verdrängt hat. Für die Synthese des Silylethers $\mathbf{5 0}$ erfolgte gemäß Schmidt et al. die Umsetzung vom Natriumsalz des rac-3-Hydroxybutyrats (43) mit TBS-Chlorid und Imidazol in wasserfreiem DMF bei Raumtemperatur (s. Schema 3) ${ }^{54}$ Da auch die Säurefunktion TBSgeschützt wurde, musste diese anschließend basisch hydrolysiert werden. Dies ergab den TBS-geschützten Silylether 50 in einer Ausbeute von $85 \%$ über zwei Stufen. Dieser wurde mit $\alpha$-Amino- $\gamma$-butyrolactonhydrobromid (44) durch EDC.HCl-vermittelte Kupplung in wasserfreiem DMF bei Raumtemperatur für $21 \mathrm{~h}$ umgesetzt. ${ }^{55}$ Das erhaltene Rohprodukt wurde ohne weitere Reinigung eingesetzt und zur Entschützung des Silylethers mit HF.Pyridin $(70 \%)$ in Dichlormethan bei $0{ }^{\circ} \mathrm{C}$ entschützt. ${ }^{56}$

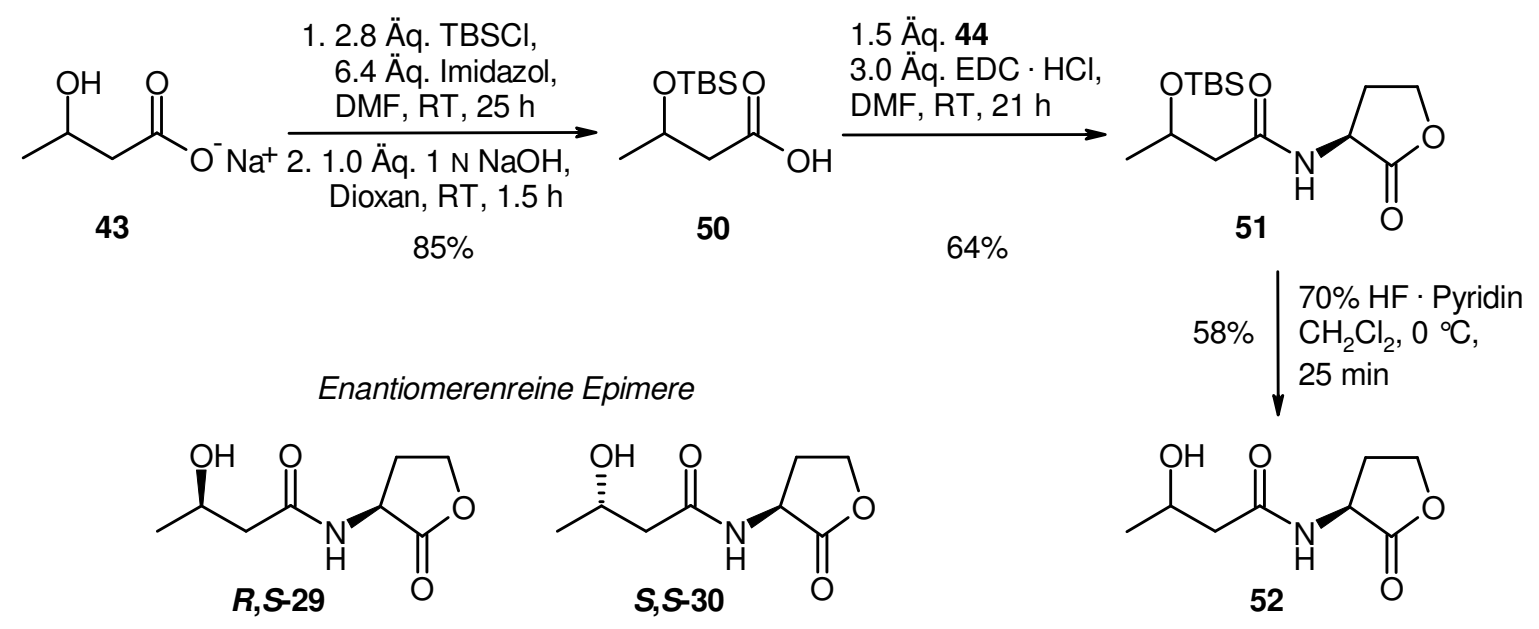

Schema 3. Optimierte Totalsynthese des Epimerengemisches 52 und der enantiomerenreinen Epimere $(R, S)$-AI$1(\boldsymbol{R}, \boldsymbol{S - 2 9})$ und $(S, S)-\mathrm{AI}-1(\boldsymbol{S}, \boldsymbol{S}-\mathbf{3 0})$ in einer Gesamtausbeute von $30 \%$.

Hierbei war die Ausbeute von der Qualität der HF.Pyridin-Charge abhängig. Die hohe Polarität des Produktes $\mathbf{5 2}$ erschwerte eine wässrige Aufarbeitung und anschließende 
Extraktion mit organischen Lösungsmitteln. Daher musste nach Zerstören des HF durch ges. $\mathrm{NaHCO}_{3}$-Lösung die gesamte Reaktionsmischung in vacuo eingeengt und der Rückstand mit Aceton extrahiert werden. Auch der Versuch Butanol als Extraktionslösungsmittel einzusetzen scheiterte, zumal hierbei eine anteilige Bildung des Butylesters von AI-1 (53, s. Abbildung 17) erfolgte. Zur Optimierung der Aufarbeitung wurde der pH-Wert der wässrigen Phase mit ges. $\mathrm{NaHCO}_{3}$-Lösung auf $\mathrm{pH}=7.0$ korrigiert, mit Ethylacetat extrahiert und anschließend zur vollständigen Isolierung die wässrige Phase bis zur Trockne eingeengt und der Rückstand mit Aceton wiederholt extrahiert. Bei der chromatographischen Reinigung führte die Instabilität des Lactonringes bereits an Kieselgel $\left(\mathrm{CH}_{2} \mathrm{Cl}_{2} / \mathrm{MeOH} 10: 1\right)$ zur Bildung des Methylesters von AI-1 (54, s. Abbildung 17). Zur Optimierung der chromatographischen Reinigung des nach Entschützung erhaltenen AI-1 (52) wurden verschiedene Methoden wie Gelchromatographie an Sephadex LH-20 (Aceton) und reversed-phase Kieselgel (Aceton/ $\mathrm{H}_{2} \mathrm{O} 3: 2$ ) ohne eine vollständige Reinigung des Rohproduktes eingesetzt. Eine vollständige Reinigung des Rohproduktes konnte erst nach Flashchromatographie an Kieselgel (Cyclohexan/Aceton 1:2) erzielt werden.

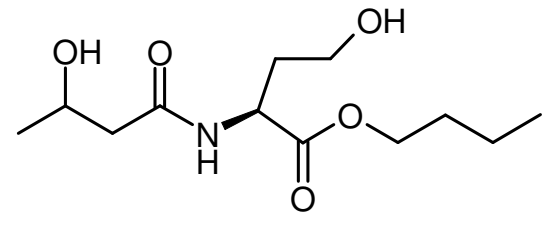

Butylester von Al-1 (53)<smiles>COC(=O)[C@H](CCO)NC(=O)CC(C)O</smiles>

Methylester von Al-1 (54)

Abbildung 17. Strukturen des Butylesters (53) und Methylesters (54) von AI-1.

Die Synthese der enantiomerenreinen Epimere $(R, S)$-AI-1 (29) und $(S, S)$-AI-1 (30) wurde analog durchgeführt. Für die Synthese des $(R, S)$-AI-1 (29) konnte, nach säulenchromatographischer Reinigung an Kieselgel (Cyclohexan/Aceton 1:2) eine Gesamtausbeute von $30 \%$ über 4 Stufen erzielt werden. Der Lactonring des $N$-Acylhomoserinlactons ist sehr hydrolyseempfindlich, wie die Bildung des Butylesters bei der Aufarbeitung und der Methylester bei der Säulenchromatographie zeigten. Somit schwanken die Ausbeuten je nach Säuregehalt bei der Aufarbeitung und Verweildauer der Rohprodukte an Kieselgel. Zur Überprüfung der biologischen Aktivität wurden das Epimerengemisch und die enantiomerenreinen Epimere im Arbeitskreis K. Jung auf ihren Einfluss bei der Induktion von Biolumineszenz in verschiedenen Konzentrationen von $c=5 \mu \mathrm{M}, 100 \mu \mathrm{M}$ und $250 \mu \mathrm{M}$ hin untersucht. Hierbei zeigte das $(R, S)$-AI-1 (29) der Literatur entsprechend die stärkste Stimulation der Biolumineszenz (s.

\section{Abbildung 18).}




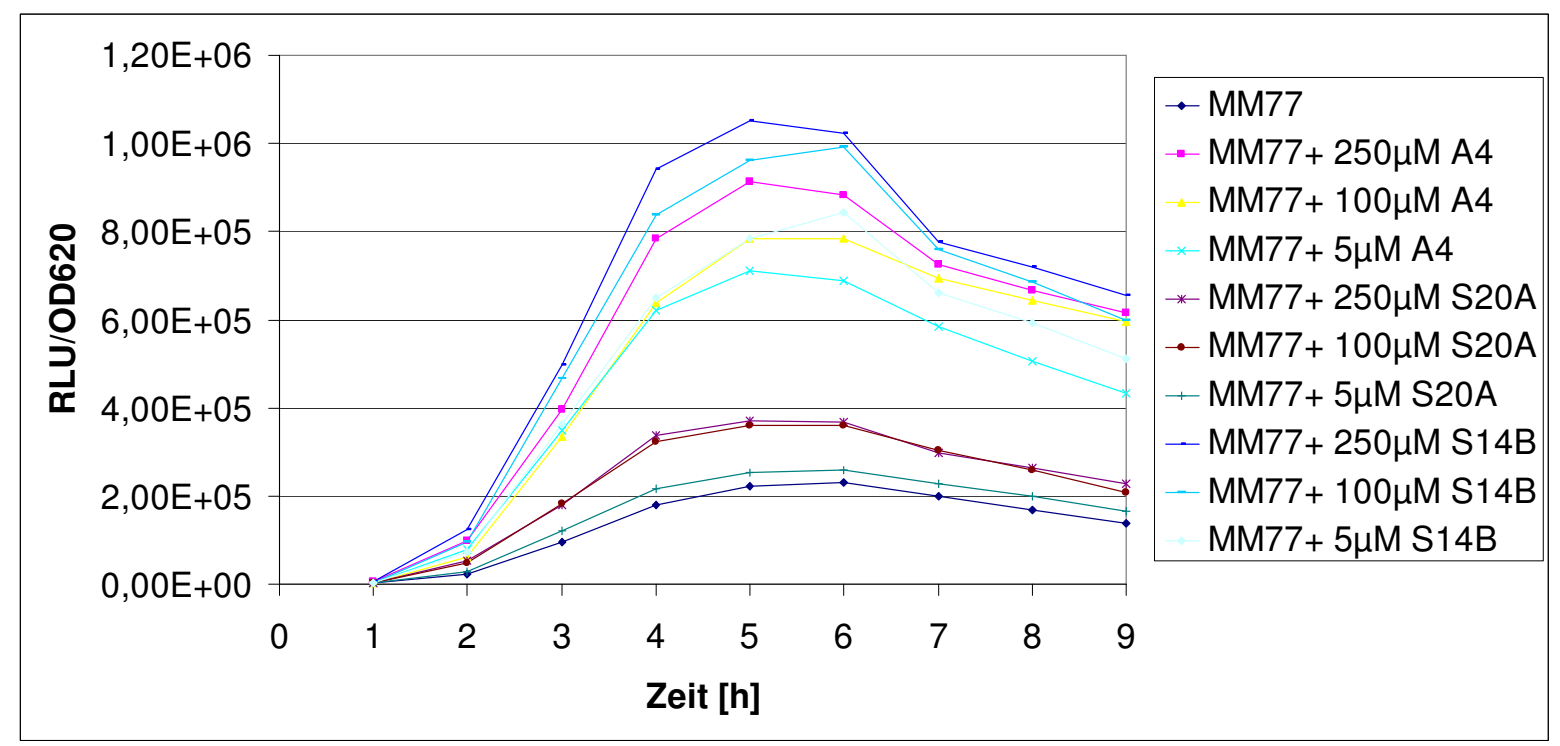

Abbildung 18. Der Einfluss vom Epimerengemisch und der enantiomerenreinen Epimere auf die Induktion von Biolumineszenz in V. harveyi A4: Epimerengemisch. S20A: $(S, S)$-AI-1. S14B: $(R, S)$-AI-1. MM77: Mutante von $V$. harveyi, produziert kein AI-1 und AI-2. Angabe in RLU $=\mathrm{cpm} \times 103 / \mathrm{cfu} / \mathrm{mL}(\mathrm{cpm}=$ counts per million, cfu = colony forming units). OD620: Optische Dichte der Zellen.

\subsubsection{Reinigung des enzymatisch hergestellten Autoinducers AI-2 (20)}

Die enzymatische Synthese des Autoinducers AI-2 (20) wurde in Kooperation mit der Arbeitsgruppe K. Jung (LMU München) mit C. Anetzberger durchgeführt. Für die in vitroSynthese des AI-2-Vorläufers DPD (31) wurden die von C. Anetzberger aufgereinigten Enzyme $P f s(1 \mathrm{mg} / \mathrm{mL})$ und $\operatorname{LuxS}(1 \mathrm{mg} / \mathrm{mL})$ mit dem Substrat $N$-Adenosylhomocystein (SAH, $1 \mathrm{mM})$ in Natrium-Phosphat-Puffer $(10 \mathrm{mM})$ wie in Abschnitt B 2.2.1 beschrieben zusammengegeben. Der enzymatische Reaktionsansatz wurde für $1 \mathrm{~h}$ bei $37^{\circ} \mathrm{C}$ inkubiert. Anschließend wurde der Reaktionsansatz zur Abtrennung der Proteine mittels VIVASPIN ${ }^{\circledR}$ 20 zentrifugiert. Die Bestimmung der Konzentration an gebildetem AI-2-Vorläufer DPD (31) wurde mit einem Ellmann-Test durchgeführt (s. Abschnitt B 2.2.1 ). Für die Reinigung wurde in Anlehnung an Semmelhack et al. ${ }^{57}$ eine Affinitätschromatographie mit immobilisiertem Boronsäuregel durchgeführt. Hierbei wird das gebildete DPD (31) durch die Boronsäuresubstituenten des Gels komplexiert, während das toxische Nebenprodukt Homocystein (34) im Eluat verbleibt (s. Abbildung 19). Um eine vollständige Entfernung des Homocysteins (34) zu gewährleisten, wird noch einmal mit ges. $\mathrm{NaHCO}_{3}$-Lösung ( $\mathrm{pH}$ 8.8) gewaschen. Die Elution und Dekomplexierung des komplexierten DPDs (31) erfolgt mit Ameisensäure (10\%ig). In der Vorlage wird Borsäure vorgelegt und so wird aus dem freigesetzten DPD (31) AI-2 (20) erhalten, dessen Konzentration mit Hilfe des Ellmann-Tests bestimmt werden kann. 


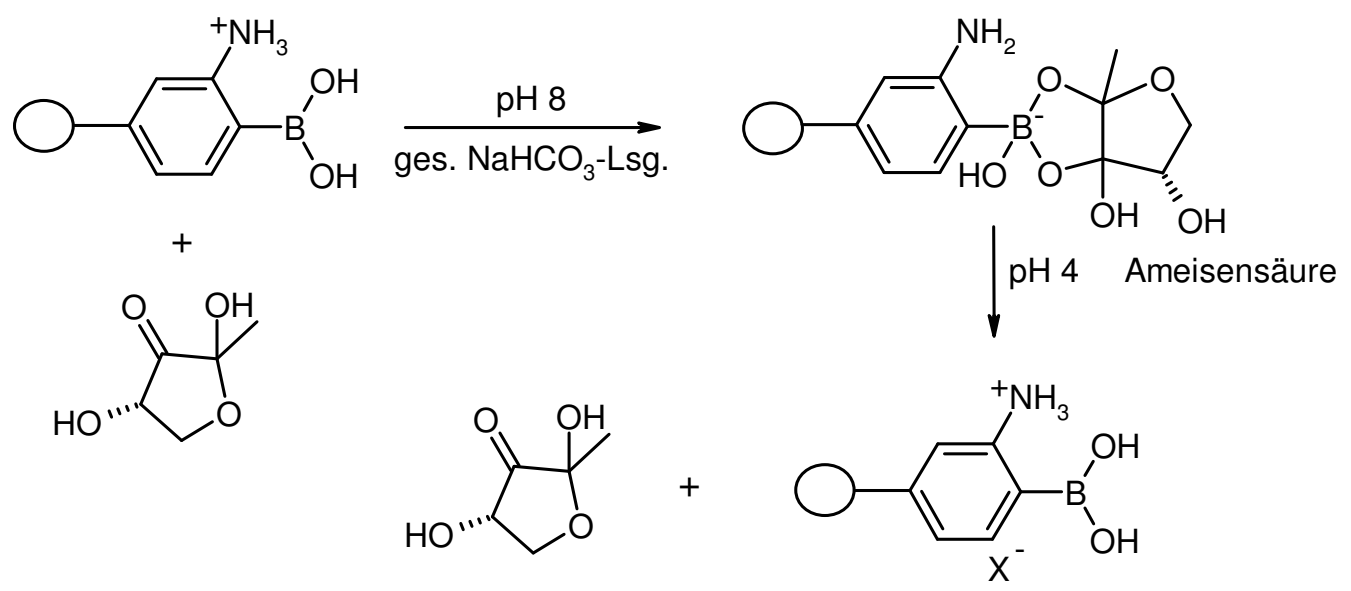

Abbildung 19. Prinzip der Affinitätschromatographie mit immobilisierten Boronsäuregel.

Mit Hilfe dieser Reinigungsmethode konnte eine $98 \%$ ige Reinigung bei der enzymatischen Synthese des Autoinducers AI-2 (20) erzielt werden, die mit dem Reporterstamm V. harveyi MM77 überprüft werden konnte (s. Abbildung 20). Dieses Ergebnis ermöglicht sowohl eine hohe Reproduzierbarkeit im etablierten Bioassay als auch Langzeitmessungen mit AI-2 (20). Damit konnte durch die Arbeitsgruppe S. Grond für die Arbeitsgruppe K. Jung eine erfolgreiche Reinigungsmethode etabliert werden, die einen schnellen Zugang zu ausreichenden Mengen an AI-2 (20) bietet.

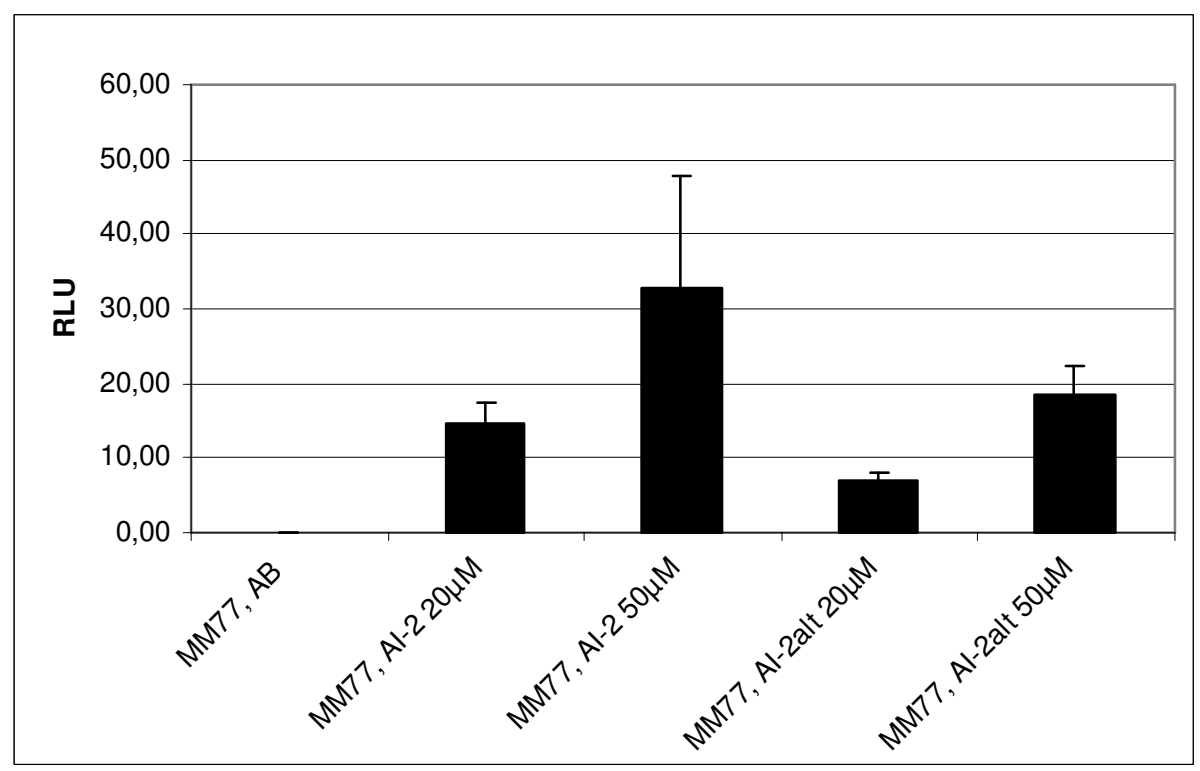

Abbildung 20. Der Einfluss von AI-2 (20) auf die Induktion von Biolumineszenz in V. harveyi MM77. MM77: Mutante von V. harveyi, produziert kein AI-1 und AI-2. MM77, AB: Kontrolle. AI-2: Kontrolle, AI-2 nach Reinigung mittels Boronsäuregel in verschiedenen Konzentrationen. AI-2alt: Kontrolle, AI-2 ohne Reinigung mittels Boronsäuregel. Angabe in RLU $=\mathrm{cpm} \times 103 / \mathrm{cfu} / \mathrm{mL}(\mathrm{cpm}=$ counts per million, $\mathrm{cfu}=$ colony forming units). 


\subsubsection{Aufbau einer Substanzbibliothek}

Im Rahmen der Kooperation mit der Arbeitsgruppe $K$. Jung (Universität München) wurde für die Suche nach neuen Quorum-Sensing (QS)- und Anti-Quorum-Sensing (AQS)-Molekülen in der Arbeitsgruppe von S. Grond mit dem Aufbau einer Substanzbibliothek begonnen. Hierfür wurden zunächst zehn mikrobielle Naturstoffe unterschiedlicher Naturstoffklassen, die in der Arbeitsgruppe A. Zeeck und S. Grond aus verschiedenen Streptomyceten-Stämmen isoliert und gereinigt worden waren, in München auf QS- oder AQS-Aktivität untersucht (s. Abbildung 21 und Abbildung 22).

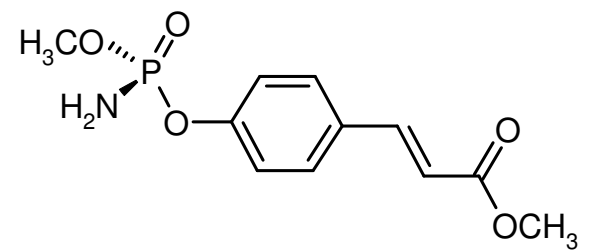

Cinnamoylphosphoramid (21)<smiles>CC[C@@H](O)[C@H]1C[C@@H](C/C=C/C(=O)O)CO1</smiles>

Communiol B<smiles>COC(=O)c1coc(C(C)=O)c1</smiles>

Dimethylfuran-2,4-dicarboxylat<smiles>C[C@@H]1CCC[C@]2(OC[C@@H](CO)[C@@H]2O)O1</smiles>

Okaspirodiol<smiles>[B][Ge]([B])([O-])/C([Ge])=C/Cc1[nH]c(=O)c(C)c(O)c1CCC</smiles>

Abbildung 21. Isolierte Substanzen aus verschiedenen Streptomyceten-Stämmen ohne QS- oder AQS-Aktivität.

Für die Analyse der Naturstoffe wurde der Einfluss auf die QS-kontrollierte Biolumineszenz in dem Reporterstamm Vibrio harveyi MM77 überprüft. Hierbei zeigte sich ein inhibitorischer Effekt von vier Substanzen, Iromycin A (55), Collinolacton (56) $p$-Hydroxyzimtsäuremethylester (57) und Desoxyconcanolid A (58) auf die Biolumineszenz in V. harveyi MM77 (s. Abbildung 22). Zurzeit werden in Kooperation mit der Arbeitsgruppe K. Jung von T. Pirch weitere Untersuchungen, insbesondere mit Iromycin A (55) zur Verifizierung der biologischen Aktivität durchgeführt. Für diesen Naturstoff, einem Vertreter einer neuen Familie von seltenen $\alpha$-Pyridon-Metaboliten, ist bereits eine Aktivität als NOS-Inhibitor beschrieben worden. ${ }^{58}$ Aus diesem Grund sollen weitere Untersuchungen zeigen, ob der für $\mathbf{5 5}$ beobachtete inhibitorische Effekt auf eine Aktivität als AQS-Molekül oder eine cytotoxische Wirkung zurückzuführen ist. 
<smiles>CCCc1c(C/C=C(\C)C/C=C/C(C)C)[nH]c(=O)c(C)c1O</smiles>

Iromycin A (55)

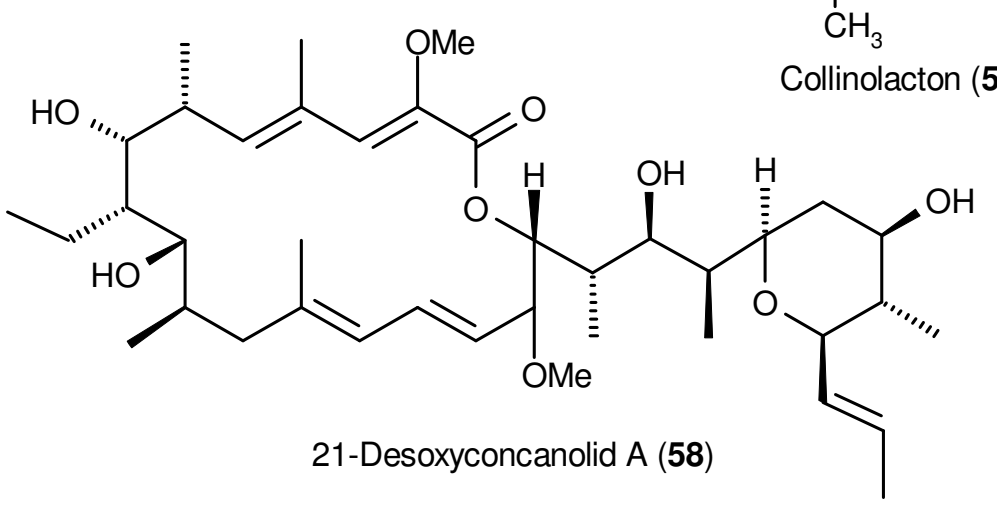<smiles>COC(=O)/C=C/c1ccc(O)cc1</smiles>
methylester (57)<smiles>C/C=C/C=C/C(O)C1(O)C(=O)OCC1CO</smiles>

Butyrolacton I (59)

Abbildung 22. Isolierte Substanzen aus verschiedenen Streptomyceten-Stämmen mit QS- oder AQS-Aktivität.

Das aus Streptomyces sp. isolierte $\gamma$-Butyrolacton I (59) zeigte eine Steigerung der Biolumineszenz. In der Literatur konnte bereits für strukturell verwandte $\gamma$-Butyrolactone gezeigt werden, dass sie die Differenzierung von Zellen und auch die Sekundärstoffproduktion induzieren. ${ }^{59}$ Beispielsweise ist das $\gamma$-Butyrolacton (60) in der Literatur auch als A-Faktor (Khokhlov-Faktor) ${ }^{60}$ beschrieben worden und für die Luftmycelbildung und Produktion von Streptomycin in Streptomyces griseus notwendig. Ein weiteres Beispiel ist das $\gamma$-Butyrolacton (61) aus Streptomyces viridochromogenes, auch als I-Faktor bezeichnet, dass für die Luftmycelbildung und Anthracyclinproduktion verantwortlich ist (s. Abbildung 23). ${ }^{61}$<smiles>CC(C)CCCCC(=O)C1C(=O)OC[C@H]1CO</smiles>

Khokhlov-Faktor (60)<smiles>CC(C)CCCC(O)C1C(=O)OC[C@H]1CO</smiles>

Faktor I (61)

Abbildung 23. Literatur bekannte $\gamma$-Butyrolactone aus Streptomyces sp..

\subsection{Anti-Biofilmklone aus dem Metagenom}

Im Arbeitskreis W. Streit (Universität Hamburg) wurden Metagenom-Bibliotheken aus Boden, Abflüssen und anderen terrestrischen Habitaten erstellt. Diese wurden in einem neu entwickelten Screeningsystem auf kleine und stabile Enzyme daraufhin untersucht, ob sie $N$-Acylhomoserinlactone als Signalmoleküle der Host-Organismen abbauen. Hierfür wurde 
ein funktionsbasierter Screening-Ansatz gewählt, da dieser das Finden neuer Enzymfamilien oder Klassen mit Quorum-Quenching-Aktivität aus dem Metagenom ermöglicht (s. Abschnitt 1.2 ). Das verwendete Detektionssystem beruht auf einem einfachen Reporterstamm des Gram-negativen Bakteriums Agrobakterium tumefaciens NTL4. A.tumefaciens ist ein pflanzenpathogenes Bodenbakterium, das über die Fähigkeit verfügt, DNA in pflanzliche Zellen zu übertragen. Dieser Vorgang ist QS-gesteuert, als Autoinducer dient hierbei das $N$ (3-Oxooctanoyl)-L-Homoserinlacton (3-Oxo-C $\mathrm{C}_{8}$-HSL, 62, s. Abbildung 24). Der im Testsystem eingesetzte Reporterstamm produziert selbst keine Signalmoleküle mehr und trägt zudem ein induzierbares Markergen. Die Idee dieses Detektionssystems beruht auf dem Prinzip des „Blau-Weiß-Screenings“: In Gegenwart des von außen zugefügten Autoinducers (3-Oxo-C ${ }_{8}-\mathrm{HSL}, 62$ ) wird das QS-kontrollierte Gen (TraI-Gen) abgelesen und die Expression des Markergens induziert (lacZ-Gen). Die Expression des lacZ-Gens führt zur Produktion des Enzyms $\beta$-Galaktosidase, dessen Aktivität durch die Zugabe des Substrats (X-Gal, 5-Bromo4-chloro-3-indoyl- $\beta$-D-galaktopyranosid) nachgewiesen werden kann. In Anwesenheit der $\beta$-Galaktosidase wird das Substrat (X-Gal) gespalten und eine resultierende Blaufärbung kann beobachtet werden. Trägt ein Metagenomklon ein Insert, das ein Enzym mit einer QuorumSensing-inhibierenden Aktivität (QSI) codiert, tritt keine Färbung auf, da das QS-Molekül abgebaut und die $\beta$-Galaktosidase nicht exprimiert wurde.

Die in diesem entwickelten Testsystem als positiv befundenen Klone wurden nach erneuter Überprüfung ihrer QSI-Aktivität sequenziert und durch Datenbankenvergleich auf Sequenzähnlichkeiten zu bekannten Genen untersucht. Alle Klone wiesen eine Insert-Größe zwischen 1-5 kb auf. Zur weiteren biologischen Verifizierung der QSI- oder QQ-Aktivität wurden die Inserts der positiv getesteten Klone in E. coli überführt und auf ihren Einfluss auf das QS im Reporterstamm A.tumefaciens NTL4 getestet. Als Substrat für die $\beta$-Galaktosidase wurde diesmal $o$-Nitrophenyl- $\beta$-D-galaktopyranosid eingesetzt, das bei Hydrolyse durch die $\beta$ Galaktosidase zur Gelbfärbung führt (ONPG-Test). Bereits nach 2 h Inkubation der im lacZTest aktiven E. coli-Zellextrakte mit 3-Oxo-C 8 -HSL (62), konnte eine signifikante Verringerung der AHL-Moleküle quantifiziert werden. Das Vorliegen metall-abhängiger Enzyme konnte durch die Zugabe von geringen Konzentrationen an $\mathrm{Zn}^{+}$- oder $\mathrm{Ca}^{2+}$-Ionen nachgewiesen werden. Nur in Gegenwart der jeweiligen Metallionen konnte ein signifikanter Abbau des 3-Oxo- $\mathrm{C}_{8}-\mathrm{HSL}$ (62) beobachtet werden. Mit Hilfe dieses Testsystems konnte eindeutig bestätigt werden, dass es sich bei den positiv eingeschätzten Klonen um AHL-abbauende, d.h. um QQ-aktive Enzyme handelt. Zusätzlich wurde der Einfluss dieser Klone auf verschiedene QS-kontrollierte Phänotypen des Gram-negativen Bakteriums P. aeruginosa wie Motilität, 
Pyocyaninbildung und Biofilmbildung hin untersucht. Hierzu wurden die Klone zunächst in P. aeruginosa PAO1 transformiert und auf einen inhibierenden Einfluss aller Phänotypen getestet. So konnte experimentell gezeigt werden, dass die aktiven Metagenomklone die Bildung von Biofilm in einem sehr frühen Stadium verhindern bzw. dahingehend beeinflussen, dass keine Anheftung von Biofilm an der Oberfläche beobachtet werden kann. ${ }^{62}$ Zur Bestätigung des inhibierenden Einflusses auf die Phänotypen wurden für jeden Klon Knock-outMutanten hergestellt, die eindeutig die Eigenschaften des Wildtyps wieder aufwiesen (Komplementations-Experiment). Aufgrund ihrer Fähigkeit die Bildung von Biofilm zu inhibieren, werden die Klone im Folgenden als Bpi-Proteine, Biofilm Phänotyp-inhhibierende Klone, bezeichnet. ${ }^{62}$

\subsubsection{Enzymatischer Abbau von $N$-Acylhomoserinlactonen}

Für den enzymatischen Abbau oder eine enzymatische Modifikation von $N$-Acylhomoserinlactonen (AHL) werden in der Literatur bisher Lactonasen, Acylasen, Oxidoreduktasen und Oxidasen beschrieben (s. Abbildung 24). ${ }^{63}$

AHL-abbauende Enzyme<smiles>CCCCCC(=O)CC(=O)NC1CCOC1=O</smiles><smiles>CCCCCCCCCCCC(=O)N[C@H]1CCOC1=O</smiles>

AHL-modifizierende Enzyme<smiles>CCCCCC(=O)CC(=O)NC1CCOC1=O</smiles><smiles>CCCCCC(O)CC(=O)N[C@H]1CCOC1=O</smiles><smiles>CCCCCCCCCCCC(=O)NC1CCOC1=O</smiles>

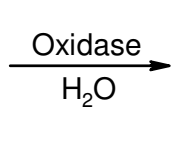<smiles>CC(O)CCCCCCCCCC(=O)N[C@H]1CCOC1=O</smiles>

Abbildung 24. Bisher literaturbekannte enzymatische Mechanismen zum Abbau bzw. zur Modifikation von $N$-Acylhomoserinlactonen. 
Alle Enzyme haben gemeinsam, dass ihre Aktivität zur Inaktivierung der $N$-Acylhomoserinlactone führt und damit die Signal-Transduktions-Kaskade des QS unterbrochen wird. Dieser Prozess wird als Quorum-Quenching (QQ) bezeichnet (s. Abschnitt 3.1.1 ).

AHL-Lactonasen führen zur Hydrolyse des Lactonringes, wobei das entsprechende $N$-Acylhomoserin freigesetzt wird, das nicht mehr als Signalmolekül fungiert. Diese Hydrolyse verläuft entsprechend der alkalischen Hydrolyse. Im sauren Medium kann sich der gespaltene Lactonring wieder reversibel schließen. Die alkalische Hydrolyse des Lactonringes von AHLs kann bereits bei schwach alkalischem pH-Wert beobachtet werden. Je kürzer die Acylkette, desto schneller wird der Lactonring gespalten und führt zum entsprechenden $N$-Acylhomoserin. $^{63}$

Lactonase-Aktivitäten wurden erstmals in Gram-positiven Bakterien der Spezies Bacillus sp. gefunden. ${ }^{64}$ In der Literatur werden zwei Familien von Lactonasen beschrieben. Hierzu gehört die Gruppe der $\mathrm{Zn}^{2+}$-abhängigen AiiA-Lactonasen, die unter den Gram-negativen und Grampositiven Bakterien weit verbreitet sind. ${ }^{63}$ Die Aktivität dieser Enzyme ist unabängig von der Acylkettenlänge und dem Substitutionsmuster des Acylrestes. Bei der anderen Gruppe handelt es sich um die $\mathrm{Zn}^{2+}$-abhängigen QsdA-Lactonasen aus Rhodococcus erythropolis, die nicht mit den AiiA-Lactonasen verwandt sind. ${ }^{63}$ Auch in Eukaryoten und im Serum von Säugetieren konnten Lactonasen identifiziert werden. Letztere sind im Gegensatz zu AHLLactonasen $\mathrm{Ca}^{2+}$-Ionen abhängig. Beispielsweise wurde von drei Paraoxonasen berichtet, die über den Abbau von AHLs die QS-kontrollierte Bildung von Biofilm in P. aeruginosa inhibieren können. ${ }^{65}$

Enzymatische Aktivitäten von AHL-Acylasen, die irreversibel die Amidbindung von AHLs hydrolysieren, wurden bisher in Eukaryoten und Prokaryoten beschrieben. ${ }^{63}$ Viele Acylasen spalten nur $\mathrm{N}$-Acylhomoserinlactone mit einer langkettigen Acylkette und sind nicht in der Lage, ein Substrat mit einer Kettenlänge kürzer als acht Kohlenstoffatome zu hydrolysieren. Enzyme, die die Acylkette von N-Acylhomoserinlactonen modifizieren und somit QS stören, sind bisher nur in Prokaryoten gefunden worden. Die erste AHL-Oxidoreduktase-Aktivität wurde in Rhodococcus erythropolis entdeckt. ${ }^{66}$ Dieses Enzym reduziert die 3-Oxo-Ketofunktion zum entsprechenden Alkohol. Die Reduktion erfolgt bei Substraten mit einer Acylkettenlänge zwischen acht und vierzehn Kohlenstoffatomen. Eine weitere Oxidase-Aktivität wurde in Bacillus megaterium gefunden. ${ }^{67}$ Dieses Enzym oxidiert langkettige AHLs mit mindestens zwölf Kohlenstoffatomen in der $\omega-1, \omega-2$ und $\omega$-3-Position, wobei es die größte Affinität zu 3-Oxo-Derivaten aufweist. 


\subsubsection{Analytik von Metagenomklonen}

In der Arbeitsgruppe W. Streit (Universität Hamburg) zeigten verschiedene mit Hilfe der Klone der Metagenom-Bank identifizierte BpiB-Proteine (Biofilm Phänotyp-inhhibierende Proteine) im ONPG-Test eine quantifizierbare Verringerung der Gelbfärbung, worauf auf die Abnahme des eingesetzten $N$-(3-Oxooctanoyl)-L-Homoserinlactons (3-Oxo- $\mathrm{C}_{8}-\mathrm{HSL}, 62$ ) geschlossen wurde und damit auf einen enzymatischen Abbau des 3-Oxo-C 8 -HSL (62). Des Weiteren wurden die verschiedenen BpiB-Proteine auf ihren inhibierenden Einfluss verschiedener Phänotypen wie Motilität, Pyocyaninbildung und Biofilmbildung bei P. aeruginosa PAO1 erfolgreich überprüft. Hierbei konnten anhand von Datenbankvergleichen (BlastP) zwei neue Familien von Lactonasen identifiziert werden und eine Quorum-Quenching-Aktivität in biologischen Tests reproduzierbar bestätigt werden. Zur Verifizierung der Quorum-Quenching-Aktivität dieser vermutlichen Lactonasen, die durch Hydrolyse des Lactonringes des $N$-Acylhomoserinlactons QS inhibieren, wurden HPLC-ESIMS-Analysen im Rahmen der vorliegenden Arbeit durchgeführt, um anhand des Hydrolyseproduktes die Lactonase-Aktivität eindeutig auf molekularer, stofflicher Ebene zu bestätigen. Hierzu wurden Inkubationsansätze mit Bpi-Proteinen (Größe der Inserts zwischen 1-5 kb) und $N$-Acylhomoserinlacton (AHL) als Substrat hergestellt. Diese Arbeiten wurden für die Bpi-Proteine BpiB01, BpiB04, BpiB05 und BpiB09 von C. Schipper (AK Streit, Hamburg) durchgeführt; für das Bpi-Protein BpiB07 von C. Hornung (AK Streit, Hamburg). Für die Proteine BpiB01, BpiB04, BpiB05 und BpiB09 wurden als Substrate N-(3-Oxooctanoyl)-LHomoserinlacton (3-Oxo- $\left.\mathrm{C}_{8}-\mathrm{HSL}, 62\right)$ und $N$-(Dodecanoyl)-DL-Homoserinlacton $\left(\mathrm{C}_{12}\right.$-HSL, 64) eingesetzt. Die mittels Protino ${ }^{\circledR}$-Säulen (Firma Macherey-Nagel) aufgereinigten Proteine BpiB01, BpiB04, BpiB05 und BpiB09 oder deren Rohextrakte wurden mit dem jeweiligen AHL für $20 \mathrm{~h}$ bei $30^{\circ} \mathrm{C}$ inkubiert. Vor Zugabe des jeweiligen Substrats wurde bei der Dialyse der Proteine BpiB01, BpiB04 und BpiB09 $\mathrm{ZnCl}_{2}$ oder beim Protein $B p i B 05 \mathrm{CaCl}_{2}$ als benötigter Cofaktor in einer Endkonzentration von $2 \mathrm{mM}$ zugefügt. Das aufgereinigte Protein BpiB07 wurde mit 3-Oxo-C $\mathrm{C}_{8}$-HSL für $20 \mathrm{~h}$ bei $30^{\circ} \mathrm{C}$ inkubiert. Vor Zugabe des Substrats wurde bei der Dialyse $\mathrm{ZnCl}_{2}$ in einer Endkonzentration von $0.2 \mathrm{mM}$ zugegeben. Zur Kontrolle wurde das Eluat der Kultur des Kontrollstammes mit Leervektor ebenfalls zunächst dialysiert und anschließend mit dem jeweiligen Substrat für $20 \mathrm{~h}$ bei $30^{\circ} \mathrm{C}$ inkubiert. Alle Inkubationsansätze wurden mit Ethylacetat extrahiert.

Mit Hilfe der HPLC-ESI-MS-Analyse sollten die erhaltenen Extrakte auf ein mögliches Spaltprodukt des Substrats untersucht werden. Dazu wurde die Detektion von Massenaddukten der 
$N$-Acylhomoserine 3-Oxo- $\mathrm{C}_{8}$-HS (63) und $\mathrm{C}_{12}$-HS (65) für die QQ-Aktivität der BpiBProteine als Beleg für die Lactonase-Aktivität herangezogen (s. Abbildung 25).

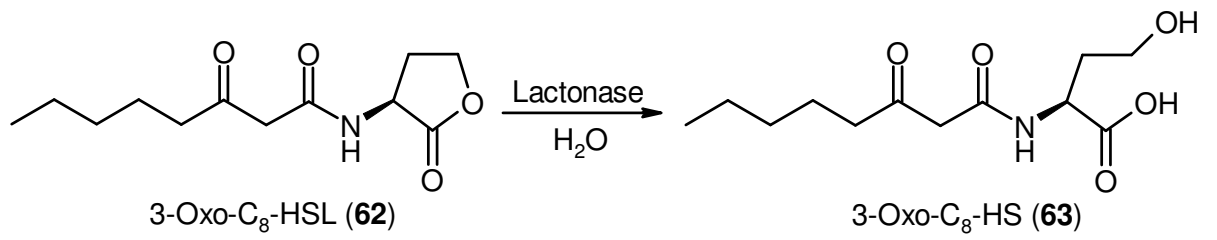<smiles>CCCCCCCCCCCC(=O)NC1CCOC1C(=O)OCCCCCCCCCCCCC(=O)NC(CCO)C(=O)O</smiles>

Abbildung 25. Enzymatische Hydrolyse der Substrate 3-Oxo- $\mathrm{C}_{8}-\mathrm{HSL}$ (62) und $\mathrm{C}_{12}$-HSL (64).

Zur Probenvorbereitung wurden die erhaltenen Ethylacetat-Extrakte aus den Inkubationsansätzen mit BpiB-Proteinen und „Leervektor“ in $110 \mu \mathrm{L}$ Methanol gelöst. Die Messung der Proben erfolgte mittels HPLC-ESI-MS (HPLC D, Säule A: Grom Superspher 100, RP-18, Programm B: $\mathrm{MeOH} / \mathrm{H}_{2} \mathrm{O}$, jeweils mit $0.05 \%$ Ameisensäure, Gradient; s. Abschnitt B 1.2 im positiven und negativen Modus.

\section{HPLC-ESI-MS-Proben für ein BpiB-Protein mit Lactonase-Aktivität}

1. Inkubationsansatz des jeweiligen Bpi-Proteins (2 Ansätze)

2. „Leervektor“ mit Substrat als Kontrollexperiment

3. 10-20 $\mu \mathrm{L}$ der jeweiligen Stammlösung (in DMSO) des Autoinducers als Kontrolle

4. Hydrolyseprodukt des jeweiligen Autoinducer-Substrats aus chemischer Hydrolyse (Standard mit $c=1.0 \mathrm{mg} / \mathrm{mL}$ ) als Kontrolle

\section{Etablierung der HPLC-ESI-MS-Methode zur QQ-Analyse}

In Vorversuchen für die HPLC-ESI-MS-Analytik wurde zunächst versucht, die genaue Nachweisgrenze von 3-Oxo- $\mathrm{C}_{8}$-HSL (62) zu bestimmen, um für die spätere Analytik der Inkubationsansätze eine noch detektierbare Konzentration an Spaltprodukt 63 zu gewährleisten. Im ONPG-Test wurden zur Quantifizierung des Abbaus von AHLs Konzentrationen von $c=5.0 \mathrm{nM}$ (Endkonzentration im Inkubationsansatz) für 62 eingesetzt. Dies entspricht einem Konzentrationsbereich, in dem eine chemische Analyse bei gegebener Ausstattung nicht erfolgen konnte. Aus diesem Grund wurde zuerst das 3-Oxo-C ${ }_{8}-\mathrm{HSL}$ (62) mit $1 \mathrm{~N} \mathrm{NaOH}$ in DMSO teilweise hydrolysiert, um das hierbei erhaltene Spaltprodukt 3-Oxo- $\mathrm{C}_{8}-\mathrm{HS}$ (63) als Referenzsubstanz in der folgenden Analytik einsetzen zu können. ${ }^{64}$ Es wurden sowohl das 
Substrat 62 als auch das chemisch unvollständig hydrolysierte Spaltprodukt 63 in verschiedenen Konzentrationen von $c=1.0 \mathrm{mg} / \mathrm{mL}, 0.5 \mathrm{mg} / \mathrm{mL}, 50 \mu \mathrm{g} / \mathrm{mL}$ und $5 \mu \mathrm{g} / \mathrm{mL}$ in

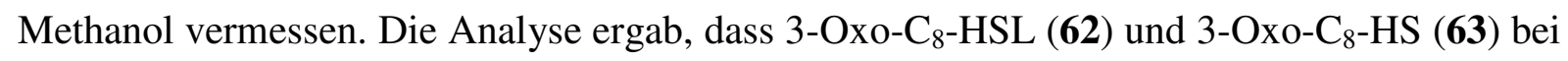
einer Konzentration von $c=5 \mu \mathrm{g} / \mathrm{mL}$ massenspektrometrisch nicht mehr nachgewiesen werden können, wohingegen bei einer Konzentration von $c=50 \mu \mathrm{g} / \mathrm{mL}$ eine Detektion sowohl im UV- als auch im Massenspektrum noch möglich ist. Aus diesem Grunde wurde pro

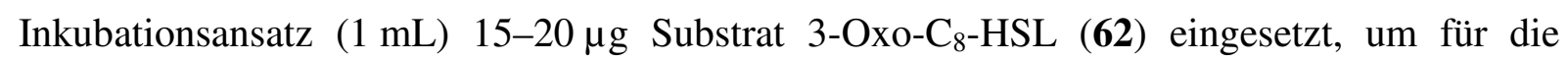
HPLC-ESI-MS-Analyse eine Endkonzentration von $c=50 \mu \mathrm{g} / \mathrm{mL}$ in $110 \mu \mathrm{L}$ Methanol sicher zu stellen. Allererste Untersuchungen von Inkubationsansätzen mit dem Substrat 3-Oxo- $\mathrm{C}_{8-}$ HSL (62) zeigten das gesuchte Hydrolyseprodukt 63 lediglich in Spuren und nicht reproduzierbar. Es wurde vermutet, dass eventuell vorhandenes Spaltprodukt 63 durch Extraktion bei alkalischem pH-Wert nicht in die Ethylacetatphase aufgenommen wurde. Zur Überprüfung erfolgte in eigenen Arbeiten eine pH-Einstellung zugeschickter Inkubationsansätze nach einmaliger Extraktion mit Ethylacetat auf $\mathrm{pH}=5.5$ mit $0.5 \mathrm{~N} \mathrm{HCl}$, um dann ein weiteres Mal mit Ethylacetat zu extrahieren. Allerdings ergab die HPLC-ESI-MS-Analyse keine Verbesserung hinsichtlich des zu beobachtbaren Umsatzes. Als nächstes wurde zur Verbesserung der Löslichkeit des Substrats dem Kooperationspartner (AK Streit) vorgeschlagen, das Substrat $\mathbf{6 2}$ anstatt in Ethylacetat in DMSO gelöst zuzugeben. Aufgrund der Reaktionsführung konnte nämlich eine permanente Durchmischung der wässrigen und organischen Phasen während der Inkubation nicht ermöglicht werden. Es wurde angenommen, dass nur an der Phasengrenze eine enzymatische Hydrolyse des Substrats stattfindet, was lediglich nur zu einem Umsatz führte, dessen Größenordnung nur geringfügig über der Nachweisgrenze lag. Die veränderte Zugabe des 3-Oxo- $\mathrm{C}_{8}-\mathrm{HSL}$ (62) führte zu einer reproduzierbaren massenspektrometrischen Detektion des Spaltprodukts 63. Allerdings konnte diese nicht im UV-Spektrum erfolgen. Für eine Quantifizierung des enzymatischen Umsatzes ist aber eine Detektion im UV-Spektrum erforderlich, um eine enzymatische Aktivität im Vergleich zur Kontrolle belegen zu können. Eine veränderte Induktion für das BpiB-Protein BpiB07, die von C. Hornung (AK Streit) erfolgreich etabliert wurde, ermöglichte eine signifikante Detektion des 3-Oxo- $\mathrm{C}_{8}-\mathrm{HS}$ (63) im UV-Spektrum. Zusätzlich zu den optimierten Inkubationsbedingungen führte die $\mathrm{Zugabe}$ von $\mathrm{Zn}^{2+}$ - bzw. $\mathrm{Ca}^{2+}$-Ionen bei allen BpiB-Proteinen zu einer reproduzierbaren Erhöhung des Spaltproduktes 63, da es sich hierbei um metallabhängige Lactonasen handelt. Allerdings ergaben Untersuchungen hinsichtlich der eingesetzten Substratkonzentration eine notwendige Konzentration von mindestens 
$c=20 \mu \mathrm{g} / \mathrm{mL}$. Bei niedrigeren Konzentrationen konnte kein Hydrolyseprodukt mittels HPLCESI-MS detektiert werden.

Im Folgenden wird die Verifizierung der Lactonase-Aktivität der BpiB-Proteine BpiB07, BpiB04 und BpiB01 mittels der hier etablierten HPLC-ESI-MS-Methode vorgestellt. ${ }^{62}$ Hierbei handelt es sich bei den BpiB-Proteinen BpiBO1 und BpiBO4 um die ersten Vertreter zwei neuer Lactonase-Familien, wohingegen BpiB07 Sequenzähnlichkeiten zu bekannten Lactonasen aufweist. ${ }^{62}$

Die Untersuchungen der Extrakte ergaben für jedes der BpiB-Proteine, dass bei der enzymatischen Spaltung des 3-Oxo- $\mathrm{C}_{8}$-Homoserinlactons (62) ein Gemisch aus 3-Oxo- $\mathrm{C}_{8}-$ HSL (62) und einer polareren Verbindung entsteht, für die Retentionszeiten von 8.3 min und 7.4 min resultierten (s. Abbildung 28, A). Zusätzlich trat bei $9.1 \mathrm{~min}$ der Methylester des 3-Oxo-C $\mathrm{C}_{8}$-HSL (62a) auf, der möglicherweise unter den gegebenen HPLC-MS-Bedingungen durch saure Methanolyse des Substrats gebildet wird. Weitere auftretende Signale sind Substanzen aus dem Medium zuzuordnen. ESI-MS-Analysen der polareren Komponente zeigten Massenaddukte bei $\mathrm{m} / z=260.1[\mathrm{M}+\mathrm{H}]^{+}, 282.1[\mathrm{M}+\mathrm{Na}]^{+}$und $540.1[2 \mathrm{M}+\mathrm{Na}]^{+}(\mathrm{s}$. Abbildung 28, B). Diese Massenzunahme von 18 stimmt mit der Spaltung des Lactonrings von 3-Oxo-C - $_{8}$ HSL (62, M= $\left.241.2 \mathrm{~g} / \mathrm{mol}\right)$ überein, bei der das $\mathrm{N}$-Acylhomoserin 3-Oxo- $\mathrm{C}_{8}$ HS (63, M = 259.2 g/mol) erhalten wird (s. Abbildung 26).

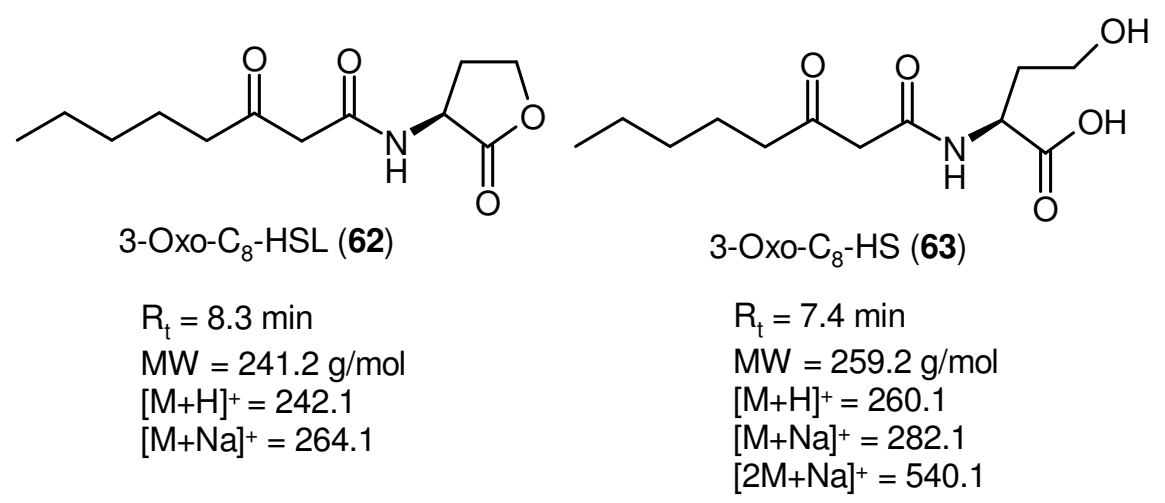

Abbildung 26. Massen und entsprechende Massenaddukte des 3-Oxo- $\mathrm{C}_{8}-\mathrm{HSL}$ (62) und des Hydrolyseprodukts 3-Oxo-C 8 -HS (63).

Für das Substrat 3-Oxo-C 8 -HSL wurden in der ESI-MS Massenaddukte bei $\mathrm{m} / \mathrm{z}=$ von 242.1 $[\mathrm{M}+\mathrm{H}]^{+}$und $264.1[\mathrm{M}+\mathrm{Na}]^{+}$detektiert. (s. Abbildung 29, F). Der bei der HPLC-MSAnalytik gebildete Methylester konnte anhand der Massenionen bei $\mathrm{m} / \mathrm{z}=272.1[\mathrm{M}+\mathrm{H}]^{+}$und $294.1[\mathrm{M}+\mathrm{Na}]^{+}$identifiziert werden. 


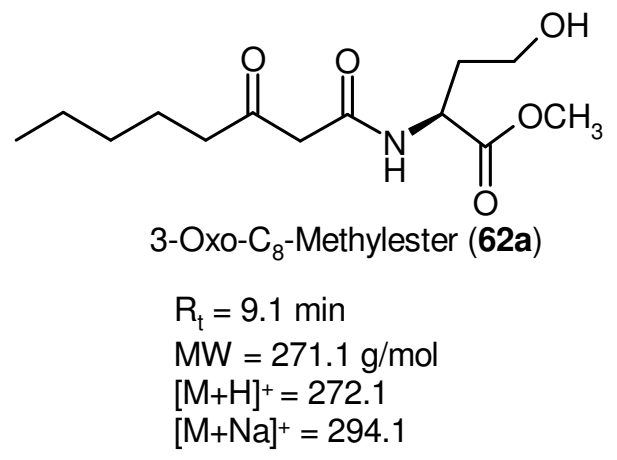

Abbildung 27. Massen und entsprechende Massenaddukte des Methylesters von 3-Oxo- $\mathrm{C}_{8}-\mathrm{HSL}$ (62a).

Zusätzliche beobachtbare Massenaddukte sind auch hier Substanzen aus dem Medium zuzuordnen. Tandem-MS des Massenions bei $\mathrm{m} / \mathrm{z}=260.1[\mathrm{M}+\mathrm{H}]^{+}$zeigte die charakteristischen Tochterionen bei $m / z=242$ und 102 des Reaktionsprodukts 3-Oxo- $\mathrm{C}_{8}-\mathrm{HS}(\mathbf{6 3})$. Zusätzlich bestätigte die aus der HRMS des $[\mathrm{M}+\mathrm{H}]^{+}$-Ions bei $\mathrm{m} / z=260.1$ erhaltene Summenformel $\mathrm{C}_{12} \mathrm{H}_{21} \mathrm{NO}_{5}$ das $\mathrm{N}$-Acylhomoserin 3-Oxo- $\mathrm{C}_{8}$-HS (63).

Die BpiB-Proteine BpiB07, BpiBO4 und BpiB01 sind in der Abbildung 28 entsprechend ihres abnehmenden enzymatischen Umsatzes abgebildet. Die beobachtete Abnahme stimmt mit der Stärke ihres inhibierenden Einflusses auf die Ausbildung von Biofilm in P. aeruginosa PAO1 überein. Hierbei hemmte das BpiB-Protein BpiB07 die Biofilmbildung am stärksten, während das BpiB-Protein BpiB01 die geringste Hemmung aufwies. ${ }^{62}$

Zur weiteren Verifizierung der Lactonase-Aktivität wurde das 3-Oxo- $\mathrm{C}_{8}$-L-HSL (62) unvollständig und vollständig alkalisch hydrolysiert (s. Abbildung 29, A und C). HPLC-MSAnalysen zeigten, dass sowohl die Retentionszeiten als auch die Massenspektren des synthetischen Reaktionsprodukts mit denen des enzymatischen Spaltprodukts übereinstimmten (s. Abbildung 28 und Abbildung 29). Die unvollständige Hydrolyse von 3-Oxo- $\mathrm{C}_{8}-\mathrm{HSL}$ (62) zeigt das Spaltprodukt mit dem geöffneten Lactonring (7.4 min) und den zugehörigen Massenaddukten bei $m / z=260.0[\mathrm{M}+\mathrm{H}]^{+}, 282.1[\mathrm{M}+\mathrm{Na}]^{+}$und $540.9[2 \mathrm{M}+\mathrm{Na}]^{+}$sowie das Substrat 3-Oxo-C $\mathrm{C}_{8}$-HSL $(8.3 \mathrm{~min}) \mathrm{mit}$ den entsprechenden Massenionen bei $\mathrm{m} / \mathrm{z}=242.1$ $[\mathrm{M}+\mathrm{H}]^{+}$und $264.1[\mathrm{M}+\mathrm{Na}]^{+}$, die zusätzlichen Schultern der Signale sind vermutlich auf die jeweiligen Tautomere der Keto-Enol-Tautomerie zurückzuführen (s. Abbildung 29, A und C). Die vollständige Hydrolyse weist dahingegen nur das Spaltprodukt 63 auf (s. Abbildung 29, C). Bei der unvollständigen Hydrolyse des Substrats 62 konnte ebenfalls die Bildung des Methylesters (62a) bei einer Retentionszeit von $9.8 \mathrm{~min}$ und entsprechende Massenaddukte bei $m / z=272.1[\mathrm{M}+\mathrm{H}]^{+}$und $294.1[\mathrm{M}+\mathrm{Na}]^{+}$beobachtet werden, wohingegen bei der vollständigen Hydrolyse keine Veresterung der freien Säure mit Methanol detektiert wird (s. Abbildung 29 C). 
A

$\operatorname{BpiB07}(\mathrm{UV})$

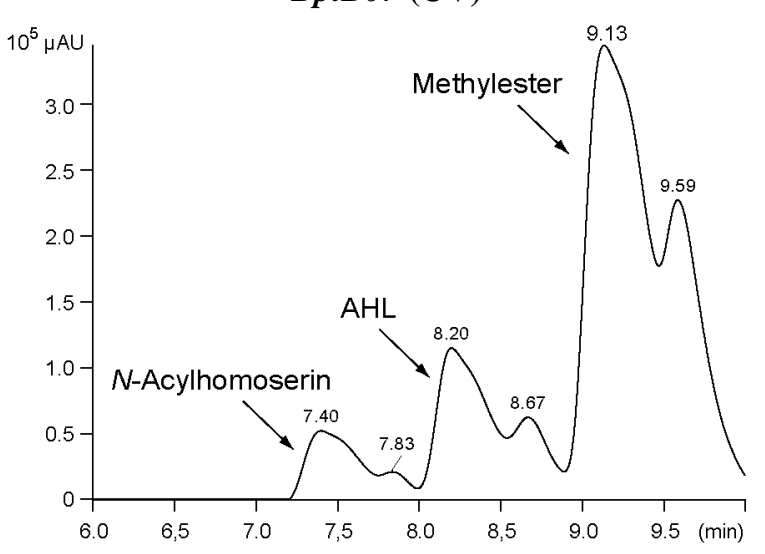

BpiB04 (UV)

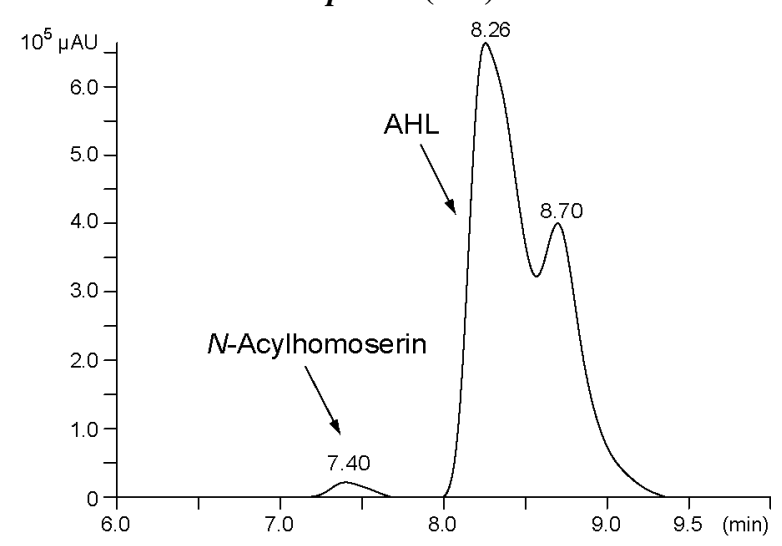

BpiB01 (UV)

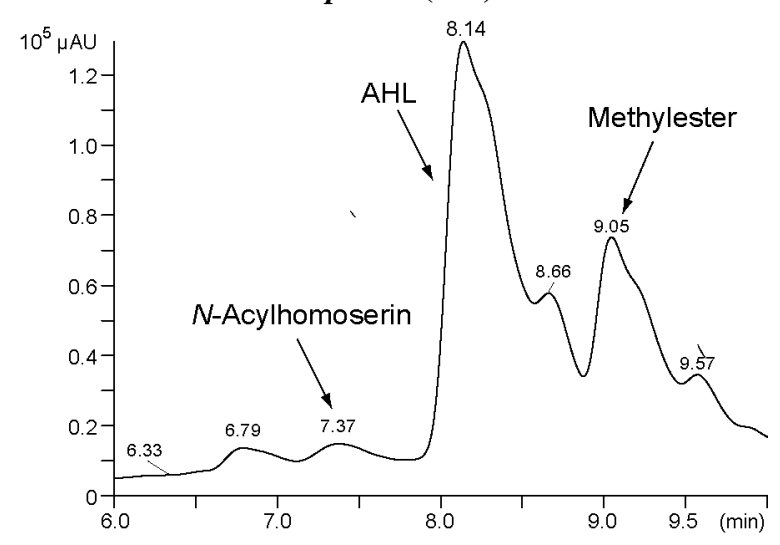

B

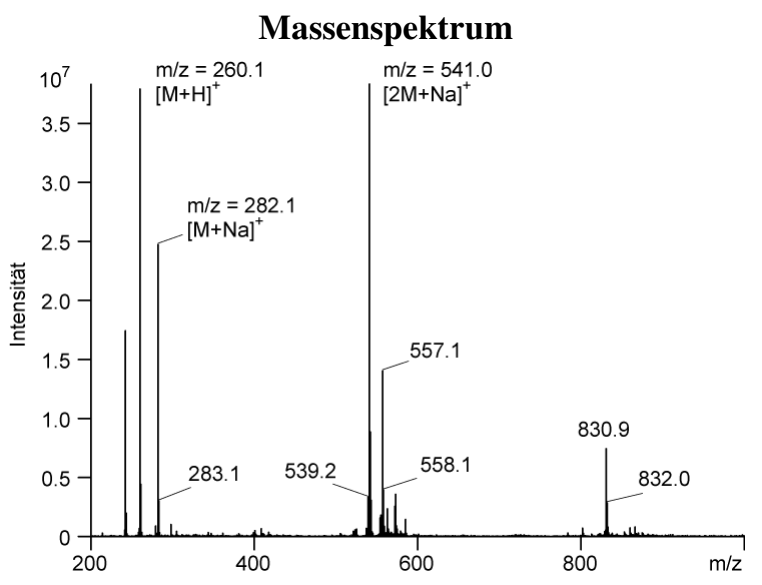

Massenspektrum
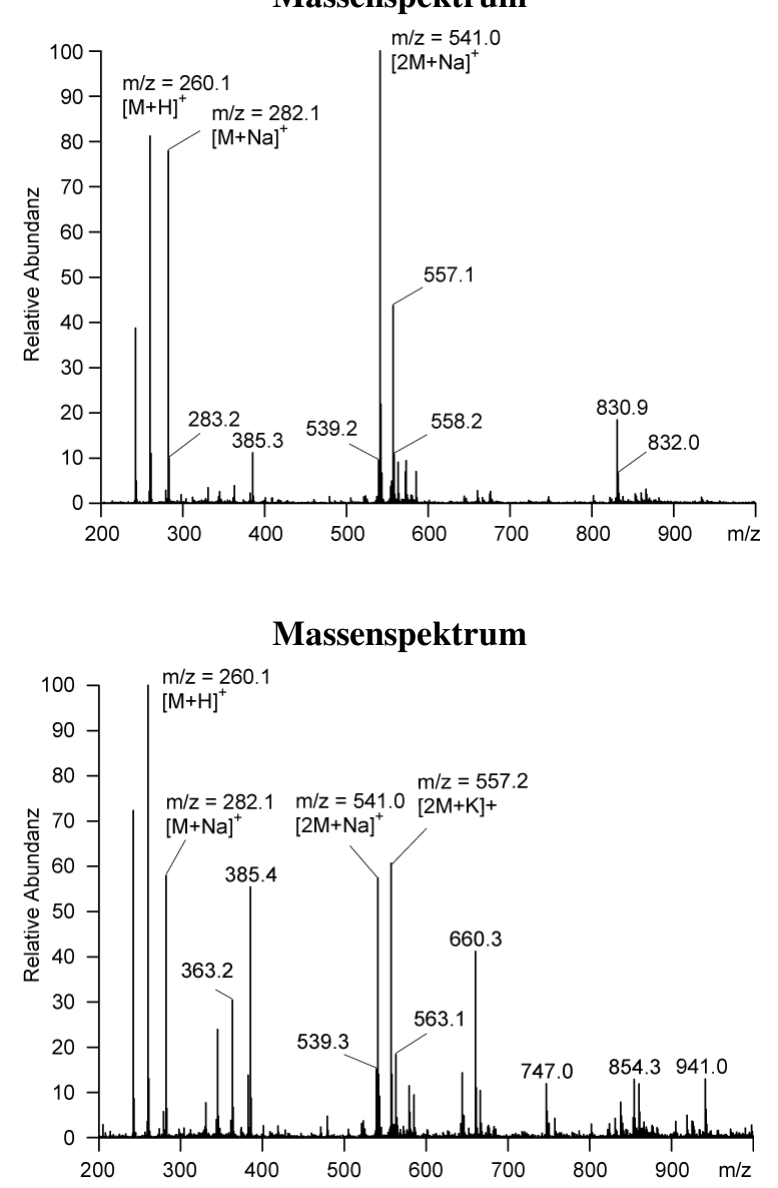

Abbildung 28. HPLC-ESI-MS-Analysen der Inkubationsansätze von den BpiB-Proteinen BpiB07, BpiB04, BpiB01 mit 3-Oxo-C $\mathrm{C}_{8}-\mathrm{HSL}$ (62). A: HPLC-UV-Chromatogramme der BpiB-Proteine bei $252 \mathrm{~nm}$ mit Substrat (AHL, 62), Spaltprodukt (N-Acylhomoserin, 63) und Methylester (62a). Die BpiB-Proteine zeigen von oben nach unten einen abnehmenden enzymatischen Umsatz. B: Massenspektren des Spaltprodukts ( $N$-Acylhomoserin 63) mit gekennzeichneten Massenaddukten.

Mit Hilfe des vollständig hydrolysierten Spaltprodukts 63 kann außerdem eine unter sauren Bedingungen reversible Ringschließung des geöffneten Lactonringes in signifikantem 
Umfang ausgeschlossen werden, da das Produkt dieser Ringschließung, 3-Oxo- $\mathrm{C}_{8}$-HSL (62), lediglich in Spuren im UV- und Massenspektrum detektiert wurde. Damit ist gezeigt, dass der geringe enzymatische Umsatz der BpiB-Proteine nicht auf eine reversible Ringschließung unter den gegebenen HPLC-MS-Bedingungen zurückzuführen ist.

Die Analyse der Kontrollen, in denen 3-Oxo- $\mathrm{C}_{8}$-HSL mit Rohextrakten bzw. Eluaten der Leervektorkontrollen von E. coli BL21 inkubiert worden war, ergaben ebenfalls keine signifikanten Mengen des $N$-Acylhomoserins 3-Oxo-C ${ }_{8}$-HS (63, s. Abbildung 29, E und F), so dass eine umfangreiche unspezifische Spaltung von E. coli-eigenen Proteinen bei den stattgefundenen Analysen der BpiB-Proben ausgeschlossen werden kann. Die lediglich sehr geringen Mengen an detektierbarem 63 können auf die in der Literatur beschriebene Hydrolyse-Instabilität von $N$-Acylhomoserinlactonen zurückgeführt werden. (s. Abbildung 29 E). Die durchgeführten HPLC-MS-Analysen bestätigen die Annahme, dass es sich bei den QS-inhibierenden BpiB-Proteinen BpiB01, BpiB04 und BpiB07 um Lactonasen handelt. Es konnte gezeigt werden, das 3-Oxo- $\mathrm{C}_{8}$-HSL (62) in Gegenwart der BpiB-Proteine durch enzymatische Hydrolyse des Lactonringes in das entsprechende $N$-Acylhomoserin (63) überführt wird und damit das Signalmolekül inaktiviert wird. Damit konnte eindeutig die QQAktivität dieser Lactonasen verifiziert werden. Hierbei handelt es sich bei den Bpi-Proteinen BpiB01 und BpiB04 um die ersten Vertreter zwei neuer Lactonase-Familien. ${ }^{62}$ 
A

Unvollständige Hydrolyse (UV)

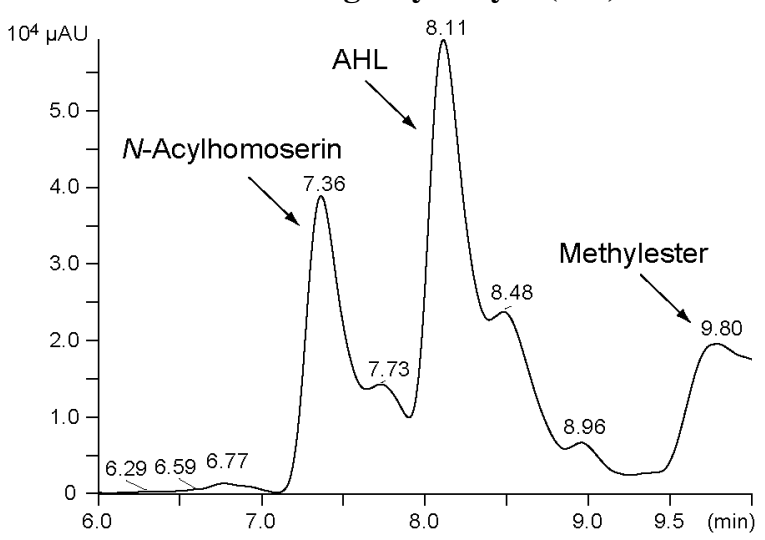

C

Vollständige Hydrolyse (UV)

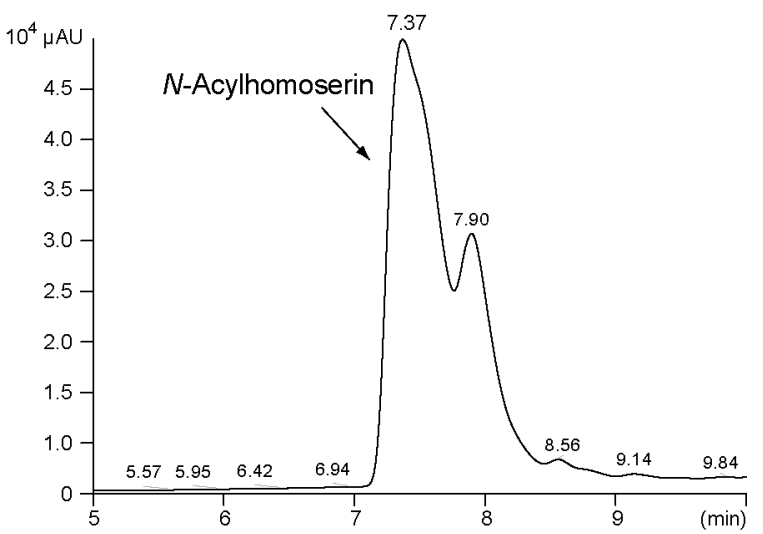

$\mathbf{E}$

\section{Leervektor mit AHL (UV)}

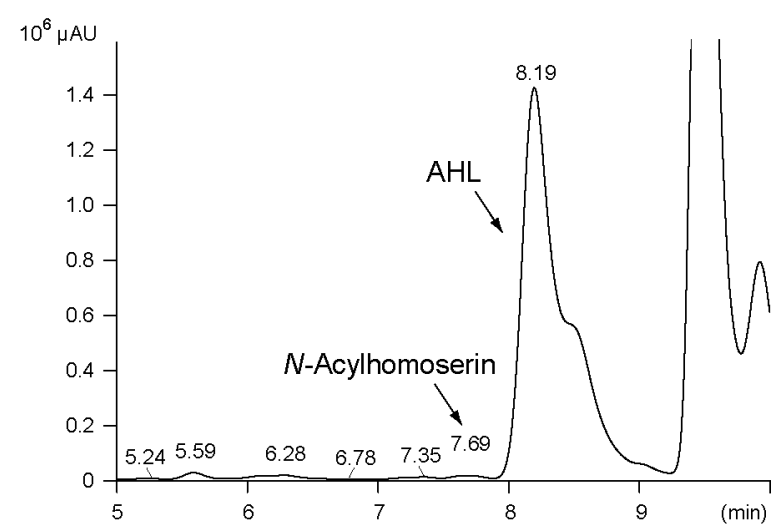

B

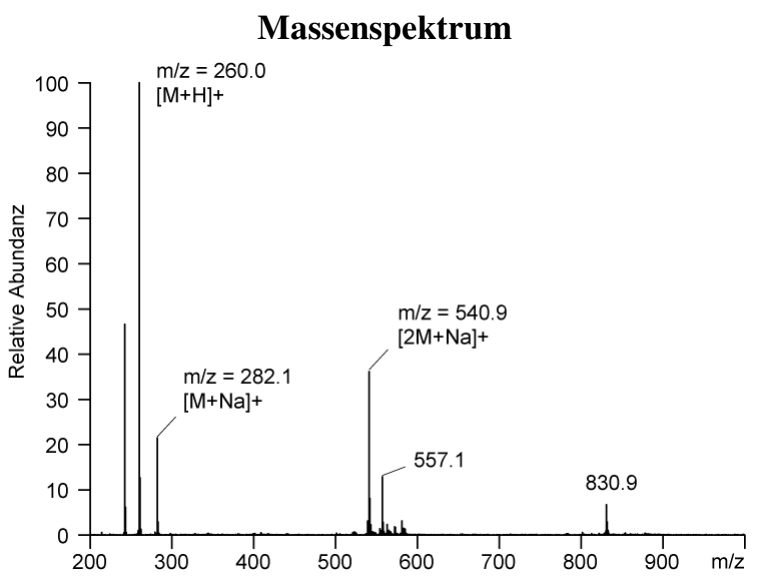

D

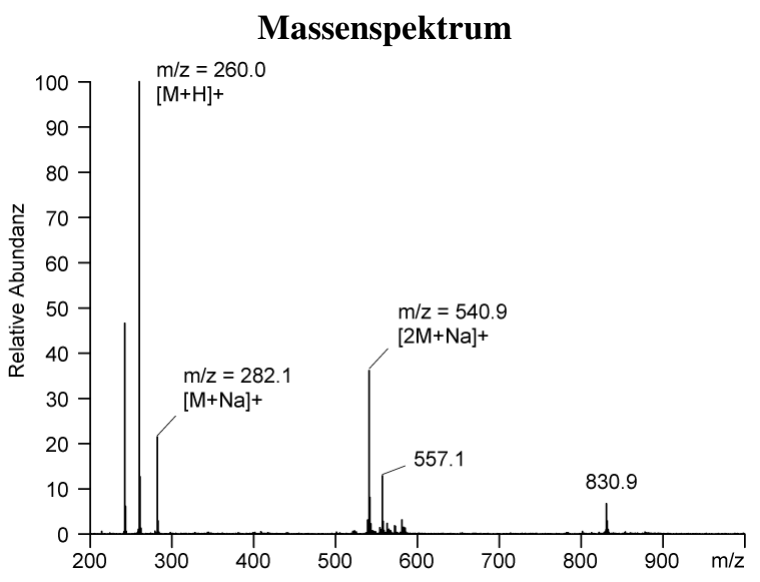

$\mathbf{F}$

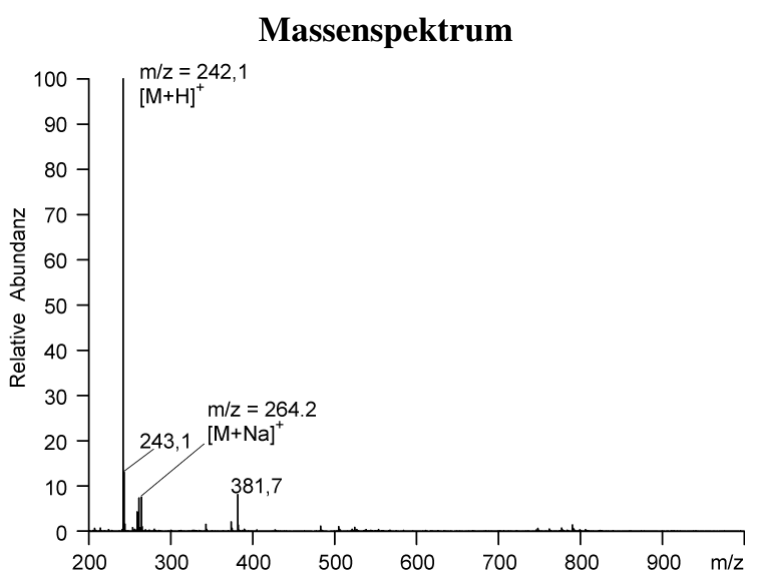

Abbildung 29. HPLC-ESI-MS-Analysen der alkalischen Hydrolysen 3-Oxo- $\mathrm{C}_{8}-\mathrm{HSL}$ (62) und der Negativkontrolle zur Verifizierung der Lactonase-Aktivität von BpiB-Proteinen. A und C: HPLC-UV-Chromatogramme der unvollständigen und vollständigen alkalischen Hydrolyse bei $252 \mathrm{~nm}$. Substrat (AHL) und Spaltprodukt ( $N$-Acylhomoserin) sind markiert. B und D: Massenspektren des Spaltprodukts 63 mit gekennzeichneten Massenaddukten. E: HPLC-UV Chromatogramm der Kontrolle des Leervektor-Rohextrakts nach Inkubation mit 3-Oxo-C ${ }_{8}$-HSL (62) bei $252 \mathrm{~nm}$ mit Substrat (AHL, 62), Spaltprodukt ( $N$-Acylhomoserin, 63) und Methylester (62a). F: Massenspektren des Substrats 62 mit gekennzeichneten Massenaddukten. 


\section{Erweiterung des AHL-Substratspektrums}

Zur weiteren Steigerung des enzymatischen Umsatzes wurde unserem Kooperationspartner (AK Streit) vorgeschlagen, Substrate mit unterschiedlichen Seitenketten einzusetzen. Hiermit sollte überprüft werden, ob möglicherweise ein anderes $N$-Acylhomoserinlacton ein für die jeweilige Lactonase geeigneteres Substrat darstellt. Als weitere Substrate wurden das $\mathrm{C}_{12}$-HSL (64) und 3-Oxo-C 6 -HSL (68) auf ihre Eignung getestet (s. Abbildung 25 und Abbildung 30). Erste Untersuchungen zeigten, dass mittels HPLC-ESI-MS für das $\mathrm{C}_{12}$-HSL (64) massenspektrometrisch nur geringe Mengen an Spaltprodukt 65 beobachtet werden konnten. Dahingegen wies eine Probe allein mit dem Substrat 3-Oxo-C 6 -HSL (68) schon signifikante Mengen des Spaltprodukts 69 mit entsprechender Masse auf, wodurch von vornherein die Quantifizierung einer enzymatischen Hydrolyse nicht möglich war.

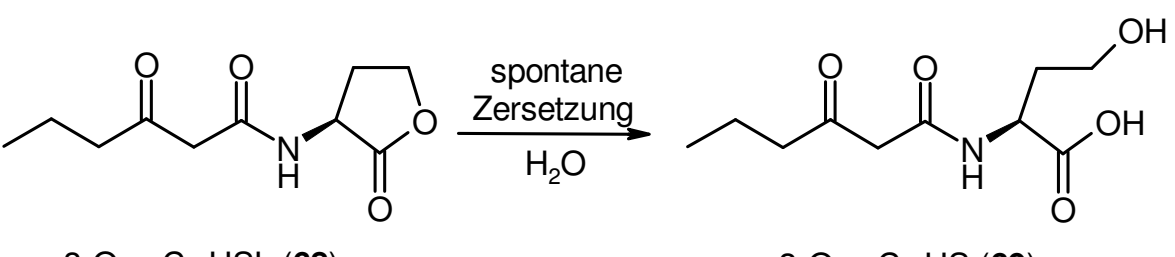

$3-\mathrm{O} \times 0-\mathrm{C}_{6}-\mathrm{HSL}(68)$

$3-\mathrm{O} \times 0-\mathrm{C}_{6}-\mathrm{HS}(69)$

Abbildung 30. Struktur des Substrats 3-Oxo- $\mathrm{C}_{6}$-HSL (68) und dem entsprechendem Spaltprodukt 69.

Aus diesem Grund wurden für die BpiB-Proteine BpiB01, BpiB04, BpiB05 und BpiB09 Inkubationsansätze mit racemischen $\mathrm{C}_{12}$-DL-HSL (64) als Substrat mittels HPLC-MS-Analysen untersucht. Zur Überprüfung der Retentionszeiten und Massenaddukte wurde $\mathrm{C}_{12}$-DL-Homoserinlacton (64) vollständig in Dioxan mit $1 \mathrm{~N} \mathrm{NaOH}$ für $24 \mathrm{~h}$ bei Raumtemperatur hydrolysiert. Die HPLC-MS-Analysen der mit $\mathrm{C}_{12}$-HSL-inkubierten Ansätzen ergaben übereinstimmende Ergebnisse bezüglich der Retentionszeiten und Massenspektren des synthetischen Reaktionsprodukts und des enzymatischen Spaltprodukts. Die Massenspektren des synthetischen und enzymatischen Spaltprodukts 65 wiesen Massenaddukte bei $\mathrm{m} / \mathrm{z}=284$ $\left[\mathrm{M}-\mathrm{H}_{2} \mathrm{O}+\mathrm{H}\right]^{+}, 302[\mathrm{M}+\mathrm{H}]^{+}, 324[\mathrm{M}+\mathrm{Na}]^{+}$und $625[2 \mathrm{M}+\mathrm{Na}]^{+}$bei einer Retentionszeit von 17.3 min auf. In den Negativkontrollen mit Rohextrakten bzw. Eluaten von E. coli BL21Leervektorkontrollen wurden diese Massenaddukte nicht in signifikanten Mengen detektiert. Allerdings führte der Einsatz dieses Substrat nicht zu der erhofften Umsatzsteigerung. Außerdem ist es für eine Quantifizierung nicht geeignet, da es keine UV-Absorption aufweist. Des Weiteren tritt in der HPLC-ESI-MS-Analyse bei entsprechender Retentionszeit ein Phtalester auf. Dieser ist bei jeder HPLC-ESI-MS-Messung zu beobachten, da dieser sich aus den Weichmachern von Schlauchmaterialien löst. 
Bisherige, intensive Versuche zur Optimierung eines geeigneten Programms für das $\mathrm{C}_{12}$-HSL (64) führten zu keiner Erfolg versprechenden Methode ohne HPLC-störende Signalüberlagerungen, zumal möglicherweise mit Überlagerungen von Verunreinigungen aus dem Medium der Inkubationsansätze gerechnet werden müsste. Dahingegen würde der Einsatz des 3-Oxo- $\mathrm{C}_{12}$-Derivats als Substrat aufgrund einer UV-Absorption bei $252 \mathrm{~nm}$ eine Quantifizierung hinsichtlich der Enzymaktivität ermöglichen. Außerdem würden sich die Retentionszeiten des Substrats und des entsprechenden Spaltprodukts aufgrund der polareren Eigenschaften zu niedrigeren Zeiten verschieben und die Verwendung der etablierten HPLC-ESIMS-Methode zulassen.

Die durchgeführten HPLC-MS-Analysen bestätigen die Annahme, dass es sich bei den QS-inhibierenden BpiB-Proteinen BpiB01, BpiB04 und BpiB07 sowie den weiteren untersuchten Proteinen BpiB05 und BpiB09 um Lactonasen handelt. Diese Lactonasen inaktivieren das 3-Oxo- $\mathrm{C}_{8}$-HSL (62) und $\mathrm{C}_{12}$-HSL (64) durch die Spaltung des Lactonringes. Allerdings ist der enzymatische Umsatz dieser Proteine noch weiter zu optimieren. Erste Untersuchungen mit anderen Substraten wie $\mathrm{C}_{12}$-HSL (64) oder 3-Oxo-C 6 -HSL (68) führten bisher nicht zu der erhofften Steigerung der enzymatischen Hydrolyse, der Einsatz von 3-Oxo-C 12 -HSL wäre aus chemisch-analytischer Sicht äußerst reizvoll.

\subsection{Screening von Quorum-Sensing-Inhibitoren aus dem Metagenom}

In der Arbeitsgruppe R. Schmitz-Streit (Universität Kiel) wurden Metagenombanken aus marinen Habitaten angelegt. Diese wurden mittels eines neuen Reporterstamms auf QuorumSensing-inhibierende (QSI) Wirkstoffe hin untersucht, die mit Signalmolekülen des AI-2-Typs interferieren. Das entwickelte Screeningsystem beruht auf der Idee von Givskov et al. ${ }^{68}$, die als Reporterstamm P. aeruginosa einsetzen, der ein Plasmid mit einem QS-kontrolliertem Promotor und einem letalen Gen enthält. In Gegenwart von AHL-Signalmolekülen wird der QS-kontrollierte Promotor aktiviert, damit das letale Gen exprimiert wird. In Folge dessen, wächst der Reporterstamm nicht. In Gegenwart eines QSI-Moleküls, oder QSIhaltigen Extrakten eines wachsenden Klons wird der QS-kontrollierte Promotor nicht aktiviert und der Reporterstamm wächst. Bei einem analogen Testsystem wird anstelle des letalen Gens ein Antibiotikaresistenzgen mit Repressor verwendet. ${ }^{68}$ In der Arbeitsgruppe R. Schmitz-Streit (Universität Kiel) etablierte N. Weiland ein Testsystem, das auf E. coli als Reporterstamm basiert und so aufgebaut wurde, dass der QS-kontrollierte Promotor in Gegenwart von Signalmolekülen des AI-2-Typs aktiviert wird. Diese Aktivierung führt zur 
Exprimierung eines letalen Gens und die Zellen sterben ab. In den letzten Jahren zeigten eingehende Untersuchungen, dass die Bildung von Biofilmen in E.coli vermutlich durch Signalmoleküle des AI-2-Typs kontrolliert wird. ${ }^{69}$ Wie bereits im Abschnitt 3.2.1 beschrieben, leiten sich die Signalmolekülen des AI-2-Typs vom Vorläufer DPD (31) ab, das spontan zum $S$-THMF (37) oder $R$-THMF (38) cyclisiert (s. Abbildung 16). Aus letzterem bildet sich in Gegenwart von Borsäure AI-2 (20). $R$-THMF (38) ist das Signalmolekül von E. coli, während AI-2 (20) als Signalmolekül bei $V$. harveyi fungiert. Ein weiteres Signalmolekül, das zum AI-2-Typ gehört, ist MHF (4-Hydroxy-5-methyl-3(2H)-furanon, 39), welches eine 1000fach geringere Aktivität als Signalmolekül im Vergleich zu AI-2 (20) aufweist. ${ }^{48}$ Dieses MHF (39) wird als QS-Signalmolekül im obigen Testsystem eingesetzt, da die Chemikalie kommerziell günstig erhältlich ist (110€/100 g), während DPD (31) erst sehr arbeitsintensiv mit den Enzymen $\operatorname{LuxS}$ und $P f S$ ausgehend vom Substrat S-Adenosylhomocystein (SAH, 33) erhalten werden kann. Zusätzlich konnte N. Weiland auch ein AHLbasiertes Testsystem mit E. coli als Reporterstamm etablieren.

\subsubsection{Analytik von Metagenomklonen}

\section{Vorversuche zur Extraktherstellung}

Beim Screening der Metagenom-Banken aus marinen Habitaten auf Quorum-SensingInhibition (QSI) wurden bereits einige Klone als positiv eingeschätzt, deren Insertgrößen zwischen 15-32 kb lagen. Die Größe einer Biosynthesegensequenz für einen kleinen strukturell einfach aufgebauten Naturstoff liegt bei Anwesenheit einer kleinen PKS oder NRPS zwischen 30-40 kb. Zudem ist auch ein modifizierter Metabolit des Primärstoffwechsels nicht auszuschließen. Um zu prüfen, ob es sich bei den ausgewählten Metagenomklonen um Proteine bzw. höher molekulare, peptidische Substanzen oder small molecules handelt, wurden im Rahmen dieser vorliegenden Arbeit erste Vorversuche in Kooperation mit der Arbeitsgruppe Schmitz-Streit durchgeführt. Hierzu wurden zunächst von N. Weiland zwei Klone aus Bakterienisolaten (NCFS9, $15 \mathrm{~kb}$ Insert; NC K14, $32 \mathrm{~kb}$ Insert) und zwei metagenomische Klone (NC III 6/C8, $22 \mathrm{~kb}$ Insert; NC III6/G5, 29 kb Insert) mit QSIAktivität angezogen. Die auf QSI-Aktivität getesteten Kulturfiltrate wurden in Göttingen mit verschiedenen polaren Lösungsmittelgemischen wie Methanol/Aceton 6:4 und Wasser/Methanol/Aceton 2:6:4 extrahiert. Parallel wurden in Kiel Ethylacetat-Extrakte hergestellt (ohne Korrektur des pH-Werts). Alle Extrakte wurden in Kiel auf eine reproduzierbare QSI-Aktivität überprüft, allerdings konnte diese nach der Extraktion der Kulturfiltrate nicht mehr nachgewiesen werden. Aufgrund dieser Beobachtung wurde angenommen, dass es 
sich bei den Klonen mit QSI-Aktivität um bioaktive Proteine handeln muss. Eine Bioaktivität, die auf das Vorliegen eines small molecules zurückgeführt werden kann, hätte sich andernfalls nach der Extraktion reproduzierbar nachweisen lassen sollen.

Zur Überprüfung dieser Beobachtungen wurde zur Extraktherstellung diesmal die sehr schonende Methode des Lyophilisierens eingesetzt. Hierzu wurden die Volumina der zuvor in Kiel als positiv getesteten Kulturüberstände von drei verschiedenen Klonen (NC FS9, NC K14, NC III 6/C8) nach einer $\mathrm{pH}-$ Wert-Korrektur auf $\mathrm{pH}=5.0$ in zwei Teile aufgeteilt. Der eine Teil wurde zweimal mit Ethylacetat extrahiert, während der andere Teil zunächst lyophilisiert wurde. Das erhaltene Lyophilisat wurde nacheinander mit Methanol/Aceton 6:4 und Wasser/Methanol/Aceton 2:6:4 extrahiert. Alle erhaltenen Rohextrakte wurden in einer Konzentration zwischen $c=10-20 \mathrm{mg} / \mathrm{mL}$ in dem jeweiligen Extraktionslösungsmittel gelöst, je 1 mL-Proben entnommen und zur Überprüfung der QSI-Aktivität nach Kiel geschickt. Da die erstellten Proben keine QSI-Aktivität mehr zeigten, wurden erneut Kulturüberstände der Klone NC FS9, NC K14 und NC III 6/G5 ohne Korrektur des pH-Wertes lyophilisiert, um einen Einfluss einer pH-Wert-Änderung auszuschließen. Das jeweilige Lyophilisat wurde in einer Konzentration von $c=100 \mathrm{mg} / \mathrm{mL}$ in bidest. Wasser aufgenommen, je $1.5 \mathrm{~mL}$-Proben entnommen, damit eine die QSI-Aktivität in Kiel überprüft werden konnte. Auch hierbei konnte keine QSI-Aktivität mehr nachgewiesen werden. Aufgrund dieser Beobachtungen sollte man ausschließen, dass es sich bei diesen Klonen um small molecules handelt.

\section{HPLC-ESI-MS-Analytik}

Zur Untersuchung eines weiteren metagenomischen Klons (NC XIX 69/B2, 2 kb Insert) auf Reaktionsprodukte einer möglichen Quorum-Quenching-Aktivität wurden Inkubationsansätze dieses Klons mit $N$-(3-Oxooctanoyl)-L-Homoserinlacton (3-Oxo- $\left.\mathrm{C}_{8}-\mathrm{HSL}, 62\right)$ als Substrat von $N$. Weiland hergestellt. Hierfür wurden jeweils $100 \mu \mathrm{L}$ konzentrierter Kulturüberstand des metagenomischen Klons mit 3-Oxo- $\mathrm{C}_{8}$-HSL (62) in Tris-Puffer ( $\left.\mathrm{pH} 8.0\right)$ über Nacht bei $37^{\circ} \mathrm{C}$ und $150 \mathrm{U} / \mathrm{min}$ inkubiert. Zur Kontrolle wurden Kulturen mit dem Leervektor ebenfalls mit 3-Oxo-C 8 -HSL (62) in Tris-Puffer ( $\mathrm{pH} 8.0$ ) über Nacht bei $37^{\circ} \mathrm{C}$ und $150 \mathrm{U} / \mathrm{min}$ inkubiert. Anschließend wurden die Inkubationsansätze mit Ethylacetat extrahiert.

Für die HPLC-ESI-MS-Messung wurden die erhaltenen Extrakte in $110 \mu \mathrm{L} \mathrm{MeOH}$ aufgenommen. Die Messung der Proben erfolgte mittels HPLC-ESI-MS (HPLC D, Säule A: Grom Superspher 100, RP-18, Programm B: $\mathrm{MeOH} / \mathrm{H}_{2} \mathrm{O}$, jeweils mit $0.05 \%$ Ameisensäure, Gradient; s. Abschnitt B 1.2 ) im positiven und negativen Modus. 


\section{HPLC-ESI-MS-Proben:}

1. Inkubationsansatz des metagenomischen Klons NC XIX 69/B2 (3 Ansätze)

2. „Leervektor“ mit AHL-Substrat (3 Ansätze)

3. $150 \mu \mathrm{L}$ der AHL-Stammlösung (100 mM in Ethylacetat) als Kontrolle

4. Hydrolyseprodukt $\mathbf{6 3}$ des Substrats aus chemischer Hydrolyse (Standard mit $c=1.0 \mathrm{mg} / \mathrm{mL}$ ) als Kontrolle

Die Datenbankenvergleiche der aus der Sequenzierung erhaltenen Daten für den zu untersuchenden Klon (NC XIX 69/B2) wiesen auf das Vorliegen einer Transkriptase hin. Es wurde angenommen, dass die QSI-Aktivität dieses Enzyms nicht auf Quorum-Quenching zurückgeht, d. h., dass das Signalmolekül nicht enzymatisch abgebaut wird. Es wird anderweitig in die Signal-Tranduktions-Kaskade eingegriffen und somit QS-inibiert. Mit Hilfe der HPLCESI-MS-Analyse konnte diese Annahme unterstützt werden, da keine Hinweise auf einen enzymatischen Abbau des Signalmoleküls beobachtet wurden, sondern nur das AHL-Substrat detektiert wurde. Lediglich Spuren des Hydrolyseproduktes (63) konnten massenspektrometrisch detektiert werden. Diese geringfügige Hydrolyse konnte im gleichen Maße in der Negativkontrolle des Leervektors beobachtet werden. Damit kann die Hydrolyse auf die Instabilität des 3-Oxo- $\mathrm{C}_{8}$-HSLs (62) beim eingesetzten Puffer bei $\mathrm{pH}=8.0$ zurückgeführt werden.

Weitere in Kiel durchgeführte Untersuchungen bestätigten die Annahme, dass der vorliegende Klon innerhalb der Signal-Transduktions-Kaskade eingreift und damit QS-inhibiert. ${ }^{70}$

Im Rahmen dieser Arbeit bestand für die Etablierung weiterer Methoden zur Analyse von QSI-Klonen, die etwa mit dem AI-2-Typ-Signalweg interferieren, keine Notwendigkeit. Für zukünftige Arbeiten wird in der Literatur eine Methode beschrieben, die mit Hilfe einer chemischen Derivatisierung von MHF (39) die Detektion und Quantifizierung mittels HPLCESI-MS-Analyse in Kulturüberständen ermöglichte. ${ }^{48}$ Hierbei wurde die Hydroxygruppe des MHF (39) mit Chloroformiat gemäß Husek et al. verestert. ${ }^{71}$ Der Einsatz von Benzylchloroformiat bietet bei der Derivatisierung von MHF (39) den Vorteil, dass das Benzylderivat eine Detektion durch UV-Absorption ermöglichen würde und damit auch dessen Quantifizierung erreicht werden kann.

\subsection{Diskussion der Ergebnisse}

\section{Kooperation Arbeitsgruppe K. Jung}

Die Totalsynthese des Autoinducer AI-1 (19) und seiner enantiomerenreinen Epimere R,S-29 und S,S-30 gelang über die Schützung der Hydroxyfunktion vom Natriumsalz des 3-Hydroxy- 
butyrats (43) mit TBS-Chlorid, EDC-vermittelter Kupplung mit $\alpha$-Amino- $\gamma$-butyrolactonhydrobromid (44) und anschließender Entschützung des Silylethers 50 in einer Gesamtausbeute von $30 \%$ über 4 Stufen. Zur Überprüfung der biologischen Aktivität wurden das Epimerengemisch 52 und die enantiomerenreinen Epimere $R, S-29$ und $S, S-30$ auf ihren Einfluss bei der Induktion von Biolumineszenz in verschiedenen Konzentrationen gemessen. Hierbei zeigte das $(R, S)$-AI-1 (29) der Literatur entsprechend die stärkste Stimulation der Biolumineszenz.

Mit Hilfe einer Affinitätschromatographie (immobilisiertes Boronsäuregel) konnte eine $98 \%$ ige Reinigung bei der enzymatischen Synthese des Autoinducers AI-2 (20) erzielt werden, die mit dem Reporterstamm V. harveyi MM77 überprüft werden konnte. Damit konnte eine erfolgreiche Reinigungsmethode etabliert werden, die einen schnellen Zugang zu ausreichenden Mengen an AI-2 (20) bietet, so dass die biologischen Kooperationspartner eine hervorragende Grundlage für ihre Forschungsarbeiten haben.

\section{Kooperation Arbeitsgruppe W. Streit}

Die Quorum-Quenching-Aktivität von Biofilm-inhibierenden Metagenom-Klonen (BpiBProteine) wurde im Rahmen der vorliegenden Arbeit mit Hilfe der HPLC-ESI-MS-Analyse eindeutig als Lactonase-Aktivität verifiziert. Lactonasen führen zur Hydrolyse des Lactonringes von $\mathrm{N}$-Acylhomoserinlactonen (AHL), wobei das entsprechende $\mathrm{N}$-Acylhomoserin freigesetzt wird. Es wurde die enzymatische Aktivität der neuen Lactonasen mit den Substraten 3-Oxo- $\mathrm{C}_{8}$-HSL (62) und $\mathrm{C}_{12}$-HSL (64) untersucht. In Vorversuchen wurde zunächst als Nachweisgrenze eine Konzentration von $c=50 \mu \mathrm{g} / \mathrm{mL}$ für die Detektion von 3-Oxo- $\mathrm{C}_{8}$-HSL (62) und seinem Spaltprodukt 63 bestimmt. Aufgrund der geringen Mengen an detektiertem Spaltprodukt wurde vermutet, dass eventuell vorhandenes Hydrolyseprodukt bei alkalischem pH-Wert nicht in die Ethylacetatphase aufgenommen wurde. Das konnte jedoch durch Extraktion des Inkubationsansatzes unter sauren Bedingungen widerlegt werden, da keine größeren Mengen beobachtet wurden. Erst die Zugabe des AHL in DMSO anstatt in Ethylacetat zu BpiB-Proteinen sowie optimierte Inkubationsbedingungen führten zu einer Erhöhung der enzymatischen Aktivität. Eine Detektion der spezifischen Massenaddukte der $\mathrm{N}$-Acylhomoserine 3-Oxo- $\mathrm{C}_{8}$-HS (63) und der Vergleich mit chemisch hydrolysiertem Spaltprodukt, bestätigte die Lactonase-Aktivität der BpiB-Proteine. Zudem wurden neben dem 3-Oxo- $\mathrm{C}_{8}$-HSL (62) zwei weitere Substrate wie $\mathrm{C}_{12}$-HSL (64) und 3-Oxo- $\mathrm{C}_{6}$-HSL (62) hinsichtlich einer Erhöhung der Enzymaktivität untersucht, allerdings erbrachte dies keine signifikante Erhöhung an Hydrolyseprodukt. 
Kooperation Arbeitsgruppe R. Schmitz-Streit

Für Untersuchungen der biologischen Aktivität von Quorum-Sensing-inhibierenden Metagenom-Klonen wurden mit Hilfe verschiedener chemischer Methoden Rohextrakte von Kulturüberständen hergestellt und erneut in der Arbeitsgruppe $R$. Schmitz-Streit auf eine Bioaktivität getestet. Hierüber sollte das Vorliegen eines small molecule als Anti-QuorumSensing-Molekül verifiziert werden, da dieses eine reproduzierbare Aktivität zeigen sollte. Die hergestellten Rohextrakte wurden alle negativ auf eine reproduzierbare Aktivität überprüft, so dass ein small molecule als Anti-Quorum-Sensing-Molekül ausgeschlossen werden konnte.

Unter den aktiven Klonen konnte in der Arbeitsgruppe R. Schmitz-Streit eine mögliche Transkriptase identifiziert werden, für deren Quorum-Sensing-inhibierende Wirkung ein Eingriff auf die Signal-Transduktions-Kaskade angenommen wurde. Um diese Annahme zu prüfen, wurde der Klon auf mögliche Reaktionsprodukte eines Quorum-Quenching-Mechanismus mittels HPLC-ESI-MS untersucht, die jedoch nicht detektiert werden konnten. Weitere molekulargenetische Arbeiten zur Charakterisierung dieses Metagenom-Klons in der Arbeitsgruppe R. Schmitz-Streit bestätigten diese Annahme, dass es sich hierbei um einen QSI-aktiven Klon handelt. 


\section{Assoziierte Streptomyceten von marinen Invertebraten}

Aus marinen Invertebraten wie Schwämmen, Manteltieren, Moos- oder Weichtierchen wurde eine große Vielfalt an strukturell einzigartigen Sekundärmetaboliten isoliert, von denen viele interessante pharmakologische Eigenschaften besitzen. ${ }^{72}$ Viele der aus marinen Invertebraten isolierten Naturstoffe sind auf Bakterien oder andere Mikroorganismen zurückzuführen, die als wahre Produzenten entweder im Rahmen der Nahrungskette aufgenommen worden sind oder in einer stabilen Lebensgemeinschaft mit dem Makroorganismus leben. ${ }^{25}$ Diese Hypothese wird durch zahlreiche Evidenzen unterstützt. So zeigen viele der aus marinen Habitaten isolierten Naturstoffe ausgeprägte strukturelle Ähnlichkeiten zu bekannten Metaboliten mikrobiellen Ursprungs oder sind Substanzklassen, wie z. B. den Polyketiden zuzuordnen, die unter den Mikroorganismen weit verbreitet sind. ${ }^{73}$ Ein Beispiel hierfür ist das Antitumormittel Ecteinascidin ET-743 (70) ${ }^{74}$ aus dem Manteltier Ecteinascidia turbinata, dessen Struktur eine große Ähnlichkeit zum mikrobiellen Sekundärmetaboliten Safracin $B \quad(\mathbf{7 1})^{75}$ aus Pseudomonas fluorescens aufweist (s. Abbildung 31). Diese Strukturverwandtschaft ermöglichte die Partialsynthese des nur in sehr geringen Mengen zu isolierenden marinen Naturstoffs 70 aus dem leicht zugänglichen mikrobiellen Metaboliten $\mathbf{7 1}^{76}$
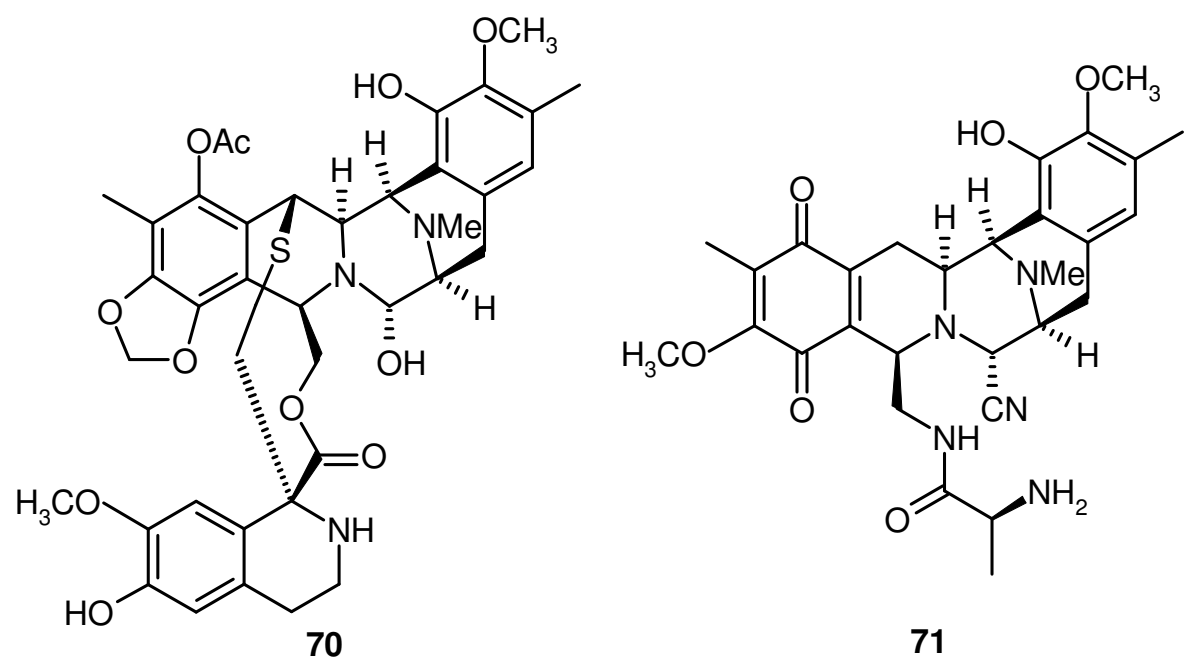

71

Abbildung 31. Beispiel für Strukturverwandtschaften zwischen marinen und mikrobiellen Sekundärmetaboliten.

Ein vermuteter bakterieller Ursprung solcher strukturell komplexer Naturstoffe kann durch Charakterisierung des Biosynthese-Genclusters mit Hilfe molekularbiologischer Methoden nachgewiesen werden. Ein Beispiel hierfür sind das Polyketidamid Pederin (72) aus dem afrikanischen Blasenkäfer Paederus sabaeus und den Pederin-verwandten Naturstoffen Theopederin A (73) und Onnamid A (74) aus dem Schwamm Theonella swinhoei (s. Abbildung 32). ${ }^{25}$ 
<smiles>[R2]O[C@H](NC(=O)[C@@H](O)[C@]1(O)CC(=C)C(C)C(C)O1)[C@H]1C[C@H](O)C(C)(C)[C@@H](C[C@@H](COC)OC)O1</smiles>

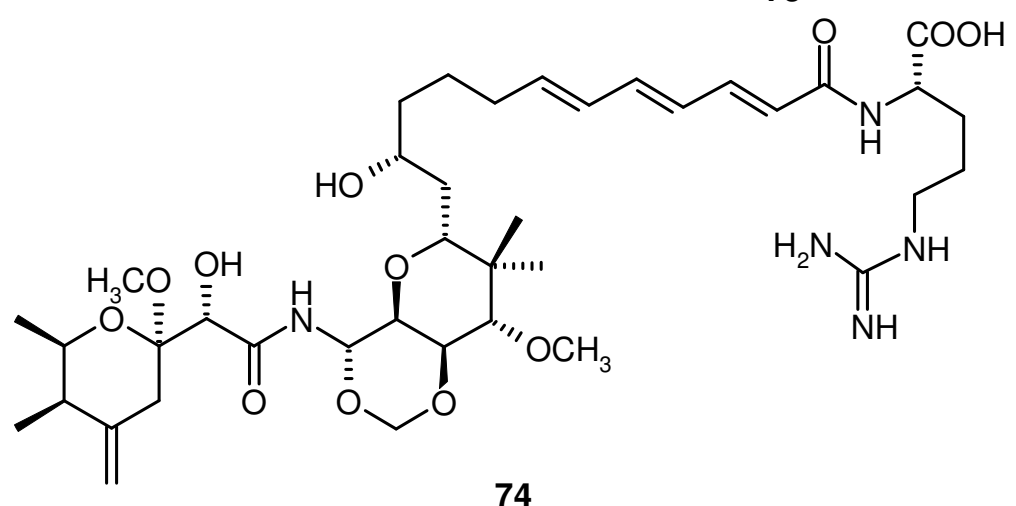

Abbildung 32. Pederin (72) und Pederin-verwandte Naturstoffe 73 und $\mathbf{7 4 .}$

Die Klonierung und Sequenzierung der Biosynthese-Gene ergab, dass offensichtlich in beiden Fällen bisher nicht kultivierte bakterielle Symbionten die Wirkstoffe produzieren. ${ }^{25,77}$

Die Identifizierung dieser mit marinen Invertebraten assoziierten Mikroorganismen, welche häufig zu den nicht-kultivierbaren Mikroorganismen gehören, und die systematische Untersuchung ihrer möglichen Rolle als Produzenten von Sekundärmetaboliten sowie die Untersuchung ihres Metabolitenmusters auf neue Naturstoffe sind wichtige Forschungsschwerpunkte in der marinen Naturstoffforschung. ${ }^{78}$

\subsection{Der Produzent Streptomyces sp. JP90}

In der Arbeitsgruppe von Prof. J. Piel (Universität Bonn) wurden verschiedene Bakterienstämme aus der marinen Ascidiacea (Seescheide, zum Unterstamm Manteltiere gehörend) Aplidium lenticulum isoliert, die dem Great Barrier Reef vor Heron Island (Australien) entnommen worden waren. Diese Spezies ist in der Literatur als Produzent von 5-Desoxyenterocin (75b) beschrieben, ein Naturstoff, der sowohl aus dem Manteltier als auch aus Bakterien isoliert worden ist (s. Abbildung 33). ${ }^{79}$ Die mikrobiologische Diversität der Tunikaten und die Rolle dieser assoziierten Bakterien in der Sekundärmetabolitenproduktion sollten näher untersucht werden, da es bisher diesbezüglich erst wenige Studien gab. ${ }^{73,80}$ Von besonderem Interesse war, einen Produzenten für das 5-Desoxyenterocin (75b) zu finden. 


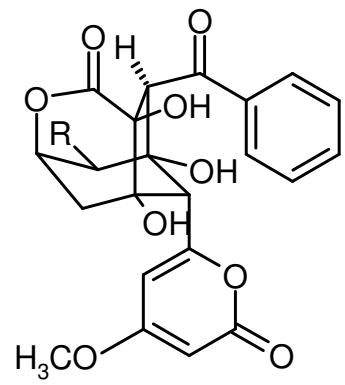

75a: $\mathbf{R}=\mathrm{H}$

75b: $\mathbf{R}=\mathrm{OH}$

Abbildung 33. Struktur des Enterocin (75a) und 5-Desoxyenterocin (75b).

Aus der marinen Ascidiacea Aplidium lenticulum wurden zehn verschiedene Bakterienstämme isoliert, mittels 16S-rRNA-Analyse phylogenetisch bestimmt und deren Metabolitenmuster in einem chemisch-biologischen Screening analysiert. In einem chemischen Screening der Isolate nach OSMAC ${ }^{81}$ das $N$. Czempinski im Rahmen ihrer Diplomarbeit durchführte, ${ }^{82}$ fiel Streptomyces sp. Stamm JP90 durch eine Reihe unterschiedlicher UV-aktiver sowie mit gängigen Sprühreagenzien anfärbenden Zonen auf. Die weitere Bearbeitung des Stammes JP90 erfolgte durch T. Schuhmann im Rahmen seiner Dissertation. ${ }^{28}$ Aus einer Fermentation im 4 L-Maßstab konnten die bereits aus Mikroorganismen isolierten Verbindungen $N$-Acetyltyramin (76), Cyclo(prolyltyrosyl) (77), Desferrioxamin E (78), 3-Indolcarbonsäure (79), das bisher nur als Pflanzenmetabolit beschriebene Monoterpen Rosiridol (23) sowie die bislang unbekannten Verbindungen 6-Hydroxy-6-methylheptansäure (80), und das ungewöhnliche Cinnamoylphosphoramid (21) isoliert werden (s. Abbildung 34).<smiles>CC(=O)NCCc1ccc(O)cc1</smiles>

Abbildung 34. Isolierte Metaboliten aus Streptomyces sp. JP90. ${ }^{28}$ 
Das isolierte Cinnamoylphosphoramid (21) wurde anhand der spektroskopischen Daten als (E)-3-(p-Aminomethoxyphosphoryloxyphenyl)acrylsäuremethylester identifiziert. Zwar ergaben sich aus den spektroskopischen Untersuchungen die Strukturvorschläge 21 und 81, doch ist aufgrund von Stabilitätsüberlegungen nur die Methylesterstruktur plausibel (s. Abbildung 35), da Imidoester in wässrigen Medien sehr rasch hydrolysiert werden, wobei die entsprechende Carbonsäure entsteht. ${ }^{83}$ Die Phosphoramidgruppierung ist dagegen gegenüber einer Hydrolyse relativ stabil. ${ }^{84}$

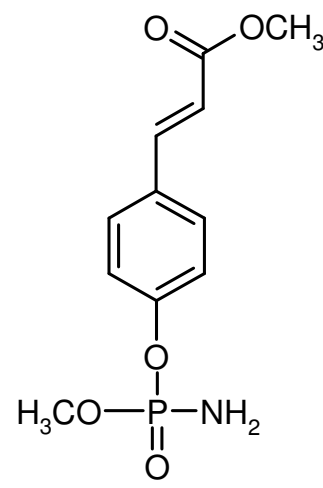

21<smiles>COC(=N)/C=C/c1ccc(OP(=O)(O)OC)cc1</smiles>

81

Abbildung 35. Strukturvorschläge für den isolierten Sekundärmetaboliten 21.

\subsubsection{Eigene Vorarbeiten}

Im Rahmen der Diplomarbeit sollte mithilfe einer Totalsynthese von $\mathbf{2 1}$ ein Vergleich der spektroskopischen Daten eine eindeutige Strukturzuordnung ermöglichen und damit die Strukturaufklärung des isolierten Sekundärmetaboliten abgeschlossen werden.

Die Totalsynthese des racemischen Naturstoffs erfolgte über die Synthese des (E)-3-( $p$ Hydroxyphenyl)acrylsäuremethylesters (82) in einer Heck-Reaktion von $p$-Bromphenol (83) und Methylacrylat (84) in einer Lösung von Triethylamin. Als Palladium-Quelle diente $\mathrm{Pd}(\mathrm{OAc})_{2}$, das mit Tri-o-tolylphosphan als Liganden bei $90{ }^{\circ} \mathrm{C}$ eingesetzt wurde. Die Synthese von 82 lieferte nach säulenchromatographischer Reinigung eine Ausbeute von $90 \%$. Zur Synthese des Cinnamoylphosphoramids (21) wurde der phosphorhaltige funktionelle Substituent ausgehend von $\mathbf{8 2}$ sukzessiv aufgebaut. Hierfür wurde zunächst nach Tacke et al. mit $\mathrm{NaH}$ das Natriumsalz des Heck-Produktes 82 in wasserfreiem Dichlormethan gebildet und dies als Suspension in Dichlormethan portionsweise $\mathrm{zu}$ einem Überschuss des Phosphorylierungsreagenzes Methoxyphosphoryldichlorid (85) bei $0{ }^{\circ} \mathrm{C}$ gegeben. ${ }^{85} \mathrm{Nach} 16 \mathrm{~h}$ Rühren bei Raumtemperatur konnte das Intermediat 86 erhalten werden. Das Phosphorylierungsreagenz 85 wurde dabei gemäß Quast et al. durch Methanolyse von Phosphoryltri- 
chlorid erhalten. ${ }^{86}$ Im abschließenden Schritt des Aufbaus der phosphorhaltigen Gruppe erfolgte die Einführung der Aminofunktion. Gemäß Fosters et al. wurde durch eine Lösung von Intermediat 86 in wasserfreiem Dichlormethan für 50 min bei $-10^{\circ} \mathrm{C}$ gasförmiges Ammoniak geleitet und so racemisches Cinnamoylphosphoramid (21) in einer Ausbeute von $16 \%$ erhalten (s. Schema 4) ${ }^{87}$ Die relativ geringe Ausbeute wurde durch die Zersetzung von 21 an Kieselgel bei der säulenchromatographischen Reinigung verursacht. Eine Zersetzung des nativen 21 an Kieselgel wurde von T. Schuhmann in seiner Dissertation für die Isolierung des Naturstoffs 21 aus dem Kulturfiltrat nicht beschrieben, ist aber aufgrund der sehr geringen Menge an isoliertem Naturstoff (1.4 mg/L) nicht auszuschließen. ${ }^{28}$

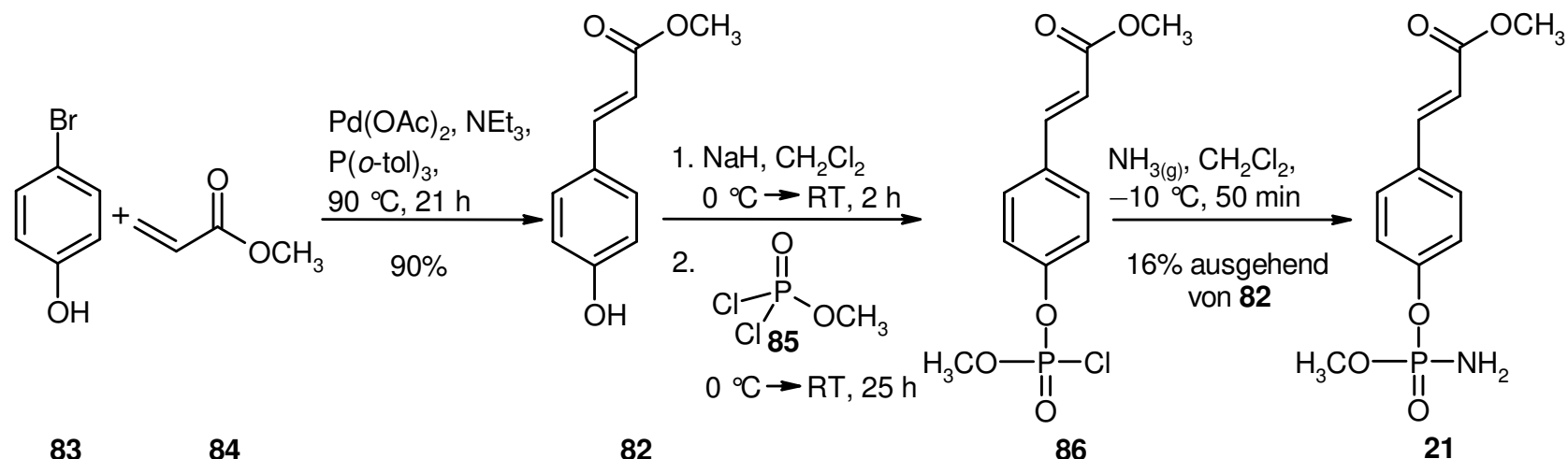

Schema 4. Totalsynthese des Cinnamoylphosphoramids (21).

Ein Vergleich der spektroskopischen Daten der synthetisierten Verbindung 21 mit denjenigen des isolierten Naturstoffs ermöglichte die eindeutige Bestätigung der Struktur des Cinnamoylphosphoramids, es besteht Identität zwischen synthetischem und nativem 21.

Die Bestimmung der absoluten Konfiguration am Phosphor des isolierten Naturstoffs 21 erfolgte über die Synthese beider Enantiomere von 21 ausgehend von den diastereomeren Phosphoramiden des L-Phenylalaninethylesters gemäß Koizumi et al. und einem Vergleich von physikochemischen Eigenschaften der diastereomeren Phosphoramid-Intermediaten mit bekannten Verbindungen. ${ }^{88}$ Vergleichende HPLC-Analysen von nativem und totalsynthetischem Cinnamoylphosphoramid (21) an chiraler stationärer Phase zeigten eindeutig, dass der Naturstoff $(S)$-konfiguriert vorliegt. ${ }^{29,89}$

Weiterhin sollte der neue Naturstoff 21 biochemisch charakterisiert werden. Cinnamoylphosphoramid (21) weist das für Sekundärmetaboliten eher ungewöhnliche Element Phosphor auf. Nur wenige phosphorhaltige Naturstoffe sind aus Streptomyceten in der Literatur beschrieben. Hierzu gehören das Herbizid Bialaphos (87), das potente Anti-Malariamittel Fosmidomycin (88) und das insektizid wirkende Cyclophostin (89), welches auch ein starker 
Inhibitor der Acetylcholinesterase ist (s. Abbildung 36). Das für einen Metaboliten ungewöhnliche phosphorhaltige Strukturelement und der einfache Aufbau lassen vermuten, dass 21 ein aktivierter Biosynthesevorläufer bislang unbekannter Metaboliten sein könnte.

Des Weiteren ist das Cinnamoylphosphoramid (21) hinsichtlich seiner biologischen Aktivität von großem Interesse, da die chemische Struktur dieses Moleküls dem Grundgerüst von Organophosphorsäureestern entspricht wie z. B. dem bekannten synthetischen Insektizid Methylparaoxon (90), ein Inhibitor der Acetylcholinesterase. Auch Anti-HIV-Präparate wie z. B. L-Alaninyl-d4T-MP (2',3'-Didesoxy-2',3'-dihydro-thymidin-5'-monophosphat) $(\mathbf{9 1})^{90}$ oder Anti-Hepatitis C-Präparate ${ }^{91}$ beinhalten eine Phosphoramidstruktur (s. Abbildung 36).<smiles>CCCC(C)C(=O)NC(C)C(=O)NC(C)CCP(C)(=O)O</smiles>

87<smiles>COP(=O)(OC)Oc1ccc([N+](=O)[O-])cc1</smiles><smiles>O=CN(O)CCCP(=O)(O)O</smiles>

88<smiles>COP1(=O)OC[C@H]2COC(=O)C2=C(C)O1</smiles>

89

Abbildung 36. Strukturen phosphorhaltiger Wirkstoffe.

Zur Untersuchung der Funktion der Verbindung 21 wurde das racemische Syntheseprodukt dem Streptomyceten sp. Stamm JP90 zugefüttert, um zu untersuchen, ob aus dadurch beeinflussten Stoffwechselwegen neue Metaboliten in ausreichender Menge zur Isolierung und Strukturaufklärung produziert werden.

Hierbei konnte eine neue Substanz aus den Kulturfiltraten mit Zufütterung von 21 isoliert werden, bei der es sich um Molekül der Molmasse $M_{R}=1171.35 \mathrm{~g} / \mathrm{mol}$ handelt. Die Struktur konnte im Rahmen der Diplomarbeit nicht mehr abschließend aufgeklärt werden. Die abschließende Strukturaufklärung dieses Naturstoffs erfolgte im Rahmen der vorliegenden Dissertation. Des Weiteren wurden in dieser vorliegenden Arbeit Fütterungsexperimente mit Struktur-Analoga von 21 als potentielle Biosynthesevorläufer durchgeführt, die zeigten, dass das Cinnamoylphosphoramid (21) kein Biosynthesevorläufer des bisher noch nicht isolierten Sekundärmetaboliten ist. 


\subsubsection{Synthetische Arbeiten zum Cinnamoylphosphoramid (21) und seinem Säurederivat (92)}

Die Totalsynthese des racemischen Naturstoffs erfolgte über die Synthese des (E)-3-( $p$ Hydroxyphenyl)acrylsäuremethylesters (82) in einer Heck-Reaktion und dem sukzessiven Aufbau der phosphorhaltigen funktionellen Gruppe ausgehend von 82 (s. Abschnitt 4.1.1 ). Aufgrund der teilweisen Zersetzung des Rohprodukts bei der säulenchromatographischen Reinigung an Kieselgel sollte die Reinigung des Rohprodukts an reversed-phase Kieselgel optimiert und die Gesamtausbeute bestimmt werden. Des Weiteren sollten ausreichende Mengen der Zielverbindung $\mathbf{2 1}$ für biologische Testung und Zufütterungsexperimente bereitgestellt werden.

Der Versuch, die Ausbeute bei der Umsetzung von 82 mit dem Phosphorylierungsreagenz 85 durch eine verbesserte Löslichkeit des Natriumphenolats im polareren Lösungsmittel THF zu erhöhen, führte zu keinem höheren Umsatz als die Reaktion in Dichlormethan. Aus diesem Grund erfolgte die Reaktion weiterhin in Dichlormethan. Zur Vermeidung der Zersetzung des nach Ammonolyse erhaltenen Rohprodukts an Kieselgel (s. Abschnitt 4.1.1 )erfolgte die Reinigung durch Mitteldrucksäulenchromatographie an reversed-phase Kieselgel (RP-18, Größe C, $\mathrm{MeOH} / \mathrm{H}_{2} \mathrm{O}$ 6:4). Dies führte ausgehend von 82 zu einer Optimierung der Gesamtausbeute des Cinnamolyphosphoramids (21) von zuvor $16 \%$ nach Reinigung an Kieselgel auf $55 \%$ nach Reinigung an reversed-phase Kieselgel (s. Schema 5). ${ }^{89}$

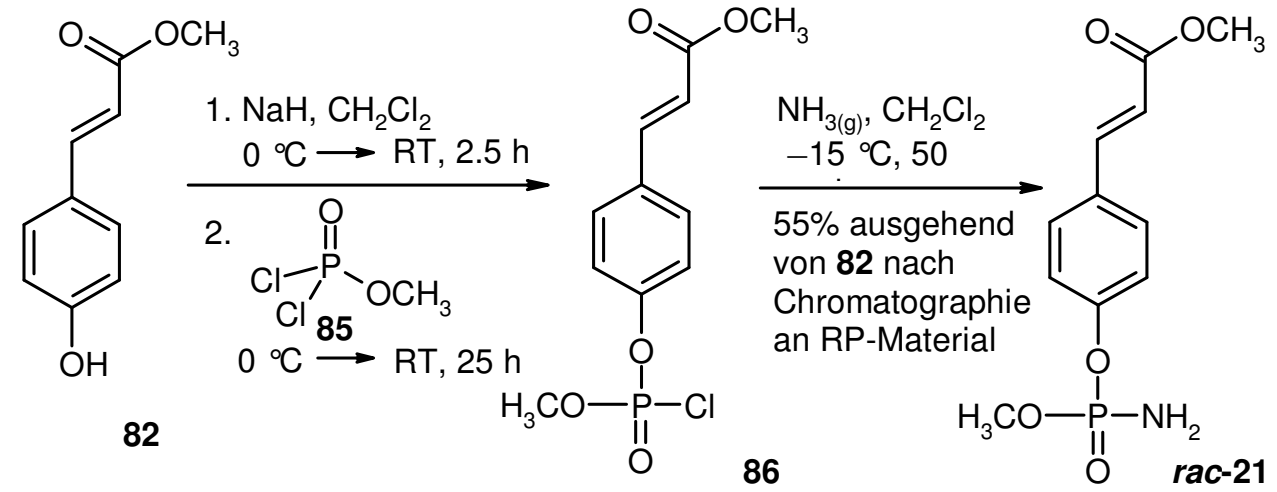

Schema 5. Optimierung der Totalsynthese von Zielverbindung 21. 


\section{Synthesearbeiten zum Säurederivat 92}

Die Bioaktivität des Cinnamoylphosphoramids (21) ist von großem Interesse, da die chemische Struktur dieses Moleküls dem Grundgerüst von Organophosphorsäureestern entspricht, welches durch die Schrader-Formel beschrieben wird (s. Abbildung 74, S.117). Im Rahmen der Diplomarbeit wurden Untersuchungen zur möglichen inhibitorischen Wirkung auf die Acetylcholinesterase (AChE) von 21 in einer Kooperation mit der Arbeitsgruppe Prof. U. Holzgrabe (Universität Würzburg) von E. Kugelmann begonnen. Aufgrund der schlechten Löslichkeit von 21 im verwendeten Phosphatpuffer konnte nur eine sehr schwache Hemmung der $\mathrm{AChE}\left(I C_{50}>350 \mu \mathrm{M}\right)$ gemessen werden. Zur genauen Bestimmung des $I C_{50}$-Wertes sollte das Säurederivat von 21 als wasserlösliches Analogon dargestellt werden. Bei der Wahl möglicher Synthesestrategien zur Darstellung eines solchen Derivats musste von vornherein die Instabilität von 21 sowohl gegenüber sauren als auch basischen Bedingungen berücksichtigt werden, da diese Instabilität zur Dephosphorylierung von 21 führt.

\section{Hydrolyse unter mild basischen oder enzymatischen Bedingungen}

Zunächst sollte ausgehend vom Cinnamoylphosphoramid (21) das Säurederivat 92 synthetisiert werden. Bei den Versuchen den Methylester 21 in wasserfreiem THF mit $\mathrm{LiOH} \times \mathrm{H}_{2} \mathrm{O}$ unter milden basischen Bedingungen zu verseifen, wurde vollständige Zersetzung zum Phenol 82 beobachtet (s. Tabelle 1, Eintrag 1, 2). Enzyme sind enantioselektive Biokatalysatoren, die regioselektiv unter milden Bedingungen arbeiten. Diese Eigenschaften sollten eine Darstellung von 92 ohne Zersetzung zum Phenol ermöglichen. Die enzymatische Hydrolyse mit dem Enzym Schweineleberesterase (PLE, Porcine liver esterase, Fa. Sigma), eine oft in der asymmetrischen Synthese eingesetzte Esterase, sollte zuerst an einer Modellverbindung untersucht werden. ${ }^{92}$ Hierzu wurde zunächst das Enzym PLE am Zimtsäuremethylester (93) getestet. Das Substrat wurde in Wasser $(\mathrm{pH}=7.7)$ gelöst, das Enzym zugegeben und das Reaktionsgemisch bei Raumtemperatur stark gerührt. Der $\mathrm{pH}-$ Wert wurde alle 5 min geprüft, und mit $0.5 \mathrm{~N} \mathrm{NaOH}$ auf pH 7.7 eingestellt. Dünnschichtchromatographische Analyse an reversedphase Kieselgel zeigte nach 25 min einen vollständigen Umsatz des Zimtsäuremethylesters zur entsprechenden Säure, welche nach Aufarbeitung in einer Ausbeute von $59 \%$ isoliert werden konnte (s. Tabelle 1, Eintrag 3). Nach erfolgreicher enzymatischer Hydrolyse der Modellverbindung wurde die Hydrolyse des Methylesters 21 untersucht. Die Durchführung erfolgte analog zur Modellverbindung. Es wurden trotz starker Erhöhung der Enzymbeladung nur Spuren einer polareren Verbindung bei dünnschichtchromatographischer Analyse detektiert. Die Reaktion wurde nach 14 d ergebnislos abgebrochen (s. Tabelle 1, Eintrag, 4). 


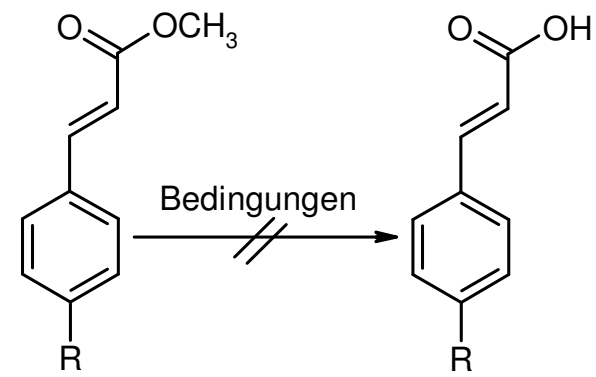

Schema 6. Versuche zur Hydrolyse des Methylesters 21.

Tabelle 1. Hydrolyse unter mild basischen oder enzymatischen Bedingungen.

\begin{tabular}{|c|c|c|c|}
\hline $\mathbf{R}$ & & Bedingungen & Anmerkungen \\
\hline $\begin{array}{c}\prod^{--} \\
\mathrm{O} \\
\mathrm{I} \\
\mathrm{M}-\mathrm{O} \\
\mathrm{O}\end{array}$ & 1 & $\begin{array}{l}\text { A) } 2.4 \text { Äq. LiOH } \cdot \mathrm{H}_{2} \mathrm{O} \text {, THF, RT, } 2 \mathrm{~h} \text {, } \\
\text { DC-Kontrolle } \\
\text { B) } 1.0 \text { Äq. LiOH } \cdot \mathrm{H}_{2} \mathrm{O} \text {, THF, RT, } 30 \mathrm{~min} \text {, } \\
\text { DC-Kontrolle }\end{array}$ & $\begin{array}{l}\text { Zersetzung zum } \\
\quad \text { Phenol } 82\end{array}$ \\
\hline $\mathrm{H}$ & 3 & $\begin{array}{c}1.0 \text { Äq. Schweineleberesterase, } \\
\mathrm{H}_{2} \mathrm{O}(\mathrm{pH}=7.7), \mathrm{RT}, 25 \mathrm{~min}, \text { DC-Kontrolle }\end{array}$ & $\begin{array}{c}\text { Reiner und } \\
\text { vollständiger Umsatz }\end{array}$ \\
\hline $\begin{array}{c}\prod_{\mathrm{O}}^{--} \\
\mathrm{O} \\
\mathrm{MeO}-\mathrm{P} \\
\mathrm{O} \\
\mathrm{O}\end{array}$ & 5 & $\begin{array}{c}\text { A) 1.0-10 Äq. Schweineleberesterase, } \\
\mathrm{H}_{2} \mathrm{O}(\mathrm{pH}=7.7), \mathrm{RT}, 14 \mathrm{~d}, \text { DC-Kontrolle } \\
\text { B) 1.0-3.0 Äq. Cholesterinesterase, } \\
\mathrm{H}_{2} \mathrm{O}(\mathrm{pH}=7.0), 37^{\circ} \mathrm{C}, 14 \mathrm{~d}, \text { DC-Kontrolle }\end{array}$ & $\begin{array}{c}\text { DC-Analyse: Spuren } \\
\text { einer polareren } \\
\text { Komponente, Keine } \\
\text { Isolierung }\end{array}$ \\
\hline $\mathrm{OH}$ & 6 & $\begin{array}{c}\text { 1.0-3.0 Äq. Schweine-Pankreas-Lipase, } \\
\mathrm{H}_{2} \mathrm{O}(\mathrm{pH}=7.4), 37^{\circ} \mathrm{C}, 14 \mathrm{~d} \text {, DC-Kontrolle }\end{array}$ & $\begin{array}{l}\text { DC-Analyse: Spuren } \\
\text { einer polareren } \\
\text { Komponente, Keine } \\
\text { Isolierung }\end{array}$ \\
\hline
\end{tabular}

Da als möglichen Grund für den nicht erfolgten Umsatz sterische Effekte des Phosphoramidsubstituenten angenommen werden könnten, wurde in einem weiteren Versuch die Cholesterolesterase, isoliert aus dem Pankreas von Schweinen (Fa. Fluka) eingesetzt, welche in der Literatur für die enantioselektive hydrolytische Spaltung von Acetatschutzgruppen in Gegenwart von chiralen Phosphanen oder Phosphanoxiden verwendet wurde. ${ }^{93}$ Auch für dieses Enzym konnte lediglich die Bildung einer polareren Komponente in Spuren beobachtet werden, die Reaktion wurde ebenfalls nach $14 \mathrm{~d}$ abgebrochen (s. Tabelle 1, Eintrag 5). Um den Einfluss des phosphorhaltigen Substituenten zu untersuchen, wurde der Methylester 82 
mit Schweine-Pankreas-Lipase (porcine-pancreas-lipase, PPL, Fa. Sigma) umgesetzt. ${ }^{94}$ Doch auch dieser nicht phosphorylierte 4-Hydroxyzimtsäureester konnte enzymatisch nicht hydrolysiert werden (s. Tabelle 1, Eintrag 6). Der para-ständige Hydroxy- bzw. der Phosphoryloxysubstituent führen zu einer Erhöhung der Elektronendichte am Aromaten, welcher in Konjugation mit dem $\alpha, \beta$-ungesättigten Methylester steht. Da die enzymatische Hydrolyse des Zimtsäuremethylesters (93) vollständig verlief, führte vermutlich die Erhöhung der Elektronendichte am Methylester zu dem nicht erfolgten enzymatischen Umsatz.

\section{Versuche zur Reduktion-Oxidationssequenz}

Eine weitere Strategie beruhte auf der Reduktion des Methylesters 21 zum Alkohol und anschließender Oxidation zur Säure.

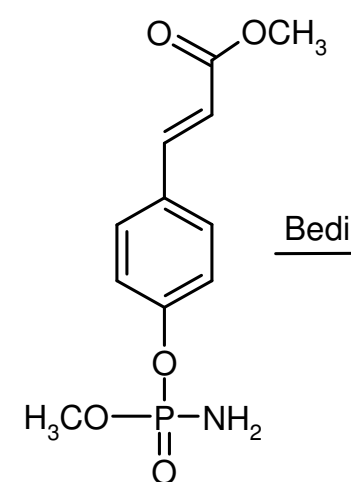

21

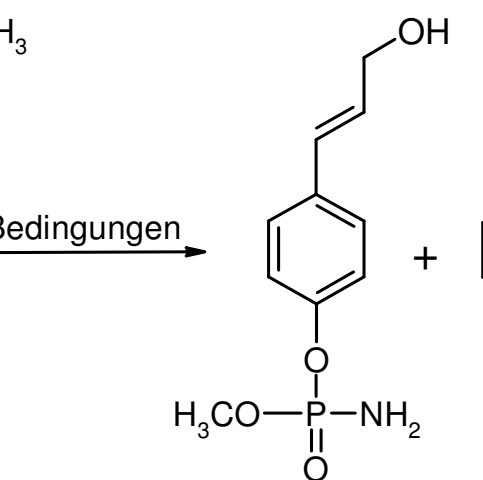

94<smiles>OC/C=C/c1ccc(O)cc1</smiles>

95

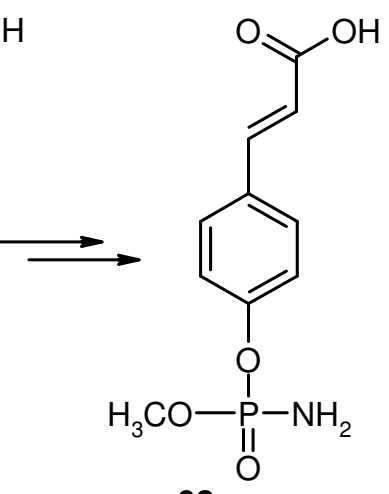

92

Schema 7. Geplante Reduktion-Oxidations-Sequenz zur Synthese von 92.

Zunächst sollte die Reduktion von 21 mit DIBAL-H im polaren Lösungsmittel THF bei $-78{ }^{\circ} \mathrm{C}$ zum allylischen Alkohol und im unpolaren Dichlormethan bei $-78{ }^{\circ} \mathrm{C}$ zum Aldeyhd untersucht werden (s. Tabelle 2, Eintrag 1,2). Beide Reaktionen wurden nach $3.5 \mathrm{~h}$ durch Zugabe von Methanol und Rochelle-Salz beendet und aufgearbeitet. Das ${ }^{1}$ H-NMR-Spektrum des Reaktionsansatzes in THF zeigte ein Gemisch aus dem allylischen Alkokol mit Phosphoramidsubstituenten 94 und dem allylischem Alkohol des Phenols 95 (s. Schema 7); beim Ansatz in Dichlormethan konnte lediglich ein Multikomponentengemisch detektiert werden. Zur Optimierung der Reduktion in THF wurde der Ansatz wiederholt und die Reaktion nach 40 min unter Zugabe von $\mathrm{NH}_{4} \mathrm{Cl}$-Lösung beendet (s. Tabelle 2, Eintrag 3). Allerdings erwies sich diese Variante der Aufarbeitung nicht als geeignete Methode, da das ${ }^{1} \mathrm{H}-\mathrm{NMR}$-Spektrum des Rohprodukts ein Gemisch aus dephosphoryliertem Substrat, Produkt 94 und reduziertem Zersetzungsprodukt 95 aufwies. Alle weiteren Versuche, den phosphorylierten allylischen Alkohol in ausreichenden Mengen zu erhalten, führten zur vollständigen Zersetzung des 
Substrats. Bei der Verwendung von $\mathrm{LiAlH}_{4}$ als Reduktionsmittel in THF bei $-78{ }^{\circ} \mathrm{C}$ wurde lediglich Zersetzung beobachtet (s. Tabelle 2, Eintrag 4).

Tabelle 2. Versuche zur Reduktion des Methylesters 21.

\begin{tabular}{|c|c|c|c|}
\hline & Reagenzien & Bedingungen & Anmerkungen \\
\hline 1 & DIBAL-H (1.0 M) & A) 2.0 Äq., THF, $-78^{\circ} \mathrm{C}, 3.5 \mathrm{~h}$ & $94+95$ \\
\hline 2 & DIBAL-H (1.0 M) & B) 1.0 Äq., $\mathrm{CH}_{2} \mathrm{Cl}_{2},-78^{\circ} \mathrm{C}, 3.5 \mathrm{~h}$ & Zersetzung zum Phenol 82 \\
\hline 3 & DIBAL-H (1.0 M) & C) 2.0 Äq., THF, $-78^{\circ} \mathrm{C}, 40 \mathrm{~min}$ & Zersetzung zum Phenol 82 \\
\hline 4 & $\mathrm{LiAlH}_{4}$ & 1.3 Äq., THF, $-78^{\circ} \mathrm{C}, 30 \mathrm{~min}$ & Zersetzung zum Phenol 82 \\
\hline
\end{tabular}

\section{Totalsynthese eines wasserlöslichen Analogons}

Da die bisherigen Ansätze zur Synthese des wasserlöslichen Analogons sich als nicht geeignet erwiesen hatten, sollte die Synthese ausgehend vom Silyl-geschützten Ester der 4-Hydroxyzimtsäure (96) analog zur Totalsynthese von 21 durchgeführt werden. Aufgrund der hohen Instabilität des Phosphoramidsubstituenten unter sauren und basischen Bedingungen sollte die Synthese vom TIPS-Ester 98 ausgehen, da die Abspaltung der Schutzgruppe bereits unter der Ammonolyse erfolgen könnte. Ansonsten schien es möglich, unter Verwendung milder Bedingungen etwa mit TBAF eine Entschützung zu erreichen und 92 zu erhalten (s. Schema 8).

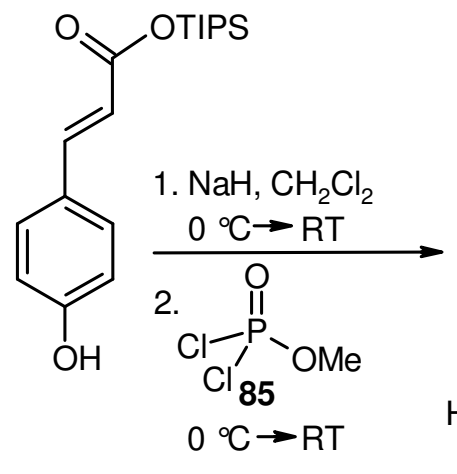

97

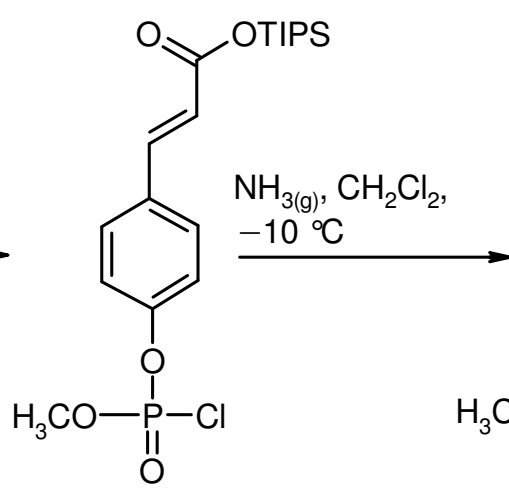

98

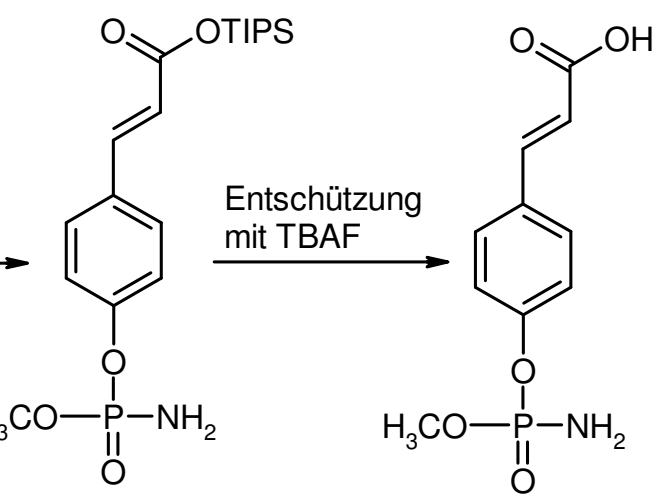

99
92

Schema 8. Synthesestrategie zur Synthese des wasserlöslichen Analogons 92.

Für die Synthese des Silylesters 97 erfolgte zunächst gemäß Wipf et al. die Umsetzung von 4Hydroxyzimtsäure (96) mit TIPS-Chlorid und Triethylamin als Base in wasserfreiem THF/DMF bei $0{ }^{\circ} \mathrm{C} .{ }^{95}$ Dünnschichtchromatographische Analyse des Reaktionsgemisches zeigte die Bildung von zwei Produkten (s. Tabelle 3, Eintrag 1). Um eine ausschließliche 
Bildung des Silylesters zu erhalten, wurde der Einsatz der schwächeren Basen Imidazol und Morpholin untersucht und die Reaktion zunächst im NMR-Röhrchen unter ${ }^{1} \mathrm{H}-\mathrm{NMR}$ Kontrolle durchgeführt (s. Tabelle 3, Eintrag 2, 3). Sowohl die Verwendung von Imidazol als auch von Morpholin als Base in deuteriertem DMSO- $\mathrm{d}_{6}$ zeigte in den ${ }^{1} \mathrm{H}-\mathrm{NMR}-\mathrm{Spektrum}$ lediglich die Bildung des einfach silylierten Produkts 97, allerdings wurde für Imidazol ein wesentlich schlechter Umsatz detektiert. Bei der Synthese des Silylesters mit Morpholin als Base in DMF bei $0{ }^{\circ} \mathrm{C}$ wurde die gewünschte Verbindung lediglich in einer Ausbeute von $36 \%$ erhalten (s. Tabelle 3, Eintrag 4).

Tabelle 3. Untersuchungen zur TIPS-Schützung der 4-Hydroxyzimtsäure (96).

\section{Bedingungen}

$1 \quad 1.3$ Äq. TIPSCl, 1.2 Äq. Et ${ }_{3} \mathrm{~N}, \mathrm{THF} / \mathrm{DMF} 1: 1,0{ }^{\circ} \mathrm{C}, 2 \mathrm{~h}$, DC-Kontrolle

$2 \quad 1.1$ Äq. TIPSCl, 1.4 Äq. Imidazol, DMSO-d 6 , RT, 0.5 h, ${ }^{1} \mathrm{H}$-NMR-Kontrolle (alle $5 \mathrm{~min}$ )

$3 \quad$ 1.1 Äq. TIPSCl, 1.3 Äq. Morpholin, DMSO-d 6 , RT, 0.5 h, ${ }^{1}$ H-NMR-Kontrolle (alle 5 min)

4

\section{Anmerkungen}

DC-Analyse: Bildung von zwei Produkten

Bildung eines

Produkts

Bildung eines

Produkts

Isolierung von 97

Der Aufbau der phosphorhaltigen funktionellen Gruppe sollte analog zur Totalsynthese von 21 erfolgen. Hierfür wurde das Natriumphenolat 97 portionsweise zu einem Überschuss Methoxyphosphoryldichlorid (85) bei $0{ }^{\circ} \mathrm{C}$ gegeben und anschließend für $25 \mathrm{~h}$ bei Raumtemperatur gerührt (s. Schema 9). Nach der Ammonolyse gemäß dem oben beschriebenen Verfahren wurde zur Aufarbeitung die wässrige Phase zunächst ohne $\mathrm{pH}$-Korrektur mit Ethylacetat extrahiert und die Extraktion nach vorsichtigem Ansäuern auf pH 5.6-5.8 wiederholt. Es konnte allerdings in keiner der erhaltenen Rohproduktfraktionen die Zielverbindung 99 detektiert werden. 


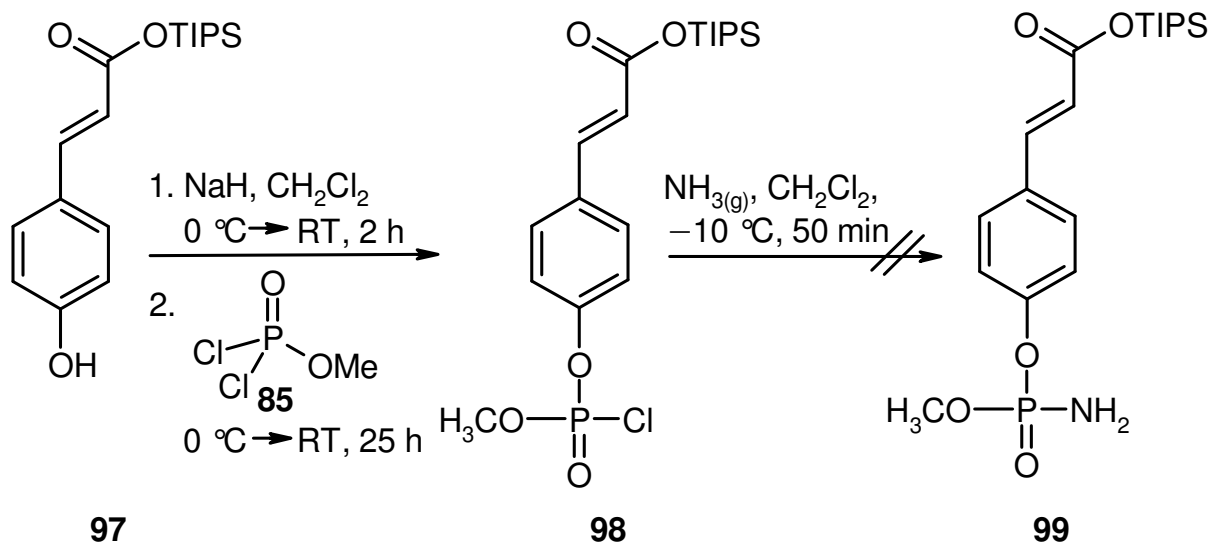

Schema 9. Synthese des Intermediats 98 und Einführung der Aminofunktion.

Um Ausschließen zu können, dass aufgrund der Zersetzung des Reagenzes 85 der Aufbau der funktionellen Gruppe nicht erfolgreich verlaufen war, wurde das Methoxyphosphoryldichlorid (85) gemäß der Literatur Fehler! Textmarke nicht definiert. neu hergestellt und die Synthese wiederholt. Unglücklicherweise konnte 99 jedoch auch mit dieser neuen Charge nicht erhalten werden.

Da die bisherigen Versuche ausgehend von einem TIPS-silylierten Zimtsäureester nicht zum Säurederivat führten, sollte als Substrat der sterisch weniger gehinderte TBS-Ester 100 eingesetzt werden, welcher auch bereits unter den Reaktionsbedingungen der Ammonolyse entschützt werden könnte. Für die Umsetzung von 4-Hydroxyzimtsäure (96) zum TBS-Ester wurde zunächst die Verwendung der Basen Triethylamin und Morpholin untersucht. Hierfür wurde die aromatische Carbonsäure in wasserfreiem THF gelöst, auf $0{ }^{\circ} \mathrm{C}$ abgekühlt und TBS-Chlorid in Toluol (2.5 M) sowie die jeweilige Base zugegeben (s. Tabelle 4, Eintrag 1, 2).

Tabelle 4. Untersuchungen zur TBS-Schützung der 4-Hydroxyzimtsäure (96).

\section{Bedingungen}

$1 \quad 1.0$ Äq. TBSCl in Toluol (1.0 M), 1.0 Äq. Et ${ }_{3} \mathrm{~N}, \mathrm{THF}, 0{ }^{\circ} \mathrm{C}$, 20 min, DC-Kontrolle

$2 \quad 1.0$ Äq. TBSCl in Toluol (1.0 M), 1.0 Äq. Morpholin, THF, $0{ }^{\circ} \mathrm{C}, 20 \mathrm{~min}, \mathrm{DC}-$ Kontrolle

3

1.0 Äq. TBSCl in Toluol (1.0 M), 1.0 Äq. $\mathrm{Et}_{3} \mathrm{~N}, \mathrm{THF}, 0^{\circ} \mathrm{C}$,

\section{Anmerkungen}

Bildung von zwei Produkten

Bildung von zwei Produkten Isolierung von $\mathbf{1 0 0}$ $20 \mathrm{~min}$ 
Dünnschichtchromatographische Analyse zeigte für Triethylamin als Base nur eine neu gebildete unpolarere Substanz, während für Morpholin zwei unpolarere Substanzen detektiert wurden. Allerdings erfolgte die Umsetzung von 96 zum TBS-Ester mit Trieythlamin als Base lediglich in einer Ausbeute von $56 \%$ (s. Tabelle 4, Eintrag 3). Der Aufbau der funktionellen Gruppe wurde analog zum oben beschriebenen Verfahren (s. Schema 9) durchgeführt. Abweichend zur vorher durchgeführten Isolierung des Intermediats $\mathbf{9 8}$ wurde jedoch in das nach Umsetzung mit Methoxyphosphoryldichlorid (85) erhaltene Reaktionsgemisch direkt gasförmiges Ammoniak bei $-10{ }^{\circ} \mathrm{C}$ eingeleitet. Die Zielverbindung 92 konnte jedoch nicht isoliert werden.

In der Arbeitsgruppe von Prof. P. v. Zezschwitz führte die inverse Zugabe des Reagenzes, d. h. Methoxyphosphoryldichlorid (85) wurde portionsweise zum Natriumalkoholat bei $78^{\circ} \mathrm{C}$ gegeben und damit zum Intermediat 101 umgesetzt. Die direkte Umsetzung des erhaltenen Reaktionsgemisches mit gasförmigen Ammoniak führte zur Zielverbindung 92 in einer Ausbeute von $43 \%$ (s. Schema 10). ${ }^{89}$ Die anschließende Reinigung des Rohprodukts, ein 10:1 Gemisch aus Produkt und durch Zersetzung erhaltenes Phenol, wurde im Rahmen dieser Dissertation mittels Gelchromatographie an Sephadex-LH $20(\mathrm{MeOH})$ durchgeführt.

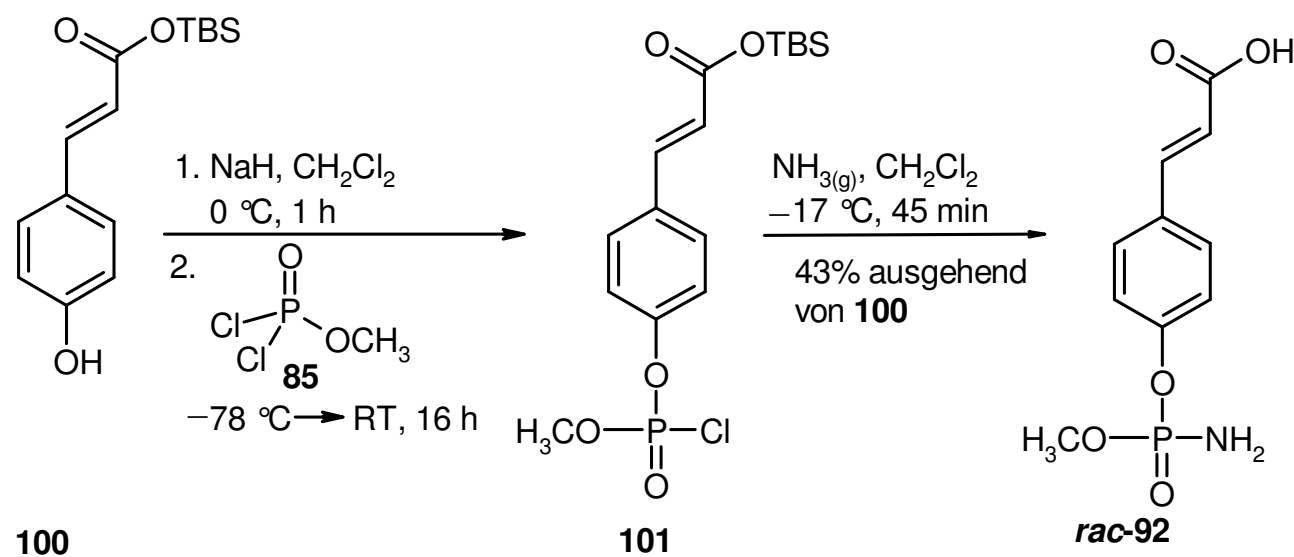

Schema 10. Synthese des wasserlöslichen Analogons 92 nach $v$. Zezschwitz. ${ }^{89}$

Sowohl das Cinnamoylphosphoramid (21) als auch das wasserlösliche Säurederivat 92 wurden auf ihre biologische Aktivität gegenüber der Acetyl- und Butyrylcholinesterase getestet. Die Ergebnisse werden im Abschnitt 4.1.9 beschrieben.

\subsubsection{Fermentation und Isolierung der Metaboliten}

Der Stamm Streptomyces JP90 wurde in 1 L-Schüttelkolben mit Schikane, befüllt mit $150 \mathrm{~mL}$ Medium $\mathrm{S}$ bei $28^{\circ} \mathrm{C}$ und $180 \mathrm{U} / \mathrm{min}$ kultiviert. Die Hauptkulturen wurden mit je $5 \mathrm{~mL}$ einer $48 \mathrm{~h}$ alten Vorkultur inokuliert. Nach $96 \mathrm{~h}$ wurde die Fermentation beendet und die Kultur- 
brühe nach $\mathrm{pH}$-Einstellung ( $\mathrm{pH}=5.0$ ) durch Filtration (Celite-Zusatz) vom Mycel abgetrennt. Das Kulturfiltrat wurde dreimal mit Ethylacetat (Volumina Ethylacetat:Kulturfiltrat ca 1:1) extrahiert und das Lösungsmittel i. Vak. entfernt. Hierbei fielen die Rohextrakte durch eine intensive Rosa-Färbung auf.

Zur Isolierung des unbekannten Metaboliten, dessen Struktur im Rahmen der Diplomarbeit nicht abschließend strukturaufgeklärt werde konnte, wurde das aus dem Kulturfiltrat erhaltene Rohprodukt zunächst an Kieselgel $\left(\mathrm{CHCl}_{3} / \mathrm{MeOH} 95: 5\right)$ vorgereinigt und fraktioniert. Die mit Anisaldehyd braun anfärbende Substanz 22 enthaltende Fraktion, wurde durch zweifache Mitteldrucksäulenchromatographie an reversed-phase Kieselgel (Lobar ${ }^{\circledR}$, Größe B, Aceton/ $\mathrm{H}_{2} \mathrm{O}$ 3:1) gereinigt und $5.6 \mathrm{mg} / \mathrm{L}$ des Spirotetronats (22a) sowie $4.2 \mathrm{mg} / \mathrm{L}$ des Spirotetronats (22b) gewonnen. Zusätzlich konnten hierbei $2.0 \mathrm{mg} / \mathrm{L}$ Rosiridol (23) und Cinnamoylphosphoramid (21) erhalten werden; diese Fraktionen waren leicht verunreinigt. Bei der Isolierung dieser Substanzen konnten nach Säulenchromatographie an Kieselgel in den weiteren Fraktionen einige der bereits von T. Schuhmann isolierten Substanzen identifiziert werden. Hierzu wurden die Fraktionen spektroskopisch untersucht und durch Vergleich der ${ }^{1}$ H-NMR Spektren $N$-Acetyltyramin (76), Cyclo(prolyltyrosyl) (77) und eine weitere Substanz, die zur Stoffklasse der Diketopiperazine gehört, erneut isoliert.

Für Versuche zur Isolierung des Rosa-Farbstoffs wurden $31.6 \mathrm{mg}$ des Rohextraktes mittels Gelchromatographie an Sephadex LH-20 (Aceton) fraktioniert, die erhaltene Hauptfraktion an reversed-phase Kieselgel (Lobar- ${ }^{\circledR}$, Aceton $/ \mathrm{H}_{2} \mathrm{O}$ 3:1) weiter gereinigt und die Fraktionen dünnschichtchromatographisch an Kieselgel (Cyclohexan/EE/MeOH 5:10:2) und an reversedphase Kieselgel (Aceton/ $\mathrm{H}_{2} \mathrm{O}$ 3:1) analysiert. Die Fraktionen, die sehr polare, mit Anisaldehyd orange und rot anfärbende Verbindungen enthielten, wurden spektroskopisch untersucht. Die ${ }^{1} \mathrm{H}-\mathrm{NMR}$ Spektren zeigten jedoch keine interessanten oder charakteristischen Signale, so dass von einer weiteren Bearbeitung abgesehen wurde. Damit konnte die für die Rosa-Färbung verantwortliche Substanz nicht identifiziert werden.

\subsubsection{Charakterisierung der Spirotetronate (22)}

Struktur des Spirotetronats (22a)

Die Verbindung 22a wurde als farbloser Feststoff in einer Ausbeute von $5.6 \mathrm{mg} / \mathrm{L}$ isoliert. Es zeigte neben UV-Löschung bei $254 \mathrm{~nm}$ eine braune Farbe nach Besprühen mit Anisaldehyd in der Wärme. Das ESI-Massenspektrum wies Ionen bei $m / z=1171.57[\mathrm{M}+\mathrm{H}]^{+}$und 1193.54 $[\mathrm{M}+\mathrm{Na}]^{+}$auf. Die Bestimmung der Summenformel aus der Hochauflösung eines dieser Addukte ergab zunächst widersprüchliche Ergebnisse, so dass mithilfe von Derivatisierung 
die Strukturaufklärung des Naturstoffs 22 ermöglicht werden sollte (s. Abschnitt 4.1.5 ). Erst nachdem für die Anzahl der möglichen O- und N-Atome eine größere Zahl als je 20 zugelassen wurde, konnte die korrekte Summenformel $\mathrm{C}_{61} \mathrm{H}_{86} \mathrm{O}_{22}$ (19 Doppelbindungsäquivalente) vorgeschlagen werden. Dies erfolgte aus der Hochauflösung des $[\mathrm{M}+\mathrm{H}]^{2+}$-Ions bei $m / z=597.29$ für den Metaboliten 22a. Für diesen Summenformelvorschlag lieferte eine Datenbankrecherche mit Antibase ${ }^{96}$ und Chapman \& Hall ${ }^{97}$ eine Übereinstimmung zu den bereits 1990 veröffentlichten Naturstoffen mit antibiotischer Wirkung gegen anaerobe Bakterien, die aus Streptomyces $\mathrm{Pa}-46101$ isoliert wurden. ${ }^{98}$ Es handelt sich hierbei um zwei Makrolid-Antibiotika, die zur Stoffklasse der Spirotetronate gehören. Diese weisen ein ungewöhnliches Aglykon mit charakteristischen Strukturelementen wie eine trans-Decalin-, eine Tetronsäure- und eine Cyclohexen-Einheit auf. Die beiden letzteren sind miteinander spiroverknüpft.

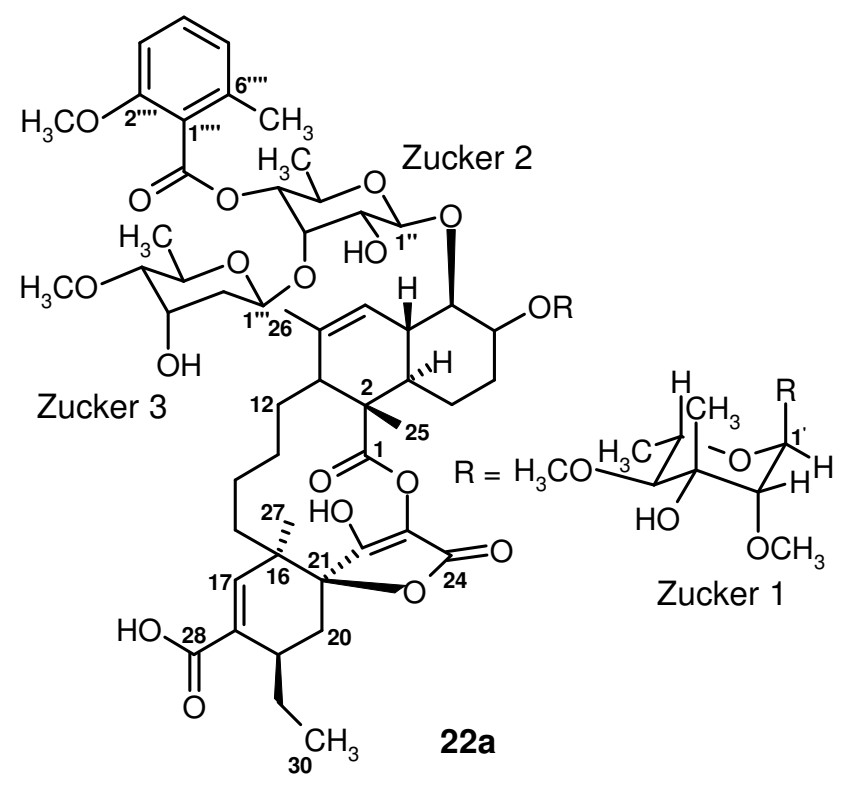

Für eine bessere Vergleichbarkeit der spektroskopischen Daten von 22a mit den Literaturdaten wurden zuvor in deuteriertem Methanol- $\mathrm{d}_{4}$ aufgenommene ${ }^{1} \mathrm{H}-,{ }^{13} \mathrm{C}-$, und 2D-NMRSpektren erneut in deuteriertem Chloroform- $\mathrm{d}_{1}$ gemessen, wobei das in deuteriertem Methanol gemessenen ${ }^{1}$ H-NMR Spektrum diskretere Resonanzen aufweist als das Vergleichsspektrum in deuteriertem Chloroform- $\mathrm{d}_{1}$ (s. Abbildung 37).

Das ${ }^{1}$ H-NMR-Spektrum enthält Signale für 82 Protonen, die verbleibenden vier sind Hydroxygruppen zuzuordnen. Im Tieffeldbereich des Spektrums bilden drei aromatische Signale $\left(\delta_{\mathrm{H}}=6.74,6.78,7.23 \mathrm{ppm}\right)$ ein ABC-Spinsystem, wobei die beiden Dubletts $\left(\delta_{\mathrm{H}}=6.74,6.78 \mathrm{ppm}\right)$ in ${ }^{2-4} J_{\mathrm{C}, \mathrm{H}}$-Korrelationen aus dem HMBC-Experiment ihre Nachbarschaft zu aromatisch gebundenen Methoxy- bzw. Methylgruppe zeigen. Weiterhin weisen zwei breite Singuletts $\left(\delta_{\mathrm{H}}=5.79,6.50 \mathrm{ppm}\right)$ auf olefinische Methinprotonen hin. Drei weitere 
Methinprotonen $\left(\delta_{\mathrm{H}}=4.54,4.81,5.27 \mathrm{ppm}\right)$ konnten aufgrund der typischen, zugehörenden ${ }^{13} \mathrm{C}$-NMR-Verschiebungen bei $\delta_{\mathrm{C}}=98.1,99.7$ und $103.5 \mathrm{ppm}$ als anomeres Proton von Zuckern erkannt werden. Außerdem sind im ${ }^{1} \mathrm{H}-\mathrm{NMR}-\mathrm{Spektrum}$ vier Methoxygruppen $\left(\delta_{\mathrm{H}}=3.38,3.51,3.56,3.81 \mathrm{ppm}\right) \mathrm{zu}$ beobachten, die ebenfalls aufgrund ihrer ${ }^{13} \mathrm{C}-\mathrm{NMR}-$ Resonanzen bei $\delta_{\mathrm{C}}=55.8,57.4,59.0$, und $61.6 \mathrm{ppm}$ als solche erkannt werden konnten. Das ${ }^{13} \mathrm{C}-\mathrm{NMR}-\mathrm{Spektrum}$ beinhaltet die Resonanzen von $61 \mathrm{C}$-Atomen, darunter vier Carbonylverbindungen und elf Signale für olefinische und aromatische C-Atome. Durch HSQC- ${ }^{1} J_{\mathrm{C}, \mathrm{H}^{-}}$ Kopplungen wurden die Kohlenstoffatome den daran gebundenen Protonen zugeordnet. Die Zuordnung der trans-Decalin-, und Cyclohexen-Einheiten konnte aus ${ }^{1} \mathrm{H},{ }_{1}^{1} \mathrm{H}-\mathrm{COSY}$ Experimenten und ${ }^{2-4} J_{\mathrm{C}, \mathrm{H}}$-Korrelationen aus dem HMBC-Experiment abgeleitet werden. Deren Verknüpfung über die Alkylkette bzw. die Tetronsäure-Einheit erfolgte anhand der ${ }^{2-4} J_{\mathrm{C}, \mathrm{H}}$-Korrelationen aus dem HMBC-Experiment und einen Vergleich mit den in der Literatur angegebenen NMR-Daten. ${ }^{98}$ Die Zuordnung, insbesondere die des Aglykons, konnte im Verlauf dieser Arbeit durch ${ }^{13} \mathrm{C}-{ }^{13} \mathrm{C}$-Kopplungen, welche aus Fütterungsexperimenten mit ${ }^{13} \mathrm{C}$-markierten Vorläufern erhalten wurden, bestätigt werden.

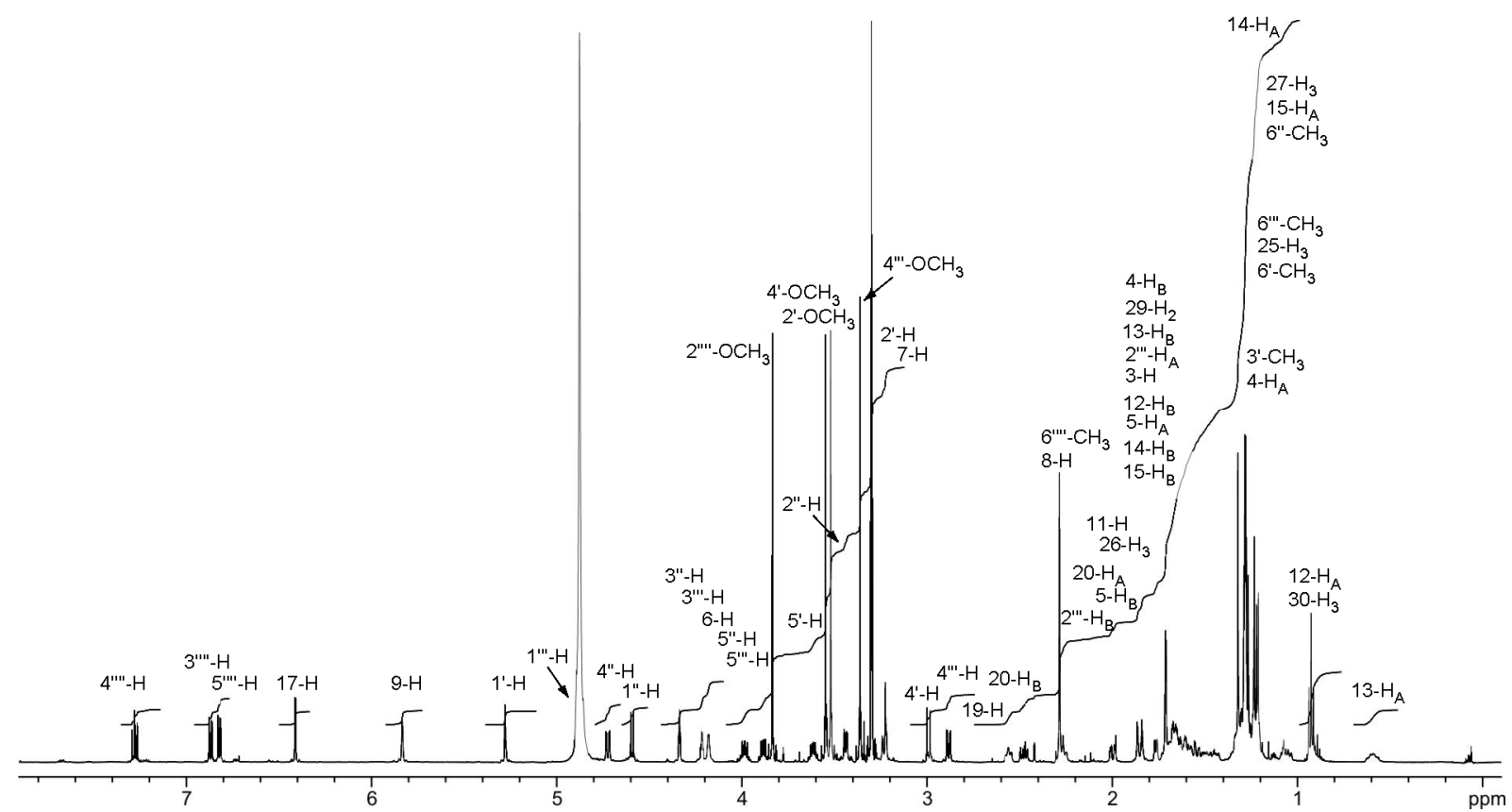

Abbildung 37. ${ }^{1} \mathrm{H}-\mathrm{NMR}-\mathrm{Spektren}$ des Spirotetronats (22a); $600 \mathrm{MHz}, \mathrm{CD}_{3} \mathrm{OD}$ und $\mathrm{CDCl}_{3}$ sowie ${ }^{13} \mathrm{C}-\mathrm{NMR}$ Spektrum; $150 \mathrm{MHz}, \mathrm{CDCl}_{3}$. 

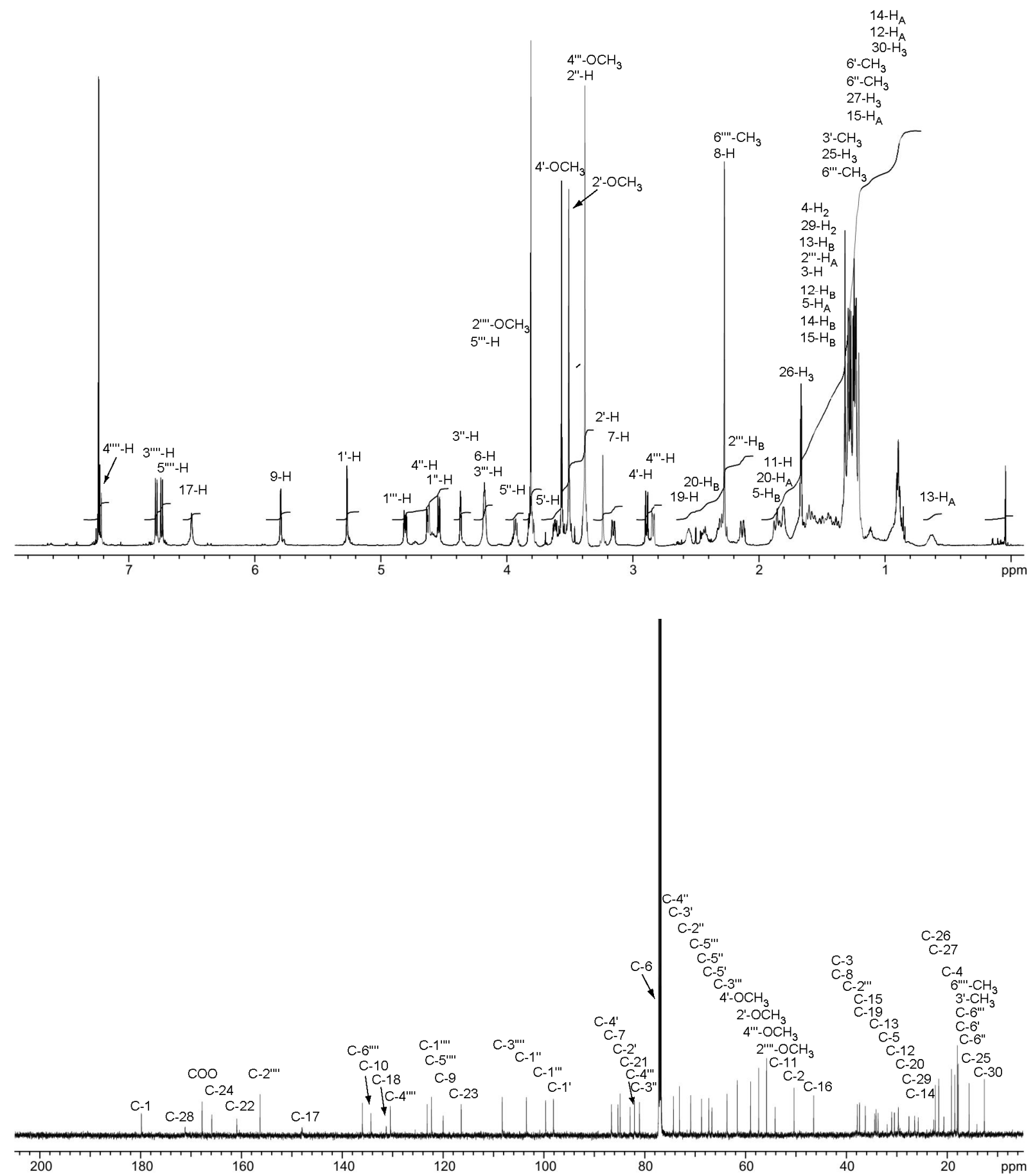

Abbildung 37 (Fortsetzung). ${ }^{1} \mathrm{H}-\mathrm{NMR}$-Spektren des Spirotetronats (22a); $600 \mathrm{MHz}, \mathrm{CD}_{3} \mathrm{OD}$ und $\mathrm{CDCl}_{3}$ sowie ${ }^{13} \mathrm{C}-\mathrm{NMR}$-Spektrum; $150 \mathrm{MHz}, \mathrm{CDCl}_{3}$.

Zur Überprüfung der relativen Konfiguration am Kohlenstoffatom C-3' der 2,4-Di-O-methyl3-C-methyl-rhamnose (Zucker 1, s. Abbildung 38) wurde zusätzlich zu den Informationen aus dem ${ }^{1} \mathrm{H},{ }^{1} \mathrm{H}$-COSY-Experiment ein 2D-NOESY-Experiment aufgenommen. Im ${ }^{1} \mathrm{H}$-NMRSpektrum kann zwischen 4'-H und 5'-H eine Kopplungskonstante von ${ }^{3} J_{\mathrm{HH}}=9.7 \mathrm{~Hz}$ beobachtet werden, somit müssen die benachbarten Protonen eine diaxiale Position einnehmen. 


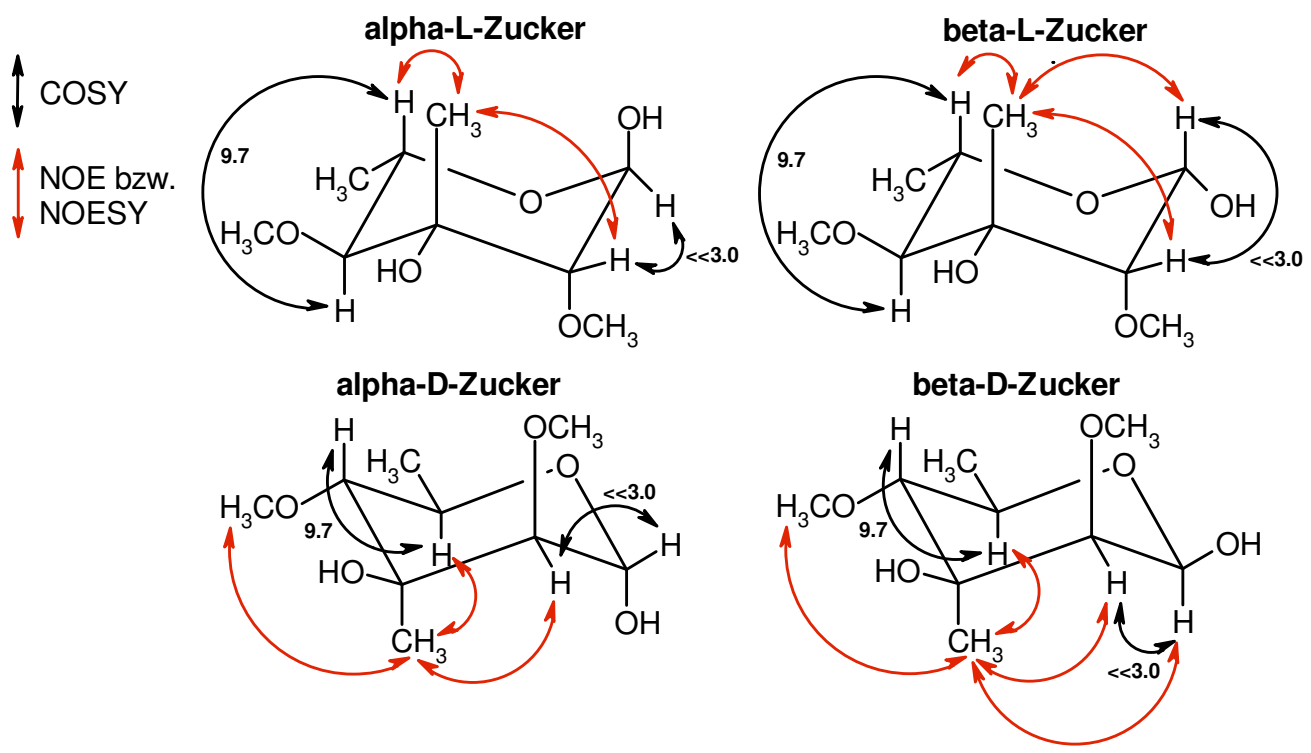

Abbildung 38. ${ }^{1} \mathrm{H},{ }^{1} \mathrm{H}-\mathrm{COSY}$-Korrelationen und NOESY- bzw. NOE-Korrelationen zur Bestimmung der relativen Konfiguration am anomeren Kohlenstoffatom der 2,4-Di- $O$-methyl-3- $C$-methyl-rhamnose (Zucker 1).

Da das 4'-H als Dublett vorliegt und keine weitere Kopplungskonstante aufweist, ist auch hier für die benachbarte $3^{\prime}-\mathrm{CH}_{3}$-Gruppe eine axiale Anordnung $\mathrm{zu}$ vermuten. Im NOESYSpektrum konnte keine Korrelation zwischen 4'-H und 3'- $\mathrm{CH}_{3}$ detektiert werden, was jeweils eine axiale Anordnung dieser benachbarten Substituenten bestätigt, die somit auf unterschiedlichen Seiten der Ringebene stehen. Weiterhin spricht eine NOE-Korrelation zwischen 3'- $\mathrm{CH}_{3}$ und 5'-H für eine diaxiale Anordnung dieser Substituenten. Außerdem kann eine NOEKorrelation zwischen 3 '- $\mathrm{CH}_{3}$ und 2'-H detektiert werden, aufgrund dieser eine axiale Position der 2'- $\mathrm{OCH}_{3}$-Gruppe anzunehmen ist. Die relative Konfiguration am anomeren Kohlenstoffatom C-1' wurde aus 1D-NOE-Experimenten abgeleitet, da eine Bestimmung der ${ }^{1} J_{\mathrm{CH}^{-}}$ Kopplungskonstanten nicht möglich war. Es konnte keine NOE-Korrelation zwischen dem anomeren Proton 1'-H und 3'- $\mathrm{CH}_{3}$ detektiert werden, was darauf hinweist, dass beide Substituenten auf unterschiedlichen Seiten der Ringebene stehen. Aufgrund der bereits abgeleiteten axialen Stellung der 3'- $\mathrm{CH}_{3}$-Gruppe ist somit eine axiale Position für die Hydroxygruppe am anomeren Kohlenstoffatom C-1' anzunehmen. Dies wird durch die kleine geminale Kopplungskonstante von ${ }^{3} J_{\mathrm{HH}}=<<3.0 \mathrm{~Hz}$ unterstützt. Die empirisch gefundene Klyne-Regel besagt, dass in bakteriellen Naturstoffen Zucker der D- Reihe $\beta$-verknüpft und die der L-Reihe $\alpha$-verknüpft vorliegen. ${ }^{99}$ Allerdings würden beim Vorliegen der Rhamnose in der DKonfiguration mit $\beta$-Verknüpfung die Substituenten 1'-H und $3^{\prime}-\mathrm{CH}_{3}$ auf der gleichen Seite der Ringebene stehen und damit eine NOE-Korrelation zeigen, was auch beim Vorliegen einer L-Konfiguration mit $\beta$-Verknüpfung der Fall wäre. Da die NOE-Korrelation zwischen 
1'-H und 3'- $\mathrm{CH}_{3}$ nicht beobachtet wurde, ist für die 2,4-Di- $O$-methyl-3- $\mathrm{C}$-methyl-rhamnose (Zucker 1) eine L-Konfiguration anzunehmen, bei der das begünstigte Anomer mit der axialständigen anomeren Hydroxygruppe vorliegt und damit $\alpha$-verknüpft ist. Zur Absicherung der absoluten Stereokonfiguration müsste bei einer Methanolyse von 22a der Zucker in ausreichenden Mengen isoliert werden, um die Drehwerte der entstehenden Methylglykoside mit Literaturdaten zu vergleichen. Außerdem kann mit Hilfe der Hudsonschen Isorotationsregel durch Vergleich der Drehwerte von $\alpha$ - und $\beta$-Anomeren die Zugehörigkeit zur D- oder LReihe bestimmt werden. ${ }^{100}$ Bei L-Zuckern dreht das $\alpha$-Anomer stärker links als das $\beta$-Anomer, in der D-Reihe umgekehrt. Diese Regel ist im Gegensatz zur Klyne-Regel allgemeingültig und bisher ohne Ausnahme. Im Rahmen von durchgeführten Derivatisierungsarbeiten konnte bei der sauren Methanolyse des Spirotetronats (22a) kein abgespaltener Zucker isoliert werden und damit keine Bestimmung der absoluten Stereokonfiguration erfolgen.

\section{Struktur des Spirotetronats (22b)}

22b wurde als farbloser Feststoff in einer Ausbeute von $4.2 \mathrm{mg} / \mathrm{L}$ isoliert. Die Verbindung 22b zeigte neben UV-Löschung bei $254 \mathrm{~nm}$ eine braune Farbe nach Besprühen mit Anisaldehyd in der Wärme. Das ESI-Massenspektrum wies ein Ion bei $m / z=1006[\mathrm{M}+\mathrm{Na}]^{+}$auf. Die Hochauflösung des $[\mathrm{M}+\mathrm{Na}]^{2+}{ }_{-}$Ions bei $\mathrm{m} / \mathrm{z}=503.23$ ergab für den Metaboliten $22 \mathbf{b}$ die Summenformel $\mathrm{C}_{52} \mathrm{H}_{70} \mathrm{O}_{18}$ (18 Doppelbindungsäquivalente). Eine Datenbankrecherche ${ }^{96,97}$ ergab, dass es sich bei diesem Sekundärstoff um das zweite, 1990 erstmalig isolierte Spirotetronat handelt. $^{98}$

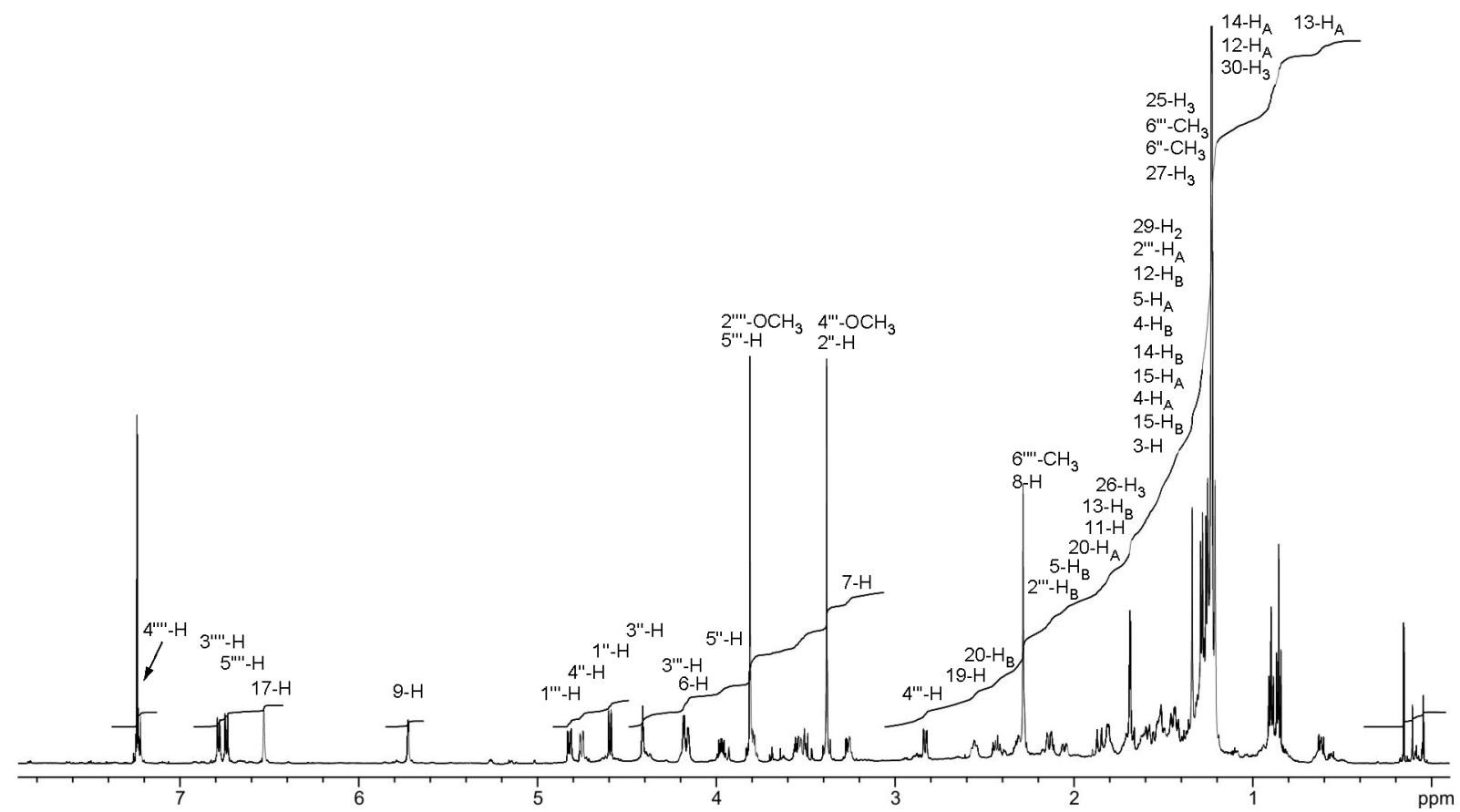




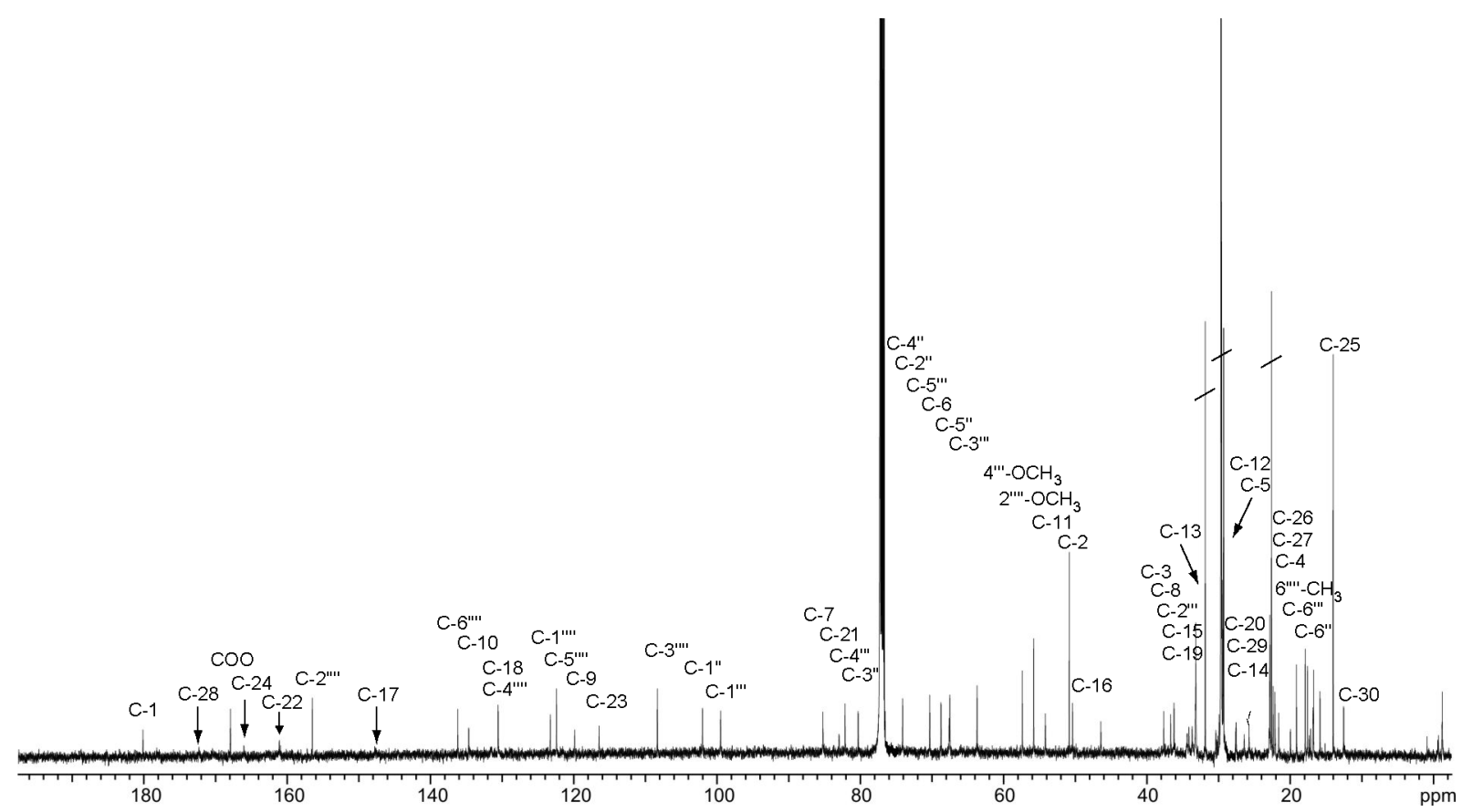

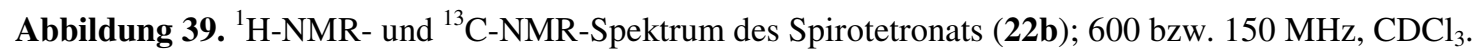

Das ${ }^{1}$ H-NMR-Spektrum zeigt Signale für 66 Protonen und ähnelt sehr den spektroskopischen Daten von Spirotetronat 22a. Nur die Signale eines Zuckers (Zucker 1 von 22a) fehlen, was u. a. durch die Abwesenheit des Methinprotons bei $\delta_{\mathrm{H}}=5.27 \mathrm{ppm}$ und der zugehörigen ${ }^{13} \mathrm{C}$ NMR-Resonanz bei $\delta_{\mathrm{C}}=99.7 \mathrm{ppm}$ als anomeres Kohlenstoffatom des Zuckers präsentiert wurde (s. Abbildung 40).

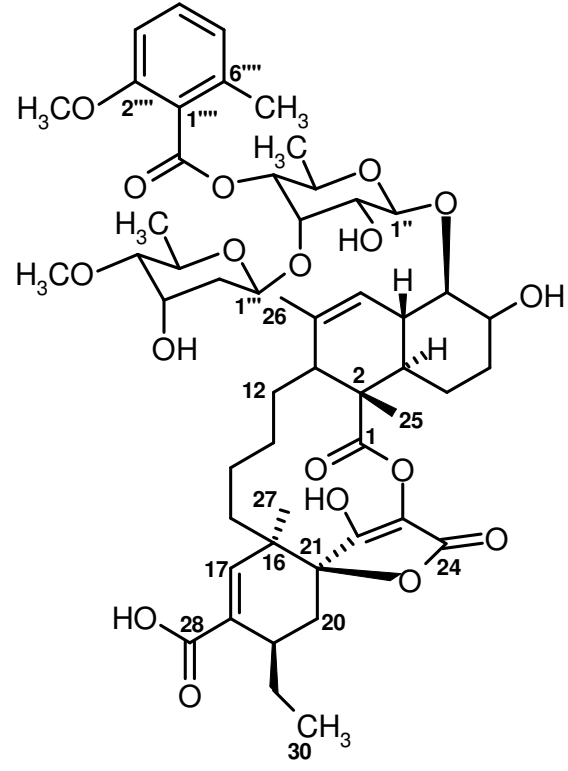

22b

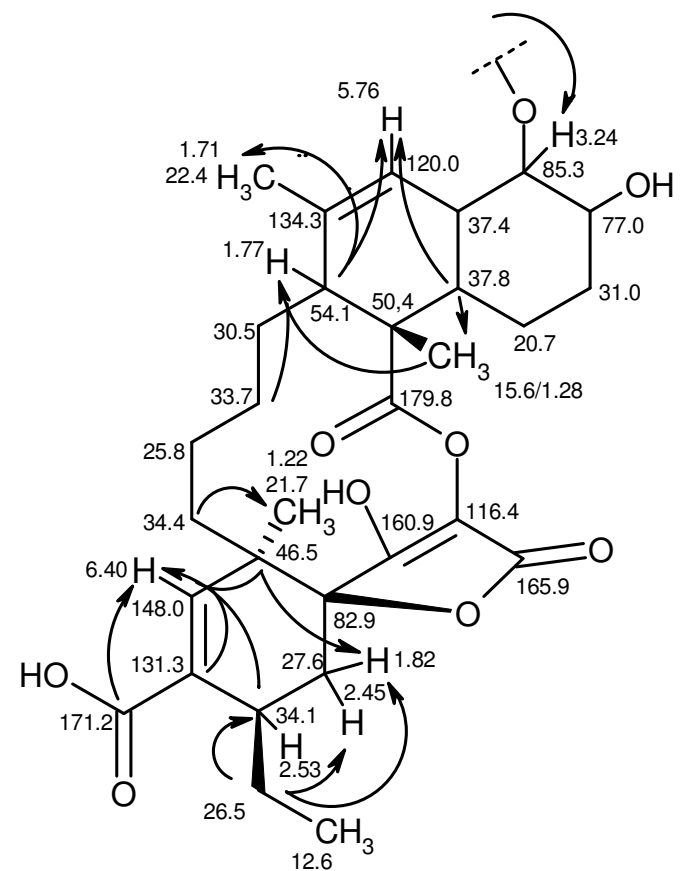

Abbildung 40. Struktur des Spirotetronats (22b) sowie dessen Aglykon mit ${ }^{2-4} J_{\mathrm{C}, \mathrm{H}}-$ Korrelationen aus dem HMBC-Experiment. 
Auch im ${ }^{13}$ C-NMR-Spektrum finden sich bis auf die Signale des Zuckers 1 die Resonanzen von 22a. Die Strukturzuordnung und Verknüpfungen der einzelnen Strukturelemente erfolgten mit Hilfe von ${ }^{1} J_{\mathrm{C}, \mathrm{H}^{-}}$und ${ }^{2-4} J_{\mathrm{C}, \mathrm{H}^{-}}$Korrelationen aus dem HSQC- bzw. HMBC-Experiment und Vergleiche mit den bekannten NMR-Daten. ${ }^{98}$

\subsubsection{Chemische Derivatisierung des Spirotetronats (22a)}

Aufgrund widersprüchlicher Ergebnisse aus hochaufgelösten ESI-Messungen bezüglich der Summenformel für den neuen Sekundärstoff 22a sollte mithilfe von Derivatisierungsarbeiten die zweifelsfreie Strukturaufklärung ermöglicht werden. Durch die Acetylierung bzw. Methylierung vorhandener Hydroxyfunktionen im Molekül sollten spezifische Signalverschiebungen im ${ }^{1} \mathrm{H}$ - und ${ }^{13} \mathrm{C}$-NMR-Spektrum induziert werden, welche Indizien für die Strukturaufklärung liefern könnten. Weiterhin sollte durch saure Methanolyse mindestens einer der drei vorliegenden Zucker von 22a abgespalten werden, um die Strukturzuordnung zu erleichtern. Eine Isolierung der abgespaltenen Zucker sollte die Bestimmung der absoluten Stereokonfiguration ermöglichen. Für die Derivatisierungsarbeiten musste im Rahmen der vorliegenden Arbeit zunächst der Metabolit 22a in ausreichenden Mengen isoliert und gereinigt werden. Ein Fermentationsansatz des Stammes JP90 im Fermenter (15 L) führte zu keiner Sekundärmetabolitenproduktion, so dass zur Isolierung von ausreichenden Mengen an 22a eine Kultivierung im $5 \mathrm{~L}-\mathrm{Ma}$ stab unter Standardbedingungen in $1 \mathrm{~L}$ Schüttelkolben durchgeführt wurde. Hierbei wurde 22a in einer Ausbeute von $5.6 \mathrm{mg} / \mathrm{L}$ gewonnen (s. Abschnitt 4.1.3 ). Im Folgenden werden die aus den durchgeführten Derivatisierungsarbeiten gewonnenen Derivate von 22a beschrieben, mit deren Hilfe die Struktur des Spirotetronats (22a) zusätzlich zum Vergleich mit den Literaturdaten ${ }^{98}$ verifiziert werden konnten.

\section{Acetylierung}

Zur Umsetzung mit Acetanhydrid wurde die Verbindung 22a in Pyridin gelöst, die Lösung auf $0{ }^{\circ} \mathrm{C}$ gekühlt und Acetanhydrid zugegeben. Unter dünnschichtchromatographischer Analyse, wurde das Reaktionsgemisch für $27 \mathrm{~h}$ bei Raumtemperatur gerührt, da nur ein geringer Umsatz detektiert wurde. Nach Aufarbeitung und säulenchromatographischer Reinigung an Kieselgel konnten aber lediglich Zersetzungsprodukte isoliert werden.

\section{Methylierung zum Spirotetronat 102a}

Die Methylierung der Substanz 22a erfolgte mit etherischer Diazomethanlösung (ca. $0.4 \mathrm{M}$ ) bei $0{ }^{\circ} \mathrm{C}$ in Methanol/Wasser 19:1. Nach Aufarbeitung und säulenchromatographischer Reini- 
gung an Kieselgel wurde das zweifach methylierte Produkt 102a als farbloser Feststoff in einer Ausbeute von $71 \%$ erhalten.

Das ESI-Massenspektren des nach Methylierung erhaltene Produkts lieferte ein Ion bei $m / z=1199[\mathrm{M}+\mathrm{H}]^{+}, 1222[\mathrm{M}+\mathrm{Na}]^{+}$, dessen Masse auf ein zweifach methyliertes Produkt schließen ließ. Das ${ }^{1} \mathrm{H}-\mathrm{NMR}-$ Spektrum wies zwei zusätzliche Methylgruppen bei $\delta_{\mathrm{H}}=3.53$ und $4.11 \mathrm{ppm}$ auf, die aufgrund ihrer Tieffeldverschiebung am Sauerstoff gebunden sein müssen. Es sind also zwei Hydroxygruppen methyliert worden. Dieses wird im ${ }^{13} \mathrm{C}-\mathrm{NMR}$ Spektrum durch zwei zusätzliche Signale bei $\delta_{\mathrm{C}}=52.3$ und $62.7 \mathrm{ppm}$ bestätigt. Des Weiteren zeigt das ${ }^{13} \mathrm{C}-\mathrm{NMR}$-Spektrum für die C-Atome C-22 und C-24 eine Tieffeldverschiebung von $\delta_{\mathrm{C}}=160.9 \mathrm{zu} \delta_{\mathrm{C}}=169.0 \mathrm{ppm}$ für C-22 bzw. $\delta_{\mathrm{C}}=165.9 \mathrm{zu} \delta_{\mathrm{C}}=169.9 \mathrm{ppm}$ für C-24, die Resonanz der Carbonsäure (C-28) ist nur geringfügig von $\delta_{\mathrm{C}}=171.2$ auf $\delta_{\mathrm{C}}=171.5 \mathrm{ppm}$ ins Tieffeld verschoben. Aufgrund dieser Beobachtungen ist zum einen die Säurefunktion (C-28) in den entsprechenden Methylester überführt worden, wofür die zusätzliche Resonanz bei $\delta_{\mathrm{C}}=52.3 \mathrm{ppm}$ spricht. Außerdem ist das Enol an C-22 in den entsprechenden Enolether der Tetronsäure-Einheit umgewandelt worden. Dieser Methylenolether stimmt mit der stark ins Tieffeld verschobenen Resonanz für die Methylgruppe bei $\delta_{\mathrm{C}}=62.7 \mathrm{ppm}$ überein.

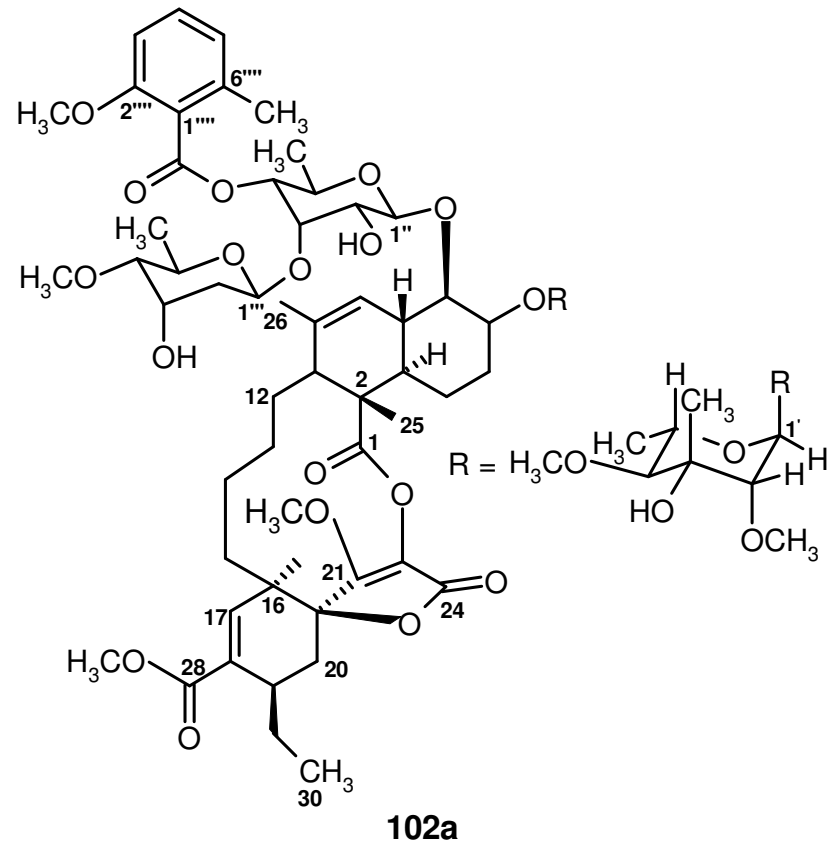

Abbildung 41. Struktur des zweifach methylierten Derivats 102a.

\section{Methanolyse zum Spirotetronat 103a und 104a}

Die Verbindung 22a $(18.1 \mathrm{mg}, 15 \mu \mathrm{mol})$ wurde in methanolischer Salzsäure gelöst und 15 min im Ultraschallbad behandelt. Nach Mitteldrucksäulenchromatographie am reversed- 
phase Kieselgel wurden die Derivate 103a und 104a in einer Ausbeute von $45 \%$ bzw. $15 \%$ isoliert.

Für die nach Methanolyse isolierte polarere Hauptkomponente 103a wurde im ESI-Massenspektrum ein Ion bei $\mathrm{m} / z=1050[\mathrm{M}+\mathrm{Na}]^{+}$detektiert, dessen Hochauflösung die Summenformel $\mathrm{C}_{54} \mathrm{H}_{74} \mathrm{O}_{19}$ (18 Doppelbindungsäquivalente) ergab. Das ${ }^{1} \mathrm{H}-\mathrm{NMR}$-Spektrum zeigt Signale für 70 Protonen und ähnelt den spektroskopischen Daten von Spirotetronat 22a. Nur die Signale eines Zuckers (Zucker 3 von 22a) fehlen, was u. a. durch die Abwesenheit des Methinprotons bei $\delta_{\mathrm{H}}=4.81 \mathrm{ppm}$ und der zugehörigen ${ }^{13} \mathrm{C}-\mathrm{NMR}-$ Resonanz bei $\delta_{\mathrm{C}}=98.1 \mathrm{ppm}$ als anomeres Kohlenstoffatom des Zuckers bestätigt. Ebenso zeigt das ${ }^{13} \mathrm{C}-\mathrm{NMR}-$ Spektrum bis auf die Signale des Zuckers 3 die Resonanzen von 22a. Die Strukturzuordnung und Verknüpfungen der einzelnen Strukturelemente erfolgten mit Hilfe von ${ }^{1} J_{\mathrm{C}, \mathrm{H}^{-}}$und ${ }^{2-4} J_{\mathrm{C}, \mathrm{H}^{-}}$ Korrelationen aus dem HSQC- bzw. HMBC-Experiment und Vergleich mit der Strukturzuordnung von 22a (s. Abbildung 42).
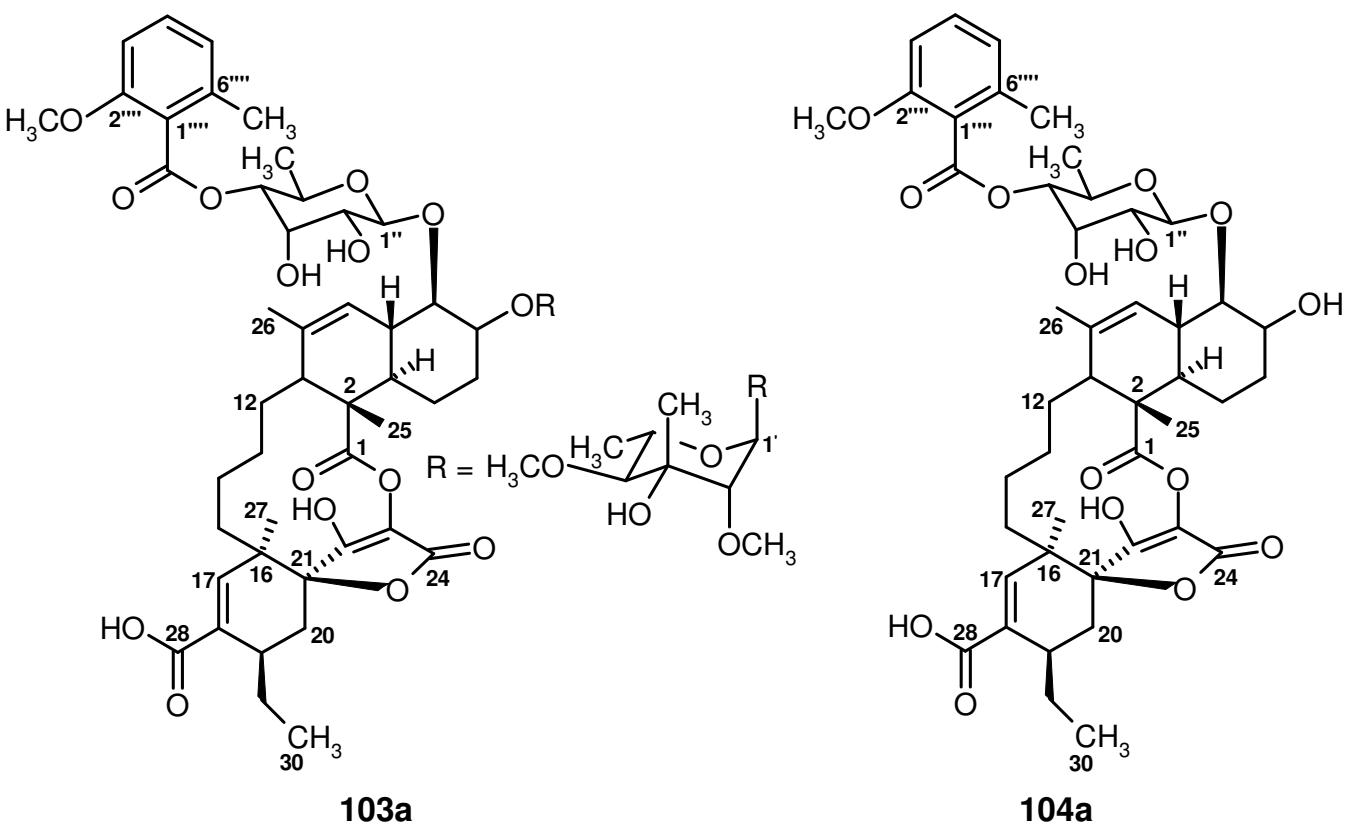

Abbildung 42. Strukturen der Derivate 103a und 104a aus saurer Methanolyse von Spirotetronat (22a).

Für die nach Methanolyse isolierte polarere Nebenkomponente 104a trat im ESI-Massenspektrum ein Ion bei $\mathrm{m} / z=861[\mathrm{M}+\mathrm{Na}]^{+}$auf, dessen Hochauflösung die Summenformel $\mathrm{C}_{45} \mathrm{H}_{58} \mathrm{O}_{15}$ (17 Doppelbindungsäquivalente) ergab. Das ${ }^{1} \mathrm{H}-\mathrm{NMR}-$ Spektrum enthält Signale für 70 Protonen und ähnelt den spektroskopischen Daten von Spirotetronat 22a bzw. der Hauptkomponente 103a. Allerdings fehlen die Resonanzen der Zucker 1 und 3 von 22a, wie auch im ${ }^{13}$ C-NMR-Spektrum. Die Strukturzuordnung und Verknüpfungen der einzelnen 
Strukturelemente erfolgten mit Hilfe von ${ }^{1} J_{\mathrm{C}, \mathrm{H}^{-}}$und ${ }^{2-4} J_{\mathrm{C}, \mathrm{H}^{-}}$Korrelationen aus dem HSQCbzw. HMBC-Experiment und Vergleich mit der Strukturzuordnung von 22a bzw. 103a (s. Abbildung 42).

Die bei der Methanolyse abgespaltenen Zucker 1 und 3 konnten jedoch aufgrund unzureichender Detektion mit Orcin/Schwefelsäure bei der chromatographischen Reinigung nicht isoliert werden.

\subsubsection{Die absolute Konfiguration des Rosiridols (23)}

Zur Bestimmung der absoluten Konfiguration des hydroxylierten Monoterpens Rosiridol (23) wurde der Naturstoff mit den synthetisch dargestellten Verbindungen rac-(23)- und $S$-(23)Rosiridol in einer vergleichenden HPLC-Analyse an chiraler stationärer Phase untersucht. Die Arbeiten zur Totalsynthese des rac-Rosiridols und seines (S)-Enantiomers, dessen absolute Stereokonfiguration mithilfe von Moshers-Estern des rac-Rosiridols abgeleitet worden war, wurden in der Arbeitsgruppe von T. Lindel (Technische Universität Braunschweig) von K. Simon durchgeführt. ${ }^{101}$ Für eine vergleichende HPLC-Analyse an chiraler stationärer Phase wurde zunächst eine geeignete HPLC-Methode zur analytischen Trennung des rac-Rosiridols entwickelt. Vorversuche zur analytischen Trennung von rac-(23) ergaben eine vollständige Trennung der beiden Enantiomere an chiraler stationärer Phase vom Typ Daicel Chiralcel OD bei einem Injektionsvolumen von $15 \mu \mathrm{L}$ einer Stammlösung mit einer definierten Konzentration von $c=1.0 \mathrm{mg} / \mathrm{mL}$. Für die HPLC-Analyse (HPLC C, Säule F: Daicel Chiralcel OD, Programm G: n-Hexan/Isopropanol, isokratisch; s. Abschnitt B 1.2 ) wurden Mischungen aus rac-(23)- mit $S$-(23)-Rosiridol und Naturstoff mit $S$-(23)-Rosiridol im Verhältnis von 1:1 hergestellt (mit Stammlösung von $c=1.0 \mathrm{mg} / \mathrm{mL}$ ). ${ }^{102}$ Zur Überprüfung der Retentionszeiten wurden die einzelnen Substanzen (natives (23)-, totalsynthetisches rac-(23)- und $S$-(23)Rosiridol) vor dem jeweiligen Mischungsexperiment gemessen (s. Abbildung 43). Um die Retentionszeiten auf Konsistenz zu überprüfen, wurde zwischen den Einzelmessungen jeweils rac-Rosiridol gemessen. 


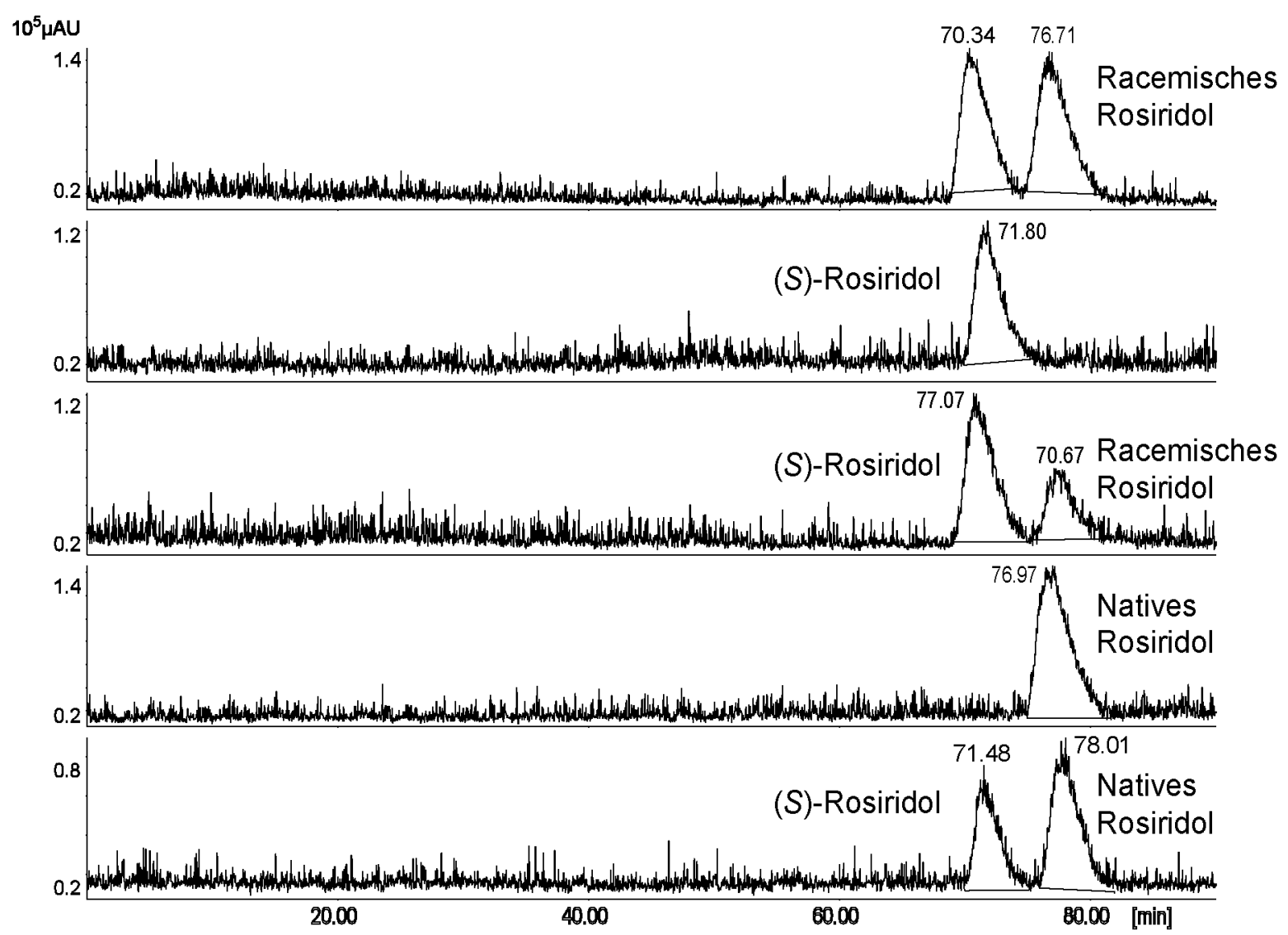

Abbildung 43. Mischungsexperimente zur Bestimmung der absoluten Konfiguration des hydroxylierten Monoterpens Rosiridol (23). Die Abbildung der Mischungsreihe zeigt von oben nach unten: 1. rac-Rosiridol; 2. $(S)$ Rosiridol; 3. Mischungsexperiment mit rac-Rosiridol und (S)-Rosiridol (1:1 Gemisch); 4. Natives Rosiridol; 5. Mischungsexperiment mit nativem Rosiridol und $(S)$-Rosiridol (1:1 Gemisch).

Beim Mischungsexperiment des (S)-Rosiridols mit dem rac-Rosiridols ist eine Vergrößerung der Fläche des ersten Peaks zu beobachten, während beim Mischungsexperiment des nativen Rosiridols mit rac-Rosiridol eine Vergrößerung der Fläche des zweiten Peaks auftritt. Damit ist zweifelsfrei bewiesen, dass synthetisches $(S)$-Enantiomer und natives Rosiridol nicht die gleiche Konfiguration aufweisen und das aus Streptomyces sp. JP90 isolierte Rosiridol (23) somit $(R)$-konfiguriert ist.<smiles>CC(C)=CCC(O)C(C)=CCO</smiles>

Abbildung 44. Natives Rosiridol (23) mit der absoluten $4 R$-Konfiguration. 


\subsubsection{Studien zur Biosynthese ausgewählter Metaboliten}

Das Metabolitenspektrum des Stammes Streptomyces JP90 zeigt eine biogenetische Vielfalt, die auf verschiedenen Terpen-, Polyketid-, Shikimat- und Aminosäure-Quellen basiert (s. Abbildung 45). Dieser mikrobielle Produzent ist damit ein ,äußerst begabter“ Stamm zu nennen. Im Rahmen der vorliegenden Arbeit sollten einige ausgewählte Sekundärmetaboliten hinsichtlich ihres biosynthetischen Aufbaus mit ${ }^{13} \mathrm{C}$-markierten Vorläufern untersucht werden.<smiles>CC(=O)NCCc1ccc(O)cc1</smiles><smiles>CC(C)=CCC(O)C(C)=CCO</smiles>

Rosiridol (23)<smiles>CC(C)(O)CCCCC(=O)O</smiles>

6-Hydroxy-6-methyl-heptansäure (80)<smiles>O=C1NC(Cc2ccc(O)cc2)C(=O)N2CCCC12</smiles>

Cyclo(prolyltyrosyl) (77)

$N$-Acetyltyramin (76)<smiles>O=C(O)c1c[nH]c2ccccc12</smiles>

Indol-3-carbonsäure (79)<smiles>CCC(=O)NC</smiles><smiles>CC(=O)N1CCCCCNC(=O)CCC(=O)NO1</smiles>

$\mathrm{H}_{3} \mathrm{CO}$ \%"<smiles>COC(=O)/C=C/c1ccc(OPN)cc1</smiles>

Cinnamoylphosphoramid (21)

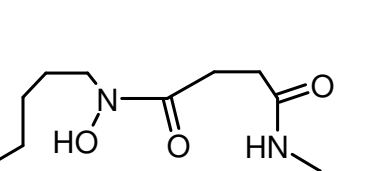<smiles>COc1cccc(C)c1C</smiles>

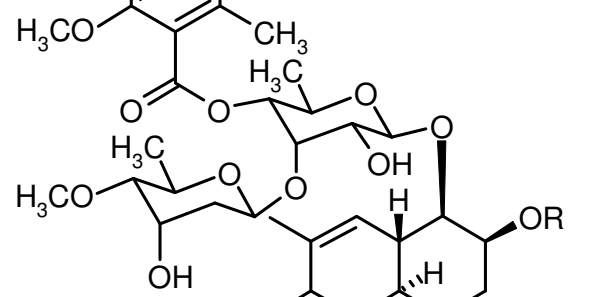

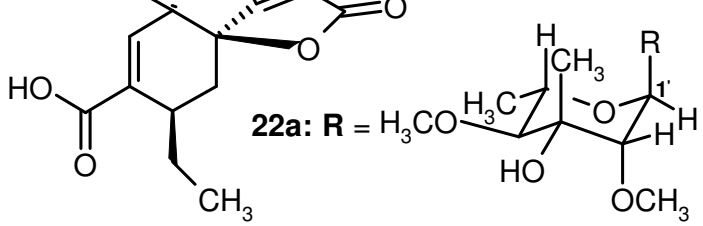

22b: $\mathbf{R}=\mathrm{H}$

Spirotetronate (22)

Abbildung 45. Metabolitenspektrum des Stammes Streptomyces JP90. Die Spirotetronate (22) sind im Rahmen dieser Dissertation isoliert worden.

Die Spirotetronate (22) gehören zur Klasse der Spirotetronat-Antibiotika, deren Aglykon aus einer trans-Decalin-, einer Tetronsäure-, und einer Cyclohexen-Einheit bestehen, wobei die Tetronsäure-Einheit mit dem Cyclohexenring spiroverknüpft ist und über einen Carbonsäureester an das trans-Decalin gebunden ist. Die aus dem Stamm Streptomyces JP90 isolierten Spirotetronate (22) wurden erstmalig Anfang der 90er Jahre aus einem Streptomyceten gewonnen und weisen eine hohe strukturelle Ähnlichkeit zum bekannten Chlorothricin (105) aus Streptomyces antibioticus auf. ${ }^{103}$ Aufgrund dieser großen Strukturverwandtschaft sollten 
anhand von Biosynthesestudien mit ${ }^{13} \mathrm{C}$-markierten Vorläufern der polyketidische Ursprung des Aglykons von 22 überprüft und der biosynthetische Aufbau der Tetronsäure-, transDecalin- und Cyclohexen-Einheiten im Vergleich zum Chlorothricin (105) untersucht werden. Rosiridol (23) ist ein bisher nur aus Pflanzen isolierter Naturstoff, der zur großen Klasse der Terpene gehört. Die Biosynthese von Terpenen kann in Pflanzen, Grünalgen und Mikroorganismen über zwei Biosyntheserouten erfolgen: Den Acetat-Mevalonatweg, der über vierzig Jahre als universeller Biosynthesemechanismus für den Aufbau von Terpenbausteinen angenommen wurde oder den Triose-Pyruvat-Weg, dessen Hypotheseschema erstmalig 1993 von Rohmer et al. ${ }^{104}$ und Arigoni et al. ${ }^{105}$ veröffentlicht wurde. Viele Bakterien benutzen zur Biosynthese der Terpene entweder den Acetat-Mevalonat- oder den Triose-Pyruvat-Weg, wobei Streptomyceten ungewöhnlicherweise beide Biosynthesemechanismen nutzen können, wie biosynthetische Untersuchungen mit ${ }^{13} \mathrm{C}$-markierten Vorläufern zeigten. ${ }^{106}$ Aus diesem Grund sollte untersucht werden, über welchen Stoffwechselweg der Stamm Streptomyces JP90 das Monoterpen 23 aufbaut.

Des Weiteren sollte das in seiner Struktur ungewöhnliche Cinnamoylphosphoramid (21) biochemisch charakterisiert werden und Untersuchungen zur möglichen Funktion des Metaboliten als Biosynthesevorläufer durchgeführt werden.

\subsubsection{Fermentationskurve}

Für eine Durchführung von Biosynthesestudien sind Kenntnisse über den zeitabhängigen Produktionsverlauf der Sekundärmetaboliten notwendig. Mit Hilfe von Fermentationskurven können wichtige Informationen über den $\mathrm{pH}$-Verlauf und die Produktbildung der Metaboliten gewonnen werden, auf deren Grundlage der geeignete Zeitpunkt und die Dauer von Fütterungsexperimenten ermittelt werden. Um eine genügend hohe Anreicherung im Naturstoff zu erzielen, erfolgt die Fütterung der markierten Vorläufer zu Beginn der Produktion des anzureichernden Sekundärmetaboliten und endet mit dem Erreichen von dessen maximaler Konzentration. Hierbei ermöglichen kontinuierliche Fütterungsverfahren eine Zufütterung der markierten Vorläufer über einen längeren Zeitraum, die dem natürlichen Stoffwechsel gerecht wird.

Zur Aufnahme der Fermentationskurve wurde der Stamm JP90 in 1 L Schüttelkolben mit Schikane (je $150 \mathrm{~mL}$ Nährmedium S, $28^{\circ} \mathrm{C}, 180 \mathrm{U} / \mathrm{min}$ ) sowie im Fermenter Biostat M, kultiviert (950 ml Nährlösung Medium S, $28{ }^{\circ} \mathrm{C}, 600 \mathrm{U} / \mathrm{min}, 1.6$ vvm, s. Abschnitt B 3.6.1 ). Alle sechs bzw. über Nacht acht Stunden wurden 25 mL Kulturbrühe aus dem Fermenter und $10 \mathrm{~mL}$ Kulturbrühe aus den Schüttelkolben entnommen, erstmals nach Animpfen bis zur 
78. Inkubationsstunde. Die Aufarbeitung erfolgte wie unter Abschnitt B 3.6.1 beschrieben. Die erhaltenen Rohextrakte aus dem Kulturfiltrat wurden mit einer definierten Konzentration von $c=4 \mathrm{mg} / \mathrm{mL}$ in Methanol gelöst und dünnschichtchromatographisch an Kieselgel $\left(\mathrm{CHCl}_{3} / \mathrm{MeOH}\right.$ 85:15) untersucht. Hierbei konnte die Sekundärstoffproduktion aus der Intensität der UV-Löschung bei $254 \mathrm{~nm}$ und aus der Intensität der Farbreaktion mit Anisaldehyd detektiert werden. Die dünnschichtchromatographische Analyse der Rohextrakte wies daraufhin, dass bei der Kultivierung in Schüttelkolben der Stamm JP90 eine gute Sekundärmetabolitenproduktion zeigte, während dies bei der Kultivierung im Fermenter nicht erfolgte. Für die analytische Untersuchung der Sekundärstoffproduktion in den Rohextrakten mittels HPLC wurden jeweils $150 \mu \mathrm{L}$ entnommen, zentrifugiert und anschließend analysiert (HPLC A, Säule A: Grom Superspher 100 RP-18, Programm A: $\mathrm{MeOH} / \mathrm{H}_{2} \mathrm{O}$, jeweils mit $0.05 \%$ Ameisensäure, Gradient; s. Abschnitt B 1.2 ). Über die HPLC-Analyse wurde der relative Gehalt an Spirotetronaten (22) über die Fermentationszeit abgeschätzt (s. Abbildung 46).

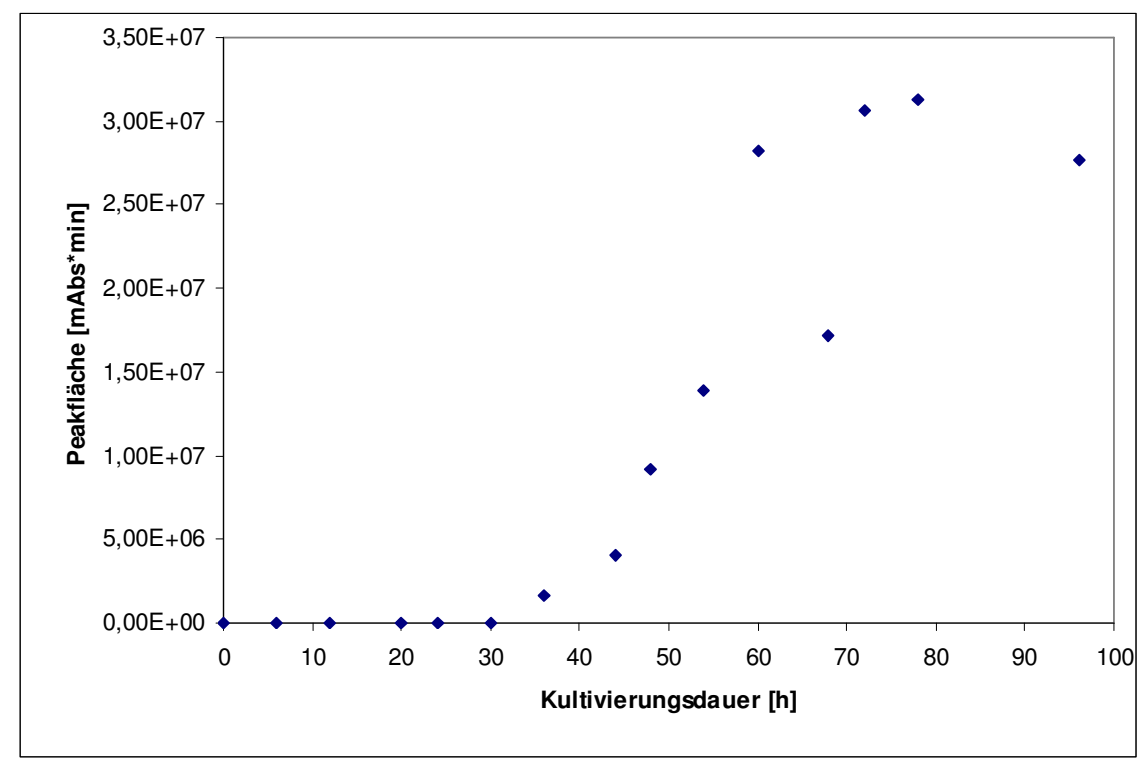

Abbildung 46. Fermentationskurve der Spirotetronate (22a,b) aus Stamm Streptomyces JP90.

Es wurde deutlich, dass die Produktion der Spirotetronate (22) nach der 36. Stunde beginnt und ihr erstes Maximum nach 58 Stunden Inkubationszeit erreicht. Ab der $72 \mathrm{~h}$ steigt die Menge an Spirotetronaten (22) kontinuierlich an und erreicht ihr Maximum mit der 78. Stunde der Fermentation. Anhand dieser Ergebnisse erfolgte die Zufütterung ${ }^{13} \mathrm{C}$-markierter Vorläufer ab der 48. Stunde über einen Zeitraum von ca. $12 \mathrm{~h}$, um eine optimale Anreicherung der Metaboliten 22 zu erzielen. 


\subsubsection{Fütterungsexperimente mit ${ }^{13} \mathrm{C}$-markierten Vorläufern}

Zur Biosynthese der Spirotetronate (22)

Spirotetronat-Antibiotika sind einer Substanzklasse zuzuordnen, deren Strukturen ein ungewöhnliches Aglykon besitzen. Dieses weist neben einem trans-Decalin eine charakteristische Tetronsäure auf, die mit einem Cyclohexenring spiroverknüpft ist. Bekannte Spirotetetronate sind Chlorothricin (105) ${ }^{103}$, Tetrocarcin A $(\mathbf{1 0 6})^{107}$ und Kijanimicin $(\mathbf{1 0 7})^{108}$, wobei die spiroverknüpfte Tetronsäure in Chlorothricin (105) über einen Carbonsäureester an das transDecalin gebunden ist und somit der Familie der Makrolide angehört. Tetrocarcin A (106) und Kijanimicin (107) besitzen hingegen eine Ketogruppe und erhalten so die AcyltetronsäureStruktur (s. Abbildung 47).

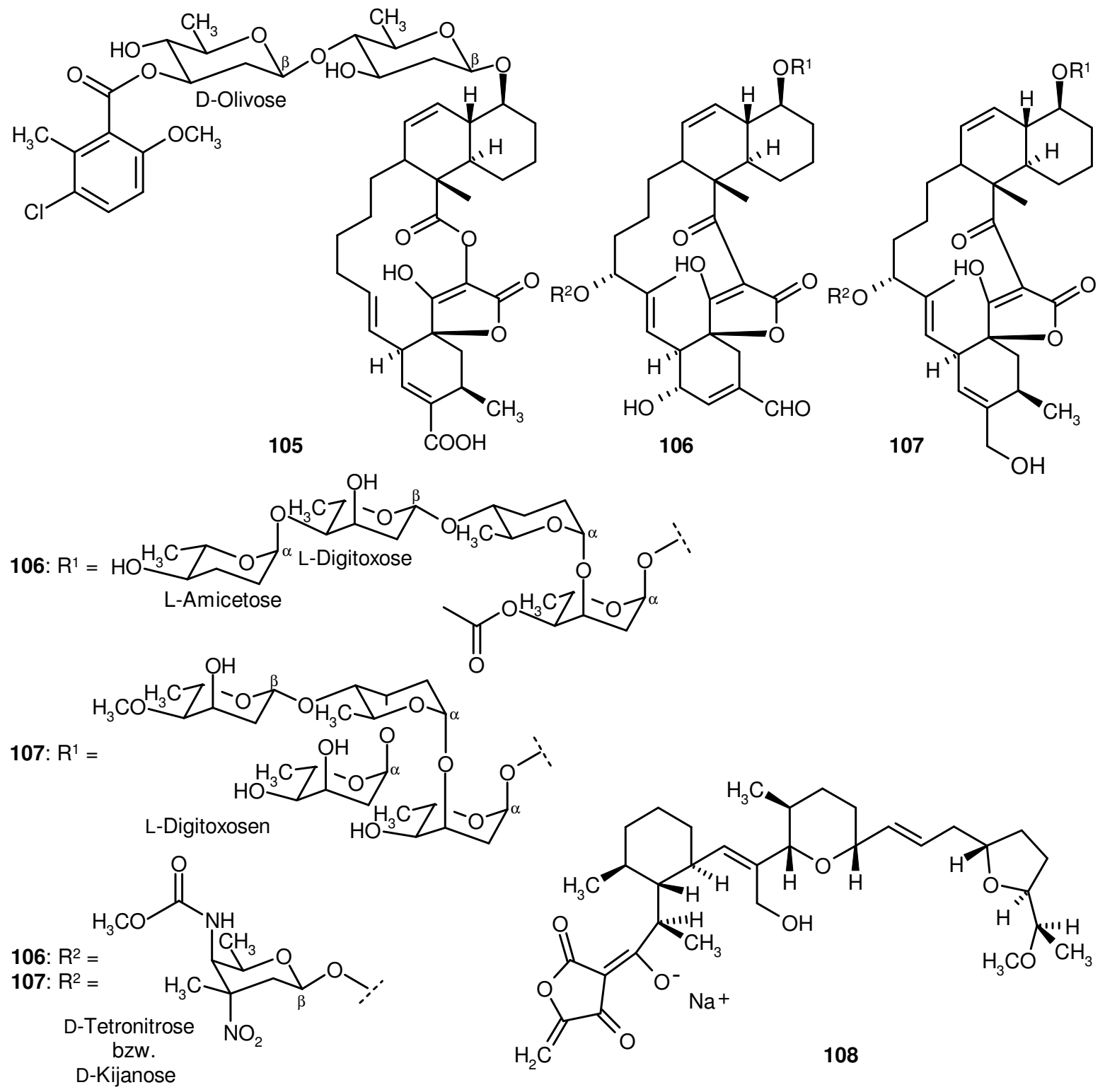

Abbildung 47. Strukturen von Chlorothricin (105), Tetrocarcin A (106), Kijanimicin (107) und Tetronomycin (108). 
Die Metaboliten 22 aus dem Stamm Streptomyces JP90 zeigen neben den charakteristischen Strukturelementen der Spirotetronate eine große strukturelle Ähnlichkeit zum Chlorothricin (105). So erfolgt die Bindung der Tetronsäure-Einheit im Aglykon von 22 ebenfalls über einen Carbonsäureester. 22 weist einen Salicylat-Substituenten auf, der allerdings im Gegensatz zu 105 keinen Chlorsubstituenten trägt und außerdem an dem ersten direkt am Aglykon gebundenen Zucker substituiert ist. Weiterhin trägt das Aglykon von 22 eine D-Digitoxose, eine 2,6-Didesoxy-D-Allose und eine 2-Desoxy-L-rhamnose, wohingegen im Naturstoff 105 zwei 2-Desoxy-D-rhamnosen (D-Olivosen) zu finden sind (s. Abbildung 48).

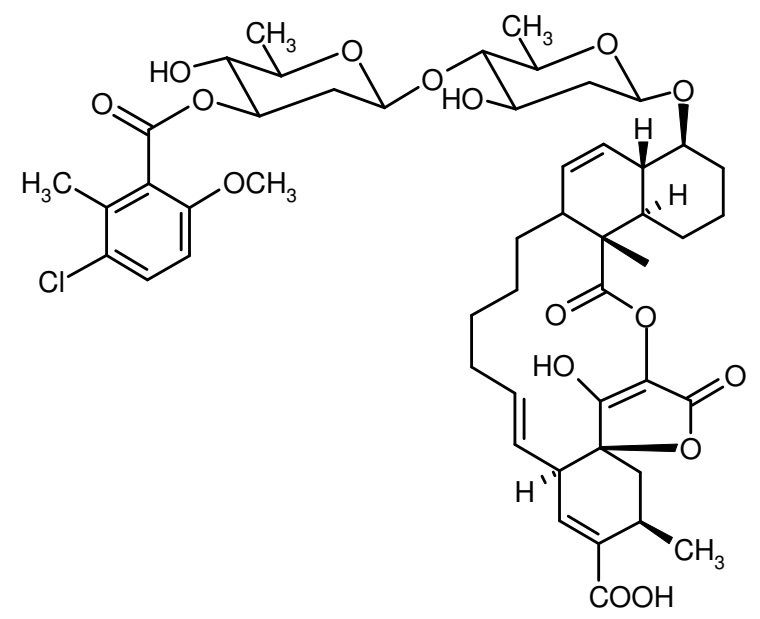

105

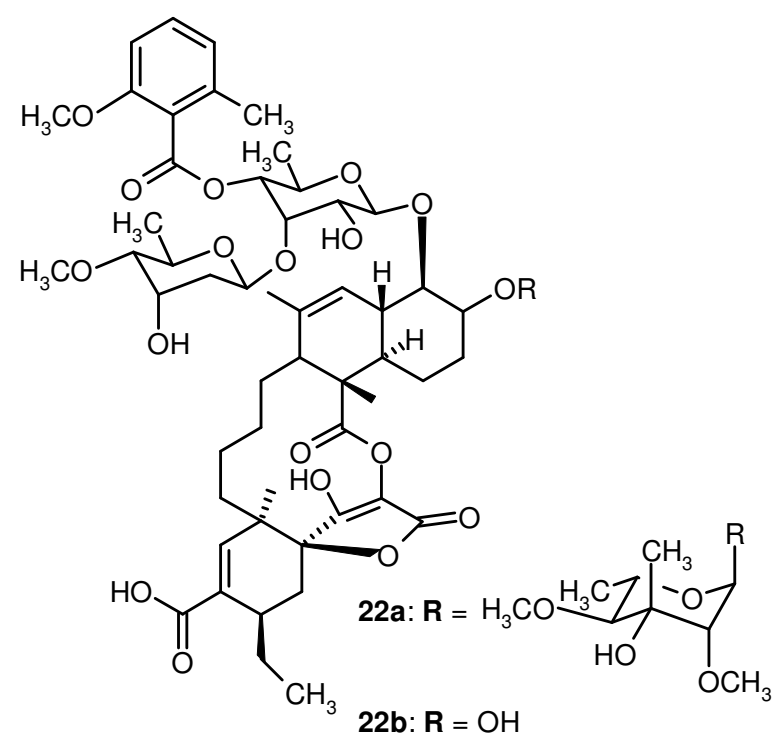

22

Abbildung 48. Strukturen der Makrolid-Spirotetronate Chlorothricin (105) und Spirotetronate (22).

\section{Bekanntes zur Biosynthese von Chlorothricin (105) und anderen Spirotetronaten}

Die Biosynthese von Chlorothricin (105) wurde von Floss et al. in Fütterungsexperimenten mit Streptomyces sp. Tü99 zunächst mit radioaktiven Tracern ${ }^{109}$ und danach mit ${ }^{13} \mathrm{C}$ markierten Vorläufern eingehend untersucht. ${ }^{110}$ Die Zufütterung von ${ }^{13} \mathrm{C}$-markiertem Acetat und Propionat ergaben, dass der Acyl-Substituent aus vier Acetat-Einheiten und das Aglykon aus zehn Acetat- und zwei Propionat-Einheiten aufgebaut wird, die ausgehend von einer Acetat-Einheit (C-29/C-21) eine Polyketidkette bilden (s. Abbildung 49). Allerdings zeigten die C-Atome C-22, C-23 und C-24 keine Anreicherung. Zur Klärung des biosynthetischen Ursprungs dieser C-Atome wurden neben $\left[{ }^{13} \mathrm{C}_{3}\right]$ Pyruvat und $\left[{ }^{13} \mathrm{C}_{3}\right]$ Lactat weitere mögliche Vorläufer getestet, die alle zu keiner Anreicherung in der $\mathrm{C}_{3}$-Einheit führten, bis ein Fütterungsexperiment mit $\left[\mathrm{U}_{-}{ }^{13} \mathrm{C}_{3}\right]$ Glycerin einen vollständigen Einbau als intakte Einheit ergab. Untersuchungen zur „Orientierung“ des Glycerins in die C-Atome C-22/C-23/C-24 mit deuteriertem $(2 R)-\left[1-{ }^{1} \mathrm{H}_{2}\right]$ Glycerin ergaben, dass C-3 von Glycerin zu C-24 vom Aglykon und 
C-1 zu C-22 wird. Aufgrund dieser Ergebnisse postulierte Floss et al. für den biosynthetischen Aufbau des Aglykons 108, dass nicht Glycerin selbst, sondern Phosphoenolpyruvat als Metabolit von Glycerin mit der Polyketidkette kondensiert. ${ }^{110}$ Glycerin wird hierbei über Glycerinaldeyd-3-phosphat zu Phosphoenolpyruvat bzw. weiter zu Acetyl-CoA umgewandelt (s. Abbildung 51). Weitere Biosyntheseuntersuchungen von Floss et al. ergaben, dass die 2Desoxy-D-rhamnosen aus Glucose stammen.

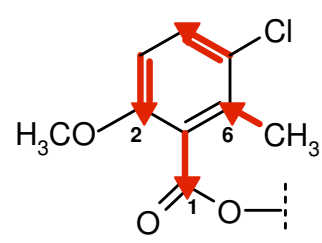

109

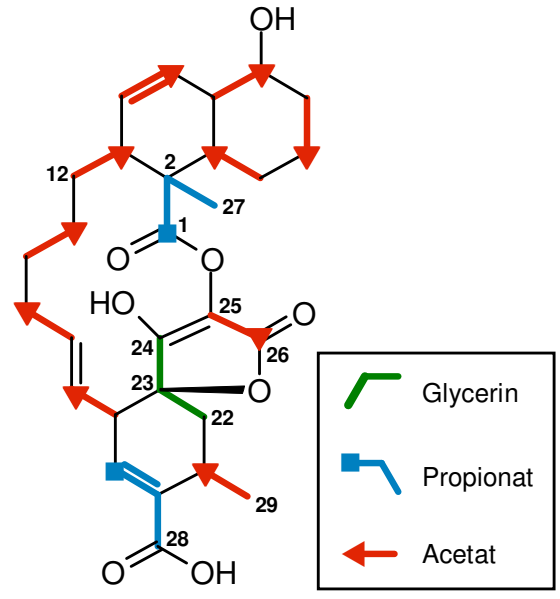

110

Abbildung 49. Einbau von isotopenmarkierten Vorläufern in die Acyl-Einheit (109) und in das Aglykon (110) von Chlorothricin (105).

Ein ähnliches Einbaumuster wird in der Literatur aus Fütterungsexperimenten für Tetrocarcin A (106) beobachtet. Hierbei wird analog zu 105 ein polyketidischer Aufbau aus Acetat- und Propionat-Einheiten für das Aglykon beschrieben, wobei auch kein Einbau in eine $\mathrm{C}_{3}$-Einheit erfolgte. $^{111} 2006$ konnte der Biosynthese-Gencluster für Chlorothricin (105) ${ }^{112}$ publiziert werden, die für Kijanimicin $(\mathbf{1 0 7})^{113}$ und Tetrocarcin A (106) ${ }^{114}$ folgten 2007 und 2008. Die Analyse des Biosynthese-Genclusters von Chlorothricin (105) ergab folgenden Biosynthesemechanismus für den Aufbau des Aglykons: Eine Kondensationsreaktion zwischen einem aus Glycerin stammenden $\mathrm{C}_{3}$-Baustein mit einer aus Acetat- und Propionat-Einheiten aufgebauten Polyketidkette, zwei Cycloadditionen - möglicherweise Diels-Alder-Reaktionen die zur Bildung der trans-Decalin- sowie der Cyclohexen-Einheit führen und eine abschließende Umwandlung der Acyltetronsäure in ein Makrolid durch eine Bayer-VilligerOxygenase (s. Schema 11).

Für den Mechanismus, der sich aus dem klonierten Chlorothricin-Biosynthese-Gencluster ableitete, wurde in Anlehnung an den mechanistischen Biosynthesevorschlag von Floss et al. Phosphoenolpyruvat als mögliches Substrat postuliert, das mit der Polyketidkette zur Tetronsäure-Struktur kondensiert. ${ }^{110}$ 


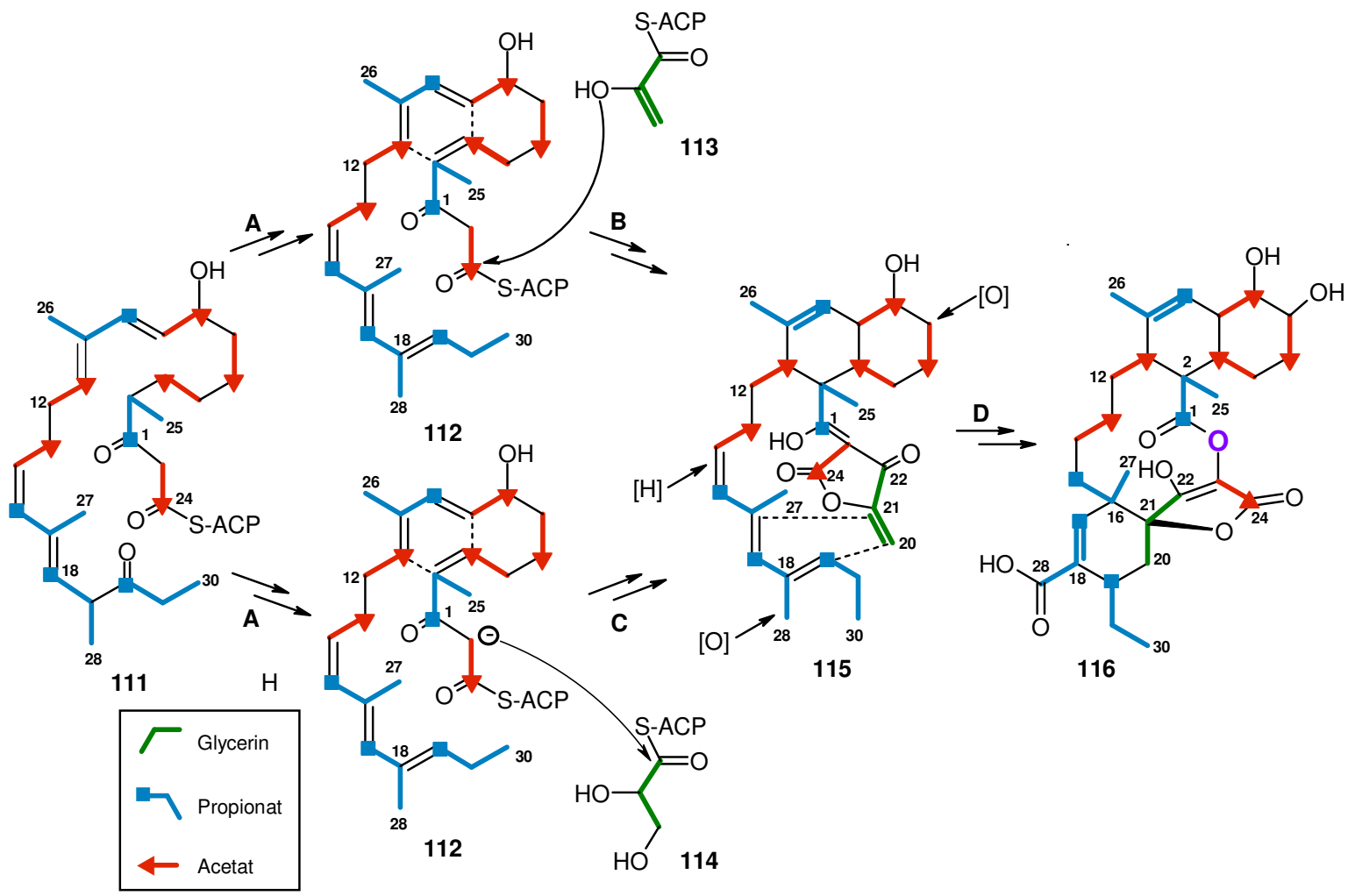

Schema 11. Postulierte Biosynthesemechanismen für den Aufbau des Makrolids 116 (Aglykon der Spirotetronate 22). A: Bildung der trans-Decalin-Einheit durch intramolekulare Cycloaddition der Polyketidkette 111.

B: Kondensation der Phosphoenolpyruvat-Spezies 113 mit Intermediat 112. C: Bildung der spiroverknüpften Acyltetronsäure 115 durch Kondensation der Glycerin-Spezies 114 mit Intermediat 112 und nachfolgender intramolekularer Cycloaddition. D: Umwandlung von 115 in das Makrolid 116 durch eine Bayer-VilligerOxygenase.

Des Weiteren wird aber auch ein allgemeingültiger Biosynthesemechanismus zum Aufbau von Spirotetronaten nicht ausgeschlossen, bei dem 1,3-Bisphosphoglycerat, ein Intermediat der Glykolyse als direkter Vorläufer für den $\mathrm{C}_{3}$-Baustein (s. auch Abbildung 51) angenommen wird. Weitere enzymatische Umwandlungen der Glykolyse können diesen Metaboliten in Phosphoenolpyruvat überführen, das aber leicht zu Pyruvat umlagern kann (s. Abbildung 50). ${ }^{115}$

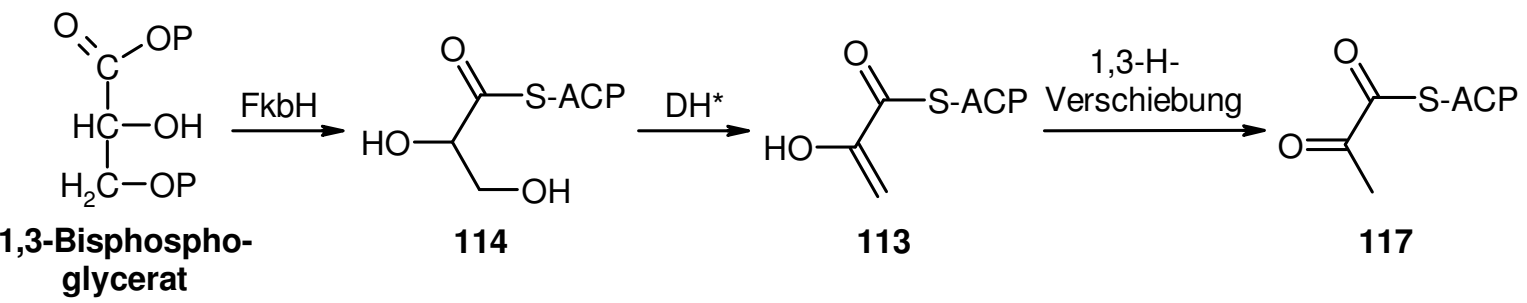

Abbildung 50. Postulierter Mechanismus für die enzymatische Umwandlung des Glykolyse-Intermediats 1,3Bisphosphoglycerat in einen $\mathrm{C}_{3}$-Baustein, der Substrat zum Aufbau der Tetronsäure sein könnte ${ }^{115}$. 
<smiles>O=C(O)COC(=O)C(O)C(O)CO</smiles>

[U-13 $\mathrm{C}_{3}$ ]Glycerin<smiles>OCC(O)COP</smiles>

Glycerin-3-phosphat

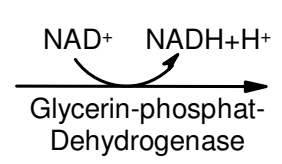

Glycerin-phosphat-
Dehydrogenase

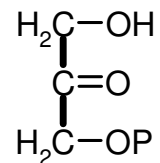

Dihydroxyacetonphosphat

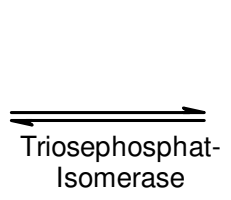<smiles>O=CC(O)CO</smiles>

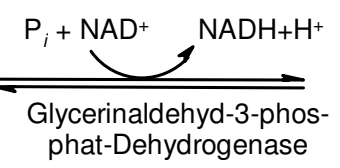
Glycerinaldehyd3-phosphat<smiles>O=C([O-])C(O)C[18O]</smiles>

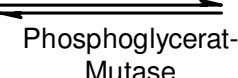
3-Phosphoglycerat Mutase<smiles>CCCCCCC(=O)C(=O)[O-]</smiles>

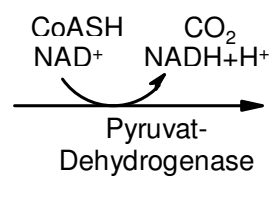

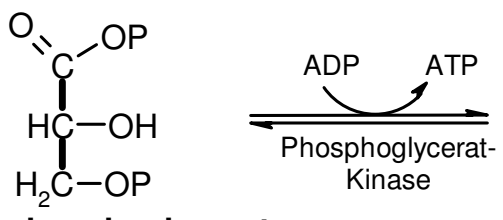

\section{1,3-Bisphosphoglycerat}

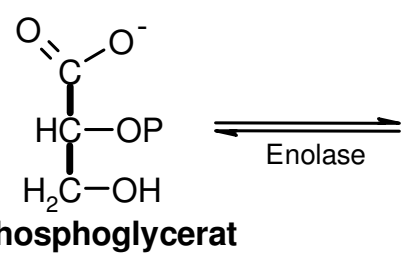<smiles>CCOSC(=O)C(C)=O</smiles>

Acetyl-CoA

Abbildung 51. Glycerin-Metabolismus zu Acetyl-CoA.

Zugefüttertes Glycerin wird hierbei in Glycerinaldehyd-3-phosphat umgewandelt, welches als Intermediat in die Glykolyse eingespeist wird (s. Abbildung 51). ${ }^{116,117}$

Die Biosynthesehypothesen für Kijanimicin (107) ${ }^{113}$ und Tetrocarcin A (106) ${ }^{114}$ schlagen ebenfalls 1,3-Bisphosphoglycerat als direkten Vorläufer des $\mathrm{C}_{3}$-Bausteins vor, der die Kondensationsreaktion mit einer Polyketidkette eingeht. Für die anschließende Cycloaddition ist allerdings eine weitere Doppelbindung notwendig. Ob diese enzymatisch oder zur Schaffung eines konjugierten Systems spontan geschaffen wird, um das Spirotetronat-Gerüst vollständig aufzubauen, ist noch ungeklärt. Aufgrund der Arbeiten am Biosynthese-Gencluster vom Polyether Tetronomycin (108, s. Abbildung 47) ${ }^{118}$ postulierte Leadlay et al. ebenfalls einen allgemeingültigen Mechanismus für die Bildung von Spirotetronat-Einheiten, der für den Aufbau der Tetronsäure 1,3-Bisphosphoglycerat als direkten Vorläufer für den $\mathrm{C}_{3}$-Baustein annimmt. Allerdings ist hier anzumerken, dass Leadley et al. ${ }^{118}$ für den Aufbau der Tetronsäure im Chlorothricin (105) in seiner Publikation irrtümlicherweise den falschen $\mathrm{C}_{3}$-Baustein gewählt hat. Anstelle der C-Atome C-22/C-23/C-24 sind C-24/C-25/C-26 als $\mathrm{C}_{3}$-Baustein markiert, deren biosynthetischer Einbau nicht mit den experimentellen Ergebnissen der literaturbekannten Fütterungsexperimente übereinstimmen würde (s. Abbildung 49). 
Fütterungsexperiment mit Natrium $\left[1,2-{ }^{13} \mathrm{C}_{2}\right]$ acetat

Im Rahmen eigener Biosyntheseuntersuchungen mit dem Stamm JP90 an den Spirotetronaten (22) erfolgte zunächst ein Fütterungsexperiment mit Natrium[1,2- $\left.{ }^{13} \mathrm{C}_{2}\right]$ acetat, um den biosynthetischen Aufbau des Aglykons und der Acyl-Einheit über einen Polyketidmechanismus in Analogie zum Chlorothricin (105) zu überprüfen. Des Weiteren sollte über ${ }^{13} \mathrm{C}-{ }^{13} \mathrm{C}$ Kopplungen intakter $\left[1,2-{ }^{13} \mathrm{C}_{2}\right]$ Acetat-Einheiten eine eindeutige Strukturzuordnung am Aglykon ermöglicht werden.

Der Stamm Streptomyces JP90 wurde in sieben 1 L Schüttelkolben mit Schikane, befüllt mit $150 \mathrm{~mL}$ Medium $\mathrm{S}$ bei $28^{\circ} \mathrm{C}$ und $180 \mathrm{U} / \mathrm{min}$ kultiviert. Die Hauptkulturen wurden mit je $5 \mathrm{~mL}$ einer $48 \mathrm{~h}$ alten Vorkultur inokuliert. Entsprechend der Ergebnisse aus der Fermentationskurve wurde die wässrige Lösung von $\left[1,2-{ }^{13} \mathrm{C}_{2}\right]$ Acetat ab der 48 . Stunde mittels einer Schlauchpumpe über einen Zeitraum von $7 \mathrm{~h}$ kontinuierlich zugegeben. Dabei wurde dem Stamm $550 \mathrm{mg} / \mathrm{L} \quad(5.9 \mathrm{mmol} / \mathrm{L})$ Natrium[1,2- $\left.{ }^{13} \mathrm{C}_{2}\right]$ acetat in $250 \mathrm{~mL}$ wässriger Lösung ( $\mathrm{pH}=7.0)$ zugefüttert. Nach der 96. Stunde wurde die Fermentation beendet. Nach der Aufarbeitung und säulenchromatographischen Reinigung (s. Abschnitt B 3.3.3 ) des aus dem Kulturfiltrat erhaltenen Rohextraktes wurden angereichertes Spirotetronat 22a und Spirotetronat 22b in einer Ausbeute von $30.0 \mathrm{mg} / \mathrm{L}$ und $9.0 \mathrm{mg} / \mathrm{L}$ isoliert. Die Ergebnisse der Fütterung für das jeweilige Aglykon sind in Tabelle 5 zusammengefasst und in Abbildung 52 dargestellt.

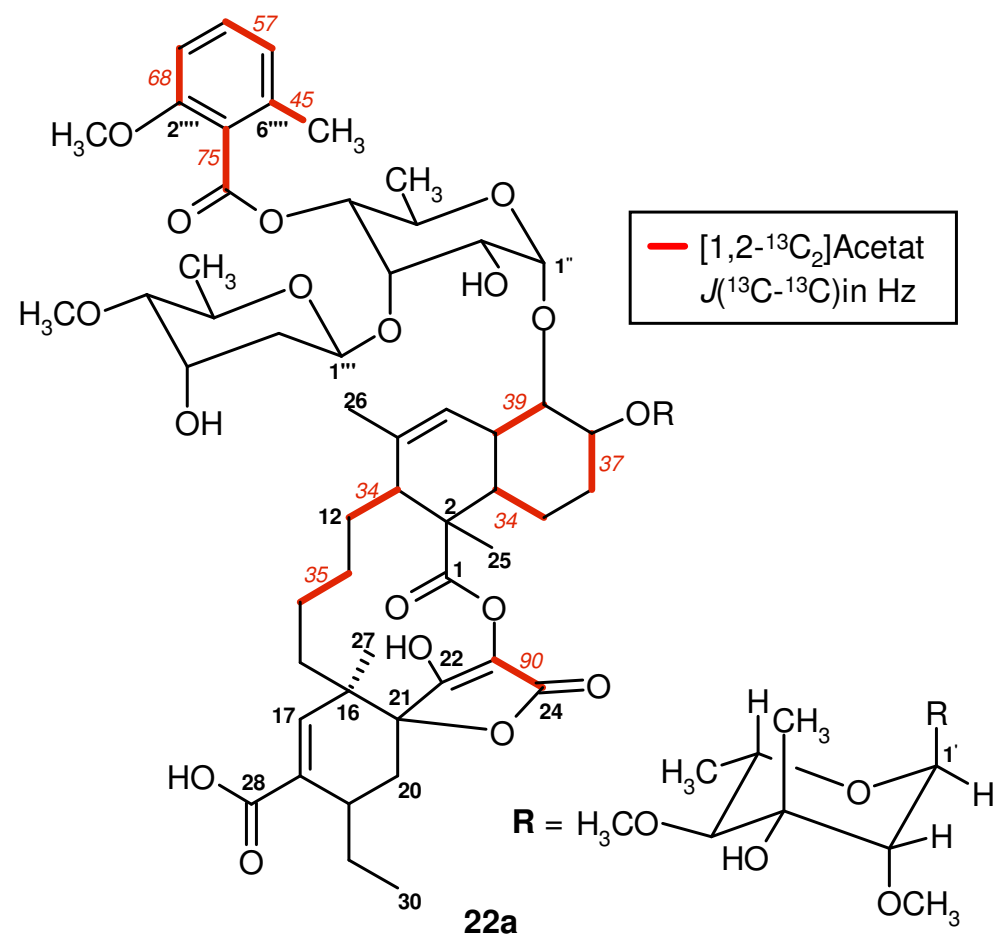

Abbildung 52. Beobachtetes Einbaumuster in Spirotetronat (22a) aus dem Fütterungsexperiment mit $\left[1,2-{ }^{13} \mathrm{C}_{2}\right]$ Acetat. 
Tabelle 5. ${ }^{13} \mathrm{C}-\mathrm{NMR}$ Analyse der angereicherten Spirotetronate (22) aus dem Fütterungsexperiment mit $\left[1,2-{ }^{13} \mathrm{C}_{2}\right]$ Acetat.

\begin{tabular}{|c|c|c|c|c|}
\hline $\begin{array}{c}\text { C- } \\
\text { Atom }\end{array}$ & $\begin{array}{c}\delta_{\mathrm{C}^{[\mathrm{a}]}} \\
(\mathbf{2 2} \mathbf{a}) \\
{[\mathrm{ppm}]}\end{array}$ & $\begin{array}{c}{\left[1,2-{ }^{13} \mathrm{C}_{2}\right]} \\
\text { Acetat }^{[\mathrm{b}]}\end{array}$ & $\begin{array}{c}\delta_{\mathrm{C}}{ }^{[\mathrm{a}]} \\
(\mathbf{2 2 b}) \\
{[\mathrm{ppm}]}\end{array}$ & $\begin{array}{c}{\left[1,2-{ }^{13} \mathrm{C}_{2}\right]} \\
\text { Acetat }^{[\mathrm{b}]}\end{array}$ \\
\hline$\overline{C-1}$ & 179.8 & - & 180.1 & - \\
\hline C-2 & 50.4 & - & 50.4 & - \\
\hline C-3 & 37.8 & 34 & 37.7 & 35 \\
\hline C-4 & 20.7 & 34 & 20.0 & 34 \\
\hline C-5 & 31.0 & 36 & 29.9 & 36 \\
\hline C-6 & 76.6 & 36 & 67.6 & 36 \\
\hline C-7 & 85.3 & 39 & 85.2 & 39 \\
\hline C-8 & 37.4 & 39 & 36.7 & 39 \\
\hline C-9 & 120.0 & - & 119.9 & - \\
\hline C-10 & 134.3 & - & 134.6 & - \\
\hline C-11 & 54.1 & 34 & 54.2 & - \\
\hline C-12 & 30.5 & 34 & 30.4 & 34 \\
\hline C-13 & 33.7 & 34 & 33.7 & 35 \\
\hline C-14 & 25.8 & 34 & 25.7 & 35 \\
\hline C-15 & 34.4 & - & 34.4 & - \\
\hline C-16 & 46.5 & - & 46.4 & - \\
\hline C-17 & 148.0 & - & 147.8 & - \\
\hline C-18 & 131.3 & - & 131.5 & - \\
\hline C-19 & 34.1 & - & 34.1 & - \\
\hline C-20 & 27.6 & - & 27.6 & - \\
\hline C-21 & 82.9 & - & 83.0 & - \\
\hline C-22 & 160.9 & - & 160.9 & - \\
\hline C-23 & 116.4 & 90 & 116.4 & 93 \\
\hline C-24 & 165.9 & 90 & 166.0 & 93 \\
\hline C-25 & 15.6 & - & 15.8 & - \\
\hline C-26 & 22.4 & - & 22.4 & - \\
\hline C-27 & 21.7 & - & 21.6 & - \\
\hline C-28 & 171.2 & - & 172.3 & - \\
\hline C-29 & 26.5 & - & 26.4 & - \\
\hline C-30 & 12.6 & - & 12.3 & - \\
\hline
\end{tabular}

[a] ${ }^{13} \mathrm{C}$-NMR Spektrum (150.8 MHz; $\mathrm{CDCl}_{3}$ ); [b] Kopplungskonstanten (in $\mathrm{Hz}$ ).

Das ${ }^{13}$ C-NMR Spektrum der Spirotetronate (22) präsentierte signifikante Kopplungsmuster und wies auf einen hohen Einbau von $\left[1,2-{ }^{13} \mathrm{C}_{2}\right]$ Acetat in 22 hin. Es ließen sich intakte $\mathrm{C}_{2}$-Einheiten in der Acyl-Einheit für die C-Atome COO/C-1"'", C-2"'"/C-3"'", C-4"'"/C-5"'" und C-6"'"/6"'"- $\mathrm{CH}_{3}$ ableiten sowie im Aglykon für die C-Atome C-3/C-4, C-5/C-6, C-7/C-8, C-11/C-12, C-13/C-14 und C-23/C-24. Mithilfe der gefundenen ${ }^{13} \mathrm{C}-{ }^{13} \mathrm{C}-K o p p l u n g e n ~ d e s$ 
Aglykons konnte die Zuordnung der Kohlenstoffatome überprüft werden. Die beobachtete große ${ }^{1} J_{C, C}$-Kopplung zwischen $\mathrm{C}-23$ und C-24 von $90 \mathrm{~Hz}$ bestätigte die Existenz einer Tetronsäure-Einheit, da Spin-Spin-Kopplungen für derartige Systeme in dieser Größenordnung beschrieben wurden. Gemäß der bereits beschriebenen Ergebnisse aus Fütterungsexperimenten an Chlorothricin $(\mathbf{1 0 5})^{110}$ und Tetrocarcin $\mathrm{A}(\mathbf{1 0 6})^{111}$ wurde für eine $\mathrm{C}_{3}$-Einheit, die C-Atome C-20, C-21, C-22 keine Anreicherung beobachtet, weshalb ein weiteres Fütterungsexperiment mit $\left[\mathrm{U}_{-}{ }^{13} \mathrm{C}_{3}\right]$ Glycerin durchgeführt wurde, um die Herkunft dieser Einheit zu überprüfen.

\section{Fütterungsexperiment mit $\left[U_{-}{ }^{13} C_{3}\right]$ Glycerin}

Zur Klärung des biosynthetischen Ursprungs der $\mathrm{C}_{3}$-Einheit bestehend aus den C-Atomen C-20/C-21/C-22 wurde in Anlehnung an Biosynthesearbeiten von Floss et al. ${ }^{110}$ $\left[\mathrm{U}_{-}{ }^{13} \mathrm{C}_{3}\right]$ Glycerin zum Stamm Streptomyces JP90 zugefüttert.

Der Stamm JP90 wurde in vier 1-L Schüttelkolben mit Schikane, befüllt mit $150 \mathrm{~mL}$ Medium $\mathrm{S}$ bei $28{ }^{\circ} \mathrm{C}$ und $180 \mathrm{U} / \mathrm{min}$ kultiviert. Die Hauptkulturen wurden mit je $5 \mathrm{~mL}$ einer $48 \mathrm{~h}$ alten Vorkultur inokuliert. Abweichend zum Medium S wurde ein Glyceringehalt von $1.8 \mathrm{~g} / \mathrm{L}$ eingestellt. Dieses wurde durchgeführt, um in der Kulturbrühe nach Zufütterung des $\left[\mathrm{U}_{-}{ }^{13} \mathrm{C}_{3}\right]$ Glycerin ein Verhältnis von 3:1 für unmarkiertes Glycerin zu isotopenmarkiertem Glycerin zu erzielen. Hiermit sollte die Entstehung statistischer Kopplungen, die aus einem möglichen Einbau intakter ${ }^{13} \mathrm{C}$-markierten Einheiten in benachbarte Positionen resultieren, verhindert werden. Entsprechend des Fütterungsexperiments mit $\left[1,2-{ }^{13} \mathrm{C}_{2}\right]$ Acetat erfolgte die kontinuierliche Zugabe der Lösung von $\left[\mathrm{U}_{-}{ }^{13} \mathrm{C}_{3}\right]$ Glycerin ab der 48. Stunde mittels einer Schlauchpumpe über einen Zeitraum von ca. $12 \mathrm{~h}$. Dabei wurde $500 \mathrm{mg} / \mathrm{L}(9.1 \mathrm{mmol} / \mathrm{L})$ $\left[\mathrm{U}_{-}{ }^{13} \mathrm{C}_{3}\right]$ Glycerin in $160 \mathrm{~mL}$ wässriger Lösung $(\mathrm{pH}=7.0)$ zugefüttert. Nach der 96. Stunde wurde die Fermentation beendet. Nach der Aufarbeitung und säulenchromatographischen Reinigung (s. Abschnitt B 3.3.3 ) des aus dem Kulturfiltrat erhaltenen Rohextraktes wurden angereichertes Spirotetronat 22a und Spirotetronat 22b in einer Ausbeute von $28.0 \mathrm{mg} / \mathrm{L}$ und $7.0 \mathrm{mg} / \mathrm{L}$ isoliert. Die Ergebnisse der Fütterung für das jeweilige Aglykon sind in Tabelle 6 zusammengefasst. 
Tabelle 6. ${ }^{13}$ C-NMR Analyse der angereicherten Spirotetronate (22) aus dem Fütterungsexperiment mit $\left[\mathrm{U}_{-}{ }^{13} \mathrm{C}_{3}\right]$ Glycerin.

\begin{tabular}{|c|c|c|c|c|}
\hline $\begin{array}{c}\text { C- } \\
\text { Atom }\end{array}$ & $\begin{array}{c}\delta_{\mathrm{C}}{ }^{[\mathrm{a}]} \\
(\mathbf{2 2 a}) \\
{[\mathrm{ppm}]}\end{array}$ & $\begin{array}{c}{\left[\mathrm{U}_{-}{ }^{13} \mathrm{C}_{3}\right]} \\
\text { Glycerin }^{[\mathrm{b}]}\end{array}$ & $\begin{array}{c}\delta_{\mathrm{C}}{ }^{[\mathrm{a}]} \\
(\mathbf{2 2} \mathbf{b}) \\
{[\mathrm{ppm}]}\end{array}$ & $\begin{array}{c}{\left[\mathrm{U}-{ }^{13} \mathrm{C}_{3}\right]} \\
\text { Glycerin }^{[\mathrm{b}]}\end{array}$ \\
\hline$\overline{C-1}$ & 179.8 & - & 180.1 & - \\
\hline C-2 & 50.4 & 36 & 50.4 & 36 \\
\hline C-3 & 37.8 & 34 & 37.7 & 34 \\
\hline C-4 & 20.7 & 34 & 20.0 & 34 \\
\hline C-5 & 31.0 & 37 & 29.9 & 37 \\
\hline C-6 & 76.6 & 37 & 67.6 & 37 \\
\hline C-7 & 85.3 & 39 & 85.2 & 39 \\
\hline C-8 & 37.4 & 39 & 36.7 & 39 \\
\hline C-9 & 120.0 & - & 119.9 & - \\
\hline C-10 & 134.3 & 44 & 134.6 & 44 \\
\hline C-11 & 54.1 & 34 & 54.2 & 34 \\
\hline C-12 & 30.5 & 34 & 30.4 & 34 \\
\hline C-13 & 33.7 & 35 & 33.7 & 35 \\
\hline C-14 & 25.8 & 35 & 25.7 & 35 \\
\hline C-15 & 34.4 & - & 34.4 & - \\
\hline C-16 & 46.5 & 34 & 46.4 & 34 \\
\hline C-17 & 148.0 & - & 147.8 & - \\
\hline C-18 & 131.3 & 70 & 131.5 & 70 \\
\hline C-19 & 34.1 & - & 34.1 & - \\
\hline C-20 & 27.6 & 37 & 27.6 & 37 \\
\hline $\mathrm{C}-21$ & 82.9 & 37,51 & 83.0 & 37,51 \\
\hline $\mathrm{C}-22$ & 160.9 & 51 & 160.9 & 51 \\
\hline C-23 & 116.4 & 91 & 116.4 & 91 \\
\hline C-24 & 165.9 & 91 & 166.0 & 91 \\
\hline C-25 & 15.6 & 36 & 15.8 & 36 \\
\hline C-26 & 22.4 & 44 & 22.4 & 44 \\
\hline C-27 & 21.7 & 34 & 21.6 & 34 \\
\hline C-28 & 171.2 & 70 & 172.3 & 70 \\
\hline C-29 & 26.5 & 35 & 26.4 & 35 \\
\hline C-30 & 12.6 & 35 & 12.3 & 35 \\
\hline
\end{tabular}

[a] ${ }^{13} \mathrm{C}$-NMR Spektrum (150.8 MHz; $\mathrm{CDCl}_{3}$ ); [b] Kopplungskonstanten (in $\mathrm{Hz}$ ). 


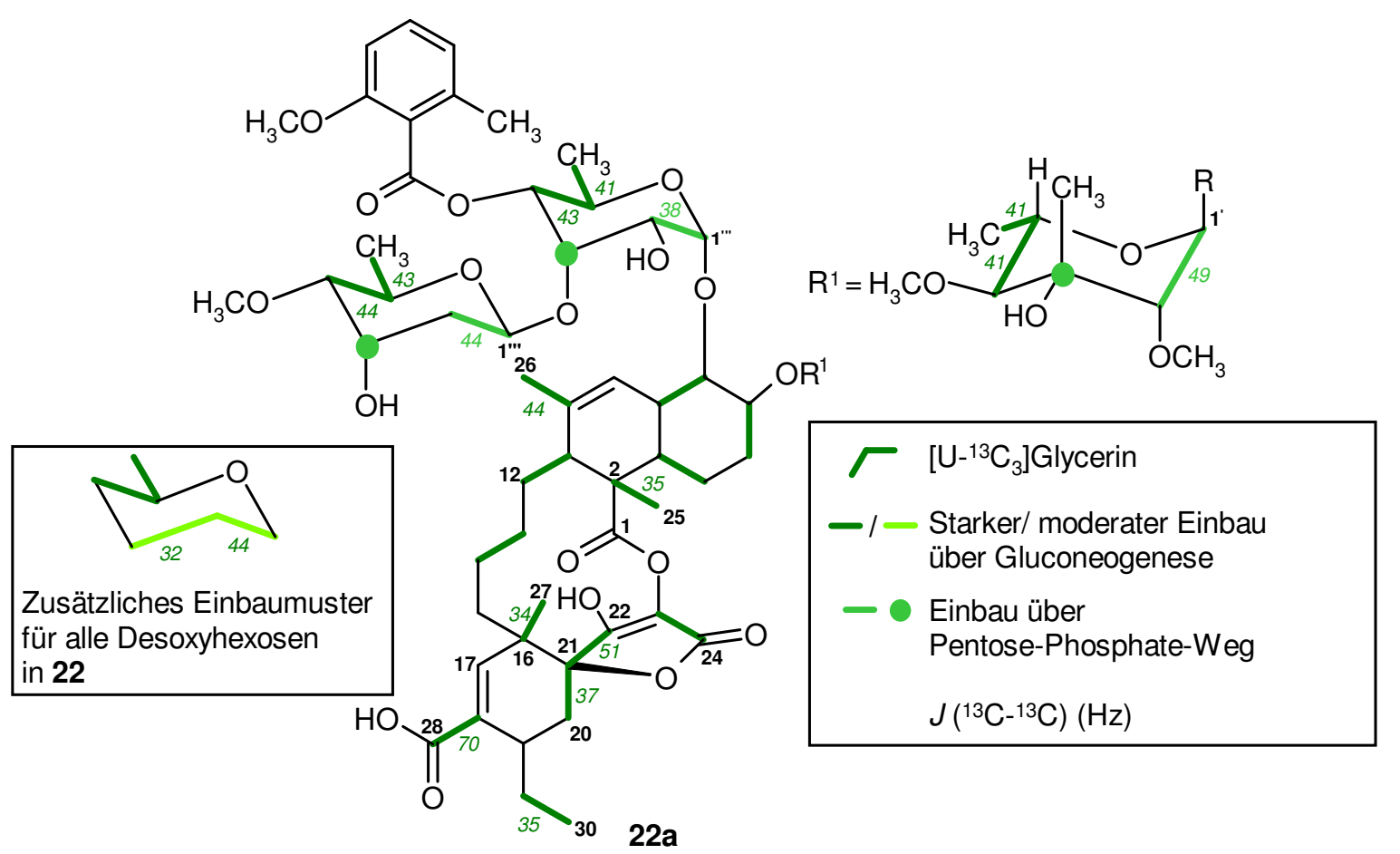

Abbildung 53. Beobachtetes Einbaumuster in Spirotetronat (22a) aus dem Fütterungsexperiment mit $\left[\mathrm{U}-{ }^{13} \mathrm{C}_{3}\right]$ Glycerin.

Die ${ }^{13} \mathrm{C}-\mathrm{NMR}$ Analyse des Fütterungsexperiment mit $\left[\mathrm{U}_{-}{ }^{13} \mathrm{C}_{3}\right]$ Glycerin zeigte für die C-Atome der $\mathrm{C}_{3}$-Einheit C-20/C-21/C-22 eine signifikante Anreicherung und einen intakten Einbau von $\left[\mathrm{U}_{-}{ }^{13} \mathrm{C}_{3}\right]$ Glycerin mit ${ }^{13} \mathrm{C}^{13} \mathrm{C}$-Kopplungen von $37.0 \mathrm{~Hz}$ zwischen den C-Atomen C-20/C-21 und 51.0 Hz zwischen C-21/C-22 (s. Abbildung 53). Das Vorliegen einer intakten $\mathrm{C}_{3}$-Einheit zeigt eindeutig das Kopplungsmuster vom C-Atom C-21, welches beide Kopplungskonstanten von ${ }^{1} J_{\mathrm{c}-\mathrm{c}}=37.0 \mathrm{~Hz}$ und ${ }^{1} J_{\mathrm{c}-\mathrm{c}}=51.0 \mathrm{~Hz}$ zu C-20 bzw. C-22 aufweist. Des Weiteren sind aus dem Fütterungsexperiment mit $\left[\mathrm{U}_{-}{ }^{13} \mathrm{C}_{3}\right]$ Glycerin für die Spirotetronate (22) signifikante Anreicherungen an intakten $\mathrm{C}_{2}$-Einheiten für die Kohlenstoffatome des Aglykons, C-3/C-4, C-5/C-6, C-7/C-8, C-11/C-12, C-13/C-14, und C-23/C-24 sowie für die Acyl-Einheit, COO/C-1"'", C-2"'"/C-3"'", C-4"'"/C-5"'" und C-6"'"/6"'"-CH $\mathrm{CH}_{3}$ zu beobachten. Das Entstehen von $\mathrm{C}_{2}$-Einheiten aus dem $\mathrm{C}_{3}$-Körper Glycerin ist über dessen Umwandlung in Glycerinaldehyd-3-phosphat zu Acetyl-CoA zu erklären (s. Abbildung 51). ${ }^{116,117}$ Ein vergleichsweise geringer Einbau von angereichertem Glycerin in die Kohlenstoffatome C-2/C-25, C-10/C-26, C-16/C-27, C-18/C-28 und C-29/C-30 ist auf die hierüber identifizierten Propionat-Einheiten zurückzuführen. Das aus Glycerin gebildete Acetyl-CoA wird in den Citratcyclus eingeschleust und über Succinyl-CoA in Methylmalonyl-CoA umgewandelt, das durch Decarboxylierung mit der Methylmalonyldecarboxylase in Propionat über- 
führt wird, und zum Einbaumuster nur noch einer intakten $\mathrm{C}_{2}$-Einheit an den Kohlenstoffatomen C-2/C-3 des Propionats führt. ${ }^{116,117,119}$

Das beobachtete Einbaumuster der D-Digitoxosen und der L-Rhamnose entspricht zum einen einem starkem bis moderaten Einbau über die Gluconeogenese, wobei angereichertes Glycerin über Glycerinaldehyd-3-phosphat in Pyruvat umgewandelt wird (s. Abbildung 53) ${ }^{116,117}$. Zusätzlich weisen die ${ }^{13} \mathrm{C}$-NMR Spektren aber Isotopomere auf, die mit einem Aufbau der Zucker über den Pentosephosphatweg übereinstimmt, hierbei wird das für den Aufbau benötigte Hexosegerüst über Ribulose-5-phosphat, Sedoheptulose-7-phosphat und Erythrose-4-phosphat gebildet. ${ }^{120,121}$

\section{Biosynthesehypothese zum Aufbau des Makrolids 116}

Die Ergebnisse der Fütterungsexperimente mit $\left[1,2-{ }^{13} \mathrm{C}_{2}\right]$ Acetat und $\left[\mathrm{U}^{13} \mathrm{C}_{3}\right]$ Glycerin zur Überprüfung des polyketidischen Aufbaus des Aglykons von Spirotetronaten (22) stimmen mit den Ergebnissen aus klassischen Biosynthesestudien an den bekannten Spirotetronaten Chlorothricin $(\mathbf{1 0 5})^{110}$ und Tetrocarcin A (106) ${ }^{111}$ überein. Die beobachteten Einbaumuster aus beiden Fütterungsexperimenten belegen einen polyketidischen Ursprung des Aglykons, bestehend aus sechs Acetat- und fünf Propionat-Einheiten. Ebenso wird der Acyl-Substituent wie erwartet aus vier Acetat-Einheiten aufgebaut, die Methylgruppe der Methoxygruppe stammt vermutlich aus Methionin, was Floss et al. ${ }^{110}$ durch Zufütterung von ${ }^{13} \mathrm{C}$-markiertem Methionin zum Chlorothricin-Produzenten im Chlorothricin (105) nachweisen konnte. Aufgrund der sehr starken strukturellen Verwandtschaft der Metaboliten 22 zum Chlorothricin (105) und den ähnlichen Einbaumustern konnte auf die Zufütterung vom markierten $\left[1-{ }^{13} \mathrm{C}\right]$ Acetat verzichtet werden, da die Richtung der Polyketidkette aus dem Einbaumuster des Chlorothricin-Aglykons (109) bzw. dessen Acyl-Einheit abgeleitet werden konnte. Die Herkunft der beim Fütterungsexperiment mit $\left[1,2-{ }^{13} \mathrm{C}_{2}\right]$ Acetat nicht angereicherten $\mathrm{C}_{3}$-Einheit, bestehend aus den Kohlenstoffatomen C-20/C-21/C-22, konnte in Anlehnung an Floss et al. ${ }^{110}$ mithilfe der Zufütterung von $\left[\mathrm{U}_{-}{ }^{13} \mathrm{C}_{3}\right]$ Glycerin auf den Vorläufer Glycerin zurückgeführt werden. Dieses belegen beobachtete ${ }^{13} \mathrm{C}-{ }^{13} \mathrm{C}-$ Kopplungen zwischen den C-Atomen des $\mathrm{C}_{3}$-Bausteins mit Kopplungskonstanten von ${ }^{1} J_{\mathrm{c}-\mathrm{c}}=37.0 \mathrm{~Hz}$ und ${ }^{1} J_{\mathrm{c}-\mathrm{c}}=51.0 \mathrm{~Hz}$, wobei dem ${ }^{13} \mathrm{C}-\mathrm{NMR}$-Signal von C-21 beide Kopplungskonstanten zu entnehmen sind. In der Literatur werden Biosynthesehypothesen für die Spirotetronate $\mathbf{1 0 5}^{112}, \mathbf{1 0 6}^{113}, \mathbf{1 0 7}^{114}$ beschrieben, die aus deren Biosynthese-Genclustern abgeleitet wurden. Aus diesen Hypothesen ergeben sich zwei Möglichkeiten für den biosynthetischen Aufbau des Makrolids (116, s. Schema 11). 


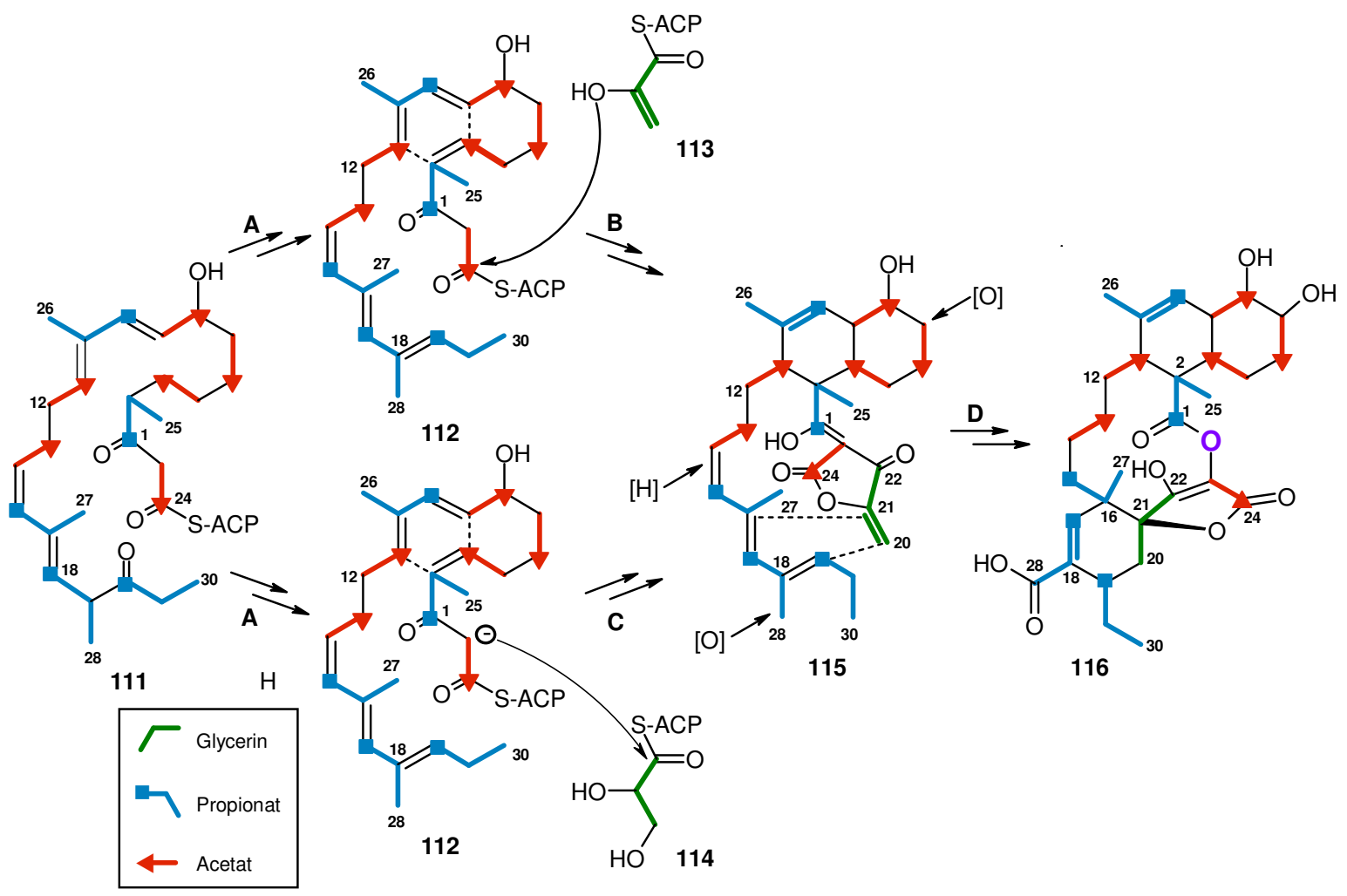

Schema 11. Postulierte Biosynthesemechanismen für den Aufbau des Makrolids 116. A: Bildung der transDecalin-Einheit durch intramolekulare Cycloaddition der Polyketidkette 111. B: Kondensation der Phosphoenolpyruvat-Spezies 113 mit Intermediat 112. C: Bildung der spiroverknüpften Acyltetronsäure 115 durch Kondensation der Glycerin-Spezies 114 mit Intermediat 112 und nachfolgender intramolekularer Cycloaddition. D: Umwandlung von 115 in das Makrolid 116 durch eine Bayer-Villiger-Oxygenase.

Zunächst erfolgt aus fünf Acetat- und sechs Propionat-Einheiten der Aufbau einer Polyketidkette, die ausgehend von einer Propionat-Einheit (C-30/C-29/C-19) startet (Intermediat 111). Die Anordnung der Polyketidkette ermöglicht auch in 22 die Bildung des trans-DecalinRingsystems über eine Cycloaddition (Intermediat 112). Im nächsten Schritt entsteht durch eine Kondensationsreaktion zwischen einem aus Glycerin stammenden $\mathrm{C}_{3}$-Baustein mit der aus Acetat- und Propionat-Einheiten aufgebauten Polyketidkette und nachfolgender intramolekularer Cycloaddition die spiroverknüpfte Acyltetronsäure-Struktur (Intermediat 115), wobei die zweite Cycloaddition zum Aufbau der Cyclohexen-Einheit führt.

Für die Kondensationsreaktion sind beide derzeit in der Literatur diskutierten möglichen Wege präsentiert: Weg B zeigt als Substrat eine Phosphoenolpyruvat-Spezies 113, deren Hydroxylgruppe nukleophil an C-24 der Polyketidkette angreift. Es schließt sich eine C-CBindungsknüpfung zwischen C-23 der Polyketidkette und dem Carboxylkohlenstoff von 113 an, der in der Tetronsäure-Einheit als C-22 beziffert ist. Die vorliegende Doppelbindung der Phosphoenolpyruvat-Spezies 113 ermöglicht die nachfolgende Cycloaddition zum Cyclo- 
hexenring. Weg $\mathbf{C}$ geht von einer aus 1,3-Bisphosphoglycerat abgeleiteten Glycerin-Spezies (114, s. Abbildung 50) aus. Dieser beginnt mit der Acylierung von C-23 der Polyketidkette durch die Glycerin-Spezies 114, gefolgt von einem nukleophilen Angriff der Hydroxylgruppe von 114 an C-24 der Polyketidkette unter Aufbau einer Tetronsäure-Einheit. Für eine anschließende Cycloaddition muss die notwendige Doppelbindung entweder enzymatisch oder spontan durch Dehydratisierung gebildet werden. Die erhaltene spiroverknüpfte Acyltetronsäure (Intermediat 115) wird dann durch eine Bayer-Villiger-Oxygenase in das Makrolid 116 umgewandelt. Die Umwandlung in ein Makrolidringsystem ist nur für Chlorothricin (105) beschrieben, Tetrocarcin A (106) und Kijanimicin (107) sind beides keine Makrolide, bei beiden Spirotetronaten bleibt die Acyltetronsäure-Struktur erhalten.

\section{Zur Biosynthese des Rosiridols (23)}

\section{Mevalonat- und Nicht-Mevalonat-Weg}

Seit den 50er Jahren wurde der Acetat-Mevalonat-Weg als universeller Biosyntheseweg zum Aufbau von Isoprenoid-Einheiten (IPP) angesehen, deren Verknüpfung zur Naturstoffklasse der Terpene führt. ${ }^{122}$ Die Biogenese der Terpene konnte an der Steroid-Biosynthese detailliert aufgeklärt werden. ${ }^{123}$ Drei Moleküle Acetyl-CoA werden in zwei Kondensationsreaktionen über Acetoacetyl-CoA in 3-Hydroxy-3-methylglutaryl-CoA (HMG-CoA) überführt. HMG$\mathrm{CoA}$ wird unter Beteiligung von $\mathrm{NADPH} / \mathrm{H}^{+}$zu Mevalonat reduziert (s. Abbildung 54). Anschließend entsteht durch drei Phosphorylierungen das Intermediat Mevalonsäure-5-pyrophosphat, welches unter Decarboxylierung und Dehydratisierung zum Isopentenylpyrophosphat (IPP) umgewandelt wird. Ausgehend von $\left[1-{ }^{13} \mathrm{C}\right]$ Acetat ist im IPP eine Markierung der Kohlenstoffatome C-1 und C-3 zu beobachten.

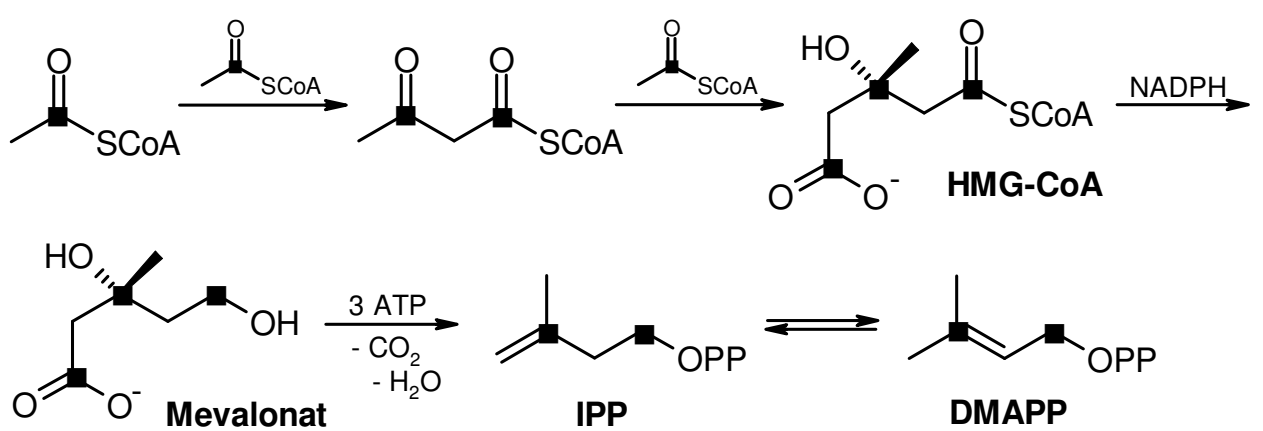

Abbildung 54. Isoprenoidbiosynthese über HMG-CoA mit Markierung von $\left[1-{ }^{13} \mathrm{C}\right]$ Acetat im Acetat-MevalonatWeg. 
In der Vergangenheit gab es ausgehend vom Acetat-Mevalonat-Weg als universelle Biosyntheseroute oft widersprüchliche Ergebnisse bei Biosyntheseuntersuchungen von Terpenen an Pflanzen und Mikroorganismen. Häufig wurden mit markierter Mevalonsäure oder Acetat nur sehr geringe Einbauraten in Terpenen erzielt. ${ }^{124}$ Auch konnten in pflanzlichen Systemen einige Enzyme des Acetat-Mevalonat-Wegs nicht in den Chloroplasten nachgewiesen werden. ${ }^{125}$ In den 80er Jahren führte Rohmer et al. ${ }^{104}$ Fütterungsexperimente zur Aufklärung der Biosynthese von Hopanoiden durch, deren Ergebnisse nicht mit dem Acetat-MevalonatWeg erklärt werden konnten. ${ }^{126}$ Anfang der 90er Jahre wurde von Rohmer et al. ${ }^{104}$ und Arigoni et al. ${ }^{105}$ unabhängig voneinander erstmals ein hypothetisches Schema des TriosePyruvat-Wegs publiziert. Rohmer et al. entwickelte dieses ausgehend von Biosyntheseuntersuchungen mit ${ }^{13} \mathrm{C}$-markierter Glucose als Substrat an Zymomonas mobilis und E. coli ${ }^{104}$, während Arigoni et al. dieses anhand von Biosyntheseuntersuchungen an terpenoiden Verbindungen aus Ginkgo biloba ableitete. ${ }^{105}$
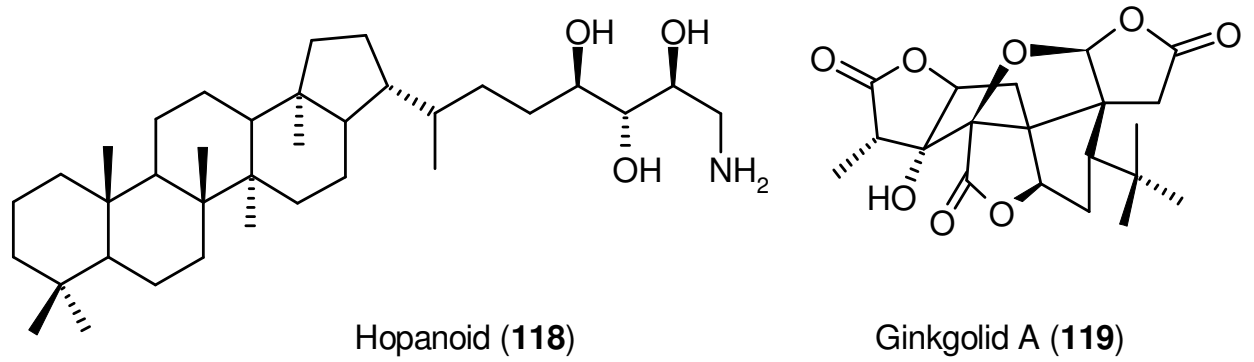

Abbildung 55. Strukturen des Hopanoid (118) und Ginkgolid A (119).

Die Isoprenoidbiosynthese erfolgt im Triose-Pyruvat-Weg über das Intermediat 1-Desoxy-DXylulose-5-phosphat (DMP), das aus der Triose Glycerinaldeyhd-3-phosphat (GAP) und aus der $\mathrm{C}_{2}$-Einheit aus Pyruvat gebildet wird, wobei vermutlich Thiamindiphosphat (Vitamin $\mathrm{B}_{6}$ ) als Cofaktor fungiert. Eine nachfolgende Umlagerung führt zum Intermediat 2-Methyl-Derythritol-4-phosphat (MEP) (s. Abbildung 56). Die anschließenden Schritte, welche MEP in IPP umwandeln, konnten bisher mechanistisch noch nicht vollständig aufgeklärt werden. ${ }^{127}$ Die enzymatische Umwandlung von MEP in das cyclische Intermediat 2C-Methyl-D-erythritol-2,4-cyclodiphosphate (MECP) wurde mithilfe von Kristallstrukturen der jeweiligen Enzym-Substrat-Komplexe formuliert, während die Transformation des MECP in IPP mit Hilfe dieser noch nicht abschließend aufgeklärt werden konnte. Aufgrund bisher durchgeführter Studien wird hierfür zunächst ein Reduktion-Eliminierungsschritt zum 4-Hydroxy-2methyl-2-(E)-butenyl-4-diphosphat angenommen, welches dann in IPP überführt wird. ${ }^{128}$ Ausgehend von $\left[1-{ }^{13} \mathrm{C}\right]$ Acetat ist IPP nur an Kohlenstoffatom C-4 markiert. 


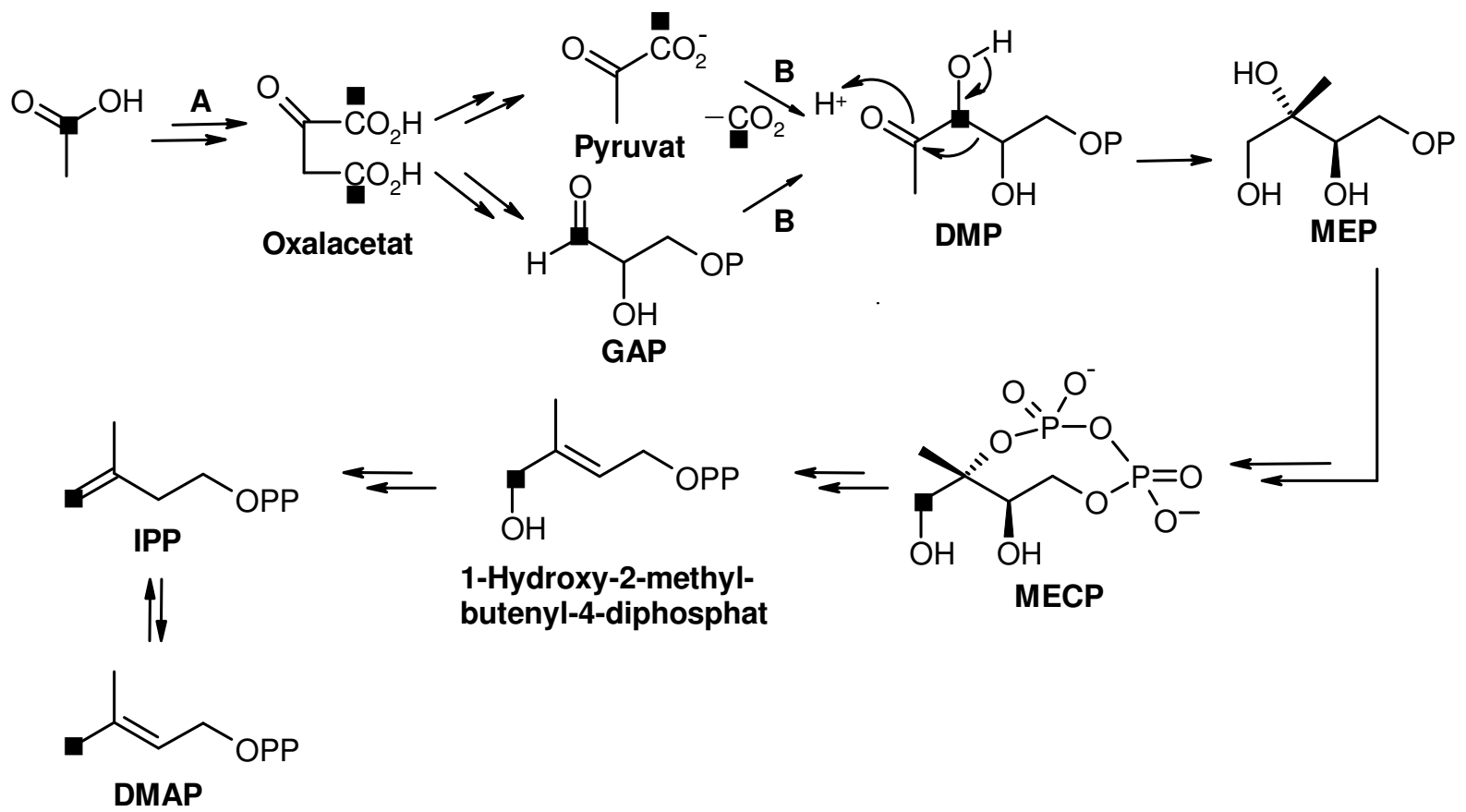

\begin{abstract}
Abbildung 56. Isoprenoidbiosynthese über 1-Desoxyxylulose-5-phosphat mit Markierung $\left[1{ }^{13} \mathrm{C}\right]$ Acetat (A: Citratcyclus; B: Glycerinaldeyhd-3-phosphat (GAP)/Pyruvatweg).
\end{abstract}

Die Existenz des Triose-Pyruvat-Wegs wurde bisher in Pflanzen, Grünalgen und Bakterien nachgewiesen, nicht aber in tierischen Organismen und Pilzen. In höheren Pflanzen existieren in der Regel beide Biosynthesewege nebeneinander. Es wird vermutet, dass der TriosePyruvat-Weg vor allem in den Chloroplasten abläuft, während im Cytosol gebildete Terpene überwiegend über den Acetat-Mevalonat-Weg aufgebaut werden. ${ }^{122}$ Viele Bakterien benutzen zur Biosynthese der Terpene entweder den Acetat-Mevalonat- oder den Triose-Pyruvat-Weg. Erstaunlicherweise zeigten von Seto et al. ${ }^{106}$ durchgeführte Fütterungsexperimente mit ${ }^{13} \mathrm{C}$ markierten Vorläufern, dass Streptomyceten beide Wege einsetzen können, um Terpene aufzubauen. Für Biosynthesestudien am Naturstoff Menaquinone (120) und Naphterpin (121) wurden zu unterschiedlichen Zeitpunkten ${ }^{13} \mathrm{C}$-markierte Glucose zum Produzenten zugefüttert. Hierbei konnte gezeigt werden, dass bei einem frühen Fütterungszeitpunkt das beobachtete Einbaumuster in $\mathbf{1 2 0}$ dem Triose-Pyruvat-Weg entsprach, während bei einem späteren Fütterungszeitpunkt der Acetat-Mevalonat-Weg beschritten wird. Beim Sekundärmetaboliten 121 konnte nur ein Einbaumuster gemäß dem Acetat-Mevalonat-Weg gefunden werden, was bedeuten könnte, dass der Stamm diesen Metaboliten erst in der stationären Phase produziert (s. Abbildung 57). ${ }^{106}$ 
<smiles>CCC(C=C(C)CC(C)(C=C(C)C)CC)C(CC)C(C)CCCC(C)=CCC1=C(C)C(=O)c2ccccc2C1=O</smiles>

Menaquinon (120)<smiles>CC1=CC2C3=C(OC(C)(C)C2CC1)C(=O)c1c(cc(O)c(C)c1O)C3=O</smiles>

Naphterpin (121)

Abbildung 57. Strukturen des Menaquinon (120) und Naphterpin (121).

\section{Fütterungsexperiment mit Natrium- $\left[1,2-{ }^{13} \mathrm{C}_{2}\right]$ acetat}

Im Rahmen der biosynthetischen Arbeiten mit dem Stamm Streptomyces JP90 wurde aus dem Fütterungsexperiment mit Natrium $\left[1,2-{ }^{13} \mathrm{C}_{2}\right]$ acetat auch das angereicherte Monoterpen Rosiridol (23) in einer Ausbeute von $1.8 \mathrm{mg} / \mathrm{L}$ isoliert. $\mathrm{Im}{ }^{13} \mathrm{C}$-NMR Spektrum der mit $\left[1,2-{ }^{13} \mathrm{C}_{2}\right]$ Acetat angereicherten Substanz wurden keine signifikanten Spin-Spin-Kopplungen beobachtet. Da bei einem biosynthetischen Aufbau von 23 über HMG-CoA (AcetatMevalonat-Weg) die C-Atome C-1/C-2, C-3/C-10, C-5/C-6 sowie C-7/C-9 aus intakten $\left[1,2-{ }^{13} \mathrm{C}_{2}\right]$ Acetat-Einheiten aufgebaut wären, welche charakteristische ${ }^{13} \mathrm{C}-{ }^{13} \mathrm{C}$-Kopplungen zeigen würden, konnte anhand dieser fehlenden Kopplungen eine Isoprenoidbiosynthese über HMG-CoA ausgeschlossen werden (s. Abbildung 58).
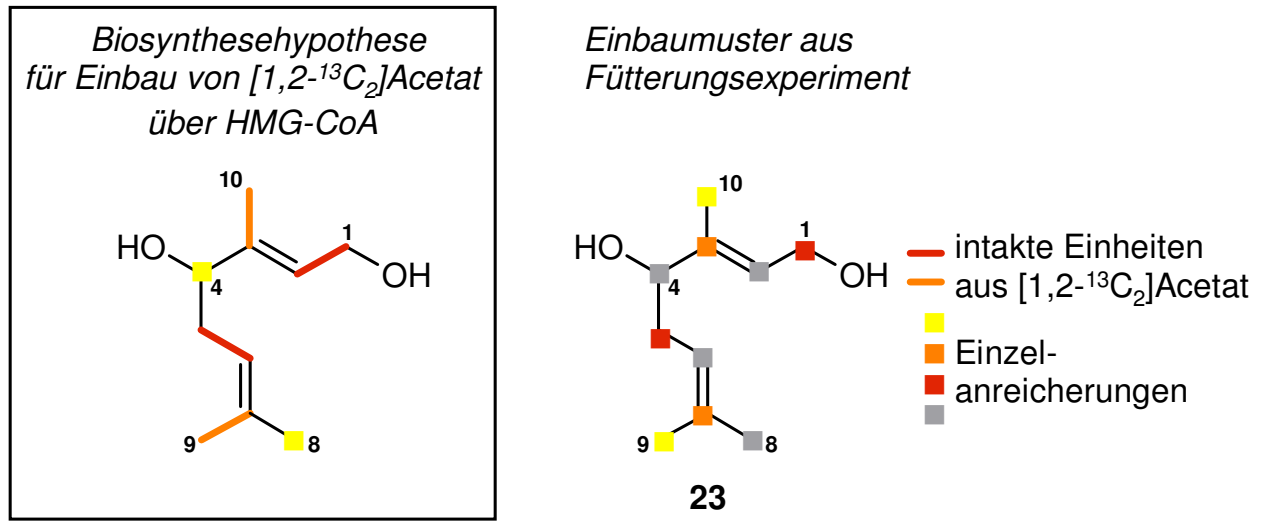

Abbildung 58. Hypothetischer Einbau von $\left[1,2-{ }^{13} \mathrm{C}_{2}\right]$ Acetat über HMG-CoA und das beobachtete Einbaumuster in Rosiridol (23) aus dem Fütterungsexperiment mit $\left[1,2-{ }^{13} \mathrm{C}_{2}\right]$ Acetat.

Zur Bestimmung der spezifischen Einbaurate gemäß der Formel in Abschnitt B 1.5 .6 wurde nacheinander folgend auf jedes einzelne Kohlenstoffatom referenziert. Dabei ergab sich für die C-Atome C-1, C-3, C-5, C-7, C-9 und C-10 eine ähnlich große Einbaurate. Zudem zeigten die Berechnungen, dass die C-Atome C-2, C-4, C-6 und C-8 ebenfalls angereichert waren. Die hierbei resultierenden negativen Werte ließen auf eine ähnliche Einbaurate für 
diese C-Atome schließen. Damit ergaben die Berechnungen für die spezifische Einbaurate, dass alle Kohlenstoffatome des Rosiridols (23) nach Zufütterung von [1,2- $\left.{ }^{13} \mathrm{C}_{2}\right]$ Acetat signifikant angereichert waren. Um den spezifischen Einbau bestimmen zu können, wurde das Rosiridol (23) mit Acetanhydrid in Pyridin umgesetzt. Dieses Experiment sollte zur Einführung eines unmarkierten Kohlenstoffatoms dienen, was nicht gelang und der spezifische Einbau daher nicht ermittelt werden konnte. Zur weiteren Untersuchung der Terpenbiosynthese von Rosiridol sollte $\mathbf{2 3}$ im Rahmen der Biosyntheseuntersuchungen an den Metaboliten 22 aus einem weiteren Fütterungsexperiment mit $\left[\mathrm{U}_{-}{ }^{13} \mathrm{C}_{3}\right.$ ]Glycerin isoliert werden und eine mögliche Anreicherung im ${ }^{13} \mathrm{C}$-NMR-Spektrum analysiert werden.

\section{Fütterungsexperiment mit $\left[U_{-}{ }^{13} C_{3}\right]$ Glycerin}

Im Rahmen des Fütterungsexperiments mit $\left[\mathrm{U}_{-}{ }^{13} \mathrm{C}_{3}\right]$ Glycerin konnte ein Gemisch aus angereichertem Monoterpen Rosiridol (23) und nicht angereichertem Cinnamoylphosphoramid (21) in einer Ausbeute von $2.3 \mathrm{mg} / \mathrm{L}$ isoliert werden. Im ${ }^{13} \mathrm{C}-\mathrm{NMR}$ Spektrum des mit $\left[\mathrm{U}_{-}{ }^{13} \mathrm{C}_{3}\right]$ Glycerin angereicherten 23 wurden signifikante Spin-Spin-Kopplungen beobachtet, die charakteristisch für eine Isoprenoidbiosynthese über den Triose-Pyruvat-Weg sind. Die C-Atome C-1/C-2/C-4 sowie C-5/C-6/C-8 stammen alle aus je einer $\mathrm{C}_{3}$-Einheit, dem Glycerinaldeyhd-3-phosphat (GAP), was durch eine ${ }^{1} J_{C, C}$-Kopplung zwischen C-1/C-2 und C-5/C-6 angezeigt wird. Diese intakten Einheiten weisen zusätzlich ${ }^{2} J_{C, C}$-Kopplungen zwischen den C-Atomen C-2 und C-4 sowie zwischen C-6 und C-8 mit $3.8 \mathrm{~Hz}$ und ${ }^{3} J_{C, C}$-Fernkopplungen zwischen den C-Atomen C-1 und C-4 sowie zwischen C-5 und C-8 mit $5.1 \mathrm{~Hz}$ auf (s. Tabelle 7). ${ }^{124}$

Tabelle 7. ${ }^{13} \mathrm{C}$-NMR Analyse des angereicherten Rosiridols (23) aus dem Fütterungsexperiment mit $\left[\mathrm{U}_{-}{ }^{13} \mathrm{C}_{3}\right]$ Glycerin.

\begin{tabular}{ccc}
\hline C-Atom & $\begin{array}{c}\delta_{\mathrm{C}}{ }^{[\mathrm{a}]}(\mathbf{2 3}) \\
{[\mathrm{ppm}]}\end{array}$ & $\begin{array}{c}{\left[\mathrm{U}_{-}{ }^{13} \mathrm{C}_{3}\right]} \\
\mathrm{Glycerin}^{[\mathrm{b}]}\end{array}$ \\
\hline $\mathrm{C}-1$ & 59.3 & $48.0,5.1$ \\
$\mathrm{C}-2$ & 126.2 & $48.0,3.8$ \\
$\mathrm{C}-3$ & 140.6 & 43.0 \\
$\mathrm{C}-4$ & 78.1 & $3.8,5.1$ \\
$\mathrm{C}-5$ & 34.8 & $45.0,4.5$ \\
$\mathrm{C}-6$ & 121.7 & $45.0,3.8$ \\
$\mathrm{C}-7$ & 134.0 & 42.5 \\
$\mathrm{C}-8$ & 26.0 & $3.8,4.5$ \\
$\mathrm{C}-9$ & 18.0 & 42.5 \\
$\mathrm{C}-10$ & 118.0 & 43.0 \\
\hline
\end{tabular}

[a] ${ }^{13}$ C-NMR Analyse (125.5 MHz; in $\left.\mathrm{CD}_{3} \mathrm{OD}\right)$. [b] Kopplungskonstanten (in $\left.\mathrm{Hz}\right)$ 


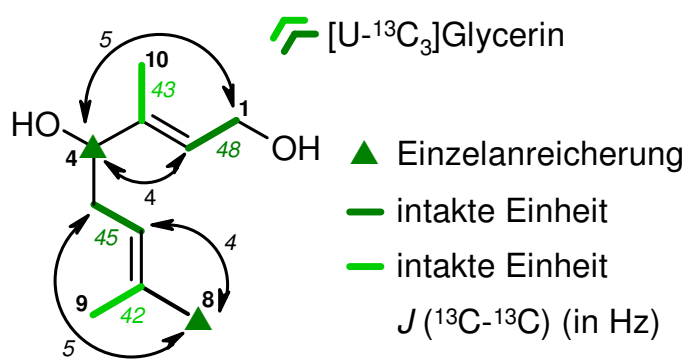

Abbildung 59. Beobachtetes Einbaumuster in Rosiridol (23) aus dem Fütterungsexperiment mit $\left[\mathrm{U}_{-}{ }^{13} \mathrm{C}_{3}\right]$ Glycerin.

Es gibt keine signifikante Menge an Molekülen, deren C-1/C-2- bzw. C-5/C-6-Einheit nicht durch eine $\left.{ }^{2} J_{C, C^{-}}\right|^{3} J_{C, C}$-Kopplung aufgespalten ist. D. h. jede intakte angereicherte ${ }^{13} \mathrm{C}_{2}$-Einheit ist immer mit dem ebenfalls angereichertem einzelnen ${ }^{13} \mathrm{C}$-Atom bei C-4 bzw. C-8 eingebaut worden. Des Weiteren sind ${ }^{1} J_{C, C}$-Kopplungen zwischen den C-Atomen C-3/C-10 und C-7/C-9 zu beobachten, die keine weiteren Spin-Spin-Kopplungen zeigen. Diese intakten $\mathrm{C}_{2}$-Einheiten werden nach Decarboxylierung aus Pyruvat erhalten (s. Abbildung 59 und s. Abbildung 60). Zusätzlich wiesen die Kohlenstoffatome C-1/C-2 eine weitere ${ }^{1} J_{C, C}$-Kopplung auf, die zwischen C-5/C-6 lediglich schwach erkennbar ist, und somit auf das Vorliegen von Isotopomeren hinweisen. Dies führt zu der Annahme, dass die Bildung von Rosiridol (23) möglicherweise nicht nur und ausschließlich über den Triose-Pyruvat-Weg erfolgen könnte, sondern auch in geringem Anteil über den Acetat-Mevalonat-Weg. (s. Abbildung 60). 

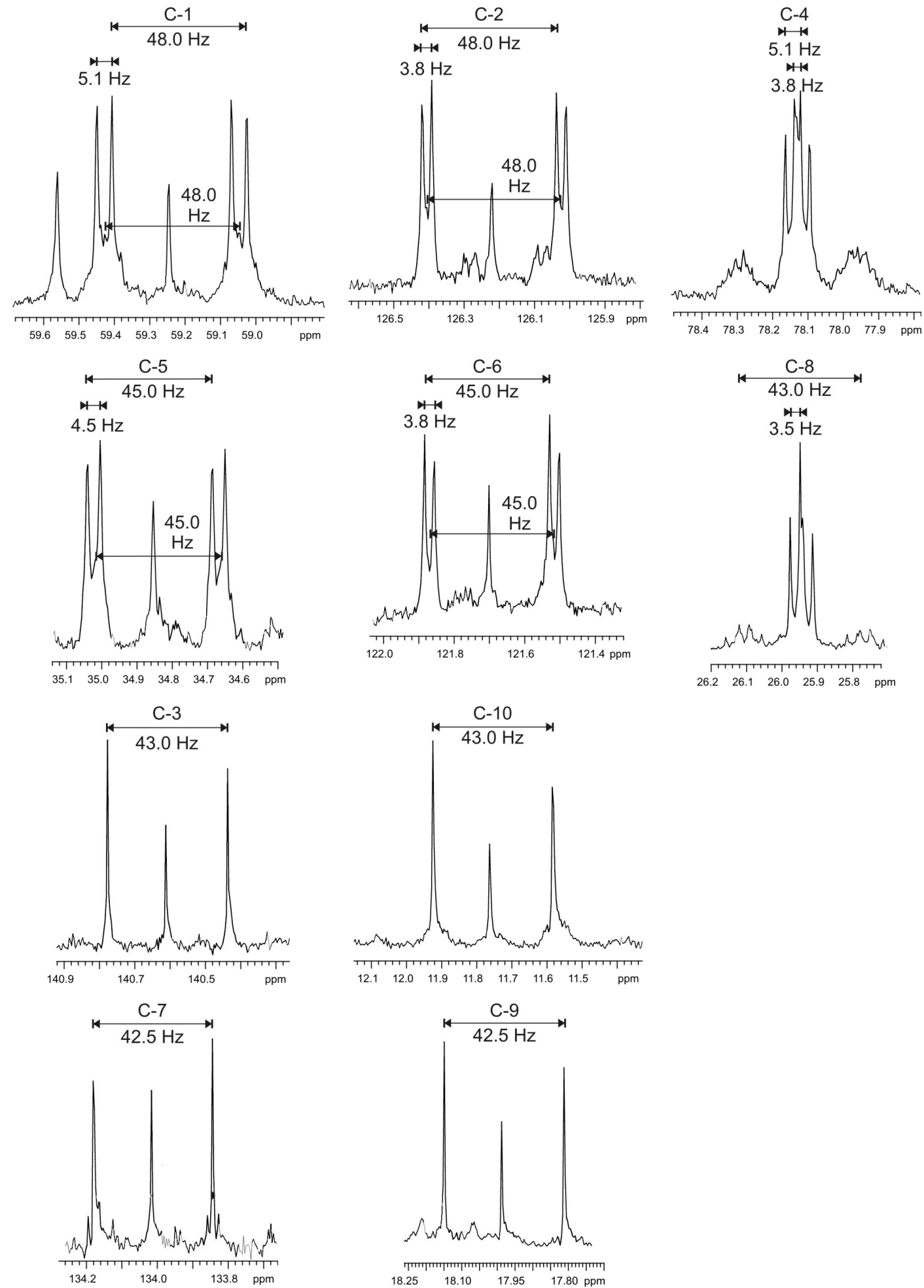

Abbildung 60. ${ }^{13} \mathrm{C}-\mathrm{NMR}$-Dehnungen der einzelnen Kohlenstoffatome des Rosiridols (23) aus dem Fütterungsexperiment mit $\left[1,2-{ }^{13} \mathrm{C}_{2}\right]$ Acetat.

Biosynthese des Rosiridols (23)

Die beobachteten Einbaumuster in Rosiridol (23) aus den Fütterungsexperimenten mit $\left[1,2-{ }^{13} \mathrm{C}_{2}\right]$ Acetat und $\left[\mathrm{U}_{-}{ }^{13} \mathrm{C}_{3}\right]$ Glycerin weisen auf einen biosynthetischen Aufbau aus 
Glycerinaldehyd-3-phosphat (GAP) und Pyruvat über das Intermediat 1-Desoxy-D-xylulose5-phosphat (DMP) hin (s. Abbildung 56). Im ${ }^{13} \mathrm{C}$-NMR-Spektrum des Fütterungsexperiments mit $\left[1,2-{ }^{13} \mathrm{C}_{2}\right]$ Acetat weist isoliertes Rosiridol (23) keine intakten $\mathrm{C}_{2}$-Einheiten auf, sondern zeigt in allen Kohlenstoffatomen signifikante Einzelanreicherungen. Für den biosynthetischen Aufbau von 23 über den Triose-Phosphat-Weg durchläuft vollständig angereichertes AcetylCoA den Citratcyclus oder Glyoxylatweg und führt zur Bildung von Oxalacetat (s. Abbildung 61). ${ }^{117}$ Decarboxylierung, katalysiert durch die PEP-Carboxykinase, überführt Oxalacetat in Gegenwart von GTP zu Phosphoenolpyruvat (PEP), welches in mehreren Schritten zu Glycerinaldehyd-3-phosphat (GAP) umgewandelt oder durch die Pyruvat-Kinase in einem Schritt in Pyruvat überführt wird. (s. Abbildung 51). ${ }^{116,117}$

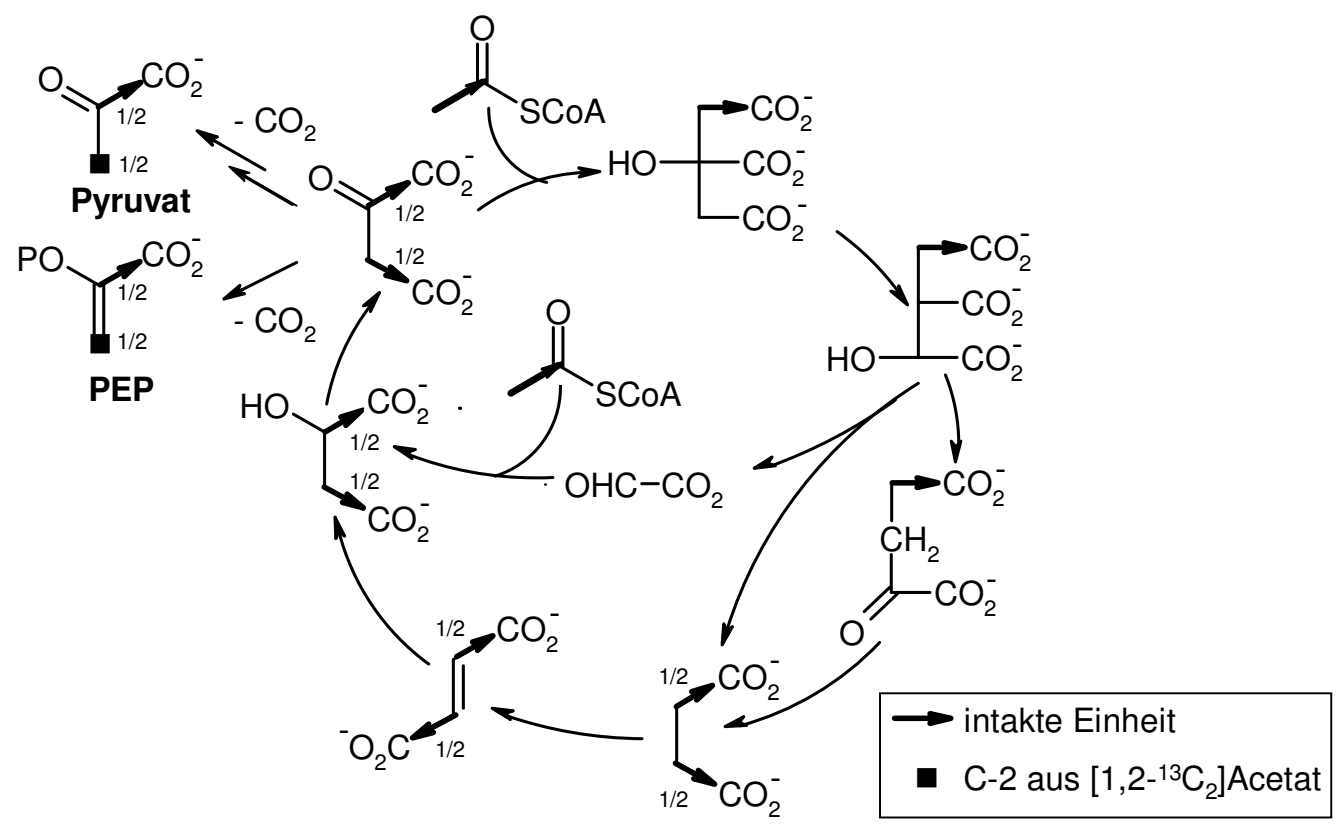

Abbildung 61. Acetat-Metabolismus in Oxalacetat über Citratcyclus und/oder Glyoxylat-Weg.

Die so aus angereichertem Acetyl-CoA über Oxalacetat aufgebauten Grundbausteine des Triose-Pyruvat-Wegs würden ein Einbaumuster wie in Abbildung 62 nach Fütterung mit $\left[1,2-{ }^{13} \mathrm{C}_{2}\right]$ Acetat ergeben. Das Pyruvat weist nach Decarboxylierung von C-1 keine intakte $\mathrm{C}_{2}$-Einheit auf, sondern zwei einzeln angereicherte $\mathrm{C}$-Atome, die von C-2 aus [1,2${ }^{13} \mathrm{C}_{2}$ ]Acetat stammen. Der $\mathrm{C}_{3}$-Baustein GAP zeigt eine intakte $\mathrm{C}_{2}$-Einheit und eine Einzelanreicherung, die aus der Decarboxylierung von Oxalacetat zu PEP resultiert und auf C-2 aus $\left[1,2-{ }^{13} \mathrm{C}_{2}\right]$ Acetat zurückzuführen ist. Bei der Semi-Pinakolumlagerung des Intermediats 1-Desoxy-D-xylulose-5-phosphat (DMP) zum 2-Methyl-D-erythritol-4-phosphat (MEP, s. Abbildung 56) wird in die intakte $\mathrm{C}_{2}$-Einheit des Glycerinaldehyd-3-phosphats die aus Pyruvat stammende $\mathrm{C}_{2}$-Einheit eingebaut, so dass anstelle einer ${ }^{1} J_{C, C^{-K o p p l u n g}}$ zwischen $\mathrm{C}-1$ und $\mathrm{C}-2$ von GAP eine ${ }^{2} J_{C, C}$-Kopplung im ${ }^{13} \mathrm{C}-\mathrm{NMR}-$ Spektrum tritt. Die ${ }^{13} \mathrm{C}-\mathrm{NMR}-$ 
Analyse des mit $\left[1,2-{ }^{13} \mathrm{C}_{2}\right]$ Acetat angereicherten Rosiridols (23) zeigte aber keine Spin-SpinKopplungen zwischen den C-Atomen C-2 und C-4 oder zwischen C-6 und C-8. Diese Kopplung ist jedoch zu erwarten, da die C-Atome C-2/C-4 bzw. C-6/C-8 jeweils aus einer intakten $\mathrm{C}_{2}$-Einheit des Glycerinaldehyd-3-phosphats stammen.

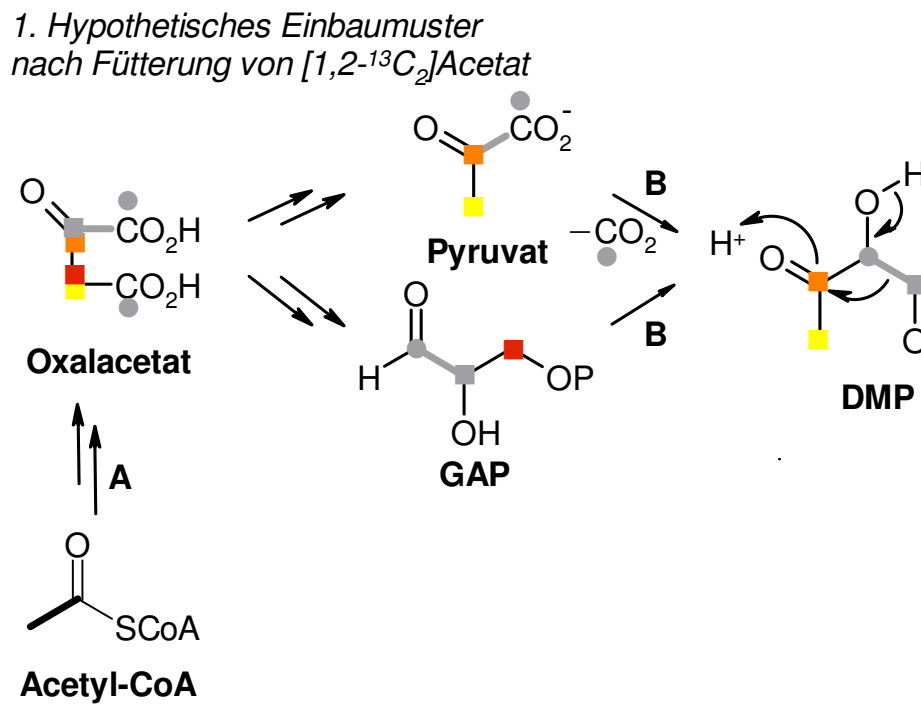

Oxalacetat GAP

DMP

Acetyl-CoA

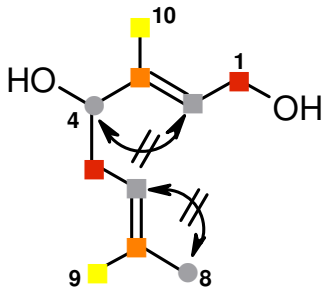

23

C-2 aus $\left[1,2-{ }^{13} \mathrm{C}_{2}\right]$ Acetat

C-2 aus $\left[1,2-{ }^{-13} \mathrm{C}_{2}\right]$ Acetat

C-I intakte Einheit

- $\mathrm{C}-1$ aus $\left[1,2-{ }^{13} \mathrm{C}_{2}\right]$ Acetat - C-2 aus $\left[1,2-{ }^{13} \mathrm{C}_{2}\right]$ Acetat H keine Kopplung

Abbildung 62. 1. Hypothetisches Einbaumuster für Rosiridol (23) aus dem Fütterungsexperiment mit $\left[1,2-{ }^{13} \mathrm{C}_{2}\right]$ Acetat (A: Umwandlung von Pyruvat in Acetyl-CoA und anschließende Metabolisierung im Citratcyclus/Glyoxylatweg zum Oxalacetat; B: Glycerinaldehyd-3-phosphat (GAP)/ Pyruvatweg).

Aus diesem Grund wurde für den biosynthetischen Aufbau eine 2. Biosynthesehypothese aufgestellt (s. Abbildung 64). Hierbei wird angenommen, dass das aus angereichertem AcetylCoA aufgebaute Oxalacetat über Phosphoenolpyruvat (PEP) zu Pyruvat verstoffwechselt wird. Dieses angereicherte Pyruvat wird über den Pyruvat-Dehydrogenase-Multienzymkomplex in Acetyl-CoA umgewandelt, welches in den Citratcyclus oder Glyoxylatweg gespeist wird (s. Abbildung 63).

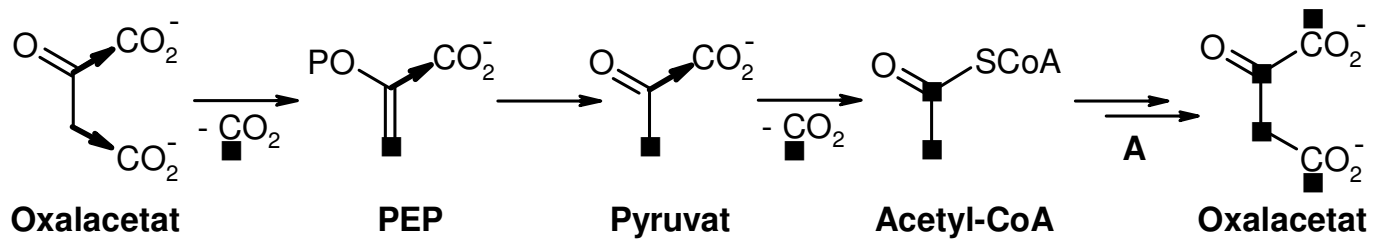

Abbildung 63. Weitere Metabolisierung von angereichertem Oxalacetat aus $\left[1,2-{ }^{13} \mathrm{C}_{2}\right]$ Acetat über Pyruvat zu Acetyl-CoA. (A: Angereichertes Acetyl-CoA aus Pyruvat wird wieder über den Citratcyclus/Glyoxylatweg zum Oxalacetat, welches keine intakten $\mathrm{C}_{2}$-Einheiten aus $\left[1,2-{ }^{13} \mathrm{C}_{2}\right]$ Acetat mehr aufweist).

Das hierbei aufgebaute Oxalacetat wird wie bereits beschrieben in angereichertes GAP und Pyruvat überführt, die aber keine intakten $\mathrm{C}_{2}$-Einheiten aus $\left[1,2-{ }^{13} \mathrm{C}_{2}\right]$ Acetat mehr aufweisen, 
sondern nur einzelne ${ }^{13} \mathrm{C}$-Markierungen. Die Semi-Pinakolumlagerung des DMP führt zu einem wie in der 2. Biosynthesehypothese gezeigtem Einbaumuster (s. Abbildung 64), mit dem die Beobachtungen aus der ${ }^{13} \mathrm{C}$-NMR-Analyse übereinstimmen. Alle Kohlenstoffatome sind hier angereichert, stammen jedoch alle von C-2 aus $\left[1,2-{ }^{13} \mathrm{C}_{2}\right]$ Acetat und zeigen damit keine Spin-Spin-Kopplungen.
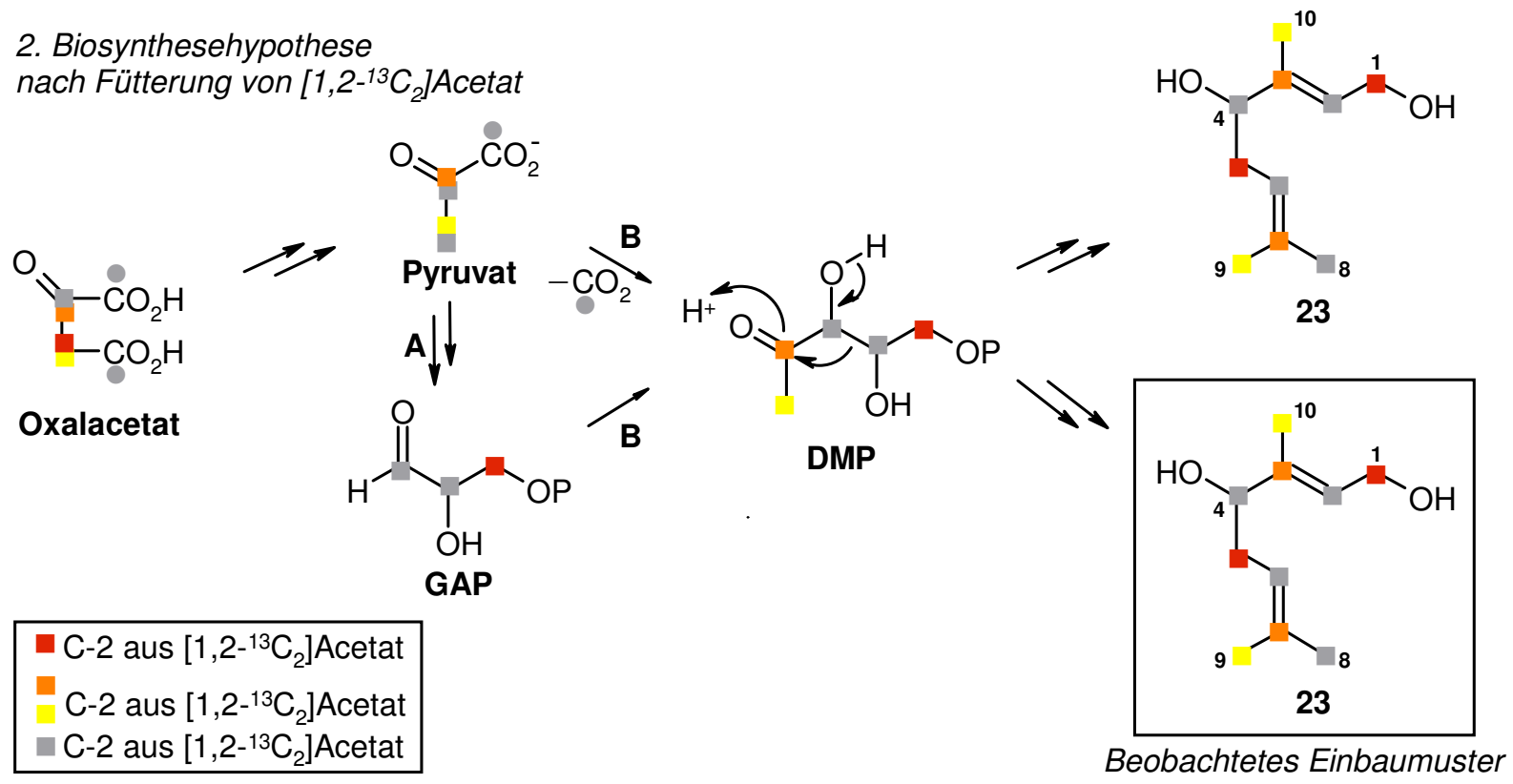

Abbildung 64. 2. Biosynthesehypothese und beobachtetes Einbaumuster in Rosiridol (23) aus dem Fütterungsexperiment mit $\left[1,2-{ }^{13} \mathrm{C}_{2}\right]$ Acetat (A: Umwandlung von Pyruvat in Acetyl-CoA und anschließende Metabolisierung im Citratcyclus/Glyoxylatweg zum Oxalacetat, das GAP liefert; B: Glycerinaldehyd-3-phosphat (GAP)/ Pyruvatweg).

Die ${ }^{13} \mathrm{C}-\mathrm{NMR}$ Analyse des Fütterungsexperiments mit $\left[\mathrm{U}-{ }^{13} \mathrm{C}_{3}\right]$ Glycerin zeigte für Rosiridol (23) signifikante Spin-Spin-Kopplungen, die charakteristisch für eine Isoprenoidbiosynthese über den Triose-Pyruvat-Weg sind. Das vollständig angereicherte Glycerin wird über das Glycerinaldeyd-3-phosphat (GAP) zu Pyruvat umgewandelt, und resultiert in vollständig angereicherten $\mathrm{C}_{3}$ - und $\mathrm{C}_{2}$-Bausteinen für den Triose-Pyruvat-Weg. Die Umwandlung von DMP zum 2-Methyl-D-erythritol-4-phosphat (MEP, s. Abbildung 56) führt zum Einbau von Pyruvat zwischen $\mathrm{C}$-1 und $\mathrm{C}-2$ der $\mathrm{C}_{3}$-Einheit, wodurch die zur Triose gehörenden $\mathrm{C}$-Atome C-1/C-2/C-3 voneinander getrennt werden und zusätzliche ${ }^{2} J_{C, C^{-}}$und ${ }^{3} J_{C, C^{-}}$Kopplungen aufweisen, während der intakte $\mathrm{C}_{2}$-Baustein aus Pyruvat (C-3/C-10 und C-7/C-9) nur eine ${ }^{1} J_{C, C^{-}}$ Kopplung zeigt (s. Abbildung 65). Das beobachtete Einbaumuster in Rosiridol (23) aus Zufütterung mit $\left[\mathrm{U}^{13} \mathrm{C}_{3}\right]$ Glycerin stimmt mit der Biosynthesehypothese über den TriosePyruvat-Weg überein. ${ }^{124}$ 


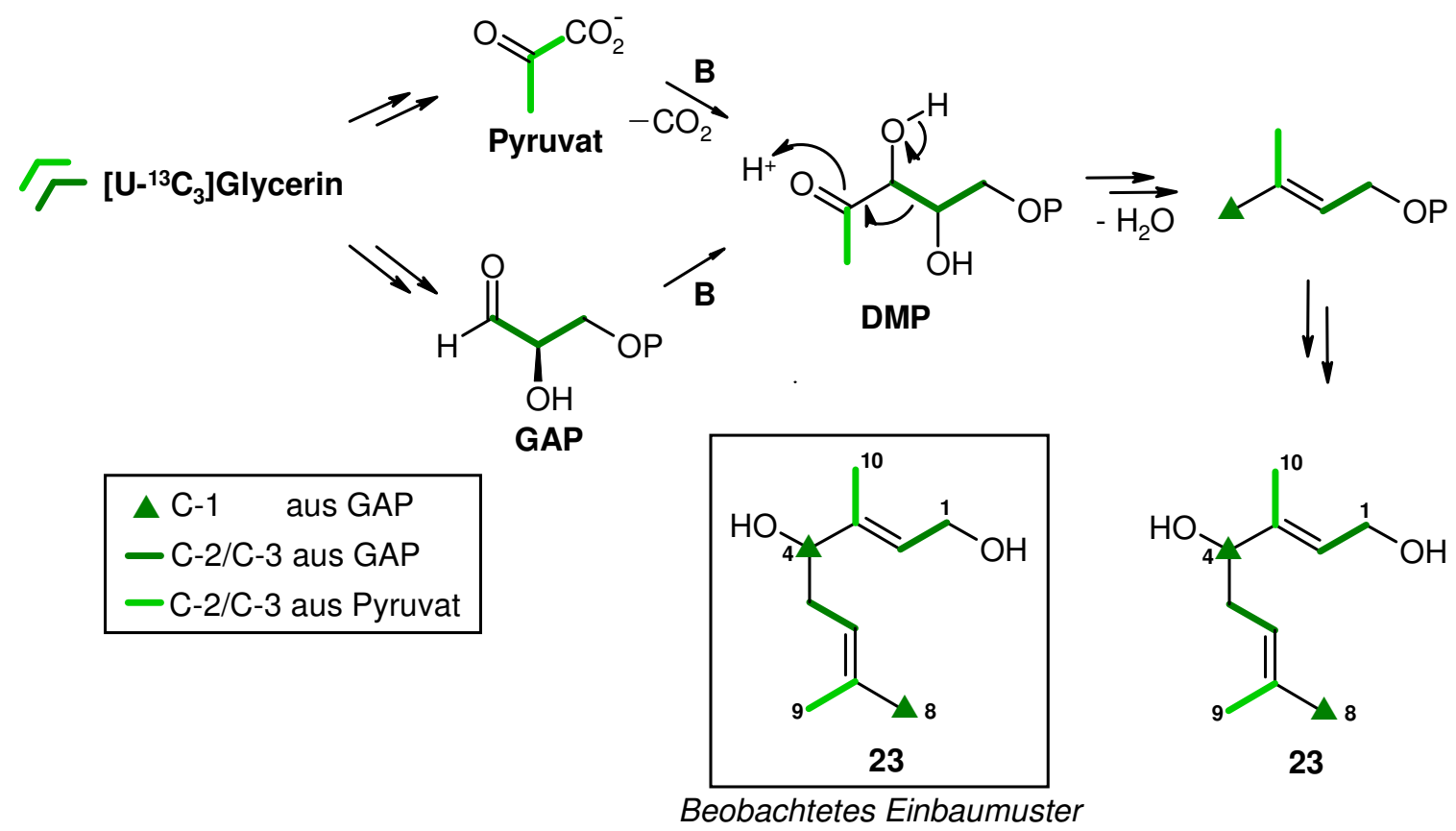

Abbildung 65. Biosynthesehypothese nach dem Triose-Pyruvat-Weg und beobachtetes Einbaumuster in Rosiridol (23) aus dem Fütterungsexperiment mit $\left[\mathrm{U}-{ }^{13} \mathrm{C}_{3}\right]$ Glycerin (B: Glycerinaldehyd-3-phosphat (GAP)/ Pyruvatweg).

Die zusätzlich beobachteten ${ }^{1} J_{C, C}$-Kopplungen zwischen den C-Atomen C-1/C-2 sowie vermutlich zwischen C-5/C-6 können auf intakte $\mathrm{C}_{2}$-Einheiten zurückgeführt werden, die keine weitere ${ }^{2} J_{C, C} C^{3} J_{C, C}$-Kopplung zu C-4 bzw. C-8 haben. Dies könnten zusätzliche ${ }^{1} J_{C, C}$-Kopplungen sein, die auf einen biosynthetischen Aufbau von 23 über den Acetat-Mevalonat-Weg hinweisen. Dies wäre auf die bereits beschriebene starke Vernetzung der verschiedenen Stoffwechselwege zurückzuführen.

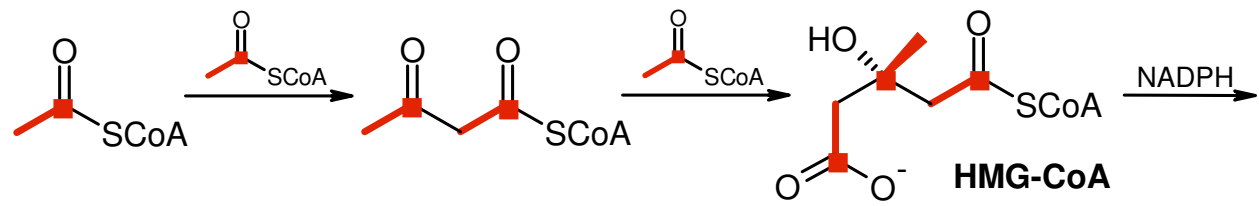<smiles>CC(C)=CCC(O)C(C)=CC(C)=CC(=O)O</smiles>

23

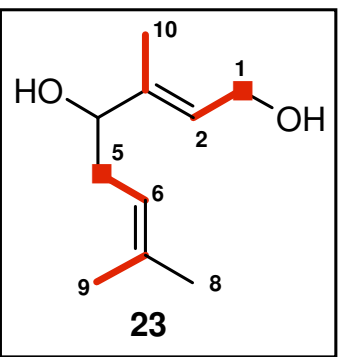

Beobachtetes Einbaumuster

Abbildung 66. Biosynthesehypothese nach Acetat-Mevalonat-Weg und zusätzlich beobachtetes Einbaumuster in Rosiridol (23) aus dem Fütterungsexperiment mit [U- $\left.{ }^{13} \mathrm{C}_{3}\right]$ Glycerin. 
Das ursprünglich aus $\left[\mathrm{U}_{-}{ }^{13} \mathrm{C}_{3}\right]$ Glycerin stammende Pyruvat kann durch oxidative Decarboxylierung, katalysiert durch den Pyruvat-Dehydrogenase-Multienzymkomplex zu Acetyl-CoA umgewandelt werden. Dieses kann als Substrat in den Acetat-Mevalonat-Weg eingespeist werden und so zum in Abbildung 66 gezeigten Einbaumuster führen. Damit sind die zusätzlich beobachteten ${ }^{1} J_{C, C}$-Kopplungen zwischen den C-Atomen C-1/C-2 und auch zwischen C-5/C-6 Hinweise auf einen weiteren Stoffwechselweg über den 23 aufgebaut werden könnte. Das Verhältnis der beiden Stoffwechselwege Acetat-Mevalonat- und Triose-Pyruvat-Weg ist aufgund der ${ }^{13} \mathrm{C}$-NMR-Signalintensitäten auf 1:5 zu schätzen.

\section{Zur Biosynthese des Cinnamoylphosphoramids (21)}

Im Rahmen des Fütterungsexperiments mit $\left[\mathrm{U}_{-}{ }^{13} \mathrm{C}_{3}\right]$ Glycerin konnte ein Gemisch aus angereichertem Monoterpen Rosiridol (23) und nicht angereichertem Cinnamoylphosphoramid (21) in einer Ausbeute von $2.3 \mathrm{mg} / \mathrm{L}$ isoliert werden. Vermutlich wird der Sekundärmetabolit 21 deutlich vor der 48. Stunde gebildet, so dass der Beginn der Zufütterung von $\left[\mathrm{U}_{-}{ }^{13} \mathrm{C}_{3}\right] \mathrm{Gly}-$ cerin zu einem früheren Zeitpunkt hätte erfolgen müssen, um eine Anreicherung in $\mathbf{2 1}$ zu erzielen. Das Strukturelement einer Hydroxyzimtsäuremethylester-Einheit lässt für das Cinnamoylphosphoramid (21) einen biosynthetischen Aufbau ausgehend von Shikimisäure vermuten (s. Abbildung 67). Aus dieser entsteht in mehreren Stufen über Chorisminsäure L-Phenylalanin (L-Phe), welches durch die Phenylalanin-Ammoniak-Lyase $(P A L)$ zu Zimtsäure (122) umgewandelt wird.

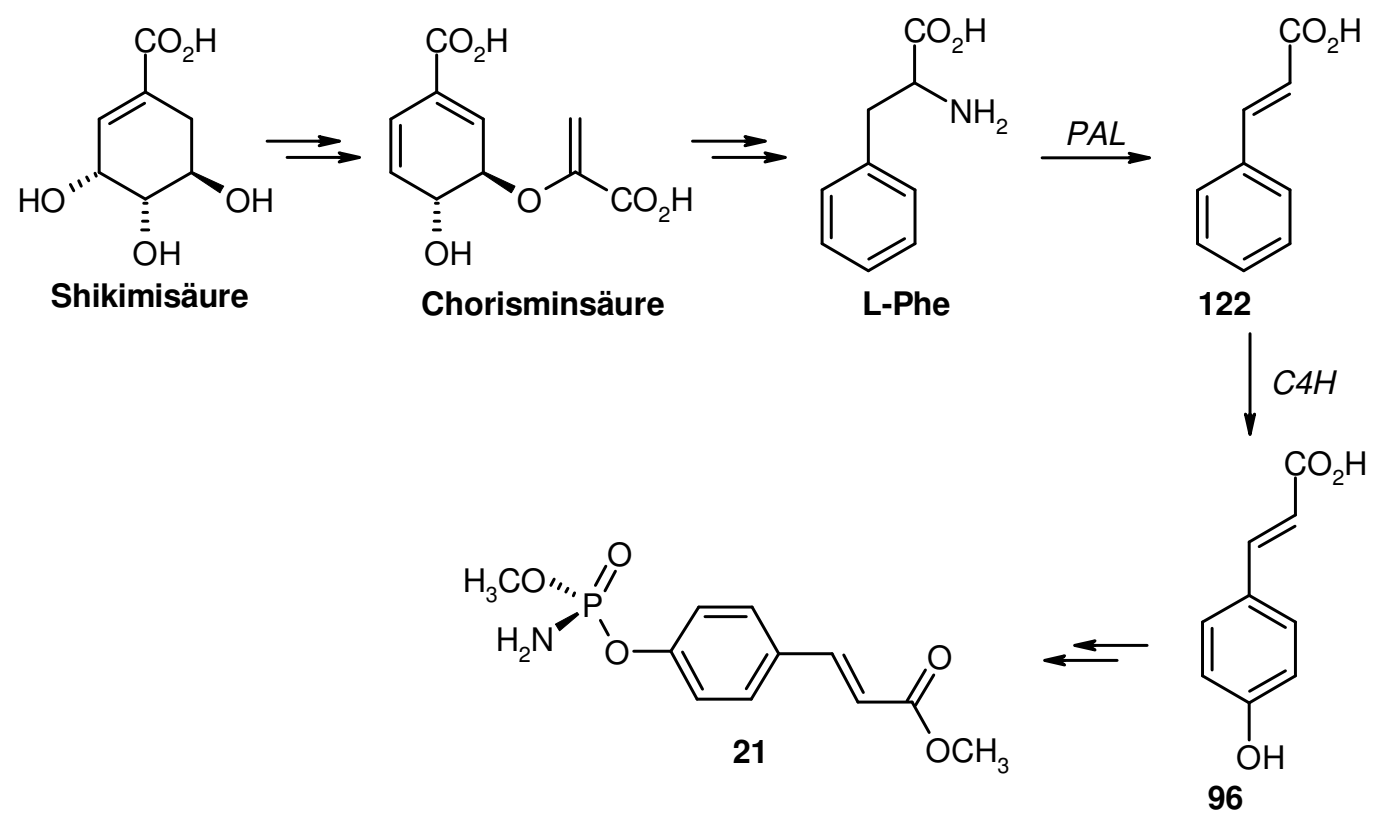

Abbildung 67. Biosynthesehypothese für 21 (PAL: Phenylalanin-Ammoniak-Lyase; C4H: Cinnamat 4Hydroxylase). 
Weitere enzymatische Transformation, katalysiert durch die Cinnamat-4-Hydroxylase $(\mathrm{C} 4 \mathrm{H})$ ergibt 4-Hydroxyzimtsäure (96), die anschließend durch Methylierung, Phosphorylierung sowie Einführung der Methoxy- und Aminofunktion am Phosphatsubstituenten in das Cinnamoylphosphoramid (21) überführt wird, wobei die Reihenfolge sowie der genaue enzymatische Ablauf dieser Transformationsschritte bisher noch unbekannt ist.

Dass die Metabolisierung von Phenylalanin zu Zimtsäure in marinen Streptomyceten analog zu Pflanzen verläuft, konnten Moore et al. im Jahr 2000 anhand von Fütterungsexperimenten mit ${ }^{2} \mathrm{H}$ - und ${ }^{13} \mathrm{C}$-markierten Vorläufern am marinen Bakterium Streptomyces maritimus zeigen. ${ }^{129}$ Hierbei untersuchte Moore et al. die Biosynthese von Benzoyl-CoA, das als Startereinheit für eine Typ II-Polyketidsynthase zur Produktion des bakteriostatisch wirkenden Polyketids Enterocin (75a, Abbildung 33) dient. Mit Hilfe dieser Fütterungsstudien konnte die zuvor aus dem Enterocin-Biosynthese-Gencluster abgeleitete Biosynthesehypothese bestätigt werden.

\subsubsection{Fütterungsexperimente mit potentiellen Biosynthesevorläufern}

Cinnamoylphosphoramid (21) weist neben einem einfachen Aufbau, ein für mikrobielle Sekundärmetaboliten ungewöhnliches phosphorhaltiges Strukturelement auf (s. Abbildung 36). Da phosphorhaltige funktionelle Gruppen zur Aktivierung organischer Stoffe dienen, könnte dieser Metabolit ein aktivierter Biosynthesevorläufer bislang unbekannter Metaboliten sein. Aus diesem Grund wurden im Rahmen der Diplomarbeit ${ }^{29}$ bereits erste Untersuchungen zur möglichen Funktion des Metaboliten als Biosynthesevorläufer durchgeführt. Die Zufütterung der synthetischen Verbindung 21 sollte zeigen, ob aus dadurch beeinflussten Stoffwechselwegen neue Metaboliten in ausreichender Menge zur Isolierung und Strukturaufklärung produziert werden. Die bisher von T. Schuhmann ${ }^{28}$ aus Kulturbrühen des Stammes JP90 isolierten Metaboliten (s. Abbildung 34) zeigten keine Strukturelemente, die auf biosynthetische Verwandtschaft mit 21 schließen lassen.

Zur Untersuchung der möglichen Funktion des Cinnamoylphosphoramids (21) als Biosynthesevorläufer wurde das racemische Syntheseprodukt 21 einer Standardfermentation in Schüttelkolben (acht 1 L Erlenmeyerkolben mit je 150 mL Nährlösung) nach der 12. und 16. Stunde zu vier der Hauptkulturen zugefüttert, die anderen vier dienten als Kontrolle (0.61 mM, Endkonzentration in der Kulturbrühe). Geerntet wurde sobald ein pH-Wert von 7.7 überschritten wurde. Nach Aufarbeitung der Hauptkulturen wurden zwei Rohextrakte aus den Kulturbrühen mit Zufütterung erhalten. Bei der dünnschichtchromatographischen Analyse der aus Zufütterung erhaltenen Rohextrakte an Kieselgel $\left(\mathrm{CHCl}_{3} / \mathrm{Methanol} 85: 15\right)$ fiel eine 
Substanz durch ihre Absorption bei $254 \mathrm{~nm}$ auf. In den Vergleichskulturen konnte diese Substanz nur in Spuren detektiert werden. Diese Verbindung zeigte bereits bei Tageslicht auf der Kieselgelplatte eine schwache violette Färbung. Nach Anfärbung mit Anisaldehyd trat eine blau-violette Farbreaktion auf. Ein Vergleich der beiden Extrakte aus den Kulturen mit Zufütterung von 21 ergab nach Anfärben des Dünnschichtchromatogramms mit Anisaldehyd keine exakte Übereinstimmung des Metabolitenmusters, so dass zur Isolierung der neuen, bisher in ihrer Struktur unbekannten Substanz die Extrakte einzeln an Kieselgel gereinigt wurden $\left(\mathrm{CH}_{2} \mathrm{Cl}_{2} / \mathrm{Methanol}\right.$ 95:5). Die Fraktion, die neben dieser unbekannten, mit Anisaldehyd blau-violett anfärbenden Verbindung auch eine mit Anisaldehyd braun anfärbende Substanz enthielt, wurde durch Mitteldrucksäulenchromatographie an reversed-phase Kieselgel (Lobar ${ }^{\circledR}$, Größe B, Aceton/ $\mathrm{H}_{2} \mathrm{O}$ 4:1) gereinigt. Hierbei konnte die unbekannte Verbindung zwar nicht isoliert werden, aber es konnte die mit Anisaldehyd braun anfärbende Verbindung in einer Ausbeute von $5.1 \mathrm{mg}$ als farbloser Feststoff gewonnen werden. Im Rahmen der vorliegenden Arbeit wurde die Struktur dieser Verbindung anhand spektroskopischer und spektrometrischer Daten sowie Datenbankrechere als Spirotetronat (22a) strukturaufgeklärt (s. Abschnitt 4.1.4 ). Allerdings liegen auch für diesen Sekundärmetaboliten keine Strukturelemente vor, die auf biosynthetische Verwandtschaft mit $\mathbf{2 1}$ schließen lassen.

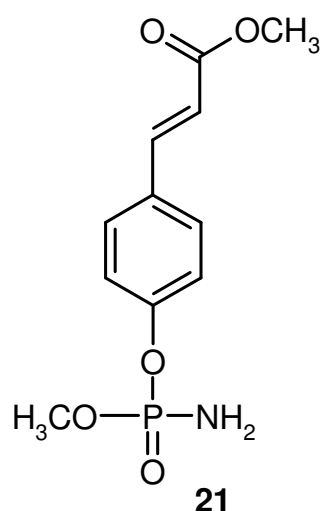

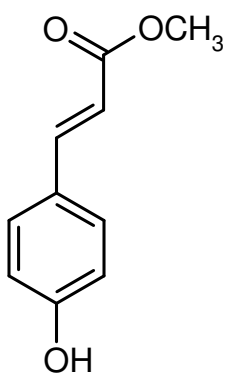

82

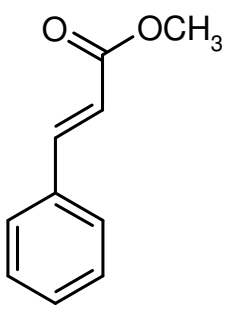

93<smiles>O=C(O)/C=C/c1ccccc1</smiles>

122

Abbildung 68. Zugefütterte potentielle Biosynthesevorläufer rac-Cinnamoylphosphoramid (21), 4-Hydroxyzimtsäuremethylester (82), Zimtsäuremethylester (93) und Zimtsäure (122).

In der vorliegenden Arbeit wurden weitere Fütterungsexperimente mit unmarkierten potentiellen Biosynthesevorläufern durchgeführt, um zu überprüfen, ob dadurch eine Ausbeutesteigerung des unbekannten Metaboliten aus JP90 reproduzierbar erreicht werden kann (s. Abbildung 68). Als potentielle Vorläufer wurde racemisches Cinnamoylphosphoramid (21, $0.59 \mathrm{mM}$, Endkonzentration im Kolben) und die Strukturanaloga 4-Hydroxyzimtsäuremethylester (82, 0.94 mM, Endkonzentration im Kolben), Zimtsäuremethylester (93, 
1.03 mM, Endkonzentration im Kolben) und Zimtsäure (122, $1.12 \mathrm{mM}$, Endkonzentration im Kolben) zugefüttert. Die Kultivierung erfolgte unter Standardbedingungen in Schüttelkolben (pro gefütterte Substanz vier 1 L Schüttelkolben mit je 150 mL Nährlösung, s. Abschnitt B 3.6.3 ). Die Substanzen wurden in je $2 \mathrm{~mL}$ sterilem DMSO gelöst und nach der 12. und 16. Stunde in jeweils $0.25 \mathrm{~mL}$ dieser Lösung zu jeweils vier der Hauptkulturen gegeben, vier weitere Kulturen dienten als Kontrolle. Jeder Ansatz wurde nach 96 h geerntet und wie in Abschnitt B 3.3.3 beschrieben aufgearbeitet. Die erhaltenen Rohextrakte wurden mit einer Konzentration von $c=10.0 \mathrm{mg} / \mathrm{mL}$ in Methanol gelöst und dünnschichtchromatographisch an Kieselgel $\left(\mathrm{CHCl}_{3} / \mathrm{Methanol} \mathrm{85:15)}\right.$ untersucht. Ein Vergleich aller Rohextrakte ergab, dass der unbekannte Metabolit aus dem vorherigen Fütterungsexperiment nicht reproduziert werden konnte. Andererseits konnte im Rohextrakt, das nach Zufütterung von 4-Hydroxyzimtsäuremethylester (82) erhalten wurde, ein neuer Sekundärmetabolit detektiert werden. Dieser fiel durch Absorption bei $254 \mathrm{~nm}$ auf und zeigte nach Anfärben mit Anisaldehyd eine pink-violette Färbung. Zur Isolierung dieser Substanz wurde das Rohextrakt zunächst an Kieselgel $\left(\mathrm{CHCl}_{3} / \mathrm{Methanol} \mathrm{95:5)}\right.$ vorgereinigt und eine anschließende Gelchromatographie an Sephadex-LH 20 (Methanol) ergab $4.9 \mathrm{mg}$ der durch Zufütterung von 82 induzierten Verbindung 123.

Zur weiteren Analyse der Rohextrakte wurden diese mittels HPLC-ESI-MS untersucht (HPLC D, Säule A: Grom Superspher 100 RP-18, Programm B: $\mathrm{MeOH} / \mathrm{H}_{2} \mathrm{O}$, jeweils mit $0.05 \%$ Ameisensäure, Gradient; s. Abschnitt B 1.2 ). Eine Auswertung der HPLC-ESIMS-Chromatogramme zeigte bis auf die Zufütterung von 82 ebenfalls keine Veränderung des Metabolitenmusters hinsichtlich neuer oder in ihrer Produktion gesteigerten Sekundärmetaboliten. Damit konnte trotz weiterer Fütterungsexperimente mit potentiellen Biosynthesevorläufern eine biologische Funktion des Cinnamoylphosphoramids (21) als aktivierter Biosynthesevorläufer für den Produzenten Stamm JP90 nicht verifiziert werden.

\section{Charakterisierung des 4-Hydroxy-3-methoxy-zimtsäuremethylesters (123)}

Der nach Zufütterung von 82 in einer Ausbeute von $10.9 \mathrm{mg} / \mathrm{L}$ isolierte hellgelbe Feststoff zeigte im ESI-Massenspektrum eine Molmasse von 194 g/mol und die Hochauflösung ergab die Summenformel $\mathrm{C}_{11} \mathrm{H}_{12} \mathrm{O}_{5}$, (6 Doppelbindungsäquivalente). Das ${ }^{1} \mathrm{H}-\mathrm{NMR}$-Spektrum zeigt eine sehr starke Ähnlichkeit zur zugefütterten Substanz 82, die sich nur durch das Substitutionsmuster am Aromaten unterscheiden. Es sind sieben Signale im ${ }^{1} \mathrm{H}-\mathrm{NMR}-$ Spektrum zu beobachten, darunter zwei Methoxygruppen $\left(\delta_{\mathrm{H}}=3.75\right.$ und $\left.3.87 \mathrm{ppm}\right)$, zwei Methingruppen im olefinischen Bereich $\left(\delta_{\mathrm{H}}=6.34\right.$ und $\left.7.60 \mathrm{ppm}\right)$, deren hohe vicinale Kopplungskonstante von ${ }^{3} J_{\mathrm{HH}}=15.9 \mathrm{~Hz}$ auf eine trans-ständige Anordnung der olefinischen 
Protonen hinweist und drei Signale im Aromatenbereich $\left(\delta_{\mathrm{H}}=6.79,7.05\right.$ sowie $\left.7.16 \mathrm{ppm}\right)$. Zwei der aromatischen Protonen $\left(\delta_{\mathrm{H}}=6.79\right.$ und $\left.7.05 \mathrm{ppm}\right)$ sind aufgrund ihrer Kopplung von ${ }^{3} J_{(\mathrm{H}, \mathrm{H})}=8.0 \mathrm{~Hz}$ ortho-ständig; eine Kopplung von ${ }^{3} J_{(\mathrm{H}, \mathrm{H})}=2.1 \mathrm{~Hz}$ der Signalen bei $\delta_{\mathrm{H}}=7.05$ und 7.16 ppm zeigt, dass diese meta-ständig sind. Das ${ }^{13} \mathrm{C}-\mathrm{NMR}-$ Spektrum enthält Signale für zwei Methoxyguppen, neun olefinische/aromatische Kohlenstoffatome und eine Carbonylfunktion, deren chemische Verschiebung einem $\alpha, \beta$-ungesättigte Carbonsäureester entspricht. Auch hier ist eine große strukturelle Verwandtschaft zur Verbindung $82 \mathrm{zu}$ finden. ${ }^{1} J_{(\mathrm{C}, \mathrm{H})}-$ und ${ }^{2-4} J_{(\mathrm{C}, \mathrm{H})}$-Korrelationen aus HSQC- bzw. HMBC-Experimenten erlaubten die Zuordnung der Struktur 123.
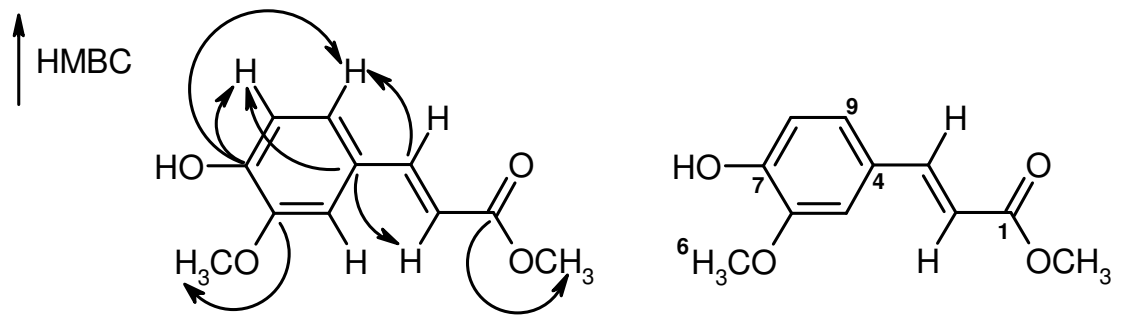

Abbildung 69. Ausgewählte ${ }^{2-4} J_{(\mathrm{C}, \mathrm{H})}-$ Korrelationen aus dem HMBC-Experiment von 4-Hydroxy-3-MethoxyZimtsäuremethylester (123).

Der zugefütterte Zimtsäuremethylester 82 wird vermutlich gemäß einer biosynthetischen Umwandlung des Zwischenprodukts 4-Hydroxyzimtsäure (96) zur 4-Hydroxy-3-methoxyzimtsäure zunächst ortho-ständig zur Hydroxyfunktion hydroxyliert und anschließend in Gegenwart von $S$-Adenosinmethionin (SAM) methyliert. ${ }^{130}$
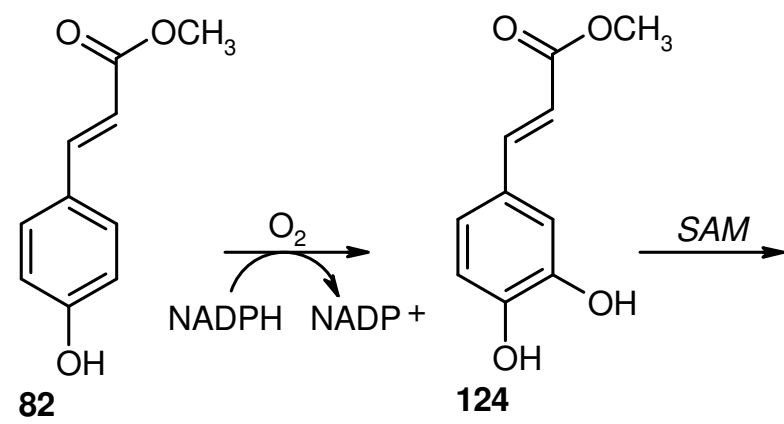<smiles>COC(=O)/C=C/c1ccc([18OH])c(OC)c1</smiles>

Abbildung 70. Biosynthetische Umwandlung von 82 (SAM: S-Adenosylmethionin).

\subsubsection{Diskussion und Ergebnisse der Biosynthesestudien}

Der Produzent Streptomyces sp. Stamm JP90, ein aus marinen Invertebraten isoliertes assoziiertes Bakterium, zeigt als Produzent von Naturstoffen eine große strukturelle Vielfalt. Neben bekannten niedermolekularen Naturstoffen beinhaltet sein Metabolitenspektrum auch neue und ungewöhnliche Strukturen wie Cinnamoylphosphoramid (21), Rosiridol (23) und 
Spirotetronate (22). Die biogenetische Vielfalt bedient sich verschiedener Terpen-, Polyketid-, Shikimat- und Aminosäure-Quellen für den biosynthetischen Aufbau dieser Sekundärstoffe, so dass der Stamm als „begabt“ einzustufen ist, der vielseitig, verzweigte Biosynthesewege unterhält.

Im Rahmen der vorliegenden Arbeit wurde diese Mannigfaltigkeit mit Biosynthesestudien an ausgewählten Metaboliten untersucht. Mit Hilfe von Fütterungsexperimenten mit ${ }^{13} \mathrm{C}$-markierten Biosynthesevorläufern konnte die starke strukturelle Ähnlichkeit der Spirotetronate (22) mit dem bekannten Chlorothricin (105) auch auf biosynthetischer Ebene verifiziert werden. Die von Floss et al. ${ }^{110}$ durchgeführten Fütterungsexperimente an Chlorothricin (105) und die hieraus abgeleitete Biosynthesehypothese für den mechanistischen Aufbau des Spirotetronat-Aglykons stimmen mit der aus dem Chlorothricin-Biosynthese-Gencluster abgeleiteten Hypothese nahezu überein. Seit 2007 sind weitere Biosynthesehypothesen aus klonierten Biosynthese-Gencluster anderer Spirotetronate wie Tetrocarcin A (106) und Kijanimicin (107) postuliert worden, die auf einen allgemeingültigen mechanistischen Aufbau solcher Spirotetronate schließen lassen. Die aus den Fütterungsexperimenten resultierenden Ergebnisse für die aus dem Stamm JP90 isolierten Verbindungen 22a und 22b unterstützen diese Biosynthesehypothese. In der aktuellen Literatur wird am Beispiel des Polyethers Tetronomycin (108), dessen Struktur eine Tetronsäure-Einheit aufweist, ein allgemeiner Mechanismus für den biosynthetischen Aufbau von Tetronsäure-Einheiten postuliert und diskutiert. Eine Bestätigung dieser Hypothese erfordert derzeit noch weitere systematische Untersuchungen aller Biosynthese-Gencluster und vor allem der beteiligten Enzyme. Aufgrund der aus den Fütterungsexperimenten resultierenden sehr ähnlichen Ergebnisse für Spirotetronate (22) und Chlorothricin (105) erschienen Studien am Biosynthese-Gencluster der Spirotetronate zunächst nicht erstrebenswert. Möglicherweise bieten diese aber im Hinblick auf die derzeitige Diskussion eines allgemeingültigen Mechanismus für den biosynthetischen Aufbau von Tetronsäure-Einheiten in der Natur eine potentielle Quelle, um weitere Indizien zu sammeln, die die Biosynthese von Tetronsäuren klären könnten.

Streptomyceten sind in der Literatur als einzige Mikroorganismen beschrieben, die nachweislich für den biosynthetischen Aufbau der Terpene beide möglichen Biosynthesewege benutzen können, den Acetat-Mevalonat- und den Triose-Pyruvat-Weg. Mit Hilfe von Biosyntheseuntersuchungen mit Fütterungsexperimenten von ${ }^{13} \mathrm{C}$-markierten Vorläufern am Monoterpen Rosiridol (23) sollte geklärt werden, über welchen Stoffwechselweg das Monoterpen 23 aufgebaut wird. Hierbei ergaben sich Hinweise, dass der Produzent Streptomyces 
JP90 möglicherweise beide Biosynthesewege einsetzen kann, um das Rosiridol (23) zu bilden. In der Literatur gibt es Beispiele, wonach der Triose-Pyruvat-Weg in der exponentiellen, der Acetat-Mevalonat-Weg in der stationären Wachstumsphase beobachtet wurde. Anhand der Ergebnisse aus dem Fütterungsexperiment mit $\left[\mathrm{U}^{13} \mathrm{C}_{3}\right]$ Glycerin, bei dem die kontinuierliche Zugabe des Vorläufers zum Stamm JP90 zwischen der 48. Stunde bis zur 60. Stunde erfolgte, ergab die ${ }^{13} \mathrm{C}$-NMR-Analyse anhand des beobachtenden Einbaumusters, dass Rosiridol (23) über den Triose-Pyruvat-Weg aufgebaut wird. Zusätzlich können im beobachteten Einbaumuster aus dem Fütterungsexperiment mit $\left[\mathrm{U}_{-}{ }^{13} \mathrm{C}_{3}\right]$ Glycerin Hinweise auf den Acetat-Mevalonat-Weg gefunden werden. Dies könnte bedeuten, dass der Stamm JP90 für den biosynthetischen Aufbau von 23 in der exponentiellen Wachstumsphase den Triose-Pyruvat-Weg und in der stationären Phase den Acetat-Mevalonat-Weg nutzt (s. Abbildung 71).

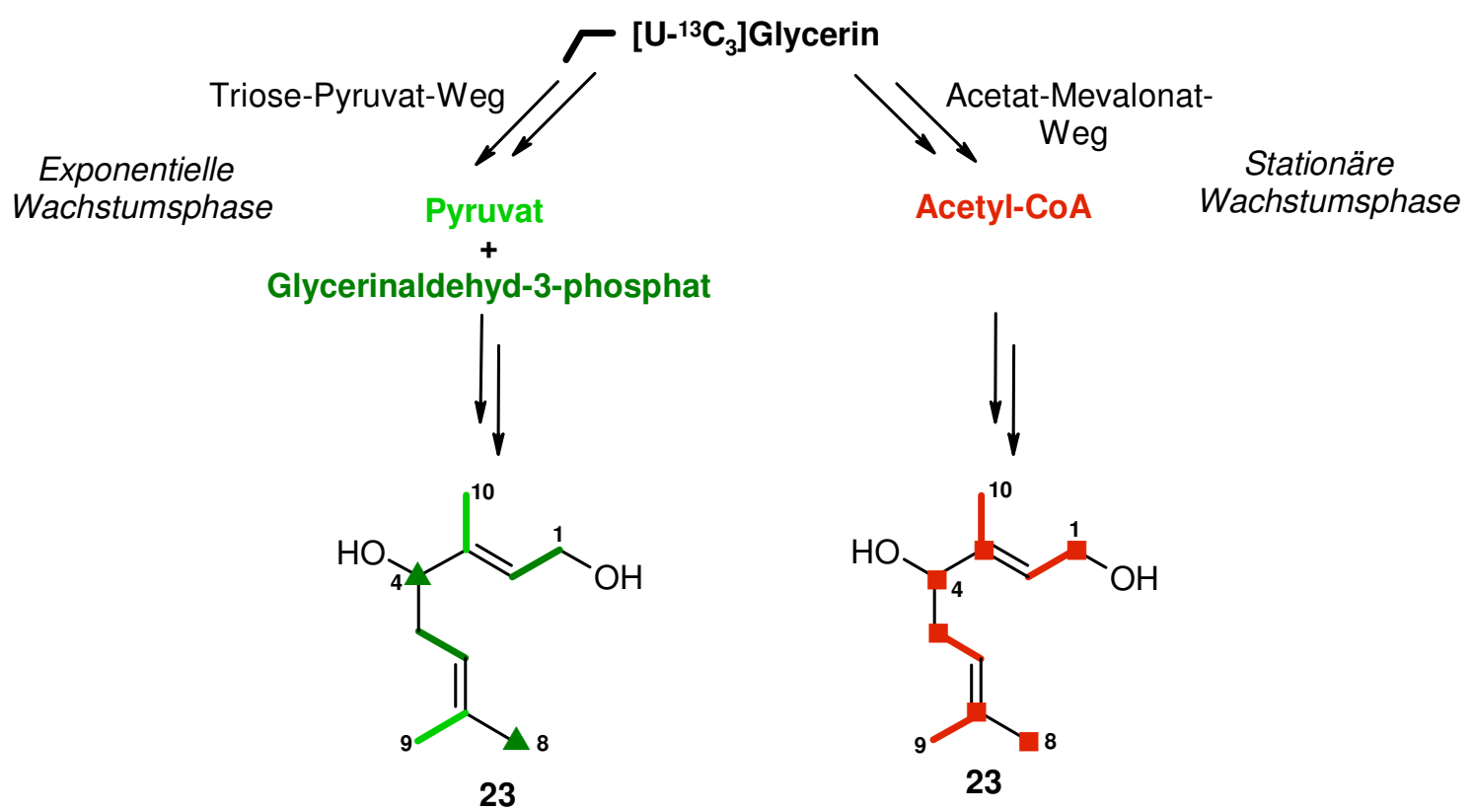

Abbildung 71. Graphischer Überblick der verschiedenen Stoffwechselpfade zur Biosynthese des Rosiridols (23).

Diese Hypothese wird durch das beobachtete Einbaumuster in $\mathbf{2 3}$ aus der Zufütterung von $\left[1,2-{ }^{13} \mathrm{C}_{2}\right]$ Acetat unterstützt, welches nur einen biosynthetischen Aufbau allein über den Triose-Pyruvat-Weg zeigt. Bei diesem Fütterungsexperiment erfolgte die kontinuierliche Zugabe des Vorläufers nur zwischen der 48. Stunde und 55. Stunde. Da die ${ }^{13} \mathrm{C}-\mathrm{NMR}-$ Analyse nur einen Biosyntheseweg als sehr eindeutig zulässt, nämlich den Triose-Pyruvat-Weg, ist zu vermuten, dass die Zufütterung von $\left[1,2-{ }^{13} \mathrm{C}_{2}\right]$ Acetat bereits in der exponentiellen Wachstumsphase abgeschlossen war, während die Fütterung von $\left[\mathrm{U}_{-}{ }^{13} \mathrm{C}_{3}\right]$ Glycerin noch in die beginnende stationäre Phase hineinreichte. Um diese Hypothese zu verifizieren, müssten zu 
unterschiedlichen Fütterungszeitpunkten weitere Fütterungsexperimente mit ${ }^{13} \mathrm{C}$-markierten Vorläufern durchgeführt werden. Im Falle eines Fütterungsbeginns nach der 60. Stunde könnte das zu beobachtende Einbaumuster in Rosiridol einen biosynthetischen Aufbau über den Acetat-Mevalonat-Weg zeigen.

Für das Cinnamoylphosphoramid (21) konnte die postulierte Biosynthesehypothese anhand von Fütterungsexperimenten mit ${ }^{13} \mathrm{C}$-markiertenVorläufern nicht unterstützt werden, da diese zu keiner Anreicherung in $\mathbf{2 1}$ führten. Die Produktion dieses Sekundärstoffs startet vermutlich schon weit vor der 48. Stunde, welche als optimaler Zufütterungsbeginn für eine Anreicherung der Spirotetronate gewählt wurde. Die vorgeschlagene Biosynthesehypothese für 21, ausgehend von Shikimisäure über Zimtsäure als Intermediat, wird durch literaturbekannte Fütterungsexperimente mit ${ }^{13} \mathrm{C}$-markieten Vorläufern an einem anderen marinen Streptomyceten ${ }^{129}$ unterstützt.

\subsubsection{Zur biologischen Aktivität ausgewählter Metaboliten}

\section{Cinnamoylphosphoramid (21)}

Cinnamoylphosphoramid (21) weist nicht nur einen für mikrobielle Sekundärmetaboliten ungewöhnlichen Phosphoramidsubstituenten auf, sondern seine chemische Struktur entspricht dem Grundgerüst der Organophosphate. Organische Phosphorverbindungen gehören zu den irreversiblen Inibitoren der Acetylcholinesterase (AChE). Das Acetylcholin (125) zählt zu den wichtigsten Neurotransmittern und spielt bei der neuromuskulären Übertragung sowie im vegetativen Nervensystem eine wichtige Rolle. Die Erregungsübertragung zwischen Nerven und den nachgeschalteten Nerven-, Muskel- oder Drüsenzellen erfolgt bei cholinergen Synapsen durch Ausschüttung von Acetylcholin in den synaptischen Spalt. An der postsynaptischen Membran befindet sich in räumlicher Nähe zum Acetylcholinrezeptor ortsfest die Acetylcholinesterase, die die Hydrolyse von Acetylcholin (125) zu Cholin (126) und Acetat (127) katalysiert und somit eine Dauererregung der postsynaptischen Rezeptoren verhindert (s. Abbildung 72). ${ }^{131}$

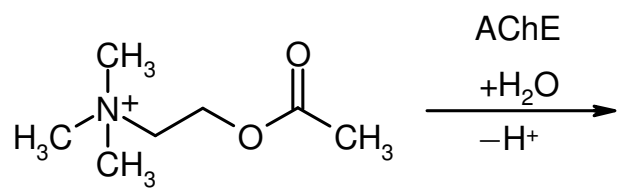

125<smiles>C[N+](C)(C)CCO</smiles>

126<smiles>CC(=O)[O-]</smiles>

127

Abbildung 72. Hydrolyse des Acetylcholins (125). 
Die Organophosphate hemmen die AChE irreversibel und verhindern so die Hydrolyse des Acetylcholins (125). Viele Vertreter dieser Stoffklasse besitzen sehr starke insektizide Wirkung und zerfallen nach der Anwendung schnell, so dass sie häufig als Pflanzenschutzmittel eingesetzt wurden. Beispiele sind das extrem toxische Nervengift Fluostigmin (Diisopropylfluorphosphat, DIPF, 128) und das Insektizid Nitrostigmin (E 605, Parathion, 129), in dem in vivo der Schwefel gegen Sauerstoff ausgetauscht wird. Erst der dadurch entstehende Metabolit, Paraoxon genannt, besitzt die hohe Affinität zur Esterase (s. Abbildung 73). ${ }^{131}$<smiles>CC(C)OP(=O)(F)OC(C)C</smiles>

128<smiles>CCOP(=S)(OCC)Oc1ccc([N+](=O)[O-])cc1</smiles>

129

Abbildung 73. Strukturen zweier irreversibler AChE-Inhibitoren.

Die chemische Struktur der Organophosphate und der daraus resultierende Wirkmechanismus kann durch die Schrader-Formel (130) beschrieben werden (s. Abbildung 74). ${ }^{132}$

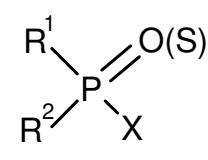

130

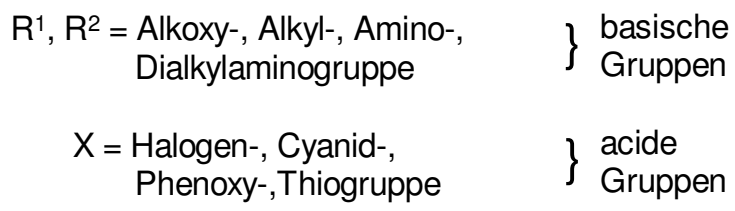

basische

Gruppen

\} $\begin{aligned} & \text { acide } \\ & \text { Gruppen }\end{aligned}$

Abbildung 74. Die Schrader-Formel (130).

Die acide Gruppe der Grundstruktur 130 ist die wichtigste Voraussetzung für die Reaktion mit dem Enzym. Nach Aufnahme der Organophosphate werden diese im menschlichen Körper durch oxidative und hydrolytische Prozesse verstoffwechselt. Die oxidativen Prozesse werden durch Cytochrom P-450 katalysiert und die hydrolytische Spaltung möglicher Esterbindungen erfolgt durch Esterasen. Des Weiteren werden die Phosphorsäureester durch Transferasen demethyliert. Unter Abspaltung der aciden Gruppe phosphorylieren Organophosphate die AChE an der Serin-OH-Gruppe und inhibieren somit das Enzym. Die Inaktivierung der AChE verhindert die Hydrolyse des Neurotransmitters Acetylcholin (125), wodurch der reguläre Ablauf von Nervenimpulsen beeinflusst wird und die Toxizität der Organophosphate verursacht wird. ${ }^{131}$

Die Struktur von 21 lässt sich auf die Grundstruktur 130 der Organophosphate, der SchraderFormel, zurückführen. Die Phenoxygruppe entspricht der aciden Gruppe, die Methoxy- und 
die Aminofunktion den Resten $\mathrm{R}^{1}$ und $\mathrm{R}^{2}$. Dieses lässt vermuten, dass es sich bei der Verbindung um einen Acetylcholinesterase-Hemmstoff handeln könnte.

Im Rahmen der Diplomarbeit ${ }^{29}$ wurden erste Untersuchungen zu einer möglichen inhibitorischen Aktivität auf die $\mathrm{AChE}$ in einer Kooperation mit Prof. U. Holzgrabe (Universität Würzburg) von E. Kugelmann durchgeführt. Aufgrund der schlechten Löslichkeit von 21 im verwendeten Phosphatpuffer konnte nur eine sehr schwache Hemmung der AChE $\left(I C_{50}>350 \mu \mathrm{M}\right)$ gemessen werden, während Kontrollexperimente mit dem Parasympathomimetikum Tacrin $\left(\operatorname{Cognex}^{\circledR}\right)$ die erwartete Hemmung der AChE erbrachten $\left(\mathrm{IC}_{50}=1.5 \mathrm{nM}\right) .{ }^{133}$ Zur genauen Bestimmung des $\mathrm{IC}_{50}$-Wertes wurde das Säurederivat von 21 als wasserlösliches Analogon dargestellt (s. Abschnitt 4.1.2 ) und zusammen mit dem racemischen Syntheseprodukt 21 die inhibitorischen Aktivitäten auf die AChE mit Hilfe des spektrophotometrischen Ellmann-Test untersucht. ${ }^{134,135}$ Hierfür wurde das Enzym (AChE) mit dem potentiellen Inhibitor, in diesem Fall das racemische Syntheseprodukt 21 und das wasserlösliche Säurederivat 92, in einem Phosphatpuffer $(\mathrm{pH}=8)$ inkubiert. Anschließend wurde das Ellmann-Reagenz (DTNB = 5,5'-Dithiobis-2-nitrobenzoesäure, 131) zugegeben und schließlich das Substrat Acetylthiocholin (ATCh, 132), dessen Zugabe die Reaktion startet (s. Abbildung 75).<smiles>C[N+](C)(C)CCSC=O</smiles><smiles>CCOC(C)C</smiles><smiles>C[N+](C)(C)CC[S-]</smiles><smiles>CC(=O)[O-]</smiles><smiles>C[N+](C)(C)CC[S-]</smiles><smiles>O=C([O-])c1ccc(SSc2ccc([N+](=O)[O-])c([N+](=O)[O-])c2)cc1C(=O)[O-]</smiles>

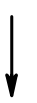
131<smiles>C[N+](C)(C)CCSSc1ccc([N+](=O)[O-])c(C(=O)[O-])c1</smiles>
134<smiles>O=C([O-])c1cc([S-])ccc1[N+](=O)[O-]</smiles>

135

Abbildung 75. Farbreaktion des Ellmann-Tests.

Nach Spaltung des ATCh (132), vom Enzym zu Thiocholin (133) und Acetat (127), reagiert das Spaltprodukt Thiocholin (133) mit DTNB (131) zu einem gelb gefärbten Produkt, dem Anion der 5-Thio-2-nitrobenzoesäure (135), dessen Konzentration spektrometrisch bei 
$\lambda=412 \mathrm{~nm}$ vermessen werden kann. Die Stärke der Farbentwicklung ist proportional der AChE-Aktivität. Bereits mit bloßem Auge kann das Ausmaß der Farbbildung beobachtet werden. Schwache bis gar keine Farbbildung ist ein Indiz für starke Inhibitoren. Umgekehrt deutet eine intensiv gelb gefärbte Lösung in der Messküvette auf eine schwache Inhibition hin.

Die Untersuchungen von 21 und seinem Säurederivat 92 zeigten für beide nur eine sehr schwache inhibitorische Aktivität $\left(\mathrm{IC}_{50}>350 \mu \mathrm{M}\right)$, während das Kontrollexperiment mit Tacrin dem erwarteten Ergebnis $\left(\mathrm{IC}_{50}=1.5 \mathrm{nM}\right)$ entsprach. Weitere Untersuchungen der potentiellen Inhibitoren wurden mit der Butyrylcholinesterase (BChE) in Kooperation mit Prof. C. Meier (Universität Hamburg) von N. Gisch durchgeführt und ergaben für 21 einen $I C_{50}=250 \mu \mathrm{M}$ und keine signifikante Aktivität für $92 .{ }^{136}$ Die aus den in vitro-Tests bestimmten, nur sehr schwachen inhibitorischen Aktivitäten des Cinnamoylphosphoramids (21) schließen allerdings eine starke insektizide Wirkung nicht aus. Bereits Anfang der 50er Jahre wurde die Hypothese, dass organische Phosphorverbindungen, die in-vitro die AChE oder BChE hemmen, eine entsprechende Aktivität in vivo zeigen, widerlegt. ${ }^{137}$ Es konnte gezeigt werden, dass einige organische Phosphorverbindungen, die eine starke insektizide Wirkung besaßen, in vitro gar keine oder nur eine sehr geringe hemmende Wirkung auf AChE oder BChE aufwiesen.

Der Ansatz, die Löslichkeit des potentiellen Inhibitors 21 zu erhöhen, indem sein Säurederivat 92 synthetisiert wurde, war nicht erfolgreich. Eine andere Möglichkeit ein wasserlösliches Analogon darzustellen, ohne die Carbonsäureesterfunktionalität zu verlieren, besteht in der Bildung eines Esters mit Ethanolaminderivaten, die Aminseitenketten tragen. Vorstellbar wäre etwa das tertiäre $N, N$-Dimethylaminoethanolamin oder das quartäre $N, N, N$-Trimethylammoniumethanol. Ein Beispiel für die Erhöhung der Wasserlöslichkeit durch die Einführung eines $\mathrm{N}, \mathrm{N}$-Dimethylaminoethanol-Substituenten ist das glycosidische Duocarmycin-Ana$\operatorname{logon}^{138}$ (136, s. Abbildung 76), das sich derzeit in Untersuchungen für eine selektive Krebstherapie befindet; ein Beispiel für einen quartärnisierten TrimethylaminoethanolSubstituenten ist das Phospholipid Miltefosin (137, s.Abbildung 77). 


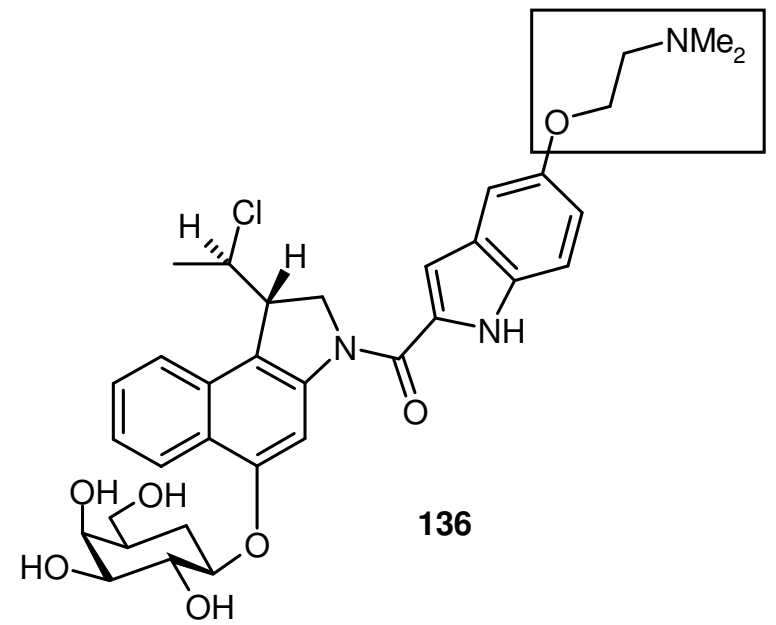

Abbildung 76. Wasserlösliches gylcosidisches Duocarmycin-Analogon (136).

Des Weiteren wurde die cytostatische und cytotoxische Wirkung der $R$ - und $S$-Enantiomere des Cinnamoylphosphoramids (21) auf das Wachstum von verschiedenen Tumorzelllinien in vitro vergleichend untersucht. Die Untersuchungen wurden in der Arbeitsgruppe von Prof. W. Beil an der Medizinischen Hochschule (MH Hannover) mit den Tumorzelllinien AGS (Magenadenokarzinom), HepG2 (Leberkarzinom) und MCF 7 (Mammakarzinom) durchgeführt. $^{139}$

Tabelle 8. Ermittelte GI50- und TGI-Werte für die $R$ - und $S$-Enantiomere. Alle Werte sind in $\mu \mathrm{g} / \mathrm{mL}$ angegeben.

\begin{tabular}{ccccccc}
\hline \multirow{2}{*}{ Substanz } & \multicolumn{2}{c}{ AGS } & \multicolumn{2}{c}{ HepG2 } & \multicolumn{2}{c}{ MCF 7 } \\
\hline & GI50 $^{*}$ & TGI $^{*}$ & GI50 & TGI $^{*}$ & GI50 $^{*}$ & TGI $^{*}$ \\
\cline { 2 - 7 }$(R)-\mathbf{2 1}$ & 0.01 & 0.065 & 0.015 & 1.0 & 0.01 & 0.026 \\
$(S)-\mathbf{2 1}$ & 0.032 & 0.09 & 0.038 & $>10^{\mathrm{a}}$ & 0.038 & 0.049
\end{tabular}

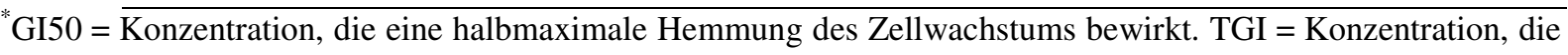
eine vollständige Hemmung des Zellwachstums bewirkt.

${ }^{\mathrm{a}}>10 \mu \mathrm{g} / \mathrm{mL}$ (90\% Hemmung mit $0.1 \mu \mathrm{g} / \mathrm{mL}$, dann keine weitere Zunahme der Hemmwirkung bis zur höchsten Konzentration.

Beide Enantiomere besitzen starke cytostatische und cytotoxische Wirkung, wobei das $(R)-\mathbf{2 1}$ etwas stärker wirksam ist, als das $(S)$-21.

Synthetisches racemisches Cinnamoylphosphoramid (21) wurde in Kooperation mit M. Kaiser (Schweizer Tropeninstitut, Basel) auf Aktivitäten gegen die Parasiten Trypanosoma brucei rhodesiense, Trypanosoma cruzi, Leishmania donovani, Plasmodium falciparum getestet. Die mit dem Parasiten L. donovani durchgeführten in vitro-Tests zeigte eine höhere Aktivität als der Standard Miltefosin (137, s. Abbildung 77), ein Phospholipid, welches unter 
dem Namen Impavido ${ }^{\circledR}$ als Arzneistoff gegen Leishmaniose auf dem Markt ist. ${ }^{140}$ Zur Verifizierung der Aktivität sollen die beiden Enantiomere $(R)$-21 und $(S)$-21 auf ihre Wirkung gegen den Erreger L. donovani untersucht werden.

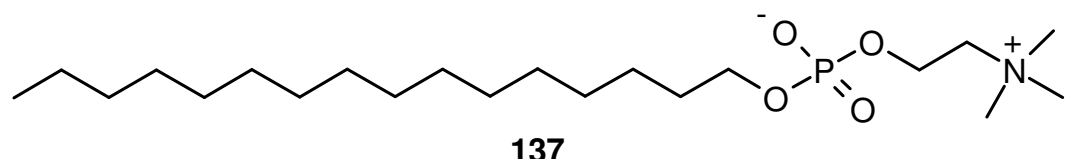

Abbildung 77. Miltefosin (137), ein Arzneistoff gegen den Erreger der Leishmaniose.

Tabelle 9. Ermittelte $\mathrm{IC}_{50}$-Werte für rac-21 und den Standard 137. Alle Werte sind in $\mu \mathrm{g} / \mathrm{mL}$ angegeben.

\begin{tabular}{cc}
\hline Substanz & L. donovani \\
\hline & $\mathrm{IC}_{50}$ \\
\cline { 2 - 2 } Miltefosin (137) & 0.206 \\
$\operatorname{rac}-\mathbf{2 1}$ & 0.111 \\
\hline
\end{tabular}

Viszerale Leishmaniose, auch bekannt als „Kala-azar“ (Schwarze Krankheit, „black fever“) gehört $\mathrm{zu}$ den weit verbreiteten Infektionskrankheiten mit hoher Todesrate. ${ }^{141}$ Nach Schätzung der Weltgesundheitsorganisation (WHO) sind zurzeit etwa 350 Millionen Menschen in 88 Ländern der Welt mit Leishmanianen infiziert. ${ }^{142}$ Leishmanianen sind Protozoen, die durch die Sand- und Schmetterlingsmücke der Gattung Phlebotomus auf Schafe, Hunde und Menschen übertragen werden. Die Leishmaniose tritt in verschiedenen Formen auf, es wird zwischen kutanen und viszeralen Formen unterschieden. Die kutane Form führt zu geschwürartigen Hautveränderungen, die in der Regel von selbst abheilen und nicht lebensbedrohlich sind. Die durch den Erreger $L$. donovani verursachte viszerale Form ist gefährlich und lebensbedrohlich, da sich die Parasiten in der Leber, Milz und im Knochenmark ausbreiten und unbehandelt innerhalb von spätestens 24 Monaten zum Tode führen. Die Behandlung erfolgte vor Markteinführung des Miltefosins (137) mit sehr giftigen Antimonverbindungen, z. B. mit Pentostam ${ }^{\circledR}$ (138, s. Abbildung 78) oder mit dem Polyen-Makrolacton aus Streptomyces nodosum Amphotericin B (139, s. Abbildung 78). 


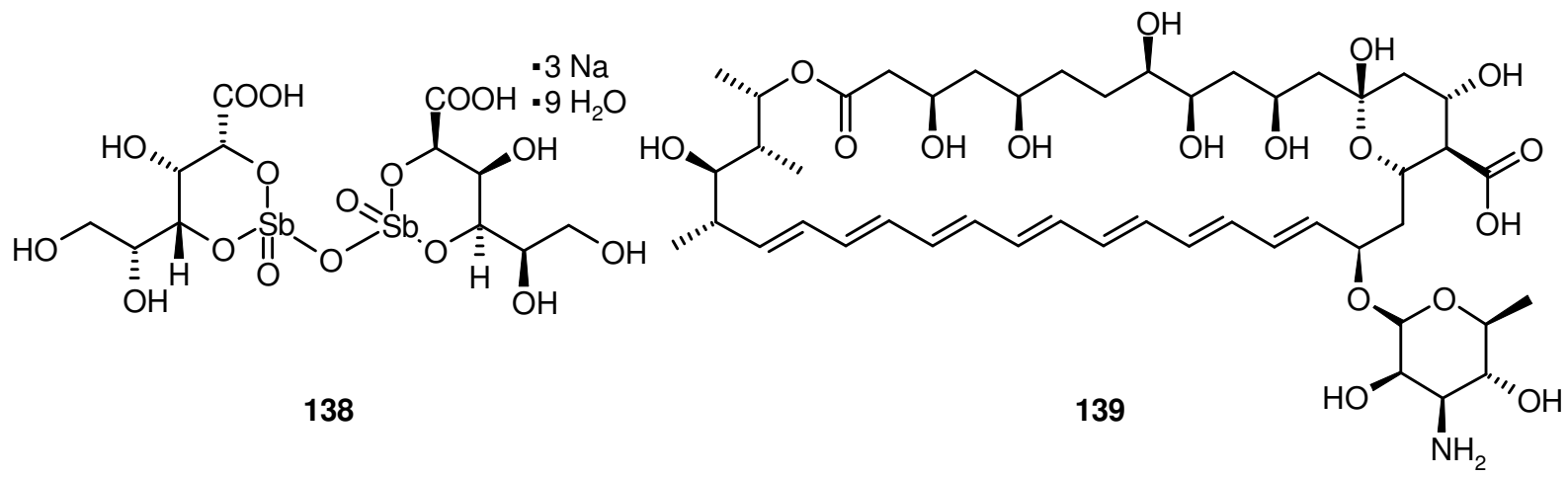

Abbildung 78. Wirkstoffe gegen Leishmaniose.

Zunehmende Resistenzentwicklung und die aufwendige intravenöse Therapien mit Antimonverbindungen erforderten die Entwicklung eines neuen Medikaments, welches idealerweise nach Möglichkeit oral appliziert werden kann. Seit 2004 ist in Deutschland das oral wirksame Medikament Miltefosin (Impavido $\left.{ }^{\circledR}, 137\right)$ zugelassen, das von Prof. $H$. Eibl am MPI für biophysikalischen Chemie, Göttingen zusammen mit Prof. C. Unger, damals Universitätsklinikum Göttingen, heute Klinik für Tumorbiologie an der Universität Freiburg, durch Struktur-Wirkungsbeziehungen antitumoral wirksamer (Alkyl)-Lysophospholipide entdeckt und in vitro und in vivo auf seine Wirkung gegen Leishmaniose und Malaria getestet wurde. 137 wird inzwischen auch erfolgreich bei der Bekämpfung von Hautmetastasen bei Brustkrebs eingesetzt. ${ }^{141}$

Synthetisches und natives Cinnamoylphosphoramid (21) wurden im Plattendiffusionstest auf antibakterielle und antimykotische Wirkung geprüft. Als Testkeime dienten Bacillus subtilis, Staphylococcus aureus, Escherichia coli und Candida albicans. Hierbei zeigte die Verbindung 21 keine hemmende Wirkung. Das ist ein hervorragender Hinweis, dass 21 nicht allgemein cytotoxische Wirkung hat, also weniger Nebenwirkungen im gerichteten Einsatz haben könnte.

\section{Spirotetronate (22)}

Spirotetronate gehören zu einer Klasse von Naturstoffen, die eine Bandbreite an biologischen Aktivitäten aufweist und die antibakterielle, antivirale und cytostatische Eigenschaften ${ }^{143}$, aber auch Aktivitäten als Anti-Malariamittel wie das Kijanimicin (107) oder als Cholesterinsenker wie das Chlorothricin (105) ${ }^{144}$ umfasst. Für die erstmals Anfang der 90er Jahre aus Streptomyces sp. PA-46101 isolierten Spirotetronate (22) wurde eine mäßige bis schwache 
antibiotische Wirkung gegen anerobe und aerobe Gram-positive und Gram-negative Bakterien beschrieben. ${ }^{98}$

Beide Spirotetronate wurden im Plattendiffusionstest auf antibakterielle und antimykotische Wirkung untersucht. Als Testkeime dienten Bacillus subtilis, Staphylococcus aureus, Escherichia coli und Candida albicans. Lediglich gegen B. subtilis zeigten beide Substanzen eine mäßige antibiotische Wirkung.

Des Weiteren wurde das Spirotetronat (22a) in der Arbeitsgruppe von Prof. W. Beil an der Medizinischen Hochschule (MH Hannover) auf seine cytotoxische und cytostatische Wirkung gegen die Tumorzelllininen AGS (Magenadenokarzinom), HepG2 (Leberkarzinom) und MCF 7 (Mammakarzinom) untersucht. ${ }^{139}$ Allerdings wurden in vitro nur sehr geringe Aktivitäten gegen die Krebszelllinien beobachtet.

Tabelle 10. Ermittelte $\mathrm{GI}_{50^{-}}$und TGI-Werte für 22a. Alle Werte sind in $\mu \mathrm{g} / \mathrm{mL}$ angegeben.

\begin{tabular}{ccccccc}
\hline \multirow{2}{*}{ Substanz } & \multicolumn{2}{c}{ AGS } & \multicolumn{2}{c}{ HepG2 } & \multicolumn{2}{c}{ MCF 7 } \\
\hline \multirow{2}{*}{$22 \mathbf{a}$} & $\mathrm{GI}_{50}{ }^{*}$ & $\mathrm{TGI}^{*}$ & $\mathrm{GI}_{50}{ }^{*}$ & $\mathrm{TGI}^{*}$ & $\mathrm{GI}_{50}{ }^{*}$ & TGI $^{*}$ \\
\cline { 2 - 7 } & 5.0 & $>10^{\mathrm{a}}$ & $>10^{\mathrm{b}}$ & $>10$ & 2.5 & $>10^{\mathrm{c}}$
\end{tabular}

*GI50 = Konzentration, die eine halbmaximale Hemmung des Zellwachstums bewirkt. TGI = Konzentration, die eine vollständige Hemmung des Zellwachstums bewirkt.

${ }^{\mathrm{a}}>10 \mu \mathrm{g} / \mathrm{mL}(83 \%$ Hemmung bei $10 \mu \mathrm{g} / \mathrm{mL}) ;{ }^{b}>10 \mu \mathrm{g} / \mathrm{mL}(38 \%$ Hemmung bei $10 \mu \mathrm{g} / \mathrm{mL}) ;{ }^{\mathrm{c}}>10 \mu \mathrm{g} / \mathrm{mL}$ (70\% Hemmung bei $10 \mu \mathrm{g} / \mathrm{mL}$ ).

\section{Rosiridol (23)}

Der Extrakt aus dem Wurzelstock des Rosenwurzes (Rhodiola rosea) wird besonders in Russland und Skandinavien seit Jahrhunderten als traditionelles Arzneimittel verwendet. Es wird eine Kraft und Ausdauer fördernde sowie die körperliche und geistige Leistungsfähigkeit bei Erschöpfung und Schwächezuständen steigernde Wirkung zugeschrieben. Außerdem soll er bei Potenzstörungen und im Klimakterium helfen. Im Volksmund wird der Rosenwurz auch als „Goldene Wurzel“ bezeichnet. Die adaptogene Wirkung wird auf die Substanzen Rosin (140), Rosiridin (141) und Salidrosid (142) zurückgeführt. Das glykosidierte Terpen Rosiridin (141) macht über $3 \%$ der Trockenmasse des Extaktes aus (s. Abbildung 79). ${ }^{145}$ Bisher konnte für das Monoterpen Rosiridol (23) noch kein Beitrag zur biologischen Wirkung des Extraktes gefunden werden. 
<smiles>OCC1OC(OCC=Cc2ccccc2)C(O)C(O)C1O</smiles><smiles>OCC1OC(OCCc2ccc(O)cc2)C(O)C(O)C1O</smiles>

142<smiles>CC(C)=CC/C(O)=C(\C)CCOC(O)C1OC(CO)C(O)C(O)C1C</smiles>

141<smiles>CC(C)=CC[C@@H](O)/C(C)=C/CO</smiles>

Abbildung 79. Wirkstoffe mit adaptogener Wirkung und Rosiridol (23) aus Rhodiola rosea.

23 wurde im Plattendiffusionstest auf antibakterielle und antimykotische Wirkung geprüft Als Testkeime dienten Bacillus subtilis, Staphylococcus aureus, Escherichia coli und Candida albicans. Hierbei zeigte die Verbindung 23 keine hemmende Wirkung.

\subsubsection{Ausblick}

\section{Biologische Funktion der Metaboliten}

Das ungewöhnliche Cinnamoylphosphoramid (21) und das bisher nur als Pflanzeninhaltsstoff bekannte Rosiridol (23) führen zur Frage, welche biologischen Funktionen diese Metaboliten für den Produzenten Streptomyces sp. JP90 oder die Tunikate als Habitat des Streptomyces sp. JP90 haben. Bisherige Untersuchungen zur möglichen Funktion von 21 als aktiviertes Biosynthese-Intermediat mit Hilfe von Fütterungsexperimenten potentieller Vorläufer konnten jedoch keine Hinweise hierfür erbringen. Ob die strukturelle Ähnlichkeit zu Organophosphaten eine Bedeutung für die Tunikate hat, ist eine interessante Fragestellung, die es noch zu erforschen gilt. Bisherige Untersuchungen zur biologischen Aktivität des de novo in ausreichenden Mengen erfolgreich hergestellten Cinnamoylphosphoramids (21) zeigen, das Naturstoffe aus marinen Habitaten ein attraktives Potential zukünftiger Leitstrukturen darstellen. Insbesondere die Aktivität gegen Leishmania donovani ist hier hervorzuheben.

Die Isolierung des Rosiridols (23) als bekannter Pflanzeninhaltsstoff aus Bakterien, führt zu der Vermutung, dass nicht die Pflanze, sondern möglicherweise ein Bakterium der eigentliche Produzent dieses Sekundärstoffs sein könnte. Zurzeit werden in der Arbeitsgruppe Prof. D. Ober (Universität Kiel) die Samen der Rhodiola rosea, aus deren Wurzeln bisher der Metabolit 23 gewonnen wurde, unter sterilen Bedingungen angezogen, um zu untersuchen, ob bakterienfreie Pflanzen das Rosiridol (23) produzieren. Sollte 23 auch aus diesen Pflanzen isoliert werden, soll neben der Biosynthese des Rosiridols (23) in der Pflanze auch die Frage- 
stellung, warum Bakterien und Pflanzen dieselbe Struktur biosynthetisieren, näher erforscht werden.

\subsection{Der Produzent Streptomyces sp. Pol001}

In der Arbeitsgruppe von Prof. U. Hentschel (Universität Würzburg) wurden Streptomyceten aus verschiedenen marinen Schwämmen isoliert und von M. Scheuermayer ${ }^{30}$ in einem funktionsbasierten Screening auf ihre Produktion antimikrobiell wirksamer Sekundärstoffe untersucht. Hierzu wurden mit Streptomyceten bewachsene Agarplatten mit den jeweiligen Teststämmen, Staphylococcus aureus, Escherichia coli und Candida albicans überschichtet. Nach Inkubation bei $30^{\circ} \mathrm{C}$ bzw. $37^{\circ} \mathrm{C}$ über Nacht wurden die Platten auf die Bildung von Hemmhöfen untersucht. Der Stamm Streptomyces Pol001 aus dem marinen Schwamm Axinella polypoides zeigte bei diesem funktionsbasierten Screening eine hemmende Wirkung gegen das Gram-positive Bakterium S. aureus. Zur Untersuchung dieser antimikrobiellen Aktivität wurden im Rahmen der Dissertation von M. Scheuermayer ${ }^{30}$ erste Kultivierungsarbeiten mit dem Stamm Pol001 durchgeführt. Hierbei konnten aus dem Ethylacetatextrakt einer Festphasenkultivierung des Stammes Pol001 in Kooperation mit der Arbeitsgruppe von Prof. G. Bringmann (Universität Würzburg) mittels HPLC vier Substanzen isoliert werden. Diese Reinsubstanzen zeigten unterschiedlich starke wachstumshemmende Wirkung gegen S. aureus WT und konnten als Tetromycine, die zur Klasse der Spirotetronate gehören, identifiziert werden. Die Tetromycine C, zu deren Substanzfamilie die isolierten Verbindungen gehören, sind in der Literatur als Wirkstoffe mit antibiotischer Aktivität u. a. gegenüber

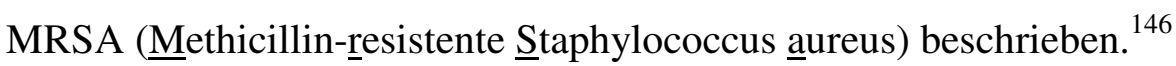

Des Weiteren wurden beim Stamm Pol001 im Rahmen eines genetischen Screenings Gene einer $\mathrm{FADH}_{2}$-abhängigen Halogenase mit Hilfe von PCR und degenerierten Primern identifiziert. $\mathrm{FADH}_{2}$-abhängige Halogenasen sind Enzyme, die an der Modifizierung von Sekundärmetaboliten aus verschiedenen Actinomycetenstämmen durch Einführung eines oder mehrerer Halogenatome in diverse Phenol- und Pyrrol-Einheiten von Naturstoffen beteiligt sind. ${ }^{147}$ Die Bedeutung dieser Enzyme bei der Erschaffung struktureller Diversität wird durch die Anzahl von bisher 4000 bekannten chlor-, oder bromsubstituierten Naturstoffen verschiedenster Naturstoffklassen deutlich ${ }^{148}$, außerdem spielt die Halogenierung bei der biologischen Aktivität von Naturstoffen eine wichtige Rolle. ${ }^{149}$ Für das genetische Screening bietet die Suche nach Sequenzhomologien zu solchen Enzymen auch einen großen Vorteil. Auch bei der massenspektrometrischen Analytik des Metabolitenspektrums von Bakterienstämmen ist eine Halogensubstitution günstig. Halogenierte Naturstoffe können in der Massenspektro- 
metrie nämlich anhand eines charakteristischen Isotopenmusters erkannt werden, welches durch seine Isotopenverteilung zusätzlich eine Aussage bezüglich der Art und der Anzahl des Halogensubstituenten ermöglicht. Somit sollte ein genetisch und chemisch-analytisch geleiteter Ansatz in der Regel eine schnelle Überprüfung des Metabolitenspektrums hinsichtlich der Produktion eines halogenierten Naturstoffs erlauben.

Im Rahmen der Dissertation von M. Scheuermayer ${ }^{30}$ konnte gezeigt werden, dass die im Streptomyces sp. Pol001 nachgewiesene $\mathrm{FADH}_{2}$-abhängige Halogenase der Gruppe von Halogenasen zuzuordnen ist, die an der Biosynthese von Glykopeptiden wie Vancomycin (1, Abbildung 1) beteiligt sind. Basierend auf diesem Ergebnis wurde eine Genbank von Pol001 erstellt und auf Sekundärmetabolit-Operons durchgemustert. Hierbei wurde ein neuer Glykopeptid-Biosynthesegencluster gefunden, dessen Sequenzierung und in silico Analyse auf ein strukturell neues Glykopeptid hinwiesen, welches Ähnlichkeiten zum Vancomycin (1) besitzt.

\subsubsection{Der Glykopeptid-Biosynthesegencluster}

\section{Glykopeptid-Antibiotika}

Glykopeptid-Antibiotika sind Medikamente, die bei der Bekämpfung von lebensbedrohlichen Infektionen durch multiresistente Gram-positive Bakterien wie Staphylokokken und Enterokokken eingesetzt werden. Vancomycin (1) wurde Mitte der 50er Jahre als erstes Glykopeptid aus Amycolatopsis orientalis (früher Streptomyces orientalis) isoliert und bereits 1959 erstmals klinisch eingesetzt. ${ }^{150}$

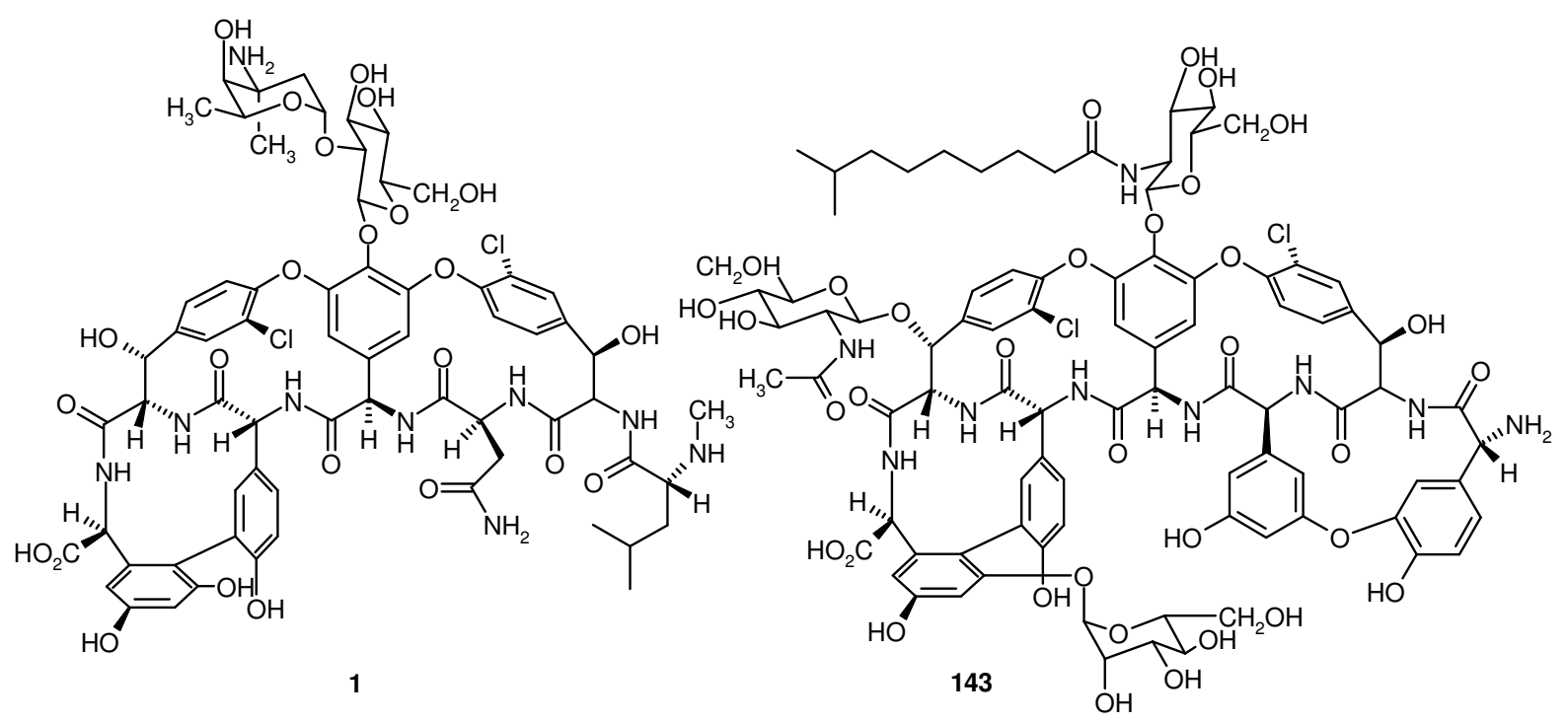

Abbildung 80. Die Glykopeptid-Antibiotika Vancomycin (1) und Teicoplanin (143).

Seitdem wurden viele verwandte Glykopeptid-Antibiotika aus Amycolatopsis- und Streptomyces- Stämmen isoliert ${ }^{151}$, wobei sich nur die Vertreter Vancomycin (1) und Teico- 
planin (143) in der klinischen Anwendung befinden (s. Abbildung 80). Die Glykopeptide werden in zwei Untergruppen unterteilt, den Vancomycin- und Teicoplanin-Typ, die beide eine Heptapeptideinheit als zentrales Strukturelement aufweisen. Die Arylseitenketten der Aminosäurenreste sind über Biarylether- bzw. Biarylbrücken miteinander verknüpft, was zu einer starren kuppelförmigen Gestalt des Peptidgerüsts führt. Das Peptidgerüst hat in beiden Verbindungen die Konfiguration D-D-L-D-D-L-L, wobei die Nummerierung am $N$-Terminus beginnt. Aus der Konfiguration und der starren kuppelförmigen Konstitution resultiert die hohe Affinität zur Ausbildung von Wasserstoffbrückenbindungen mit dem N-Acyl-D-AlaninD-Alanin-Ende des Zellwandbausteins Muropeptid, dem Target der Glykopeptide (s. Abbildung 81). ${ }^{152}$ Durch eine Quervernetzung des aus Peptidoglykansträngen aufgebauten Muropeptids erlangt die bakterielle Zellwand Gram-positiver Bakterien erst ihre mechanische Stabilität und schützt die Bakterienzelle bei Änderungen des osmotischen Drucks. Glykopeptide blockieren die Quervernetzung der Peptidoglykanstränge, indem sie das Substrat hierfür komplexieren.

Seit Ende der 80er Jahre sind Vancomycin-resistente Enterokokken (VRE) bekannt, erste Vancomycin-resistente Staphylokokken (VR-MRSA) traten ca. zehn Jahre später auf. Die Resistenz gegen Vancomycin (1) beruht auf der Biosynthese eines alternativen Muropeptids mit einem D-Alanin-D-Lactat-Ende. Diese Variation führt wie in Abbildung 81 gezeigt nur noch zur Ausbildung von vier anstatt von fünf Wasserstoffbrückenbindungen, und es treten zusätzlich elektrostatische Abstoßungskräfte auf. Hierdurch wird die Affinität des Glykopeptids zum Zellwandbaustein-Analogon (145) um den Faktor 1000 im Vergleich zum Muropeptid mit dem D-Alanin-D-Alanin-Ende (144) herabgesetzt. Für eine vergleichbare therapeutische Wirkung müsste nun 100-1000mal soviel Vancomycin (1) verabreicht werden. Damit ist Vancomycin (1) kein akzeptables Antibiotikum mehr und es bedarf neuer Antibiotika zur Bekämpfung dieser multiresistenten Erreger.

Glykopetide des Vancomycin-Typs enthalten fünf aromatische Aminosäurereste, darunter $\beta$ Hydroxytyrosin in Position 2 und 6, sowie die nichtproteinogenen Aminosäuren 4-Hydroxyphenylglycin (Hpg) in Position 4 und 5 und 3,5-Dihydroxyphenylglycin (Dpg) in Position 7. Bei den zwei weiteren Aminosäuren handelt es sich um Leucin in Position 1 und Asparagin in Position 3. 

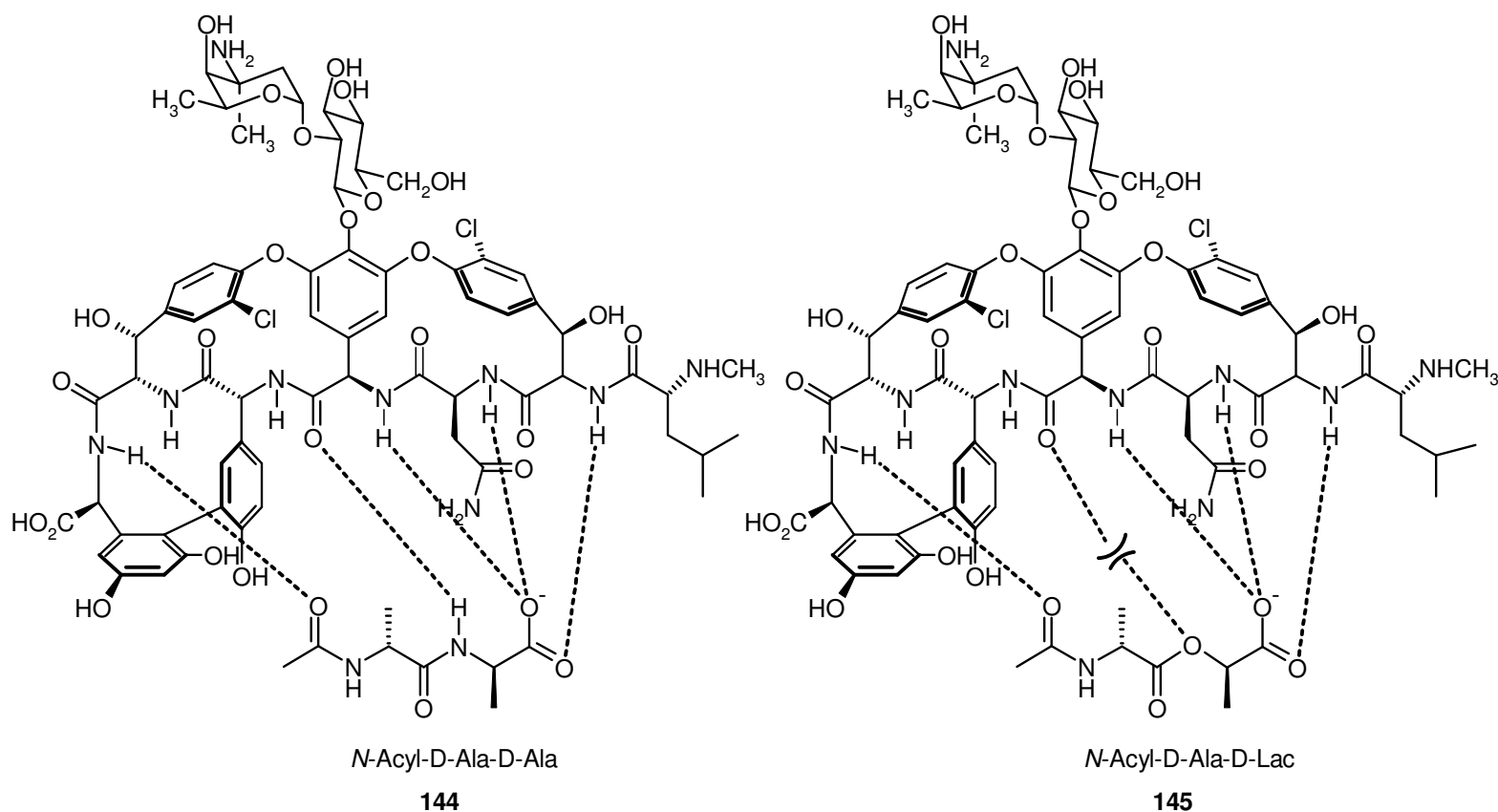

Abbildung 81. Wasserstoffbrückenbindungen bei der Wechselwirkung von Vancomycin (1) mit $N$-Acyl-DAlanin-D-Alanin (144) und mit $N$-Acyl-D-Alanin-D-Lactat (145).

Dahingegen weist der Teicoplanin-Typ sieben aromatische Reste auf, wobei anstelle der aliphatischen Aminosäuren die nichtproteinogenen Aminosäuren 4-Hydroxyphenylglycin (Hpg) in Position 1 und 3,5-Dihydroxyphenylglycin (DPG) in Position 3 auftreten. Im Unterschied zum Vancomycin-Typ ist die aromatische Aminosäure in Position 2 nicht $\beta$-Hydroxytyrosin, sondern Tyrosin. Darum hat Vancomycin drei oxidativ geknüpfte Querverbindungen zwischen den Arylseitenketten 2-4, 4-6 und 5-7, während in Teicoplanin zwischen den zusätzliche Arylseitenketten in Position 1 und 3 eine weitere Biaryletherbrücke auftritt. Die Vielzahl der Glykopeptid-Antibiotika unterscheiden sich in den weiteren Modifikationen des Peptidgerüsts, wie Chlorsubstituenten an den aromatischen Resten 2 und/oder 6, eine $\beta$ Hydroxygruppe an den Resten 2 und 6 und diversen Zuckerbausteinen an den Seitenketten in Position 4, 6, 7. Die Kombination dieser Modifikationen ist dafür verantwortlich, in welchem Maße die einzelnen Glykopeptide eine antibiotische Wirkung zeigen. ${ }^{152}$

\section{Bekanntes zur Biosynthese von Glykopeptiden}

Für die Erzeugung neuer Glykopeptid-Analoga mit Hilfe kombinatorischer Biosynthese ist ein Verständnis auf genetischer und struktureller Ebene erforderlich. In den letzten Jahren gab es auf diesem Forschungsgebiet beachtliche Fortschritte mit Hilfe von Kombinationen aus molekulargenetischen, biochemischen und chemischen Methoden. Bisherige Untersuchungen der Glykopeptid-Biosynthesegencluster, beispielsweise von Balhimycin (146) oder Chloro- 
eremomycin (147) (s. Abbildung 82), beides Glykopeptide des Vancomycin-Typs, lieferten Informationen über die Art und Reihenfolge der Biosyntheseschritte: Nach Synthese der Aminosäurebausteine verknüpfen nicht-ribosomale Peptidsynthetasen (NRPS) insgesamt sieben Aminosäuren zu einem linearen Peptidgerüst. ${ }^{152,153}$ Die aromatischen Aminosäurereste werden durch P450-Monooxygenasen in einer definierten Reihenfolge verbrückt ${ }^{154,155}$ und im Anschluss das Heptapeptidgerüst weiter modifiziert, dazu gehören Chlorierung, Methylierung und Glykosidierung. ${ }^{156}$

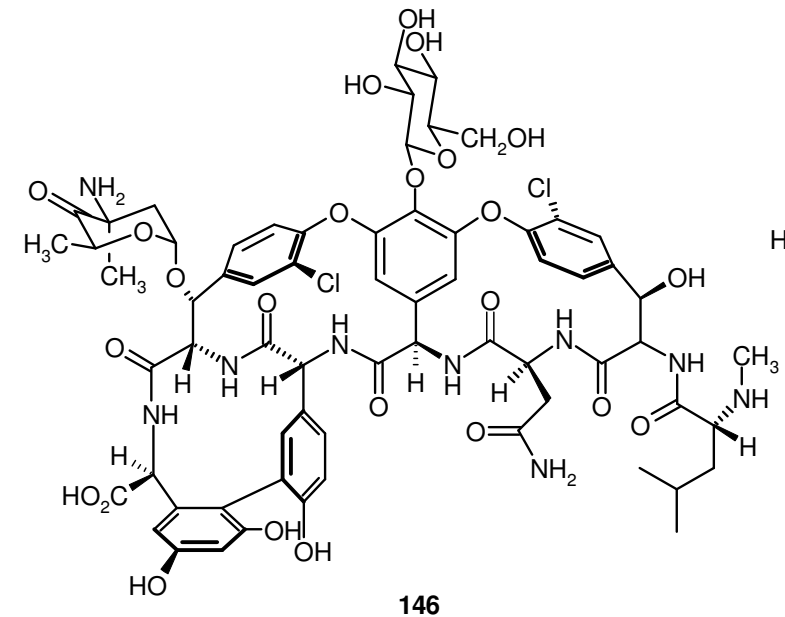

146

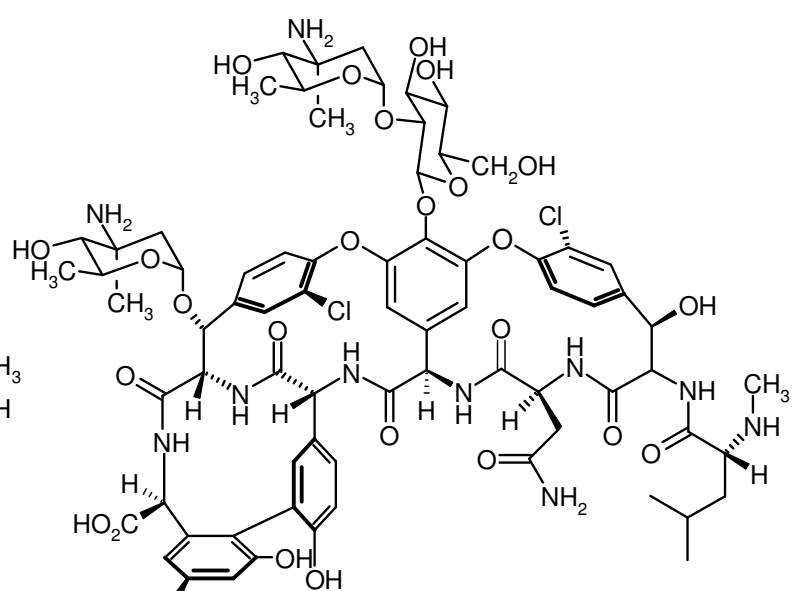

147

Abbildung 82. Strukturen der Glykopeptide Balhimycin (146) und Chloroeremomycin (147).

In allen Glykopeptiden ist an jeder oxidativen Verknüpfung ein 4-Hydroxyphenylglycin-Rest (Hpg) beteiligt, so dass diese Aminosäure für den Aufbau des Glykopeptids notwendig ist. Durch Fütterungsexperimente mit ${ }^{13} \mathrm{C}$-markiertem Tyrosin konnte gezeigt werden, dass die nichtproteinogene Aminosäure 4-Hydroxyphenylglycin aus Tyrosin aufgebaut wird. ${ }^{157}$ Daher wurde für die Biosynthese eine direkte Umwandlung von Tyrosin zu 4-Hydroxyphenylglycin über 4-Hydroxyphenylpyruvat vorgeschlagen. Aufgrund der Untersuchungen an GlykopeptidBiosynthesegenclustern wurde diese Hypothese revidiert und angenommen, dass die Biosynthese von Hpg von Prephensäure ausgeht. ${ }^{152}$ Hierbei bildet die Prephenatdehydrogenase $(P d h)$ aus Prephenat unter Decarboxylierung 4-Hydroxyphenylprephenat, welches wiederum durch die Reduktase HmaS zu 4-Hydroxymandelsäure umgesetzt wird (s. Abbildung 83). Aus dieser wird unter Beteilung der Oxidase Hmo 4-Hydroxybenzoylformiat gebildet, das dann durch die Pyridoxalphosphat-abhängige Transaminase HpgT in Gegenwart von L-Tyrosin in 4-Hydroxyphenylglycin unter Freisetzung von 4-Hydroxyphenylpyruvat umgewandelt wird. ${ }^{152}$ Hierbei verläuft der biosynthetische Aufbau katalytisch in Bezug auf Prephenat und stöchiometrisch für L-Tyrosin ab. Da alle Hpg-Reste im Glykopeptid D-konfiguriert vorliegen, erfolgt eine in-situ-Epimerisierung am NRPS-Enzymkomplex. 


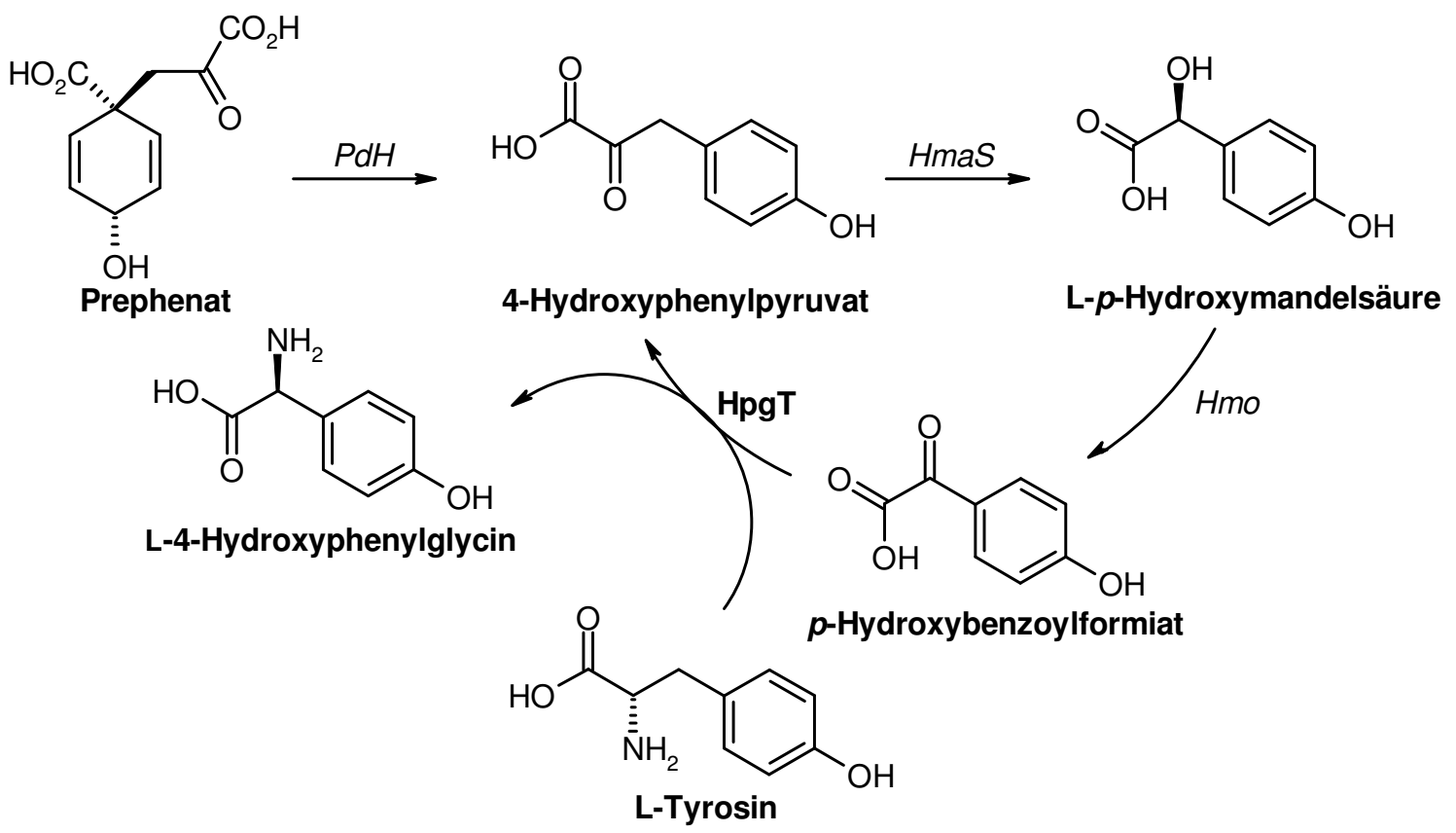

Abbildung 83. Biosynthese von L-4-Hydroxyphenylglycin ( $P d H$ : Prephenatdehydrogenase, Hmas: Reduktase, Hmo: Oxidase, HpgT: Transaminase).

Für die Biosynthese der nichtproteinogenen Aminosäure 3,5-Dihydroxyphenylglycin ergaben Fütterungsexperimente mit $\left[1,2-{ }^{13} \mathrm{C}_{2}\right]$ Acetat, dass $D p g$ über eine Polyketid-Synthase aus vier Acetat-Einheiten aufgebaut wird. ${ }^{152}$ Für die an der Biosynthese dieser Aminosäure beteiligten Enzyme $D p g A, D p g B, D p g C$ und $D p g D$ sind die Gene bisher in allen bekannten GlykopeptidBiosynthesegenclustern gefunden worden. ${ }^{158}$ Hierbei wird angenommen, dass DpgA vier Malonyl-CoA-Einheiten in ein lineares Polyketid umwandelt und an der anschließenden regioselektiven Cyclisierung beteiligt ist (s. Abbildung 84). Unter Beteiligung der Enzyme $\operatorname{DpgB}$ und $\operatorname{Dpg} D$ wird das aus der Cylisierung erhaltene Intermediat zum 3,5-Dihydroxyphenylacetyl-CoA umgewandelt. Aus diesem Intermediat wiederum wird durch $\operatorname{DpgC} 3,5$-Dihydroxyglyoxylat gebildet, welches dann durch HpgT in Gegenwart von L-Tyrosin zu 3,5-Dihyxdroxyphenylglycin transaminiert wird. 
$4 \mathrm{X}$<smiles>O=C([O-])CC(=O)[Se]O</smiles><smiles>[C+][C+]=C</smiles>

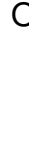<smiles>CC(=O)C=C(C)O</smiles><smiles>CCCCCCCCCCCC(=O)C(=O)O</smiles><smiles>NC(C(=O)O)c1cc(O)cc(O)c1</smiles>

3,5-Dihydroxyphenylglycin

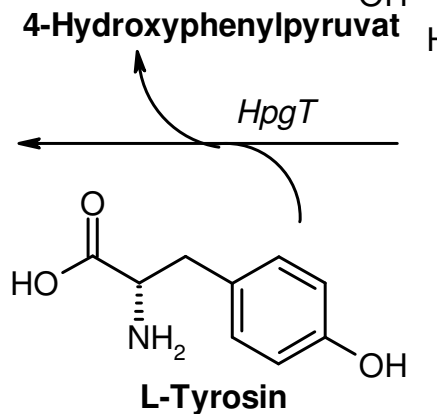<smiles>O=C(O)c1cc(O)cc(O)c1</smiles><smiles>O=C(Cc1cc(O)cc(O)c1)SCCCO</smiles>

3,5-Dihydroxyphenylacetyl-CoA

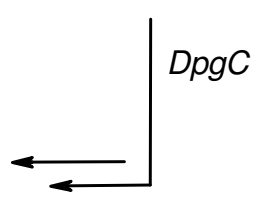

Abbildung 84. Biosynthese von L-3,5-Dihydroxyphenylglyin.

\section{Strukturvorschlag des Glykopeptids aus Streptomyces Pol001}

Die Arbeiten zur Erstellung und Durchmusterung einer Genbank aus Pol001 auf Sekundärmetabolitbiosynthesegene führte im Rahmen der Dissertation von M.Scheuermayer ${ }^{30}$ zur Beschreibung eines neuen Glykopeptid-Biosynthesegenclusters. Die Sequenzierung und in silico Analyse weist auf ein strukturell neues Glykopeptid hin, welches Ähnlichkeit um Vancomycin (1) besitzt. Bei dem aus den erhaltenen Geninformationen abgeleiteten Glykopeptid würde es sich um das erste des Vancomycin-Typs handeln, welches eine oder mehrere Sulfatgruppe(n) trägt (s. Abbildung 85).

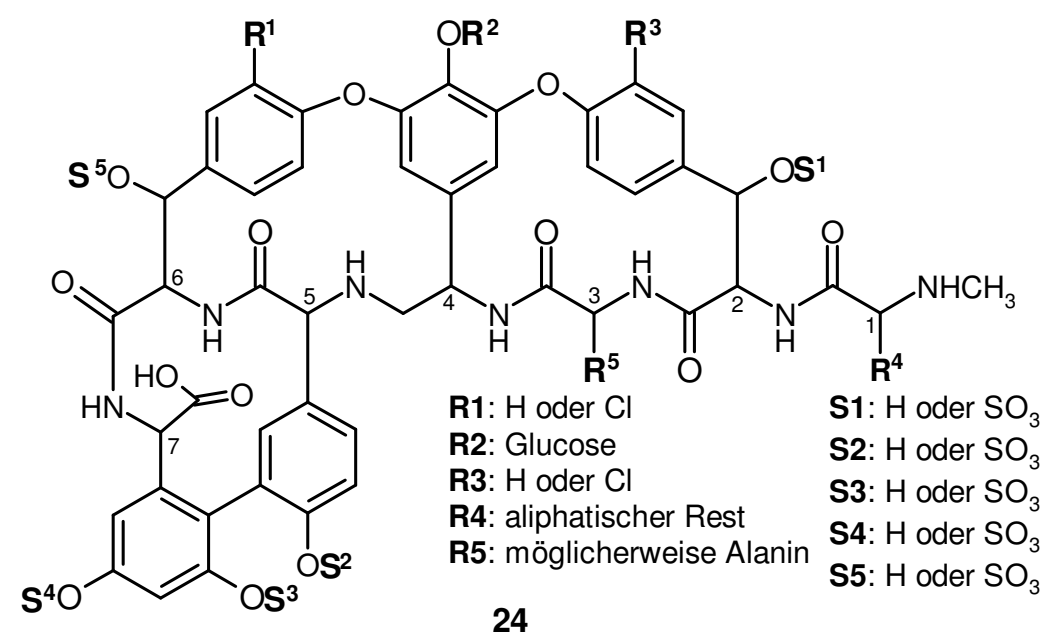

Abbildung 85. Vermutliche Strukturen des Glykopeptids aus Pol001. 
Im Stamm Streptomyces Pol001-Biosynthesegencluster fehlt jeweils ein Gen für die Bildung der Vorstufen von den nichtproteinogenen Aminosäuren 4-Hydroxyphenylglycin und 3,5-Dihydroxyphenylglycin, die in allen anderen bekannten Glykopeptid-Biosynthesegenclustern beschrieben sind. ${ }^{30}$ Es konnte im Biosynthesegencluster kein Gen gefunden werden, das die Prephenatdehydrogenase ( $P d h)$ kodiert (s. Abbildung 83). Allerdings sind Homologe zu Pdh mit dem Shikimatstoffwechsel assoziiert, so dass es auch im Primärstoffwechsel zur Bildung von 4-Hydroxyphenylpyruvat kommt, welches möglicherweise als Vorstufe für das 4-Hydroxyphenylglycin eingesetzt werden könnte. Damit sollte die Biosynthese des 4-Hydroxyphenylglycin trotz fehlender Prephenatdehydrogenase prinzipiell möglich sein. ${ }^{30}$ Für die Darstellung der anderen nichtproteinogenen Aminosäure 3,5-Dihydroxyphenylglycin fehlt ein Homologon des Gens DpgD (s. Abbildung 84). Die Funktion der einzelnen DpgGene aus A. balhimycina wurde bereits von Wohlleben et al. schon näher untersucht. ${ }^{158}$ Demnach sind den Genen $\operatorname{PpgB}$ und $\operatorname{PpgD}$ nur Hilfsfunktionen zuzuordnen, so dass die Biosynthese des 3,5-Dihydroxyphenylglycin auch ohne dieses Gen ablaufen sollte. ${ }^{30}$

Für die Vorhersage der Aminosäuren in Position 1 und 3 des Strukturvorschlags 24, aus denen sich das Heptapeptidgerüst aufbaut, konnte anhand der gesammelten Daten keine eindeutige Aussage erfolgen. Es konnte lediglich abgeleitet werden, dass es sich hierbei um zwei aliphatische Aminosäuren handelt, möglicherweise Alanin in Position 3. Da sich im Teicoplanin-Typ an diesen Positionen aromatische Aminosäurereste befinden, erhöht dieses Resultat die Ähnlichkeit zum Vancomycin-Typ. Des Weiteren sind im Gencluster von Stamm Pol001 drei homologe Gene lokalisiert worden, die Ähnlichkeiten zu Oxygenasen aufweisen, die an der Verknüpfung der Aminosäurereste 2-4, 4-6 und 5-7 in Glykopeptiden des Vancomycin-Typs beteiligt sind.

Das Heptapeptidgerüst von Glykopeptiden trägt verschiedene weitere Modifikationen, bei denen es sich meistens um Glykosylierung, Chlorierung und Methylierung des Peptids handelt. Für das Glykosylierungsmuster konnte im Stamm Pol001 nur ein Gen identifiziert werden, das Sequenzähnlichkeiten zu einem Enzym im Balhimycin-Gencluster aufweist. Dieses Enzym ist für die Übertragung eines Glucoserestes auf 4-Hydroxyphenylglycin in Position 4 des Heptapeptids verantwortlich. Da keine weiteren Homologen $\mathrm{zu}$ anderen Glykosyltransferasen gefunden wurden, wird angenommen, dass das Glykopeptid aus Pol001 nur einen Glucoserest an Aminosäureposition 4 aufweist. ${ }^{30}$ Über die Präsenz einer FADH $_{2}-$ abhängigen Halogenase konnte der vorliegende Biosynthesegencluster mit Hilfe von PCR und degenerierten Primern im Stamm Pol001 identifiziert werden. Es ist ein Homologon des Enzyms, welches in allen bekannten Glykopeptidgenclustern Chlorsubstituenten einführt. 
Weiterhin wurde ein Homologon der $N$-Methyltransferase gefunden, die zum Beispiel bei der Biosynthese von Balhimycin (146) eine Methylgruppe auf die Aminofunktion der Aminosäure in Position 1, Leucin, überträgt. Außerdem konnte ein Sulfotransferasegen abgeleitet werden, zu dem nur im Biosynthesegencluster von A47934 (149) ein sehr ähnliches Gen gefunden wurde, das eine Sulfatgruppe auf die Aminosäure in Position 1 überträgt. Bisher werden in der Literatur nur drei Glykopeptide des Teicoplanin-Typs beschrieben, die zusätzlich Sulfatgruppen tragen, A47934 (148) ${ }^{159}$ aus Streptomyces toyocaensis, UK69542-A (149) $^{160}$ aus Saccharothrix aerocolonigenes und UK68597 (150) $)^{161}$ aus Actinoplanes sp.. Damit wäre das vorhergesagte Glykopeptid aus Streptomyces Pol001 das erste Sulfatgruppentragende Glykopeptid des Vancomycin-Typs.
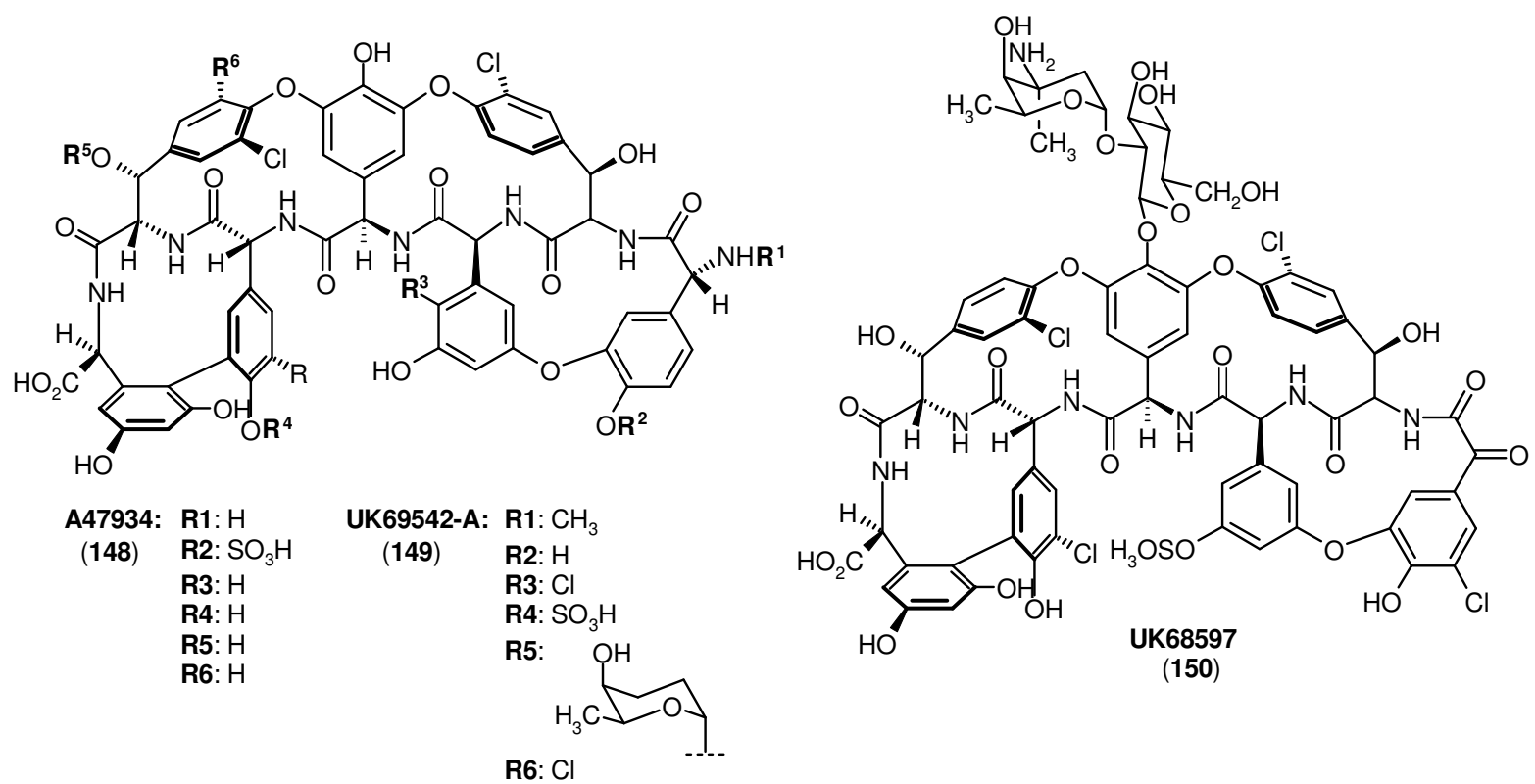

Abbildung 86. Strukturen der Glykopeptide A47934 (148), UK69542-A (149) und UK68597 (150) mit Sulfatgruppen.

\subsubsection{Analyse des Metabolitenspektrums auf Glykopeptide}

Im Rahmen der vorliegenden Arbeit sollte das Metabolitenspektrum des Stammes Streptomyces sp. Pol001 auf die Produktion des aus dem Biosynthesegencluster abgeleiteten Glykopeptids (24) untersucht werden, welches das erste Glykopeptid des Vancomycin-Typs darstellt, das mindestens eine Sulfatgruppe als Substituenten trägt (s. Abbildung 85). Die Analyse des Glykopeptid-Biosynthesegenclusters aus Pol001 offenbarte, dass für die Biosynthese der nichtproteinogenen Aminosäuren L-4-Hydroxyphenylglycin (L-Hpg) und L-3,5-Dihydroxyphenylglycin (L-Dpg) jeweils ein Gen für die Bildung der Vorstufen fehlt. ${ }^{30}$ Dennoch 
ist die Bildung des neuen Glykopeptids (24) nicht auszuschließen, allerdings könnten sich Auswirkungen auf die Produktionsgeschwindigkeit und die Produktmenge ergeben.

Mit Hilfe von Fermentationsstudien sollte untersucht werden, ob der Stamm Pol001 dieses neue Glykopeptid (24) produziert und gegebenenfalls durch Variation der Kultivierungsbedingungen und durch Fütterung von potentiellen Biosynthesevorläufern oder anderen $\mathrm{Zu}$ sätzen die Produktion des vorhergesagten Glykopeptids (24) reproduzierbar gesteigert werden kann. Außerdem sollten verschiedene Aufarbeitungs- sowie Isolierungsmethoden getestet werden, um einen effizienten Zugang für die Gewinnung des neuen Glykopeptids zu erreichen. Ferner sollte das neue Glykopeptid mittels spektrometrischer und spektroskopischer Methoden strukturaufgeklärt werden, um den aus dem Biosynthesegencluster abgeleiteten Strukturvorschlag $24 \mathrm{zu}$ verifizieren. Weiterhin sollten hierüber Aufschlüsse über die noch fehlenden Strukturinformationen hinsichtlich des Heptapeptidgerüsts und dessen Substitutionsmuster erhalten werden, um die Struktur abschließend aufzuklären.

\section{Fermentationsoptimierung und Fütterungsexperimente potentieller Vorläufer}

\section{Bekanntes zur Produktion von Glykopeptiden}

Für die Produktion von Glykopeptiden wird der jeweilige Produzent in komplexen Nährmedien kultiviert, da diese über die notwendigen Stickstoff- und Kohlenstoffquellen verfügen. Als Stickstoffquellen werden meistens Sojamehl, Pepton oder Hefeextrakt eingesetzt, während als Kohlenstoffquelle häufig Glucose, Glycerin, Stärke oder Dextrin dienen. ${ }^{162}$ Glykopeptide können nicht nur aus Fermentationsbrühen, sondern auch aus dem zurückbleibenden Zellmaterial isoliert werden, hierbei werden sie oft in geringen Ausbeuten und als Mischung von Glykopeptiden mit verschiedenen Modifizierungsgraden am Heptapeptidgerüst gewonnen. ${ }^{163}$ Glykopeptide tragen verschiedenste Zuckersubstituenten, die je nach Glykosidierungsgrad die Löslichkeit der Glykopeptide in Wasser stark erhöhen. Außerdem weisen sie je nach Art bzw. Substitutionsmuster der Aminosäurereste und des $N$-Terminus des Peptidgerüsts unterschiedliche isoelektrische Punkte auf, beispielsweise besitzt Vancomycin (1) einen $\mathrm{pH}_{\mathrm{i}}=5.0$, während das eine Sulfatgruppe tragende Glykopeptid A4739 (148) einen $\mathrm{pH}_{\mathrm{i}}=3.2$ aufweist. ${ }^{162}$ Damit ist die Strategie der Aufarbeitung und Isolierung von Glykopeptiden aus der Kulturbrühe oder aus dem Mycel von der jeweiligen Struktur abhängig, was natürlich Kenntnisse über die Struktur voraussetzt. Das neue Glykopeptid (24) aus Pol001 weist gemäß des vorhergesagten Strukturvorschlags (s. Abbildung 85) einen Zuckerbaustein an Position 4 auf, anstatt der aliphatischen Aminosäure Asparagin in Position 2 vermutlich 
Alanin, und es trägt mindestens eine Sulfatgruppe, deren Anzahl aber auch insgesamt fünf betragen könnte. Damit ist sowohl bei der Aufarbeitung als auch bei der Isolierung zu berücksichtigen, dass es sich bei dem vorhergesagten Glykopeptid (24) aufgrund mindestens einer Sulfatgruppe um eine Verbindung mit noch polareren Eigenschaften als Vancomycin (1) handeln sollte.

\section{Eigene Arbeiten zum neuen Glykopeptid (24) des Vancomycin-Typs}

Im Folgenden werden die verschiedenen Fermentationen des Stammes Pol001 zur Optimierung der Kultivierungsbedingungen beschrieben. Die einzelnen Fermentationsvarianten sind als Variante $A$ bis Variante $P$ bezeichnet. Zur Optimierung wurden verschiedene Strategien zur Produktionssteigerung untersucht: Nährmedienwechsel, Temperatur, Variation der Kultivierungsdauer, Fermentation in Schüttelkolben, P-Kolben, Fermenter sowie Festphasenkultivierung und Fütterung verschiedener Vorläufersubstanzen sowie anderer Zusätze. Weiterhin wurden die Bedingungen der Fermentation als auch die Aufarbeitungs- und Isolierungsmethoden optimiert, um einen möglichst effizienten Zugang für die Gewinnung des Glykopeptids (24) zu erreichen. Die einzelnen Aufarbeitungsmethoden sind als Variante I bis Variante VI aufgeführt.

\section{Vorarbeiten im Arbeitskreis Grond}

Im Rahmen ihrer Staatsexamensarbeit führte M. Westermann ${ }^{164}$ erste Kultivierungsarbeiten des Stammes Streptomyces sp. Pol001 in verschiedenen Nährmedien durch. Der Stamm Pol001 wurde im Rahmen der Dissertation von M. Scheuermayer ${ }^{30}$ auf antimikrobiell wirkende Sekundärmetaboliten untersucht (s. Abschnitt 4.2.1 ). Der Stamm Pol001 zeigte auf Agarplatten mit Soja-Mannit-Medium (SM-Medium) und Meerwasser-Medium (M1Medium) eine wachstumshemmende Wirkung gegenüber dem Gram-Positiven Bakterium S. aureus. Aus diesem Grund erfolgte zunächst eine Kultivierung des Streptomyces Pol001 in $1 \mathrm{~L}$ Erlenmeyerkolben mit Schikane bei $28^{\circ} \mathrm{C}$ und $180 \mathrm{U} / \mathrm{min}$ im SM-Medium mit Zusatz von Spur 11 (2.5 mL/L) und M1-Medium. Als weiteres Nährmedium wurde das komplexe Medium S unter Zusatz von Spur $11(2.5 \mathrm{~mL} / \mathrm{L})$ und Natriumchlorid (2.5 g/L) eingesetzt (pro Ansatz: 1 L-Maßstab). Nach 96 Stunden wurde geerntet und aufgearbeitet. Die Aufarbeitung erfolgte nach Einstellung des $\mathrm{pH}$-Wertes mit $2 \mathrm{~N} \mathrm{HCl}$ auf $\mathrm{pH}=5.2$, gefolgt von einer Abtrennung des Mycels durch Filtration unter Zusatz von Celite. Das Kulturfiltrat wurde mit Ethylacetat extrahiert, das Mycel wurde verworfen. Die Rohextrakte wurden dünnschichtchromatographisch an Kieselgel und reversed-phase Kieselgel (RP-18 Kieselgel) und mittels HPLC-ESI-MS-Analyse untersucht (HPLC D, Säule A: Grom Superspher 100, RP-18, Pro- 
gramm B: $\mathrm{MeOH} / \mathrm{H}_{2} \mathrm{O}$, jeweils mit $0.05 \%$ Ameisensäure, Gradient, s. Abschnitt B 1.2 ). Allerdings konnten keine Hinweise auf die Produktion des neuen Glykopeptids (24) gewonnen werden.

\section{Variante A, Variante B und Variante $G$}

Erste Kultivierungsarbeiten und Untersuchungen der nach Extraktion mit Ethylacetat erhaltenen Kulturfiltrat-Rohextrakte von $M$. Westermann ergaben keine Hinweise auf eine Produktion des neuen Glykopeptids. Aus diesem Grund wurde zunächst die Kultivierung des Streptomyces Pol001 in $1 \mathrm{~L}$ Erlenmeyerkolben mit Schikane bei $28{ }^{\circ} \mathrm{C}$ und $180 \mathrm{U} / \mathrm{min}$ im SM-Medium (Variante A) und M1-Medium (Variante B) wiederholt (pro Ansatz: 1 L-Maßstab).

Zu einer Kultivierung (Variante $G$ ) von Pol001 in $1 \mathrm{~L}$ Schüttelkolben mit Schikane bei $28{ }^{\circ} \mathrm{C}$ und $180 \mathrm{U} / \mathrm{min}$ im SM-Medium wurden $24 \mathrm{~h}$ nach Kultivierungsbeginn $\mathrm{zu}$ je einem $1 \mathrm{~L}-$ Ansatz 5 mL Kulturbrühe einer Übernachtkultur des Bakteriums S. aureus pro Schüttelkolben hinzugefügt bzw. $5 \mathrm{~mL}$ steril filtriertes Kulturfiltrat einer weiteren Übernachtkultur des Bakteriums $S$. aureus pro Schüttelkolben hinzugegeben. Durch die Co-Kultivierung mit S. aureus wurde eine Produktionssteigerung hinsichtlich des gesuchten Glykopeptids (24) vermutet, da der Streptomyces Pol001 möglicherweise die Produktion von antibiotisch wirksamen Sekundärstoffen in Anwesenheit des Bakteriums steigern könnte.

Fortlaufend erfolgte zur Aufarbeitung aller Fermentationsansätze (Variante A bis Variante P) zunächst die Einstellung des $\mathrm{pH}-$ Wertes mit $2 \mathrm{~N} \mathrm{HCl}$ auf $\mathrm{pH}=5.0$, gefolgt von einer Abtrennung des Mycels durch Zentrifugieren unter Zusatz von Celite mit anschließender Filtration. Das Kulturfiltrat und der Rückstand (Mycel, Celite) wurden getrennt voneinander aufgearbeitet.

Nachdem sich im Rohprodukt einer Ethylacetat-Extraktion kein Hinweis auf die Produktion von 24 ergeben hatte, wurde das Kulturfiltrat der einzelnen 1 L-Ansätze gemäß der Aufarbeitungs-Variante I an Amberlite ${ }^{\circledR}$ XAD-2 adsorbiert, mit demin. Wasser gewaschen und mit Methanol eluiert. In der Literatur ${ }^{160,161}$ wird für die Isolierung der Sulfatgruppentragenden Teicoplanine UK69542-A (149) und UK68597 (150) ebenfalls der Einsatz des Adsorberharzes XAD-2 beschrieben. Nach der Extraktion mit Amberlite ${ }^{\circledR}$ XAD-2 wurden je $100 \mathrm{~mL}$ Proben des Kulturfiltrats mit Ethylacetat extrahiert. Da Glykopeptide nicht nur aus dem Kulturfiltrat sondern auch aus dem Mycel isoliert werden können, wurde der Rückstand (Mycel, Celite) zur Aufarbeitung erst mit Methanol, dann mit Aceton/Methanol extrahiert (Ultraschallbad, $30 \mathrm{~min}$ ). 
Zur dünnschichtchromatographischen Analyse aller erhaltener Rohextrakte an Kieselgel und RP-18-Kieselgel wurden verschiedene polare Laufmittelgemische getestet: Für Untersuchungen an Kieselgel wurden die Laufmittelgemische $\mathrm{CHCl}_{3} / \mathrm{MeOH} / 20 \% \mathrm{NH}_{3}$ 2:2:1 und $\mathrm{BuOH} / \mathrm{HOAc} / \mathrm{H}_{2} \mathrm{O}$ 4:1:5 eingesetzt bzw. an RP-18-Kieselgel $\mathrm{MeOH} / \mathrm{H}_{2} \mathrm{O}$ 2:1. Das Dünnschichtchromatogramm der Rohextrakte nach XAD-2-Extraktion zeigte unabhängig von Nährmedium und Co-Kultivierung fast keine, mit Anfärbereagenzien nachweisbare Sekundärstoffproduktion, während die Rohextrakte nach Ethylacetat-Extraktion für die Kultivierung im SM-Medium mit Anisaldeyhd schwarz, violett, braun oder lila anfärbende Zonen aufwies. Dagegen präsentierte das Dünnschichtchromatogramm der aus dem Mycel erhaltenen Rohextrakte für die Kultivierung im SM-Medium eine Vielzahl mit Anisaldehyd anfärbbarer Zonen, wohingegen die Kultivierung im M1-Medium auch hier eine geringere Anzahl anfärbbarer Zonen aufwies. Auch bei dieser Kultivierung ergab die dünnschichtchromatographische Analyse analog zu den Vorarbeiten keine Hinweise auf die Produktion eines Glykopeptids. Allerdings konnten im Polaritätsbereich von Vancomycin (1) eine Reihe von sehr polaren mit Anisaldeyhd rosa und grün anfärbenden Zonen detektiert werden, welche als Nährmedienbestandteile im Vergleich mit einer Nährmedienkontrolle identifiziert wurden. Da eine mögliche Überlagerung von Sekundärmetaboliten und Substanzen aus dem Nährmedium nicht ausgeschlossen werden konnte, wurden zunächst alle Rohextrakte mittels HPLC-ESI-MS analysiert (HPLC D, Säule A: Grom Superspher 100 RP-18, Programm B: $\mathrm{MeOH} / \mathrm{H}_{2} \mathrm{O}$, jeweils mit $0.05 \%$ Ameisensäure, Gradient, s. Abschnitt B 1.2 ). Allerdings konnte in keinem der Rohextrakte eine halogenierte Substanz aufgrund ihres charakteristischen Isotopenmusters nachgewiesen werden. Zur Untersuchung des Metabolitenspektrums auf mögliche überlagerte Substanzen, wurde das Mycelrohextrakt aus der Kultivierung gemäß Variante A durch Gelchromatographie an Sephadex LH-20 (Methanol) fraktioniert und die einzelnen Fraktionen dünnschichtchromatographisch an Kieselgel $\left(\mathrm{CHCl}_{3} / \mathrm{MeOH} / 20 \% \mathrm{NH}_{3}\right.$ 2:2:1) untersucht. Hierbei wurde eine mit Anisaldehyd pink anfärbbare Substanz (s. Abbildung 87, Fraktion 8) detektiert, die sowohl in ihrer Polarität als auch im Anfärbeverhalten Vancomycin (1) gleicht (s. Abbildung 87, Vancomycin (1) als Standard ganz rechts aufgetragen). Außerdem konnte diese Verbindung in der Nährmediumkontrolle nicht nachgewiesen werden. 


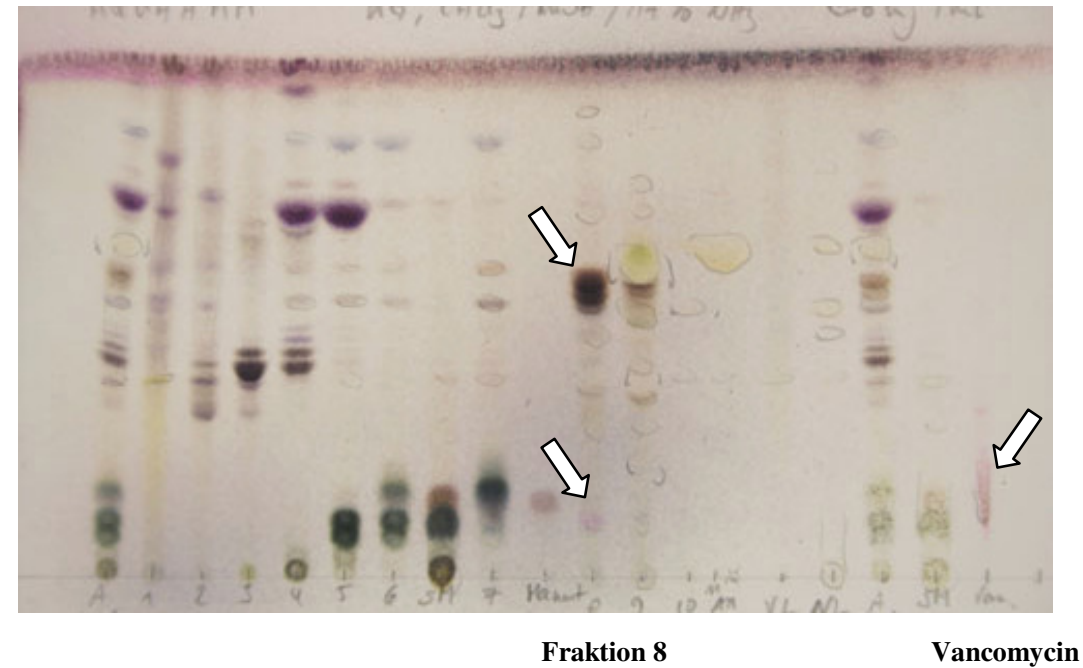

Abbildung 87. Dünnschichtchromatographische Analyse an Kieselgel $\left(\mathrm{CHCl}_{3} / \mathrm{MeOH} / 20 \% \mathrm{NH}_{3} 2: 2: 1\right)$ nach Gelchromatographie an Sephadex LH-20 (Methanol). Mit Pfeilen gekennzeichnet sind die mit Anisaldeyhd pink und braun anfärbbaren Metaboliten aus Pol001 sowie der Standard Vancomycin (1).

Da es sich bei diesem mit Anisaldehyd pink anfärbbaren Metaboliten möglicherweise um das gesuchte Glykopeptid (24) handeln könnte, wurde Fraktion 8 weiter bearbeitet. Hierbei erwies sich eine chromatographische Reinigung an RP-18-Kieselgel als nicht geeignet, wie Vorversuche in verschiedenen Laufmittelgemischen mit Aceton/Wasser und Methanol/Wasser zeigten. Durch Säulenchromatographie an Kieselgel (Aceton $/ \mathrm{H}_{2} \mathrm{O}$ 9:1) konnte zwar auch keine vollständige Reinigung der Substanz erreicht werden, aber bei einer HPLC-ESI-MSAnalyse der erhaltenen Fraktionen konnte in der zweiten Fraktion bei Retentionszeiten von $R_{\mathrm{t}}=2.20 \mathrm{~min}$ Vancomycin (1) und bei 4.75 min eine unpolarere Verbindung mit Massenaddukten bei $m / z=1448[\mathrm{M}+\mathrm{H}]^{+}$für Vancomycin (1) bzw. $1460[\mathrm{M}+\mathrm{H}]^{+}$für die unpolarere Substanz im positiven Modus detektiert werden (HPLC D, Säule A: Grom Superspher 100 RP-18, Programm B: MeOH/ $\mathrm{H}_{2} \mathrm{O}$, jeweils mit $0.05 \%$ Ameisensäure, Gradient, s. Abschnitt B 1.2 ). Beide Massenaddukte wiesen ein typisches Isotopenmuster für eine zweifach chlorsubstituierte Verbindung auf, allerdings wies diese in beiden Fällen nicht die erwartete Isotopenverteilung auf, was vermutlich auf leichte Verunreinigungen zurückgeführt werden könnte (s. Abbildung 88). ${ }^{165}$ Im negativen Modus konnten für Vancomycin (1) und die ebenfalls zweifach chlorierte Verbindung Massenpeaks bei $m / z=1446[\mathrm{M}-\mathrm{H}]^{-}$bzw. bei $m / z=1458[\mathrm{M}-\mathrm{H}]^{-}$beobachtet werden. 
A

\section{Vancomycin aus Stamm Pol001}

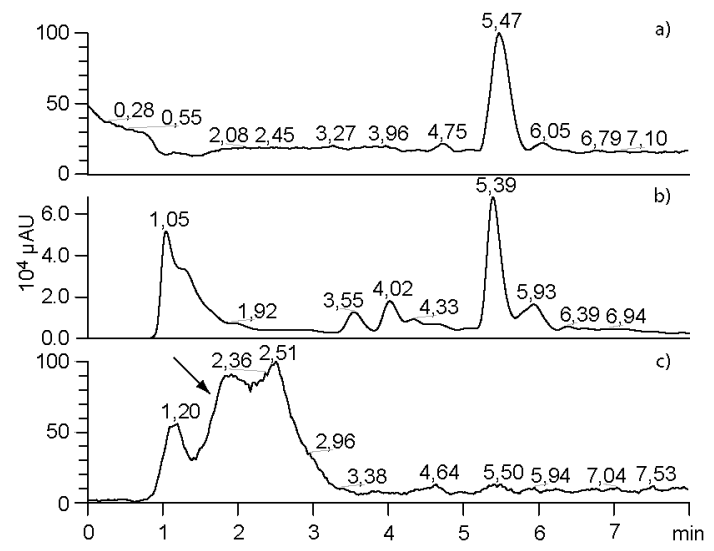

\section{Standard Vancomycin}

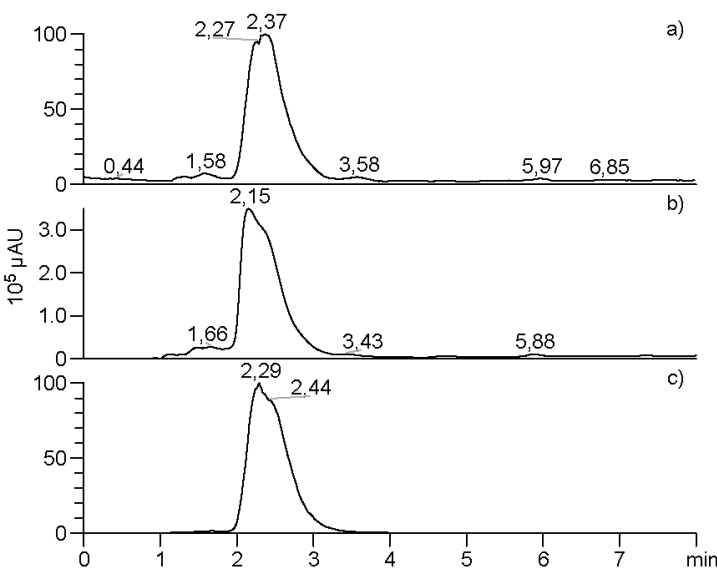

Weitere chlorsubstituierte Verbindung

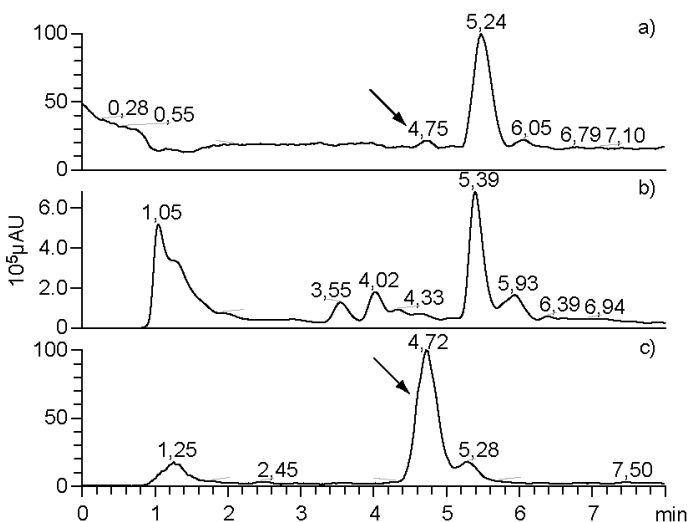

B

\section{Massenspektrum}

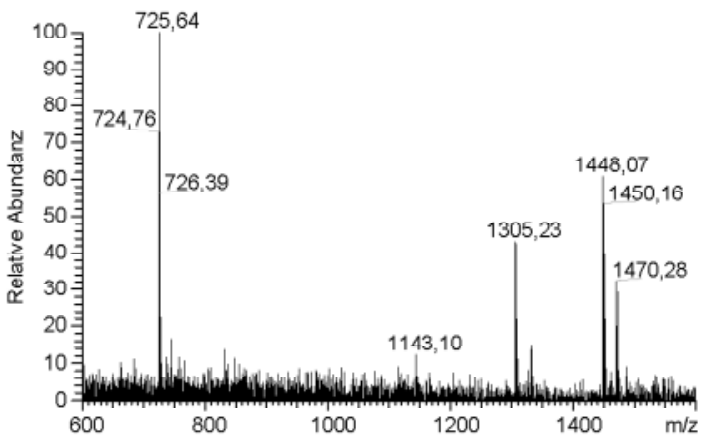

Massenspektrum

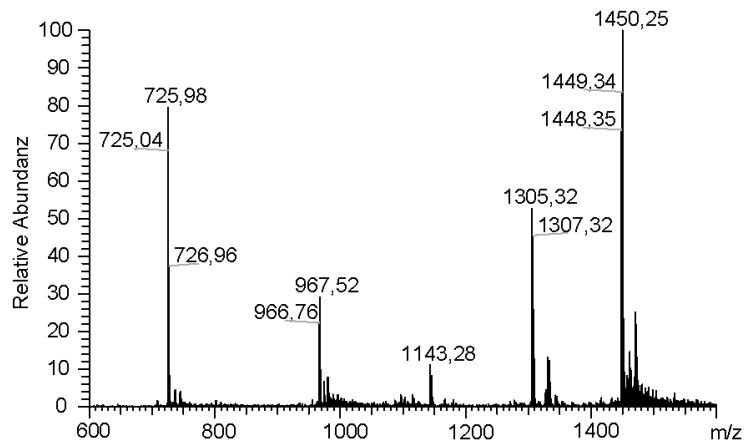

Massenspektrum

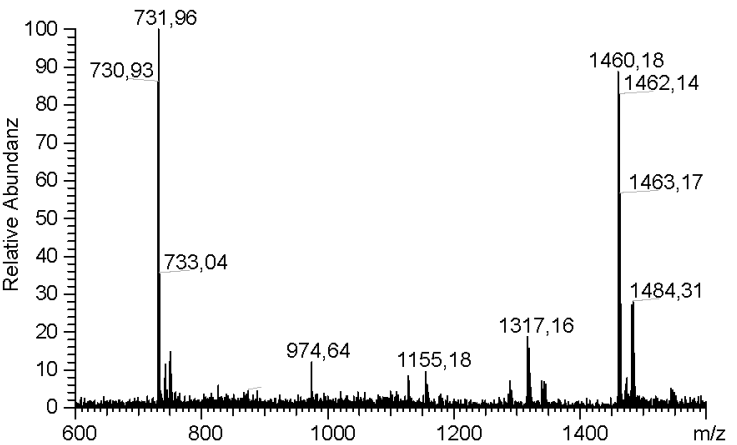

Abbildung 88. HPLC-ESI-MS-Analysen der weiter gereinigten Fraktion 8 aus Stamm Pol001 und Vancomycin (1) als Vergleich. A: HPLC-ESI-MS-Chromatogramme: a) Massenchromatogramm, b) UV-Chromatogramm bei $280 \mathrm{~nm}, \mathrm{c})$ Massenchromatogramm mit spezieller Suche von $\mathrm{m} / z=1448$ für Vancomycin aus Stamm Pol001 bei $\mathrm{R}_{\mathrm{t}}=2.20$ min und dem Standard 1 und von $\mathrm{m} / \mathrm{z}=1460$ bei $\mathrm{R}_{\mathrm{t}}=4.75 \mathrm{~min}$ für die weitere chlorsubstituierte Verbindung aus Pol001. B: Massenspektren der chlorsubstituierten Verbindungen aus Stamm Pol001 und Vancomycin (1). 
Des Weiteren zeigte die HPLC-ESI-MS-Analyse für beide Substanzen ein zusätzliches Fragmentierungsmuster auf. Beispielsweise ist der Massenverlust von 143 Da oder 305 Da auf die Abspaltung des Aminozuckers Vancosamin bzw. auch der Glucose zurückzuführen, die entsprechenden Massenionen der Produkte sind bei $m / z=1305[\mathrm{M}+\mathrm{H}]^{+}$und $1143[\mathrm{M}+\mathrm{H}]^{+} \mathrm{zu}$ beobachten. Weitere charakteristische Bruchstücke sind die Massenionen bei $\mathrm{m} / \mathrm{z}=967$ $[\mathrm{M}+\mathrm{H}]^{+}$und $725[\mathrm{M}+\mathrm{H}]^{+}$, deren Isotopenmuster nur noch die Anwesenheit eines Chloratoms in dem jeweiligen Fragment widerspiegelte. Der Einsatz von Vancomycinhydrochlorid als Standard ermöglichte im Rahmen der HPLC-ESI-MS-Analyse einen Vergleich der Retentionszeiten und des Fragmentierungsmuster und damit die Verifizierung von Vancomycin (1) in der nach Säulenchromatographie an Kieselgel erhaltenen zweiten Fraktion.

Ein ähnliches Fragmentierungsmuster kann auch für das Massenaddukt bei $\mathrm{m} / z=1460$ $[\mathrm{M}+\mathrm{H}]^{+}$beobachtet werden. Es sind Massenionen der Produkte bei $\mathrm{m} / z=1317[\mathrm{M}+\mathrm{H}]^{+}$und bei $m / z=1155[\mathrm{M}+\mathrm{H}]^{+}$vorhanden, deren Massendifferenz dem Aminozucker Vancosamin mit $m / z=143$ entsprechen könnte bzw. auf eine zusätzliche Abspaltung des Glucosezuckers mit $m / z=305$ zurückgeführt werden könnte. Außerdem entspricht das zum Massenaddukt bei $m / z=1460[\mathrm{M}+\mathrm{H}]^{+}$gehörende UV-Spektrum mit einem Maximum bei $280 \mathrm{~nm}$ den Glykopeptiden. Diese Beobachtungen lassen vermuten, dass es sich bei der unpolareren Verbindung um ein Glykopeptid des Vancomycin-Typs handeln könnte. Ob es sich hierbei jedoch um das gesuchte Glykopeptid (24) handelt, ist aufgrund des Polaritätsunterschieds zum mit Anisaldeyhd pink anfärbenden Metaboliten an Kieselgel vermutlich auszuschließen.

Die in der zweiten Fraktion auch enthaltenen, mit Anisaldeyhd braun anfärbenden Verbindungen konnten mittels HPLC-ESI-MS-Analyse den bereits im Rahmen der Dissertation von M. Scheuermayer ${ }^{30}$ identifizierten Tetromycinen zugeordnet werden (s. Abbildung 87).

Zur weiteren massenspektrometrischen Analyse des zweiten möglichen Glykopeptids mit einer Masse bei $m / z=1460[\mathrm{M}+\mathrm{H}]^{+}$wurden MS-MS-Experimente in Kooperation mit $\mathrm{Dr}$. D. Wunderlich und Dr. J. Fuchser durchgeführt. ${ }^{166}$ Eine Hochauflösung des Massenpeaks bei $m / z=732[\mathrm{M}+2 \mathrm{H}]^{2+}$ ergab einen Summenformelvorschlag mit $\mathrm{C}_{67} \mathrm{H}_{77} \mathrm{Cl}_{2} \mathrm{~N}_{9} \mathrm{O}_{24}$, der auf $N$-Methylvancomycin (151) oder Vancomycin-Methylester (152) deuten könnte, jedoch beruht diese Summenformel auf einem Massenion bei $m / z=1462[\mathrm{M}+\mathrm{H}]^{+}$, das sich mit $\mathrm{m} / \mathrm{z}=2$ vom Massenion bei $\mathrm{m} / \mathrm{z}=1459$ unterscheidet und einer zusätzlichen Reduktion bedarf, um der vorgeschlagenen Summenformel zu genügen (s. Abbildung 89). 


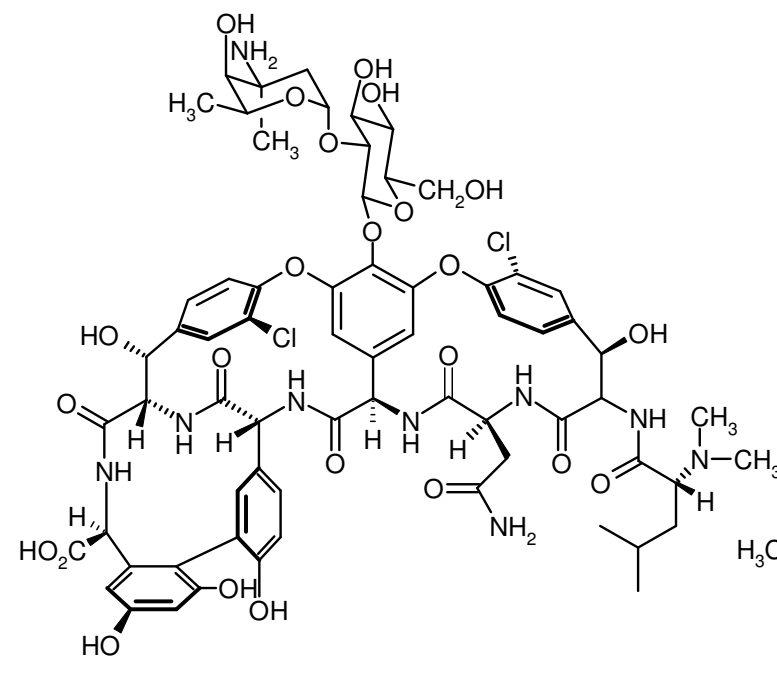

151

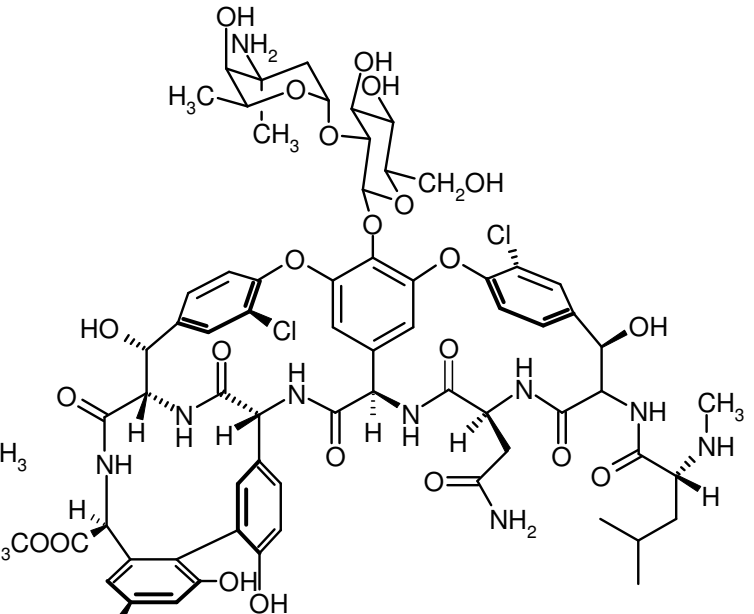

152

Abbildung 89. Strukturen von N-Methylvancomycin (151) und Vancomycinmethylester (152).

Eine im negativen Modus detektierte Massendifferenz mit $\mathrm{m} / \mathrm{z}=44$ resultiert in einem Massenaddukt bei $m / z=1414[\mathrm{M}-\mathrm{H}]^{-}$, welches der Abspaltung von Diethylamin entsprechen könnte und den Strukturvorschlag von $N$-Methylvancomycin (148) unterstützen würde. ${ }^{165} \mathrm{Im}$ Rahmen weiterer HPLC-ESI-MS-Untersuchungen konnten auch im Standard von Vancomycin (1) diese Masse von $1459 \mathrm{~g} / \mathrm{mol}$ sowohl im positiven als auch negativen Modus bei einer Retentionszeit von 5.30 min gefunden werden. Bis auf eine Retentionszeitdifferenz von $\sim 0.5$ min stimmen die beobachtete Isotopenverteilung und Fragmentierung mit der zuvor aus dem Mycelrohextrakt isolierten Verbindung überein. Diese Beobachtungen bestätigen die bisherige Annahme, dass der Stamm Pol001 neben Vancomycin (1) ein weiteres Glykopeptid des Vancomycin-Typs produziert, bei dem es sich aber nicht um das aus dem Biosynthesegencluster abgeleiteten Glykopeptid (24) handelt.

Um die Produktion des mit Anisaldehyd pink anfärbbaren, sehr polaren Metaboliten auf dessen Reproduzierbarkeit im Mycelextrakt zu überprüfen, erfolgte eine weitere Kultivierung im $1 \mathrm{~L}$ Schüttelkolben mit Schikane bei $28^{\circ} \mathrm{C}$ und $180 \mathrm{U} / \mathrm{min}$ im SM-Medium. Nach 96 Stunden wurde geerntet und wie unter Variante II beschrieben aufgearbeitet, wobei die Extraktion des Kulturfiltrats mit XAD-2 und die Extraktion des Mycels mit Methanol im Ultraschallbad erfolgten. Erst nach Fraktionierung eines Anteils des Mycelrohextraktes durch Gelchromatographie an Sephadex LH-20 (Methanol) konnte die Reproduzierbarkeit des pink anfärbbaren Metaboliten dünnschichtchromatographisch an Kieselgel $\left(\mathrm{CHCl}_{3} / \mathrm{MeOH} /\right.$ $20 \% \mathrm{NH}_{3}$ 2:2:1) bestätigt werden. Zur weiteren Reinigung der pink anfärbbaren Verbindung wurde die entsprechende Fraktion an Kieselgel (Aceton/ $\mathrm{H}_{2} \mathrm{O}$ 8:1) chromatographiert und die erhaltenen Fraktionen mittels HPLC-ESI-MS untersucht. Es konnte jedoch in keiner Fraktion 
eine chlorsubstituierte Substanz mit entsprechendem Isotopenmuster nachgewiesen werden. Für Hinweise auf die Naturstoffklasse der pink anfärbenden Verbindung folgte eine Untersuchung der Substanz mittels ${ }^{1} \mathrm{H}-\mathrm{NMR}-$ Spektroskopie in deuteriertem DMSO-d $\mathrm{d}_{6}$. Dem erhaltenen Spektrum konnten Resonanzsignale im Tief- und Hochfeld entnommen werden, eine genaue Klassifizierung war jedoch nicht möglich, da hierfür die Untersuchung einer größeren Substanzmenge nötig wäre. Auch ein Vergleich mit den ${ }^{1} \mathrm{H}-\mathrm{NMR}-$ Signalen von Vancomycin (1) zeigte keine direkte Übereinstimmung.

Die Fraktionierung der Mycelrohextrakte aus den Kultivierungen mit S. aureus an Sephadex LH-20 (Methanol) und dünnschichtchromatographische Analyse der erhaltenen Fraktionen an Kieselgel $\left(\mathrm{CHCl}_{3} / \mathrm{MeOH} / 20 \% \mathrm{NH}_{3}\right.$ 2:2:1) zeigte keine Produktionssteigerung hinsichtlich des mit Anisaldeyhd pink anfärbbaren Metaboliten. Auch konnte mittels HPLC-ESI-MS keine chlorsubstituierten Substanzen detektiert werden.

Des Weiteren wurden alle bisher erhaltenen Rohextrakte und den pink anfärbbaren Metaboliten enthaltenen Fraktionen sowie die Fraktion aus der NMR-Probe auf eine mögliche wachstumshemmende Wirkung gegenüber $S$. aureus getestet. Hierbei zeigte keiner der Rohextrakte eine antibiotische Wirkung, während alle Fraktionen, die die mit Anisaldeyhd braun anfärbenden Spirotetronate, die Tetromycine enthielten, wie erwartet eine wachstumshemmende Wirkung aufwiesen. Dieses Ergebnis bestätigte die Identifizierung der Tetromycine mittels HPLC-ESI-MS, zeigte aber auch, dass eine Verifizierung des gesuchten Glykopeptids (24) über seine mögliche biologische Aktivität in Gegenwart der Tetromycine nicht erreicht werden konnte. Damit bestand neben einer Produktionssteigerung des pink anfärbbaren Substanz die Notwendigkeit, eine bessere Isolierungsstrategie zu etablieren, um die Tetromycine getrennt von dem pink anfärbbaren Metaboliten zu erhalten.

\section{Variante $C$}

Für erste Experimente zur Produktionssteigerung des aus dem Biosynthesegencluster abgeleiteten Glykopeptids (24) wurde die Kultivierung des Stamms Pol001 als Ruhekultur in P-Kolben durchgeführt. In der Literatur ${ }^{167}$ wird zur Produktionssteigerung von Vancomycin (1) ein Dextrin-Medium bei einer Kultivierungstemperatur von $30^{\circ} \mathrm{C}$ verwendet. Da es sich beim gesuchten Glykopeptid (24) um ein Glykopeptid des Vancomycin-Typs handelt, wurde der Einfluss dieses Dextrin-Mediums ebenfalls bei erhöhter Kultivierungstemperatur auf die Produktion von 24 untersucht. Als Medium für die Vorkulturen wurde Glucose als Kohlenstoffquelle und Bactopepton, Hefe-, und Malzextrakt als Stickstoffquelle, für die Hauptkulturen wurde als Kohlenstoffquelle Dextrin und als Stickstoffquelle Sojamehl und Bactopepton eingesetzt. Die P-Kolben wurden mit $72 \mathrm{~h}$ alten Vorkulturen inokuliert, welche bei 
$30{ }^{\circ} \mathrm{C}$ und $225 \mathrm{U} / \mathrm{min}$ kultiviert worden waren, und für vier Wochen bei $30^{\circ} \mathrm{C}$ als Ruhekulturen inkubiert. Am Erntetag waren anstatt einer vollständigen Sporenschicht nur einzelne Kolonien in den Fermentationsansätzen zu erkennen. Es folgte die Aufarbeitung der Kulturen gemäß Variante III. Nachdem eine Extraktion mit XAD-2 bezüglich des dabei erhaltenen Metabolitenspektrums keine Hinweise auf den pink anfärbbaren Metaboliten ergeben hatte, wurde das Kulturfiltrat mit Ethylacetat extrahiert. Die Zellmasse wurde mit Methanol/Wasser 9:1 im Ultraschallbad für insgesamt 30 min aufgeschlossen.

Die dünnschichtchromatographische Analyse der erhaltenen Rohextrakte an Kieselgel erfolgte mit dem noch polareren Laufmittelgemisch $\mathrm{CHCl}_{3} / \mathrm{MeOH} / 20 \% \mathrm{NH}_{3}$ 1:2:1, das die Detektion des pink anfärbbaren Metaboliten bereits im Rohextrakt erlauben sollte. Da aber die Produktion dieses Metaboliten mittels Dünnschichtchromatographie nicht beobachtet werden konnte, wurde als mögliche Fehlerquelle eine $\mathrm{zu}$ geringe Luftzufuhr während der Fermentation in Betracht gezogen. Eine wiederholte Kultivierung in Schüttelkolben mit Schikane sollte Aufschlüsse hierüber geben.

Außerdem war die Stammhaltung von Pol001 am Anfang der eigenen Arbeiten von M1- auf SM-Agarplatten umgestellt worden, da dabei ein besseres Wachstum erzielt werden konnte. Allerdings konnte ein Einfluss der Sekundärstoffproduktion durch eine veränderte Stammhaltung des Streptomyces Pol001 ebenfalls nicht ausgeschlossen werden, so dass für die folgende Fermentation frisch bewachsene Agarplatten aus dem Arbeitskreis U. Hentschel verwendet wurden und im weiteren Verlauf, die Stammhaltung nur noch auf M1-Agarplatten erfolgte.

\section{Variante D}

Die Kultivierung wurde in $1 \mathrm{~L}$ Schüttelkolben mit Schikane bei $30{ }^{\circ} \mathrm{C}$ und $200 \mathrm{U} / \mathrm{min}$ mit Dextrin-Medium für 120 h durchgeführt, um eine ausreichende Luftzufuhr für eine Sekundärstoffproduktion zu gewährleisten. Die Aufarbeitung erfolgte analog zur Variante III. Allerdings zeigte die dünnschichtchromatographische Analyse der Rohextrakte an Kieselgel $\left(\mathrm{CHCl}_{3} / \mathrm{MeOH} / 20 \% \mathrm{NH}_{3}\right.$ 1:2:1) wieder keine Produktion des mit Anisaldeyhd pink anfärbbaren Metaboliten. Um eine eventuelle Überlagerung des Sekundärstoffs mit Substanzen aus dem Nährmedium auszuschließen, wurde ein Teil des Mycelrohextraktes an Sephadex LH-20 (Methanol/Wasser 2:1) fraktioniert. Aufgrund der besseren Löslichkeit des Rohextraktes in Methanol/Wasser 2:1 wurde dieses auch als Lösungsmittel für die Gelchromatographie eingesetzt. Jedoch bestätigte die Fraktionierung an Sephadex LH-20, dass der Stamm Pol001 den pink anfärbbaren Metaboliten nicht produziert hatte. Aus diesem Grund wurde die folgende Kultivierung wieder im SM-Medium bei $28^{\circ} \mathrm{C}$ und $180 \mathrm{U} / \mathrm{min}$ durchgeführt. 


\section{Variante $E$}

Die Fermentation erfolgte unter den bewährten Kultivierungsbedingungen der Variante $A$ in $1 \mathrm{~L}$ Schüttelkolben mit Schikane bei $28^{\circ} \mathrm{C}$ und $180 \mathrm{U} / \mathrm{min}$ mit $\mathrm{SM}^{*}$-Medium für $96 \mathrm{~h}$. Beim $\mathrm{SM}^{*}$-Medium wird neben Mannit als Kohlenstoff- und Sojamehl als Stickstoffquelle, Fleischextrakt als zusätzliche Stickstoffquelle verwendet. Diese Variation wurde aus Kultivierungsarbeiten zum Peptidlacton Hormaomycin entnommen, welches auch durch eine nicht-ribosomale Peptidsynthase (NRPS) produziert wird. ${ }^{168}$

Die Aufarbeitung erfolgte analog zur Variante III.

Die dünnschichtchromatographische Analyse der erhaltenen Rohextrakte an Kieselgel $\left(\mathrm{CHCl}_{3} / \mathrm{MeOH} / 20 \% \mathrm{NH}_{3}\right.$ 1:2:1) zeigte im Metabolitenspektrum von Pol001 den pink anfärbbaren Metaboliten im Mycelrohextrakt, welches anschließend durch Gelchromatographie an Sephadex LH-20 (Methanol/Wasser 2:1) fraktioniert wurde. Im Folgenden stand die Optimierung der Isolierungsmethode im Vordergrund, um eine möglichst vollständige Abtrennung der Tetromycine vom pink anfärbbaren Metaboliten zu erreichen. Eine Chromatographie an Nano Sil ${ }^{\circledR}$ Diol-Kieselgel-Aluplatten mit Methanol/Wasser 7:3 und 9:1 erwies sich als ungeeignet. Dieses Material liegt im Polaritätsbereich zwischen Kieselgel und RP-18Kieselgel. Im weiteren Verlauf wurde zunächst an Sephadex G-25 (Methanol/Wasser 1:1) fraktioniert. Dieses Material wird für eine Größentrennung von Molekülmassen ab 1000 Da MW verwendet, während Sephadex LH-20 nur einen Bereich zwischen 100-1000 Da MW abdeckt. Da Glykopeptide eine Molmasse >1000 g/mol aufweisen und die Tetromycine Molmassen von $\sim 900 \mathrm{~g} / \mathrm{mol}$ besitzen, sollte Sephadex G-25 für eine Trennung geeignet sein. Nachdem auch bei dieser Methode keine vollständige Abtrennung der Tetromycine erzielt werden konnte, folgte eine Reinigung an Kieselgel $\left(\mathrm{CHCl}_{3} / \mathrm{MeOH} / 20 \% \mathrm{NH}_{3}\right.$ 1:2:1), welche abschließend eine vollständige Abtrennung der Tetromycine gewährleistete. Die so erhaltene, noch leicht verunreinigte pink anfärbbare Verbindung zeigte im durchgeführten ${ }^{1} \mathrm{H}-\mathrm{NMR}-\mathrm{Ex}-$ periment (DMSO- $\mathrm{d}_{6}$ ) Resonanzen im Tief- und Hochfeldbereich, aber keine Signalübereinstimmung zu der nach Säulenchromatographie an Kieselgel (Aceton/ $\mathrm{H}_{2} \mathrm{O}$ 8:1) erhaltenen Substanz (s. Variante A). Eine optimierte HPLC-ESI-MS-Analyse zeigte wiederholt kein Isotopenmuster einer chlorsubstituierten Verbindung (HPLC D, Säule C: Phenomenex Synergi Hydro RP, Programm C: $\mathrm{MeOH} / \mathrm{H}_{2} \mathrm{O}$, jeweils mit $0.05 \%$ Ameisensäure, Gradient, s. Abschnitt B 1.2 ).

\section{Variante $F$}

Zur Produktionssteigerung durch Variation der Kultivierungsbedingungen wurde auch eine Festphasenkultivierung auf $\mathrm{SM}^{*}$-Agarplatten durchgeführt, welche mit je $500 \mu \mathrm{L}$ einer gut 
gewachsenen Vorkultur beimpft wurden und bei $28^{\circ} \mathrm{C}$ für $6 \mathrm{~d}$ bis zur Ausbildung einer vollständigen Sporenschicht inkubiert wurden.

Die Aufarbeitung (Variante IV) erfolgte mit Methanol/Wasser 9:1 als Extraktionslösungsmittel, um eine vollständige Extraktion aller polaren Substanzen zu gewährleisten. Für die weitere Aufarbeitung wurde das Mycelrohextrakt in Wasser aufgenommen und mittels einer Mitteldruckpumpe auf eine mit dem Adsorberharz MCI-Gel ${ }^{\circledR}$-gefüllte Säule aufgebracht. Nach Waschen mit demin. Wasser wurde anschließend mit Methanol/Wasser 1:2, Methanol/Wasser 1:1, Methanol/Wasser 2:1 und Methanol gemäß der optimierten Vorschrift (Variante VI) eluiert. Die dünnschichtchromatographische Analyse an Kieselgel $\left(\mathrm{CHCl}_{3} / \mathrm{MeOH} / 20 \% \mathrm{NH}_{3}\right.$ 1:2:1) zeigte das Vorliegen des pink anfärbbaren Metaboliten in der wässrigen Waschphase.

\section{Variante $H$}

Bisherige Fermentationsstudien zeigten, dass die Produktion des pink anfärbbaren Metaboliten in $1 \mathrm{~L}$ Schüttelkolben mit Schikane bei $28^{\circ} \mathrm{C}$ und $180 \mathrm{U} / \mathrm{min}$ mit SM- bzw. SM* Medium zwar reproduzierbar war, aber zu keiner ersichtlichen Produktionssteigerung führte. Auch eine Fermentation unter Zusatz des Bakteriums S. aureus übte keinen Einfluss auf das Metabolitenspektrum von Pol001 aus. Die Analyse des Glykopeptid-Biosynthesegenclusters aus Pol001 im Rahmen der Dissertation von M. Scheuermayer ${ }^{30}$ hatte gezeigt, dass für die Biosynthese der nichtproteinogenen Aminosäuren L-4-Hydroxyphenylglycin (L-Hpg) und L-3,5-Dihydroxyphenylglycin (L-Dpg) jeweils ein Gen für die Bildung der Vorstufen fehlt. ${ }^{30}$ Mit Hilfe von HPLC-ESI-MS-Analysen konnte die Produktion von Glykopeptiden im Pol001 anhand von chlorsubstituierten Isotopenmustern experimentell belegt werden (s. Fermentationsansatz Variante A). Damit kann Streptomyces Pol001 Glykopeptide generell in sehr geringen Mengen produzieren, so dass die Bildung des neuen Glykopeptids (24) trotz fehlender Gene nicht auszuschließen ist. Allerdings ist die Annahme, dass sich das Fehlen der Gene auf die Produktionsgeschwindigkeit und damit auf die Produktmenge auswirken könnte, aufgrund der bisherigen Ergebnisse bestätigt worden. Im Folgenden wurden zur Produktionssteigerung hinsichtlich des gesuchten Glykopeptids (24) Kultivierungen mit Zufütterung von potentiellen Vorläufern und anderen Zusätzen durchgeführt.

Die Kultivierung von vier verschiedenen Fermentationsansätzen erfolgte parallel unter den oben genannten Kultivierungsbedingungen mit $\mathrm{SM}^{*}$-Medium. Außerdem wurde direkt nach der Inokulierung der Hauptkulturen zu jedem Schüttelkolben eine wässrige Vitaminlösung gegeben $(1 \mathrm{~mL} / \mathrm{L})$, da das Vitamin $\mathrm{B}_{12}$ (Cyanocobalamin) eine wichtige Schlüsselfunktion bei vielen Stoffwechselprozessen einnimmt. Zwar sind Mikroorganismen im Gegensatz zu 
Mensch und Tier in der Lage, dieses Cobalt-haltige Coenzym vollständig aufzubauen ${ }^{169}$, es sollte aber die Zugabe in Kombination mit zugefütterten Vorläufersubstanzen eine Produktionssteigerung positiv beeinflussen. Die im Folgenden beschriebenen potentiellen Vorläufersubstanzen und anderen Zusätze wurden portionsweise nach der 24. und 32. Stunde zum jeweiligen Ansatz zugegeben.

Die aromatischen Aminosäuren L-Tyrosin und L-Phenylalanin sind in den beschriebenen Biosynthesewegen der nichtproteinogenen Aminosäuren L-Hpg und L-Dpg (s. Abbildung 83) potentielle Vorläufer. In Gegenwart von L-Tyrosin findet die durch das Enzym HpgT katalysierte Transaminierung statt, aus der die Aminosäuren L-Hpg und L-Dpg hervorgehen. Hierbei werden bei beiden Biosynthesewegen stöchiometrische Mengen an L-Tyrosin verbraucht, während bei der Bildung der Vorstufe L-Hpg nur katalytische Mengen an Prephenat eingesetzt werden, welches u.a. aus L-Phenylalanin aufgebaut werden kann. Aus diesem Grund wurden zur Produktionssteigerung zu den Fermentationsansätzen Variante $H$ - $A$ und Variante $H-B$ L-Tyrosin als Suspension in DMSO bzw. L-Tyrosin in DMSO und L-Phenylalanin hinzugefügt, wobei der Zusatz DMSO die Aufnahme der Vorläufer in die Zellen verbessern sollte. ${ }^{170}$ Zusätzlich wurde das Adsorberharz XAD-2 zur Variante $H-B$ nach der 24 . Stunde zugegeben. Hierbei sollte die Zugabe von XAD-2 zur Kulturbrühe nach dem „Prinzip von Le Chatelier“ wirken. Das gebildete Glykopeptid (24) bindet an das Adsorberharz XAD-2 und wird so aus dem Reaktionsgleichgewicht der Kulturbrühe entfernt. Das System sollte entsprechend mit Nachproduktion reagieren, das Ergebnis würde einer Produktionssteigerung gleichen. Weiterhin wurde der Einfluss der Fütterung von Natriumacetat und Glycerin in Kombination mit XAD-2 und Glycerin in Kombination mit DMSO in den Varianten $\mathrm{H}-\mathrm{C}$ und $H$-D untersucht.

Für die Aufarbeitung der entsprechenden Kulturen wurde das Mycel zur Extraktion mit Methanol/Wasser 9:1 behandelt und das erhaltene Mycelrohextrakt in Wasser aufgenommen. Die wässrige Extraktlösung wurde mittels einer Mitteldruckpumpe auf eine mit dem Adsorberharz MCI-Gel ${ }^{\circledR}$-gefüllte Säule aufgebracht. Hierbei sollte untersucht werden, ob der Einsatz dieser Aufarbeitungsmethode eine Abtrennung der unpolareren Tetromycine ermöglicht. Nach Waschen mit demin. Wasser wurde zunächst mit dem Rohextrakt der Variante $H$-A die Reinigung durch MCI-Gel optimiert. Hierzu wurde zuerst mit Methanol/Wasser 2:8, Methanol/Wasser 4:6, Methanol/Wasser 5:5, Methanol/Wasser 6:4, Methanol/Wasser 8:2 und Methanol eluiert (Variante V). Mit Hilfe einer dünnschichtchromatographischen Analyse der einzelnen Fraktionen an Kieselgel $\left(\mathrm{CHCl}_{3} / \mathrm{MeOH} / 20 \% \mathrm{NH}_{3}\right.$ 1:2:1) konnte eine Produktion des pink anfärbbaren Metaboliten nicht bestätigt werden. Zur Verifizierung dieser Aufarbei- 
tungsmethode wurde diese mit Mycelrohextrakt aus der vorherigen Fermentation gemäß Variante A durchgeführt, bei der eine Produktion mittels Dünnschichtchromatographie überprüft worden war. Hierbei wurde der pink anfärbbare Metabolit in der Waschphase, dem sogenannten Vorlauf, detektiert. Aus diesem Grund wurden bei den folgenden Aufarbeitungen am MCI-Gel nach dem Waschen mit Wasser folgende Lösungsmittelgemische zur Elution eingesetzt: Methanol/Wasser 1:2, Methanol/Wasser 1:1, Methanol/Wasser 2:1 und Methanol (Variante VI).

Die dünnschichtchromatographische Analyse an Kieselgel $\left(\mathrm{CHCl}_{3} / \mathrm{MeOH} / 20 \% \mathrm{NH}_{3}\right.$ 1:2:1) der aus Variante $H-A$ bis $H-D$ erhaltenen Fraktionen zeigte keine Produktion des pink anfärbbaren Metaboliten. Ebenso konnte in der HPLC-ESI-MS kein chlorsubstituierter Naturstoff nachgewiesen werden. Mit Hilfe der Analysemethoden konnte gezeigt werden, dass die Tetromycine an MCI-Gel adsorbiert werden und erst mit dem Lösungsmittelgemisch Methanol/Wasser 2:1 bzw. reinem Methanol eluiert werden. Somit konnte eine Aufarbeitungsmethode etabliert werden, die eine Abtrennung des pink anfärbbaren Metaboliten von den Tetromycinen ermöglichte.

\section{Variante I}

Da bei der Kultivierung mit Zufütterung der Vorläufersubstanzen (aromatische Aminosäuren, Natriumacetat und Glycerin) keine Produktionssteigerung des pink anfärbbaren Metaboliten beobachtet wurde, erfolgte eine weitere Fermentation des Stammes Pol001 unter Zugabe der nichtproteinogenen Aminosäure L-4-Hydroxyphenylglycin (L-Hpg), einer Kombination von L-Hpg und Malonsäure sowie D-Hpg und Malonsäure. Die nichtproteinogene Aminosäure L-3,5-Dihydroxyphenylglycin (L-Dpg) wird aus vier Molekülen Malonyl-CoA aufgebaut (s. Abbildung 84), so dass als direkter Vorläufer für diese Vorstufe Malonsäure zugefüttert wurde. Es sollte untersucht werden, ob die direkte Zufütterung von L-Hpg alleine oder nur in Kombination mit Malonsäure zur Produktionssteigerung führt. Weiterhin sollte untersucht werden, ob die Fütterung von L-Hpg oder D-Hpg einen spezifischen Einfluss auf die Produktion ausübt. Es liegen alle Hpg-Reste im Glykopeptid D-konfiguriert vor, so dass L-Hpg durch in-situ-Epimerisierung am NRPS-Enzymkomplex umgewandelt werden muss, während die Epimerisierung im Fall von zugefüttertem D-Hpg nicht erfolgen muss.

Die Kultivierung der drei verschiedenen Fermentationsansätze erfolgte parallel unter den oben genannten Kultivierungsbedingungen bei $28{ }^{\circ} \mathrm{C}$ und $180 \mathrm{U} / \mathrm{min}$ mit SM${ }^{*}$-Medium. Die potentiellen Vorläufersubstanzen wurden portionsweise nach der 24. und 32. Stunde zum jeweiligen Ansatz zugegeben. Die Zugabe der Vitaminlösung erfolgte diesmal erst nach der 24. 
Stunde. Als Kontrolle wurde der Stamm Pol001 ebenfalls im 1 L-Maßstab ohne Zufütterung kultiviert.

Die Aufarbeitung der einzelnen Fermentationen wurde gemäß der optimierten Variante VI durchgeführt. Die dünnschichtchromatographische Analyse der gewonnenen Mycelrohextrakte an Kieselgel $\left(\mathrm{CHCl}_{3} / \mathrm{MeOH} / 20 \% \mathrm{NH}_{3}\right.$ 1:2:1) wies eine Produktionssteigerung des pink anfärbbaren Metaboliten bei der Kultivierung mit Zufütterung von L-Hpg und Malonsäure (Variante I-B) sowie von D-Hpg und Malonsäure (Variante I-C) auf, wobei anhand der beobachteten Intensitäten, die letztere Kombination für eine größere Produktmenge sprach. Sowohl der Ansatz mit alleiniger Zufütterung von L-Hpg (Variante I-A) als auch die Negativkontrolle ohne Zufütterung zeigten nur eine sehr geringe Produktion des pink anfärbbaren Metaboliten. Dünnschichtchromatographie der nach MCI-Gel-Trennung erhaltenen Fraktionen von Variante $I-A$ und $I-B$ zeigten deutlich den pink anfärbbaren Metaboliten im Vorlauf. Die Lyophilisatextrakte aus dem Kulturfiltrat wiesen keine pink anfärbbare Substanz auf. Zur Überprüfung der Reproduzierbarkeit und Bereitstellung von Substanzmenge wurde die Kultivierung mit Zufütterung von D-Hpg und Malonsäure in Schüttelkolben wiederholt. Parallel wurde die Kultivierung im Fermenter (Ansatz 3 L, s. Variante $J$ ) durchgeführt. Außerdem erfolgte eine weitere säulenchromatographische Reinigung der Vorlauf-Fraktion an Sephadex LH-20 (Methanol/Wasser 2:1), gefolgt von einer Mitteldrucksäulenchromatographie an reversed-phase Kieselgel (Lobar ${ }^{\circledR}$ Größe B oder C, $\mathrm{MeOH} / \mathrm{H}_{2} \mathrm{O}$ 1:9) und einer abschließenden Säulenchromatographie an Kieselgel $\left(\mathrm{CHCl}_{3} / \mathrm{MeOH} / 20 \% \mathrm{NH}_{3}\right.$ 1:2:1), die den pink anfärbbaren Metaboliten als farblosen Feststoff (17.2 mg/L) lieferte.

\section{Variante $J$}

Für die Produktion des pink anfärbbaren Metaboliten im 3 L Maßstab wurde der Stamm Pol001 im Fermenter unter Zufütterung kultiviert. Die Fermentation erfolgte bei $28^{\circ} \mathrm{C}$, $400 \mathrm{U} / \mathrm{min}$ und einer Belüftung von $1 \mathrm{vvm}$ im SM${ }^{*}$-Medium für 96 h. Dabei wurde der pHVerlauf durch eine $\mathrm{pH}$-Sperre $(\mathrm{pH}=6.5 \pm 1.5)$ reguliert und der Verbrauch an $\mathrm{O}_{2}$ kontrolliert. Für die Zufütterung wurden die Vorläufer D-Hpg $(5 \mathrm{mM})$ und Malonsäure $(5 \mathrm{mM})$ mittels einer Schlauchpumpe über einen Zeitraum von $10 \mathrm{~h}$ kontinuierlich zugegeben. Nach der 24. Stunde wurde der Kulturbrühe auch die wässrige Vitaminlösung $(1 \mathrm{~mL} / \mathrm{L})$ hinzugefügt. Die Aufarbeitung erfolgte gemäß Variante VI. Die dünnschichtchromatographische Analyse der gewonnenen Mycelrohextrakte an Kieselgel $\left(\mathrm{CHCl}_{3} / \mathrm{MeOH} / 20 \% \mathrm{NH}_{3}\right.$ 1:2:1) zeigte im Vergleich zur Kultivierung in Schüttelkolben eine geringere Produktionssteigerung. Aufgrund eines großen Fettanteils am Mycelrohextrakt wurde auf eine weitere Aufarbeitung zunächst verzichtet. 


\section{Variante $K$}

Zur Überprüfung der Reproduzierbarkeit und Bereitstellung von Substanzmenge des pink anfärbbaren Metaboliten wurde die Kultivierung mit Zufütterung von D-Hpg und Malonsäure in Schüttelkolben wiederholt. Die Zufütterung erfolgte wie unter Variante I bereits beschrieben. Die Aufarbeitung wurde analog zur Variante VI durchgeführt, wobei das Kulturfiltrat verworfen wurde.

Die dünnschichtchromatographische Analyse des gewonnenen Mycelrohextraktes an Kieselgel $\left(\mathrm{CHCl}_{3} / \mathrm{MeOH} / 20 \% \mathrm{NH}_{3}\right.$ 1:2:1) ergab eine reproduzierbare Produktionssteigerung bezüglich des pink anfärbbaren Metaboliten. Die anschließende HPLC-ESI-MS-Analyse (HPLC D, Säule C: Phenomenex Synergi Hydro RP, Programm C: $\mathrm{MeOH} / \mathrm{H}_{2} \mathrm{O}$, jeweils mit $0.05 \%$ Ameisensäure, Gradient, s. Abschnitt B 1.2 ) des nach MCI-Gel-Trennung erhaltenen Vorlaufs zeigte bei der Retentionszeit von $\mathrm{R}_{\mathrm{t}}=5.70$ min deutlich Vancomycin (1) mit einem Massenion bei $m / z=1448[\mathrm{M}+\mathrm{H}]^{+}$. Ein Vergleich der Retentionszeiten und der Fragmentierungsmuster mit dem Standard verifizierte eindeutig die Substanz als Vancomycin (1) (s. Abbildung 90).

Eine polarere Substanz mit ebenfalls charakteristischem Isotopenmuster konnte nicht detektiert werden. Bei den polareren Verbindungen im Chromatogramm handelte es sich um Nährmedienbestandteile. Eine Übereinstimmung zwischen Vancomycin (1) und dem pink anfärbbaren Metaboliten kann aufgrund der $\mathrm{R}_{\mathrm{f}}$-Werte an Kieselgel ausgeschlossen werden. Die Isolierung des pink anfärbbaren Metaboliten erfolgte wie unter Variante I beschrieben. Zusätzlich wurden die nach MCI-Gel-Chromatographie erhaltenen Fraktionen und die isolierte pink anfärbende Verbindung auf eine wachstumshemmende Wirkung gegenüber S. aureus und B. subtilis in Konzentrationen von $5.0 \mathrm{mg} / \mathrm{mL}$ und $10 \mathrm{mg} / \mathrm{mL}$ getestet. Hierbei konnte keine antibiotische Aktivität beobachtet werden. 
A

\section{Vancomycin aus Stamm Pol001}

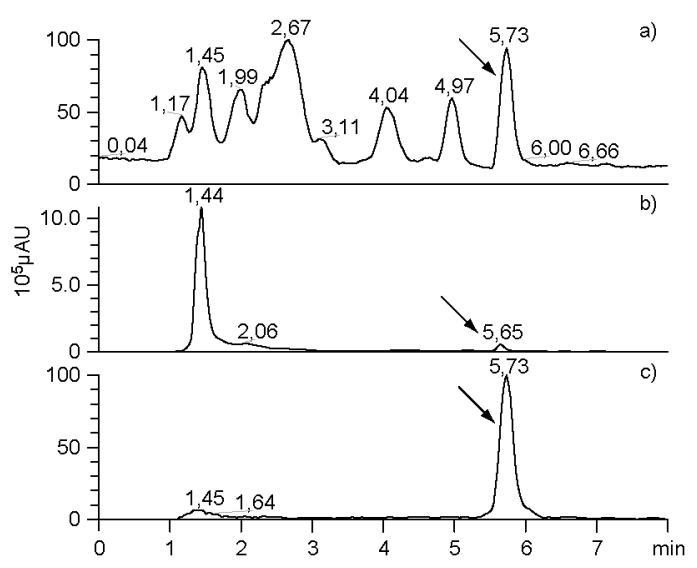

Standard Vancomycin

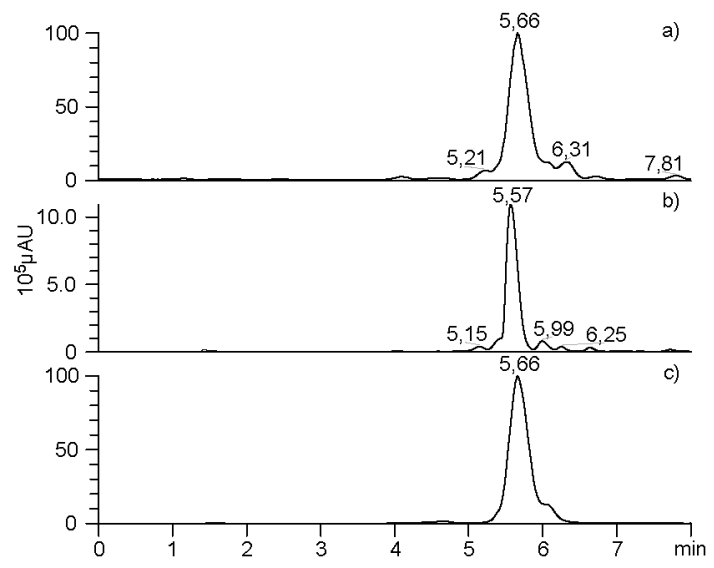

B

\section{Massenspektrum}

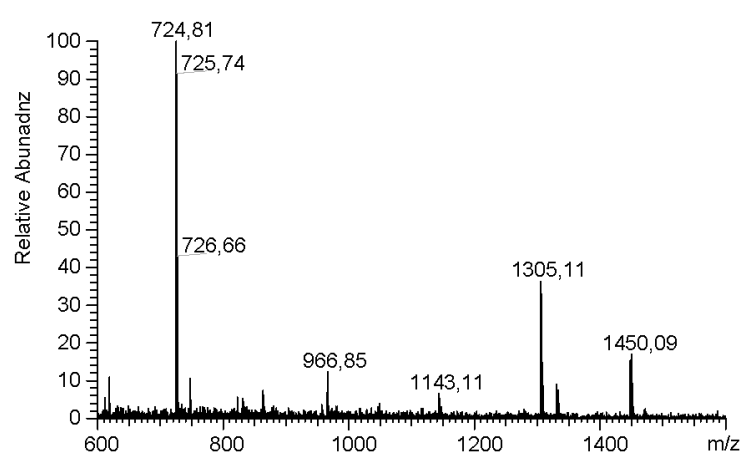

Massenspektrum

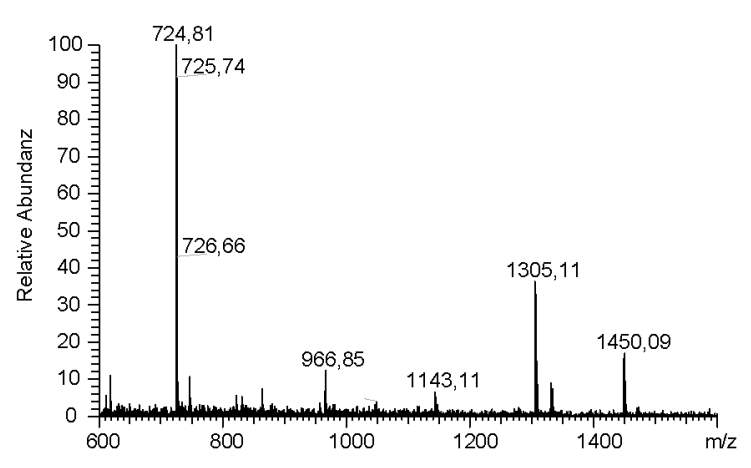

Abbildung 90. HPLC-ESI-MS-Analysen des nach MCI-Gel-Trennung erhaltenen Vorlaufs und Vancomycin (1) als Vergleich. A: HPLC-ESI-MS-Chromatogramme: a) Massenchromatogramm, b) UV-Chromatogramm bei $280 \mathrm{~nm}$, c) Massenchromatogramm mit spezieller Suche von $m / z=1448$ für Vancomycin aus Stamm Pol001 bei $\mathrm{R}_{\mathrm{t}}=5.70$ min und dem Standard 1. B: Massenspektren der chlorsubstituierten Verbindung aus Stamm Pol001 und Vancomycin (1).

\section{Variante L}

Um den Einfluss von Malonsäure auf die Produktion des pink anfärbbaren Metaboliten zu prüfen, wurde Pol001 unter alleiniger Zufütterung von Malonsäure gemäß Variante I kultiviert. Die Aufarbeitung wurde analog zur Variante VI durchgeführt.

Die dünnschichtchromatographische Analyse des gewonnenen Mycelrohextraktes an Kieselgel $\left(\mathrm{CHCl}_{3} / \mathrm{MeOH} / 20 \% \mathrm{NH}_{3}\right.$ 1:2:1) zeigte eindeutig eine reproduzierbare Produktionssteigerung bezüglich des pink anfärbbaren Metaboliten (s. Abbildung 91). Allerdings konnte bei der anschließenden HPLC-ESI-MS-Analyse des nach MCI-Gel-Trennung erhaltenen 
Vorlaufs kein typisches Isotopenmuster eines Glykopeptids detektiert werden (HPLC D, Säule C: Phenomenex Synergi Hydro RP, Programm D: $\mathrm{MeOH} / \mathrm{H}_{2} \mathrm{O}$, jeweils mit $0.05 \%$ Ameisensäure, Gradient, s. Abschnitt B 1.2 ). Für die HPLC-Analyse wurde im Vergleich zur vorherigen ein noch polarerer Gradient gewählt, um eine Detektion des gesuchten Glykopeptids (24) zu ermöglichen. Zusätzlich wurde der aus der Kultivierung mit alleiniger Zufütterung von L-Hpg erhaltene Vorlauf auch mittels HPLC-ESI-MS auf ein chlorsubstituiertes Glykopeptid hin untersucht. Auch hier konnte kein Glykopeptid detektiert werden.

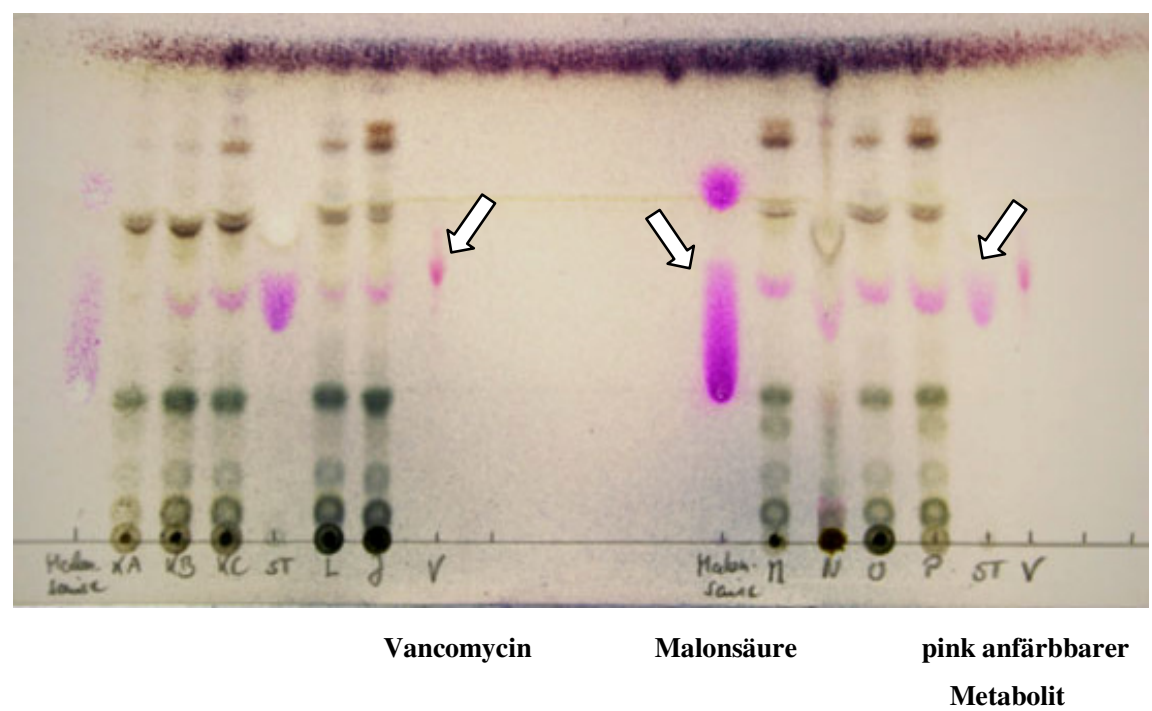

Abbildung 91. Dünnschichtchromatographische Analyse an Kieselgel $\left(\mathrm{CHCl}_{3} / \mathrm{MeOH} / 20 \% \mathrm{NH}_{3}\right.$ 1:2:1) mit den Fermentationen Variante $K$ bis Variante P. Alle Fermentationen bis auf Variante $L$ und $J$ erfolgten mit Zufütterung von: $K A=\mathrm{L}-\mathrm{Hpg} ; K B=\mathrm{L}-\mathrm{Hpg}$ und Malonsäure; $K C, M, N, O=\mathrm{D}-\mathrm{Hpg}$ und Malonsäure; $P=$ Malonsäure. Mit Pfeilen gekennzeichnet sind der Standard Vancomycin (V, 1), Malonsäure und der isolierte pink anfärbbare Metabolit (ST) aus Pol001.

Die Isolierung des pink anfärbbaren Metaboliten erfolgte wie unter Variante I beschrieben. Zudem wurde anstatt der Gelchromatographie an Sephadex LH-20 (Methanol/Wasser 2:1) diese auch an Toyopearl HW-40F (Methanol/Wasser 2:1) durchgeführt. Dieses Material kann zur Trennung von Molekülen im Größenbereich von 100-7000 Da MW eingesetzt werden und sollte einen Zugang zu einem Glykopeptid ermöglichen.

Die nach MCI-Gel-Trennung erhaltenen Fraktionen und die isolierte pink anfärbbare Verbindung wurden ebenfalls auf eine wachstumshemmende Wirkung gegenüber S. aureus und B. subtilis in Konzentrationen von $5.0 \mathrm{mg} / \mathrm{mL}$ und $10 \mathrm{mg} / \mathrm{mL}$ getestet. Hierbei konnte auch keine antibiotische Aktivität beobachtet werden.

\section{Variante $\mathrm{M}-\mathrm{O}$ und Variante $\mathrm{P}$}

Die bisherigen Beobachtungen ließen vermuten, dass es sich möglicherweise bei dem pink anfärbbaren Metaboliten nicht um das gesuchte Glykopeptid (24) handelt. Um diese Annahme 
zu prüfen, wurde der Stamm Pol001 in den Medien SM*, SD, SG und S mit Zufütterung von Malonsäure und als Kontrolle ohne Zufütterung kultiviert. Zudem wurde als zusätzliche Kontrolle der Stamm JP90 im SM*-Medium mit Zufütterung von Malonsäure kultiviert. Die Fermentation erfolgte analog zur Variante I. Für die Aufarbeitung wurde das Mycel mit Methanol/Wasser 9:1 extrahiert und nicht weiter aufgearbeitet.

Die dünnschichtchromatographische Analyse der gewonnenen Mycelrohextrakte an Kieselgel $\left(\mathrm{CHCl}_{3} / \mathrm{MeOH} / 20 \% \mathrm{NH}_{3}\right.$ 1:2:1) ließ eindeutig erkennen, dass bei Zufütterung von Malonsäure die Substanzmenge des pink anfärbbaren Metaboliten deutlich zunahm. Auch die Kontrolle JP90 zeigte die Bildung der pink anfärbbaren Verbindung. Diese Beobachtungen ließen vermuten, dass es sich bei dem pink anfärbbaren Metaboliten um ein Derivat der Malonsäure handeln könnte.

\subsubsection{Detaillierte Analytik des gesuchten Metaboliten}

Mit Hilfe verschiedener Analytikmethoden sollte untersucht werden, ob es sich bei dem pink anfärbbaren Metaboliten aus Pol001 um das gesuchte Glykopeptid (24) oder einen anderen Metaboliten handelt.

Bisherige HPLC-ESI-MS-Analysen erbrachten weder Hinweise auf das Vorliegen des gesuchten Glykopeptids (24) anhand seines typischen Isotopenmusters, das einem die Identifizierung erlauben würde, noch auf das Vorliegen eines anderen Metaboliten. Zur Bestimmung einer Molekülmasse und der dazugehörigen Summenformel wurden verschiedene massenspektrometrische Methoden verwendet. Aber auch der Einsatz der MALDI-TOF-Methode, mit welcher die Analytik der sulfatierten Glykopeptide UK68597 (149) gelang, erbrachte keinen Anhaltspunkt für das Vorliegen eines Glykopeptids.

Für die Aufnahme eindeutiger spektroskopischer Daten wurde aufgrund der schlechten Löslichkeit der pink anfärbbaren Verbindung in deuteriertem DMSO- $\mathrm{d}_{6}$ verschiedene polare Lösungsmittel und Lösungsmittelgemische verwendet, wie beispielsweise $\mathrm{D}_{2} \mathrm{O}, \mathrm{CD}_{3} \mathrm{OD} / \mathrm{D}_{2} \mathrm{O}$ 2:1, $\mathrm{CD}_{3} \mathrm{CN} / \mathrm{D}_{2} \mathrm{O}$ 1:1, $\mathrm{NH}_{3}-\mathrm{d}_{3}\left(20 \%\right.$ ig in $\mathrm{D}_{2} \mathrm{O}$ ) und DMSO- $\mathrm{d}_{6} / \mathrm{D}_{2} \mathrm{O}$ 9:1. Allerdings konnten die anfänglichen spektroskopischen Daten nicht reproduziert werden, sondern lediglich nur Resonanzen im ${ }^{1}$ H-NMR-Spektrum gefunden werden, die auf das Vorliegen eines kleinen Moleküls hinwiesen. Das ${ }^{1}$ H-NMR-Spektrum der Verbindung $(\sim 2 \mathrm{mg})$ zeigt eine Methylgruppe $\left(\delta_{\mathrm{H}}=3.14 \mathrm{ppm}\right)$, zwei Methylenprotonen $\left(\delta_{\mathrm{H}}=3.31,3.39 \mathrm{ppm}\right)$ und ein Methinproton $\left(\delta_{\mathrm{H}}=3.49 \mathrm{ppm}\right)$, die aufgrund der Tieffeldverschiebung an einem Heteroatom oder in direkter Nachbarschaft zu Carbonylgruppen gebunden sein müssen. Die Multiplizitäten deuteten auf ein Derivat der Malonsäure hin. Das zugehörige ${ }^{13} \mathrm{C}-\mathrm{NMR}-$ Spektrum weist drei Resonanzen 
bei $\delta_{\mathrm{C}}=49.3,63.5,72.9 \mathrm{ppm}$ auf, deren Tieffeldverschiebung auch auf die Präsenz von Heteroatomen oder Carbonylgruppen schließen ließ. Eine weitere Resonanz bei $\delta_{\mathrm{C}}=175.1 \mathrm{ppm}$ ist einer Carbonylgruppe zuzuordnen. Ein dünnschichtchromatographischer Vergleich der Malonsäure mit dem pink anfärbbaren Metaboliten ergab keine eindeutige Übereinstimmung, zeigte aber ein sehr ähnliches Anfärbeverhalten mit Anisaldeyhd, was auf das Vorliegen eines Metaboliten der Malonsäure deuten könnte.

Des Weiteren besaß die pink anfärbende Substanz keine signifikanten UV-Absorptionen oder charakteristische IR-Banden für Ester- oder Amidbindungen, die für das Vorliegen eines Glykopeptids sprachen. Mit Hilfe einer Elementaranalyse wurde die isolierte Substanz auf die Anwesenheit von Schwefel überprüft. Hierbei konnte dieser zwar nachgewiesen werden, allerdings ergab die Zusammensetzung nur einen sehr geringen Kohlenstoffanteil von $15 \%$, während dieser in Glykopeptiden einen Anteil von über $50 \%$ ausmacht. Zusätzlich wurde für die Substanz ein sehr hoher Stickstoffanteil von $14 \%$ gemessen.

Versuche zum Erhalt einer Kristallstruktur, mit dessen Hilfe sich Kenntnisse über das Vorliegen eines Glykopeptids oder eines von Malonsäure abstammenden Metaboliten erlangt werden sollten, resultierten in einem Einkristall. Hierfür wurde die Diffusionsmethode angewendet, wobei die Verbindung in deuteriertem Methanol/Wasser 2:1 gelöst vorlag und Methanol als Diffusionslösungsmittel eingesetzt wurde. Allerdings ergab die Kristallstrukturanalyse in der Arbeitsgruppe von Prof. G. Sheldrick, die von A. Thorn durchgeführt wurde ${ }^{171}$, dass es sich bei dem Einkristall um das Salz $\left(\mathrm{NH}_{4}\right)_{2} \mathrm{SO}_{4}$ handelte. Vermutlich war dieses auch für den positiven Schwefelnachweis und den hohen Anteil an Stickstoff im Rahmen der Elementaranalyse verantwortlich.

\subsubsection{Versuche zur enzymatischen und chemischen Derivatisierung}

\section{Enzymatische Untersuchungen mit einer Arylsulfatase}

In der Literatur wurde das Teicoplanin-ähnliche Glykopeptid UK68597 (149) mit einer Arylsulfatase aus Patella vulgata, Typ V inkubiert, um die spektroskopischen Daten mit dem nicht Sulfatgruppen-tragenden Glykopeptid vergleichen zu können. Hierüber konnte das Substitutionsmuster am sulfatierten Glykopeptid UK68597 (149) eindeutig zugeordnet werden. Mit Hilfe der Inkubation des pink anfärbbaren Metaboliten mit der Arylsulfatase sollten die spektroskopischen Daten des isolierten Produkts klären, ob es sich bei der pink anfärbbaren isolierten Verbindung aus Pol001 um das gesuchte Glykopeptid (24) oder einen Metaboliten der Malonsäure handeln könnte. Hierfür wurde die isolierte Substanz in 0.2 M NatriumacetatPuffer ( $\mathrm{pH}=5.0)$ gelöst und mit dem Enzym bei $37^{\circ} \mathrm{C}$ für $48 \mathrm{~h}$ inkubiert und anschließend 
der Reaktionsansatz lyophilisiert. Nach säulenchromatographischer Reinigung an Kieselgel $\left(\mathrm{CHCl}_{3} / \mathrm{MeOH} / 20 \%\right.$ ig $\mathrm{NH}_{3}$ 1:2:1) wurde die Substanz reisoliert. Das ${ }^{1} \mathrm{H}-\mathrm{NMR}$-Spektrum zeigte keine Veränderung im Vergleich zum eingesetzten Substrat. Bei der Wiederholung des Inkubationsansatzes mit isolierter Substanz aus einem anderen Fermentationsansatz wurde zur Aufarbeitung das Lyophilisat in Methanol/Wasser 2:1 aufgenommen und ein Teil über einen Spinfilter mit einer Ausschlußgröße von 5000 Da MW zentrifugiert, um das Enzym abzutrennen. Sowohl im Filtrat als auch im Rückstand konnte durch HPLC-ESI-MS-Analyse kein Glykopeptid detektiert werden.

\section{Chemische Derivatisierung}

Um zu klären, ob es sich bei dem pink anfärbbaren Metaboliten um das gesuchte Glykopeptid (24) oder um einen Metaboliten der Malonsäure handeln könnte, folgte eine methanolische Hydrolyse. Die isolierte Substanz wurde in methanolische Salzsäure suspendiert und für 5 min im Ultraschallbad behandelt. Zur vollständigen Lösung wurde zum Reaktionsgemisch Methanol/Wasser 2:1 gegeben, dieses für weitere $10 \mathrm{~min}$ im Ultraschallbad behandelt und anschließend das Lösungsmittel bis zur Trockne entfernt. Der Rückstand wurde in Methanol/Wasser 2:1 aufgenommen und dünnschichtchromatographisch an Kieselgel $\left(\mathrm{CHCl}_{3} / \mathrm{MeOH} / 20 \%\right.$ ig $\mathrm{NH}_{3}$ 1:2:1) sowie mittels HPLC-ESI-MS analysiert (HPLC D, Säule B: Phenomenex Synergi Hydro RP, Programm D: $\mathrm{MeOH} / \mathrm{H}_{2} \mathrm{O}$, jeweils mit $0.05 \%$ Ameisensäure, Gradient, s. Abschnitt B 1.2 ). Hierbei konnte in Spuren bei einer Retentionszeit von $\mathrm{R}_{\mathrm{t}}=8.50$ min Vancomycin (1) detektiert werden und anhand eines Vergleichs der Retentionszeiten und der Fragmentierungsmuster mit dem Standard eindeutig identifiziert werden. Allerdings wurde in der unbehandelten isolierten Substanz in der gleichen Größenordnung liegend ebenfalls Vancomycin (1) gefunden, so dass nicht erst die methanolische Hydrolyse zu 1 geführt hat, sondern dieses in Spuren mit der isolierten Substanz zusammen bereits vorlag. Eine Wiederholung mit isolierter Substanz aus einer anderen Kultivierung mit Zufütterung von D-Hpg und Malonsäure zeigte vor und nach der Hydrolyse kein chlorsubstituiertes Isotopenmuster. Zur Kontrolle wurde Vancomycin (1) ebenfalls mit methanolischer Salzsäure behandelt. Hierzu wurde 1 in Methanol/Wasser 2:1 vollständig gelöst und nach Zugabe von methanolischer Salzsäure für 15 min im Ultraschallbad behandelt. Der Rückstand wurde mittels HPLC-ESI-MS analysiert und ergab eine vollständige Zersetzung des Vancomycins (1). Vermutlich erfolgte keine Zersetzung des Vancomycins (1) bei der methanolischen Hydrolyse der pink anfärbbaren Substanz, da sich dieses zunächst nicht in methanolischer Salzsäure gelöst hatte. Zudem war die Behandlung im Ultraschallbad nach vollständiger Lösung auch kürzer als im Vergleich mit 1 und führte somit noch nicht zur Zersetzung. 


\subsubsection{Diskussion der Ergebnisse und Ausblick}

\section{Diskussion der Ergebnisse}

Im Rahmen der vorliegenden Arbeit sollte mit Hilfe von Fermentationsstudien untersucht werden, ob der Stamm Pol001 das aus dem Biosynthesegencluster abgeleitete neue Glykopeptid (24) mit mindestens einem Sulfatsubstituenten produziert. Gegebenenfalls sollte durch Variation der Kultivierungsbedingungen und durch Fütterung von potentiellen Biosynthesevorläufern oder anderen Zusätzen die Produktion des vorhergesagten Glykopeptids (24) gesteigert werden. Hierbei zeigten erste Untersuchungen des Metabolitenspektrums vom Stamm Pol001, dass nach chromatographischer Trennung an Sephadex LH-20 (Methanol) ein mit Anisaldehyd pink anfärbbarer Metabolit im Mycelrohextrakt detektiert werden konnte, der ein ähnliches Anfärbeverhalten wie Vancomycin (1) aufwies und in dessen Polaritätsbereich lag (s. Abbildung 87, Fraktion 8). Nach weiterer chromatographischer Reinigung dieser Fraktion an Kieselgel (Aceton/ $\mathrm{H}_{2} \mathrm{O}$ 9:1) konnte mittels HPCL-ESI-MS-Analyse die Produktion von Vancomycin (1) in Fraktion 8 (s. Abbildung 88) verifiziert werden. Ein weiteres Glykopeptid oder Derivat von Vancomycin mit einer Molmasse von $1459 \mathrm{~g} / \mathrm{mol}$ konnte ebenfalls in Fraktion 8 detektiert, aber nicht identifiziert werden. Die hochauflösende massenspektrometrische Untersuchung eines Massenion bei $\mathrm{m} / z=732[\mathrm{M}+2 \mathrm{H}]^{2+}$ ergab einen Summenformelvorschlag mit $\mathrm{C}_{67} \mathrm{H}_{77} \mathrm{Cl}_{2} \mathrm{~N}_{9} \mathrm{O}_{24}$, allerdings mit einer entsprechenden Molmasse von $1461 \mathrm{~g} / \mathrm{mol}$. Ein weiteres chlorsubstituiertes Isotopenmuster, das möglicherweise zu dem vorhergesagten neuen Glykopeptid (24) gehören könnte, wurde nicht beobachtet.

Die Optimierung der Fermentationsbedingungen des Stammes Pol001 führte unter Zusatz der Vorläufer L-Hpg/Malonsäure und D-Hpg/Malonsäure zu einer Produktionssteigerung der pink anfärbbaren Substanz. HPLC-ESI-MS-Analysen ließen ebenfalls eine Produktionssteigerung von 1 erkennen, jedoch kein spezifisches Chlor-Isotopenmuster, hinweisend auf das gesuchte Glykopeptid (24). Eine Übereinstimmung von Vancomycin (1) und dem pink anfärbbaren Metaboliten konnte aufgrund der unterschiedlichen $\mathrm{R}_{\mathrm{f}}$-Werte ausgeschlossen werden. Auch konnte bei der alleinigen Zufütterung von L-Hpg zum Stamm Pol001 nur eine schwache Produktion der pink anfärbbaren Verbindung durch dünnschichtchromatographische Analyse sowie keine Produktion von Glykopeptiden in der HPLC-ESI-MS beobachtet werden. Aus diesem Grund wurde der alleinige Einfluss von Malonsäure-Zugabe während der Fermentation auf die Produktion der pink anfärbbaren Verbindung näher untersucht. Hierbei zeigte die dünnschichtchromatographische Analyse eine genau so starke Produktionssteigerung wie bei Zufütterung der Vorläufer D-Hpg und Malonsäure, dennoch ließen sich erneut keine Massensignale des gesuchten Glykopeptids (24) nachweisen. Dies führte zu der Annahme, 
dass es sich bei dem pink anfärbbaren Metaboliten aus Pol001 nicht um das gesuchte sulfatierte Glykopeptid (24) handelt, sondern um einen anderen, durch Malonsäure induzierten Metaboliten.

Weitere Fütterungsexperimente ergaben, dass die Zufütterung von Malonsäure zur Produktion dieses Metaboliten führt. Aufgrund des sehr ähnlichen Anfärbeverhalten von Malonsäure und diesem Metaboliten und der spektroskopischen Daten (s. Abschnitt 4.2.3 ) ist zu vermuten, dass es sich bei dieser pink anfärbbaren Verbindung um einen Metaboliten der Malonsäure handelt. Diese Annahme wird durch die weiteren analytischen Arbeiten unterstützt, die zur Verifizierung durchgeführt worden sind. So weisen die UV- und IR-Daten keine Ähnlichkeit zu Vancomycin (1) auf, obwohl es sich bei dem gesuchten Glykopeptid (24) um eines des Vancomycin-Typs handeln soll. Weiterhin führten Versuche zur enzymatischen Hydrolyse der Sulfatgruppen nur zur Reisolierung der pink anfärbbaren Substanz. Außerdem erbrachte die Elementaranalyse zwar einen Nachweis von Schwefel für die Substanz, aber einen viel zu geringen Kohlenstoffanteil, der mit $15 \%$ weit unter dem erwarteten von über $50 \%$ für ein Glykopeptid liegt. Vermutlich ist der Schwefelanteil auf das Vorliegen des Salzes $\left(\mathrm{NH}_{4}\right)_{2} \mathrm{SO}_{4}$ zurückzuführen, das durch eine Kristallstrukturanalyse bestätigt wurde, zumal der gemessene Stickstoffanteil für die Substanz bei $14 \%$ liegt.

Im Rahmen dieser Arbeiten sollten außerdem verschiedene Aufarbeitungs- sowie Isolierungsmethoden getestet werden, um einen effizienten Zugang für die Gewinnung des neuen Glykopeptids zu erreichen. Für die Aufarbeitung erwies sich eine Trennung des erhaltenen Mycelrohextraktes am Adsorberharz MCI-Gel als sehr geeignet, um die Tetromycine abzutrennen, die mit Hilfe von Gel- oder Säulenchromatographie an Kieselgel zuvor nicht abgetrennt werden konnten. Die Eignung dieser Aufarbeitungsmethode konnte mittels HPLC-ESI-MSAnalyse bestätigt werden, da im Vorlauf der MCI-Gel-Trennung Vancomycin (1) detektiert wurde. Die erarbeitete Methode erwies sich als optimal für die Isolierung für den pink anfärbbaren Metaboliten. Das zuvor im Vorlauf detektierte Vancomycin (1) konnte aufgrund zu geringer Mengen trotz Produktionssteigerung und unzureichender dünnschichtchromatographischer Detektion nicht isoliert werden. Es konnte am Ende der Reinigung des pink anfärbbaren Metaboliten nur noch in Spuren mittels HPLC-ESI-MS nachgewiesen werden. Möglicherweise werden die Sulfatgruppen des gesuchten Glykopeptids (24) bereits in der Kulturbrühe oder bei der Aufarbeitung hydrolysiert. Zudem kann auch das Vorliegen einer Desulfatase nicht ausgeschlossen werden, dessen enzymatische Aktivität ebenfalls zur Desulfatierung von 24 führen würde. Dies könnte bedeuten, dass das mittels HPLC-ESI-MS nachgewiesene Vancomycin (1) das Produkt einer solchen Desulfatierung wäre, da es sich bei 
dem neuen Glykopeptid (24) um ein Glykopeptid des Vancomycin-Typs handeln soll. Unter Umständen sind die nach Säulenchromatographie an Kieselgel mit ammoniakalischem Laufmittelgemisch $\mathrm{CHCl}_{3} / \mathrm{MeOH} / 20 \%$ ig $\mathrm{NH}_{3}$ 1:2:1) als Ammoniumsalz $\left(\left(\mathrm{NH}_{4}\right)_{2} \mathrm{SO}_{4}\right)$ vorliegenden Sulfationen ein weiteres Indiz für die Produktion von 24.

\section{Ausblick}

Im Rahmen dieser Arbeiten konnte die Produktion von Vancomycin (1) im Pol001 verifiziert werden und dessen Produktionssteigerung durch Zufütterung der Vorläufer D-4-Hydroxyphenylglycin und Malonsäure erreicht werden. Jedoch produziert der Stamm Pol001 1 immer noch in sehr geringen Mengen. Das gesuchte Glykopeptid weist laut seinem Biosynthesegencluster eine starke Ähnlichkeit zu Vancomycin (1) auf. Für eine eindeutige Bestätigung der vorhergesagten Struktur für das neue Glykopeptid (24) wären Arbeiten zur Strukturaufklärung mit ausreichenden Substanzmengen von 24 nötig. Zunächst müsste mit Hilfe molekulargenetischer Methoden eine Aktivierung des Glykopeptid-Biosynthesegencluster erreicht werden, um eine generelle und zuverlässige Produktion von 24 im Stamm Pol001 zu ermöglichen. Ein Beispiel für eine erfolgreiche Aktivierung eines Biosynthesgenclusters im Pilz Aspergillus nidulans sind Arbeiten von Hertweck et al. ${ }^{172}$. Aus PKS-NRPS-Hybrid-Genclustern abgeleitete Metaboliten konnten dort mittels HPLC-ESI-MS-Analyse nicht im Metabolitenspektrum detektiert werden. Die Aktivierung dieser Biosynthesegene erfolgte über die Expression eines spezifischen Regulators, der mit Hilfe eines induzierbaren Promotors „,angeschaltet“ werden konnte. Dieser neue Ansatz führte zur Isolierung und Strukturaufklärung zwei neuer cytotoxischer Naturstoffe, Aspyridone A und B (153).

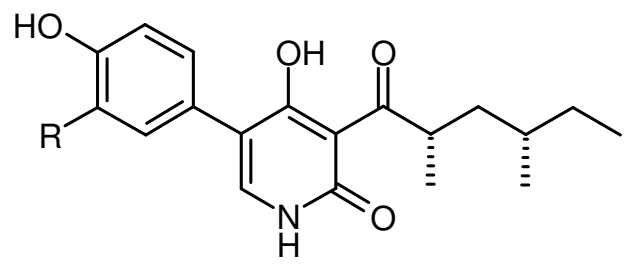

153

$$
\text { Aspyridon } \begin{aligned}
\mathrm{A}: \mathrm{R} & =\mathrm{H} \\
\mathrm{B}: \mathrm{R} & =\mathrm{OH}
\end{aligned}
$$

Abbildung 92. Struktur der Aspyridone A und B (153) aus Aspergillus nidulans.

Mit Hilfe chemisch-analytischer Methoden sollte auch eine experimentelle Überprüfung der erfolgreichen Aktivierung zur Produktion des neuen Glykopeptids (24) im Stamm Pol001 erfolgen können. Hierzu würde der Stamm Pol001 unter den optimierten Kultivierungsbedingungen angezogen werden und die Analyse des Mycelrohextraktes bzw. nach Trennung 
an MCI-Gel die Produktion des Glykopeptids mittels HPLC-ESI-MS-Analyse untersucht werden. Zudem könnten parallel Kultivierungen mit Zufütterung der Vorläufer D-Hpg/Malonsäure und L-Hpg/Malonsäure durchgeführt werden, um möglicherweise eine zusätzliche Produktionssteigerung für eine bessere Isolierung von $\mathbf{2 4}$ zu erzielen.

Bei der Isolierung von Glykopeptiden werden in der Literatur häufig Ionenaustauscher eingesetzt, wobei sich diese im Falle eines Glykopeptids mit mindestens einer Sulfatgruppe aufgrund zu starker Wechselwirkungen mit dem Trägermaterial nicht eignen. Eine andere Möglichkeit bietet die Affinitätschromatographie. Hierbei wird die Affinität der Glykopeptide zum Dipeptid D-Alanyl-D-Alanin ausgenutzt, welches an Agarosegel gebunden wird. Diese Methode ist auch bei der Isolierung der Sulfatgruppen-tragenden Glykopeptide UK69542-A (149) UK68597 (150) erfolgreich eingesetzt worden. Aber auch der Einsatz des Materials Toyopearl HW40F zur Gelchromatographie oder eine säulenchromatographische Reinigung an HPLC sind potentielle Methoden zur Isolierung des neuen Glykopeptids (24). 


\section{Mykotoxine aus dem Pilz Aspergillus nidulans}

Bis heute sind mehr als 400 Mykotoxine aus Schimmelpilzen isoliert worden. Zu den Produzenten dieser bereits in geringsten Mengen akut oder chronisch toxisch wirkenden Sekundärmetaboliten gehören Pilze der Gattung Aspergillus, Penicillium und Fusarium spp.. ${ }^{173}$ Die bekanntesten Vertreter sind die Aflatoxine aus Aspergillus flavus, hierbei ist Aflatoxin $\mathrm{B}_{1}$ (154, s. Abbildung 93) eine sehr kanzerogene Verbindung ( $\mathrm{IC}_{50}$-Wert: $21.9 \mathrm{mg} / \mathrm{mL}$ ). Der Mensch nimmt Mykotoxine über kontaminierte Nahrungsmittel auf, insbesondere Getreide, Mais und ölhaltige Samen, Nüsse, und natürlich verschimmelte Nahrungsmittel sind hiervon betroffen.

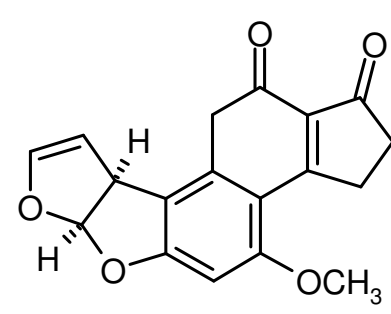

154<smiles>COc1cc2c(c3oc4cccc(O)c4c(=O)c13)[C@H]1C=CO[C@@H]1O2</smiles>

155

Abbildung 93. Strukturen der Mykotoxine Aflatoxin $B_{1}$ (154) und Sterigmatocystin (155).

In der Arbeitsgruppe von PD M. Müller (Arbeits- und Sozialmedizin, Universität Göttingen) wurden Extrakte von Schimmelpilzen der Gattung Aspergillus und Penicillium spp. auf ihre Cytotoxizität und Mutagenität getestet, nachdem diese als Ursache für chronische Atemwegserkrankungen bei Mitarbeitern einer Kompostieranlage identifiziert worden waren. Für weitere Untersuchungen der Mykotoxine wurden die Extrakte zunächst mittels präparativer HPLC-Methoden in 5-Minuten-Fraktionen getrennt. Hierbei fiel ein Extrakt des Pilzes Aspergillus nidulans durch eine Cytotoxizität auf, deren Stärke nicht allein auf den Gehalt von Sterigmatocystin (155, s. Abbildung 93) im Extrakt zurückgeführt werden konnte. ${ }^{174}$ Aus diesem Grund sollte das für diese Cytotoxizität verantwortliche Mykotoxin aus dem Extrakt isoliert und in seiner Struktur aufgeklärt werden.

\subsection{Arbeiten zur Strukturaufklärung}

Im Rahmen der vorliegenden Arbeit wurden Arbeiten zur Strukturaufklärung von isolierten Metaboliten aus dem Pilz A. nidulans in Kooperation mit der Arbeits- und Sozialmedizin M. Müller (Universität Göttingen) durchgeführt. Die Kultivierungsarbeiten sowie die Isolierung und Reinigung der Metaboliten mittels HPLC-Methoden wurden von C. Handrich im Rahmen ihrer Dissertation ausgeführt. 


\section{Cycloisoemericellinol (156), ein Neues Derivat von Cycloisoemericellin (157)}

Das ESI-Massenspektrum des gelben Feststoffs („Peak 25“, interne Bezeichnung der Arbeitsund Sozialmedizin) zeigt Massenaddukte bei $\mathrm{m} / z=425[\mathrm{M}+\mathrm{H}]^{+}, 447[\mathrm{M}+\mathrm{Na}]^{+}$und $407[\mathrm{M}-$ $\left.\mathrm{H}_{2} \mathrm{O}+\mathrm{H}\right]^{+}$. Die Hochauflösung des Massenions bei $m / z=425[\mathrm{M}+\mathrm{H}]^{+}$ergibt einen Summenformelvorschlag von $\mathrm{C}_{25} \mathrm{H}_{28} \mathrm{O}_{6}$ (12 Doppelbindungsäquivalente). Das ${ }^{1} \mathrm{H}-\mathrm{NMR}$-Spektrum enthält Signale für insgesamt 26 Protonen. Im Hochfeld befinden sich drei Singuletts, davon entsprechen die Intensitäten der Signale bei $\delta_{\mathrm{H}}=1.33$ und $1.54 \mathrm{ppm}$ vier Methylgruppen und das Singulett bei $\delta_{\mathrm{H}}=2.41 \mathrm{ppm}$ ist einer aromatisch gebundenen Methylgruppe zuzuordnen. Außerdem weisen zwei mit ${ }^{3} J_{\mathrm{H}, \mathrm{H}}=6.0 \mathrm{~Hz}$-koppelnde Tripletts bei $\delta_{\mathrm{H}}=2.07$ und $4.10 \mathrm{ppm}$ auf benachbarte Methylengruppen hin, von denen eine aufgrund der Tieffeldverschiebung an ein Sauerstoffatom gebunden ist. Im Tieffeldbereich des Spektrums treten bei $\delta_{\mathrm{H}}=5.61$ und $6.30 \mathrm{ppm}$ zwei Singuletts auf, deren Kopplungskonstante von ${ }^{3} J_{\mathrm{H}, \mathrm{H}}=10.0 \mathrm{~Hz}$ auf vicinale olefinische Methinprotonen hinweist. Zusätzlich sind drei aromatische Signale zu erkennen, wovon zwei Dubletts $\left(\delta_{\mathrm{H}}=6.84\right.$ und $\left.7.23 \mathrm{ppm}\right) \mathrm{mit}^{3} \mathrm{~J}_{\mathrm{H}, \mathrm{H}}=8.5 \mathrm{~Hz}$ koppeln und das Singulett bei $\delta_{\mathrm{H}}=7.18 \mathrm{ppm} \mathrm{im}{ }^{1} \mathrm{H},{ }^{1} \mathrm{H}$-COSY-Spektrum eine direkte Nachbarschaft zur aromatisch gebundenen Methylgruppe zeigt. Im ${ }^{13} \mathrm{C}$-NMR-Spektrum sind 14 Kohlenstoffatome in dem Bereich der $\mathrm{sp}^{2}$-hybridisierten C-Atome zu erkennen. Von diesen scheinen vier aufgrund der Tieffeldverschiebung an Sauerstoff gebunden zu sein. Zusätzlich ist eine Carbonylfunktion bei $\delta_{\mathrm{C}}=179.1 \mathrm{ppm}$ zu entnehmen sowie zwei weitere aliphatische quartäre Kohlenstoffatome bei $\delta_{\mathrm{C}}=77.9$ und $70.3 \mathrm{ppm}$, deren Verschiebung für eine Substitution durch ein Sauerstoffatom spricht. Ferner sind drei Methylengruppen, deren Tieffeldverschiebung ebenfalls auf Sauerstoff zurückzuführen ist und vier weitere Methylgruppen zu beobachten. Die Carbonylgruppe und die vierzehn Kohlenstoffatome im aromatischen/olefinischen Bereich ergeben zusammen unter Berücksichtigung von zwei aromatischen Systemen nur zehn Doppelbindungsäquivalente, so dass die vorliegende Struktur insgesamt vier Ringe aufweisen muss. Durch HSQC- ${ }^{1} J_{\mathrm{C}, \mathrm{H}^{-}}$Kopplungen wurden die Kohlenstoffatome den daran gebundenen Protonen zugeordnet. Mit Hilfe von ${ }^{2-4} J_{\mathrm{C}, \mathrm{H}}$-Korrelationen aus HMBC-Experimenten konnten die Kohlenstoffatome zugeordnet werden. Bei einer Datenbankrecherche mit Antibase ${ }^{96}$ und Chapman \& Hall ${ }^{97}$ fiel das Cycloisoemericellin (157, s. Abbildung 95) mit der Summen-

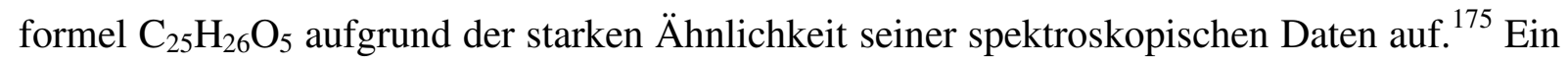
Vergleich ergab, dass bei dem vorliegenden Molekül eine Addition von einem Molekül Wasser an die Doppelbindung des 1"-O-Prenylsubstituenten des Cycloisoemericellin (157) vorlag, was auch der beobachteten Massendifferenz von 18 entspricht. Dies führt zu einer gesättigten Alkylkette, zu der die als Triplett vorliegenden Methylengruppen zuzuordnen sind. 
Zur weiteren Verifizierung der Literaturdaten wurde die Substanz mittels EIMassenspektromtrie auf charakteristische Massenfragmente hin untersucht. Das beobachtete Hauptfragment mit $m / z=337$ weist auf den Verlust des 1 "-O-Substituenten (C-1" bis C-5") hin, das ebenfalls für 157 detektierte Hauptfragment von $m / z=337$ kann auf den Verlust des 1 "-O-Prenylsubstituenten zurückgeführt werden. ${ }^{175}$

$\mathrm{Ob}$ es sich bei der isolierten Substanz um Cycloisoemericellinol (156), ein neues, geniunes Derivat von Cycloisoemericellin (157) handelt oder ob sich dieses erst bei der sauren Aufarbeitung aus 156 bildet, wurde in eigenen Arbeiten untersucht (s. Abschnitt 5.1.1 ).

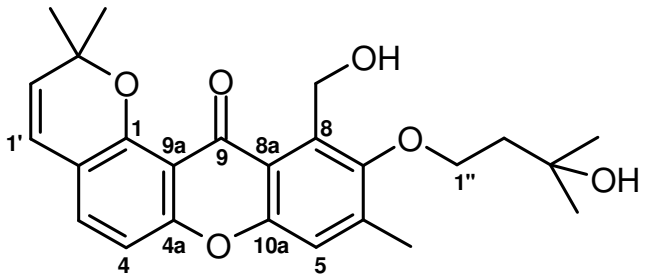

156

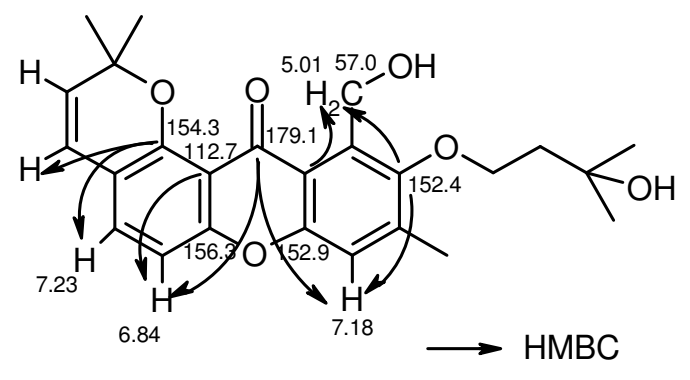

156

Abbildung 94. Neues Derivat vom Cycloisoemericellinol (156) und ausgewählte ${ }^{2-4} J_{\mathrm{C}, \mathrm{H}}-\mathrm{HMBC}-$ Korrelationen.

Die Reinsubstanz weist keine mutagene Wirkung auf, zeigt aber eine gegenüber den Zelllinien A-549 (humane Lungenpneumocyten), Hep-G2 (humane Leberkrebszellen), L-929 (Mausfibroblasten) und Neuro-2a (neuronales Gewebe) cytotoxische Aktivität. Aufgrund von Strukturähnlichkeiten zu bekannten Topoisomerase-Hemmstoffen wurde die mögliche katalytische Hemmung der Topoisomerase durch das neue Cycloisoemericellin-Derivat untersucht. Hierbei konnte $C$. Handrich in zellfreien Assays eine katalytische Hemmung der Topoisomerase I ab einer Konzentration von $c=25 \mu \mathrm{g} / \mathrm{mL}$, eine Hemmung der Topoisomerase II konnte ab Konzentrationen von $c=25 \mathrm{mg} / \mathrm{ml}$ bis $50 \mathrm{mg} / \mathrm{mL}$ beobachtet werden. ${ }^{194}$

\section{Weitere Struktur-verwandte Substanzen}

Aus einer Festphasenkultivierung des Stammes A. nidulans konnte $C$. Handrich ein Gemisch von zwei weiteren Substanzen isolieren, das bei einem Cytotoxizitätsscreening in den Zelllinien A-549 (humane Lungenpneumocyten), Hep-G2 (humane Leberkrebszellen) und L-929 (Mausfibroblasten) $\mathrm{IC}_{50}$-Werte kleiner $10 \mu \mathrm{g} / \mathrm{mL}$ erzielte. Aufgrund $\mathrm{zu}$ geringer Mengen konnte dieses Gemisch („Peak 31“, interne Bezeichnung der Arbeits- und Sozialmedizin) chromatographisch nicht weiter gereinigt werden, so dass in eigenen Arbeiten keine abschließende Strukturaufklärung für die zwei weiteren Substanzen erfolgte, sondern lediglich Strukturfragmente aus ${ }^{1} \mathrm{H},{ }_{1}^{1} \mathrm{H}$-COSY-Experimenten abgeleitet werden konnten. 
Ein ESI-Massenspektrum des Substanzgemisches („Peak 31“) zeigt Massenaddukte bei $m / z=407[\mathrm{M}+\mathrm{H}]^{+}, 429[\mathrm{M}+\mathrm{Na}]^{+}$und $445[\mathrm{M}+\mathrm{K}]^{+}$. Die Hochauflösung des Massenions bei $m / z=407[\mathrm{M}+\mathrm{H}]^{+}$ergibt einen Summenformelvorschlag von $\mathrm{C}_{25} \mathrm{H}_{26} \mathrm{O}_{5}$ (13 Doppelbindungsäquivalente). Das ${ }^{1} \mathrm{H}-\mathrm{NMR}$-Spektrum zeigt mit Ausnahme des verbreiterten Signals der aromatisch gebundenen Sauerstoff-substituierten Methylengruppe und der beiden Methylengruppen vom 1"-O-gebundenen Substituenten eine große Ähnlichkeit zum neuen Derivat Cycloisoemericellinols (156) auf. Hier treten zwei neue Multipletts bei $\delta_{\mathrm{H}}=3.82$ und $5.18 \mathrm{ppm}$ auf, die im ${ }^{1} \mathrm{H},{ }_{1}^{1} \mathrm{H}$-COSY-Spektrum eine Kopplung zeigen. Die chemische Verschiebung des Signals bei $\delta_{\mathrm{H}}=5.18 \mathrm{ppm}$ deutet auf das Vorliegen eines 1"- $O$-Prenylsubstituenten hin. Des Weiteren zeigt das Signal im ${ }^{1} \mathrm{H},{ }^{1} \mathrm{H}-\mathrm{COSY}$-Spektrum eine ${ }^{4} J$-Kopplung $\mathrm{zu}$ den beiden Methylgruppen des 1"- $O$-Prenylsubstituenten bei $\delta_{\mathrm{H}}=1.65$ und $1.72 \mathrm{ppm}$. Anhand dieser Daten kann als Struktur Cycloisoemericellin (157) vorgeschlagen werden. Allerdings liegen die chemische Verschiebungen des 1"-O-Prenylsubstituenten gemäß Literaturdaten ${ }^{175}$ in $\mathrm{CDCl}_{3}$ für die Methylengruppe bei $\delta_{\mathrm{H}}=4.45 \mathrm{ppm}$, für das Methinproton bei $\delta_{\mathrm{H}}=5.62 \mathrm{ppm}$ und die Methylgruppen bei $\delta_{\mathrm{H}}=1.72$ und $1.83 \mathrm{ppm}$ (s. Abbildung 95). Möglicherweise ist die Hochfeldverschiebung dieser Signale auf das Vorliegen der anderen Substanz und Verunreinigungen zurückzuführen. Damit könnte auch erklärt werden, warum die am Aromaten gebundene, in $\mathrm{CDCl}_{3}$ als verbreitertes Singulett auftretende, Methylengruppe vermutlich ins Tieffeld verschoben und von anderen Signalen überlagert wird. Für eine abschließende Strukturaufklärung sind größere Substanzmengen erforderlich, um mit Hilfe von ${ }^{13} \mathrm{C}$-NMR-Daten und ${ }^{2-4} J_{\mathrm{C}, \mathrm{H}}$-Korrelationen aus HSQC- und HMBC-Experimenten eine exakte Strukturzuordnung durchführen zu können.
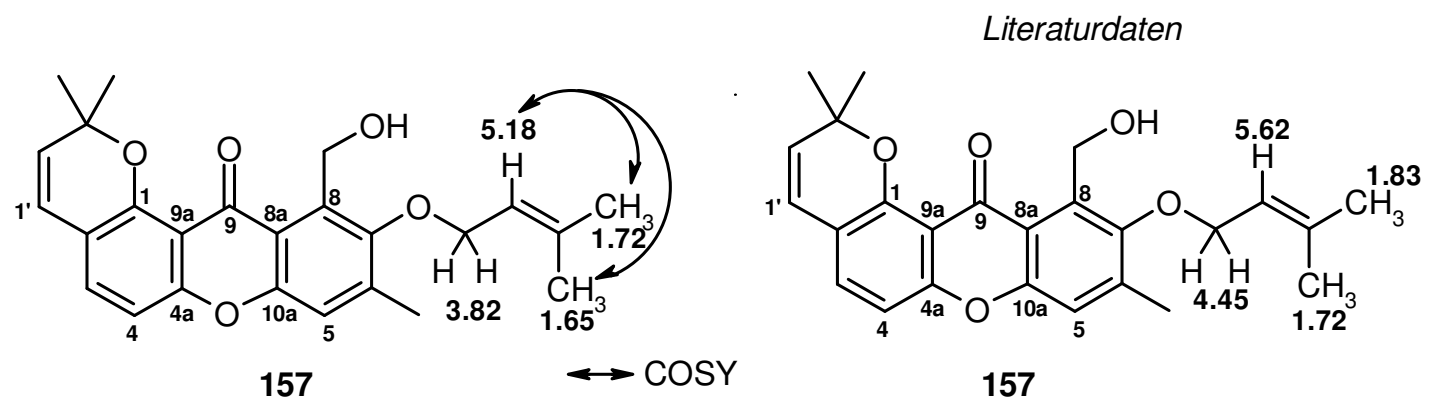

Abbildung 95. Vergleich des 1"-O-Prenylsubstituenten vom Strukturvorschlag mit ${ }^{1} \mathrm{H}-\mathrm{NMR}-\mathrm{Literaturdaten}$ (gemessen in $\mathrm{CDCl}_{3}$ ) des Cycloisoemericellins (157).

Für die zweite Substanz weist das ESI-Massenspektrum Massenaddukte bei $\mathrm{m} / \mathrm{z}=339$ $[\mathrm{M}+\mathrm{H}]^{+}, 361[\mathrm{M}+\mathrm{Na}]^{+}$und $321\left[\mathrm{M}-\mathrm{H}_{2} \mathrm{O}+\mathrm{H}\right]^{+}$auf. Die Hochauflösung des Massenions bei $m / z=339[\mathrm{M}+\mathrm{H}]^{+}$ergibt einen Summenformelvorschlag von $\mathrm{C}_{20} \mathrm{H}_{18} \mathrm{O}_{5}$ (12 Doppelbindungs- 
äquivalente). Eine Datenbankrecherche ${ }^{96,97}$ ergab Übereinstimmung mit einem weiteren Xanthon, dem De- $C$-prenylepishamixanthon (158). ${ }^{176}$ Das ${ }^{1} \mathrm{H}$-NMR-Spektrum des Gemisches zeigt weitere aromatische Signale, die sich allerdings mit denen des vermuteten Cycloisoemericellin (157) überlagern. Weiterhin weisen die Signal bei $\delta_{\mathrm{H}}=2.84,4.18,4.24$, $5.35 \mathrm{ppm}$ im ${ }^{1} \mathrm{H},{ }^{1} \mathrm{H}-\mathrm{COSY}$-Spektrum Kopplungen auf, die zum Strukturfragment des Dihydropyranrings von 158 gehören können, wobei das Signal bei $\delta_{\mathrm{H}}=2.84 \mathrm{ppm}$ im Gegensatz zur Literatur Tieffeld verschoben ist. Außerdem treten zwischen 4.80 und 5.00 ppm nicht wie erwartet die Protonen der exoständigen Doppelbindung des Alkylsubstituenten am Dihydropyranring auf. Ob diese aufgrund des Substanzgemisches oder Verunreinigungen Tieffeld verschoben sind, ist nicht zu klären. Damit kann das Vorliegen des aus der Summenformel erhaltenen Strukturvorschlags nicht verifiziert werden. Auch in diesem Fall kann eine abschließende Strukturaufklärung erst mit größeren Substanzmengen durchgeführt werden, um mit Hilfe von ${ }^{13} \mathrm{C}-\mathrm{NMR}$-Daten und ${ }^{1} J_{\mathrm{C}, \mathrm{H}}$-Korrelationen aus HSQC- bzw. ${ }^{2-4} J_{\mathrm{C}, \mathrm{H}}$-Korrelationen aus HMBC-Experimenten weitere Daten über die Struktur zu erhalten.

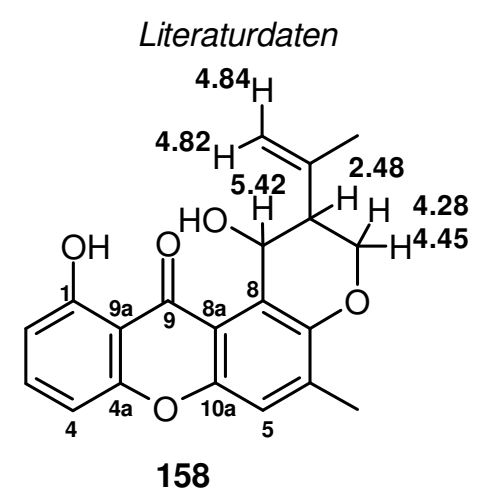

Abbildung 96. Ausgewählte Literaturdaten des De- $C$-Prenylepihamixanthons (158) (gemessen in $\mathrm{CDCl}_{3}$ ).

\section{Emerin (159)}

Das ESI-Massenspektrum zeigt für diese Substanz (,Peak-Neu“, interne Bezeichnung der Arbeits- und Sozialmedizin) Massenaddukte bei $m / z=317[\mathrm{M}+\mathrm{H}]^{+}$und bei $\mathrm{m} / z=339$ $[\mathrm{M}+\mathrm{Na}]^{+}$. Für das Massenion bei $m / z=317[\mathrm{M}+\mathrm{H}]^{+}$ergibt die Hochauflösung die Summenformel $\mathrm{C}_{20} \mathrm{H}_{16} \mathrm{~N}_{2} \mathrm{O}_{2}$. Das ${ }^{1} \mathrm{H}-\mathrm{NMR}$-Spektrum weist zwei Signalsätze auf, von denen einer zugeordnet werden konnte. Im Hochfeld tritt bei $\delta_{\mathrm{H}}=3.86 \mathrm{ppm}$ eine Methoxygruppe auf. Im Tieffeld sind drei Signale zu beobachten, darunter zwei Dubletts aromatischer Protonen $\left(\delta_{\mathrm{H}}=6.79\right.$ und $\left.7.86 \mathrm{ppm}\right)$ die mit ${ }^{3} J_{\mathrm{H}, \mathrm{H}}=9.0 \mathrm{~Hz}$ koppeln und ein AA'BB'-Spinsystem bilden. Das verbliebene Singulett bei $\delta_{\mathrm{H}}=7.54 \mathrm{ppm}$ ist einem olefinischen Methinproton zuzuordnen. Eine Datenbankrecherche ${ }^{96,97}$ ergab Übereinstimung mit Emerin (159), welches auch als Dimethyletherderivat des Xanthocillin bekannt ist. ${ }^{177}$ Ein Vergleich der spektroskopischen 
Daten belegte das Vorliegen von Emerin (159). Zusätzlich wurde ein long-range- ${ }^{1} \mathrm{H},{ }^{1} \mathrm{H},-$ COSY-Experiment durchgeführt, um anhand der ${ }^{4} J$ - und ${ }^{5} J$-Kopplungen zwischen den Protonen 1'-H und 2"/6"-H bzw. 3"/5"-H eindeutig die Struktur zu belegen. Ein zur Überprüfung gemessenes IR-Spektrum zeigte deutlich das Vorliegen der Nitrile mit ihrer charakteristischen Schwingungsbande bei $2222 \mathrm{~cm}^{-1}$.

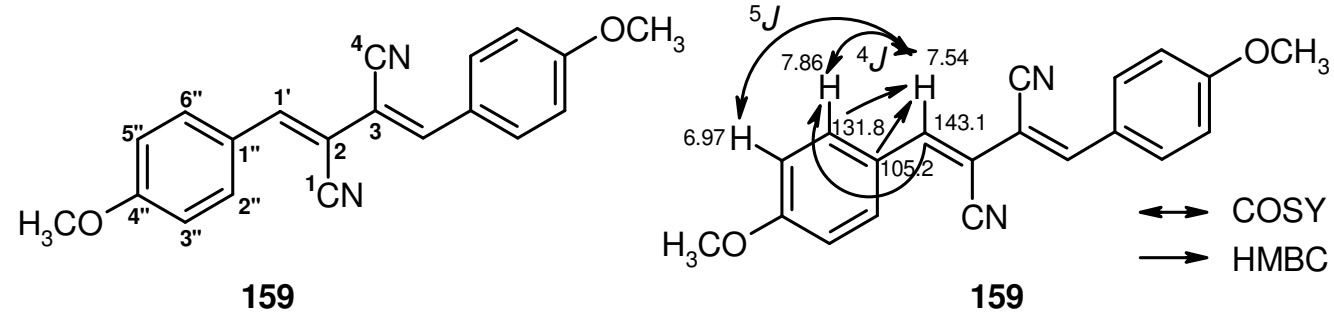

Abbildung 97. Struktur des Emerins (159), ausgewählte ${ }^{2-4} J_{\mathrm{C}, \mathrm{H}}-\mathrm{HMBC}$-Korrelationen sowie ${ }^{4} J$ - und ${ }^{5} J$-Kopplungen aus dem Long-range- ${ }^{1} \mathrm{H},{ }^{1} \mathrm{H}$-COSY-Experiment.

Für das Emerin wird in der Literatur eine antibiotische und antivirale Wirkung beschrieben. ${ }^{177}$ In der biologischen Testung zeigte Emerin keine ausgeprägte Cytotoxizität oder Gentoxizität. ${ }^{194}$

\section{Demethylsterigmatocystin (160)}

Das EI-Massenspektrum eines orange-gelben Feststoffs („Peak 42“, interne Bezeichnung der Arbeits- und Sozialmedizin) zeigt ein Massenion bei $m / z=310$. Die hochauflösende Massenspektrometrie ergab für dieses Ion die Summenformel $\mathrm{C}_{17} \mathrm{H}_{10} \mathrm{O}_{6}$ (13 Doppelbindungsäquivalente). Das ${ }^{1} \mathrm{H}-\mathrm{NMR}$-Spektrum weist im Tieffeld das Spinsystem eines 1,2,3-trisubstituierten Aromaten auf $\left(\delta_{\mathrm{H}}=6.76,6.86,7.54 \mathrm{ppm}\right)$. Zusätzlich treten bei $\delta_{\mathrm{H}}=11.2$ und 12.1 ppm zwei Singuletts von chelatisierenden Hydroxygruppen auf. Ferner können die Resonanzen von fünf Methinprotonen $\left(\delta_{\mathrm{H}}=4.68,5.43,6.45,6.78 \mathrm{ppm}\right)$ beobachtet werden.

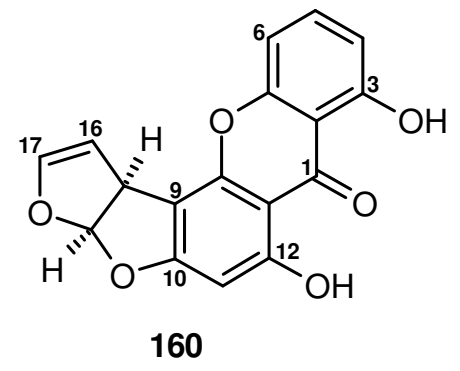

Dem ${ }^{13}$ C-NMR-Spektrum sind Signale von 14 Kohlenstoffatomen im aromatischen/olefinischen Bereich $\mathrm{zu}$ entnehmen, darüber hinaus eine Carbonylfunktion bei $\delta_{\mathrm{C}}=184.7 \mathrm{ppm}$, ein tertiäres C-Atom bei $\delta_{\mathrm{C}}=90.3 \mathrm{ppm}$ und ein aliphatisches tertiäres C- 
Atom bei $\delta_{\mathrm{C}}=47.4 \mathrm{ppm}$, dessen chemische Verschiebung auf einen in direkter Nachbarschaft gebundenen Sauerstoff hinweist. Eine Datenbanksuche ${ }^{96,97}$ führte zum Demethylsterigmatocystin (160), ein Vergleich der gemessenen Daten mit den NMR-Literaturdaten ${ }^{178}$ bestätigte eindeutig das Vorliegen von Demethylsterigmatocystin (160).

160 zeigte bei der biologischen Testung nach metabolischer Aktivierung eine mutagene Wirkung. ${ }^{194} 160$ zählt zu den Mykotoxinen und weist die für die mutagene Wirkung verantwortliche endständige Doppelbindung am Furanring (zwischen C-16 und C-17) auf. Es stellt eine Vorstufe in der Biosynthese des Sterigmatocystins (155) dar, ein von Aspergillus nidulans produziertes Mykotoxin, das akut toxisch und kanzerogen wirkt (s. Abbildung 98). ${ }^{179}$ In Aspergillus flavus und Aspergillus parasiticus bildet es die Vorstufe für das Aflatoxin $B_{1}$ (154), ein Mykotoxin, das erstmals 1960 entdeckt wurde. ${ }^{180}$

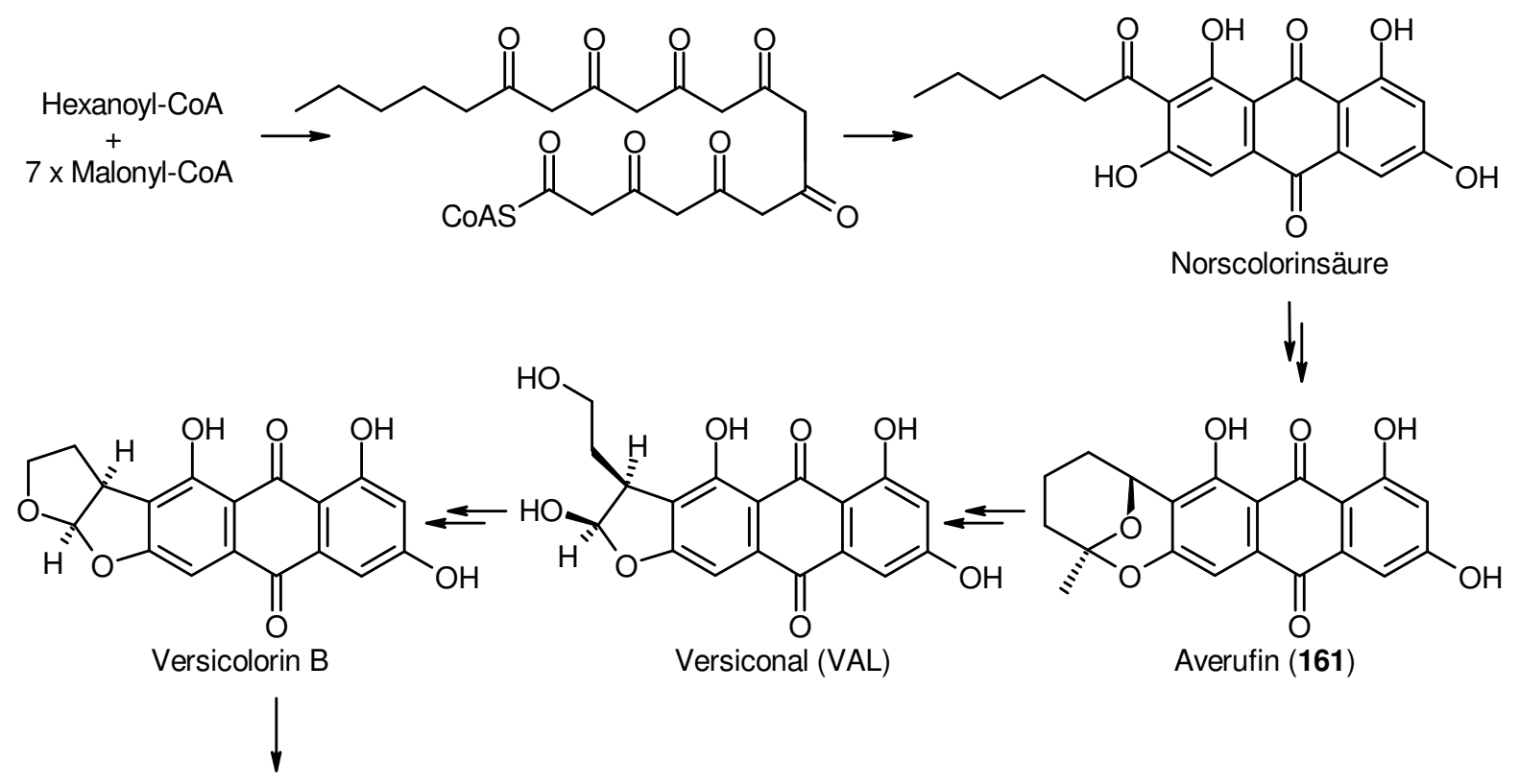

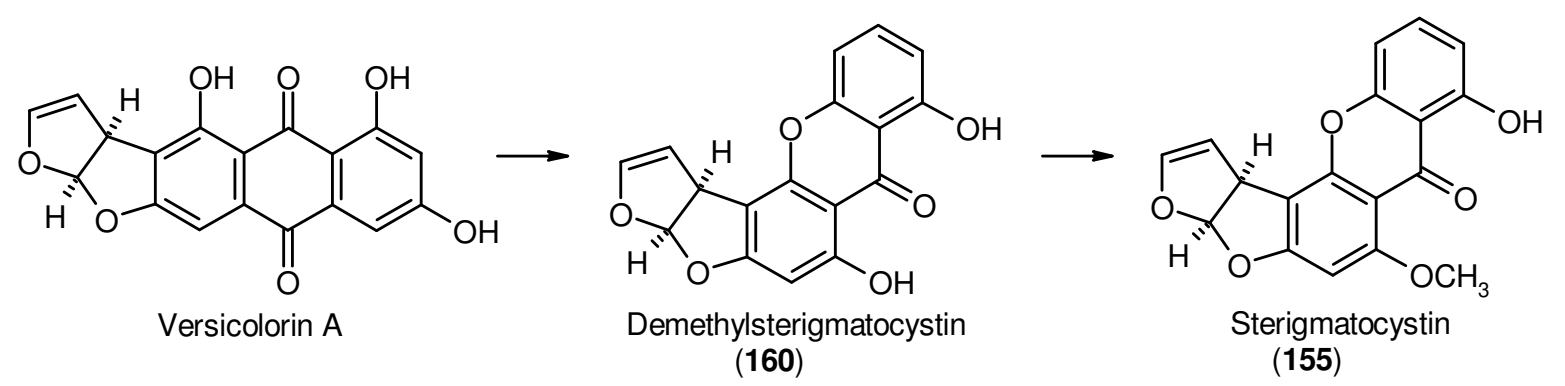

Abbildung 98. Die Biosynthese des Sterigmatocystins (155).

\section{Averufin (161)}

Der rote Farbstoff (,Peak 82“, interne Bezeichnung der Arbeits- und Sozialmedizin) zeigt im ESI-Massenspektrum die Massenaddukte bei $\mathrm{m} / z=391[\mathrm{M}+\mathrm{Na}]^{+}, 759[2 \mathrm{M}+\mathrm{Na}]^{+}$und 367 $[\mathrm{M}-\mathrm{H}]^{-}$. Die Hochauflösung des Massenions bei $m / z=367[\mathrm{M}-\mathrm{H}]^{-}$ergibt die Summenformel 
$\mathrm{C}_{20} \mathrm{H}_{16} \mathrm{O}_{7}$ (13 Doppelbindungsäquivalente). Das ${ }^{1} \mathrm{H}-\mathrm{NMR}-$ Spektrum zeigt Signale für insgesamt 15 Protonen. Im Hochfeld tritt eine aliphatische Alkylkette von drei Methylengruppen auf, zu deren Spinsystem das Singulett eines Methinprotons bei $\delta_{\mathrm{H}}=5.28 \mathrm{ppm}$ gehört, dessen Tieffeldverschiebung auf Sauerstoff zurückzuführen ist. Im Tieffeld des Spektrums sind drei Resonanzen bei $\delta_{\mathrm{H}}=6.47,7.04$ und $7.06 \mathrm{ppm}$ aromatischen Protonen zuzuordnen und zwei verbreiterte Singuletts chelatisierenden Hydroxylgruppen bei $\delta_{\mathrm{H}}=12.1$ und 12.7 ppm. Im ${ }^{13} \mathrm{C}$-NMR-Spektrum treten 20 Kohlenstoffatome auf, darunter zwölf eines Aromaten, wovon vier aufgrund ihrer Tieffeldverschiebung an Sauerstoff gebunden sind. Des Weiteren sind zwei Carbonylfunktionen bei $\delta_{\mathrm{C}}=187.6$ und $181.1 \mathrm{ppm}$ sowie drei Methylengruppen, eine Methylgruppe und ein aliphatisches tertiäres Sauerstoff gebundenes C-Atom bei $\delta_{\mathrm{C}}=66.0 \mathrm{ppm}$. Eine Datenbanksuche ${ }^{96,97}$ ergab Averufin (161), ein Vergleich der gemessenen Daten mit den NMR-Literaturdaten ${ }^{178}$ belegte eindeutig das Vorliegen von Averufin (161). Dies ist ebenfalls eine Vorstufe aus der Biosynthese von Sterigmatocystin (155, s. Abbildung 98).

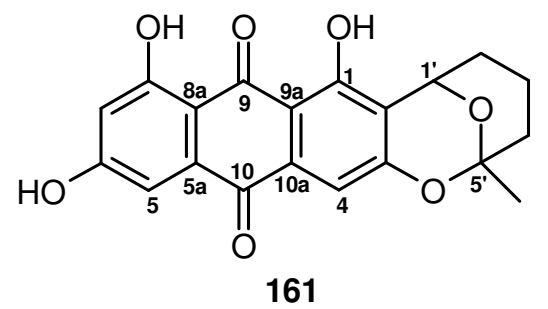

\subsubsection{Verifizierung des neuen Derivats Cycloisoemericellinol (156)}

Zur Untersuchung des Metabolitenspektrums von Pilz Aspergillus nidulans auf Mykotoxine wurden Festphasenkultivierungen und Isolierungsarbeiten von C. Handrich (AK Müller, Arbeits- und Sozialmedizin, Göttingen) durchgeführt. Zur Aufarbeitung wurden die Festphasenkulturen (60-70 Agarplatten, YES-Agar) zerkleinert und mit $\left(\mathrm{CH}_{2} \mathrm{Cl}_{2} / \mathrm{MeOH} 2: 1\right.$, Zusatz von $150 \mu \mathrm{L}$ Ameisensäure auf $30 \mathrm{~mL}$ Lösungsmittel) extrahiert und das Lösungsmittel i. Vak. entfernt. Das Rohprodukt wurde in DMSO aufgenommen und mittels präperativer HPLC (Eurospher 100-7 C18, AcCN/ $\mathrm{H}_{2} \mathrm{O}$, jeweils mit $0.05 \%$ TFA, Gradient, s. Abschnitt B 5.2.1 ) in 5 min-Fraktionen fraktioniert. Die jeweiligen Fraktionen wurden auf Mutagenität und Cytotoxizität untersucht und aktive Fraktionen dann mittels präperativer HPLC (ODSAQ, AcCN/ $\mathrm{H}_{2} \mathrm{O}$, jeweils mit $0.05 \%$ TFA, Gradient, s. Abschnitt B 5.2.1 ) weiter aufgereinigt. $^{181}$

Um zu untersuchen, ob das aus Aspergillus nidulans isolierte Cycloisoemericellinol (156) zum Metabolitenspektrum des Pilzes gehört, oder diese Verbindung erst bei der Aufarbeitung 
durch Zugabe der Ameisensäure zum Extraktionslösungsmittel aus Cycloisoemericellin (157) gebildet wird, wurde die Aufarbeitung variiert. Hierzu wurde zu Festphasenkulturen als Extraktionslösungsmittel $\mathrm{CH}_{2} \mathrm{Cl}_{2} / \mathrm{MeOH}$ 2:1 ohne Zusatz von Säure gegeben und aufgearbeitet. Die wässrige Phase wurde noch einmal mit Dichlormethan extrahiert, die organischen Phasen vereinigt und das Lösungsmittel bis zur Trockne entfernt.

\section{HPLC-ESI-MS-Analytik}

Für die vergleichende HPLC-ESI-MS-Analyse wurden die Rohextrakte der jeweiligen Aufarbeitungen mit und ohne Säure sowie die Reinsubstanz (156) im positiven und negativen Mode gemessen (HPLC D, Säule A: Grom Superspher 100, RP-18, Programm B: $\mathrm{MeOH} / \mathrm{H}_{2} \mathrm{O}$, jeweils mit $0.05 \%$ Ameisensäure, Gradient; s. Abschnitt B 1.2 ). Hierfür wurden die Rohextrakte in einer Konzentration von $c=5.0 \mathrm{mg} / \mathrm{mL}$ in Methanol gelöst, die Reinsubstanz (156) in einer Konzentration von $c=1.0 \mathrm{mg} / \mathrm{mL}$ in Methanol gelöst und alle Proben mittels HPLC-ESI-MS analysiert.

Die HPLC-ESI-MS-Analyse zeigte für die Reinsubstanz (156) bei einer Retentionszeit von $\mathrm{R}_{\mathrm{t}}=25.9$ min die zugehörigen Massenaddukte bei $\mathrm{m} / \mathrm{z}=425[\mathrm{M}+\mathrm{H}]^{+}, 447[\mathrm{M}+\mathrm{Na}]^{+}$und 871 $[2 \mathrm{M}+\mathrm{Na}]^{+}$. Bei $\mathrm{R}_{\mathrm{t}}=28.0 \mathrm{~min}$ konnten in sehr geringen Mengen die Ionen bei $\mathrm{m} / \mathrm{z}=407$ $[\mathrm{M}+\mathrm{H}]^{+}, 429[\mathrm{M}+\mathrm{Na}]^{+}$und $835[2 \mathrm{M}+\mathrm{Na}]^{+}$detektiert werden. Diese Massenaddukte entsprechen einer Abspaltung von Wasser, das hierbei resultierende Produkt weist das Massenion bei $m / z=407[\mathrm{M}+\mathrm{H}]^{+}$vom Cycloisoemericellin (157) auf. Für das Lyophilisat, das aus der sauren Aufarbeitung erhalten wurde, konnte bei gleicher Retentionszeit von $R_{t}=25.9$ min die der Reinsubstanz 156 entsprechenden Massenaddukte beobachtet werden. Die nach Abspaltung von Wasser resultierende Masse bei $m / z=407[\mathrm{M}+\mathrm{H}]^{+}$konnte mit entsprechenden Massenaddukten bei $\mathrm{R}_{\mathrm{t}}=28.0$ min detektiert werden. Die HPLC-ESI-MS-Analyse für das aus eigenen Arbeiten erhaltene Rohextrakt zeigte mit dem Lyophilisat und der Reinsubstanz (156) übereinstimmende Retentionszeiten und Massen. Auch hier konnte die Bildung von 157 beobachtet werden. Allerdings lassen die lediglich in Spuren detektierten Massen auf eine Abspaltung von Wasser unter den Lösungsmittelbedingungen der Analyse schließen. Eine Addition von Wasser an die Doppelbindung ist unter den gewählten Bedingungen der Analysenmethode in sehr geringen Mengen nicht auszuschließen, aber eine vollständige Derivatisierung sollte nicht möglich sein. Damit konnte im Rahmen der eigenen Arbeiten eindeutig gezeigt werden, dass der Pilzstamm A. nidulans dieses neue Derivat Cycloisoemericellinol (156) selbst produziert und eine Bildung während der Aufarbeitung ausgeschlossen werden kann. 


\section{Zusammenfassung der Ergebnisse}

\subsection{BMBF-Verbundprojekt}

Im Rahmen des vom BMBF geförderten Netzwerks „Neue Anti-Biofilmstrategien aus dem Metagenom“ war die Identifizierung von neuen Biofilminhibitoren zur Hemmung der Biofilmbildung mit Hilfe der Metagenom-Strategie das Ziel. In der vorliegenden Arbeit ging es um das Teilprojekt „Synthese und Chemische Analyse neuer Biofilminhibitoren“.

\section{Kooperation Arbeitsgruppe K. Jung (LMU München)}

Durch Totalsynthese und Reinigung der Quorum-Sensing-Moleküle Autoinducer 1 (AI-1, 19) und Autoinducer 2 (AI-2, 20) wurden diese in ausreichenden Mengen und ohne die bisher üblichen toxischen Nebenprodukte für den Projektpartner $K$. Jung dargestellt: Die Totalsynthese des Autoinducer AI-1 (19) und seiner enantiomerenreiner Epimere $R, S$-29 und S,S-30 gelang über die Schützung der Hydroxyfunktion vom Natriumsalz des 3-Hydroxybutyrats (43) mit TBS-Chlorid, EDC-vermittelter Kupplung mit $\alpha$-Amino- $\gamma$-butyrolactonhydrobromid (44) und anschließender Entschützung des Silylethers 50 in einer Gesamtausbeute von $30 \%$ über 4 Stufen. Die biologische Aktivität der Reinstoffe aus der Synthese wurde im Bioassay mit $V$. harveyi in München getestet. Hierbei zeigte das $(R, S)$-AI-1 (29) die stärkste Stimulation der Biolumineszenz.

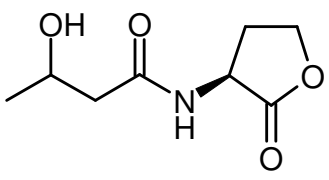

Al1 (19)

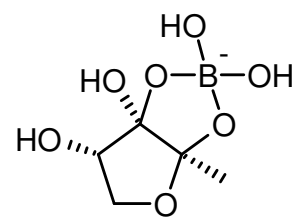

Al-2 (20)

Der Autoinducer AI-2 (20) konnte nach enzymatischer Synthese mit Hilfe einer Affinitätschromatographie bis auf $98 \%$ gereinigt werden. Dies wurde mit dem Reporterstamm V. harveyi MM77 überprüft. Damit war eine erfolgreiche Reinigungsmethode für die Arbeitsgruppe K. Jung etabliert worden, die einen schnellen und effizienten Zugang zu reinem AI-2 (20) bot und geplante molekularbiologische Forschungsarbeiten überhaupt erst ermöglichte.

\section{Kooperation Arbeitsgruppe W. Streit (Universität Hamburg)}

Die Quorum-Quenching-Aktivität von Biofilm-inhibierenden Metagenom-Klonen (BpiBProteine) wurde im Rahmen der vorliegenden Arbeit mit Hilfe der HPLC-ESI-MS-Analyse eindeutig als Lactonase-Aktivität verifiziert. Lactonasen führen durch Hydrolyse des Lactonringes von $N$-Acylhomoserinlactonen (AHL) zum biologisch inaktiven $N$-Acylhomoserin. Es 
wurde die enzymatische Aktivität der neuen Lactonasen mit den Substraten 3-Oxo- $\mathrm{C}_{8}-\mathrm{HSL}$ (62) und $\mathrm{C}_{12}$-HSL (64) untersucht.
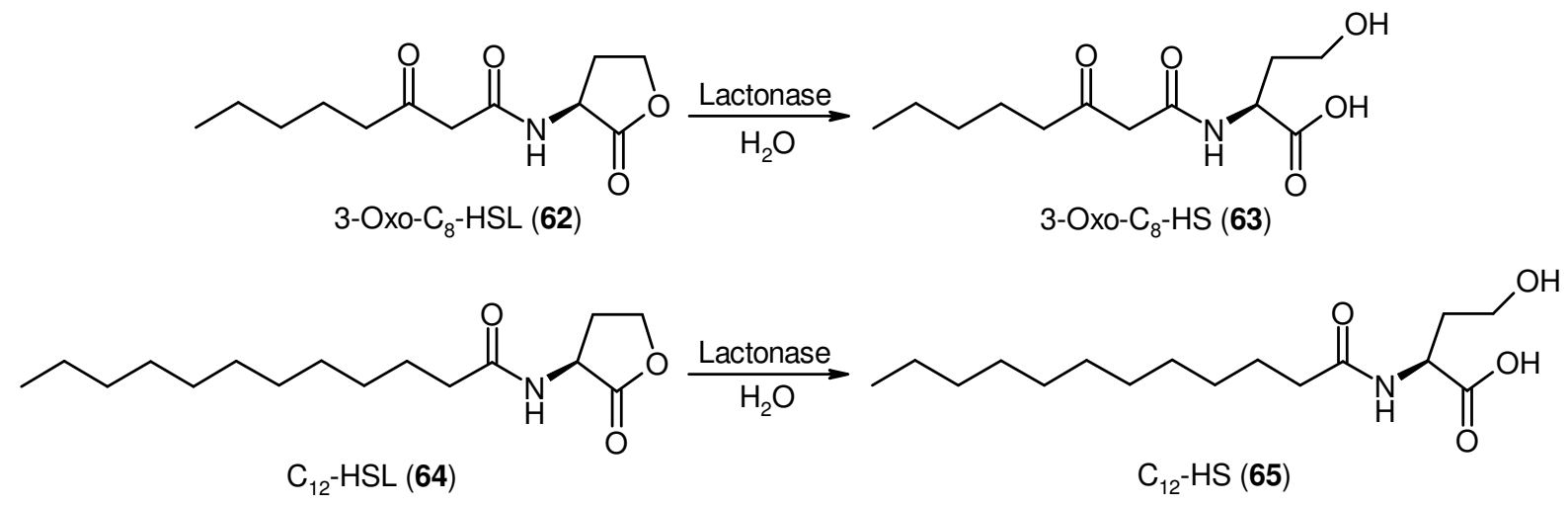

Ein reproduzierbares und verlässlich effizientes Protokoll zur HPLC-ESI-MS-Analyse wurde entwickelt, die Nachweisgrenze bestimmt, Kontrollexperimente etabliert und auch die Enzymreaktionen bei den biologischen Partnern in reger Absprache intensiv optimiert. So führte die Zugabe des AHL in DMSO zu optimierten Inkubationsbedingungen für die BpiBProteine und damit zu einer Erhöhung der enzymatischen Aktivität. Eine Detektion der spezifischen Massenaddukte des $\mathrm{N}$-Acylhomoserins 3-Oxo- $\mathrm{C}_{8}-\mathrm{HS}$ (63) und der Vergleich mit chemisch hydrolysiertem Spaltprodukt, bestätigte die Lactonase-Aktivität der BpiB-Proteine. Zudem wurden neben dem 3-Oxo-C $\mathrm{C}_{8}$-HSL (62) zwei weitere Substrate wie $\mathrm{C}_{12}$-HSL (64) und 3-Oxo-C 6 -HSL (62) hinsichtlich einer Erhöhung der Enzymaktivität untersucht.

\section{Kooperation Arbeitsgruppe R. Schmitz-Streit (Universität Kiel)}

Für Untersuchungen der biologischen Aktivität von Quorum-Sensing-inhibierenden Metagenom-Klonen wurden mit Hilfe verschiedener chemischer Methoden Rohextrakte von Kulturüberständen hergestellt. Keiner der Extrakte zeigte in Folgeexperimenten eine reproduzierbare Bioaktivität, so dass small molecules als Anti-Quorum-Sensing-Moleküle ausgeschlossen werden und nun Proteinanalytik zum Einsatz kommt.

Mit Hilfe der etablierten HPLC-ESI-MS-Analyse für die Detektion von Reaktionsprodukten aus dem enzymatischen Abbau von $N$-Acylhomoserinlactonen konnte ein QuorumQuenching-Mechanismus für einen positiv eingeschätzten Klon ausgeschlossen werden. Die Entwicklung von Methoden zur Analyse von Quorum-Sensing-inhibierenden Klonen des AI-2-Typs ist ein reizvolles weiteres Ziel der chemischen Analyse in Kooperation mit der Arbeitsgruppe R. Schmitz-Streit. 


\subsection{Assoziierte Streptomyceten aus marinen Invertebraten}

\subsubsection{Der Produzent Streptomyces sp. JP90}

Synthetische Arbeiten zum Cinnamoylphosphoramid und seinem Säurederivat

Im Rahmen der vorliegenden Arbeit konnte die chromatographische Reinigung des Rohprodukts von synthetisch hergestelltem Cinnamoylphosphoramid (21) an reversed-phase Kieselgel optimiert werden. Dies führte ausgehend von $82 \mathrm{zu}$ einer Optimierung der Gesamtausbeute des Cinnamoylphosphoramids (21) von zuvor $16 \%$ nach Reinigung an Kieselgel auf $55 \%$ nach Reinigung an reversed-phase Kieselgel.

Die Bioaktivität des Cinnamoylphosphoramids (21) ist von großem Interesse, da die chemische Struktur dieses Moleküls dem Grundgerüst von Organophosphorsäureestern entspricht. Erste Untersuchungen zur Inhibition der Acetylcholinesterase ergaben jedoch aufgrund der schlechten Löslichkeit nur eine schwache Hemmung. Zur genauen Bestimmung des $\mathrm{IC}_{50}$-Wertes wurde das Säurederivat von 21 als wasserlösliches Analogon dargestellt. Versuche das Säurederivat (92) ausgehend von 21 durch enzymatische oder milde basische Hydrolyse zu synthetisieren oder eine geplante Sequenz zur Reduktion des Methylesters 21 zum Alkohol und anschließender Oxidation zur Säure führten nicht zum Ziel. Daher wurde die Synthese ausgehend vom Silyl-geschützten Ester der 4-Hydroxyzimtsäure (96) analog zur Totalsynthese von 21 durchgeführt. Aufbauend auf den synthetischen Arbeiten zum $\mathbf{2 1}$ gelang P. v. Zezschwitz die Synthese der Zielverbindung 92 in einer Ausbeute von $43 \%$. Die anschließende Reinigung des Rohprodukts, ein 10:1 Gemisch aus Produkt und durch Zersetzung erhaltenes Phenol, wurde im Rahmen dieser Dissertation mittels Gelchromatographie an Sephadex-LH 20 (Methanol) durchgeführt. 21 und das Säurederivat 92 zeigten nur eine sehr schwache inhibitorische Aktivität gegenüber der Acetylcholinesterase $\left(\mathrm{IC}_{50}>350 \mu \mathrm{M}\right)$. Weitere Untersuchungen der potentiellen Inhibitoren mit der Butyrylcholinesterase (BChE) ergaben für 21 einen $\mathrm{IC}_{50}=250 \mu \mathrm{M}$ und keine signifikante Aktivität für das Säurederivat 92 . Synthetisches racemisches Cinnamoylphosphoramid (21) zeigte jedoch in durchgeführten in vitro-Tests mit dem Parasiten Leishmania donovani mit einem $\mathrm{IC}_{50}$-Wert $=0.11 \mu \mathrm{g} / \mathrm{mL}$ eine höhere Aktivität als der Standard Miltefosin $\left(\mathbf{1 3 7}, \mathrm{IC}_{50}\right.$-Wert $=0.21 \mu \mathrm{g} / \mathrm{mL}$ ) (in Kooperation mit M. Kaiser, Schweizer Tropeninstitut, Basel). Zur Verifizierung der Aktivität sollen die beiden synthetischen Enantiomere $(R)$-21 und $(S)$-21 auf ihre Wirkung gegen den Erreger der L. donovani untersucht werden. 


\section{Studien zur Biosynthese und ökologischen Chemie}

Die im Rahmen der Diplomarbeit begonnenen Arbeiten zur Strukturaufklärung des aus Stamm JP90 isolierten Sekundärstoffs wurden in der vorliegenden Arbeit erfolgreich abgeschlossen. Die Naturstoffklasse der Spirotetronate aus Stamm JP90 wurde um ein literaturbekanntes Analogon (22b) erweitert, seine Struktur wurde aufgeklärt und abgesichert.

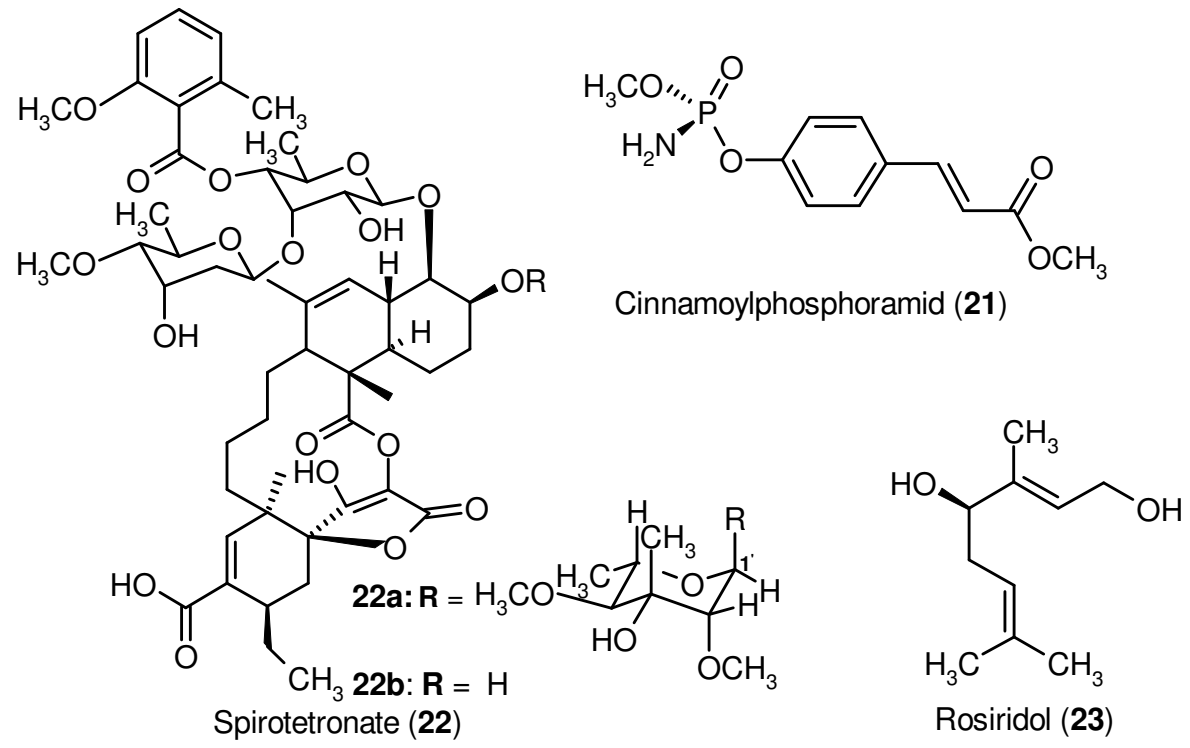

Mit Hilfe von Fütterungsexperimenten mit ${ }^{13} \mathrm{C}$-markierten Biosynthesevorläufern konnte die Biosynthese der Spirotetronate (22) mit dem bekannten Chlorothricin (105) verglichen werden. Die beobachteten Einbaumuster aus Fütterungsexperimenten mit $\left[1,2-{ }^{13} \mathrm{C}_{2}\right]$ Acetat und $\left[\mathrm{U}_{-}{ }^{13} \mathrm{C}_{3}\right]$ Glycerin belegen einen polyketidischen Ursprung des Aglykons, bestehend aus sechs Acetat- und fünf Propionat-Einheiten. Die Herkunft der mit $\left[1,2-{ }^{13} \mathrm{C}_{2}\right]$ Acetat nicht angereicherten $\mathrm{C}_{3}$-Einheit (C-20/C-21/C-22) konnte mit Hilfe von $\left[\mathrm{U}_{-}{ }^{13} \mathrm{C}_{3}\right]$ Glycerin auf den Vorläufer Glycerin zurückgeführt werden. Die Anordnung der Polyketidkette ermöglicht auch in 22 die Bildung des trans-Decalin-Ringsystems über eine Cycloaddition. Im nächsten Schritt entsteht durch eine Kondensationsreaktion zwischen dem aus Glycerin stammenden $\mathrm{C}_{3}$-Baustein mit der Polyketidkette und nachfolgender intramolekularer Cycloaddition die spiroverknüpfte Acyltetronsäure, welche abschließend in ein Makrolid umgewandelt wird.

Rosiridol (23) ist bisher nur ein aus Pflanzen isoliertes Monoterpen, dessen biosynthetischer Aufbau hinsichtlich Acetat-Mevalonat- oder Triose-Pyruvat-Weg ungeklärt ist.

Fütterungsexperimente mit den ${ }^{13} \mathrm{C}$-markierten Vorläufern Natrium-[1,2- $\left.{ }^{13} \mathrm{C}_{2}\right]$ Acetat und $\left[\mathrm{U}_{-}{ }^{13} \mathrm{C}_{3}\right]$ Glycerin zeigten, über welchen Stoffwechselweg der Stamm JP90 das Monoterpen Rosiridol (23) aufbaut. Die ${ }^{13} \mathrm{C}-\mathrm{NMR}$-Analyse der beobachteten Einbaumuster ergab, dass die Biosynthese von 23 über den Triose-Pyruvat-Weg erfolgt. Zusätzlich konnten im beob- 
achteten Einbaumuster aus dem Fütterungsexperiment mit $\left[\mathrm{U}_{-}{ }^{13} \mathrm{C}_{3}\right]$ Glycerin Hinweise auf einen geringen Anteil von Rosiridol (23) aus dem Acetat-Mevalonat-Weg gefunden werden. In der vorliegenden Arbeit wurde zur Untersuchung der Funktion von 21 dem Stamm JP90 rac-Syntheseprodukt 21 und die Strukturanaloga 4-Hydroxyzimtsäuremethylester (82), Zimtsäuremethylester (93) und Zimtsäure (122) zugefüttert. Es konnte jedoch keine Veränderung des Metabolitenmusters oder eine Produktionssteigerung hinsichtlich neuer Sekundärmetaboliten beobachtet werden. Damit konnte keine naheliegende ökologische Funktion des Cinnamoylphosphoramids (21) als aktivierter Biosynthesevorläufer für den Produzenten Stamm JP90 aufgezeigt werden.

\subsubsection{Der Produzent Streptomyces sp. Pol001}

In diesem Kooperationsprojekt mit U. Hentschel (Universität Würzburg) wurde das Metabolitenspektrum des Streptomyces Stamm Pol001 auf die Produktion eines neuen Glykopeptids (24) untersucht. Die Struktur dieses neuen Glykopeptids (24), bei dem es sich um das erste Glykopeptid des Vancomycin-Typs mit mindestens einem Sulfatsubstituenten handeln könnte, wurde von M. Scheuermayer ${ }^{30}$ aus dem identifizierten Biosynthesegencluster abgeleitet.

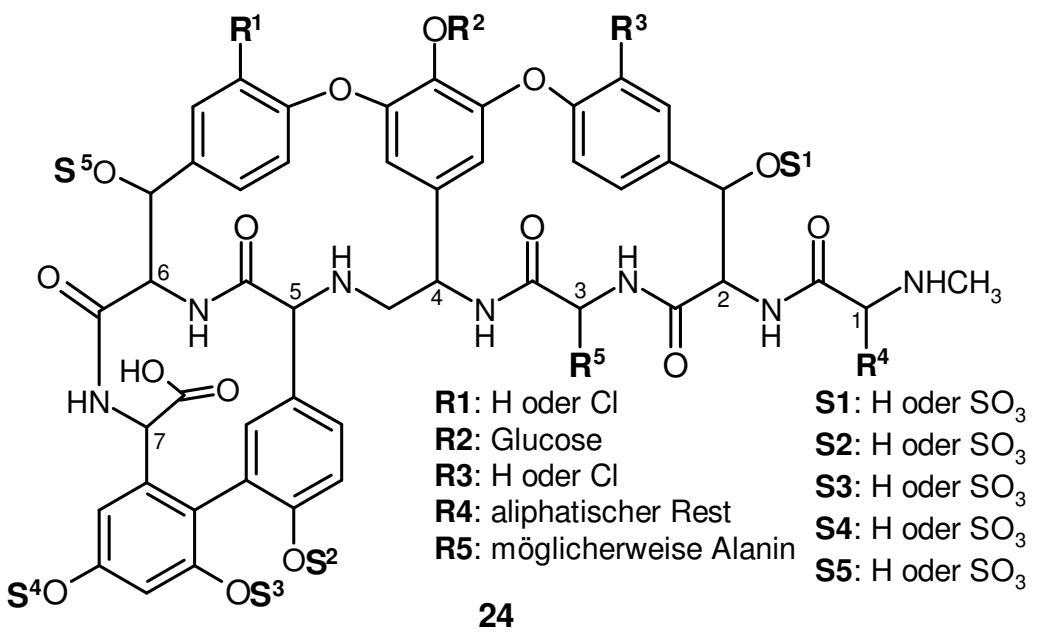

Mit Hilfe von HPLC-ESI-MS-Analysen konnte die Produktion von zwei Glykopeptiden, Vancomycin (1) und vermutlich $N$-Methylvancomycin (151) aufgezeigt werden. Weitere Glykopeptide des Vancomycin-Typs mit spezifischem Chlor-Isotopenmuster wurden nicht gefunden. Allerdings konnte im Mycelrohextrakt ein mit Anisaldehyd pink anfärbbarer Metabolit im Polaritätsbereich von Vancomycin (1) detektiert werden. Die Optimierung der Fermentationsbedingungen gemäß des OSMAC-Ansatzes ${ }^{182}$ des Stammes Pol001 führte unter Zusatz der Vorläufer L-Hpg/Malonsäure bzw. D-Hpg/Malonsäure zur Produktionssteigerung dieses pink anfärbbaren Metaboliten. Es handelt sich vermutlich um einen Metaboliten der 
zugefütterten Malonsäure. HPLC-ESI-MS-Analysen ließen ebenfalls eine Produktionssteigerung von Vancomycin (1) erkennen, jedoch konnte kein spezifisches Chlor-Isotopenmuster für das vorhergesagte Glykopeptid (24) detektiert werden. Damit konnte im Rahmen dieser Arbeit die Produktion eines neuen Glykopeptids (24) nicht nachgewiesen werden, es handelt sich um einen sogenannten „stillen Biosynthesegencluster“.

\subsection{Mykotoxine aus Aspergillus nidulans}

In der Arbeitsgruppe M. Müller (Arbeits- und Sozialmedizin, Universität Göttingen) wurden verschiedene Schimmelpilz-Extrakte auf Cytotoxizität und Gentoxizität untersucht, nachdem diese als Ursache für chronische Atemwegserkrankungen bei Mitarbeitern einer Kompostieranlage identifiziert worden waren. Ein Extrakt des Pilzes Aspergillus nidulans fiel durch einen besonders starken cytotoxischen Effekt auf, dessen Stärke nicht allein auf den Gehalt von Sterigmatocystin (155) im Extrakt zurückgeführt werden konnte. Aus diesem Grund sollte das für diese Cytotoxizität verantwortliche Mykotoxin aus dem Extrakt isoliert und in seiner Struktur aufgeklärt werden.

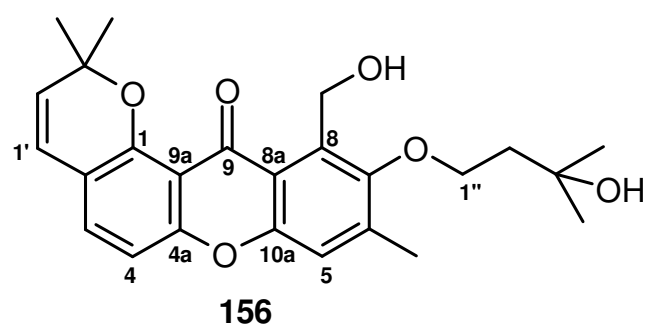

Für die von C. Handrich (Arbeitsgruppe M. Müller) isolierten Sekundärstoffe aus dem Pilz Aspergillus nidulans erfolgte die Strukturaufklärung mit Hilfe von spektroskopischen und spektrometrischen Methoden. Hierbei wurde die Struktur des neuen Derivats Cycloisoemericellinol (156) aufgeklärt, das formal eine Addition von Wasser am $O$-Prenylsubstituenten aufweist. Um zu prüfen, ob diese Verbindung erst bei der sauren Aufarbeitung gebildet wurde und nicht zum nativen Metabolitenspektrum des A. nidulans gehört, erfolgte in eigenen Arbeiten eine Aufarbeitung ohne Zugabe von Säure. Eine HPLC-ESI-MS-Analyse der Rohextrakte aus den Aufarbeitungen mit und ohne Säure sowie der Reinsubstanz im Vergleich zeigte eindeutig, dass es sich bei Verbindung 156 um einen ursprünglich gebildeten Sekundärstoff aus dem Metabolitenspektrums des A. nidulans handelt. 156 weist eine cytotoxische Wirkung als Topoisomerasehemmer auf.

Als weitere Metaboliten konnten Demethylsterigmatocystin (160) und Averufin (161), zwei Vorstufen aus der Biosynthese von Sterigmatocystin (155) identifiziert werden. Letzteres weist wie Sterigmatocystin (155) eine gentoxische Wirkung auf. Außerdem konnte das 
Emerin (159) identifiziert werden, das weder eine cytotoxische noch mutagene Wirkung besitzt.<smiles>O=c1c2c(O)cccc2oc2c3c(cc(O)c12)O[C@H]1O[I+]C[C@H]31</smiles>

160<smiles></smiles>

161<smiles>COc1ccc(C=C(C#N)C(C#N)=Cc2ccc(OC)cc2)cc1</smiles> 



\section{B EXPERIMENTELLER TEIL}

\section{Allgemeines}

\subsection{Instrumentelle Analytik}

Massenspektren: ESI-MS: Finnigan Ion-Trap-Massenspektrometer LC-Q. EI-MS: Finnigan Doppelfokussierendes Sektorfeld-Massenspektrometer MAT 95, 70 eV. Hochauflösungen wurden mit Perfluorkerosin als Vergleichssubstanz gemessen. DCI-MS: Finnigan MAT $95200 \mathrm{eV}$ (Reaktandgas: NH$_{3}$ ). HR-ESI-MS: Bruker Apex IV (FTICR), 7 Tesla, Bruker microTOF (TOF-MS). Angegeben sind jeweils die Quotienten aus Masse zu Ladung $(\mathrm{m} / \mathrm{z})$ sowie die relativen Intensitäten bezogen auf den Basispeak.

Infrarotspektren: Alle IR-Spektren wurden mit einem FT-IR Spektrometer der Firma Perkin-Elmer Modell 1600 gemessen. Die Substanzen wurden in Form von KBr-Presslingen vermessen. Abkürzungen: $\mathrm{br}=$ breit, $\mathrm{sh}=$ Schulter.

UV-VIS-Spektren: Alle Elektronenspektren wurden mit einem Spektrometer der Firma Varian Modell Cary 3E gemessen. Die UV-Spektren wurden im sauren und basischen Milieu nach Zugabe von einem Tropfen $1 \mathrm{M} \mathrm{HCl}$ bzw. $1 \mathrm{M} \mathrm{NaOH}$ zu $2 \mathrm{~mL}$ einer methanolischen Lösung der Substanzen vermessen. Die Wellenlänge $(\lambda)$ ist in $[\mathrm{nm}]$ angegeben, $\mathrm{sh}=$ Schulter. Der molare Extinktionskoeffizient $\varepsilon$ ist in $\left[1000 \mathrm{~cm}^{2} \mathrm{~mol}^{-1}\right]$ angegeben, und wurde unter Berücksichtigung gerätespezifischer Konstanten mit nachfolgender Gleichung berechnet:

$$
\varepsilon\left[1000 \mathrm{~cm}^{2} \mathrm{~mol}^{-1}\right]=\frac{E \cdot \text { Molmasse } \cdot 10}{\text { Einwaage }[\mathrm{mg}]}
$$

Circulardichroismus-Spektren: Jasco Modell J 810. Die molaren Elliptizitäten $\theta$ sind in $\left[10^{-1} \mathrm{deg} \mathrm{cm}^{2} \mathrm{~mol}^{-1}\right]$ angegeben.

Drehwerte: Die Drehwerte wurden an einem Perkin-Elmer Modell 343 Digital-Polarimeter bei einer Wellenlänge von $589 \mathrm{~nm}$ (Na-D-Linie) in einer $1.0 \mathrm{dm}$-Messzelle mit einem Volumen von $1 \mathrm{~mL}$ gemessen. Die Angabe des Drehwertes $[\alpha]_{D}^{20}$ erfolgt in Grad pro Dezimeter bei der angegebenen Temperatur und einer Konzentrationsangabe in Gramm pro $100 \mathrm{~mL}$ des verwendeten Lösungsmittels. 
Schmelzpunkte: Heiztischmikroskop der Fa. Reichert; die Schmelzpunkte sind unkorrigiert.

Elementaranalysen: Mikroanalytische Labore des Instituts für Organische und Biomolekulare Chemie sowie des Instituts für Anorganische Chemie der Universität Göttingen.

${ }^{\mathbf{1} H-N M R-S p e k t r e n: ~ V a r i a n ~ I n o v a-600 ~(600 ~ M H z), ~ V a r i a n ~ M e r c u r y-300 ~(300 ~ M H z), ~ V a r i a n ~}$ Inova-300 (300 MHz). Chemische Verschiebungen wurden in $\delta$-Werten (ppm) relativ zum jeweiligen Lösungsmittel als internen Standard angegeben; Kopplungskonstanten $(J)$ in Hertz $(\mathrm{Hz})$. Soweit nicht anders angegeben, handelt es sich bei den Kopplungen um skalare ${ }^{3} J(\mathrm{H}, \mathrm{H})$-Kopplungen. Die ${ }^{1} \mathrm{H}-\mathrm{NMR}-$ Spektren wurden näherungsweise als Spektren erster Ordnung interpretiert. Abkürzungen: $\mathrm{s}=$ Singulett, $\mathrm{d}=$ Dublett, $\mathrm{t}=$ Triplett, $\mathrm{q}=$ Quartett, dd $=$ Dublett vom Dublett, ddd $=$ Dublett vom Dublett vom Dublett, dddd $=$ Dublett vom Dublett vom Dublett vom Dublett, $\mathrm{dt}=$ Dublett vom Triplett, $\mathrm{tt}=$ Triplett vom Triplett, $\mathrm{qt}=$ Quartett vom Triplett, $\mathrm{m}=$ Multiplett, $\mathrm{br}=$ breit .

${ }^{13}$ C-NMR-Spektren: Varian Inova 600 (150.8 MHz), Varian Inova 500 (125.7 MHz) unter Verwendung einer Kryosonde ${ }^{13} \mathrm{C}\left\{{ }^{1} \mathrm{H}\right\} \quad P F G$ Cold Probe der Firma Varian bei einer Empfänger- und Verstärkertemperatur von $25 \mathrm{~K}$ gemessen, Varian Mercury-300 (75.5 MHz). Alle chemischen Verschiebungen wurden in $\delta$-Werten (ppm) relativ zum jeweiligen Lösungsmittel als internem Standard angegeben. ${ }^{13} \mathrm{C}$ - ${ }^{1} \mathrm{H}$-Multiplizitäten wurden aus ${ }^{1} J_{\mathrm{CH}}-$ Korrelationsexperimenten oder APT-Spektren entnommen. Abkürzungen: $s=$ Singulett, $d=$ Dublett, $\mathrm{t}=$ Triplett, $\mathrm{q}=$ Quartett, APT $=\underline{\text { Attached Proton }}$ Test: $\mathrm{CH}(\mathrm{d})$ und $\mathrm{CH}_{3}(\mathrm{q})$ stehen nach oben, $\mathrm{C}(\mathrm{s})$ und $\mathrm{CH}_{2}(\mathrm{t})$ stehen nach unten.

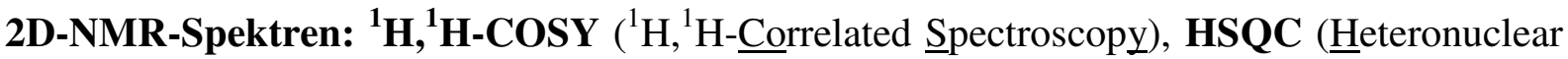

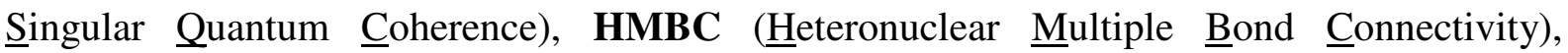

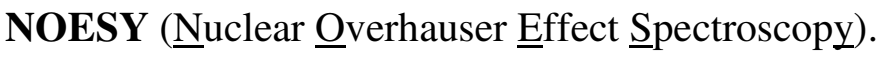

\subsection{Chromatographische Methoden}

Lösungsmittel: Die Lösungsmittel für die Chromatographie wurden zuvor destilliert. Für die HPLC wurden nur analysenreine Lösungsmittel (Merck) und bidestilliertes Wasser verwendet. Vor Benutzung wurden die Lösungsmittel für die HPLC zunächst für jeweils 10 Minuten im Ultraschallbad und anschließendem Durchleiten von Helium entgast. 
Dünnschichtchromatographie (DC): Merck HPTLC-Fertigplatten Kieselgel $60 \mathrm{~F}_{254}$, 10 x $10 \mathrm{~cm}$, Schichtdicke $0.2 \mathrm{~mm}$; Merck DC-Alufolien Kieselgel $60 \mathrm{~F}_{254}, 20$ x $20 \mathrm{~cm}$, Schichtdicke $0.2 \mathrm{~mm}$; Merck DC-Alufolien RP-18 $\mathrm{F}_{254 \mathrm{~s}}, 20$ x $20 \mathrm{~cm}$, Schichtdicke $0.2 \mathrm{~mm}$. Angegeben sind $\mathrm{R}_{\mathrm{f}}$-Werte (Laufhöhe relativ zur Laufmittelfront).

Anfärbereagenzien: Nach Merck, Anfärbereagenzien für die Dünnschichtchromatographie $^{183}$. Die DC-Platten wurden nach dem Ansprühen auf ca. $100^{\circ} \mathrm{C}$ erwärmt.

Anisaldehyd (Nr. 21): $1.0 \mathrm{~mL}$ Anisaldehyd in einer Lösung aus $85 \mathrm{~mL}$ Methanol, $10 \mathrm{~mL}$ Eisessig und $5 \mathrm{~mL}$ konz. Schwefelsäure, Sprühreagenz.

Ehrlichs Reagenz (Nr. 91): 1 g 4-Dimethylaminobenzaldehyd in einer Lösung aus $25 \mathrm{~mL}$ Salzsäure (36\%) und 75 mL Methanol, Sprühreagenz.

Orcin-Sprühreagenz (Nr. 120-122): $1 \mathrm{~g}$ Eisen-(III)-chlorid in $100 \mathrm{~mL}$ Schwefelsäure gelöst, wurden mit gleichen Anteilen einer Orcinlösung (6\% in Ethanol) gemischt, Sprühreagenz.

Vanillin-Schwefelsäure (Nr. 322): $1 \mathrm{~g}$ Vanillin wird in $100 \mathrm{~mL}$ konz. Scwefelsäure gegeben. Ninhydrin (Nr. 231): 0.2 g Ninhydrin in 100 mL Ethanol gelöst, Sprühreagenz.

Palladium(II)-chlorid (Nr. 251): 0.5 g Palladium(II)-chlorid in einer Lösung aus $100 \mathrm{~mL}$ Wasser unter Zusatz einiger Tropfen Salzsäure (25\%), Sprühreagenz.

Dragendorffs Reagenz (Nr. 121): $0.85 \mathrm{~g}$ Bismutnitrat in $10 \mathrm{~mL}$ Eisessig und $40 \mathrm{~mL}$ Wasser gelöst und mit gleichen Anteilen einer Kaliumjodidlösung $(8 \mathrm{~g}$ Kaliumjodid in $20 \mathrm{~mL}$ Wasser) gemischt, Tauchreagenz.

Molybdatophosphorsäure (Nr. 204): Eine 5-10 \%ige Lösung von Molybdatophosphorsäure in Ethanol, Tauchreagenz.

Adsorberharz: Serva Amberlite ${ }^{\circledR}$ XAD-2, Mitsubishi Kasei Corporation MCI-Gel ${ }^{\circledR}$ $\mathrm{CHP}_{2} \mathrm{OP}$.

Säulenchromatographie und Gelchromatographie: Chromatographische Trennungen erfolgten an Macherey-Nagel Kieselgel 60 (40-63 $\mu$ m, 230-400 mesh ASTM) (als Flash-Chromatographie nach Still et al. $\left.{ }^{184}\right)$ und an Merck Kieselgel 60 RP-18 (40-63 $\left.\mu \mathrm{m}\right)$. Für die Gelchromatographie wurden Pharmacia Sephadex ${ }^{\circledR}$ LH-20; Fluka Sephadex ${ }^{\circledR}$ LH-20; Tosoh Toyopearl ${ }^{\circledR}$ HW-40F eingesetzt. 
Mitteldrucksäulenchromatographie: Pumpe: Kronwald HPP-100/150, Pumpe: Knauer Wellchrom Maxi-Star K-1000; Säule: Merck Lobar $^{\circledR}$-Fertigsäule, Größe A (240-10), Größe B (310-25), Größe C (440-37); Säulenmaterial: Merck Li Chroprep ${ }^{\circledR}$ RP-18 (40-63 $\mu$ m).

\section{High Performance Liquid Chromatography (HPLC):}

\section{Analytische/Semipräparative HPLC mit DAD-Kopplung:}

HPLC A: Pumpe: Jasco PU-2080 Plus; Mischkammer: Jasco LG-2080-02; Entgaser: Jasco DG-2080-53; PDA-Detektor: Jasco MD-210 Plus; Autosampler: Jasco AS-2055 Plus mit Rheodyne $100 \mu \mathrm{L}$ Aufgabeschleife; Säulenofen: Jasco CO-2065; Datensystem: Jasco Borwin $^{\circledR}$ mit Jasco Borwin ${ }^{\circledR}$ PDA Version 1.50 (Chromatographie), Jasco Borwin ${ }^{\circledR}$ HSS2000 Version 3.5.2. (Steuerung).

HPLC B: Pumpe: Kontron Modell 322; Autosampler: Kontron 360; Detektor: Kontron Diode Array Detektor 440; Mischkammer: Kontron HPLC 360; Datensystem: Kontron Kromasystem 2000 Version 1.60; analytische Aufgabenschleife.

HPLC C: Pumpe: Jasco PU-2080 Plus; Mischkammer: Jasco Vierkanalgradientenmischkammer LG-1590-04; Vierkanalentgaser: Jasco DG 1580-54; PDA-Detektor: Jasco MD-2010 Plus mit LC-Net II/ADC (Steuerung); Autosampler: Jasco AS-2055 Plus; Datensystem: Jasco Borwin $^{\circledR}$ mit Jasco Borwin ${ }^{\circledR}$ PDA Version 1.50 (Chromatographie), Jasco Borwin ${ }^{\circledR}$ HSS2000 Version 3.5.2. (Steuerung).

\section{Analytische HPLC mit ESI-MS-Kopplung:}

HPLC D: Pumpe und Mischkammer: Flux Instruments Rheos 4000; Entgaser: Flux Instruments ERC-3415 $\alpha$; Autosampler: Jasco 851-AS mit variabler Aufgabeschleife 0-100 $\mu \mathrm{L}$; PDA-Detektor: Finnigan Surveyor; Massendetektor: Finnigan LC-Q; Datensysteme: HPLC: Flux Instruments Janeiro (Steuerung); PDA- und MS-Detektor: Finnigan Xcalibur ${ }^{\circledR}$ Version 1.3 (Chromatographie- und Steuerung).

\section{Präparative HPLC:}

HPLC E: Pumpe: Jasco PU-1587 (0-50 mL/min), Mischkammer: Jasco $1000 \mu \mathrm{L}$; UVDetektor: Jasco UV 1575; manuelles Probenaufgabeventil: Rheodyne, präparative $2.0 \mathrm{~mL}$ Aufgabeschleife; Datensystem: Jasco Borwin ${ }^{\circledR}$ Ver. 1.50 (Chromatographie), Jasco Borwin ${ }^{\circledR}$ HSS-200 Version 3.5.2 (Steuerung). 


\section{HPLC-Säulen:}

\section{Analytisch:}

Säule A: (Standardsäule 1 für HPLC-ESI-MS) Grom Superspher-100 RP-18, endcapped, 100 x 2 mm, $4 \mu \mathrm{m}$, mit Vorsäule: Grom Superspher 100 RP-18, endcapped, $10 \times 2$ mm, $4 \mu \mathrm{m}$, Flussrate: $0.3 \mathrm{~mL} / \mathrm{min}$.

Säule B: (Standardsäule 2 für HPLC-ESI-MS) Phenomenex Synergi Hydro-RP C18, endcapped, $250 \times 3 \mathrm{~mm}, 4 \mu \mathrm{m}$, mit Vorsäule: Phenomenex Security Guard AQ C18, 4 x $2 \mathrm{~mm}$, Flussrate: $0.4 \mathrm{~mL} / \mathrm{min}$.

Säule C: Knauer Nucleosil-100 C8, 250 x 3 mm, 5 m, mit Vorsäule: Phenomenex Security Guard AQ C18, 4 × 2 mm, Flussrate: $0.4 \mathrm{~mL} / \mathrm{min}$.

Säule D: Machery Nagel Nucleodur-100 C18, 250 x 3 mm, $5 \mu \mathrm{m}$, mit Vorsäule Security Guard C8, 4 × 2 mm Flussrate: $0.4 \mathrm{~mL} / \mathrm{min}$.

Säule E: Daicel Chiralpak IA, $250 \times 46 \mathrm{~mm}$, Flussrate: $0.8 \mathrm{~mL} / \mathrm{min}$.

Säule F: Daicel Chiralcel OD, $250 \times 46 \mathrm{~mm}$, Flussrate: $0.8 \mathrm{~mL} / \mathrm{min}$.

\section{Präparativ:}

Säule G: Jasco Nucleosil-100 C8, 250 x 20 mm, 5 m, Flussrate: 10.0 mL/min.

\section{Programme für die HPLC (analytisch):}

Programm A: (Standardprogramm 1 für die Analytik) Lösungsmittelsystem: Lösung A: Wasser, Lösung B: Methanol, jeweils mit $0.05 \%$ Ameisensäure; Gradient: von $20 \%$ auf $100 \% \mathrm{~B}$ in $20 \mathrm{~min}, 10 \mathrm{~min}$ bei $100 \% \mathrm{~B}$, von $100 \%$ auf $20 \% \mathrm{~B}$ in $2 \mathrm{~min}, 8 \mathrm{~min}$ bei $20 \% \mathrm{~B}$.

Programm B: (Standardprogramm 1 für die HPLC-ESI-MS) Lösungsmittelsystem: Lösung A: Wasser, Lösung B: Methanol, jeweils mit $0.05 \%$ Ameisensäure; Gradient: von $20 \%$ auf $100 \% \mathrm{~B}$ in $20 \mathrm{~min}, 10 \mathrm{~min}$ bei $100 \% \mathrm{~B}$, von $100 \%$ auf $20 \% \mathrm{~B}$ in $2 \mathrm{~min}, 8 \mathrm{~min}$ bei $20 \% \mathrm{~B}$.

Programm C: (Standardprogramm 2 für die HPLC-ESI-MS) Lösungsmittelsystem: Lösung A: Wasser, Lösung B: Methanol, jeweils mit $0.05 \%$ Ameisensäure; Gradient: von $10 \%$ auf $100 \% \mathrm{~B}$ in $20 \mathrm{~min}, 10 \mathrm{~min}$ bei $100 \% \mathrm{~B}$, von $100 \%$ auf $5 \% \mathrm{~B}$ in $2 \mathrm{~min}, 8 \mathrm{~min}$ bei $5 \% \mathrm{~B}$.

Programm D: (Standardprogramm 3 für die HPLC-ESI-MS) Lösungsmittelsystem: Lösung A: Wasser, Lösung B: Methanol, jeweils mit $0.05 \%$ Ameisensäure; Gradient: von $5 \%$ auf $100 \% \mathrm{~B}$ in $20 \mathrm{~min}, 5 \mathrm{~min}$ bei $100 \% \mathrm{~B}$, von $100 \%$ auf $5 \% \mathrm{~B}$ in $5 \mathrm{~min}, 10 \mathrm{~min}$ bei $5 \% \mathrm{~B}$.

Programm E: Lösungsmittelsystem: Lösung A: Wasser, Lösung B: Acetonitril; isokratisch, $30 \%$ B, Programmdauer: 25 min. 
Programm F: Lösungsmittelsystem: Lösung A: Wasser, Lösung B: Methanol, jeweils mit $0.05 \%$ Ameisensäure; Gradient: 30 min bei $35 \%$ B, in 2 min auf $100 \%$ B, 7 min bei $100 \%$ $\mathrm{B}$, von $100 \%$ auf $35 \% \mathrm{~B}$ in $2 \mathrm{~min}, 6 \mathrm{~min}$ bei $35 \% \mathrm{~B}$.

Programm G: Lösungsmittelsystem: Lösung A: Isopropanol, Lösung B: n-Hexan, isokratisch, $98 \%$ B, Programmdauer: $70 \mathrm{~min}$.

Programm H: Lösungsmittelsystem: Lösung A: Isopropanol, Lösung B: $n$-Hexan, isokratisch, 98 \% B, Programmdauer: $90 \mathrm{~min}$.

\section{Programm für die HPLC (präparativ):}

Programm I: Lösungsmittelsystem: Lösung A: Wasser, Lösung B: Acetonitril; isokratisch, $30 \%$ B, , Programmdauer: 20 min.

\subsection{Synthetische Arbeiten}

Alle Umsetzungen wurden unter inerter Atmosphäre (Argon oder Stickstoff) durchgeführt. Alle Lösungsmittel für die Synthese wurden nach üblichen Laboratoriumsmethoden getrocknet $^{185}$ und unter Stickstoff destilliert (THF und Diethylether mit Na/Benzophenon, $\mathrm{NEt}_{3}$ und $\mathrm{CH}_{2} \mathrm{Cl}_{2}$ mit $\mathrm{CaH}_{2}$, DMF über Molsieb). Acrylsäuremethylester wurde vor Gebrauch bei Raumtemperatur unter vermindertem Druck umkondensiert. Wenn nicht anders angegeben, sind Lösungen von $\mathrm{NH}_{4} \mathrm{Cl}, \mathrm{NaCl}$ und $\mathrm{NaHCO}_{3}$ gesättigte wässrige Lösungen. Feststoffe wurden, wenn nicht anders angeführt, pulverisiert eingesetzt. Nicht gesondert aufgeführte Chemikalien sind kommerziell erhältlich.

Die folgenden Substanzen wurden nach Literaturangaben dargestellt:

Tri-o-tolylphosphan nach Ziegler und Heck ${ }^{186}$, Methoxyphosphoryldichlorid (85) nach Quast, Heuschmann und Abdel-Rahmann ${ }^{187}$.

\subsection{Derivatisierung}

\subsubsection{Herstellung der methanolischen Salzsäure}

Acetylchlorid (7.1 mL, $0.1 \mathrm{~mol}$, Fa. Acros) wurde bei $0{ }^{\circ} \mathrm{C}$ langsam zu MeOH $(25 \mathrm{~mL})$ gegeben. Die so hergestellte Lösung war $4 \mathrm{M}$.

\subsection{Mikrobiologische Arbeiten}

Alle mikrobiologischen Arbeiten wurden unter den üblichen sterilen Bedingungen durchgeführt $^{188}$. 


\subsubsection{Nährmedienbestandteile}

Die verwendeten Nährmedienbestandteile wurden von folgenden Firmen bezogen: Malzextrakt, Fleischextrakt, D-Glucose, Stärke und Casein-Pepton: Fa. Merck; Hefeextrakt: Fa. Oxoid; Cornsteep Powder: Fa.Marcor; Leberextrakt, Dextrin (aus Kartoffelstärke): Fa. Fluka; Mannit, Stärke (aus Kartoffeln): Fa. Roth; Soja (fettarm): Fa. Henselwerk GmbH; Bactopepton: Fa. Bacto ${ }^{\mathrm{TM}}$; Glycerin: Fa. AppliChem; Agar: Fa. Difco.

Verwendete Nährmedien: Für alle Nährmedien wurde Leitungswasser verwendet. Der pHWert wurde vor der Sterilisation mit $0.5 \mathrm{~N} \mathrm{HCl}$ bzw. $0.5 \mathrm{~N} \mathrm{NaOH}$ eingestellt. Zur Herstellung von Agarplatten wurden $20 \mathrm{~g} / \mathrm{L}$ Agar hinzugefügt. Alle Nährmedien wurden durch Autoklavieren (feuchte Hitze, $121^{\circ} \mathrm{C}, 1$ bar Überdruck, $30 \mathrm{~min}$ ) sterilisiert.

M2: Malzextrakt $10 \mathrm{~g} / \mathrm{L}$, Hefeextrakt $4 \mathrm{~g} / \mathrm{L}$, Glucose $4 \mathrm{~g} / \mathrm{L}, \mathrm{pH}=7.0$. Für die Stammhaltung wurde ein Zusatz von $\mathrm{CaCO}_{3} 0.3 \mathrm{~g} / \mathrm{L}$, Agar $20 \mathrm{~g} / \mathrm{L}$ zugegeben.

S: Stärke $10 \mathrm{~g} / \mathrm{L}$, Glycerin $4 \mathrm{~g} / \mathrm{L}$, Casein-Pepton $4 \mathrm{~g} / \mathrm{L}$, Hefeextrakt $0.5 \mathrm{~g} / \mathrm{L}$, Fleischextrakt $0.5 \mathrm{~g} / \mathrm{L}$, Leberextrakt $0.5 \mathrm{~g} / \mathrm{L}, \mathrm{NaCl} 1 \mathrm{~g} / \mathrm{L}, \mathrm{pH}=7.0$.

SGG: Glucose $10 \mathrm{~g} / \mathrm{L}$, Glycerin $10 \mathrm{~g} / \mathrm{L}$, Stärke $10 \mathrm{~g} / \mathrm{L}$, Cornsteep Powder 2.5 g/L, CaseinPepton $5 \mathrm{~g} / \mathrm{L}$, Hefeextrakt $2 \mathrm{~g} / \mathrm{L}, \mathrm{NaCl} 1 \mathrm{~g} / \mathrm{L}, \mathrm{CaCO}_{3} 3 \mathrm{~g} / \mathrm{L}, \mathrm{pH}=7.3$.

NL 1358 : Glycerin $12.5 \mathrm{~g} / \mathrm{L}, \quad$ Casein-Pepton $2 \mathrm{~g} / \mathrm{L}, \quad \mathrm{K}_{2} \mathrm{HPO}_{4} \quad 1 \mathrm{~g} / \mathrm{L}, \quad \mathrm{NaCl} 1 \mathrm{~g} / \mathrm{L}$, $\mathrm{MgSO}_{4} \times 7 \mathrm{H}_{2} \mathrm{O} 0.5 \mathrm{~g} / \mathrm{L}$, Spur $115 \mathrm{~mL} / \mathrm{L}$.

M1: Stärke 10 g/L, Hefeextrakt 4 g/L, Casein-Pepton 2 g/L, ,Artifizielles Seewasser (ASW)“ ad 1 L. Für die Stammhaltung wurde Agar 20 g/L zugegeben.

Soja/Mannit: Sojamehl (fettarm) $20 \mathrm{~g} / \mathrm{L}$, Mannit $20 \mathrm{~g} / \mathrm{L}$, pH 7.0. Für die Stammhaltung wurde Agar $20 \mathrm{~g} / \mathrm{L}$ zugegeben.

Soja/Mannit : Sojamehl (fettarm) 20 g/L, Mannit 20 g/L, Fleischextrakt 5 g/L, pH 7.0.

Soja/Glucose: Sojamehl (fettarm) 20 g/L, Glucose 20 g/L, pH 7.0.

Soja/Dextrin: Sojamehl (fettarm) $20 \mathrm{~g} / \mathrm{L}$, Dextrin $20 \mathrm{~g} / \mathrm{L}, \mathrm{pH} 7.0$.

Glucose-Medium: Glucose $17 \mathrm{~g} / \mathrm{L}$, Bactopepton $11 \mathrm{~g} / \mathrm{L}$, Hefeextrakt $3 \mathrm{~g} / \mathrm{L}$, Malzextrakt $3 \mathrm{~g} / \mathrm{L}, \mathrm{pH} 7.0$.

Dextrin-Medium: Dextrin $140 \mathrm{~g} / \mathrm{L}$, Sojamehl (fettarm) $30 \mathrm{~g} / \mathrm{L}$, Bactopepton $25 \mathrm{~g} / \mathrm{L}, \mathrm{NaCl}$ $1.2 \mathrm{~g} / \mathrm{L}, \mathrm{pH} 7.0$.

KM1-Medium: Bacto Nutrient Broth $8 \mathrm{~g} / \mathrm{L}, \mathrm{NaCl} 5 \mathrm{~g} / \mathrm{L}$ und Agar $15 \mathrm{~g} / \mathrm{L}$, keine $\mathrm{pH}-$ Einstellung. 
Spurelementlösung 11: $\mathrm{CaCl}_{2} \times 2 \mathrm{H}_{2} \mathrm{O} 3 \mathrm{~g} / \mathrm{L}, \mathrm{Fe}(\mathrm{III})$ citrat $1 \mathrm{~g} / \mathrm{L}, \mathrm{MnSO}_{4} 0.2 \mathrm{~g} / \mathrm{L}, \mathrm{ZnCl}_{2}$ $0.1 \mathrm{~g} / \mathrm{L}, \quad \mathrm{CuSO}_{4} \times 5 \mathrm{H}_{2} \mathrm{O} \quad 0.025 \mathrm{~g} / \mathrm{L}, \quad \mathrm{Na}_{2} \mathrm{BO}_{4} \times 10 \mathrm{H}_{2} \mathrm{O} \quad 0.02 \mathrm{~g} / \mathrm{L}, \quad \mathrm{CoCl}_{2} \quad 0.004 \mathrm{~g} / \mathrm{L}$, $\mathrm{Na}_{2} \mathrm{MoO}_{4} \times 2 \mathrm{H}_{2} \mathrm{O} 0.01 \mathrm{~g} / \mathrm{L}$.

Vitaminlösung: Thiamin - $\mathrm{HCl} 1 \mathrm{~g} / \mathrm{L}$, Calcium - D-Pantothenat $1.2 \mathrm{~g} / \mathrm{L}$, Flavin - Mononukleotid $1 \mathrm{~g} / \mathrm{L}$, Nikotinsäure $2.3 \mathrm{~g} / \mathrm{L}$, Pyridoxin - $\mathrm{HCl} 12 \mathrm{~g} / \mathrm{L}, p$-Aminobenzoat $0.2 \mathrm{~g} / \mathrm{L}$, Vitamin $B_{12} 0.1 \mathrm{~g} / \mathrm{L}$, Folsäure $0.01 \mathrm{~g} / \mathrm{L}$, Biotin $0.006 \mathrm{~g} / \mathrm{L}$.

Artifizielles Seewasser: $\mathrm{NaCl} 234.7 \mathrm{~g} / \mathrm{L}, \mathrm{Na}_{2} \mathrm{SO}_{4} 39.2 \mathrm{~g} / \mathrm{L}, \mathrm{MgCl}_{2} \times 6 \mathrm{H}_{2} \mathrm{O} 106.4 \mathrm{~g} / \mathrm{L}, \mathrm{CaCl}_{2}$ 11.0 g/L, $\mathrm{NaHCO}_{3} 1.92 \mathrm{~g} / \mathrm{L}, \mathrm{KCl} 6.64 \mathrm{~g} / \mathrm{L}, \mathrm{KBr} 0.96 \mathrm{~g} / \mathrm{L}, \mathrm{H}_{3} \mathrm{BO}_{3} 0.26 \mathrm{~g} / \mathrm{L}, \mathrm{SrCl}_{2} 0.24 \mathrm{~g} / \mathrm{L}$, $\mathrm{NaF} 0.03 \mathrm{~g} / \mathrm{L}, \mathrm{H}_{2} \mathrm{O}$ ad to $10 \mathrm{~L}$.

\subsubsection{Zugefütterte Substanzen}

Folgende Substanzen wurden als Vorläufer oder Zusatz in verschiedenen Fermentationen verwendet:

Stamm Streptomyces JP90: 4-Hydroxyzimtsäuremethylester $\left(\mathrm{C}_{10} \mathrm{H}_{10} \mathrm{O}_{3}\right.$, synthetisiert), Cinnamoylphosphoramid $\left(\mathrm{C}_{10} \mathrm{H}_{12} \mathrm{NO}_{5} \mathrm{P}\right.$, synthetisiert), Zimtsäure $\left(\mathrm{C}_{9} \mathrm{H}_{8} \mathrm{O}_{2}\right.$, Fa. Merck), Zimtsäuremethylester $\left(\mathrm{C}_{10} \mathrm{H}_{10} \mathrm{O}_{2}\right.$, synthetisiert).

Stamm Streptomyces Pol001: L-Tyrosin $\left(\mathrm{C}_{9} \mathrm{H}_{11} \mathrm{NO}_{3}\right.$, Fa. Merck), L-Phenylalanin $\left(\mathrm{C}_{9} \mathrm{H}_{11} \mathrm{NO}_{2}\right.$, Fa. Jannsen Chimica), Dimethylsulfoxid (DMSO, Fa. Riedel-deHäen), Glycerin (Fa. AppliChem.), Natriumacetat $\left(\mathrm{C}_{2} \mathrm{H}_{3} \mathrm{NaO}_{2}\right.$, Fa. Fluka), 4-Hydroxy-L-phenylglycin $\left(\mathrm{C}_{8} \mathrm{H}_{9} \mathrm{NO}_{3}, \geq\right.$ 99.0\%, Fa. Fluka), D-4-Hydroxyphenylglycin $\left(\mathrm{C}_{8} \mathrm{H}_{9} \mathrm{NO}_{3}, \geq 98.0 \%\right.$, Fa. Aldrich), Malonsäure $\left(\mathrm{C}_{3} \mathrm{H}_{4} \mathrm{O}_{4}, \mathrm{Fa}\right.$. Merck).

Die Substanzen wurden in gelöster Form zugefüttert, wobei alle Lösungen einen pH-Wert von ca. $\mathrm{pH}=6-7$ besaßen. Die Herstellung der Fütterungslösungen wird in den entsprechenden Kapiteln aufgezeigt.

\subsubsection{Schüttler und Fermenter:}

Braun Inkubationsschrank BS4, Braun Certomat $^{\circledR}$ RM, Braun Certomat $^{\circledR}$ U, Braun Certomat ${ }^{\circledR}$ BS1, Braun Biostat ${ }^{\circledR}$ B (5 L), Braun Biostat ${ }^{\circledR}$ E (15 L) Braun Biostat ${ }^{\circledR}$ M (1 L).

\subsubsection{Verschiedene Geräte}

Dosierpumpe: ISMATEC Schlauchpumpe (0.019-1.9 mL/min).

Zentrifugen: Eppendorf Centrifuge 5415D, Eppendorf Centrifuge 3K30, Sigma Labaratory Centrifuge 4K10. 
Feinfilter: Sartorius Minisart ${ }^{\circledR}$, Porengröße $0.2 \mu \mathrm{m}$; Sartorius Vivaspin $20^{\circledR}$; VWR Vacuum Filtration System ${ }^{\circledR}$, Porengröße $0.2 \mu \mathrm{m}$, Millipore Spinfilter, Ausschlußgröße 5000 kDa.

\subsubsection{Stammhaltung:}

Langzeiterhaltung in flüssigem Stickstoff: Von einer gut bewachsenen Agarplatte wurden mit einseitig zugeschweißten und mit einem Bleistück beschwerten sterilen PolypropylenHalmen Agarstückchen ausgestanzt, bis der Halm gefüllt war. Der Halm wurde in einen zweiten äußeren Halm gesteckt, der an beiden Enden zugeschmolzen wurde. Mehrere Halme in einem Kryoröhrchen wurden in einem Dewargefäß über flüssigem Stickstoff eingelagert.

Stammhaltung auf Agarplatten: Für die Bakterien wurden die Nährmedien $\mathrm{M}^{+}$, SM und M1 verwendet. Die mittels einer Platinimpföse beimpften Agarplatten wurden 4-7 Tage bei $28^{\circ} \mathrm{C}$ inkubiert. Bewachsene Agarplatten wurden mit Verschlussfolie (Pechiney Parafilm ${ }^{\circledR} \mathrm{M}$ ) versiegelt und bei $4{ }^{\circ} \mathrm{C}$ für maximal 4 Monate gelagert.

Stammhaltung als Sporensuspension (Glycerin-Einlagerung): Bei Kultivierung in Flüssigkultur der jeweiligen Mikroorganismen wurden nach $48 \mathrm{~h}$ ca. $0.8-1 \mathrm{~mL}$ der jeweiligen Kulturbrühe in ein $2 \mathrm{~mL}$ Kryoröhrchen pipettiert und fügte dieselbe Menge an Glycerin (steril) hinzu. Die Suspension wurde gut durchmischt und anschließend bei -20 bis $-80^{\circ} \mathrm{C}$ gelagert.

\subsubsection{Isotopenmarkierte Verbindungen}

$\left[1,2-{ }^{13} \mathrm{C}_{2}\right]$ Natriumacetat (99\% isotopenmarkiert) wurde von der Fa. Campro Isotope Laboratories bezogen und $\left[\mathrm{U}_{-}{ }^{13} \mathrm{C}_{3}\right]$ Glycerin (99\% isotopenmarkiert) von der Fa. Chemotrade.

Berechnung der ${ }^{13} \mathrm{C}$-Anreicherung (nicht miteinander koppelnde Kerne) ${ }^{189}$ :

In diesem Verfahren wird die natürliche Häufigkeit von ${ }^{13} \mathrm{C}$-Kernen berücksichtigt, um die Anreicherung der gefütterten markierten Vorläufer im zu untersuchenden Molekül zu ermitteln. Ein erfolgreicher Einbau gilt als gesichert, wenn sich die Signalintensität eines C-Atoms verdoppelt und somit der spezifische Einbau größer eins ist. Vor der Berechnung müssen alle Intensitäten der C-Atome auf ein C-Atom, bei dem man keinen Einbau des isotopenmarkierten Vorläufers erwartet, normiert werden. 


$$
\begin{aligned}
& \% \text { Anreicherung }=1.1 \% \times \frac{(\text { Intensität des Signals der markierten Verbindung })}{(\text { Intensität des Signals der Referenzverbindung })}-1.1 \% \\
& \text { Spezifischer Einbau }=\frac{(\% \text { Anreicherung }) \times 100}{(\% \text { Anreicherung der Vorstufe })}
\end{aligned}
$$

\subsubsection{Plattendiffusionstest:}

Auf die mit verschiedenen Testkeimen angeimpfte Agarplatte wurden Filterplättchen (Durchmesser $6 \mathrm{~mm}$, Dicke $0.5 \mathrm{~mm}$ ) gelegt, die mit $15 \mu \mathrm{L}$ Substanzlösung $(\mathrm{c}=1 \mathrm{mg} / \mathrm{mL}$ in Methanol) getränkt und vor dem Auflegen unter sterilen Bedingungen getrocknet worden waren. Als Testkeime dienten Bacillus subtilis, Escherichia coli, Staphylococcus aureus und Candida albicans. Die Agarplatten wurden $24 \mathrm{~h}$ bei $25^{\circ} \mathrm{C}$ (C. albicans), bzw. bei $37^{\circ} \mathrm{C}$ (B. subtilis, E. coli und S. aureus) inkubiert.

\section{Zusammensetzung der Nährböden für die Plattendiffusionstests:}

B. subtilis und E. coli: Glucose $5 \mathrm{~g} / \mathrm{L}$, Trinatriumcitrat $\times 2 \mathrm{H}_{2} \mathrm{O} 0.5 \mathrm{~g} / \mathrm{L}, \mathrm{KH}_{2} \mathrm{PO}_{4} 3 \mathrm{~g} / \mathrm{L}$, $\mathrm{K}_{2} \mathrm{HPO}_{4} 7 \mathrm{~g} / \mathrm{L}, \mathrm{MgSO}_{4} \times 7 \mathrm{H}_{2} \mathrm{O} 0.1 \mathrm{~g} / \mathrm{L},\left(\mathrm{NH}_{4}\right)_{2} \mathrm{SO}_{4} 1 \mathrm{~g} / \mathrm{L}$ und Agar $15 \mathrm{~g} / \mathrm{L}$, keine $\mathrm{pH}-$ Einstellung.

S. aureus: Bacto Nutrient Broth $8 \mathrm{~g} / \mathrm{L}, \mathrm{NaCl} 5 \mathrm{~g} / \mathrm{L}$ und Agar $15 \mathrm{~g} / \mathrm{L}$, keine pH-Einstellung. C. albicans: Hefeextrakt $4 \mathrm{~g} / \mathrm{L}$, Malzextrakt $10 \mathrm{~g} / \mathrm{L}$, Glucose $4 \mathrm{~g} / \mathrm{L}$ und Agar $15 \mathrm{~g} / \mathrm{L}, \mathrm{pH}=5.5$. Zum Ansetzen der Testplatten-Medien wurde demineralisiertes Wasser verwendet. Die Glucose wurde erst nach 30 minütiger Sterilisation hinzugegeben. 


\section{Neue Biofilm-Inhibitoren aus dem Metagenom}

\subsection{Synthese des Autoinduktors AI-1 (19)}

\subsection{1 (3R)-3-(tert-Butyldimethylsilyloxy)butansäure (162)}

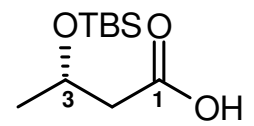

$\mathrm{Zu}$ einer Lösung von (-)-(R)-Hydroxybutyrat $(\boldsymbol{R}-\mathbf{4 3}, 300 \mathrm{mg}, 2.38 \mathrm{mmol}, 1.0$ Äq. $)$ in wasserfreiem DMF $(15 \mathrm{~mL})$ wurden unter kräftigem Rühren bei $0{ }^{\circ} \mathrm{C}$ Imidazol $(1.04 \mathrm{~g}$, 15.2 mmol, 6.4 Äq.) und tert-Butyldimethylsilylchlorid (1.04 g, 6.90 mmol, 2.8 Äq.) gegeben. Anschließend wurde die Reaktionslösung für $30 \mathrm{~h}$ bei Raumtemperatur gerührt. Danach wurde die Reaktionsmischung mit Ethylacetat $(120 \mathrm{~mL})$ verdünnt und mit $1 \mathrm{~N} \mathrm{KHSO}_{4}$ $(30 \mathrm{~mL})$ gewaschen. Die organische Phase wurde mit Wasser $(2 \times 20 \mathrm{~mL})$ und ges. $\mathrm{NaCl}$ Lösung $(2 \times 80 \mathrm{~mL})$ gewaschen, über $\mathrm{Na}_{2} \mathrm{SO}_{4}$ getrocknet und das Lösungsmittel i. Vak. entfernt. Das erhaltene Rohprodukt wurde ohne Aufreinigung in Dioxan (6 mL) gelöst, unter starkem Rühren tropfenweise $1 \mathrm{~N} \mathrm{NaOH}(2.38 \mathrm{~mL}, 2.38 \mathrm{mmol}, 1$ Äq. bezogen auf 43) zugegeben und das Reaktionsgemisch für $1 \mathrm{~h}$ bei Raumtemperatur gerührt. Anschließend wurde zur Reaktionsmischung Ethylacetat $(30 \mathrm{~mL})$ und Wasser $(30 \mathrm{~mL})$ gegeben und die wässrige Phase mit $2 \mathrm{~N} \mathrm{HCl}(1 \mathrm{~mL}) \mathrm{pH} 1.0$ eingestellt. Die wässrige Phase wurde mit Ethylacetat $(3 \times 80 \mathrm{~mL})$ extrahiert und die vereinigten organischen Phasen mit ges. NaCl-Lösung $(1 \times 150 \mathrm{~mL})$ gewaschen, über $\mathrm{Na}_{2} \mathrm{SO}_{4}$ getrocknet und das Lösungsmittel i. Vak. entfernt. Nach säulenchromatographischer Reinigung an Kieselgel (Cyclohexan/EE 7:2) wurde die Zielverbindung (162) als farbloses Öl erhalten (422 mg, 1.93 mmol, $81 \%$ ).

$\mathbf{C}_{10} \mathbf{H}_{22} \mathbf{O}_{3} \mathrm{Si}$ (218.37).

$\mathbf{R}_{\mathbf{f}}: 0.40$ (KG, Cyclohexan/EE 7:2).

MS (ESI): $m / z(\%)=219(10)[\mathrm{M}+\mathrm{H}]^{+}, 236(100)\left[\mathrm{M}+\mathrm{NH}_{4}\right]^{+}$.

${ }^{1} \mathbf{H}$-NMR $\left(300 \mathrm{MHz}\right.$, Aceton-d $\left.\mathrm{d}_{6}\right): \delta=0.05 / 0.07\left(2 \times \mathrm{s}, 2 \times 3 \mathrm{H}, \mathrm{Si}\left(\mathrm{CH}_{3}\right)_{2} \mathrm{C}\left(\mathrm{CH}_{3}\right)_{3}, 0.86(\mathrm{~s}\right.$, $\left.9 \mathrm{H}, \mathrm{Si}\left(\mathrm{CH}_{3}\right)_{2} \mathrm{C}\left(\mathrm{CH}_{3}\right)_{3}\right), 1.18\left(\mathrm{~d}, J=6.0 \mathrm{~Hz}, 3 \mathrm{H}, 4-\mathrm{H}_{3}\right), 2.38$ (m, $\left.2 \mathrm{H}, 2-\mathrm{H}_{2}\right), 4.29$ (ddq, $J=6.0,6.0,6.0 \mathrm{~Hz}, 1 \mathrm{H}, 3-\mathrm{H}) \mathrm{ppm}$. 
${ }^{1}$ H-NMR $\left(600 \mathrm{MHz}, \mathrm{CDCl}_{3}\right): \delta=0.04 / 0.06\left(2 \times \mathrm{s}, 2 \times 3 \mathrm{H}, \mathrm{Si}\left(\mathrm{C}_{\mathrm{H}_{3}}\right)_{2} \mathrm{C}\left(\mathrm{CH}_{3}\right)_{3}, 0.85(\mathrm{~s}, 9 \mathrm{H}\right.$, $\left.\mathrm{Si}\left(\mathrm{CH}_{3}\right)_{2} \mathrm{C}\left(\mathrm{C}_{3}\right)_{3}\right), 1.21\left(\mathrm{~d}, J=6.0 \mathrm{~Hz}, 3 \mathrm{H}, 4-\mathrm{H}_{3}\right), 2.46\left(\mathrm{~m}, 2 \mathrm{H}, 2-\mathrm{H}_{2}\right), 4.26(\mathrm{ddq}, J=6.0$, 6.0, $6.0 \mathrm{~Hz}, 1 \mathrm{H}, 3-\mathrm{H}) \mathrm{ppm}$.

${ }^{13}$ C-NMR $\left(125 \mathrm{MHz}, \mathrm{CDCl}_{3}\right): \delta=-5.1 /-4.6\left(\mathrm{Si}\left(\underline{C H}_{3}\right)_{2} \mathrm{C}\left(\mathrm{CH}_{3}\right)_{3}\right), 17.9\left(\mathrm{Si}_{\left(\mathrm{CH}_{3}\right)_{2}} \mathrm{C}\left(\mathrm{CH}_{3}\right)_{3}\right)$, 23.6 (C-4), $25.7\left(\mathrm{Si}\left(\mathrm{CH}_{3}\right)_{2} \mathrm{C}\left(\underline{\mathrm{C}} \mathrm{H}_{3}\right)_{3}\right), 44.3$ (C-2), 65.7 (C-3), 176.9 (C-1) ppm.

\subsubsection{N-[(3R)-3-(tert-Butyldimethylsilyloxy)butyryl]-L-homoserinlacton} (163)

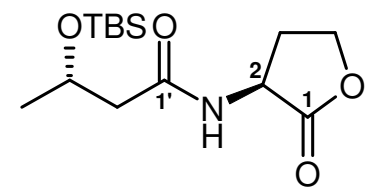

(3R)-3-tert-Butyldimethylsilyloxybutansäure (162, 234. mg, $1.08 \mathrm{mmol}, 1.0$ Äq.) wurde in wasserfreiem DMF (22 mL) gelöst, die Lösung auf $0{ }^{\circ} \mathrm{C}$ gekühlt und $\mathrm{EDC} \cdot \mathrm{HCl}(618 \mathrm{mg}$,

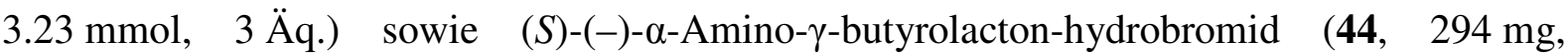
$1.61 \mathrm{mmol}, 1.5$ Äq.) zugegeben. Die Reaktionsmischung wurde für $28 \mathrm{~h}$ bei Raumtemperatur gerührt. Danach wurde die Reaktionslösung mit Ethylacetat $(70 \mathrm{~mL})$ sowie Wasser $(70 \mathrm{~mL})$ verdünnt und für 20 min gerührt. Die wässrige Phase wurde mit Ethylacetat $(4 \times 200 \mathrm{~mL})$ extrahiert und die vereinigten organischen Phasen mit ges. $\mathrm{NH}_{4} \mathrm{Cl}$-Lösung $(1 \times 200 \mathrm{~mL})$ und ges. NaCl-Lösung $(3 \times 200 \mathrm{~mL})$ gewaschen, über $\mathrm{Na}_{2} \mathrm{SO}_{4}$ getrocknet und das Lösungsmittel i. Vak. entfernt. Nach säulenchromatographischer Reinigung an Kieselgel (Flashchromatographie, Cyclohexan/Aceton 3:1) wurde die Zielverbindung (161) als farbloses Öl erhalten (207 mg, $686 \mu \mathrm{mol}, 64 \%)$.

$\mathrm{C}_{14} \mathrm{H}_{27} \mathrm{NO}_{4} \mathrm{Si}$ (301.64).

$\mathbf{R}_{\mathbf{f}}: 0.35$ (KG, Cyclohexan/Aceton 2:1).

MS (ESI): $m / z(\%)=302(28)[\mathrm{M}+\mathrm{H}]^{+}, 324(38)[\mathrm{M}+\mathrm{Na}]^{+}, 625(100)[2 \mathrm{M}+\mathrm{Na}]^{+}$.

${ }^{1}$ H-NMR (600 MHz, Aceton-d $\left.\mathrm{d}_{6}\right): \delta==0.05 / 0.07\left(2 \times \mathrm{s}, 2 \times 3 \mathrm{H}, \mathrm{Si}\left(\mathrm{C}_{\mathrm{H}_{3}}\right)_{2} \mathrm{C}\left(\mathrm{CH}_{3}\right)_{3}\right), 0.86(\mathrm{~s}$, $\left.9 \mathrm{H}, \mathrm{Si}\left(\mathrm{CH}_{3}\right)_{2} \mathrm{C}\left(\mathrm{C}_{3}\right)_{3}\right), 1.18\left(\mathrm{~d}, J=6.0 \mathrm{~Hz}, 3 \mathrm{H}, 4^{\prime}-\mathrm{H}_{3}\right), 2.21$ (dddd, $J=2.0,6.0,9.0,11.0 \mathrm{~Hz}$, $\left.1 \mathrm{H}, 3-\mathrm{H}_{\mathrm{A}}\right), 2.31\left(\mathrm{~m}, 1 \mathrm{H}, 2^{\prime}-\mathrm{H}_{\mathrm{A}}\right), 2.35\left(\mathrm{~m}, 1 \mathrm{H}, 2^{\prime}-\mathrm{H}_{\mathrm{B}}\right), 2.56$ (dddd, $J=1.5,6.0,9.0,11.0 \mathrm{~Hz}$, $\left.1 \mathrm{H}, 3-\mathrm{H}_{\mathrm{B}}\right), 4.29$ (ddd, $\left.J=6.0,9.0,11.0 \mathrm{~Hz}, 1 \mathrm{H}, 4-\mathrm{H}_{\mathrm{A}}\right), 4,27\left(\mathrm{~m}^{*}, 1 \mathrm{H}, 3{ }^{\prime}-\mathrm{H}\right), 4.38$ (ddd, 
$\left.J=1.5,9.0,11.0 \mathrm{~Hz}, 1 \mathrm{H}, 4-\mathrm{H}_{\mathrm{B}}\right), 4.73(\mathrm{ddd}, J=6.0,9.0,11.5 \mathrm{~Hz}, 1 \mathrm{H}, 2-\mathrm{H}), 7.51\left(\mathrm{~s}_{\mathrm{br}}, 1 \mathrm{H}\right.$, $\mathrm{NH}) \mathrm{ppm}$.

"Signal liegt unter anderem Signal.

${ }^{13}$ C-NMR $\left(125 \mathrm{MHz}\right.$, Aceton-d $\left.\mathrm{d}_{6}\right): \delta=-5.1 /-4.6\left(\mathrm{Si}\left(\underline{C H}_{3}\right)_{2} \mathrm{C}\left(\mathrm{CH}_{3}\right)_{3}\right), 18.5\left(\mathrm{Si}\left(\mathrm{CH}_{3}\right)_{2} \underline{C}\left(\mathrm{CH}_{3}\right)_{3}\right)$, 24.1 (C-4'), $26.2\left(\mathrm{Si}\left(\mathrm{CH}_{3}\right)_{2} \mathrm{C}\left(\mathrm{CH}_{3}\right)_{3}\right), 30.2$ (C-3), 46.9 (C-2'), 48.8 (C-2), 66.0 (C-3'), 66.9 (C-4), $171.2(\mathrm{C}-1 '), 175.6(\mathrm{C}-1) \mathrm{ppm}$.

\subsection{3 $N$-[(3R)-Hydroxybutyryl]-L-homoserinlacton $(R, S-29)$}<smiles>C[C@@H](O)CC(=O)N[C@H]1CCOC1=O</smiles>

$N$-[(3R)-3-(tert-Butyldimethylsilyloxy)butyryl]-L-homoserinlacton (163, $207 \mathrm{mg}, 686 \mu \mathrm{mol}$, 1.0 Äq.) wurde in wasserfreiem $\mathrm{CH}_{2} \mathrm{Cl}_{2}(2.3 \mathrm{~mL})$ gelöst und unter Argon in einen Falcontube $\left(15 \mathrm{~mL}, \mathrm{Fa}\right.$. Sarstedt) überführt. Die Lösung wurde auf $0{ }^{\circ} \mathrm{C}$ gekühlt und unter kräftigem Rühren HF Pyridin (70\%ig, $0.19 \mathrm{~mL})$ zugegeben. Nach $30 \mathrm{~min}$ wurde die Reaktionsemulsion mit Wasser $(5 \mathrm{~mL})$ sowie ges. $\mathrm{NaHCO}_{3}$-Lösung $(1 \mathrm{~mL})$ verdünnt. Die weitere Zugabe von ges. $\mathrm{NaHCO}_{3}$-Lösung zum Reaktionsgemisch erfolgte unter $\mathrm{pH}$ Kontrolle mittels pH-Papiers bis zu einem eingestellten $\mathrm{pH}-$ Wert von 7.0. Die wässrige Phase wurde mit Wasser $(3 \mathrm{~mL})$ auf ein Gesamtvolumen von $\sim 14 \mathrm{~mL}$ verdünnt und nach Abtrennung der $\mathrm{CH}_{2} \mathrm{Cl}_{2}$-Phase mit Ethylacetat $(3 \times 10 \mathrm{~mL})$ extrahiert. Die organischen Phasen aus der Ethylacetat -Extraktion wurden vereinigt, das Lösungsmittel i. Vak. entfernt und $N$-[(3R)-Hydroxybutyryl]-L-homoserinlacton $(\boldsymbol{R}, \boldsymbol{S}-\mathbf{2 9})$ enthaltenes Rohprodukt (26.2 mg) erhalten. Die wässrige Phase wurde bis zur Trockne konzentriert, der Rückstand mit Aceton extrahiert $(3 \times 50 \mathrm{~mL})$ und $N$-[(3R)-Hydroxybutyryl]-L-homoserinlacton $(\boldsymbol{R}, \boldsymbol{S}-\mathbf{2 9})$ enthaltenes Rohprodukt (74.4 mg) gewonnen. Die Rohprodukte wurden vereinigt, chromatographisch an Kieselgel (Flashchromatographie, Cyclohexan/Aceton 1:2) gereinigt und die Zielverbindung $(\boldsymbol{R}, \mathbf{S}-\mathbf{2 9})$ als farbloser Feststoff erhalten (73.2 mg, $391 \mu \mathrm{mol}, 57 \%)$.

\section{$\mathrm{C}_{8} \mathrm{H}_{13} \mathrm{NO}_{4} \quad$ (187.20).}

$\mathbf{R}_{\mathbf{f}}$ : 0.35 (KG, Cyclohexan/Aceton 1:2); 0.57 (RP-18, Aceton/ $\mathrm{H}_{2} \mathrm{O}$ 1:3).

MS (DCI, $200 \mathrm{eV}): \mathrm{m} / \mathrm{z}(\%)=188(8)[\mathrm{M}+\mathrm{H}]^{+}, 205(100)\left[\mathrm{M}+\mathrm{NH}_{4}{ }^{+}\right]$.

HR-ESI-MS: ber. $(\mathrm{m} / \mathrm{z})=210.07368[\mathrm{M}+\mathrm{Na}]^{+}$

$$
\text { gef. }(m / z)=210.07367[\mathrm{M}+\mathrm{Na}]^{+} \text {. }
$$


Drehwert: $[\alpha]_{D}^{20}=-50(\mathrm{c}=0.1, \mathrm{MeOH})$.

UV (MeOH): $\lambda_{\max }(\lg \varepsilon)=202 \mathrm{~nm}(2.53) ;(\mathrm{MeOH}, \mathrm{HCl}): \lambda_{\max }(\lg \varepsilon) 202 \mathrm{~nm}(2.03) ;(\mathrm{MeOH}$, $\mathrm{NaOH}): \lambda_{\max }(\lg \varepsilon)=202 \mathrm{~nm}(0.82)$.

IR $(\mathrm{KBr}): \widetilde{v}\left(\mathrm{~cm}^{-1}\right)=3421,2923,1772,1653,1541,1386,1181,1020$.

${ }^{1}$ H-NMR $\left(600 \mathrm{MHz}\right.$, Aceton- $\left.\mathrm{d}_{6}\right): \delta=1.14\left(\mathrm{~d}, J=6.0 \mathrm{~Hz}, 3 \mathrm{H}, 4^{\prime}-\mathrm{H}_{3}\right), 2.25$ (dddd, $J=1.5,7.5$, 9.0, 11.0 Hz, $\left.1 \mathrm{H}, 3-\mathrm{H}_{\mathrm{A}}\right), 2.33\left(\mathrm{~m}, 2 \mathrm{H}, 2^{\prime}-\mathrm{H}_{2}\right), 2.57$ (dddd, $J=1.5,6.5,8.0,9.0 \mathrm{~Hz}, 1 \mathrm{H}$, $\left.3-\mathrm{H}_{\mathrm{B}}\right), 4.09$ (ddq, $\left.J=1.5,6.0,7.5 \mathrm{~Hz}, 1 \mathrm{H}, 3^{\prime}-\mathrm{H}\right), 4.13\left(\mathrm{~s}_{\mathrm{br}}, 1 \mathrm{H}, \mathrm{OH}\right), 4.28$ (ddd, $J=6.0,9.0$, $11.0 \mathrm{~Hz}, 1 \mathrm{H}, 4-\mathrm{H}_{\mathrm{A}}$ ), 4.39 (ddd, $J=2.0,9.0,11.0 \mathrm{~Hz}, 1 \mathrm{H}, 4-\mathrm{H}_{\mathrm{B}}$ ), 4.65 ( ddd, $J=8.0,9.0$, $11.0 \mathrm{~Hz}, 1 \mathrm{H}, 2-\mathrm{H}), 7.70\left(\mathrm{~s}_{\mathrm{br}}, 1 \mathrm{H}, \mathrm{NH}\right) \mathrm{ppm}$.

${ }^{13}$ C-NMR (125 MHz, Aceton-d $\left.\mathrm{d}_{6}\right): \delta=23.3$ (C-4'), 29.7 (C-3), 45.2 (C-2'), 49.1 (C-2), 65.2 (C-3'), 66.1 (C-4), 172.6 (C-1'), 175.7 (C-1) ppm.

\subsection{4 (3S)-3-(tert-Butyldimethylsilyloxy)butansäure (164)}

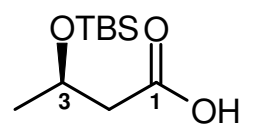

Die Synthese der Verbindung (164) erfolgte ausgehend von $(+)-(S)$-Hydroxybutyrat $(\boldsymbol{S}-\mathbf{4 3})$ wie in 2.1.1 beschrieben. Diese wurde als farbloses Öl erhalten (445 mg, 2.95 mmol, 85 \%).

\section{$\mathbf{C}_{10} \mathbf{H}_{22} \mathbf{O}_{3} \mathrm{Si}$ (218.37).}

$\mathbf{R}_{\mathbf{f}}: 0.40$ (KG, Cyclohexan/EE 7:2).

MS (ESI): $m / z(\%)=219(10)[\mathrm{M}+\mathrm{H}]^{+}, 236(100)\left[\mathrm{M}+\mathrm{NH}_{4}\right]^{+}$.

${ }^{1} \mathbf{H}-\mathbf{N M R}\left(600 \mathrm{MHz}\right.$, Aceton-d $\left.\mathrm{d}_{6}\right): \delta=0.05 / 0.07\left(2 \times \mathrm{s}, 2 \times 3 \mathrm{H}, \mathrm{Si}\left(\mathrm{CH}_{3}\right)_{2} \mathrm{C}\left(\mathrm{CH}_{3}\right)_{3}\right), 0.86(\mathrm{~s}$, $\left.9 \mathrm{H}, \mathrm{Si}\left(\mathrm{CH}_{3}\right)_{2} \mathrm{C}\left(\mathrm{CH}_{3}\right)_{3}\right), 1.19\left(\mathrm{~d}, J=6.0 \mathrm{~Hz}, 3 \mathrm{H}, 4-\mathrm{H}_{3}\right), 2.38\left(\mathrm{~m}, 2 \mathrm{H}, 2-\mathrm{H}_{2}\right), 4.28$ (ddq, $J=6.0,6.0,6.2 \mathrm{~Hz}, 1 \mathrm{H}, 3-\mathrm{H}), 10.2\left(\mathrm{~s}_{\mathrm{br}}, 1 \mathrm{H}, \mathrm{COOH}\right) \mathrm{ppm}$.

${ }^{13}$ C-NMR $\left(125 \mathrm{MHz}\right.$, Aceton-d $\left.\mathrm{d}_{6}\right): \delta=-4.8 /-4.4\left(\mathrm{Si}\left(\underline{C}_{3}\right)_{2} \mathrm{C}\left(\mathrm{CH}_{3}\right)_{3}\right), 18.5\left(\mathrm{Si}\left(\mathrm{CH}_{3}\right)_{2} \underline{C}\left(\mathrm{CH}_{3}\right)_{3}\right)$, 24.2 (C-4), $26.1\left(\mathrm{Si}\left(\mathrm{CH}_{3}\right)_{2} \mathrm{C}\left(\underline{C H}_{3}\right)_{3}\right), 44.9$ (C-2), 66.6 (C-3), 172.6 (C-1) ppm. 


\subsection{5 $N$-[(3S)-3-(tert-Butyldimethylsilyloxy)butyryl]-L-homoserinlacton} (165)<smiles>C[C@@H]([Se-])CC(=O)N[C@H]1CCOC1=O</smiles>

Die Synthese der Verbindung (165) erfolgte ausgehend von (3S)-3-(tert-Butyldimethylsilyloxy)butansäure (164) wie in 2.1.2 beschrieben. Das erhaltene Rohprodukt wurde ohne weitere Reinigung im Folgeschritt eingesetzt.

\section{$\mathrm{C}_{\mathbf{1 4}} \mathrm{H}_{27} \mathrm{NO}_{4} \mathrm{Si}$ (301.64).}

$\mathbf{R}_{\mathbf{f}}: 0.35(\mathrm{KG}$, Cyclohexan/Aceton 2:1).

MS (ESI): $m / z(\%)=302(28)[\mathrm{M}+\mathrm{H}]^{+}, 324(38)[\mathrm{M}+\mathrm{Na}]^{+}, 625(100)[2 \mathrm{M}+\mathrm{Na}]^{+}$.

${ }^{1} \mathbf{H}-\mathbf{N M R}\left(600 \mathrm{MHz}\right.$, Aceton-d $\left.\mathrm{d}_{6}\right): \delta=0.05 / 0.07\left(2 \times \mathrm{s}, 2 \times 3 \mathrm{H}, \mathrm{Si}\left(\mathrm{C}_{3}\right)_{2} \mathrm{C}\left(\mathrm{CH}_{3}\right)_{3}\right), 0.86(\mathrm{~s}$, $\left.9 \mathrm{H}, \mathrm{Si}\left(\mathrm{CH}_{3}\right)_{2} \mathrm{C}\left(\mathrm{C}_{3}\right)_{3}\right), 1.16\left(\mathrm{~d}, J=6.0 \mathrm{~Hz}, 3 \mathrm{H}, 4^{\prime}-\mathrm{H}_{3}\right), 2.27\left(\mathrm{~m}, 1 \mathrm{H}, 2^{\prime}-\mathrm{H}_{\mathrm{A}}\right), 2.29$ (dddd, $\left.J=1.5,5.0,9.0,11.0 \mathrm{~Hz}, 1 \mathrm{H}, 3-\mathrm{H}_{\mathrm{A}}\right), 2.37\left(\mathrm{~m}, 1 \mathrm{H}, 2^{\prime}-\mathrm{H}_{\mathrm{B}}\right), 2.56$ (dddd, $J=1.5,6.5,8.5$, $9.0 \mathrm{~Hz}, 1 \mathrm{H}, 3-\mathrm{H}_{\mathrm{B}}$ ), 4.27 (ddd, $J=6.0,9.0,10.5 \mathrm{~Hz}, 1 \mathrm{H}, 4-\mathrm{H}_{\mathrm{A}}$ ), 4.29 (ddq, $J=1.5,6.0$, $\left.7.5 \mathrm{~Hz}, 1 \mathrm{H}, 3{ }^{\prime}-\mathrm{H}\right), 4.39\left(\mathrm{ddd}, J=2.0,9.0,11.0 \mathrm{~Hz}, 1 \mathrm{H}, 4-\mathrm{H}_{\mathrm{B}}\right), 4.53$ (ddd, $J=7.5,8.0$, $11.5 \mathrm{~Hz}, 1 \mathrm{H}, 2-\mathrm{H}), 7.60$ ( $\left.\mathrm{s}_{\mathrm{br}}, 1 \mathrm{H}, \mathrm{NH}\right) \mathrm{ppm}$.

${ }^{13}$ C-NMR $\left(125 \mathrm{MHz}\right.$, Aceton-d $\left.\mathrm{d}_{6}\right): \delta=-4.7 /-4.5\left(\mathrm{Si}\left(\underline{C}_{3}\right)_{2} \mathrm{C}\left(\mathrm{CH}_{3}\right)_{3}\right), 18.5\left(\mathrm{Si}\left(\mathrm{CH}_{3}\right)_{2} \underline{C}\left(\mathrm{CH}_{3}\right)_{3}\right)$, 24.0 (C-4'), $26.2\left(\mathrm{Si}\left(\mathrm{CH}_{3}\right)_{2} \mathrm{C}\left(\mathrm{CH}_{3}\right)_{3}\right), 29.3$ (C-3), 46.8 (C-2'), 49.3 (C-2), 66.0 (C-3'), 66.8 (C-4), $171.2(\mathrm{C}-1$ '), 175.4 (C-1) ppm.

\subsection{6 $N$-[(3S)-Hydroxybutyryl]-L-homoserinlacton $(S, S-30)$}<smiles>CC(O)CC(=O)NC1CCOC1=O</smiles>

Die Synthese der Verbindung $(\boldsymbol{S}, \boldsymbol{S}-\mathbf{3 0})$ erfolgte ausgehend vom Rohprodukt (165) wie in 2.1.3 beschrieben. Das aus der wässrigen Phase erhaltene Rohprodukt wurde chromatographisch an Kieselgel (Flashchromatographie, Cyclohexan/Aceton 1:2) gereinigt und die 
Zielverbindung $(\boldsymbol{S}, \boldsymbol{S} \mathbf{- 3 0})$ als farbloser Feststoff erhalten $(25.1 \mathrm{mg}, 134 \mu \mathrm{mol}, 26 \%$ über zwei Stufen).

$\mathrm{C}_{8} \mathrm{H}_{13} \mathrm{NO}_{4} \quad$ (187.20).

$\mathbf{R}_{\mathbf{f}}$ : 0.35 (KG, Cyclohexan/Aceton 1:2); 0.57 (RP-18, Aceton/ $\mathrm{H}_{2} \mathrm{O}$ 1:3).

MS (DCI, $200 \mathrm{eV}): m / z(\%)=188(8)[\mathrm{M}+\mathrm{H}]^{+}, 205(100)\left[\mathrm{M}+\mathrm{NH}_{4}\right]^{+}$.

HR-ESI-MS: ber. $(\mathrm{m} / \mathrm{z})=210.07368[\mathrm{M}+\mathrm{Na}]^{+}$ gef. $(\mathrm{m} / \mathrm{z})=210.07372[\mathrm{M}+\mathrm{Na}]^{+}$.

Drehwert: $[\alpha]_{D}^{20}=-18(\mathrm{c}=0.1, \mathrm{MeOH})$.

UV (MeOH): $\lambda_{\max }(\lg \varepsilon)=202 \mathrm{~nm}(2.55) ;(\mathrm{MeOH}, \mathrm{HCl}): \lambda_{\max }(\lg \varepsilon) 202 \mathrm{~nm}(2.28) ;(\mathrm{MeOH}$, $\mathrm{NaOH}): \lambda_{\max }(\lg \varepsilon)=202 \mathrm{~nm}(1.24)$.

IR $(\mathrm{KBr}): \widetilde{v}\left(\mathrm{~cm}^{-1}\right)=3297,2966,1775,1644,1552,1383,1176,1018$.

${ }^{1}$ H-NMR $\left(600 \mathrm{MHz}\right.$, Aceton-d $\left.{ }_{6}\right): \delta=1.12\left(\mathrm{~d}, J=6.0 \mathrm{~Hz}, 3 \mathrm{H}, 4^{\prime}-\mathrm{H}_{3}\right), 2.30$ (dddd, $J=1.5,5.0$, 9.0, $\left.11.0 \mathrm{~Hz}, 1 \mathrm{H}, 3-\mathrm{H}_{\mathrm{A}}\right), 2.32\left(\mathrm{~m}, 2 \mathrm{H}, 2^{\prime}-\mathrm{H}_{2}\right), 2.57$ (dddd, $J=1.8,6.5,9.0,11.0 \mathrm{~Hz}, 1 \mathrm{H}$, 3- $\left.\mathrm{H}_{\mathrm{B}}\right), 4.10\left(\mathrm{~m}_{\mathrm{br}}, 2 \mathrm{H}, 3^{\prime}-\mathrm{H}, 3{ }^{\prime}-\mathrm{OH}\right), 4.28$ (ddd, $\left.J=6.0,9.0,11.0 \mathrm{~Hz}, 1 \mathrm{H}, 4-\mathrm{H}_{\mathrm{A}}\right), 4.39$ (ddd, $\left.J=2.0,9.0,11.0 \mathrm{~Hz}, 1 \mathrm{H}, 4-\mathrm{H}_{\mathrm{B}}\right), 4.61(\mathrm{ddd}, J=8.0,9.0,11.0 \mathrm{~Hz}, 1 \mathrm{H}, 2-\mathrm{H}), 7.68\left(\mathrm{~s}_{\mathrm{br}}, 1 \mathrm{H}\right.$, $\mathrm{NH}) \mathrm{ppm}$.

${ }^{13}$ C-NMR (125 MHz, Aceton-d $\left.\mathrm{d}_{6}\right): \delta=23.3$ (C-4'), 29.3 (C-3), 45.2 (C-2'), 49.2 (C-2), 65.2 (C-3'), 66.1 (C-4), 172.6 (C-1'), 175.6 (C-1) ppm.

\subsubsection{N-(Hydroxybutyryl)-L-homoserinmethylester (54)}<smiles>COC(=O)[C@H](CCO)NC(=O)CC(C)O</smiles>

$\mathbf{C}_{8} \mathrm{H}_{17} \mathrm{NO}_{5} \quad$ (219.24).

$\mathbf{R}_{\mathbf{f}}: 0.20\left(\mathrm{KG}, \mathrm{CH}_{2} \mathrm{Cl}_{2} / \mathrm{MeOH}\right.$ 10:1); $0.44\left(\mathrm{RP}-18\right.$, Aceton/ $\mathrm{H}_{2} \mathrm{O}$ 1:3).

MS (ESI): $m / z(\%)=242(20)[\mathrm{M}+\mathrm{Na}]^{+}, 218(30)[\mathrm{M}-\mathrm{H}]^{-}$.

${ }^{1} \mathbf{H}$-NMR $\left(600 \mathrm{MHz}\right.$, Aceton-d $\left.\mathrm{d}_{6}\right): \delta=1.14\left(\mathrm{~d}, J=6.0 \mathrm{~Hz}, 3 \mathrm{H}, 4^{\prime}-\mathrm{H}_{3}\right), 1.78$ (dddd, $J=1.5,5.0$, 7.8, 9.5 Hz, $\left.1 \mathrm{H}, 3-\mathrm{H}_{\mathrm{A}}\right), 2.00$ (dddd, $\left.J=1.5,5.0,8.0,10.0 \mathrm{~Hz}, 1 \mathrm{H}, 3-\mathrm{H}_{\mathrm{B}}\right), 2.33(\mathrm{~m}, 2 \mathrm{H}$, 
2'- $\left.\mathrm{H}_{2}\right), 3.60\left(\mathrm{ddd}, J=5.0,8.0,10.0 \mathrm{~Hz}, 2 \mathrm{H}, 4-\mathrm{H}_{2}\right), 3.65$ (s, $\left.3 \mathrm{H}, 1-\mathrm{OCH}_{3}\right), 4.09$ (ddq, $J=1.5$, 6.0, 7.5 Hz, $1 \mathrm{H}, 3$ '-H), 4.14 ( $\left.\mathrm{s}_{\mathrm{br}}, 1 \mathrm{H}, 4-\mathrm{OH}\right), 4.60$ (ddd, J = 8.0, 9.0, $\left.11.0 \mathrm{~Hz}, 1 \mathrm{H}, 2-\mathrm{H}\right), 7.54$ $\left(\mathrm{s}_{\mathrm{br}}, 1 \mathrm{H}, \mathrm{NH}\right) \mathrm{ppm}$.

${ }^{13}$ C-NMR (125 MHz, Aceton-d $\left.{ }_{6}\right): \delta=23.4(\mathrm{C}-4$ '), 35.6 (C-3), 45.2 (C-2'), 50.4 (C-2), 52.2 $\left(1-\mathrm{OCH}_{3}\right), 58.6(\mathrm{C}-4), 64.3\left(\mathrm{C}-3^{\prime}\right), 172.9\left(\mathrm{C}-1^{\prime}\right), 173.5(\mathrm{C}-1) \mathrm{ppm}$.

\subsubsection{N-(Hydroxybutyryl)-L-homoserinbutylester (53)}

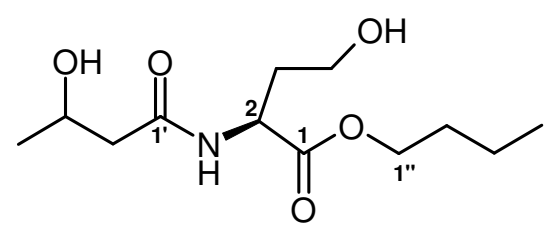

$\mathrm{C}_{11} \mathrm{H}_{21} \mathrm{NO}_{5} \quad$ (247.29).

$\mathbf{R}_{\mathbf{f}}$ : 0.37 (KG, Cyclohexan/Aceton 1:2).

${ }^{1}$ H-NMR $\left(600 \mathrm{MHz}\right.$, Aceton-d 6 ): $\delta=0.91\left(\mathrm{t}, J=7.5 \mathrm{~Hz}, 3 \mathrm{H}, 4 "-\mathrm{H}_{3}\right), 1.14(\mathrm{~d}, J=6.0 \mathrm{~Hz}, 3 \mathrm{H}$, 4'- $\mathrm{H}_{3}$ ), 1.38 (tq, $J=7.5 \mathrm{~Hz}, 2 \mathrm{H}, 3$ "- $\mathrm{H}_{2}$ ), 1.60 (tt, $J=7.5 \mathrm{~Hz}, 2^{\prime \prime}-\mathrm{H}_{2}$ ), 1.78 (dddd, $J=1.5,5.0$, 7.8, 9.5 Hz, $\left.1 \mathrm{H}, 3-\mathrm{H}_{\mathrm{A}}\right), 2.02$ (dddd, $\left.J=1.5,5.0,8.0,10.0 \mathrm{~Hz}, 1 \mathrm{H}, 3-\mathrm{H}_{\mathrm{A}}\right), 2.33(\mathrm{~m}, 2 \mathrm{H}$, 2'- $\mathrm{H}_{2}$ ), 3.61 (ddd, $\left.J=5.0,8.0,10.0 \mathrm{~Hz}, 2 \mathrm{H}, 4-\mathrm{H}_{2}\right), 4.09$ (ddq, $\left.J=1.5,6.0 .7 .5 \mathrm{~Hz}, 1 \mathrm{H}, 3^{\prime}-\mathrm{H}\right)$, $4.10\left(\mathrm{t}, J=6.8 \mathrm{~Hz}, 1 \mathrm{H}, 1 "-\mathrm{H}_{2}\right), 4,18\left(\mathrm{~s}_{\mathrm{br}}, 1 \mathrm{H}, 4-\mathrm{OH}\right), 4.59$ (ddd, $J=8.0,9.0,11.0 \mathrm{~Hz}, 1 \mathrm{H}$, 2-H), 7.58 ( $\left.\mathrm{s}_{\mathrm{br}}, 1 \mathrm{H}, \mathrm{NH}\right) \mathrm{ppm}$.

*Signal höherer Ordnung.

${ }^{13}$ C-NMR (125 MHz, Aceton-d $\mathrm{d}_{6}$ ): $\delta=13.9$ (C-4"), 19.7 (C-3"), 23.4 (C-4'), 31.3 (C-2"), 35.7 (C-3), 45.2 (C-2'), 50.6 (C-2), 58.7 (C-4), 65.3 (C-1"), 65.4 (C-3'), 172.9 (C-1'), 173.1 (C-1) ppm.

\subsection{Reinigung des enzymatisch hergestellten Autoinducers AI-2 (20)}

\subsubsection{In vitro-Synthese des AI-2-Vorläufers DPD (31)}

Die zur in vitro-Synthese benötigten Enzyme $P f s$ und LuxS wurden von C. Anetzberger (AK Jung, München) produziert und nach Proteinreinigung die jeweilige Proteinkonzentration mittels Peterson ${ }^{190}$ durch C. Anetzberger bestimmt. Für eine enzymatische Synthese mit einem Ansatzvolumen von $3 \mathrm{~mL}$ wurden Puffer (Natriumphosphat-Puffer), Enzyme ( $P f s$, 
LuxS) und Substrat (S-Adenosylhomocystein, SAH, Fa. Sigma) zusammengegeben (siehe Tabelle 11).

Zur Herstellung der 10 mM SAH-Lösung wurde SAH $(7.69 \mathrm{mg})$ in $1 \mathrm{M} \mathrm{HCl}(0.9 \mathrm{~mL})$ gelöst, anschließend unter kontinuierlichem Schwenken tropfenweise $1 \mathrm{M} \mathrm{NaOH}(0.9 \mathrm{~mL})$ und $1 \mathrm{M}$ Natriumphosphat-Puffer $(\sim 0.2 \mathrm{~mL}, \mathrm{pH}=7.5)$ zugegeben und der eingestellte $\mathrm{pH}$-Wert von 7.5 überprüft. Die Lösung wurde bei $-20{ }^{\circ} \mathrm{C}$ gelagert. ${ }^{191}$ Für den $1 \mathrm{M}$ Natriumphosphat-Puffer wurden 1 M-Lösungen von $\mathrm{Na}_{2} \mathrm{HPO}_{4}(84.5 \mathrm{~mL} ; 93.1 \mathrm{~g} / 250 \mathrm{~mL})$ und $\mathrm{NaH}_{2} \mathrm{PO}_{4}(14.5 \mathrm{~mL}$; $6.89 \mathrm{~g} / 50 \mathrm{~mL}$ ) zusammengegeben und $1 \mathrm{M} \mathrm{HCl} \mathrm{pH}=7.5$ eingestellt. ${ }^{191}$ Alle Ansätze wurden mit Wasser auf das Gesamtvolumen aufgefüllt bzw. dieses zunächst vorgelegt:

Tabelle 11. Ansatz (3 mL) für eine in-vitro Synthese des AI-2-Vorläufers DPD (31).

\begin{tabular}{ccc}
\hline $\begin{array}{c}\text { Endkonzentration im } \\
\text { Gesamtvolumen (3 mL) }\end{array}$ & $\begin{array}{c}\text { Konzentration der } \\
\text { benutzten Lösung }\end{array}$ & $\begin{array}{c}\text { Eingesetzte Menge für } \\
\text { 3 mL-Ansatz }\end{array}$ \\
\hline $1 \mathrm{mmolar}$ SAH & $10 \mathrm{mmolar}$ SAH & $300 \mu \mathrm{L}$ \\
$1 \mathrm{mg} / \mathrm{mL}$ Pfs & Hier: $15.6 \mathrm{mg} / \mathrm{mL}$ Pfs & $190 \mu \mathrm{L}^{*}$ \\
$1 \mathrm{mg} / \mathrm{mL}$ LuxS & Hier: $12.2 \mathrm{mg} / \mathrm{mL} \mathrm{LuxS}$ & $240 \mu \mathrm{L}^{*}$ \\
10 mmolar Na-Phosphat-Puffer & $1 \mathrm{M} \mathrm{Na-Phosphat-Puffer}$ & $30 \mu \mathrm{L}$ \\
\hline Bestimmung der Enzymkonzentration mittels Peterson ${ }^{190}$ (C. Anetzberger, AK Jung, München).
\end{tabular}

Bestimmung der Enzymkonzentration mittels Peterson ${ }^{190}$ (C. Anetzberger, AK Jung, München).

Der enzymatische Reaktionsansatz wurde für $1 \mathrm{~h}$ bei $37^{\circ} \mathrm{C}$ auf einer Wippe inkubiert. Danach wurde der Reaktionsansatz zur Abtrennung der Proteine mittels VIVASPIN ${ }^{\circledR} 20$ filtriert. Hierzu wurde der gesamte Ansatz auf eine VIVASPIN ${ }^{\circledR}$ 20-Minisäule gegeben und zentrifugiert (2000 g, $\left.4^{\circ} \mathrm{C}\right)$. Die Bestimmung der Konzentration an gebildeten AI-2-Vorläufer DPD (31) wurde mit einem Ellmann-Test durchgeführt. Hierzu wurde eine Probe des erhaltenen Filtrats mit Ellmann-Puffer im Verhältnis 1:10 verdünnt. Für eine Verdünnungsreihe wurden 10, 50 und $100 \mu 1$ dieser Stammlösung in Messküvetten gegeben und mit Ellmann-Puffer auf ein Gesamtvolumen von $200 \mu 1$ aufgefüllt. Je $100 \mu 1$ Ellmann-Reagenz (Dithio-Nitrobenzoat, $5 \mathrm{mM} ; 19.82 \mathrm{~g} / 10 \mathrm{~mL}$ Ellmann-Puffer) zugegeben und die Absorption bei $412 \mathrm{~nm}$ gemessen. Die Konzentrationsbestimmung erfolgte über $E=\varepsilon c d$ mit $(\mathrm{d}=1 \mathrm{~cm}, \varepsilon=14150 / \mathrm{M} \mathrm{cm}) .{ }^{191}$

Zur Herstellung des Ellmann-Puffers wurden $10 \mathrm{~mL}$ einer $1 \mathrm{M}$ Stammlösung des Natriumphosphat-Puffers mit $200 \mu \mathrm{L}$ einer $50 \mathrm{mM}$ Stammlösung von EDTA zusammengegeben und mit bidest. Wasser auf ein Gesamtvolumen von $100 \mathrm{~mL}$ aufgefüllt. 


\subsubsection{Affinitätschromatographie an Boronsäure-Gel}

Die Affinitätschromatographie wurde in Anlehnung an Semmelhack et al. durchgeführt. ${ }^{192}$ Das immobilisierte Boronsäure-Gel (Fa. Pierce) wurde bei Thermo Fisher Scientific erworben. Die enzymatische Synthese des AI-2-Vorläufers DPD wurde wie im vorherigen Abschnitt beschrieben durchgeführt.

Die Affinitätschromatographie wurde wie folgt durchgeführt:

1. Zum Entfernen des Natriumazids wurde gut gemischtes Boronsäure-Gel (200 $\mu \mathrm{L})$ in einen Mikrozentrifugenfilter (Microcon YM-30, Centrifugal Filter Unit Microcon YM-30, Ausschlußgröße: $30 \mathrm{kDA}$; Fassungsvolumen $500 \mu \mathrm{L}$ ) gegeben und bei $9000 \mathrm{U} / \mathrm{min}$ und $4{ }^{\circ} \mathrm{C}$ für 12 min zentrifugiert.

2. Zur vollständigen Entfernung des Natriumazids und Einstellen auf $\mathrm{pH} 9.0$ wurde das Boronsäure-Gel mit ges. $\mathrm{NaHCO}_{3}$-Lösung $(2 \times 250 \mu \mathrm{L}, \mathrm{pH} 8.8)$ gewaschen $(9000 \mathrm{U} / \mathrm{min}$, $\left.4{ }^{\circ} \mathrm{C}, 12 \mathrm{~min}\right)$.

3. Das aus dem enzymatischen Ansatz erhaltene Rohprodukt (Filtrat) wurde zunächst mit ges. $\mathrm{NaHCO}_{3}$-Lösung (Volumina enzym. Ansatz: $\mathrm{NaHCO}_{3}$-Lsg. 1:1) verdünnt und anschließend in Aliquots von $350 \mu \mathrm{L}$ zum Boronsäure-Gel addiert und zentrifugiert $\left(9000 \mathrm{U} / \mathrm{min}, 4{ }^{\circ} \mathrm{C}\right.$, 12 min). Der Durchfluss wurde aufgefangen und im Ellmann-Test überprüft.

4. Nach vollständiger Gabe des Rohproduktes über das Boronsäure-Gel wurde mit ges. $\mathrm{NaHCO}_{3}$-Lösung $(1 \times 200 \mu \mathrm{L})$ gewaschen $\left(9000 \mathrm{U} / \mathrm{min}, 4{ }^{\circ} \mathrm{C}, 12 \mathrm{~min}\right)$. Der Durchfluss wurde aufgefangen und im Ellmann-Test überprüft.

5. Die Elution des DPD erfolgte mit Ameisensäure (10 \%ig, $2 \times 250 \mu \mathrm{L})$. Das Eluat wurde in einem neuen $1.5 \mathrm{~mL}$ Eppendorfgefäß aufgefangen, in dem ges. $\mathrm{NaHCO}_{3}$-Lösung (14 $\left.\mu \mathrm{L}\right)$ und Borsäure (1 M, $162 \mu \mathrm{L} ; 61.8 \mathrm{~g} / \mathrm{L}$ ) vorgelegt waren. Der pH-Wert dieser Lösung wurde sofort mittels pH-Papier kontrolliert und durch weitere Zugabe von ges. $\mathrm{NaHCO}_{3}$-Lösung $(14 \mu \mathrm{L})$ auf pH 7.8 eingestellt. Die Konzentration an gebildetem AI-2 (20) wurde mittels EllmannTest bestimmt.

\subsection{Chemische Hydrolyse von $N$-Acyl-Homoserinlactonen}

Zur chemischen Analyse der Lactonase-Spaltprodukte wurde das 3-Oxo-C $\mathrm{C}_{8}-\mathrm{L}-\mathrm{Homoserin}$ lacton im Alkalischen anteilig hydrolysiert. Hierzu wurde das 3-Oxo-C - $^{-L}$-Homoserinlacton (62) $(5.8 \mathrm{mg}, 24.1 \mu \mathrm{mol})$ in DMSO $(60 \mu \mathrm{L})$ gelöst und mit $1 \mathrm{~N} \mathrm{NaOH}(1.5$ Äq., $36 \mu \mathrm{L})$ für 16 $\mathrm{h}$ bei Raumtemperatur gerührt. Anschließend wurde durch Zugabe von Wasser (10 mL) die Reaktion beendet, mit $1 \mathrm{M} \mathrm{NaH}_{2} \mathrm{PO}_{4}(39 \mu \mathrm{L}) \mathrm{pH} 6.5$ eingestellt und mit Ethylacetat 
$(3 \times 10 \mathrm{~mL})$ extrahiert. Die vereinigten organischen Phasen wurden mit ges. NaCl-Lösung (20 mL) gewaschen, über $\mathrm{Na}_{2} \mathrm{SO}_{4}$ getrocknet und das Lösungsmittel i. Vak. entfernt.

Zur vollständigen Hydrolyse wurde 3-Oxo-C $\mathrm{C}_{8}$-L-Homoserinlacton $(62)(12.1 \mathrm{mg}, 50.1 \mu \mathrm{L})$ in Dioxan $(100 \mu \mathrm{L})$ mit $1 \mathrm{~N} \mathrm{NaOH}(1.5$ Äq., $74.7 \mu \mathrm{L})$ für $24 \mathrm{~h}$ bei Raumtemperatur gerührt. Anschließend wurde die Reaktion mit Wasser $(10 \mathrm{~mL})$ beendet und wie oben beschrieben aufgearbeitet. Das $\mathrm{C}_{12}$-DL-Homoserinlacton (64) $(2.4 \mathrm{mg}, 8.47 \mu \mathrm{mol})$ wurde zur vollständigen Hydrolyse in Dioxan $(150 \mu \mathrm{L})$ mit $1 \mathrm{n} \mathrm{NaOH}(1.5$ Äq., $12.7 \mu \mathrm{L})$ für 24 h bei Raumtemperatur gerührt, danach die Reaktion mit Wasser $(10 \mathrm{~mL})$ beendet und wie oben beschrieben aufgearbeitet.

\subsubsection{Charakterisierung der $N$-Acyl-Homoserinlactone und Hydrolyse- produkte}

\section{3-Oxo-C 8 -L-Homoserinlacton (62)}

$\mathrm{C}_{12} \mathrm{H}_{19} \mathrm{NO}_{4} \quad$ (241.29).

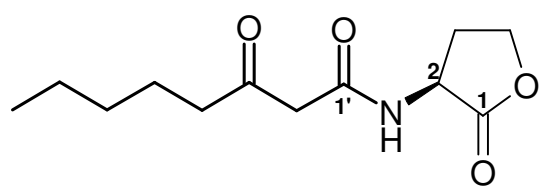

MS (DCI, $200 \mathrm{eV}): m / z(\%)=259(100)\left[\mathrm{M}+\mathrm{NH}_{4}\right]^{+}, 500(8)\left[2 \mathrm{M}+\mathrm{NH}_{4}\right]^{+}$.

MS (ESI): $m / z(\%)=242(100)[\mathrm{M}+\mathrm{H}]^{+}, 264(30)[\mathrm{M}+\mathrm{Na}]^{+}, 241(100)[\mathrm{M}-\mathrm{H}]^{-}$.

${ }^{1} \mathbf{H}-\mathbf{N M R}\left(600 \mathrm{MHz}\right.$, Aceton-d $\left.\mathrm{d}_{6}\right): \delta=0.87\left(\mathrm{t}, J=7.0 \mathrm{~Hz}, 3 \mathrm{H}, 8^{\prime}-\mathrm{H}_{3}\right), 1.25(\mathrm{tt}, J=7.0,9.0 \mathrm{~Hz}$, $\left.2 \mathrm{H}, 66^{\prime}-\mathrm{H}_{2}\right), 1.30$ (tq, $\left.J=7.0,9.0 \mathrm{~Hz}, 2 \mathrm{H}, 7^{\prime}-\mathrm{H}_{2}\right), 1.53$ (tt, $\left.J=7.5,7.5 \mathrm{~Hz}, 2 \mathrm{H}, 5^{\prime}-\mathrm{H}_{2}\right), 2.13^{*}$ $\left(\mathrm{m}, 2 \mathrm{H}, 4^{\prime}-\mathrm{H}_{2}{ }^{*}\right), 2.29$ (dddd, $\left.J=1.5,7.0,9.0,11.0 \mathrm{~Hz}, 1 \mathrm{H}, 3-\mathrm{H}_{\mathrm{A}}\right), 2.58(\mathrm{t}, J=7.5 \mathrm{~Hz}, 2 \mathrm{H}$, 4'- $\mathrm{H}_{2}$ ), 2.60 (dddd, $J=2.0,7.5,9.0,11.0 \mathrm{~Hz}, 1 \mathrm{H}, 3-\mathrm{H}_{\mathrm{B}}$ ), 3.40 (s, $2 \mathrm{H}, 2^{\prime}-\mathrm{H}_{2}$ ), 4.29 (ddd, $\left.J=6.0,9.0,11.0 \mathrm{~Hz}, 1 \mathrm{H}, 4-\mathrm{H}_{\mathrm{A}}\right), 4.40\left(\mathrm{ddd}, J=1.5,9.0,11.0 \mathrm{~Hz}, 1 \mathrm{H}, 4-\mathrm{H}_{\mathrm{B}}\right), 4.64$ (ddd, $J=7.5,9.0,11.0 \mathrm{~Hz}, 1 \mathrm{H}, 2-\mathrm{H}), 4.73^{*}\left(\mathrm{ddd}, J=7.5,9.0,11.0 \mathrm{~Hz}, 1 \mathrm{H}, 2-\mathrm{H}^{*}\right), 5.10^{*}(\mathrm{~s}, 1 \mathrm{H}$, $\left.2^{\prime}-\mathrm{H}^{*}\right), 7.45^{*}\left(\mathrm{~s}_{\mathrm{br}}, 1 \mathrm{H}, \mathrm{NH}^{*}\right), 7.81\left(\mathrm{~s}_{\mathrm{br}}, 1 \mathrm{H}, \mathrm{NH}\right), 13.6^{*}$ (s, $\left.1 \mathrm{H}, 3^{\prime}-\mathrm{OH}\right) \mathrm{ppm}$.

${ }^{13}$ C-NMR (125 MHz, Aceton- $\mathrm{d}_{6}$ ): $\delta=14.2$ (q, C-8'), 23.1 (t, C-7'), 23.7 (t, C-5'), 26.7 (t, C-5 $\left.{ }^{*}\right), 30.1(\mathrm{t}, \mathrm{C}-3), 31.9$ (t, C-6'), 35.5 (t, C-4 $\left.{ }^{*}\right), 43.1$ (t, C-4'), 48.8* (d, C-2*), 49.4 (d, C-2), 50.7 (t, C-2'), 66.1 (t, C-4), 90.6 ${ }^{*}\left(\mathrm{C}-2^{2^{*}}\right) 167.3$ (s, C-1'), 175.3 (s, C-1), 205.0 (s, C-3') ppm. 


\section{3-Oxo-C 8 -L-Homoserin (63)}

$\mathbf{C}_{12} \mathrm{H}_{21} \mathrm{NO}_{5} \quad$ (259.30).

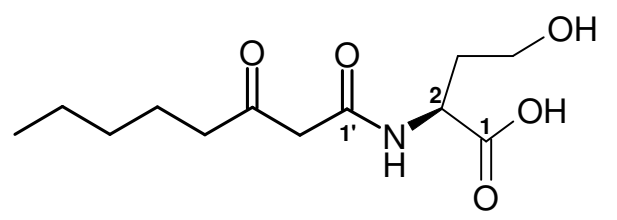

MS (ESI): $m / z(\%)=242(48)\left[\mathrm{M}-\mathrm{H}_{2} \mathrm{O}+\mathrm{H}\right]^{+}, 260(100)[\mathrm{M}+\mathrm{H}]^{+}, 282(30)[\mathrm{M}+\mathrm{Na}]^{+}, 541(50)$ $[2 \mathrm{M}+\mathrm{Na}]^{+}, 258(100)[\mathrm{M}-\mathrm{H}]^{-}, 517(35)[2 \mathrm{M}-\mathrm{H}]^{-}, 539(70)[2 \mathrm{M}-2 \mathrm{H}+\mathrm{Na}]^{-}$.

${ }^{1}$ H-NMR (600 MHz, Aceton-d $\left.\mathrm{d}_{6}\right): \delta=0.87\left(\mathrm{t}, J=7.0 \mathrm{~Hz}, 3 \mathrm{H}, 8^{\prime}-\mathrm{H}_{3}\right), 1.28\left(\mathrm{~m}_{\mathrm{br}}, 2 \mathrm{H}, 66^{\prime}-\mathrm{H}_{2}\right)$, $1.28\left(\mathrm{~m}_{\mathrm{br}}, 2 \mathrm{H}, 7^{\prime}-\mathrm{H}_{2}\right), 1.53\left(\mathrm{tt}, J=7.5,7.5 \mathrm{~Hz}, 2 \mathrm{H}, 5^{\prime}-\mathrm{H}_{2}\right), 1.80\left(\mathrm{~m}_{\mathrm{c}}, 1 \mathrm{H}, 3-\mathrm{H}_{\mathrm{A}}\right), 2.06\left(\mathrm{~m}_{\mathrm{c}}\right.$, $\left.1 \mathrm{H}, 3-\mathrm{H}_{\mathrm{B}}\right) 2.58\left(\mathrm{t}, J=7.5 \mathrm{~Hz}, 2 \mathrm{H}, 4^{\prime}-\mathrm{H}_{2}\right), 3.50^{*}\left(\mathrm{~m}_{\mathrm{br}}, 2 \mathrm{H}, 2^{\prime}-\mathrm{H}_{2}\right), 3.50^{*}\left(\mathrm{~m}_{\mathrm{br}}, 1 \mathrm{H}, 4^{\prime}-\mathrm{OH}\right)$, $3.63^{*}(\mathrm{~m}, 2 \mathrm{H}, 2-\mathrm{H}), 3.64^{*}\left(\mathrm{~m}, 1 \mathrm{H}, 4-\mathrm{H}_{\mathrm{A}}\right), 4.45$ (m, $\left.1 \mathrm{H}, 4-\mathrm{H}_{\mathrm{B}}\right), 7.90$ ( $\left.\mathrm{s}_{\mathrm{br}}, 1 \mathrm{H}, \mathrm{NH}\right), 13.8$ (s, $1 \mathrm{H}, 1-\mathrm{OH}) \mathrm{ppm}$.

${ }^{13}$ C-NMR (125 MHz, Aceton- $\left.\mathrm{d}_{6}\right): \delta=14.3\left(\mathrm{q}, \mathrm{C}-8^{\prime}\right), 23.2\left(\mathrm{t}, \mathrm{C}-7^{\prime}\right), 23.8\left(\mathrm{t}, \mathrm{C}-5^{\prime}\right), 32.0(\mathrm{t}$, C-6'), 36.1 (t, C-3), 43.6 (t, C-4'), 50.9 (d, C-2), 53.0 (t, C-2'), 59.2 (t, C-4), 168.2 (s, C-1'), 178.8 (s, C-1), 207.0 (s, C-3') ppm.

* Die Signale überlagern.

\section{$\mathrm{C}_{12}$-DL-Homoserinlacton (64)}

$\mathrm{C}_{16} \mathrm{H}_{29} \mathrm{NO}_{3} \quad(283.41)$.

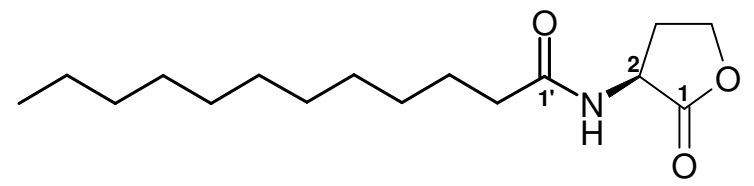

MS (ESI): $m / z(\%)=284(100)[\mathrm{M}+\mathrm{H}]^{+}, 306(90)[\mathrm{M}+\mathrm{Na}]^{+}, 589(35)[2 \mathrm{M}+\mathrm{Na}]^{+}, 282[\mathrm{M}-\mathrm{H}]^{-}$.

${ }^{1}$ H-NMR $\left(600 \mathrm{MHz}\right.$, Aceton-d $\left.\mathrm{d}_{6}\right): \delta=0.86\left(\mathrm{t}, J=7.0 \mathrm{~Hz}, 3 \mathrm{H}, 12^{\prime}-\mathrm{H}_{3}\right), 1.27\left(\mathrm{~m}_{\mathrm{br}}, 14 \mathrm{H}, 4^{\prime}-\mathrm{H}_{2}\right.$ 5'- $\mathrm{H}_{2}, 6$ '- $\left.-\mathrm{H}_{2}, 7^{\prime}-\mathrm{H}_{2}, 8^{\prime}-\mathrm{H}_{2}, 9^{\prime}-\mathrm{H}_{2}, 10^{\prime}-\mathrm{H}_{2}\right), 1.30\left(\mathrm{~m}_{\mathrm{br}}, 2 \mathrm{H}, 11^{\prime}-\mathrm{H}_{2}\right), 1.58$ (tt, J = 7.5, 7.5 Hz, $2 \mathrm{H}$, 3'- $\left.-\mathrm{H}_{2}\right), 2.19$ (dd, $J=6.8,7.9 \mathrm{~Hz}, 2 \mathrm{H}, 2^{\prime}-\mathrm{H}_{2}$ ), 2.25 (dddd, $J=2.0,7.5,9.0,11.0 \mathrm{~Hz}, 1 \mathrm{H}$, $\left.3-\mathrm{H}_{\mathrm{B}}\right), 2.55$ (dddd, $\left.J=1.5,7.0,9.0,11.0 \mathrm{~Hz}, 1 \mathrm{H}, 3-\mathrm{H}_{\mathrm{A}}\right), 4.26(\mathrm{ddd}, J=6.0,9.0,11.0 \mathrm{~Hz}, 1 \mathrm{H}$, 4- $\left.\mathrm{H}_{\mathrm{A}}\right), 4.37$ (ddd, $\left.J=1.5,9.0,11.0 \mathrm{~Hz}, 1 \mathrm{H}, 4-\mathrm{H}_{\mathrm{B}}\right), 4.61$ (ddd, $J=7.5,9.0,11.0 \mathrm{~Hz}, 1 \mathrm{H}$, 2-H), $7.48\left(\mathrm{~s}_{\mathrm{br}}, 1 \mathrm{H}, \mathrm{NH}\right) \mathrm{ppm}$.

${ }^{13}$ C-NMR (125 MHz, Aceton-d $\left.\mathrm{d}_{6}\right): \delta=14.5$ (C-12'), 23.8 (C-11'), 27.0 (C-3'), 30.2 (C-3), 30.3 (C-4'), 30.5 (C-6', C-9'), 30.7 (C-5', C-8'), 30.8 (C-7'), 33.1 (C-10'), 49.6 (C-2'), 50.5 (C-2), 66.2 (C-4), 172.6 (s, C-1'), 174.8 (s, C-1) ppm. 


\section{$\mathrm{C}_{12}$-DL-Homoserin (65)}

$\mathbf{C}_{16} \mathrm{H}_{31} \mathrm{NO}_{4} \quad$ (301.43).

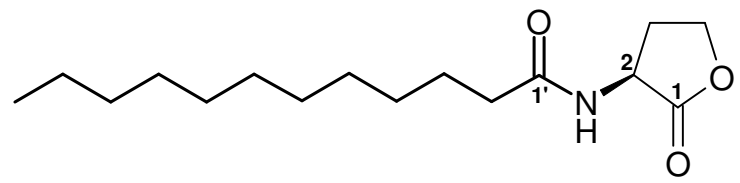

MS (ESI): $m / z(\%)=284(20)\left[\mathrm{M}-\mathrm{H}_{2} \mathrm{O}+\mathrm{H}\right]^{+}, 302(70)[\mathrm{M}+\mathrm{H}]^{+}, 324(35)[\mathrm{M}+\mathrm{Na}]^{+}, 625(100)$ $[2 \mathrm{M}+\mathrm{Na}]^{+}, 300(100)[\mathrm{M}-\mathrm{H}]^{-}, 601(25)[2 \mathrm{M}-\mathrm{H}]^{-}$.

${ }^{1}$ H-NMR $\left(600 \mathrm{MHz}, \mathrm{CD}_{3} \mathrm{OD}\right): \delta=0.89\left(\mathrm{t}, J=7.0 \mathrm{~Hz}, 3 \mathrm{H}, 12^{\prime}-\mathrm{H}_{3}\right), 1.28\left(\mathrm{~m}_{\mathrm{br}}, 14 \mathrm{H}, 4^{\prime}-\mathrm{H}_{2}\right.$ 5'- $\mathrm{H}_{2}, 6$ '- $\left.-\mathrm{H}_{2}, 7^{\prime}-\mathrm{H}_{2}, 8^{\prime}-\mathrm{H}_{2}, 9^{\prime}-\mathrm{H}_{2}, 10 '-\mathrm{H}_{2}\right), 1.31$ (m $\left.\mathrm{m}_{\mathrm{br}}, 2 \mathrm{H}, 11^{\prime}-\mathrm{H}_{2}\right), 1.61$ (tt, J = 7.5, 7.5 Hz, $2 \mathrm{H}$, 3'- $-\mathrm{H}_{2}$ ), 1.84 (dddd, $J=1.5,7.0,9.0,11.0 \mathrm{~Hz}, 1 \mathrm{H}, 3-\mathrm{H}_{\mathrm{A}}$ ), 2.08 (dddd, $J=2.0,7.5,9.0$, $\left.11.0 \mathrm{~Hz}, 1 \mathrm{H}, 3-\mathrm{H}_{\mathrm{B}}\right), 2.24\left(\mathrm{dd}, J=6.8,7.9 \mathrm{~Hz}, 2 \mathrm{H}, 2^{\prime}-\mathrm{H}_{2}\right), 3.59$ (ddd, $J=7.5,9.0,11.0 \mathrm{~Hz}$, $1 \mathrm{H}, 2-\mathrm{H}), 3.64$ (ddd, $\left.J=6.0,9.0,11.0 \mathrm{~Hz}, 1 \mathrm{H}, 4-\mathrm{H}_{\mathrm{A}}\right), 4.49$ (ddd, $J=1.5,9.0,11.0 \mathrm{~Hz}, 1 \mathrm{H}$, 4- $\left.\mathrm{H}_{\mathrm{B}}\right) \mathrm{ppm}$.

${ }^{13}$ C-NMR (125 MHz, CD 3 OD): $\delta=14.5$ (C-12'), 23.8 (C-11'), 27.0 (C-3'), 30.3 (C-4'), 30.5 (C-6', C-9'), 30.7 (C-5', C-8'), 30.8 (C-7'), 33.1 (C-10'), 35.4 (C-3), 36.9 (C-2'), 49.5 (C-2), 59.4 (C-4), 175.3 (s, C-1'), 176.3 (s, C-1) ppm.

\subsection{HPLC-ESI-MS-Analytik von Metagenomklonen}

Zur Verifizierung der Quorum-Quenching-Aktivität neuer Lactonasen aus dem Metagenom mittels HPLC-ESI-MS-Analytik wurden Inkubationsansätze mit BpiB-Proteinen (Größe der Inserts zwischen 1-5 kb) und $N$-Acyl-Homoserinlacton (AHL) als Substrat hergestellt. Diese Arbeiten wurden für die Bpi-Proteine BpiB01, BpiB04, BpiB05 und BpiB09 von C. Schipper (AK Streit, Hamburg) durchgeführt; für das Bpi-Protein BpiB07 von C. Hornung (AK Streit, Hamburg). Für die Proteine BpiB01, BpiB04, BpiB05 und BpiB09 wurden als Substrate N-(3Oxooctanoyl)-L-Homoserinlacton (3-Oxo- $\mathrm{C}_{8}$-HSL, 62) $(10 \mu \mathrm{L}$ einer Stammlösung mit einer Konzentration von $c=0.20 \mathrm{mg} / \mu \mathrm{L}$ in DMSO; Fa. Sigma) und $N$-(Dodecanoyl)-DLHomoserinlacton $\left(\mathrm{C}_{12}\right.$-HSL, 64) $(10 \mu \mathrm{L}$ einer Stammlösung mit einer Konzentration von $c=0.12 \mathrm{mg} / \mu \mathrm{L}$ inDMSO; Fa. Sigma) eingesetzt. Die aufgereinigten Proteine BpiB01, BpiB04, BpiB05 und BpiB09 oder deren Rohextrakte $(c=20 \mu \mathrm{g} / \mathrm{mL})$ wurden mit dem jeweiligen AHL in 1 mL Kaliumphosphatpuffer (100 mM, pH 7.0) oder Tris-Puffer (100 mM, $\mathrm{pH}$ 7.0) für $20 \mathrm{~h}$ bei $30^{\circ} \mathrm{C}$ inkubiert. Vor Zugabe des jeweiligen Substrats wurde bei der Dialyse der Proteine BpiB01, BpiB04 und BpiB09 $\mathrm{ZnCl}_{2}$ oder beim Protein $B p i B 05 \mathrm{CaCl}_{2}$ als benötigter Cofaktor in einer Endkonzentration von $2 \mathrm{mM}$ zugefügt. Das aufgereinigte Protein 
BpiB07 wurde mit 3-Oxo-C -HSL $(5 \mu \mathrm{L}$ einer Stammlösung mit einer Konzentration von $c=0.02 \mathrm{mg} / \mu \mathrm{L}$ in DMSO) in $1 \mathrm{~mL}$ Tris-Puffer $(100 \mathrm{mM}, \mathrm{pH} 7.0)$ für $20 \mathrm{~h}$ bei $30^{\circ} \mathrm{C}$ inkubiert. Vor Zugabe des Substrats wurde bei der Dialyse $\mathrm{ZnCl}_{2}$ in einer Endkonzentration von $0.2 \mathrm{mM}$ zugegeben. Nach der Inkubation wurden die Inkubationsansätze jeweils mit Ethylacetat (Volumina Ethylacetat:Inkubationsansatz 2:1) extrahiert und die vereinigten organischen Phasen i. Vak. bis zur Trockne konzentriert. Zur Kontrolle wurde das Eluat des Leervektors ebenfalls zunächst dialysiert, anschließend mit dem jeweiligen Substrat für $20 \mathrm{~h}$ bei $30{ }^{\circ} \mathrm{C}$ inkubiert und mit Ethylacetat extrahiert.

Die erhaltenen Extrakte aus den Inkubationsansätzen mit BpiB-Proteinen und Leervektor wurden in $110 \mu \mathrm{L}$ Methanol gelöst, für die Messung in Einsätze (Inlets) mit $200 \mu \mathrm{L}$ Fassungsvolumen überführt und zentrifugiert (10 $000 \mathrm{U} / \mathrm{min}, 5 \mathrm{~min}$ ). Die Messung der Proben erfolgte mittels HPLC-ESI-MS (HPLC D, Säule A: Grom Superspher 100, RP-18, Programm B: $\mathrm{MeOH} / \mathrm{H}_{2} \mathrm{O}$, jeweils mit $0.05 \%$ Ameisensäure, Gradient; s. 1.2 ) im positiven und negativen Mode.

\section{HPLC-ESI-MS-Proben für ein Bpi-Protein mit Lactonase-Aktivität}

5. Inkubationsansatz des jeweiligen Bpi-Proteins (2 Ansätze)

6. „Leervektor“ mit Substrat

7. 10-20 $\mu \mathrm{L}$ der jeweiligen Stammlösung (in DMSO) als Kontrolle

8. Hydrolyseprodukt des jeweiligen Substrats aus chemischer Hydrolyse (Standard mit $c=1.0 \mathrm{mg} / \mathrm{mL}$ ) als Kontrolle 


\subsection{Vorversuche zur Analytik von Metagenomklonen}

\subsubsection{Verifizierung Quorum-Sensing inhibierender Metagenomklone}

Verschiedene Klone aus marinen Habitaten wurden auf Quorum-Sensing-Inhibition (QSI) von N. Weiland (AK Schmitz-Streit, Kiel) untersucht. Zwei Klone aus Bakterienisolaten (NC FS9, NC K14) und zwei metagenomische Klone (NC III 6/C8, NC III6/G5) mit QSI-Aktivität wurden zunächst auf die Produktion von Proteinen bzw. höher molekularen, peptidischen Substanzen oder small molecules analysiert. Hierfür wurden Rohextrakte aus deren Kulturüberständen (Kulturfiltraten) hergestellt. Die Kultivierungsarbeiten, aus denen die einzelnen Proben stammten, wurden von N. Weiland (AK Schmitz-Streit, Kiel) durchgeführt sowie die Extraktion der zuvor positiv getesteten Kulturüberstände mit Ethylacetat (ohne Korrektur des $\mathrm{pH}-$ Werts).

Für die Rohextraktherstellung der zuvor positiv getesteten Kulturüberstände (NC FS9, NC K14, NC III 6/C8; je $400 \mathrm{~mL}$ ) wurde zunächst mit $2 \mathrm{~N} \mathrm{HCl}$ ein pH-Wert von 5.0 eingestellt und das jeweilige Kulturfiltrat zur weiteren Bearbeitung in $2 \times 200 \mathrm{~mL}$ aufgeteilt. Der eine Teil wurde jeweils mit Ethylacetat $(2 \times 200 \mathrm{~mL})$ extrahiert und das Lösungsmittel i. Vak. entfernt. Der andere Teil wurde jeweils lyophilisiert und das erhaltene Lyophilisat zunächst mit Methanol/Aceton 6:4 extrahiert, abfiltriert und der Rückstand noch einmal mit Wasser/Methanol/Aceton 2:6:4 extrahiert. Nach Entfernung des Lösungsmittels wurden die erhaltenen Rohextrakte in einer Konzentration zwischen $c=10-20 \mathrm{mg} / \mathrm{mL}$ in dem jeweiligen Extraktionslösungsmittel gelöst, je 1 mL-Proben entnommen und zur Überprüfung der QSIAktivität nach Kiel geschickt. Da die erstellten Proben keine QSI-Aktivität mehr zeigten, wurden Kulturüberstände (je 200 mL) der Klone NC FS9, NC K14 und NC III 6/G5 ohne Korrektur des pH-Wertes lyophilisiert und das jeweilige Lyophilisat in einer Konzentration von $c=100 \mathrm{mg} / \mathrm{mL}$ in bidest. Wasser aufgenommen, je $1.5 \mathrm{~mL}-$ Proben entnommen und zur Überprüfung der QSI-Aktivität nach Kiel geschickt.

\subsubsection{HPLC-ESI-MS-Analytik}

Zur Untersuchung eines metagenomischen Klons auf mögliche Quorum-Quenching-Aktivität wurden Inkubationsansätze dieses Klons (Größe des Inserts zwischen 1-5 kb) mit N-(3-Oxooctanoyl)-L-Homoserinlacton (3-Oxo- $\mathrm{C}_{8}$-HSL, 62) als Substrat von N. Weiland (AK SchmitzStreit, Kiel) hergestellt. Hierfür wurden jeweils $100 \mu \mathrm{L}$ konzentrierter Kulturüberstande des metagenomischen Klons mit 3-Oxo- $\mathrm{C}_{8}$-HSL $(50 \mu \mathrm{L}$ einer $100 \mathrm{mM}$ Stammlösung in Ethylacetat) in $1 \mathrm{~mL}$ Tris-Puffer $\left(50 \mathrm{mM}\right.$, pH 8.0) über Nacht bei $37^{\circ} \mathrm{C}$ und $150 \mathrm{U} / \mathrm{min}$ 
inkubiert. Zur Kontrolle wurden ebenfalls $100 \mu \mathrm{L}$ des konzentrierten Kulturüberstandes des Leervektors mit 3-Oxo- $\mathrm{C}_{8}$-HSL in $1 \mathrm{~mL}$ Tris-Puffer $(50 \mathrm{mM}, \mathrm{pH} 8.0)$ über Nacht bei $37^{\circ} \mathrm{C}$ und $150 \mathrm{U} / \mathrm{min}$ inkubiert. Anschließend wurden die Inkubationsansätze mit Ethylacetat $(2 \times 1 \mathrm{~mL})$ extrahiert und das Lösungsmittel i. Vak. entfernt. ${ }^{193}$

Für die HPLC-ESI-MS-Messung wurden die erhaltenen Extrakte in $110 \mu \mathrm{L} \mathrm{MeOH}$ aufgenommen, in Einsätze (Inlets) mit $200 \mu \mathrm{L}$ Fassungsvolumen überführt und zentrifugiert (10000 U/min, 5 min). Die Messung der Proben erfolgte mittels HPLC-ESI-MS (HPLC D, Säule A: Grom Superspher 100, RP-18, Programm B: $\mathrm{MeOH} / \mathrm{H}_{2} \mathrm{O}$, jeweils mit $0.05 \%$ Ameisensäure, Gradient; s. 1.2 ) im positiven und negativen Mode.

\section{HPLC-ESI-MS-Proben:}

1. Inkubationsansatz des metagenomischen Klons (3 Ansätze)

2. „Leervektor“ mit Substrat (3 Ansätze)

3. $150 \mu \mathrm{L}$ der Stammlösung (100 mM in Ethylacetat) als Kontrolle

4. Hydrolyseprodukt 63 des Substrats aus chemischer Hydrolyse (Standard mit $c=1.0 \mathrm{mg} / \mathrm{mL})$ als Kontrolle 


\section{Produzent Streptomyces sp. JP90}

\subsection{Optimierung der Synthese des rac-Cinnamoylphosphoramids (21)}

\subsubsection{3-(p-Hydroxyphenyl)acrylsäuremethylester (82)}

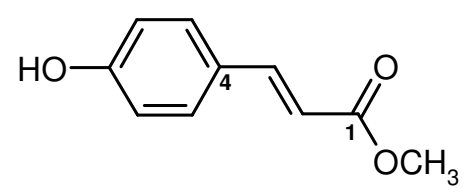

In eine dickwandige Pyrex ${ }^{\circledR}$-Flasche wurden $\mathrm{Pd}(\mathrm{OAc})_{2}(195 \mathrm{mg}, 0.869 \mathrm{mmol}, 3 \mathrm{~mol} \%)$, Tri$o$-tolylphosphan (1.58 g, $5.20 \mathrm{mmol}, 18 \mathrm{~mol} \%)$ und $p$-Bromphenol (83, $5.00 \mathrm{~g}, 28.9 \mathrm{mmol}$, 1.0 Äq.) eingewogen. Im Anschluss wurde unter Einleiten von Stickstoff wasserfreies Triethylamin $(29.0 \mathrm{~mL})$ zugegeben. Die orange-rote Suspension wurde mit Acrylsäuremethylester $(\mathbf{8 4}, 4.98 \mathrm{~g}, 57.8 \mathrm{mmol})$ versetzt und fest verschlossen für $21 \mathrm{~h}$ bei $90{ }^{\circ} \mathrm{C}$ gerührt. Nach Abkühlen auf Raumtemperatur wurde das Gemisch mit $1 \mathrm{M} \mathrm{HCl}(290 \mathrm{~mL})$ auf einen pH von ca. 1 eingestellt und die organische Phase mit Diethylether $(3 \times 150 \mathrm{~mL})$ extrahiert. Die vereinigten organischen Phasen wurden über $\mathrm{MgSO}_{4}$ getrocknet, filtriert und i. Vak. konzentriert. Säulenchromatographie an Kieselgel (270 g, Hexan/Ethylacetat 4:1) ergab die Titelverbindung 82 als hellgelben Feststoff (4.65 g, $26.1 \mathrm{mmol}, 90 \%)$.

$\mathbf{R}_{\mathbf{f}}=0.28(\mathrm{KG}$, Hexan/Ethylacetat $4: 1)$.

Schmp.: $135-137^{\circ} \mathrm{C}$.

${ }^{1} \mathbf{H}-\mathrm{NMR}\left(250 \mathrm{MHz}, \mathrm{CDCl}_{3}\right): \delta=3.80\left(\mathrm{~s}, 3 \mathrm{H}, 1-\mathrm{OC} \underline{H}_{3}\right), 5.30(\mathrm{~s}, 1 \mathrm{H}, \mathrm{OH}), 6.31(\mathrm{~d}$, $J=15.9 \mathrm{~Hz}, 1 \mathrm{H}, 2-\mathrm{H}), 6.85$ (d, $J=8.4 \mathrm{~Hz}, 2 \mathrm{H}, 6-\mathrm{H}, 8-\mathrm{H}], 7.43$ (d, J = 8.4 Hz, $2 \mathrm{H}, 5-\mathrm{H}, 9-$ H]) $7.64(\mathrm{~d}, J=15.9 \mathrm{~Hz}, 1 \mathrm{H}, 3-\mathrm{H}) \mathrm{ppm}$.

${ }^{13}$ C-NMR (75.5 MHz, $\left.\mathrm{CDCl}_{3}\right): \delta=52.0\left(\mathrm{q}, 1-\mathrm{OCH}_{3}\right), 114.9(\mathrm{~d}, \mathrm{C}-2), 116.8(\mathrm{~d}, \mathrm{C}-6, \mathrm{C}-8)$, 127.1 (s, C-4), 131.2 (d, C-5, C-9), 146.5 (d, C-3), 161.3 (s, C-7), 169.7 (s, C-1) ppm. 


\subsection{2 (E)-3-(p-Chlormethoxyphosphoryloxyphenyl)acrylsäuremethylester} (86)

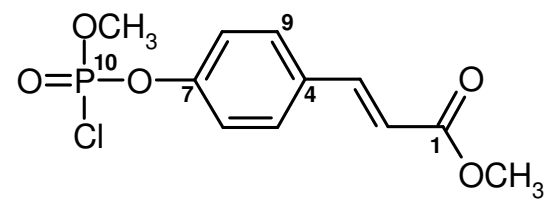

$\mathrm{Zu}$ einer Lösung von 3-(p-Hydroxyphenyl)acrylsäuremethylester (86, $301 \mathrm{mg}, 1.68$ mmol, 1.0 Äq.) in wasserfreiem Dichlormethan $(22 \mathrm{~mL})$ wurde unter kräftigem Rühren bei $0{ }^{\circ} \mathrm{C} \mathrm{NaH}$ (72.9 mg, $1.82 \mathrm{mmol}, 1.1$ Äquiv. als 60proz. Suspension in Mineralöl) gegeben. Das Reaktionsgemisch wurde bis zur Beendigung der $\mathrm{H}_{2}$-Entwicklung, d.h. nach $0.5 \mathrm{~h}$, bei $0{ }^{\circ} \mathrm{C}$ gerührt und anschließend für $2 \mathrm{~h}$ im Ultraschallbad durchmischt, bis eine einheitliche, gelbe Suspension entstanden war. Diese Suspension wurde unter kräftigem Rühren innerhalb von $9 \mathrm{~h}$ bei $0{ }^{\circ} \mathrm{C}$ zu einer Lösung von Methoxyphosphoryldichlorid (85, $503 \mathrm{mg}, 3.38 \mathrm{mmol}, 2.0$ Äq.) in wasserfreiem Dichlormethan $(6 \mathrm{~mL})$ gegeben. Anschließend wurde das Reaktionsgemisch für $16 \mathrm{~h}$ bei Raumtemperatur gerührt. Unter Schutzgasatmosphäre wurde der entstandene farblose Niederschlag über Celite filtriert, der Rückstand mit wasserfreiem Dichlormethan $(3 \times 50 \mathrm{~mL})$ gewaschen und das hellgelbe Filtrat i. Vak konzentriert. Es wurden $586 \mathrm{mg}$ des leicht verunreinigten Zielproduktes $\mathbf{8 6}$ als gelbes Öl erhalten, welches ohne weitere Reinigung im Folgeschritt verwendet wurde.

${ }^{1} \mathbf{H}-\mathbf{N M R}\left(250 \mathrm{MHz}, \mathrm{CDCl}_{3}\right): \delta=3.80\left(\mathrm{~s}, 3 \mathrm{H}, 1-\mathrm{OCH}_{3}\right), 4.03(\mathrm{~d}, J=14.1 \mathrm{~Hz}, 3 \mathrm{H}, 10$ $\left.\mathrm{OCH}_{3}\right), 6.39(\mathrm{~d}, J=15.9 \mathrm{~Hz}, 1 \mathrm{H}, 2-\mathrm{H}), 7.29(\mathrm{~d}, J=8.4 \mathrm{~Hz}, 2 \mathrm{H}, 6-\mathrm{H}, 8-\mathrm{H}), 7.54$ (d, $J=8.4 \mathrm{~Hz}, 2 \mathrm{H}, 5-\mathrm{H}, 9-\mathrm{H}), 7.66(\mathrm{~d}, J=15.9 \mathrm{~Hz}, 1 \mathrm{H}, 3-\mathrm{H}) \mathrm{ppm}$.

${ }^{31} \mathbf{P}$-NMR $\left(121.7 \mathrm{MHz}, \mathrm{CDCl}_{3}\right): \delta=1.81(\mathrm{~s}, \mathrm{P}) \mathrm{ppm}$.

\subsection{3 (E)-3-(p-Aminomethoxyphosphoryloxyphenyl)acrylsäuremethylester} (21)

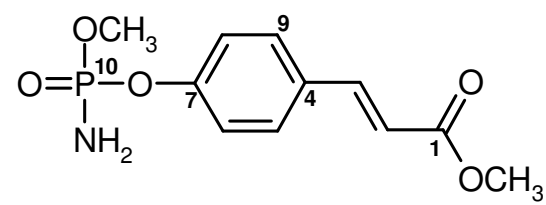

(E)-3-(p-Chlormethoxyphosphoryloxyphenyl)acrylsäuremethylester (86, 586 mg, 1.0 Äq.) wurde in wasserfreiem Dichlormethan $(18 \mathrm{~mL})$ gelöst. Durch die Reaktionslösung wurde unter kräftigem Rühren für 50 min bei $-15^{\circ} \mathrm{C}$ gasförmiger Ammoniak geleitet. Danach wurde 
das Reaktionsgemisch wurde mit NaCl-Lösung $(20 \mathrm{~mL})$ versetzt und mit Ethylacetat $(3 \times 30 \mathrm{~mL})$ extrahiert. Die vereinigten organischen Phasen wurden über $\mathrm{MgSO}_{4}$ getrocknet, filtriert und i. Vak. eingeengt. Nach Mitteldrucksäulenchromatographie an RP-18-Kieselgel (Größe C, Methanol/ $\mathrm{H}_{2} \mathrm{O}$ 1:1) wurden über zwei Stufen ausgehend von 82 die Titelverbindung 21 als farbloser Feststoff erhalten (252 mg, 0.929 mmol, 55\%).

$\mathbf{R}_{\mathbf{f}}=0.34\left(\mathrm{KG}, \mathrm{CHCl}_{3} / \mathrm{MeOH} 9: 1\right) ; 0.56\left(\mathrm{RP}-18, \mathrm{MeOH} / \mathrm{H}_{2} \mathrm{O} 7: 3\right)$.

Schmp.: $131^{\circ} \mathrm{C}$.

EI-MS: $(70 \mathrm{eV}), m / z(\%)=271(92)[\mathrm{M}]^{+}, 240(76), 178(40)\left[\mathrm{C}_{10} \mathrm{H}_{10} \mathrm{O}_{3}\right]^{+}, 147(89), 119$ (40), 94 (100), $\left[\mathrm{CH}_{6} \mathrm{NO}_{2} \mathrm{P}\right]^{+}, 91$ (39).

ESI-MS: $m / z(\%)=565(100)[2 \mathrm{M}+\mathrm{Na}]^{+}$.

$\mathbf{C}_{11} \mathbf{H}_{14} \mathrm{NO}_{5} \mathbf{P}$ (271.21): $\quad$ ber.: C 48.72, H 5.20, N 5.16 gef.: C 48.93, H 5.96, N 5.37.

UV $(\mathrm{MeOH}): \lambda_{\max }(\lg \varepsilon)=205 \mathrm{~nm}$ (4.06), 218 (4.08), 283 (4.30); (MeOH, HCl): $\lambda_{\max }$ $(\lg \varepsilon)=206 \mathrm{~nm}$ (4.05), 218 (4.06), 282 (4.30); (MeOH, NaOH): $\lambda_{\max }(\lg \varepsilon)=241 \mathrm{~nm}(3.79)$, 358 (4.39).

IR (KBr): $\tilde{v}=3363 \mathrm{~cm}^{-1}(\mathrm{~N}-\mathrm{H}), 2947(\mathrm{C}-\mathrm{H}), 1713(\mathrm{C}=\mathrm{O}), 1639(\mathrm{~N}-\mathrm{H}), 1601(\mathrm{C}=\mathrm{C}), 1507$ $(\mathrm{C}=\mathrm{C}), 1438,1317(\mathrm{P}=\mathrm{O}), 1218,1173,1060,1002,986,931,839,793$.

${ }^{\mathbf{1}} \mathbf{H}-\mathbf{N M R}\left(300 \mathrm{MHz}, \mathrm{CDCl}_{3}\right.$ ): $\delta=3.32$ (br. s, $2 \mathrm{H}, 10-\mathrm{NH}_{2}$ ), 3.77 (s, $\left.3 \mathrm{H}, 1-\mathrm{OCH}_{3}\right), 3.80$ (d, $\left.J=11.4 \mathrm{~Hz}, 3 \mathrm{H}, 10-\mathrm{OCH}_{3}\right), 6.33(\mathrm{~d}, J=15.9 \mathrm{~Hz}, 1 \mathrm{H}, 2-\mathrm{H}), 7.22(\mathrm{~d}, J=8.4 \mathrm{~Hz}, 2 \mathrm{H}, 6-\mathrm{H}$, 8-H], 7.46 (d, $J=8.4 \mathrm{~Hz}, 5-\mathrm{H}, 9-\mathrm{H}), 7.61$ (d, $J=15.9 \mathrm{~Hz}, 1 \mathrm{H}, 3-\mathrm{H}) \mathrm{ppm}$.

${ }^{13}$ C-NMR $\left(75.5 \mathrm{MHz}, \mathrm{CDCl}_{3}\right): \delta=51.7\left(\mathrm{q}, 1-\mathrm{OCH}_{3}\right), 53.8\left(\mathrm{q},{ }^{2} J_{C P}=5.3 \mathrm{~Hz}, 10-\mathrm{OCH}_{3}\right)$, 117.5 (d, C-2), 120.7 (d, $\left.{ }^{3} J_{\mathrm{CP}}=5.3 \mathrm{~Hz}, \mathrm{C}-6, \mathrm{C}-8\right), 129.5$ (d, C-5, C-9), 131.1 (s, C-4), 143.7 (d, C-3), $152.3\left(\mathrm{~s},{ }^{2} J_{\mathrm{CP}}=6.8 \mathrm{~Hz}, \mathrm{C}-7\right), 167.3(\mathrm{~s}, \mathrm{C}-1) \mathrm{ppm}$.

${ }^{31} \mathbf{P}$-NMR $\left(121.7 \mathrm{MHz}, \mathrm{CDCl}_{3}\right): \delta=7.10(\mathrm{~s}, \mathrm{P}) \mathrm{ppm}$.

\subsection{Vorversuche zur enzymatischen Hydrolyse des Cinnamoylphosphor- amids (21)}

\subsubsection{Enzymatische Hydrolyse des Zimtsäuremethylesters (93)}

Zimtsäuremethylester (93) $(14.0 \mathrm{mg}, 86.3 \mu \mathrm{mol})$ wurde in Wasser (800 $\mu \mathrm{L}, \mathrm{pH}$ 7.7) suspendiert und als Enzym Schweineleberesterase (porcine liver esterase, PLE) (29.7 $\mu \mathrm{L}$, $86.3 \mu \mathrm{mol}, 86.3$ Units, Fa. Sigma) zugegeben. Der pH-Wert der Reaktionsmischung wurde 
alle 5 min kontrolliert, indem jeweils $5 \mu \mathrm{L}$ der Reaktionsmischung entnommen und auf $\mathrm{pH}$ Papier gegeben wurden. Durch Zugabe von $0.5 \mathrm{~N} \mathrm{NaOH}$ wurde der $\mathrm{pH}$ der Reaktionsmischung auf $\mathrm{pH}=7.7$ reguliert. Die Reaktionsmischung wurde bei Raumtemperatur für 25 min unter DC-Kontrolle an reversed-phase Kieselgel $\left(\mathrm{MeOH} / \mathrm{H}_{2} \mathrm{O}\right.$ 7:3) gerührt. Nach 25 min wurde ein vollständiger Umsatz von 93 zur Zimtsäure (122) detektiert. Zur Aufarbeitung wurde durch Zugabe einiger Tropfen Chloroform das Enzym denaturiert und nach anschließender Zentrifugation das Enzym als Pellet entfernt. Die wässrige Lösung wurde mit demin. Wasser verdünnt $(10 \mathrm{~mL})$, auf $\mathrm{pH}=5.0$ mit $0.5 \mathrm{~N} \mathrm{HCl}$ angesäuert und mit Ethylacetat $(3 \times 10 \mathrm{~mL})$ extrahiert. Die vereinigten organischen Phasen wurden über $\mathrm{Na}_{2} \mathrm{SO}_{4}$ getrocknet, das Lösungsmittel i. Vak. entfernt und 122 als farblosen Feststoff erhalten (7.6 mg, $51.3 \mu \mathrm{mol}, 59 \%)$.

\subsection{Kultivierung und Aufarbeitung}

\subsubsection{Stammhaltung}

Für die Stammhaltung wurde der Streptomyces sp. Stamm JP90 mittels einer Platinimpföse auf $\mathrm{M}^{+}$-Agarplatten ausgestrichen und bis zur Ausbildung einer geschlossenen hellgrauen Sporenschicht für 6 Tage bei $28^{\circ} \mathrm{C}$ inkubiert. Nach der Inkubation wurden die Platten bei $4{ }^{\circ} \mathrm{C}$ aufbewahrt und maximal zwei Monate zum Animpfen von Schüttelkulturen verwendet.

\subsubsection{Kultivierung}

Schüttelkolben: Für die Vorkulturen dienten 300 mL Erlenmeyerkolben mit drei Schikanen, befüllt mit jeweils $100 \mathrm{~mL}$ Medium S, verschlossen mit einer Schaumstoffkappe. Jeder Kolben wurde nach Sterilisation mit einem 1/10 Stück einer gut bewachsenen Agarplatte angeimpft. Nach $48 \mathrm{~h}$ Inkubation bei $28{ }^{\circ} \mathrm{C}$ und $180 \mathrm{U} / \mathrm{min}$ wurde die Hauptkultur mit $5 \mathrm{~mL}$ Vorkultur inokuliert. Die Fermentation der Hauptkulturen erfolgte in 1 L Erlenmeyerkolben, gefüllt mit je $150 \mathrm{~mL}$ Medium S, verschlossen mit einer Schaumstoffkappe. Die Hauptkultur wurde für $96 \mathrm{~h}$ bei $28^{\circ} \mathrm{C}$ und $180 \mathrm{U} / \mathrm{min}$ inkubiert.

Fermenter: Die Kultivierung erfolgte im Fermenter Biostat M (1 L Arbeitsvolumen). Das Fermentationsgefäß wurde mit $950 \mathrm{~mL}$ Medium $\mathrm{S}$ befüllt und autoklaviert. Nach dem Inokulieren mit $100 \mathrm{~mL}$ Vorkulturlösung wurde für $96 \mathrm{~h}$ bei $28^{\circ} \mathrm{C}, 600 \mathrm{U} / \mathrm{min}$ und einer Luftzufuhr von $1.6 \mathrm{vvm}$ inkubiert. 


\subsubsection{Aufarbeitung}

Die Kulturbrühe wurde mit $0.5 \mathrm{M} \mathrm{HCl}$ auf einen $\mathrm{pH}-$ Wert von 5.5 eingestellt. Nach Zugabe von Celite (ca. 3 gehäufte Esslöffel auf 1 L Kulturbrühe) wurde das Mycel durch Filtration abgetrennt. Der Rückstand (Mycel, Celite) wurde zweimal mit Aceton/Methanol 1:1 (100$200 \mathrm{~mL}$ ) versetzt und für jeweils $15 \mathrm{~min}$ im Ultraschallbad aufgeschlossen, filtriert und das Lösungsmittel i. Vak. entfernt. Das Kulturfiltrat wurde zweimal mit Ethylacetat (Volumina Ethylacetat:Kulturfiltrat ca. 1:1) extrahiert und das Lösungsmittel i. Vak. entfernt.

\subsection{Isolierung und Charakterisierung von Metaboliten}

Zur Isolierung der Substanzen 22, 23 und 21 wurde das aus dem Kulturfiltrat erhaltene Rohprodukt zunächst an Kieselgel $\left(\mathrm{CHCl}_{3} / \mathrm{MeOH}\right.$ 95:5) vorgereinigt und fraktioniert. Die Fraktion, die die mit ANIS braun anfärbende Substanz 22 enthielt, wurde durch zweifache Mitteldrucksäulenchromatographie an reversed-phase Kieselgel (Lobar ${ }^{\circledR}$ Größe B, Aceton/ $\left.\mathrm{H}_{2} \mathrm{O} 3: 1\right)$ gereinigt und $5.6 \mathrm{mg} / \mathrm{L}$ des Spirotetronats (22a), $4.2 \mathrm{mg} / \mathrm{L}$ des Spirotetronats (22b) und je noch leicht verunreinigte $2.0 \mathrm{mg} / \mathrm{L}$ des Rosiridols (23) und des Cinnamoylphosphoramids (21) isoliert.

\section{Spirotetronat $(\mathbf{2 2 a})$}

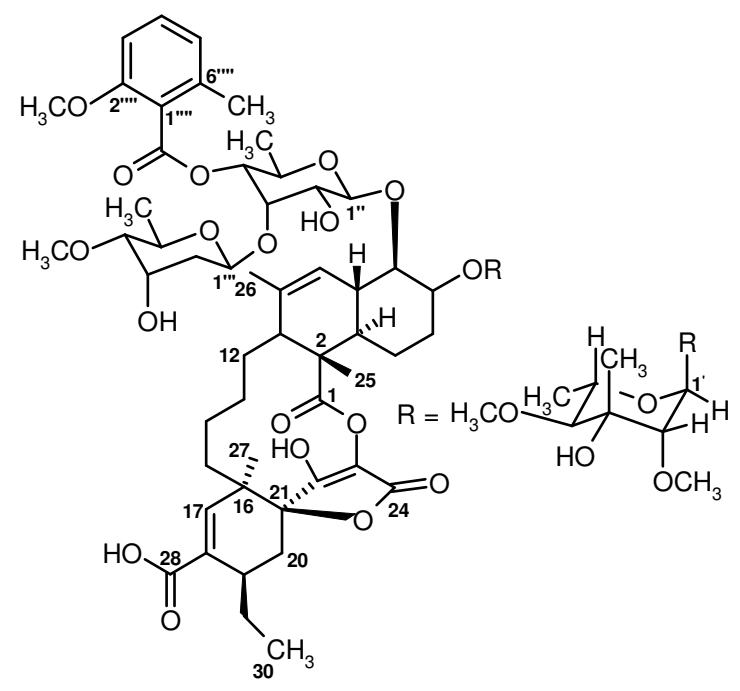

$\mathbf{C}_{61} \mathbf{H}_{86} \mathbf{O}_{22} \quad$ (1171.35).

Farbloser Feststoff.

$\mathbf{R}_{\mathbf{f}}: 0.34\left(\mathrm{KG}, \mathrm{CHCl}_{3} / \mathrm{MeOH}\right.$ 95:5), 0.40 (RP-18, Aceton/ $\left.\mathrm{H}_{2} \mathrm{O} 3: 1\right)$.

Anfärbeverhalten: braun (ANIS), grau-schwarz (ORCIN).

MS (ESI): $m / z(\%)=1194(60)[\mathrm{M}+\mathrm{Na}]^{+}, 1216(100)\left[\mathrm{M}+\mathrm{NH}_{4}\right]^{+}, 1170[\mathrm{M}-\mathrm{H}]^{-}$.

Drehwert: $[\alpha]_{D}^{20}=3(\mathrm{c}=0.5, \mathrm{MeOH})$. 
Vergleich (Saccharose): $[\alpha]_{D}^{20}=67\left(\mathrm{c}=1.0, \mathrm{H}_{2} \mathrm{O}\right)$; Lit.: $[\alpha]_{D}^{20}=65\left(\mathrm{c}=1.0, \mathrm{H}_{2} \mathrm{O}\right)$.

CD $(\mathrm{MeOH}): \lambda_{\max }[\theta]=268 \mathrm{~nm}$ (-38416), 248 (30), 230 (-8501), 203 (25486).

UV $(\mathrm{MeOH}): \lambda_{\max }(\lg \varepsilon)=202 \mathrm{~nm}$ (3.95), 242 (3.14), 266 (3.36); (MeOH, HCl): $\lambda_{\max }(\mathrm{lg}$ $\varepsilon)=203 \mathrm{~nm}$ (3.88), 268 (2.85), $280(2.87) ;(\mathrm{MeOH}, \mathrm{NaOH}): \lambda_{\max }(\lg \varepsilon)=203 \mathrm{~nm}$ (4.09), 238 (3.14), 265 (3.3945).

IR $(\mathrm{KBr}): \widetilde{v}\left(\mathrm{~cm}^{-1}\right)=3432,2934,1772,1718,1670,1587,1560,1267,1143,1094,1014$, 765.

${ }^{1} \mathbf{H}-\mathbf{N M R}\left(600 \mathrm{MHz}, \mathrm{CDCl}_{3}\right): \delta=0.63\left(\mathrm{~m}_{\mathrm{br}}, 1 \mathrm{H}, 13-\mathrm{H}_{\mathrm{A}}\right), 0.89\left(\mathrm{t}, J=7.0 \mathrm{~Hz}, 3 \mathrm{H}, 30-\mathrm{H}_{3}\right)$, $0.95^{*}\left(\mathrm{~m}^{*}, 1 \mathrm{H}, 12-\mathrm{H}_{\mathrm{A}}\right), 0.95^{*}\left(\mathrm{~m}^{*}, 1 \mathrm{H}, 14-\mathrm{H}_{\mathrm{A}}\right), 1.21\left(\mathrm{~s}, 3 \mathrm{H}, 27-\mathrm{H}_{3}\right), 1.25(\mathrm{dd}, J=6.1,6.1 \mathrm{~Hz}$, $\left.6 \mathrm{H}, 66^{\prime}-\mathrm{H}_{3}, 6 "-\mathrm{H}_{3}\right), 1.27\left(\mathrm{~d}, J=6.1 \mathrm{~Hz}, 3 \mathrm{H}, 66^{\prime \prime}-\mathrm{H}_{3}\right), 1.29$ (s, $\left.3 \mathrm{H}, 25-\mathrm{H}_{3}\right), 1.32$ (s, $3 \mathrm{H}$, $\left.3^{\prime}-\mathrm{CH}_{3}\right), 1.33^{*}\left(\mathrm{~m}^{*}, 1 \mathrm{H}, 15-\mathrm{H}_{\mathrm{A}}\right), 1.40^{*}\left(\mathrm{~m}^{*}, 1 \mathrm{H}, 3-\mathrm{H}\right), 1.45^{*}\left(\mathrm{~m}^{*}, 1 \mathrm{H}, 15-\mathrm{H}_{\mathrm{B}}\right), 1.46^{*}\left(\mathrm{~m}^{*}, 1 \mathrm{H}\right.$, $\left.14-\mathrm{H}_{\mathrm{B}}\right), 1.49^{*}\left(\mathrm{~m}^{*}, 1 \mathrm{H}, 5-\mathrm{H}_{\mathrm{A}}\right), 1.53^{*}\left(\mathrm{~m}^{*}, 1 \mathrm{H}, 12-\mathrm{H}_{\mathrm{B}}\right), 1.58^{*}\left(\mathrm{~m}^{*}, 2 \mathrm{H}, 4-\mathrm{H}_{2}\right), 1.60^{*}\left(\mathrm{~m}^{*}, 1 \mathrm{H}\right.$, $\left.2^{\prime \prime}-\mathrm{H}_{\mathrm{A}}\right), 1.62^{*}\left(\mathrm{~m}^{*}, 1 \mathrm{H}, 29-\mathrm{H}_{\mathrm{A}}\right), 1.67\left(\mathrm{~s}, 3 \mathrm{H}, 26-\mathrm{H}_{3}\right), 1.70^{*}\left(\mathrm{~m}^{*}, 1 \mathrm{H}, 29-\mathrm{H}_{\mathrm{B}}\right), 1.80\left(\mathrm{~m}_{\mathrm{br}}, 1 \mathrm{H}\right.$, 13- $\left.\mathrm{H}_{\mathrm{B}}\right), 1.84\left(\mathrm{~m}_{\mathrm{br}}, 1 \mathrm{H}, 11-\mathrm{H}\right), 1.86\left(\mathrm{~m}_{\mathrm{br}}, 1 \mathrm{H}, 5-\mathrm{H}_{\mathrm{B}}\right), 1.88\left(\mathrm{~m}_{\mathrm{br}}, 1 \mathrm{H}, 20-\mathrm{H}_{\mathrm{A}}\right), 2.14$ (ddd, $\left.J=2.0,4.0,8.0 \mathrm{~Hz}, 1 \mathrm{H}, 2^{\prime \prime \prime}-\mathrm{H}_{\mathrm{B}}\right), 2.28$ (s, $\left.3 \mathrm{H}, 66^{\prime \prime '-}-\mathrm{CH}_{3}\right), 2.29^{*}$ (m*, $\left.1 \mathrm{H}, 8-\mathrm{H}\right), 2.44$ (dd, $\left.J=8.0,15.0 \mathrm{~Hz}, 1 \mathrm{H}, 20-\mathrm{H}_{\mathrm{B}}\right), 2.56\left(\mathrm{dd}_{\mathrm{br}}, J=8.0 \mathrm{~Hz}, 1 \mathrm{H}, 19-\mathrm{H}\right), 2.84(\mathrm{dd}, J=2.8,9.7 \mathrm{~Hz}$, $1 \mathrm{H}, 4$ "'-H), 2.89 (d, $J=9.7 \mathrm{~Hz}, 1 \mathrm{H}, 4$ '-H), 3.16 (dd, $J=1.8,10.8 \mathrm{~Hz}, 1 \mathrm{H}, 7-\mathrm{H}), 3.24\left(\mathrm{~d}_{\mathrm{br}}\right.$, $\left.J=1.8 \mathrm{~Hz}, 1 \mathrm{H}, 2^{\prime}-\mathrm{H}\right), 3.38$ (s, $3 \mathrm{H}, 4$ "'--OCH $), 3.38$ (dd, $J=2.8,8.1 \mathrm{~Hz}, 1 \mathrm{H}, 2$ "-H), 3.51 (s, $3 \mathrm{H}, 2^{\prime}-\mathrm{OCH}_{3}$ ), 3.56 (s, $\left.3 \mathrm{H}, 4^{\prime}-\mathrm{OCH}_{3}\right), 3.62$ (dq, $J=6.2,9.7 \mathrm{~Hz}, 1 \mathrm{H}, 5$ '-H), 3.81 (s, $3 \mathrm{H}$,

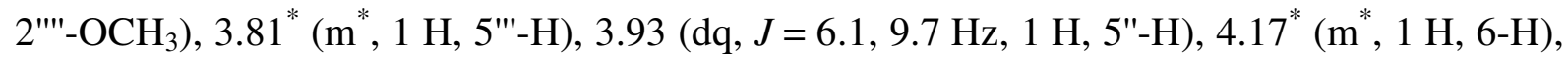
4.19 (m $\mathrm{br}, 1 \mathrm{H}, 3$ "'-H), 4.37 (mbr 1 H, 3"-H), 4.54 (d, J= 8.0 Hz, $1 \mathrm{H}, 1 "-\mathrm{H}), 4.63$ (dd, $J=2.4$, $9.7 \mathrm{~Hz}, 1 \mathrm{H}, 4 "-\mathrm{H}), 4.81$ (dd, J=1.8, 9.7 Hz, $\left.1 \mathrm{H}, 11^{\prime \prime}-\mathrm{H}\right), 5.27$ ( $\left.\mathrm{s}_{\mathrm{br}}, 1 \mathrm{H}, 1^{\prime}-\mathrm{H}\right), 5.79$ ( $\mathrm{s}_{\mathrm{br}}, 1 \mathrm{H}$, 9-H), 6.50 ( $\left.\mathrm{s}_{\mathrm{br}}, 1 \mathrm{H}, 17-\mathrm{H}\right), 6.74$ (d, J = 8.5 Hz, $\left.1 \mathrm{H}, 5^{\prime \prime '}-\mathrm{H}\right), 6.78$ (d, J= 7.5 Hz, $\left.1 \mathrm{H}, 3^{\prime \prime \prime}-\mathrm{H}\right)$, $7.23\left(\mathrm{t}, J=8.0 \mathrm{~Hz}, 1 \mathrm{H}, 4\right.$ "''-H), $10.2\left(\mathrm{~s}_{\mathrm{br}}, 1 \mathrm{H}, 28-\mathrm{OH}\right) \mathrm{ppm}$.

${ }^{1} \mathbf{H}-\mathbf{N M R}\left(600 \mathrm{MHz}, \mathrm{CD}_{3} \mathrm{OD}\right): \delta=0.60\left(\mathrm{~m}_{\mathrm{br}}, 1 \mathrm{H}, 13-\mathrm{H}_{\mathrm{A}}\right), 0.93\left(\mathrm{t}, J=7.0 \mathrm{~Hz}, 3 \mathrm{H}, 30-\mathrm{H}_{3}\right)$, $1.06^{*}\left(\mathrm{~m}^{*}, 1 \mathrm{H}, 12-\mathrm{H}_{\mathrm{A}}\right), 1.06\left(\mathrm{~m}, 1 \mathrm{H}, 14-\mathrm{H}_{\mathrm{A}}\right), 1.21\left(\mathrm{~d}, J=6.1 \mathrm{~Hz}, 3 \mathrm{H}, 6 "-\mathrm{H}_{3}\right), 1.23(\mathrm{~s}, 3 \mathrm{H}$, $\left.27-\mathrm{H}_{3}\right), 1.23^{*}\left(\mathrm{~m}^{*}, 1 \mathrm{H}, 15-\mathrm{H}_{\mathrm{A}}\right), 1.27$ (d, J = 6.1 Hz, $\left.3 \mathrm{H}, 66^{\prime}-\mathrm{H}_{3}\right), 1.28$ (s, $\left.3 \mathrm{H}, 25-\mathrm{H}_{3}\right), 1.29$ (d, $\left.J=6.1 \mathrm{~Hz}, 3 \mathrm{H}, 6^{\prime \prime}-\mathrm{H}_{3}\right), 1.32\left(\mathrm{~s}, 3 \mathrm{H}, 3^{\prime}-\mathrm{CH}_{3}\right), 1.32^{*}\left(\mathrm{~m}^{*}, 1 \mathrm{H}, 4-\mathrm{H}_{\mathrm{A}}\right), 1.43^{*}\left(\mathrm{~m}^{*}, 1 \mathrm{H}, 15-\mathrm{H}_{\mathrm{B}}\right)$, $1.47^{*}\left(\mathrm{~m}^{*}, 1 \mathrm{H}, 14-\mathrm{H}_{\mathrm{B}}\right), 1.49^{*}\left(\mathrm{~m}^{*}, 1 \mathrm{H}, 12-\mathrm{H}_{\mathrm{B}}\right), 1.58^{*}\left(\mathrm{~m}^{*}, 1 \mathrm{H}, 3-\mathrm{H}\right), 1.60^{*}\left(\mathrm{~m}^{*}, 1 \mathrm{H}, 5-\mathrm{H}_{\mathrm{A}}\right)$, $1.62^{*}\left(\mathrm{~m}^{*}, 2 \mathrm{H}, 29-\mathrm{H}_{2}\right), 1.65^{*}\left(\mathrm{~m}^{*}, 1 \mathrm{H}, 2^{\prime \prime}-\mathrm{H}_{\mathrm{A}}\right), 1.66^{*}\left(\mathrm{~m}^{*}, 1 \mathrm{H}, 4-\mathrm{H}_{\mathrm{B}}\right), 1.67^{*}\left(\mathrm{~m}^{*}, 1 \mathrm{H}, 13-\mathrm{H}_{\mathrm{B}}\right)$, $1.71\left(\mathrm{~s}, 3 \mathrm{H}, 26-\mathrm{H}_{3}\right), 1.77(\mathrm{~d}, J=7.7 \mathrm{~Hz}, 1 \mathrm{H}, 11-\mathrm{H}), 1.84\left(\mathrm{~m}_{\mathrm{br}}, 1 \mathrm{H}, 5-\mathrm{H}_{\mathrm{B}}\right), 1.86\left(\mathrm{~m}_{\mathrm{br}}, 1 \mathrm{H}\right.$,

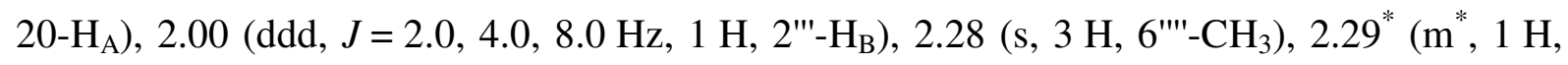
8-H), $2.48\left(\mathrm{dd}, J=8.0,15.0 \mathrm{~Hz}, 1 \mathrm{H}, 20-\mathrm{H}_{\mathrm{B}}\right), 2.56\left(\mathrm{dd}_{\mathrm{br}}, J=8.0 \mathrm{~Hz}, 1 \mathrm{H}, 19-\mathrm{H}\right), 2.88$ (dd, 
$J=2.8,9.7 \mathrm{~Hz}, 1 \mathrm{H}, 4$ '"-H), 2.99 (d, $J=9.7 \mathrm{~Hz}, 1 \mathrm{H}, 4$ '-H), 3.22 (dd, $J=1.8,10.8 \mathrm{~Hz}, 1 \mathrm{H}$, 7-H), $3.24\left(\mathrm{~d}_{\mathrm{br}}, J=1.8 \mathrm{~Hz}, 1 \mathrm{H}, 2\right.$ '-H), 3.36 (s, $3 \mathrm{H}, 4$ '"--OCH 3 ), 3.44 (dd, $J=2.8,8.1 \mathrm{~Hz}, 1 \mathrm{H}$, 2"-H), 3.52 (s, 3 H, 2'-OCH $), 3.55$ (s, 3 H, 4'- $\mathrm{OCH}_{3}$ ), 3.62 (dq, J=6.2, 9.7 Hz, 1 H, 5'-H), 3.83 (s, $3 \mathrm{H}, 2^{\prime \prime \prime '-} \mathrm{OCH}_{3}$ ), 3.88 (dq, $J=6.1,9.7 \mathrm{~Hz}, 1 \mathrm{H}, 5$ '"-H), 3.98 (dq, $J=6.1,9.7 \mathrm{~Hz}, 1 \mathrm{H}$, 5"-H), 4.18 (mbr 1 H, 6-H), $4.21\left(\mathrm{ddd}_{\mathrm{br}}, J=3.0,6.0 \mathrm{~Hz}, 1 \mathrm{H}, 3^{\prime \prime}-\mathrm{H}\right), 4.33$ (dd, $J=2.4 \mathrm{~Hz} 1 \mathrm{H}$, 3"-H), 4.59 (d, J=8.0 Hz, $1 \mathrm{H}, 1 "-\mathrm{H}), 4.72$ (dd, J=2.8, $9.8 \mathrm{~Hz}, 1 \mathrm{H}, 4 "-\mathrm{H}), 4.88$ (s $\mathrm{br}, 1 \mathrm{H}$, 1"'-H), $5.28(\mathrm{~d}, J=1.0 \mathrm{~Hz}, 1 \mathrm{H}, 1 '-\mathrm{H}), 5.83\left(\mathrm{~s}_{\mathrm{br}}, 1 \mathrm{H}, 9-\mathrm{H}\right), 6.41(\mathrm{~d}, J=1.2 \mathrm{~Hz}, 1 \mathrm{H}, 17-\mathrm{H})$, $6.82\left(\mathrm{~d}, J=7.9 \mathrm{~Hz}, 1 \mathrm{H}, 5^{\prime \prime \prime}-\mathrm{H}\right), 6.87\left(\mathrm{~d}, J=7.5 \mathrm{~Hz}, 1 \mathrm{H}, 3^{\prime \prime \prime}-\mathrm{H}\right), 7.28(\mathrm{t}, J=8.0 \mathrm{~Hz}, 1 \mathrm{H}$, 4"'"-H) ppm.

${ }^{13}$ C-NMR (150 MHz, $\mathrm{CDCl}_{3}$ ): $\delta=12.6$ (q, C-30), 15.6 (q, C-25), 17.8 (q, C-6"), 18.0 (q, C-6'), 18.0 (q, C-6"'), 18.5 (q, 3'-CH 3 ), 19.2 (q, 6"''-CH 3 ), 20.7 (t, C-4), 21.7 (q, C-27), 22.4 (q, C-26), 25.8 (t, C-14), 26.5 (t, C-29), 27.6 (t, C-20), 30.5 (t, C-12), 31.0 (t, C-5), 33.7 (t, C-13), 34.1 (d, C-19), 34.4 (t, C-15), 36.2 (t, C-2"'), 37.4 (d, C-8), 37.8 (d, C-3), 46.5 (s, C-16), 50.4

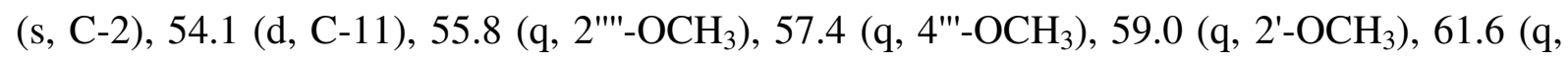
4'-OCH ${ }_{3}$ ), 63.7 (d, C-3"'), 66.7 (d, C-5'), 67.3 (d, C-5"), 68.7 (d, C-5"'), 70.9 (d, C-2"), 73.1 (s, C-3'), 74.3 (d, C-4"), 76.6 (d, C-6), 81.0 (d, C-3"), 82.0 (d, C-4"'), 82.9 (s, C-21), 84.9 (d, C-2'), 85.3 (d, C-7), 86.6 (d, C-4'), 98.1 (d, C-1'), 99.7 (d, C-1"'), 103.5 (d, C-1"), 108.3 (d, C-3"''), 116.4 (s, C-23), 120.0 (d, C-9), 122.3 (d, C-5"''), 123.2 (s, C-1"''), 130.5 (d, C-4"''), 131.3 (s, C-18), 134.3 (s, C-10), 136.0 (s, C-6"'"), 148.0 (d, C-17), 156.3 (s, C-2"'"), 160.9 (s, C-22), 165.9 (s, C-24), 167.8 (s, COO), 171.2 (s, C-28), 179.8 (s, C-1) ppm.

${ }^{13}$ C-NMR (150 MHz, CD $\left.30 D\right): \delta=12.9$ (q, C-30), 15.8 (q, C-25), 18.2 (q, C-6"), 18.4 (q, C-6'), 18.5 (q, C-6"'), 19.5 (q, 3'-CH 3 ), 19.5 (q, 6"''-CH $\mathrm{CH}_{3}$ ), 21.9 (t, C-4), 22.0 (q, C-27), 23.0 (q, C-26), 25.9 (t, C-14), 27.5 (t, C-29), 29.4 (t, C-20), 30.4 (t, C-12), 32.0 (t, C-5), 34.3 (t, C-13), 35.6 (d, C-19), 35.9 (t, C-15), 38.5 (t, C-2"'), 38.9 (d, C-8), 39.4 (d, C-3), 47.0 (s, C-16), 50.5 (s, C-2), 56.3 (d, C-11), 56.4 (q, 2"'--OCH $), 57.0$ (q, 4"'--OCH $), 59.6$ (q, 2'- $\left.\mathrm{OCH}_{3}\right), 62.0$ (q, 4'- $\mathrm{OCH}_{3}$ ), 64.0 (d, C-3"'), 68.2 (d, C-5'), 68.8 (d, C-5"), 70.2 (d, C-5"'), 72.2 (d, C-2"), 74.6 (s, C-3'), 75.6 (d, C-4"), 79.0 (d, C-6), 81.3 (d, C-3"), 83.5 (d, C-4"'), 85.2 (s, C-21), 86.4 (d, C-2'), 87.2 (d, C-7), 87.2 (d, C-4'), 100.0 (d, C-1'), 100.9 (d, C-1"'), 104.9 (d, C-1"), 109.6 (d, C-3"''), 115.5 (s, C-23), 121.3 (d, C-9), 123.3 (d, C-5"''), 124.4 (s, C-1"''), 131.8 (d, C-4"''), 133.2 (s, C-18), 136.0 (s, C-10), 137.2 (s, C-6"'"), 147.9 (d, C-17), 157.8 (s, C-2"'"), 169.3 (s, COO), 170.6 (s, C-24), 170.8 (s, C-28), 177.1 (s, C-1) ppm.

* Diese Signale überlappen mit anderen Signalen. 


\section{Spirotetronat (22b)}

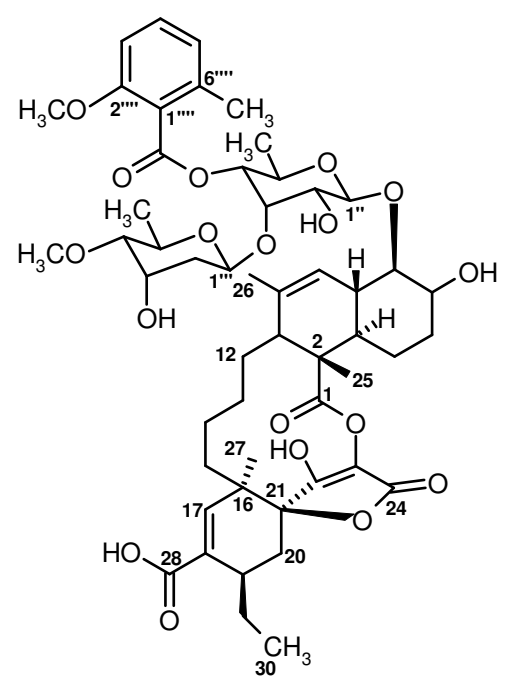

$\mathbf{C}_{\mathbf{5 2}} \mathbf{H}_{70} \mathbf{O}_{\mathbf{1 8}} \quad$ (983.13).

Farbloser Feststoff.

R. 0.72 ( $\left.\mathrm{KG} \mathrm{CHCl}_{3} / \mathrm{MeOH} 85: 5\right), 0.44$ (RP-18, Aceton/ $\left.\mathrm{H}_{2} \mathrm{O} 3: 1\right)$.

Anfärbeverhalten: braun (ANIS), grau-schwarz (ORCIN).

MS (ESI): $m / z(\%)=1006(40)[\mathrm{M}+\mathrm{Na}]^{+}, 1028(100)[\mathrm{M}-\mathrm{H}+2 \mathrm{Na}]^{+}, 982(100)[\mathrm{M}-\mathrm{H}]^{-}$.

Drehwert: $[\alpha]_{D}^{20}=44(\mathrm{c}=0.5, \mathrm{MeOH})$.

Vergleich (Saccharose): $[\alpha]_{D}^{20}=67\left(\mathrm{c}=1.0, \mathrm{H}_{2} \mathrm{O}\right)$; Lit.: $[\alpha]_{D}^{20}=65\left(\mathrm{c}=1.0, \mathrm{H}_{2} \mathrm{O}\right)$.

CD $(\mathrm{MeOH}): \lambda_{\max }[\theta]=268 \mathrm{~nm}(-32787), 248(-3454), 237$ (-11282), 228 (-9717), 219 (-12641), 206 (12030), 205 (10447), 201 (31541).

UV $(\mathrm{MeOH}): \lambda_{\max }(\lg \varepsilon)=202 \mathrm{~nm}$ (3.83), 241 (3.11), 267 (3.31); (MeOH, $\left.\mathrm{HCl}\right): \lambda_{\max }(\lg$ $\varepsilon)=201 \mathrm{~nm}$ (3.84), 268 (2.55), $280(2.64) ;(\mathrm{MeOH}, \mathrm{NaOH}): \lambda_{\max }(\lg \varepsilon)=207 \mathrm{~nm}(3.78), 239$ (3.14), 265 (3.37).

IR $(\mathrm{KBr}): \widetilde{v}\left(\mathrm{~cm}^{-1}\right)=3432,2924,1718,1586,1466,1384,1265,1092,1015,767$.

${ }^{1} \mathbf{H}-\mathbf{N M R}\left(600 \mathrm{MHz}, \mathrm{CDCl}_{3}\right): \delta=0.62\left(\mathrm{~m}_{\mathrm{br}}, 1 \mathrm{H}, 13-\mathrm{H}_{\mathrm{A}}\right), 0.90\left(\mathrm{t}, J=7.4 \mathrm{~Hz}, 3 \mathrm{H}, 30-\mathrm{H}_{3}\right)$, $0.90^{*}\left(\mathrm{~m}^{*}, 1 \mathrm{H}, 12-\mathrm{H}_{\mathrm{A}}\right), 0.90^{*}\left(\mathrm{~m}^{*}, 1 \mathrm{H}, 14-\mathrm{H}_{\mathrm{A}}\right), 1.21\left(\mathrm{~s}, 3 \mathrm{H}, 27-\mathrm{H}_{3}\right), 1.26(\mathrm{dd}, J=6.1,6.1 \mathrm{~Hz}$, $\left.3 \mathrm{H}, 6 "-\mathrm{H}_{3}\right), 1.29$ (d, J=6.1 Hz, $\left.3 \mathrm{H}, 66^{\prime \prime}-\mathrm{H}_{3}\right), 1.34$ (s, $\left.3 \mathrm{H}, 25-\mathrm{H}_{3}\right), 1.33^{*}\left(\mathrm{~m}^{*}, 1 \mathrm{H}, 15-\mathrm{H}_{\mathrm{A}}\right)$, $1.45^{*}\left(\mathrm{~m}^{*}, 1 \mathrm{H}, 15-\mathrm{H}_{\mathrm{B}}\right), 1.45^{*}\left(\mathrm{~m}^{*}, 1 \mathrm{H}, 3-\mathrm{H}\right), 1.48^{*}\left(\mathrm{~m}^{*}, 1 \mathrm{H}, 4-\mathrm{H}_{\mathrm{A}}\right), 1.50^{*}\left(\mathrm{~m}^{*}, 1 \mathrm{H}, 14-\mathrm{H}_{\mathrm{B}}\right)$, $1.55^{*}\left(\mathrm{~m}^{*}, 1 \mathrm{H}, 5-\mathrm{H}_{\mathrm{A}}\right), 1.55^{*}\left(\mathrm{~m}^{*}, 1 \mathrm{H}, 4-\mathrm{H}_{\mathrm{B}}\right), 1.60^{*}\left(\mathrm{~m}^{*}, 1 \mathrm{H}, 2^{\prime \prime}-\mathrm{H}_{\mathrm{A}}\right), 1.68\left(\mathrm{~s}, 3 \mathrm{H}, 26-\mathrm{H}_{3}\right)$, ), $1.71^{*}\left(\mathrm{~m}^{*}, 1 \mathrm{H}, 29-\mathrm{H}_{\mathrm{A}}\right), 1.77^{*}\left(\mathrm{~m}^{*}, 1 \mathrm{H}, 29-\mathrm{H}_{\mathrm{B}}\right), 1.82^{*}\left(\mathrm{~m}^{*}, 1 \mathrm{H}, 13-\mathrm{H}_{\mathrm{B}}\right), 1.81\left(\mathrm{~d}_{\mathrm{br}}, J=6.0 \mathrm{~Hz}\right.$, $1 \mathrm{H}, 11-\mathrm{H}), 1.86\left(\mathrm{~d}, J=14.8 \mathrm{~Hz}, 1 \mathrm{H}, 20-\mathrm{H}_{\mathrm{A}}\right), 2.05\left(\mathrm{~d}_{\mathrm{br}}, J=11.0 \mathrm{~Hz}, 1 \mathrm{H}, 5-\mathrm{H}_{\mathrm{B}}\right), 2.14$ (ddd,

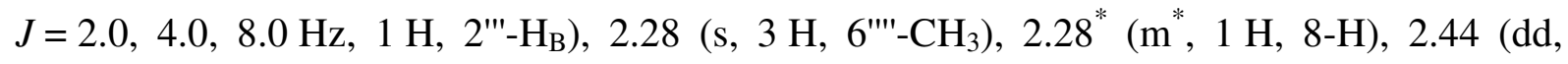
$\left.J=8.0,15.0 \mathrm{~Hz}, 1 \mathrm{H}, 20-\mathrm{H}_{\mathrm{B}}\right), 2.56\left(\mathrm{dd}_{\mathrm{br}}, J=8.0 \mathrm{~Hz}, 1 \mathrm{H}, 19-\mathrm{H}\right), 2.83(\mathrm{dd}, J=2.8,9.7 \mathrm{~Hz}$, 
$1 \mathrm{H}, 4$ "'-H), 3.26 (dd, $J=1.8,10.8 \mathrm{~Hz}, 1 \mathrm{H}, 7-\mathrm{H}), 3.39$ (s, $\left.3 \mathrm{H}, 44^{\prime \prime}-\mathrm{OCH}_{3}\right), 3.39^{*}\left(\mathrm{~m}^{*}, 1 \mathrm{H}\right.$, 2"-H), 3.81 (s, $3 \mathrm{H}, 2$ "'--OCH 3 ), 3.81 (dq, $J=6.1,9.8 \mathrm{~Hz}, 1 \mathrm{H}, 5$ "'-H), 3.93 (dq, $J=6.1$, $9.7 \mathrm{~Hz}, 1 \mathrm{H}, 5$ "-H), 4.16 (m $\mathrm{br}, 1 \mathrm{H}, 6-\mathrm{H}), 4.18$ (mbr $\left., 1 \mathrm{H}, 3^{\prime \prime \prime}-\mathrm{H}\right), 4.41$ (dd, J=2.8 Hz, $1 \mathrm{H}$, 3"-H), 4.60 (d, J=8.0 Hz, 1 H, 1"-H), 4.75 (dd, $J=2.8,10.0$ Hz, 1 H, 4"-H), 4.82 (dd, $\left.J=2.0,9.7 \mathrm{~Hz}, 1 \mathrm{H}, 1{ }^{\prime \prime}-\mathrm{H}\right), 5.73\left(\mathrm{~s}_{\mathrm{br}}, 1 \mathrm{H}, 9-\mathrm{H}\right), 6.51\left(\mathrm{~s}_{\mathrm{br}}, 1 \mathrm{H}, 17-\mathrm{H}\right), 6.74(\mathrm{~d}, J=8.5 \mathrm{~Hz}$,

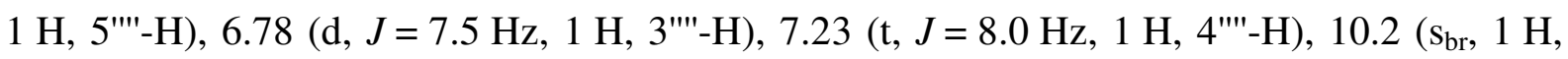
28-OH) ppm.

${ }^{13}$ C-NMR (150 MHz, $\mathrm{CDCl}_{3}$ ): $\delta=12.5$ (q, C-30), 15.8 (q, C-25), 17.6(q, C-6"), 17.9 (q, C-6"'), 19.1 (q, 6"'"-CH $), 20.0$ (t, C-4), 21.6 (q, C-27), 22.4 (q, C-26), 25.7 (t, C-14), 26.4(t, C-29), 27.6 (t, C-20), 29.9 (t, C-5), 31.0 (t, C-12), 33.7 (t, C-13), 34.1 (d, C-19), 34.4 (t, C-15), 36.2 (t, C-2"'), 36.7 (d, C-8), 37.7 (d, C-3), 46.4 (s, C-16), 50.4 (s, C-2), 54.2 (d, C-11), 55.8 (q, 2"'--OCH 3 ), 57.4 (q, 4'"--OCH 3 ), 63.7 (d, C-3"'), 67.5 (d, C-5"), 67.6 (d, C-6), 68.7 (d, C-5"'), 70.3 (d, C-2"), 74.1 (d, C-4"), 80.3 (d, C-3"), 82.1 (d, C-4"'), 83.0 (s, C-21), 85.2 (d, C-7), 99.5 (d, C-1"'), 102.0 (d, C-1"), 108.3 (d, C-3"''), 116.5 (s, C-23), 119.9 (d, C-9), 122.4 (d, C-5"''), 123.3 (s, C-1"''), 130.5 (d, C-4"''), 131.5 (s, C-18), 134.6 (s, C-10), 136.2 (s, C-6"''), 147.8 (d, C-17), 156.5 (s, C-2"''), 160.9 (s, C-22), 166.0 (s, C-24), 167.9 (s, COO), 172.3 (s, C-28), 180.1 (s, C-1) ppm.

* Diese Signale überlappen mit anderen Signalen.

Rosiridol (23)

$\mathbf{C}_{10} \mathbf{H}_{18} \mathbf{O}_{2} \quad(170.25)$.

Farbloser Feststoff.

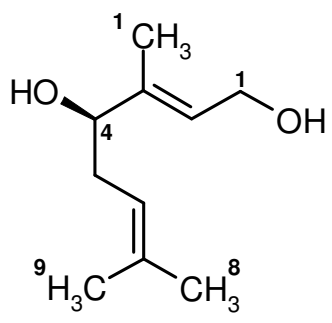

Smp.: $150{ }^{\circ} \mathrm{C}$.

$\mathbf{R}_{\mathbf{f}}=0.30\left(\mathrm{KG}, \mathrm{CHCl}_{3} / \mathrm{MeOH}\right.$ 9:1); $0.62\left(\mathrm{RP}-18\right.$, Aceton/ $\left.\mathrm{H}_{2} \mathrm{O} 3: 1\right)$.

Anfärbeverhalten: violett (ANIS).

MS (DCI, $200 \mathrm{eV}): m / z(\%)=170(100)\left[\mathrm{M}-\mathrm{H}_{2} \mathrm{O}+\mathrm{NH}_{4}\right]^{+}, 188(42)\left[\mathrm{M}+\mathrm{NH}_{4}\right]^{+}$.

Drehwert: $[\alpha]_{D}^{20}=-8(\mathrm{c}=0.05, \mathrm{MeOH})$.

UV $(\mathrm{MeOH}): \lambda_{\max }(\lg \varepsilon)=203 \mathrm{~nm}(4.65) ;(\mathrm{MeOH}, \mathrm{HCl}): \lambda_{\max }(\lg \varepsilon)=203 \mathrm{~nm}(4.68)$;

$(\mathrm{MeOH}, \mathrm{NaOH}): \lambda_{\max }(\lg \varepsilon)=206 \mathrm{~nm}(4.47)$.

IR $(\mathrm{KBr}): \widetilde{v}\left(\mathrm{~cm}^{-1}\right)=3405,2922,1669,1438,1384,1001$. 
${ }^{1} \mathbf{H}-\mathrm{NMR}\left(600 \mathrm{MHz}, \mathrm{CD}_{3} \mathrm{OD}\right): \delta=1.62\left(\mathrm{~s}_{\mathrm{br}}, 3 \mathrm{H}, 9-\mathrm{H}_{3}\right), 1.63\left(\mathrm{~s}_{\mathrm{br}}, 3 \mathrm{H}, 10-\mathrm{H}_{3}\right), 1.68\left(\mathrm{~s}_{\mathrm{br}}, 3 \mathrm{H}\right.$, 8- $\left.\mathrm{H}_{3}\right), 2.22\left(\mathrm{~m}, 2 \mathrm{H}, 5-\mathrm{H}_{2}\right), 3.93(\mathrm{dd}, J=7.0,7.0 \mathrm{~Hz}, 1 \mathrm{H}, 4-\mathrm{H}), 4.12\left(\mathrm{~m}^{*}, 2 \mathrm{H}, 1-\mathrm{H}_{2}\right), 5.10$ (m, $J=1.5,7.0 \mathrm{~Hz}, 1 \mathrm{H}, 6-\mathrm{H}), 5.52(\mathrm{~m}, J=1.2,1.5,7.0 \mathrm{~Hz}, 1 \mathrm{H}, 2-\mathrm{H}) \mathrm{ppm}$.

${ }^{13}$ C-NMR (150 MHz, CD $30 D$ ): $\delta=11.8$ (q, C-10), 18.0 (q, C-9), 26.0 (q, C-8), 34.9 (t, C-5), 59.2 (t, C-1), 78.0 (d, C-4), 121.7 (d, C-6), 126.2 (d, C-2), 133.9 (s, C-7), 140.5 (s, C-3) ppm. * Signal höherer Ordnung.

\section{Cinnamoylphosphoramid (21)}

\section{$\mathbf{C}_{11} \mathrm{H}_{14} \mathrm{NO}_{5} \mathrm{P}(271.21)$.}

Farbloser Feststoff.

UV-löschend $(254 \mathrm{~nm})$.

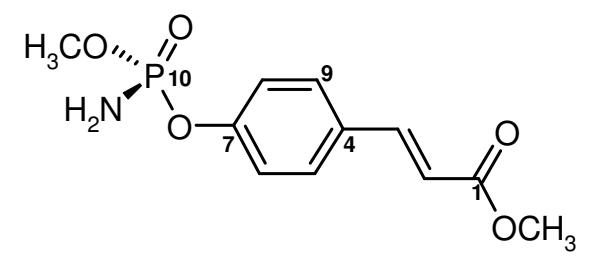

$\mathbf{R}_{\mathbf{f}}=0.34\left(\mathrm{KG}, \mathrm{CHCl}_{3} / \mathrm{MeOH} 9: 1\right) ; 0.56\left(\mathrm{RP}-18, \mathrm{MeOH} / \mathrm{H}_{2} \mathrm{O} 7: 3\right)$.

ESI-MS: $m / z(\%)=294(25)[\mathrm{M}+\mathrm{Na}]^{+}, 565(100)[2 \mathrm{M}+\mathrm{Na}]^{+}$.

Drehwert: $[\alpha]_{D}^{20}=-5.2(\mathrm{c}=0.25, \mathrm{MeOH})$.

UV (MeOH): $\lambda_{\max }(\lg \varepsilon)=204 \mathrm{~nm}(4.75), 217$ (4.70), 283 (4.86); (MeOH, HCl): $\lambda_{\max }(\lg$ $\varepsilon)=205 \mathrm{~nm}(4.80), 217$ (4.73), 316 (4.87); (MeOH, NaOH): $\lambda_{\max }(\lg \varepsilon)=240 \mathrm{~nm}(4.42), 359$ (4.96).

IR $(\mathrm{KBr}): \widetilde{v}\left(\mathrm{~cm}^{-1}\right)=3417,2953,1716,1637,1602,1508,1437,1326,1226,1171,1053$, $1014,982,925,836,796$.

${ }^{1} \mathbf{H}-\mathrm{NMR}\left(600 \mathrm{MHz}, \mathrm{CDCl}_{3}\right): \delta=3.06\left(\mathrm{~s}_{\mathrm{br}}, 2 \mathrm{H}, 10-\mathrm{NH}_{2}\right), 3.77\left(\mathrm{~s}, 3 \mathrm{H}, 1-\mathrm{OCH}_{3}\right), 3.80(\mathrm{~d}$, $\left.J=11.4 \mathrm{~Hz}, 3 \mathrm{H}, 10-\mathrm{OCH}_{3}\right), 6.33(\mathrm{~d}, J=15.9 \mathrm{~Hz}, 1 \mathrm{H}, 2-\mathrm{H}), 7.22(\mathrm{~d}, J=8.4 \mathrm{~Hz}, 2 \mathrm{H}, 6-\mathrm{H}$, 8-H), 7.46 (d, $J=8.4 \mathrm{~Hz}, 5-\mathrm{H}, 9-\mathrm{H}), 7.61$ (d, $J=15.9 \mathrm{~Hz}, 1 \mathrm{H}, 3-\mathrm{H}) \mathrm{ppm}$.

${ }^{13}$ C-NMR (125.7 MHz, $\left.\mathrm{CDCl}_{3}\right): \delta=51.8(\mathrm{q}, \mathrm{C}-12), 53.8\left(\mathrm{q},{ }^{2} J_{\mathrm{CP}}=5.3 \mathrm{~Hz}, \mathrm{C}-11\right), 117.7(\mathrm{~d}$, C-2), 120.8 (d, $\left.{ }^{3} J_{C P}=5.3 \mathrm{~Hz}, \mathrm{C}-6, \mathrm{C}-8\right), 129.6$ (d, C-5, C-9), 131.2 (s, C-4), 143.7 (d, C-3), $152.4\left(\mathrm{~s},{ }^{2} J_{\mathrm{CP}}=6.8 \mathrm{~Hz}, \mathrm{C}-7\right), 167.4(\mathrm{~s}, \mathrm{C}-1) \mathrm{ppm}$.

\subsection{Derivatisierung des Spirotetronats (22a)}

\subsubsection{Acetylierung}

22a $(12.5 \mathrm{mg}, 10.6 \mu \mathrm{mol})$ wurde in Pyridin $(1 \mathrm{~mL})$ gelöst, die Lösung auf $0{ }^{\circ} \mathrm{C}$ gekühlt und Acetanhydrid $(50 \mu \mathrm{L})$ zugegeben. Die Reaktionsmischung wurde auf Raumtemperatur erwärmt und für $27 \mathrm{~h}$ bei dieser Temperatur gerührt. Danach wurde die Reaktion durch 
Zugabe von Eiswasser $(10 \mathrm{~mL})$ und ges. $\mathrm{NaHCO}_{3}$-Lösung $(3 \mathrm{~mL})$ beendet. Das Reaktionsgemisch wurde mit $\mathrm{CH}_{2} \mathrm{Cl}_{2}(3 \times 20 \mathrm{~mL})$ extrahiert, die organische Phase i. Vak. eingeengt und mit Toluol koevaporiert. Nach säulenchromatographischer Reinigung an Kieselgel (Cyclohexan/Ethylacetat/Methanol 5:10:2) zeigten die jeweiligen ${ }^{1} \mathrm{H}-\mathrm{NMR}-S p e k t r e n$ lediglich die Isolierung von Zersetzungsprodukten.

\subsubsection{Methylierung}

22a $(9.7 \mathrm{mg}, 8.28 \mu \mathrm{mol})$ wurde bei $0{ }^{\circ} \mathrm{C}$ in Methanol/Wasser 19:1 gelöst (1 mL) und tropfenweise unter Rühren mit etherischer Diazomethanlösung $(0.4 \mathrm{M})$ bis zur bleibenden Gelbfärbung der Lösung versetzt. Anschließend wurde die Reaktionsmischung auf Raumtemperatur erwärmt, $1 \mathrm{~h}$ bei dieser Temperatur gerührt und i. Vak. bis zur Trockne eingeengt. Nach säulenchromatographischer Reinigung an Kieselgel (Cyclohexan/Ethylacetat/Methanol 5:10:2) wurde das zweifach methylierte Produkt 102a als farbloser Feststoff erhalten (7.1 mg, $5.92 \mu \mathrm{mol}, 71 \%)$.

\section{Spirotetronat (102a)}

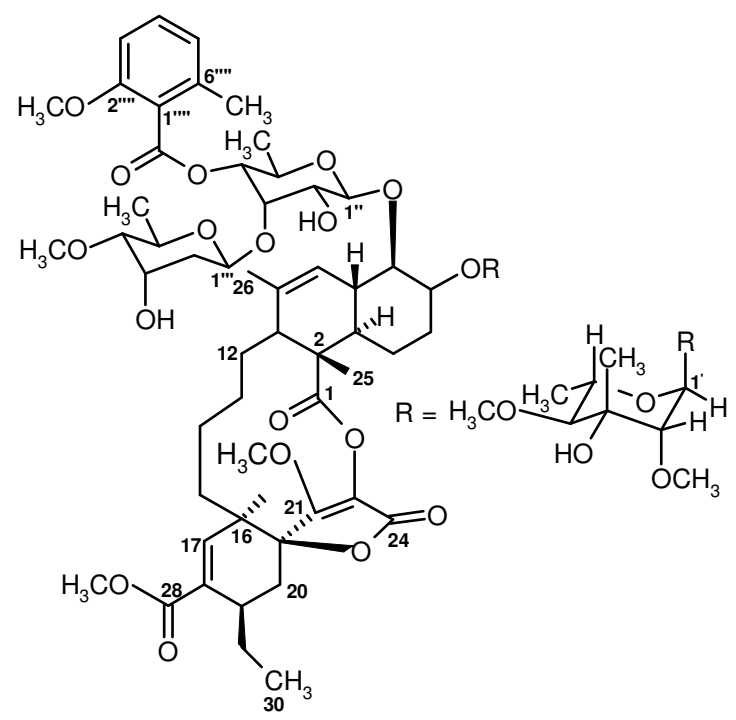

\section{$\mathbf{C}_{63} \mathbf{H}_{90} \mathbf{O}_{22} \quad$ (1199.19).}

Farbloser Feststoff.

R. 0.73 (KG, Cyclohexan/Ethylacetat/MeOH 5:10:2); 0.24 (RP-18, Aceton/ $\mathrm{H}_{2} \mathrm{O}$ 3:1).

Anfärbeverhalten: braun (ANIS), grau-schwarz (ORCIN).

MS (ESI): $m / z(\%)=1200[\mathrm{M}+\mathrm{H}]^{+}, 1218\left[\mathrm{M}+\mathrm{NH}_{4}\right]^{+}, 1223[\mathrm{M}+\mathrm{Na}]^{+}$. 
${ }^{1}$ H-NMR $\left(600 \mathrm{MHz}, \mathrm{CD}_{3} \mathrm{OD}\right): \delta=0.62\left(\mathrm{~m}_{\mathrm{br}}, 1 \mathrm{H}, 13-\mathrm{H}_{\mathrm{A}}\right), 0.92\left(\mathrm{t}, J=7.0 \mathrm{~Hz}, 3 \mathrm{H}, 30-\mathrm{H}_{3}\right)$, $1.09^{*}\left(\mathrm{~m}^{*}, 1 \mathrm{H}, 12-\mathrm{H}_{\mathrm{A}}\right), 1.09\left(\mathrm{~m}, 1 \mathrm{H}, 14-\mathrm{H}_{\mathrm{A}}\right), 1.18\left(\mathrm{~s}, 3 \mathrm{H}, 27-\mathrm{H}_{3}\right), 1.21(\mathrm{~d}, J=6.1 \mathrm{~Hz}, 3 \mathrm{H}$, 6"- $\left.\mathrm{H}_{3}\right), 1.21^{*}\left(\mathrm{~m}^{*}, 1 \mathrm{H}, 15-\mathrm{H}_{\mathrm{A}}\right), 1.27$ (d, J =6.1 Hz, $\left.3 \mathrm{H}, 6{ }^{\prime}-\mathrm{H}_{3}\right), 1.28$ (s, $\left.3 \mathrm{H}, 25-\mathrm{H}_{3}\right), 1.29$ (d, $\left.J=6.1 \mathrm{~Hz}, 3 \mathrm{H}, 6^{\prime \prime \prime}-\mathrm{H}_{3}\right), 1.31\left(\mathrm{~s}, 3 \mathrm{H}, 3^{\prime}-\mathrm{CH}_{3}\right), 1.31^{*}\left(\mathrm{~m}^{*}, 1 \mathrm{H}, 4-\mathrm{H}_{\mathrm{A}}\right), 1.43^{*}\left(\mathrm{~m}^{*}, 1 \mathrm{H}, 15-\mathrm{H}_{\mathrm{B}}\right)$, $1.47^{*}\left(\mathrm{~m}^{*}, 1 \mathrm{H}, 14-\mathrm{H}_{\mathrm{B}}\right), 1.49^{*}\left(\mathrm{~m}^{*}, 1 \mathrm{H}, 12-\mathrm{H}_{\mathrm{B}}\right), 1.58^{*}\left(\mathrm{~m}^{*}, 1 \mathrm{H}, 3-\mathrm{H}\right), 1.60^{*}\left(\mathrm{~m}^{*}, 1 \mathrm{H}, 5-\mathrm{H}_{\mathrm{A}}\right)$, $1.62^{*}\left(\mathrm{~m}^{*}, 2 \mathrm{H}, 29-\mathrm{H}_{2}\right), 1.65^{*}\left(\mathrm{~m}^{*}, 1 \mathrm{H}, 22^{\prime \prime}-\mathrm{H}_{\mathrm{A}}\right), 1.66^{*}\left(\mathrm{~m}^{*}, 1 \mathrm{H}, 4-\mathrm{H}_{\mathrm{B}}\right), 1.67^{*}\left(\mathrm{~m}^{*}, 1 \mathrm{H}, 13-\mathrm{H}_{\mathrm{B}}\right)$, $1.71\left(\mathrm{~s}, 3 \mathrm{H}, 26-\mathrm{H}_{3}\right), 1.77(\mathrm{~d}, J=7.8 \mathrm{~Hz}, 1 \mathrm{H}, 11-\mathrm{H}), 1.85\left(\mathrm{~m}_{\mathrm{br}}, 1 \mathrm{H}, 5-\mathrm{H}_{\mathrm{B}}\right), 1.87\left(\mathrm{~m}_{\mathrm{br}}, 1 \mathrm{H}\right.$, $20-\mathrm{H}_{\mathrm{A}}$ ), 2.00 (ddd, $\left.J=2.0,4.0,8.0 \mathrm{~Hz}, 1 \mathrm{H}, 2^{2 '-}-\mathrm{H}_{\mathrm{B}}\right), 2.28$ (s, $3 \mathrm{H}, 6$ '"'- $\left.\mathrm{CH}_{3}\right), 2.29^{*}$ (m, $1 \mathrm{H}$, 8-H), 2.40 (dd, $\left.J=8.0,15.0 \mathrm{~Hz}, 1 \mathrm{H}, 20-\mathrm{H}_{\mathrm{B}}\right), 2.58\left(\mathrm{dd}_{\mathrm{br}}, J=8.0,8.0 \mathrm{~Hz}, 1 \mathrm{H}, 19-\mathrm{H}\right), 2.89$ (dd, $J=2.8,9.7 \mathrm{~Hz}, 1 \mathrm{H}, 4$ '"'-H) $^{-} 2.99$ (d, $\left.J=9.7 \mathrm{~Hz}, 1 \mathrm{H}, 4^{\prime}-\mathrm{H}\right), 3.22(\mathrm{dd}, J=1.8,10.8 \mathrm{~Hz}, 1 \mathrm{H}$, 7-H), $3.24\left(\mathrm{~d}_{\mathrm{br}}, J=1.8 \mathrm{~Hz}, 1 \mathrm{H}, 2\right.$ '-H), 3.37 (s, $3 \mathrm{H}, 4$ '"--OCH 3$), 3.44$ (dd, $J=2.8,8.1 \mathrm{~Hz}, 1 \mathrm{H}$, 2"-H), 3.53 (s, 3 H, 2'- $\mathrm{OCH}_{3}$ ), 3.56 (s, 3 H, 4'- $\mathrm{OCH}_{3}$ ), 3.60 (dq, J=6.2, 9.7 Hz, 1 H, 5'-H), 3.53 (s, $3 \mathrm{H}, 28-\mathrm{OCH}_{3}$ ), 3.84 (s, $3 \mathrm{H}, 2$ '"'-OCH 3 ), 3.88 (dq, J=6.1, $9.7 \mathrm{~Hz}, 1 \mathrm{H}, 5$ "'-H), 3.98 (dq, J = 6.1, 9.7 Hz, $1 \mathrm{H}, 5 "-\mathrm{H}), 4.11\left(\mathrm{~s}, 3 \mathrm{H}, 22-\mathrm{OCH}_{3}\right), 4.19\left(\mathrm{~m}_{\mathrm{br}}, 1 \mathrm{H}, 6-\mathrm{H}\right), 4.22\left(\mathrm{~m}_{\mathrm{br}}, 1 \mathrm{H}\right.$, 3"'-H), 4.35 (dd, $J=2.4$ Hz 1 H, 3"-H), 4.60 (d, $J=8.0 \mathrm{~Hz}, 1 \mathrm{H}, 1 "-\mathrm{H}), 4.73$ (dd, $J=2.8$, $9.8 \mathrm{~Hz}, 1 \mathrm{H}, 4 "-\mathrm{H}), 4.87$ ( $\mathrm{s}_{\mathrm{br}}, 1 \mathrm{H}, 1$ '"--H), 5.28 (d, J=1.0 Hz, $\left.1 \mathrm{H}, 1^{\prime}-\mathrm{H}\right), 5.85$ ( $\left.\mathrm{s}_{\mathrm{br}}, 1 \mathrm{H}, 9-\mathrm{H}\right)$, 6.38 (d, $J=1.2 \mathrm{~Hz}, 1 \mathrm{H}, 17-\mathrm{H}), 6.83$ (d, J=7.9 Hz, $1 \mathrm{H}, 5^{\prime \prime \prime '-H), ~} 6.88$ (d, J=7.5 Hz, $1 \mathrm{H}$, 3'"'-H), 7.28 (t, $J=8.0 \mathrm{~Hz}, 1 \mathrm{H}, 4$ "'"-H) ppm.

${ }^{13}$ C-NMR (150 MHz, CD $30 D$ ): $\delta=12.8$ (q, C-30), 15.5 (q, C-25), 18.3 (q, C-6"), 18.4 (q, C-6'), 18.5 (q, C-6"'), 19.5 (q, 3'-CH 3 ), 19.5 (q, 6"'"-CH $\mathrm{CH}_{3}$ ), 22.1 (t, C-4), 22.3 (q, C-27), 23.1 (q, C-26), 24.8 (t, C-14), 27.4 (t, C-29), 29.3 (t, C-20), 30.3 (t, C-12), 31.9 (t, C-5), 33.9 (t, C-13), 35.6 (d, C-19), 36.0 (t, C-15), 38.5 (t, C-2"'), 38.8 (d, C-8), 39.9 (d, C-3), 46.9 (s, C-16), 50.5 (s, C-2), 52.3 (q, 28- $\mathrm{OCH}_{3}$ ), 56.4 (d, C-11), 56.6 (q, 2"''--OCH $), 57.0$ (q, 4"'--OCH 3 ), 59.6 (q, 2'- $-\mathrm{OCH}_{3}$ ), 62.0 (q, 4'- $\mathrm{OCH}_{3}$ ), 62.7 (q, 22- $\mathrm{OCH}_{3}$ ), 64.0 (d, C-3"'), 68.3 (d, C-5'), 68.8 (d, C-5"), 70.2 (d, C-5"'), 72.1 (d, C-2"), 74.6 (s, C-3'), 75.6 (d, C-4"), 78.8 (d, C-6), 81.3 (d, C-3"), 83.5 (d, C-4"'), 85.9 (s, C-21), 86.4 (d, C-2'), 87.0 (d, C-7), 87.2 (d, C-4'), 100.1 (d, C-1'), 100.9 (d, C-1"'), 104.9 (d, C-1"), 109.6 (d, C-3"''), 115.8 (s, C-23), 121.6 (d, C-9), 123.3 (d, C-5"'), 124.4 (s, C-1"''), 131.8 (d, C-4"''), 132.7 (s, C-18), 135.9 (s, C-10), 137.2 (s, C-6"''), 147.7 (d, C-17), 157.8 (s, C-2"'"), 169.0 (s, C-22), 169.3 (s, COO), 169.9 (s, C-24), 171.5 (s, C-28), 176.6 (s, C-1) ppm.

* Diese Signale überlappen mit anderen Signalen. 


\subsubsection{Methanolyse}

22a $(18.1 \mathrm{mg}, 15.5 \mu \mathrm{mol})$ wurde in methanolischer Salzsäure $(5 \mathrm{~mL})$ gelöst und $15 \mathrm{~min}$ im Ultraschallbad behandelt. Anschließend wurde die Reaktionsmischung i. Vak. bis zur Trockne eingeengt. Nach chromatographischer Reinigung an reversed-phase Kieselgel (Lobar $^{\circledR}$ Größe A, Aceton/ $\mathrm{H}_{2} \mathrm{O}$ 3:1) mittels MPLC wurden als Hauptprodukt 103a (7.1 mg, $6.91 \mu \mathrm{mol}, 45 \%)$ und als Nebenprodukt 104a $(2.0 \mathrm{mg}, 2.38 \mu \mathrm{mol}, 15 \%)$ als farblose Feststoffe erhalten.

\section{Spirotetronat (103a)}

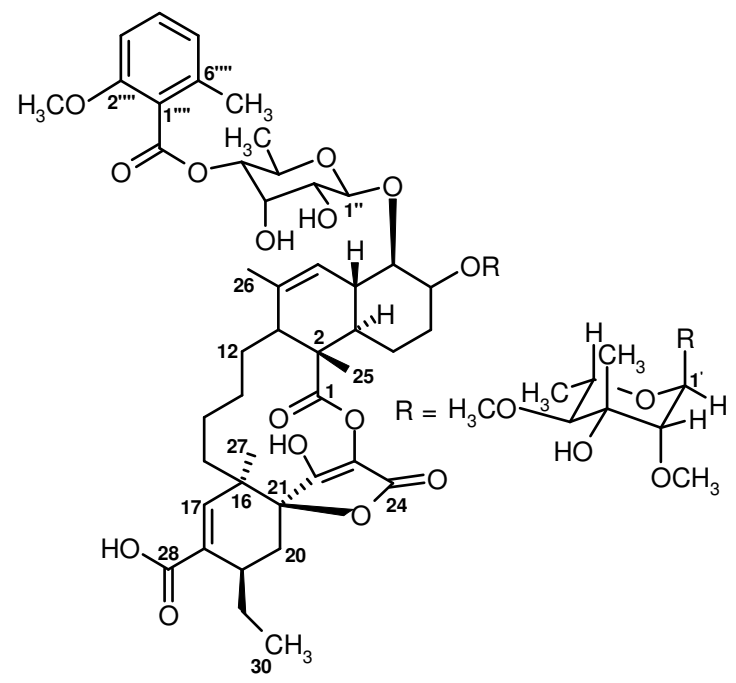

$\mathbf{C}_{54} \mathbf{H}_{74} \mathbf{O}_{19} \quad$ (1027.18).

Farbloser Feststoff.

$\mathbf{R}_{\mathbf{f}}: 0.69$ (KG, Cyclohexan/Ethylacetat/MeOH 5:10:2); 0.51 (RP-18, Aceton/ $\mathrm{H}_{2} \mathrm{O} 3: 1$ ).

Anfärbeverhalten: braun (ANIS), grau-schwarz (ORCIN).

MS (ESI): $m / z(\%)=1050(100)[\mathrm{M}+\mathrm{Na}]^{+}, 1026[\mathrm{M}-\mathrm{H}]^{-}$.

Drehwert: $[\alpha]_{D}^{20}=-80.5(\mathrm{c}=0.2, \mathrm{MeOH})$.

CD (MeOH): $\lambda_{\max }[\theta]=455 \mathrm{~nm}(904), 268$ (-38686), 249 (-1148), 231 (-10764), 227 (-8221), 223 (-10652), 201 (30176).

UV (MeOH): $\lambda_{\max }(\lg \varepsilon)=203 \mathrm{~nm}$ (3.54), 242 (2.81), 265 (3.03); (MeOH, HCl): $\lambda_{\max }(\lg$ $\varepsilon)=203 \mathrm{~nm}$ (3.56), 266 (2.00), $280(2.12) ;(\mathrm{MeOH}, \mathrm{NaOH}): \lambda_{\max }(\lg \varepsilon)=206 \mathrm{~nm}$ (3.46), 239 (2.81), 265 (3.06).

IR $(\mathrm{KBr}): \widetilde{v}\left(\mathrm{~cm}^{-1}\right)=3446,2932,1718,1587,1458,1384,1266,1092,1012,765$. 
${ }^{1} \mathbf{H}-\mathbf{N M R}\left(600 \mathrm{MHz}, \mathrm{CD}_{3} \mathrm{OD}\right): \delta=0.60\left(\mathrm{~m}_{\mathrm{br}}, 1 \mathrm{H}, 13-\mathrm{H}_{\mathrm{A}}\right), 0.92\left(\mathrm{t}, J=7.0 \mathrm{~Hz}, 3 \mathrm{H}, 30-\mathrm{H}_{3}\right)$, $1.07^{*}\left(\mathrm{~m}^{*}, 1 \mathrm{H}, 12-\mathrm{H}_{\mathrm{A}}\right), 1.07\left(\mathrm{~m}, 1 \mathrm{H}, 14-\mathrm{H}_{\mathrm{A}}\right), 1.23\left(\mathrm{~d}, J=6.1 \mathrm{~Hz}, 3 \mathrm{H}, 6 "-\mathrm{H}_{3}\right), 1.23(\mathrm{~s}, 3 \mathrm{H}$, $\left.27-\mathrm{H}_{3}\right), 1.23^{*}\left(\mathrm{~m}^{*}, 1 \mathrm{H}, 15-\mathrm{H}_{\mathrm{A}}\right), 1.28\left(\mathrm{~s}, 3 \mathrm{H}, 25-\mathrm{H}_{3}\right), 1.29$ (d, J =6.1 Hz, $\left.3 \mathrm{H}, 6-\mathrm{H}_{3}\right), 1.32$ (s, $\left.3 \mathrm{H}, 3^{\prime}-\mathrm{CH}_{3}\right), 1.32^{*}\left(\mathrm{~m}^{*}, 1 \mathrm{H}, 4-\mathrm{H}_{\mathrm{A}}\right), 1.45^{*}\left(\mathrm{~m}^{*}, 1 \mathrm{H}, 15-\mathrm{H}_{\mathrm{B}}\right), 1.47^{*}\left(\mathrm{~m}^{*}, 1 \mathrm{H}, 14-\mathrm{H}_{\mathrm{B}}\right), 1.48^{*}$ $\left(\mathrm{m}^{*}, 1 \mathrm{H}, 12-\mathrm{H}_{\mathrm{B}}\right), 1.56^{*}\left(\mathrm{~m}^{*}, 1 \mathrm{H}, 3-\mathrm{H}\right), 1.62^{*}\left(\mathrm{~m}^{*}, 1 \mathrm{H}, 5-\mathrm{H}_{\mathrm{A}}\right), 1.62^{*}\left(\mathrm{~m}^{*}, 1 \mathrm{H}, 29-\mathrm{H}_{\mathrm{A}}\right), 1.66^{*}$ $\left(\mathrm{m}^{*}, 1 \mathrm{H}, 4-\mathrm{H}_{\mathrm{B}}\right), 1.66^{*}\left(\mathrm{~m}^{*}, 1 \mathrm{H}, 29-\mathrm{H}_{\mathrm{B}}\right), 1.67^{*}\left(\mathrm{~m}^{*}, 1 \mathrm{H}, 13-\mathrm{H}_{\mathrm{B}}\right), 1.71\left(\mathrm{~s}, 3 \mathrm{H}, 26-\mathrm{H}_{3}\right), 1.76(\mathrm{~d}$, $J=7.7 \mathrm{~Hz}, 1 \mathrm{H}, 11-\mathrm{H}), 1.87\left(\mathrm{~m}_{\mathrm{br}}, 1 \mathrm{H}, 5-\mathrm{H}_{\mathrm{B}}\right), 1.82\left(\mathrm{~m}_{\mathrm{br}}, 1 \mathrm{H}, 20-\mathrm{H}_{\mathrm{A}}\right), 2.29\left(\mathrm{~s}, 3 \mathrm{H}, 6\right.$ '"'-- $\left.^{-} \mathrm{CH}_{3}\right)$, 2.29* (m* $1 \mathrm{H}, 8-\mathrm{H}), 2.47\left(\mathrm{dd}, J=8.0,15.0 \mathrm{~Hz}, 1 \mathrm{H}, 20-\mathrm{H}_{\mathrm{B}}\right), 2.55\left(\mathrm{~m}_{\mathrm{br}}, 1 \mathrm{H}, 19-\mathrm{H}\right), 2.98(\mathrm{~d}$, $\left.J=9.7 \mathrm{~Hz}, 1 \mathrm{H}, 4^{\prime}-\mathrm{H}\right), 3.22\left(\mathrm{~d}_{\mathrm{br}}, J=1.5 \mathrm{~Hz}, 1 \mathrm{H}, 2^{\prime}-\mathrm{H}\right), 3.26$ (dd, $\left.J=1.8,10.8 \mathrm{~Hz}, 1 \mathrm{H}, 7-\mathrm{H}\right)$, $3.44\left(\mathrm{dd}, J=2.8,8.1 \mathrm{~Hz}, 1 \mathrm{H}, 2^{\prime \prime}-\mathrm{H}\right), 3.53$ (s, $\left.3 \mathrm{H}, 2^{\prime}-\mathrm{OCH}_{3}\right), 3.55$ (s, $3 \mathrm{H}, 4$ '- $\left.\mathrm{OCH}_{3}\right), 3.62$ (dq, $\left.J=6.2,9.7 \mathrm{~Hz}, 1 \mathrm{H}, 5^{\prime}-\mathrm{H}\right), 3.80$ (s, $\left.3 \mathrm{H}, 2^{\prime \prime \prime '-O C H}\right), 4.05$ (dq, $J=6.1,9.7 \mathrm{~Hz}, 1 \mathrm{H}, 5$ "-H), 4.22 $\left(\mathrm{m}_{\mathrm{br}}, 1 \mathrm{H}, 6-\mathrm{H}\right), 4.27$ (dd, $\left.J=2.4 \mathrm{~Hz} 1 \mathrm{H}, 3 "-\mathrm{H}\right), 4.73$ (dd, $J=2.8,9.8 \mathrm{~Hz}, 1 \mathrm{H}, 4$ "--H), 4.73 (d, $J=8.0 \mathrm{~Hz}, 1 \mathrm{H}, 1 "-\mathrm{H}), 5.29\left(\mathrm{~d}, J=1.0 \mathrm{~Hz}, 1 \mathrm{H}, 11^{\prime}-\mathrm{H}\right), 5.81$ ( $\mathrm{s}$ br, $\left.1 \mathrm{H}, 9-\mathrm{H}\right), 6.41$ (d, $J=1.2 \mathrm{~Hz}, 1 \mathrm{H}, 17-\mathrm{H}), 6.82$ (d, J= 7.9 Hz, $\left.1 \mathrm{H}, 5^{\prime \prime \prime}-\mathrm{H}\right), 6.87$ (d, J= $\left.7.5 \mathrm{~Hz}, 1 \mathrm{H}, 3^{\prime \prime \prime}-\mathrm{H}\right), 7.28$ (t, $J=8.0 \mathrm{~Hz}, 1 \mathrm{H}, 4$ "''-H) ppm.

${ }^{13}$ C-NMR (150 MHz, CD $30 D$ ): $\delta=12.9$ (q, C-30), 15.9 (q, C-25), 18.2 (q, C-6"), 18.3 (q, C-6'), 19.3 (q, 3'-CH 3 ), 19.5 (q, 6'"'-CH 3 ), 21.9 (t, C-4), 22.0 (q, C-27), 22.8 (q, C-26), 25.9 (t, C-14), 27.5 (t, C-29), 29.4 (t, C-20), 30.4 (t, C-12), 32.0 (t, C-5), 34.3 (t, C-13), 35.6 (d, C-19), 35.9 (t, C-15), 38.9 (d, C-8), 39.4 (d, C-3), 47.0 (s, C-16), 50.5 (s, C-2), 56.3 (d, C-11), 56.3 (q, 2'"'-OCH 3 ), 59.6 (q, 2'- $\left.\mathrm{OCH}_{3}\right), 62.0$ (q, 4'--OCH 3 ), 68.3 (d, C-5'), 68.3 (d, C-5"), 71.0 (d, C-3"), 72.9 (d, C-2"), 74.6 (s, C-3'), 76.6 (d, C-4"), 79.2 (d, C-6), 85.3 (s, C-21), 86.45(d, C-2'), 87.0 (d, C-7), 87.2 (d, C-4'), 100.0 (d, C-1'), 104.9 (d, C-1"), 109.7 (d, C-3"''), 115.3 (s, C-23), 121.3 (d, C-9), 123.4 (d, C-5"''), 124.7 (s, C-1"''), 131.7 (d, C-4"'"), 133.2 (s, C-18), 136.2 (s, C-10), 137.6 (s, C-6"'"'), 148.0 (d, C-17), 157.8 (s, C-2"'"), 169.2 (s, COO), 170.7 (s, C-24), 171.2 (s, C-28), 177.1 (s, C-1) ppm.

* Diese Signale überlappen mit anderen Signalen.

Das Signal C-22 fehlt im ${ }^{13} \mathrm{C}-\mathrm{NMR}$. 


\section{Spirotetronat (104a)}

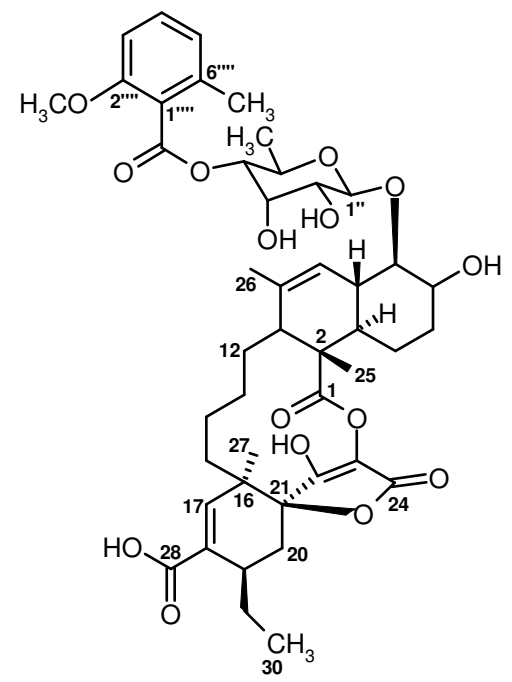

$\mathbf{C}_{45} \mathbf{H}_{58} \mathbf{O}_{15} \quad$ (838.96).

Farbloser Feststoff.

$\mathbf{R}_{\mathbf{f}}: 0.73$ (KG, Cyclohexan/Ethylacetat/MeOH 5:10:2); 0.43 (RP-18, Aceton/ $\mathrm{H}_{2} \mathrm{O} 3: 1$ ).

Anfärbeverhalten: braun (ANIS), grau-schwarz (ORCIN).

MS (ESI): $m / z(\%)=861(68)[\mathrm{M}+\mathrm{Na}]^{+}, 883(40)[\mathrm{M}-\mathrm{H}+2 \mathrm{Na}]^{+}, 838(94)[\mathrm{M}-\mathrm{H}]^{-}$.

Drehwert: $[\alpha]_{D}^{20}=-184(\mathrm{c}=0.05, \mathrm{MeOH})$.

CD $(\mathrm{MeOH}): \lambda_{\max }[\theta]=268 \mathrm{~nm}(-16489), 250$ (-1417), 220 (-8668), 204 (12502), 202 (20009).

UV (MeOH): $\lambda_{\max }(\lg \varepsilon)=204 \mathrm{~nm}$ (4.36), 244 (3.62), 266 (3.74); (MeOH, $\left.\mathrm{HCl}\right): \lambda_{\max }(\lg$ $\varepsilon)=204 \mathrm{~nm}$ (4.35), 268 (3.14), $280(3.21) ;(\mathrm{MeOH}, \mathrm{NaOH}): \lambda_{\max }(\lg \varepsilon)=208 \mathrm{~nm}$ (4.35), 244 (3.67), 265 (3.78).

IR $(\mathrm{KBr}): \widetilde{v}\left(\mathrm{~cm}^{-1}\right)=3446,2925,1772,1733,1633,1507,1457,1385,1093$.

${ }^{1} \mathbf{H}-\mathbf{N M R}\left(600 \mathrm{MHz}, \mathrm{CD}_{3} \mathrm{OD}\right): \delta=0.60\left(\mathrm{~m}_{\mathrm{br}}, 1 \mathrm{H}, 13-\mathrm{H}_{\mathrm{A}}\right), 0.92\left(\mathrm{t}, J=7.0 \mathrm{~Hz}, 3 \mathrm{H}, 30-\mathrm{H}_{3}\right)$, $1.07^{*}\left(\mathrm{~m}^{*}, 1 \mathrm{H}, 12-\mathrm{H}_{\mathrm{A}}\right), 1.07\left(\mathrm{~m}, 1 \mathrm{H}, 14-\mathrm{H}_{\mathrm{A}}\right), 1.23\left(\mathrm{~d}, J=6.1 \mathrm{~Hz}, 3 \mathrm{H}, 6 "-\mathrm{H}_{3}\right), 1.23$ (s, $3 \mathrm{H}$, $\left.27-\mathrm{H}_{3}\right), 1.23^{*}\left(\mathrm{~m}^{*}, 1 \mathrm{H}, 15-\mathrm{H}_{\mathrm{A}}\right), 1.28\left(\mathrm{~s}, 3 \mathrm{H}, 25-\mathrm{H}_{3}\right), 1.32^{*}\left(\mathrm{~m}^{*}, 1 \mathrm{H}, 4-\mathrm{H}_{\mathrm{A}}\right), 1.45^{*}\left(\mathrm{~m}^{*}, 1 \mathrm{H}\right.$, $\left.15-\mathrm{H}_{\mathrm{B}}\right), 1.47^{*}\left(\mathrm{~m}^{*}, 1 \mathrm{H}, 14-\mathrm{H}_{\mathrm{B}}\right), 1.48^{*}\left(\mathrm{~m}^{*}, 1 \mathrm{H}, 12-\mathrm{H}_{\mathrm{B}}\right), 1.56^{*}\left(\mathrm{~m}^{*}, 1 \mathrm{H}, 3-\mathrm{H}\right), 1.62^{*}\left(\mathrm{~m}^{*}, 1 \mathrm{H}\right.$, $\left.5-\mathrm{H}_{\mathrm{A}}\right), 1.62^{*}\left(\mathrm{~m}^{*}, 1 \mathrm{H}, 29-\mathrm{H}_{\mathrm{A}}\right), 1.66^{*}\left(\mathrm{~m}^{*}, 1 \mathrm{H}, 4-\mathrm{H}_{\mathrm{B}}\right), 1.66^{*}\left(\mathrm{~m}^{*}, 1 \mathrm{H}, 29-\mathrm{H}_{\mathrm{B}}\right), 1.67^{*}\left(\mathrm{~m}^{*}, 1 \mathrm{H}\right.$, 13- $\left.\mathrm{H}_{\mathrm{B}}\right), 1.71\left(\mathrm{~s}, 3 \mathrm{H}, 26-\mathrm{H}_{3}\right), 1.76(\mathrm{~d}, J=7.7 \mathrm{~Hz}, 1 \mathrm{H}, 11-\mathrm{H}), 1.87\left(\mathrm{~m}_{\mathrm{br}}, 1 \mathrm{H}, 5-\mathrm{H}_{\mathrm{B}}\right), 1.82\left(\mathrm{~m}_{\mathrm{br}}\right.$, $\left.1 \mathrm{H}, 20-\mathrm{H}_{\mathrm{A}}\right), 2.29$ (s, $\left.3 \mathrm{H}, 66^{\prime \prime}-\mathrm{CH}_{3}\right), 2.29^{*}\left(\mathrm{~m}^{*}, 1 \mathrm{H}, 8-\mathrm{H}\right), 2.42$ (dd, J = 8.0, $15.0 \mathrm{~Hz}, 1 \mathrm{H}$, $\left.20-\mathrm{H}_{\mathrm{B}}\right), 2.50\left(\mathrm{~m}_{\mathrm{br}}, 1 \mathrm{H}, 19-\mathrm{H}\right), 3.22(\mathrm{dd}, J=1.8,10.8 \mathrm{~Hz}, 1 \mathrm{H}, 7-\mathrm{H}), 3.56(\mathrm{dd}, J=2.8,8.1 \mathrm{~Hz}$, 
$1 \mathrm{H}, 2$ "-H), 3.80 (s, $3 \mathrm{H}, 2$ '"'-OCH 3 ), 4.04 (dq, J=6.1, $9.7 \mathrm{~Hz}, 1 \mathrm{H}, 5$ "-H), 4.19 (mbr, $1 \mathrm{H}$, 6-H), 4.31 (dd, $J=2.4 \mathrm{~Hz} 1 \mathrm{H}, 3 "-\mathrm{H}), 4.75$ (dd, $J=2.8,9.8 \mathrm{~Hz}, 1 \mathrm{H}, 4 "-\mathrm{H}), 4.76\left(\mathrm{~s}_{\mathrm{br}}, 1 \mathrm{H}\right.$, 1"-H), 5.73 (s $\left.\mathrm{s}_{\mathrm{br}}, 1 \mathrm{H}, 9-\mathrm{H}\right), 6.39$ (d, J=0.9 Hz, $\left.1 \mathrm{H}, 17-\mathrm{H}\right), 6.82$ (d, J= 7.9 Hz, $1 \mathrm{H}, 5$ "''-H), 6.87 (d, $J=7.5 \mathrm{~Hz}, 1 \mathrm{H}, 3^{\prime \prime \prime '-H), ~} 7.27$ (t, $J=8.0 \mathrm{~Hz}, 1 \mathrm{H}, 4^{\prime \prime \prime '-H) ~ p p m . ~}$

${ }^{13}$ C-NMR (150 MHz, CD $\left.30 D\right): \delta=13.1$ (q, C-30), 16.4 (q, C-25), 18.1 (q, C-6"), 19.5 (q, 6"''-- $\mathrm{CH}_{3}$ ), 21.4 (t, C-4), 22.1 (q, C-27), 23.0 (q, C-26), 26.0 (t, C-14), 27.6 (t, C-29), 29.4 (t, C-20), 30.8 (t, C-12), 35.6 (d, C-19), 36.8 (t, C-15), 38.5 (d, C-8), 39.4 (d, C-3), 46.1 (s, C-16), 50.0 (s, C-2), 56.1 (d, C-11), 56.3 (q, 2"'--OCH 3 ), 68.3 (d, C-5"), 70.3 (d, C-6), 70.9 (d, C-3"), 72.5 (d, C-2"), 76.5 (d, C-4"), 83.9 (s, C-21), 86.6 (d, C-7), 103.2 (d, C-1"), 109.7 (d, C-3"''), 120.8 (d, C-9), 123.4 (d, C-5"''), 124.7 (s, C-1"''), 131.7 (d, C-4'"'), 137.6 (s, C-6"''), 147.4 (d, C-17), 157.8 (s, C-2"'") ppm.

* Diese Signale überlappen mit anderen Signalen.

Diese Signale fehlen im ${ }^{13}$ C-NMR: C-1, C-5, C-10, C-13, C-18, C-22, C-23, C-24, C-28, COO.

\subsection{Studien zur Biosynthese ausgewählter Metaboliten}

\subsubsection{Fermentationskurve}

Zur Aufnahme der zeitabhängigen Sekundärstoffproduktion des Spirotetronats (22a) wurde der Stamm JP90 in 1 L Schüttelkolben mit Schikane, befüllt mit 150 mL Nährlösung Medium $\mathrm{S}$, bei $28^{\circ} \mathrm{C}$ und $180 \mathrm{U} / \mathrm{min}$ sowie im Fermenter Biostat M, befüllt mit $950 \mathrm{ml}$ Nährlösung Medium S, bei $28^{\circ} \mathrm{C}, 600 \mathrm{U} / \mathrm{min}$ und 1.6 vvm kultiviert; als Inokulum diente eine 48 Stunden alte Vorkultur (siehe Abschnitt 3.3.2 ). Der pH-Verlauf wurde während der Fermentation im Fermenter mittels pH-Elektrode aufgenommen; bei der Kultivierung in Schüttelkolben wurde der pH-Wert der entnommenen Proben bestimmt. Alle sechs bzw. über Nacht acht Stunden wurden $25 \mathrm{~mL}$ Kulturbrühe aus dem Fermenter und $10 \mathrm{~mL}$ Kulturbrühe aus den Schüttelkolben entnommen, erstmals nach Animpfen bis zur 78. Inkubationsstunde. Die Aufarbeitung erfolgte wie in Abschnitt 3.3.3 beschrieben. Die erhaltenen Rohextrakte aus dem Kulturfiltrat wurden mit einer definierten Konzentration von $c=4 \mathrm{mg} / \mathrm{mL}$ in Methanol gelöst und dünnschichtchromatographisch an Kieselgel $\left(\mathrm{CHCl}_{3} / \mathrm{MeOH} \quad 85: 15\right)$ untersucht. Für analytische HPLC-Untersuchungen der Rohextrakte wurden jeweils $150 \mu \mathrm{L}$ entnommen, zentrifugiert und anschließend analysiert (HPLC A, Säule A: Grom Superspher 100 RP-18, Programm A: $\mathrm{MeOH} / \mathrm{H}_{2} \mathrm{O}$, jeweils mit $0.05 \%$ Ameisensäure, Gradient, s. 1.2 ). 


\subsubsection{Fütterungsexperimente mit Natrium-[1,2- $\left.{ }^{13} \mathrm{C}_{2}\right]$ acetat und $\left[\mathrm{U}-{ }^{13} \mathrm{C}_{3}\right]$ Glycerin}

\section{Fütterungsexperiment mit Natrium-[1,2- $\left.{ }^{13} \mathrm{C}_{2}\right]$ acetat}

Das Fütterungsexperiment (1.05 L-Ansatz) wurde in sieben $1 \mathrm{~L}$ Erlenmeyerkolben mit Schikane, befüllt mit $150 \mathrm{~mL}$ Nährlösung Medium S, unter Standardbedingungen durchgeführt (siehe Abschnitt 3.3.2 ). Die isotopenmarkierte Substanz wurde in $20 \mathrm{~mL}$ sterilem bidest. Wasser gelöst und der pH-Wert mit $0.5 \mathrm{~N} \mathrm{HCl}$ auf 7.0 eingestellt. Die Lösung wurde steril filtriert und mit sterilem bidest. Wasser auf ein Gesamtvolumen von $250 \mathrm{~mL}$ aufgefüllt. $\mathrm{Ab}$ der 48. Stunde wurde der Vorläufer mittels einer Schlauchpumpe über einen Zeitraum von $7 \mathrm{~h}$ kontinuierlich zugefüttert. Die Aufarbeitung erfolgte wie in Abschnitt 3.3.3 beschrieben. Die Isolierung der einzelnen Substanzen aus dem Extrakt des Kulturfiltrates erfolgte wie in 3.4 beschrieben. Es wurden $550 \mathrm{mg} / \mathrm{L}(5.9 \mathrm{mmol} / \mathrm{L})$ Natrium- $\left[1,2{ }^{13} \mathrm{C}_{2}\right]$ Acetat zugefüttert und $1.8 \mathrm{mg} / \mathrm{L}$ angereichertes Rosiridol (23), $30.0 \mathrm{mg} / \mathrm{L}$ angereichertes Spirotetronat (22a) und $9.0 \mathrm{mg} / \mathrm{L}$ angereichertes Spirotetronat (22b) isoliert.

\section{Fütterungsexperiment mit $\left[\mathrm{U}-{ }^{13} \mathrm{C}_{3}\right]$ Glycerin}

Das Fütterungsexperiment $(600 \mathrm{~mL}-A n s a t z)$ wurde in vier $1 \mathrm{~L}$ Erlenmeyerkolben mit Schikane, befüllt mit $150 \mathrm{~mL}$ Nährlösung Medium S, unter Standardbedingungen durchgeführt (siehe Abschnitt 3.3.2 ). Abweichend zum Mediums S wurde ein Glyceringehalt von nur $1.8 \mathrm{~g} / \mathrm{L}$ eingestellt. Dieses wurde durchgeführt, um in der Kulturbrühe nach Zufütterung des $\left[\mathrm{U}_{-}{ }^{13} \mathrm{C}_{3}\right.$ ] Glycerin ein Verhältnis von 3:1 für unmarkiertes Glycerin zu isotopenmarkiertem Glycerin zu erzielen. Die isotopenmarkierte Substanz wurde in $20 \mathrm{~mL}$ sterilem bidest. Wasser gelöst, steril filtriert und mit sterilem bidest. Wasser auf ein Gesamtvolumen von $160 \mathrm{~mL}$ verdünnt. Ab der 48. Stunde wurde der Vorläufer mittels einer Schlauchpumpe über einen Zeitraum von $12 \mathrm{~h}$ kontinuierlich zugefüttert. Die Aufarbeitung erfolgte wie in 3.3 .3 beschrieben. Die Isolierung der einzelnen Substanzen aus dem Extrakt des Kulturfiltrates erfolgte wie in Abschnitt 3.4 aufgeführt. Es wurden $500 \mathrm{mg} / \mathrm{L}(9.1 \mathrm{mmol} / \mathrm{L})\left[\mathrm{U}_{-}{ }^{13} \mathrm{C}_{3}\right]$ Glycerin zugefüttert und $28.0 \mathrm{mg} / \mathrm{L}$ angereichertes Spirotetronat (22a), $7.0 \mathrm{mg} / \mathrm{L}$ angereichertes Spirotetronat (22b) und $2.3 \mathrm{mg} / \mathrm{L}$ eines Gemisches aus angereichertem Rosiridol (23) und nicht angereichertem Cinnamoylphosphoramid (21) isoliert.

\subsubsection{Fütterungsexperimente mit potentiellen Biosynthesevorläufern}

Die Kultivierung (je $600 \mathrm{~mL}$ Ansatz) erfolgte unter Standardbedingungen in Schüttelkolben (pro gefütterte Substanz vier 1 L Schüttelkolben mit je 150 mL Nährlösung, siehe Abschnitt 
3.3.2 ). Folgende Substanzen wurden als Vorläufer zugefüttert: Racemisches Syntheseprodukt 21 (0.59 mM, 24 mg/150 mL, Endkonzentration im Kolben), 4-Hydroxyzimtsäuremethylester (82) (0.94 mM, 25 mg/150 mL, Endkonzentration im Kolben), Zimtsäuremethylester (93) (1.03 mM, $25 \mathrm{mg} / 150 \mathrm{~mL}$, Endkonzentration im Kolben), Zimtsäure (122) (1.12 mM, $25 \mathrm{mg} / 150 \mathrm{~mL}$, Endkonzentration im Kolben). Die Substanzen wurden in je $2 \mathrm{~mL}$ sterilem DMSO gelöst und nach der 12. und 16. Stunde jeweils $0.25 \mathrm{~mL}$ dieser Lösung zu jeweils vier der Hauptkulturen gegeben, vier weitere Kulturen dienten als Kontrolle. Die Aufarbeitung erfolgte wie in Abschnitt 3.3.3 beschrieben. Die erhaltenen Rohextrakte wurden mit einer Konzentration von $c=10.0 \mathrm{mg} / \mathrm{mL}$ in Methanol gelöst und dünnschichtchromatographisch an Kieselgel $\left(\mathrm{CHCl}_{3} / \mathrm{MeOH} 85: 15\right)$ untersucht. Für HPLC-ESI-MS-Messungen der Rohextrakte wurden jeweils $150 \mu \mathrm{L}$ entnommen, zentrifugiert und anschließend analysiert (HPLC D, Säule A: Grom Supershere 100 RP-18, Programm B: $\mathrm{MeOH} / \mathrm{H}_{2} \mathrm{O}$, jeweils mit $0.05 \%$ Ameisensäure, Gradient; s. 1.2 ).

\subsubsection{Isolierung und Charakterisierung des Metaboliten (123)}

Der aus dem Kultivierungsansatz mit Zufütterung von 4-Hydroxyzimtsäuremethylester (82) erhaltene Kulturfiltrat-Extrakt wurde zunächst an Kieselgel ( $\mathrm{CHCl}_{3} / \mathrm{Methanol}$ 95:5) vorgereinigt und fraktioniert. Weitere Reinigung durch Gelchromatographie an Sephadex-LH 20 (Methanol) ergab 4.9 mg der durch Zufütterung induzierten Verbindung 123.

\section{4-Hydroxy-3-methoxy-zimtsäuremethylester (123)}

$\mathbf{C}_{11} \mathbf{H}_{12} \mathbf{O}_{4}$ (208.2).

$\mathbf{R}_{\mathbf{f}}: 0.92\left(\mathrm{KG}, \mathrm{CHCl}_{3} / \mathrm{MeOH} 85: 15\right)$.

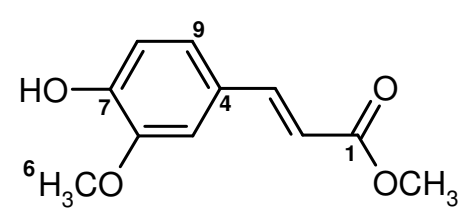

Anfärbeverhalten: violett (ANIS).

MS (ESI): $m / z(\%)=343.2[\mathrm{M}+\mathrm{Na}]^{+}, 663.1[2 \mathrm{M}+\mathrm{Na}]^{+}, 982.5[3 \mathrm{M}+\mathrm{Na}]^{+}$.

${ }^{1} \mathbf{H}-\mathrm{NMR}\left(300 \mathrm{MHz}, \mathrm{CD}_{3} \mathrm{OD}\right): \delta=3.75\left(\mathrm{~s}, 3 \mathrm{H}, 1-\mathrm{OCH}_{3}\right), 3.87$ (s, $\left.3 \mathrm{H}, 6-\mathrm{OCH}_{3}\right), 6.34$ (d, $J=15.9 \mathrm{~Hz}, 1 \mathrm{H}, 2-\mathrm{H}), 6.79(\mathrm{~d}, J=8.0 \mathrm{~Hz}, 1 \mathrm{H}, 8-\mathrm{H}), 7.05(\mathrm{dd}, J=2.1,8.0 \mathrm{~Hz}, 1 \mathrm{H}, 9-\mathrm{H})$, $7.16(\mathrm{~d}, J=2.1 \mathrm{~Hz}, 1 \mathrm{H}, 5-\mathrm{H}), 7.60(\mathrm{~d}, J=15.9 \mathrm{~Hz}, 1 \mathrm{H}, 3-\mathrm{H})$.

${ }^{13}$ C-NMR (75 MHz, CD 3 OD): $\delta=52.0$ (q, C-10), 56.4 (q, C-11), 111.6 (d, C-9), 115.0 (d, C-2), 116.5 (d, C-8), 124.2 (d, C-5), 127.5 (s, C-4), 146.9 (d, C-3), 149.4 (s, C-6), 150.9 (s, C-7), 169.8 (s, C-1). 


\subsection{Die absolute Konfiguration des Rosiridols (23)}

\subsubsection{Vergleichende HPLC-Analyse von nativen und totalsynthetischen Rosiridols an chiraler stationärer Phase}

Für die HPLC-Analyse an chiraler stationärer Phase (HPLC C, Säule F: Daicel Chiralcel OD, Programm G: $n$-Hexan/Isopropanol, isokratisch; s. 1.2 ) wurde für die einzelnen Substanzen (natives (23)-, totalsynthetisches rac-(23)- und $S$-(23)-Rosiridol) jeweils eine Konzentration von $c=1.0 \mathrm{mg} / \mathrm{mL}$ in $n$-Hexan/Isopropanol 9:1 eingestellt und als Injektionsvolumen für rac$2320 \mu \mathrm{L}$ und für 23 und $S$-23 $15 \mu \mathrm{L}$ gewählt. Für die Mischungsexperimente von rac-(23)mit $S$-(23)-Rosiridol und Naturstoff mit $S$-(23)-Rosiridol wurden Gemische im Verhältnis von 1:1 hergestellt (mit Stammlösung von $\mathrm{c}=1.0 \mathrm{mg} / \mathrm{mL}$ ) und jeweils $15 \mu \mathrm{L}$ injiziert. Um die Retentionszeiten auf Konsistenz zu überprüfen, wurde zwischen den Einzelmessungen jeweils rac-Rosiridol gemessen. 


\section{Produzent Streptomyces sp. Pol001}

\subsection{Kultivierung und Aufarbeitung}

\subsubsection{Stammhaltung}

Für die Stammhaltung wurde der Streptomyces sp. Stamm Pol001 mittels einer Platinimpföse auf M1-Agarplatten ausgestrichen und bis zur Ausbildung einzelner weißer Kolonien für 6 Tage bei $28{ }^{\circ} \mathrm{C}$ inkubiert. Nach der Inkubation wurden die Platten bei $4{ }^{\circ} \mathrm{C}$ aufbewahrt und maximal zwei Monate zum Animpfen von Schüttelkulturen verwendet. Zur Ausbildung einer geschlossenen weißen Sporenschicht wurden M1-Agarplatten mit 0.5-1 mL einer 48 Stunden alten Vorkultur (SM-Medium) beimpft und für 6 Tage bei $28^{\circ} \mathrm{C}$ inkubiert.

\subsubsection{Variationen der Kultivierungsbedingungen}

Variante A: (Ansatz: 1 L, Schüttelkolben) Die Vorkulturen wurden in $300 \mathrm{~mL}$ Erlenmeyerkolben mit Schikane, befüllt mit $100 \mathrm{~mL}$ SM-Medium und mit Schaumstoffkappen verschlossen, kultiviert. Jeder Kolben wurde nach Sterilisation mit einem $1 \mathrm{~cm}^{2}$ großen Stück einer gut bewachsenen Agarplatte beimpft und bei $28^{\circ} \mathrm{C}$ und $180 \mathrm{U} / \mathrm{min}$ für $48 \mathrm{~h}$ inkubiert. Die Fermentation der Hauptkulturen erfolgte in $1 \mathrm{~L}$ Erlenmeyerkolben mit Schikane, befüllt mit $150 \mathrm{~mL}$ SM-Medium und mit Schaumstoffkappen verschlossen. Diese wurden nach Sterilisation mit $5 \mathrm{~mL}$ Vorkultur inokuliert und bei $28^{\circ} \mathrm{C}, 180 \mathrm{U} / \mathrm{min}$ für $96 \mathrm{~h}$ kultiviert.

Variante B: (Ansatz: 1 L, Schüttelkolben) Für die Vorkulturen wurden 300 mL Erlenmeyerkolben mit Schikane mit jeweils 100 mL M2-Medium befüllt und mit Schaumstoffkappen verschlossen. Inkubation erfolgte nach Sterilisation und Animpfen mit einem $1 \mathrm{~cm}^{2}$ großen Stück einer gut bewachsenen Agarplatte bei $28{ }^{\circ} \mathrm{C}$ und $180 \mathrm{U} / \mathrm{min}$ für $48 \mathrm{~h}$. Die Fermentation der Hauptkulturen erfolgte in 1 L Erlenmeyerkolben mit Schikane, befüllt mit $150 \mathrm{~mL}$ M1Medium und mit Schaumstoffkappenverschluss. Diese wurden nach Sterilisation mit $5 \mathrm{~mL}$ Vorkultur inokuliert und bei $28^{\circ} \mathrm{C}, 180 \mathrm{U} / \mathrm{min}$ für $96 \mathrm{~h}$ kultiviert.

Variante C: (Ansatz: 5 L, P-Kolben) Die Vorkulturen wurden in $300 \mathrm{~mL}$ Erlenmeyerkolben mit Schikane, befüllt mit 100 mL Glucose-Medium und mit Schaumstoffkappen verschlossen, kultiviert. Jeder Kolben wurde nach Sterilisation mit einem $1 \mathrm{~cm}^{2}$ großen Stück einer gut bewachsenen Agarplatte beimpft und bei $30{ }^{\circ} \mathrm{C}$ und $225 \mathrm{U} / \mathrm{min}$ für $85 \mathrm{~h}$ inkubiert. Die Kultivierung der Hauptkulturen erfolgte in 5 L P-Kolben, die mit 1 L Dextrin-Medium befüllt 
und mit einer Schaumstoffkappe verschlossen wurden. Die P-Kolben wurden zweimal sterilisiert, mit jeweils $50 \mathrm{~mL}$ Vorkultur inokuliert und für 4 Wochen bei $30{ }^{\circ} \mathrm{C}$ als Ruhekultur kultiviert, wobei nach zwei Wochen die P-Kolben zur Durchmischung des Mediums vorsichtig geschwenkt wurden.

Variante D: (Ansatz: 4 L, Schüttelkolben) Für die Vorkulturen wurden 300 mL Erlenmeyerkolben mit Schikane mit jeweils $100 \mathrm{~mL}$ Glucose-Medium befüllt und mit Schaumstoffkappen verschlossen. Inkubation erfolgte nach Sterilisation und Animpfen mit einem $1 \mathrm{~cm}^{2}$ großen Stück einer gut bewachsenen Agarplatte bei $30{ }^{\circ} \mathrm{C}$ und $200 \mathrm{U} / \mathrm{min}$ für $60 \mathrm{~h}$. Die Fermentation der Hauptkulturen erfolgte in $1 \mathrm{~L}$ Erlenmeyerkolben mit Schikane, befüllt mit $150 \mathrm{~mL}$ Dextrin-Medium und mit Schaumstoffkappenverschluss. Diese wurden nach Sterilisation mit $5 \mathrm{~mL}$ Vorkultur inokuliert und bei $30{ }^{\circ} \mathrm{C}, 200 \mathrm{U} / \mathrm{min}$ für $120 \mathrm{~h}$ kultiviert.

Variante E: (Ansatz: 4 L, Schüttelkolben) Die Vorkulturen wurden in $300 \mathrm{~mL}$ Erlenmeyerkolben mit Schikane, befüllt mit $100 \mathrm{~mL} \mathrm{SM}{ }^{*}$-Medium und mit Schaumstoffkappen verschlossen, kultiviert. Jeder Kolben wurde nach Sterilisation mit einem $1 \mathrm{~cm}^{2}$ großen Stück einer gut bewachsenen Agarplatte beimpft und bei $28^{\circ} \mathrm{C}$ und $180 \mathrm{U} / \mathrm{min}$ für $48 \mathrm{~h}$ inkubiert. Die Fermentation der Hauptkulturen erfolgte in $1 \mathrm{~L}$ Erlenmeyerkolben mit Schikane, befüllt

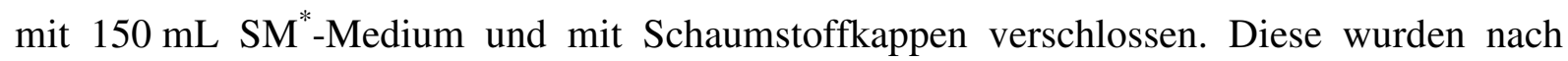
Sterilisation mit $5 \mathrm{~mL}$ Vorkultur inokuliert und bei $28^{\circ} \mathrm{C}, 180 \mathrm{U} / \mathrm{min}$ für $96 \mathrm{~h}$ kultiviert.

Variante F: (Ansatz: 37 Agarplatten, Festphasenkultivierung) Für die Vorkulturen wurden $250 \mathrm{~mL}$ Erlenmeyerkolben mit Schikane mit jeweils $50 \mathrm{~mL} \mathrm{SM}{ }^{*}$-Medium befüllt und mit Schaumstoffkappen verschlossen. Inkubation erfolgte nach Sterilisation und Animpfen mit einer einzelnen Kolonie einer Agarplatte bei $28^{\circ} \mathrm{C}$ und $180 \mathrm{U} / \mathrm{min}$ für $48 \mathrm{~h}$. Die Festphasenkultivierung erfolgte auf $\mathrm{SM}^{*}$-Agarplatten bei $28{ }^{\circ} \mathrm{C}$ für $6 \mathrm{~d}$, welche mit jeweils $500 \mu \mathrm{L}$ Vorkultur beimpft wurden.

\subsubsection{Fütterung potentieller Vorläufer und anderer Zusätze}

Folgende Substanzen wurden als Vorläufer in den verschiedenen Fermentationen verwendet: L-Tyrosin, L-Phenylalanin, Natriumacetat, Glycerin, 4-Hydroxy-L-phenylglycin (L-Hpg), D-Hydroxy-4-phenylglycin (D-Hpg), Malonsäure. Die Substanzen wurden alle in gelöster Form zugefüttert, wobei alle Lösungen auf einen $\mathrm{pH}-\mathrm{Wert}$ von etwa $\mathrm{pH}=6.0-7.0$ eingestellt wurden. Die angegebenen Konzentrationen sind die Endkonzentrationen, die nach Zufütterung im Kolben oder Fermenter erreicht werden. Als weitere Zusätze wurden 
Vitaminlösung, DMSO, XAD-2, sowie Kulturbrühe des Bakteriums S. aureus als auch das Sterilfiltrat dieser Kulturbrühe eingesetzt. Die Fütterungslösungen wurden wie folgt hergestellt:

\section{L-Tyrosin:}

L-Tyrosin $(3 \mathrm{mM}, 81.5 \mathrm{mg} / 150 \mathrm{~mL})$ wurde als $1 \%$ ige Lösung in steril filtriertem DMSO (bezogen auf das Volumen des Nährmediums) suspendiert. Auf eine Korrektur des pH-Wertes zu 6.0-7.0 wurde aufgrund der schlechten Löslichkeit verzichtet.

\section{L-Phenylalanin:}

L-Phenylalanin (3 mM, $70.8 \mathrm{mg} / 150 \mathrm{~mL})$ wurde in $\sim 1 \mathrm{~mL} 2 \mathrm{~N} \mathrm{NaOH}$ gelöst, mit bidest. Wasser $(10 \mathrm{~mL})$ verdünnt und unter vorsichtigem Schwenken der Lösung tropfenweise mit $1 \mathrm{~N} \mathrm{HCl}$ auf pH 7.0 korrigiert. Anschließend wurde die Lösung steril filtriert und mit bidest. Wasser (steril) auf das benötigte Volumen aufgefüllt, so dass $2 \times 1.5 \mathrm{~mL}$ Fütterungslösung pro Schüttelkolben (150 mL Nährmedium) bis zur Endkonzentration zugefüttert werden konnten.

\section{Natriumacetat:}

Natriumacetat $(5 \mathrm{mM}, 58.6 \mathrm{mg} / 150 \mathrm{~mL})$ wurde in bidest. Wasser gelöst und mit $1 \mathrm{~N} \mathrm{HCl}$ ein pH-Wert von 7.0 eingestellt. Die Lösung wurde steril filtriert und mit bidest. Wasser (steril) auf das benötigte Volumen aufgefüllt, so dass $2 \times 1.0 \mathrm{~mL}$ Fütterungslösung pro Schüttelkolben (150 mL Nährmedium) bis zur Endkonzentration zugefüttert werden konnten.

\section{Glycerin:}

Glycerin $(5 \mathrm{mM}, 65.8 \mathrm{mg} / 150 \mathrm{~mL})$ wurde in bidest. Wasser gelöst, die Lösung steril filtriert und mit bidest. Wasser (steril) auf das benötigte Volumen aufgefüllt, so dass $2 \times 1.0 \mathrm{~mL}$ Fütterungslösung pro Schüttelkolben $(150 \mathrm{~mL}$ Nährmedium) bis zur Endkonzentration zugefüttert werden konnten. Des Weiteren wurde eine 86 \%ige Lösung hergestellt (Vol-\%), autoklaviert und $2 \times 0.6 \mathrm{~mL}$ Fütterungslösung pro Schüttelkolben (150 mL Nährmedium) bis zu einer Endkonzentration von $5 \mathrm{~g} / \mathrm{L}$ (bezogen auf Nährmedium) zugefüttert.

\section{4-Hydroxy-L-phenylglycin (L-Hpg):}

4-Hydroxy-L-phenylglycin $(5 \mathrm{mM}, 125.4 \mathrm{mg} / 150 \mathrm{~mL})$ wurde in 1-2 mL $2 \mathrm{~N} \mathrm{HCl}$ gelöst, mit bidest. Wasser $(20 \mathrm{~mL})$ verdünnt und unter vorsichtigem Schwenken der Lösung tropfenweise zunächst mit $2 \mathrm{~N} \mathrm{NaOH}$ ein $\mathrm{pH}-$ Wert von $\sim 3.0$ eingestellt, welcher dann mit $1 \mathrm{~N} \mathrm{NaOH}$ und 
$0.5 \mathrm{~N} \mathrm{NaOH}$ auf $\mathrm{pH}=6.0$ korrigiert wurde. Anschließend wurde die Lösung steril filtriert und mit bidest. Wasser (steril) auf das benötigte Volumen aufgefüllt, so dass $2 \times 2.28 \mathrm{~mL}$ Fütterungslösung pro Schüttelkolben $(150 \mathrm{~mL}$ Nährmedium) bis zur Endkonzentration zugefüttert werden konnten.

\section{4-Hydroxy-D-phenylglycin (D-Hpg):}

4-Hydroxy-D-phenylglycin ( $5 \mathrm{mM}, 125.4 \mathrm{mg} / 150 \mathrm{~mL})$ wurde in 1-2 mL $2 \mathrm{~N} \mathrm{HCl}$ gelöst, mit bidest. Wasser $(20 \mathrm{~mL})$ verdünnt und unter vorsichtigem Schwenken der Lösung tropfenweise zunächst mit $2 \mathrm{~N} \mathrm{NaOH}$ ein $\mathrm{pH}$ von $\sim 3.0$ eingestellt, welcher dann mit $1 \mathrm{~N} \mathrm{NaOH}$ und $0.5 \mathrm{~N}$ $\mathrm{NaOH}$ auf $\mathrm{pH}=6.0$ korrigiert wurde. Anschließend wurde die Lösung steril filtriert und mit bidest. Wasser (steril) auf das benötigte Volumen aufgefüllt, so dass je nach Fermentationsansatz zwischen $2 \times 1.76 \mathrm{~mL}-2 \times 2.28 \mathrm{~mL}$ Fütterungslösung pro Schüttelkolben (150 mL Nährmedium) bis zur Endkonzentration zugefüttert werden konnten.

\section{Malonsäure:}

Malonsäure $(5 \mathrm{mM}, 78.0 \mathrm{mg} / 150 \mathrm{~mL})$ wurde in wenig bidest. Wasser gelöst und mit $2 \mathrm{~N}$ $\mathrm{NaOH}$ auf einen $\mathrm{pH}-$ Wert von 7.0 korrigiert, steril filtriert und mit bidest. Wasser (steril) auf das benötigte Volumen aufgefüllt, so dass $2 \times \sim 1.0 \mathrm{~mL}$ Fütterungslösung pro Schüttelkolben (150 mL Nährmedium) bis zur Endkonzentration zugefüttert werden konnten.

\section{Vitaminlösung:}

Das benötigte Volumen an Vitaminlösung $(1 \mathrm{~mL} / \mathrm{L}$, d. h. $150 \mu \mathrm{L}$ pro Schüttelkolben) wurde einer Stammlösung entnommen und steril filtriert, bevor die Zugabe zur Fermentation nach der 24. Stunde erfolgte.

\section{DMSO:}

1 Vol-\% steril filtriertes DMSO (bezogen auf das Volumen an Nährmedium) wurden in zwei Portionen $(2 \times 0.75 \mathrm{~mL})$ zu jedem Schüttelkolben gegeben.

\section{Amberlite $^{\circledR}$ XAD-2:}

Es wurden $30 \mathrm{~g}$ Amberlite ${ }^{\circledR}$ XAD-2 in bidest. Wasser $(40 \mathrm{~mL})$ in einem $300 \mathrm{~mL}$ Erlenmeyerkolben über Nacht aufgeschlämmt und autoklaviert. Nach $24 \mathrm{~h}$ wurde jedem Kolben des entsprechenden Fermentationsansatzes $\sim 1.5 \mathrm{~g}$ (entspricht etwa 1 Teelöffel) zugefügt. 


\section{Bakterium S. aureus:}

Kultivierung: Die Kultivierung von S. aureus erfolgte in zwei $1 \mathrm{~L}$ Erlenmeyerkolben ohne Schikane, die mit $100 \mathrm{~mL}$ Medium KM1 befüllt und mit einer Schaumstoffkappe verschlossen wurden. Nach Sterilisation wurde mit je $500 \mu \mathrm{L}$ einer Glycerineinlagerung des Stammes beimpft und anschließend bei $37^{\circ} \mathrm{C}, 180 \mathrm{U} / \mathrm{min}$ für $15 \mathrm{~h}$ inkubiert.

Fütterung: Es wurden $5 \mathrm{~mL}$ Kulturbrühe von $S$. aureus in vivo zu $150 \mathrm{~mL}$ Kulturbrühe des Streptomyces Pol001 24 h nach Kultivierungsbeginn hinzugefügt. Zu einem zweiten Fermentationsansatz von Pol001 wurden $5 \mathrm{~mL}$ steril filtriertes Kulturfiltrat pro Schüttelkolben nach der 24. Stunde zugegeben.

\section{Kultivierungen mit Zufütterung potentieller Vorläufer und anderer Zusätze}

Variante G: (Ansatz: $2 \times 1 \mathrm{~L}$, Schüttelkolben) Die Vorkulturen wurden in $300 \mathrm{~mL}$ Erlenmeyerkolben mit Schikane, mit $100 \mathrm{~mL}$ SM-Medium befüllt und mit Schaumstoffkappen verschlossen, kultiviert. Jeder Kolben wurde nach Sterilisation mit einem $1 \mathrm{~cm}^{2}$ großen Stück einer gut bewachsenen Agarplatte beimpft und bei $28^{\circ} \mathrm{C}$ und $180 \mathrm{U} / \mathrm{min}$ für $48 \mathrm{~h}$ inkubiert. Die Fermentation der Hauptkulturen erfolgte in zweimal sieben $1 \mathrm{~L}$ Erlenmeyerkolben mit Schikane, befüllt mit $150 \mathrm{~mL}$ SM-Medium und mit Schaumstoffkappenverschluss. Nach Sterilisation wurden diese mit je $5 \mathrm{~mL}$ der Vorkultur inokuliert. $24 \mathrm{~h}$ nach Kultivierungsbeginn wurde zu sieben Kolben je $5 \mathrm{~mL}$ Kulturbrühe des Bakteriums S. aureus hinzugefügt; $\mathrm{zu}$ den sieben anderen Kolben je $5 \mathrm{~mL}$ steril filtriertes Kulturfiltrat des Bakteriums S. aureus. Die Kultivierung erfolgte bei $28^{\circ} \mathrm{C}$ und $180 \mathrm{U} / \mathrm{min}$ für $96 \mathrm{~h}$.

Variante H: (Ansatz: $4 \times 1$ L, Schüttelkolben) Für die Vorkultur der Vorkultur wurden $250 \mathrm{~mL}$ Erlenmeyerkolben mit Schikane mit 50 mL SM${ }^{*}$-Medium befüllt und mit Schaumstoffkappen verschlossen. Inkubation erfolgte nach Sterilisation und Animpfen mit je einer einzelnen Kolonie einer Agarplatte bei $28{ }^{\circ} \mathrm{C}$ und $180 \mathrm{U} / \mathrm{min}$ für $48 \mathrm{~h}$. Die Vorkulturen wurden in $300 \mathrm{~mL}$ Erlenmeyerkolben mit Schikane, befüllt mit $100 \mathrm{~mL} \mathrm{SM}$-Medium und mit Schaumstoffkappen verschlossen, kultiviert. Jeder Kolben wurde nach Sterilisation mit $5 \mathrm{~mL}$ Vorkultur der Vorkultur beimpft und bei $28^{\circ} \mathrm{C}$ und $180 \mathrm{U} / \mathrm{min}$ für $48 \mathrm{~h}$ inkubiert. Die Fermentation der Hauptkulturen erfolgte in $1 \mathrm{~L}$ Erlenmeyerkolben mit Schikane, die mit Schaumstoffkappen verschlossen wurden. Jeder Kolben wurde mit $150 \mathrm{~mL} \mathrm{SM}{ }^{*}$-Medium befüllt und nach Sterilisation mit $5 \mathrm{~mL}$ Vorkultur inokuliert. Direkt im Anschluss erfolgte die Zugabe von $150 \mu \mathrm{L}$ steril filtrierter Vitaminlösung pro Schüttelkolben. Nach der 24. und der 
32. Stunde der Kultivierung wurde dem jeweiligen Fermentationsansatz folgende Kombination von Substanzen steril zugefüttert: L-Tyrosin ( $3 \mathrm{mM}$; als 1 \%ige Suspension in DMSO) und DMSO (1 Vol-\%); L-Tyrosin (3 mM, $81.5 \mathrm{mg} / 150 \mathrm{~mL}$; als 1 \%ige Suspension in DMSO), L-Phenylalanin ( $3 \mathrm{mM}, 70.8 \mathrm{mg} / 150 \mathrm{~mL})$ und Amberlite ${ }^{\circledR}$ XAD-2 (1.5 g pro Kolben); Natriumacetat ( $5 \mathrm{mM}, 58.6 \mathrm{mg} / 150 \mathrm{~mL})$, Glycerin $(5 \mathrm{mM}, 65.8 \mathrm{mg} / 150 \mathrm{~mL})$ und Amberlite $^{\circledR}$ XAD-2 (1.5 g pro Kolben); Glycerin (86\%ig) und DMSO (1 Vol-\%) (siehe Tabelle 12). Die Kultivierung erfolgte bei $28^{\circ} \mathrm{C}, 180 \mathrm{U} / \mathrm{min}$ für $96 \mathrm{~h}$.

Tabelle 12. Überblick der zugefütterten potentiellen Vorläufer und Zusätze von Variante H.

\begin{tabular}{ccccc}
\hline & $\begin{array}{c}\text { Variante } \\
\text { HA }\end{array}$ & $\begin{array}{c}\text { Variante } \\
\text { HB }\end{array}$ & $\begin{array}{c}\text { Variante } \\
\text { HC }\end{array}$ & $\begin{array}{c}\text { Variante } \\
\text { HD }\end{array}$ \\
\hline L-Tyrosin & $\begin{array}{c}3 \mathrm{mM} \\
(1 \% \text { ig in } \\
\text { DMSO })\end{array}$ & $\begin{array}{c}3 \mathrm{mM} \\
(1 \% \text { ig in } \\
\text { DMSO })\end{array}$ & & \\
L-Phenylalanin & & $3 \mathrm{mM}$ & & \\
Natriumacetat & & & $5 \mathrm{mM}$ & \\
Glycerin & & & $5 \mathrm{mM}$ & $5 \mathrm{~g} / \mathrm{L}$ \\
XAD-2 & & $\sim 1.5 \mathrm{~g}$ & $\sim 1.5 \mathrm{~g}$ & \\
DMSO & $1 \mathrm{Vol}-\%$ & & & $1 \mathrm{Vol}-\%$ \\
Vitaminlösung & $1 \mathrm{~mL} / \mathrm{L}$ & $1 \mathrm{~mL} / \mathrm{L}$ & $1 \mathrm{~mL} / \mathrm{L}$ & $1 \mathrm{~mL} / \mathrm{L}$ \\
\hline
\end{tabular}

Variante I: (Ansatz: $3 \times 1 \mathrm{~L}$, Schüttelkolben) Für die Vorkultur der Vorkultur wurden $250 \mathrm{~mL}$ Erlenmeyerkolben mit Schikane mit $50 \mathrm{~mL} \mathrm{SM}{ }^{*}$-Medium befüllt und mit Schaumstoffkappen verschlossen. Inkubation erfolgte nach Sterilisation und Animpfen mit je einer einzelnen Kolonie einer Agarplatte bei $28{ }^{\circ} \mathrm{C}$ und $180 \mathrm{U} / \mathrm{min}$ für $48 \mathrm{~h}$. Die Vorkulturen wurden in $300 \mathrm{~mL}$ Erlenmeyerkolben mit Schikane, befüllt mit $100 \mathrm{~mL} \mathrm{SM}^{*}$-Medium und mit Schaumstoffkappen verschlossen, kultiviert. Jeder Kolben wurde nach Sterilisation mit $5 \mathrm{~mL}$ Vorkultur der Vorkultur beimpft und bei $28^{\circ} \mathrm{C}$ und $180 \mathrm{U} / \mathrm{min}$ für $48 \mathrm{~h}$ inkubiert. Die Fermentation der Hauptkulturen erfolgte in $1 \mathrm{~L}$ Erlenmeyerkolben mit Schikane, die mit Schaumstoffkappen verschlossen wurden. Jeder Kolben wurde mit $150 \mathrm{~mL} \mathrm{SM}$-Medium befüllt und nach Sterilisation mit $5 \mathrm{~mL}$ Vorkultur inokuliert. Nach der 24. und der 32. Stunde der Kultivierung wurden dem jeweiligen Fermentationsansatz die potentiellen Vorläufer steril zugefüttert: L-Hpg (5 mM, $125.4 \mathrm{mg} / 150 \mathrm{~mL})$; L-Hpg (5 mM, $125.4 \mathrm{mg} / 150 \mathrm{~mL})$ und Malonsäure (5 mM, $78.0 \mathrm{mg} / 150 \mathrm{~mL})$; D-Hpg $(5 \mathrm{mM}, 125.4 \mathrm{mg} / 150 \mathrm{~mL})$ und Malonsäure $(5 \mathrm{mM}$, $78.0 \mathrm{mg} / 150 \mathrm{~mL}$ ) (siehe Tabelle 13). Ebenfalls nach der 24. Stunde nach Kultivierungsbeginn 
wurde zu jedem Schüttelkolben $150 \mu \mathrm{L}$ steril filtrierte Vitaminlösung gegeben. Die Kultivierung erfolgte bei $28^{\circ} \mathrm{C}, 180 \mathrm{U} / \mathrm{min}$ für $96 \mathrm{~h}$.

Variante J: (Ansatz: 3 L, Fermenter Biostat B): Für die Kultivierung im Biostat-B-Fermenter im $5 \mathrm{~L}$ Fermentergefäß wurde dieses mit $4.7 \mathrm{~L} \mathrm{SM}^{*}$-Medium befüllt und autoklaviert. Es wurde mit $300 \mathrm{~mL}$ Vorkultur (= 6 Vol-\% des gesamten Fermentervolumens, Kultivierung wie bei Variante I) inokuliert. Nach sieben Stunden wurde $1 \mathrm{~L}$ der Kulturbrühe aufgrund starker Schaumentwicklung abgepumpt. Ab der 24. Stunde wurden die potentiellen Vorläufer D-Hpg (5 mM, $125.4 \mathrm{mg} / 150 \mathrm{~mL})$ und Malonsäure ( $5 \mathrm{mM}, 78.0 \mathrm{mg} / 150 \mathrm{~mL})$ mittels einer Schlauchpumpe über einen Zeitraum von $10 \mathrm{~h}$ kontinuierlich zugefüttert. Nach der 24. Stunde wurden auch $5 \mathrm{~mL}$ steril filtrierte Vitaminlösung zur Kulturbrühe hinzugefügt. Die Kultivierung erfolgte bei $28^{\circ} \mathrm{C}, 400 \mathrm{U} / \mathrm{min}$ und einer Belüftung von $1.0 \mathrm{vvm}$ für $96 \mathrm{~h}$. Dabei wurde der $\mathrm{pH}$-Verlauf durch eine $\mathrm{pH}-\mathrm{Sperre}(\mathrm{pH}=6.5 \pm 1.5)$ reguliert und der Verbrauch an $\mathrm{O}_{2}$ kontrolliert.

Variante K: (Ansatz: 4 L, Schüttelkolben): Kultivierung wie bei Variante I, Zufütterung der potentiellen Vorläufer D-Hpg $(5 \mathrm{mM}, 125.4 \mathrm{mg} / 150 \mathrm{~mL})$ und Malonsäure $(5 \mathrm{mM}$, $78.0 \mathrm{mg} / 150 \mathrm{~mL})$.

Variante L: (Ansatz 4 L, Schüttelkolben): Kultivierung wie bei Variante I, aber nur Zufütterung des potentiellen Vorläufers Malonsäure $(5 \mathrm{mM}, 78.0 \mathrm{mg} / 150 \mathrm{~mL})$.

Variante M-O: (Ansatz: je Variante $2 \times 450 \mathrm{~mL}$, Schüttelkolben): Kultivierung wie bei Variante I, aber Verwendung verschiedener Nährmedien: SM-, SD-, SG-Medium und Medium S, Zufütterung des potentiellen Vorläufers Malonsäure $(5 \mathrm{mM}, 78.0 \mathrm{mg} / 150 \mathrm{~mL}) \mathrm{zu}$ jedem weiteren Ansatz von $450 \mathrm{~mL}$.

Variante P: (Ansatz: $2 \times 450 \mathrm{~mL}$, Schüttelkolben): Kultivierung des Stammes Streptomyces sp. JP90 wie bei Variante I, bei einem Ansatz von $450 \mathrm{~mL}$ Zufütterung von Malonsäure (5 mM, $78.0 \mathrm{mg} / 150 \mathrm{~mL})$. 
Tabelle 13. Überblick der zugefütterten potentiellen Vorläufer und Zusätze von Variante I-O.

\begin{tabular}{ccccc}
\hline & $\begin{array}{c}\text { Variante } \\
\text { IA }\end{array}$ & $\begin{array}{c}\text { Variante } \\
\text { IB }\end{array}$ & $\begin{array}{c}\text { Variante } \\
\text { IC, J, K }\end{array}$ & $\begin{array}{c}\text { Variante } \\
\text { L, M-O }\end{array}$ \\
\hline L-Hpg & $5 \mathrm{mM}$ & $5 \mathrm{mM}$ & & \\
D-Hpg & & & $5 \mathrm{mM}$ & \\
Malonsäure & & $5 \mathrm{mM}$ & $5 \mathrm{mM}$ & $5 \mathrm{mM}$ \\
Vitaminlösung & $1 \mathrm{~mL} / \mathrm{L}$ & $1 \mathrm{~mL} / \mathrm{L}$ & $1 \mathrm{~mL} / \mathrm{L}$ & $1 \mathrm{~mL} / \mathrm{L}$ \\
\hline
\end{tabular}

\subsubsection{Aufarbeitung}

Für die Aufarbeitung der Fermentationen wurde die Kulturbrühe mit $1 \mathrm{~N}$ bzw. $2 \mathrm{~N} \mathrm{HCl}$ auf einen $\mathrm{pH}-$ Wert von $\mathrm{pH}=5.0$ eingestellt. Anschließend wurde die Kulturbrühe mit Celite (ca. 3 gehäufte Esslöffel auf $1 \mathrm{~L}$ Kulturbrühe) versetzt, zentrifugiert (4500 U/min, $15 \mathrm{~min}, 15{ }^{\circ} \mathrm{C}$ ) und der Rückstand (Mycel, Celite) durch Filtration abgetrennt. Bei den Fermentationen der Varianten K-P wurde das Kulturfiltrat verworfen.

Variante I: Der Rückstand wurde mit Methanol (300 mL für einen $1 \mathrm{~L}-$ Ansatz) versetzt und für 15 min im Ultraschallbad aufgeschlossen, filtriert und das Lösungsmittel i. Vak. entfernt. Der Arbeitsschritt wurde mit Aceton/Methanol 1:1 als Extraktionslösungsmittel wiederholt. Das Kulturfiltrat wurde an Amberlite ${ }^{\circledR}$ XAD-2 adsorbiert, mit demin. Wasser (1:1 zur Kulturbrühe) gewaschen und mit Methanol (500 mL/1 L Kulturbrühe) eluiert. Das Lösungsmittel wurde i. Vak. entfernt und der Rückstand lyophilisiert. Nach Extraktion mit Amberlite ${ }^{\circledR}$ XAD-2 wurden $100 \mathrm{~mL}$-Proben des Kulturfiltrats zweimal mit Ethylacetat (Volumina Ethylacetat:Kulturfiltrat 1:1) extrahiert und das Lösungsmittel i. Vak. entfernt.

Variante II: Der Rückstand wurde zweimal mit Methanol (300 mL für einen 1 L-Ansatz) versetzt und für jeweils 15 min im Ultraschallbad aufgeschlossen, filtriert und das Lösungsmittel i. Vak. entfernt. Die Aufarbeitung des Kulturfiltrats erfolgte analog zu Variante I.

Variante III: Der Rückstand wurde zweimal mit Methanol/Wasser 9:1 (300 mL für einen 1 L-Ansatz) versetzt und für jeweils $15 \mathrm{~min}$ im Ultraschallbad aufgeschlossen, filtriert und das Lösungsmittel i. Vak. entfernt. Das Kulturfiltrat wurde zweimal mit Ethylacetat (Volumina Ethylacetat:Kulturfiltrat 1:1) extrahiert und das Lösungsmittel i. Vak. entfernt. 
Variante IV: Für die Aufarbeitung der Festphasenkultivierung wurden die SM*-Agarplatten

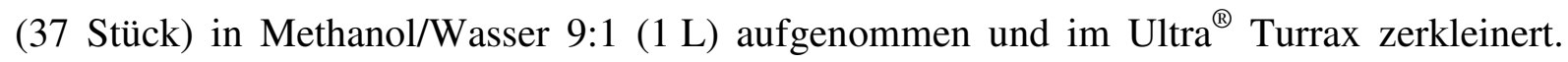
Anschließend wurden die in Methanol/Wasser 9:1 zerkleinerten Agarplatten für $30 \mathrm{~min}$ im Ultraschallbad aufgeschlossen und filtriert. Der Rückstand wurde erneut mit Methanol/Wasser 9:1 (1 L) versetzt, für $30 \mathrm{~min}$ im Ultraschallbad aufgeschlossen und filtriert. Die Methanol/Wasser-Phasen wurden vereinigt, das Lösungsmittel i. Vak. entfernt und der Rückstand lyophilisiert.

Variante V: Der Rückstand wurde zweimal mit Methanol/Wasser 9:1 (300 mL für einen 1 LAnsatz) versetzt und für jeweils $15 \mathrm{~min}$ im Ultraschallbad aufgeschlossen, filtriert und das Lösungsmittel i. Vak. entfernt. Das aus dem Mycel erhaltene Rohextrakt wurde in Wasser ( 100 mL für Rohextrakt aus 1 L-Ansatz) gelöst und mittels einer Mitteldruckpumpe auf eine MCI-Gel-Säule aufgebracht. Es wurde mit Wasser (für Mycel aus 1 L-Ansatz: $500 \mathrm{~mL}$ ) gewaschen und anschließend mit Methanol/Wasser 2:8, Methanol/Wasser 4:6, Methanol/Wasser 5:5, Methanol/Wasser 6:4, Methanol/Wasser 8:2 (jeweils $2 \times 100 \mathrm{~mL}$ ) und Methanol (300 mL) eluiert. Das Lösungsmittel wurde i. Vak. entfernt und der Rückstand lyophilisiert. Das Kulturfiltrat wurde lyophilisiert und das erhaltene Lyophilisat mit Methanol/Wasser 9:1 extrahiert, filtriert und das Lösungsmittel i. Vak. entfernt.

Variante VI: Der Rückstand wurde zweimal mit Methanol/Wasser 9:1 (300 mL für einen $1 \mathrm{~L}$-Ansatz) versetzt und für jeweils $15 \mathrm{~min}$ im Ultraschallbad aufgeschlossen, filtriert und das Lösungsmittel i.Vak. entfernt. Das aus dem Mycel erhaltene Rohextrakt wurde in Wasser ( $100 \mathrm{~mL}$ für Rohextrakt aus $1 \mathrm{~L}-$ Ansatz) gelöst und mittels einer Mitteldruckpumpe auf eine MCI-Gel-Säule aufgebracht. Es wurde mit Wasser $(2 \times 300 \mathrm{~mL})$ gewaschen und anschließend mit Methanol/Wasser 1:2, Methanol/Wasser 1:1, Methanol/Wasser 2:1, (jeweils $2 \times 100 \mathrm{~mL}$ beim 1 L-Ansatz) und Methanol (300 mL) eluiert. Das Lösungsmittel wurde i. Vak. entfernt und der Rückstand lyophilisiert. Das Kulturfiltrat wurde verworfen.

\subsection{Dünnschichtchromatographische Analytik}

Zur Überprüfung der aus Mycel und Kulturfiltrat erhaltenen Rohextrakte auf die Produktion des mit Anisaldehyd pink anfärbbaren Metaboliten wurde eine Dünnschichtchromatographie an Kieselgel durchgeführt. Hierzu wurden ca. $10 \mu \mathrm{L}$ der jeweiligen Rohextrakte mit einer Konzentration von $c=20 \mathrm{mg} / \mathrm{mL}$ in Methanol/Wasser 2:1 auf Kieselgel-DC-Alufolien aufgetragen, in $\mathrm{CHCl}_{3} / \mathrm{MeOH} / 20 \%$ ig $\mathrm{NH}_{3}$ 1:2:1 entwickelt und mit Anisaldehyd angefärbt. Die nach Fraktionierung des Mycel-Rohextraktes an MCI-Gel erhaltenen Fraktionen wurden in 
jeweils $10 \mathrm{~mL}$ Methanol/Wasser 1:1 aufgenommen und ebenfalls dünnschichtchromatographisch analysiert. Für die Isolierung des mit Anisaldehyd pink anfärbbaren Metaboliten erwies sich die Aufarbeitung nach Variante $\mathbf{V}$ als beste Strategie, da diese eine vollständige Abtrennung der mit Anisaldehyd braun anfärbbaren Tetromycine erlaubte.

\subsection{HPLC-ESI-MS-Analytik}

Für die HPLC-ESI-MS-Analytik wurden je $2 \mathrm{~mL}$ der gelösten Rohextrakte sowie der nach MCI-Gel erhaltenen Fraktionen entnommen, das Lösungsmittel bis zur Trockne entfernt und jeweils eine Konzentration von $c=5 \mathrm{mg} / \mathrm{mL}$ in Methanol/Wasser 2:1 eingestellt. Die nach Säulenchromatographie an Kieselgel erhaltenen Fraktionen sowie die mit Anisaldehyd pink anfärbbare Substanz wurden mit einer Konzentration zwischen $c=3-5 \mathrm{mg} / \mathrm{mL}$ in Methanol/Wasser 2:1 gelöst, als Standard wurde Vancomycinhydrochlorid mit einer Konzentration von $c=1 \mathrm{mg} / \mathrm{mL}$ in Methanol/Wasser 2:1 eingesetzt. Die erstellten Proben wurden zentrifugiert, je $120 \mu \mathrm{L}$ entnommen, in Inlets mit einem Fassungsvolumen von $200 \mu \mathrm{L}$ überführt und per HPLC-ESI-MS im positiven und negativen Modus gemessen. Hierbei erfolgten die Messungen zunächst mit dem Standardprogramm 1 für HPLC-ESI-MS-Analytik (HPLC D, Säule A: Grom Superspher 100, RP-18, Programm B: $\mathrm{MeOH} / \mathrm{H}_{2} \mathrm{O}$, jeweils mit $0.05 \%$ Ameisensäure, Gradient, s. 1.2 ) und wurden nach Optimierung mit dem Standardprogramm 2 (HPLC D, Säule B: Phenomenex Synergi Hydro RP, Programm C: $\mathrm{MeOH} / \mathrm{H}_{2} \mathrm{O}$, jeweils mit $0.05 \%$ Ameisensäure, Gradient, s. 1.2 ) durchgeführt.

\subsection{Isolierung des Metaboliten (166)}

Nach Fraktionierung des Mycel-Rohextraktes an MCI-Gel gemäß Aufarbeitung Variante V wurden die einzelnen Fraktionen dünnschichtchromatographisch an Kieselgel $\left(\mathrm{CHCl}_{3} / \mathrm{MeOH} / 20 \%\right.$ ig NH $\mathrm{NH}_{3}$ 1:2:1) untersucht. Der mit Anisaldehyd pink anfärbbare Metabolit wurde im Vorlauf, welcher beim Waschen der Säule mit Wasser erhalten wurde, detektiert. Diese Fraktion wurde zunächst durch Gelchromatographie an Sephadex LH-20 (Methanol/Wasser 2:1) und nachfolgende Mitteldrucksäulenchromatographie an reversedphase Kieselgel (Lobar ${ }^{\circledR}$ Größe C, $\mathrm{MeOH} / \mathrm{H}_{2} \mathrm{O}$ 1:9) weiter gereinigt. Anschließende Säulenchromatographie an Kieselgel $\left(\mathrm{CHCl}_{3} / \mathrm{MeOH} / 20 \%\right.$ ig $\left.\mathrm{NH}_{3} \quad 1: 2: 1\right)$ ergab $17.2 \mathrm{mg} / \mathrm{L}$ der Substanz (166) als farblosen Feststoff. 


\subsection{Charakterisierung des Metaboliten (166)}

Elementaranalyse (\%): $\mathrm{C}=15.57 ; \mathrm{H}=5.74 ; \mathrm{N}=14.15 ; \mathrm{S}=6.73$.

IR $(\mathrm{KBr}): \widetilde{v}\left(\mathrm{~cm}^{-1}\right)=3197,1685,1617,1404,1164,1113,670,615,577$.

${ }^{1}$ H-NMR (600 MHz, DMSO-d 6 ): $\delta=3.14(\mathrm{~s}), 3.31(\mathrm{dd}, J=6.0,11.0 \mathrm{~Hz}), 3.39(\mathrm{dd}, J=5.0$, $11.2 \mathrm{~Hz}$ ), 3.49 (tt oder dt, $J=5.0,6.0,11.0,11.2 \mathrm{~Hz}$ ) ppm.

${ }^{13}$ C-NMR (125 MHz, DMSO-d $\left.{ }_{6}\right): \delta=49.3,63.5,72.9,175.1 \mathrm{ppm}$.

\subsection{Versuche zur enzymatischen und chemischen Derivatisierung}

\subsubsection{Enzymatische Untersuchungen mit einer Sulfatase}

$22.6 \mathrm{mg}$ der Substanz (166) wurden in $0.2 \mathrm{M}$ Natriumacetat-Puffer $(2.30 \mathrm{~mL}$; $\mathrm{pH}=5.0)$ gelöst und als Enzym Arylsulfatase aus Patella vulgata, Typ V (11.0 mg, 40.7 Units; Fa. Sigma) zugegeben. Das Reaktionsgemisch wurde bei $37^{\circ} \mathrm{C}$ für $48 \mathrm{~h}$ inkubiert. Anschließend wurde das Reaktionsgemisch lyophilisiert, der Rückstand in Methanol/Wasser 2:1 gelöst und dünnschichtchromatographisch an Kieselgel $\left(\mathrm{CHCl}_{3} / \mathrm{MeOH} / 20 \% \mathrm{ig} \mathrm{NH}_{3}\right.$ 1:2:1) analysiert. Nach säulenchromatographischer Reinigung an Kieselgel $\left(\mathrm{CHCl}_{3} / \mathrm{MeOH} / 20 \%\right.$ ig $\mathrm{NH}_{3}$ 1:2:1) wurden 10.4 mg der Substanz (166) reisoliert.

\subsubsection{Methanolische Hydrolyse}

\section{Substanz (164):}

$3.0 \mathrm{mg}$ der Substanz (166) wurden in methanolischer Salzsäure $(1 \mathrm{~mL})$ suspendiert und $5 \mathrm{~min}$ im Ultraschallbad behandelt. Nach erfolgter Zugabe von Methanol/Wasser 2:1 (400 $\mu \mathrm{L})$ wurde das Reaktionsgemisch für weitere $10 \mathrm{~min}$ im Ultraschallbad behandelt und das Lösungsmittel bis zur Trockne i. Vak. entfernt. Der Rückstand wurde in Methanol/Wasser 2:1 aufgenommen und dünnschichtchromatographisch an Kieselgel $\left(\mathrm{CHCl}_{3} / \mathrm{MeOH} / 20 \%\right.$ ig $\mathrm{NH}_{3}$ 1:2:1) untersucht. $120 \mu \mathrm{L}$ wurden der Lösung entnommen, zentrifugiert und mittels HPLCESI-MS (HPLC D, Säule B: Phenomenex Synergi Hydro RP, Programm C: $\mathrm{MeOH} / \mathrm{H}_{2} \mathrm{O}$, jeweils mit $0.05 \%$ Ameisensäure, Gradient, s. 1.2 ) analysiert. 


\section{Substanz (166):}

$4.90 \mathrm{mg}$ der Substanz (166) wurden in Methanol/Wasser 2:1 (653 $\mu \mathrm{L})$ gelöst und nach Zugabe von methanolische Salzsäure $(1.60 \mathrm{~mL}) 15 \mathrm{~min}$ im Ultraschallbad behandelt. Anschließend wurde das Lösungsmittel bis zur Trockne i. Vak. entfernt. Der Rückstand wurde in Methanol/Wasser 2:1 aufgenommen und dünnschichtchromatographisch an Kieselgel $\left(\mathrm{CHCl}_{3} / \mathrm{MeOH} / 20 \%\right.$ ig $\mathrm{NH}_{3}$ 1:2:1, Sprühreagenz ANIS) untersucht. $120 \mu \mathrm{L}$ wurden der Lösung entnommen, zentrifugiert und mittels HPLC-ESI-MS (HPLC D, Säule B: Phenomenex Synergi Hydro RP, Programm C: $\mathrm{MeOH} / \mathrm{H}_{2} \mathrm{O}$, jeweils mit $0.05 \%$ Ameisensäure, Gradient, s. 1.2 ) analysiert.

\section{Vancomycin (1):}

$3.60 \mathrm{mg}$ der Substanz 1 wurden in Methanol/Wasser 2:1 (480 $\mu \mathrm{L})$ gelöst und nach Zugabe von methanolische Salzsäure (1.20 mL) 15 min im Ultraschallbad behandelt. Anschließend wurde das Lösungsmittel bis zur Trockne i. Vak. entfernt. Der Rückstand wurde in Methanol/Wasser 2:1 aufgenommen und dünnschichtchromatographisch an Kieselgel $\left(\mathrm{CHCl}_{3} / \mathrm{MeOH} / 20 \%\right.$ ig NH $\mathrm{NH}_{3}$ 1:2:1) untersucht. $120 \mu \mathrm{L}$ wurden der Lösung entnommen, zentrifugiert und mittels HPLC-ESI-MS (HPLC D, Säule B: Phenomenex Synergi Hydro RP, Programm C: $\mathrm{MeOH} / \mathrm{H}_{2} \mathrm{O}$, jeweils mit $0.05 \%$ Ameisensäure, Gradient, s. 1.2 ) analysiert. 


\section{Charakterisierung von Metaboliten aus dem Pilz Aspergillus nidulans}

\subsection{Charakterisierung der Metaboliten}

Die Kultivierungs- und Isolierungsarbeiten der Metaboliten aus dem Pilzproduzenten Aspergillus nidulans wurden von C. Handrich (AK Müller, Arbeitsmedizin Göttingen) durchgeführt.

\section{Cycloisoemericellinol (156)}

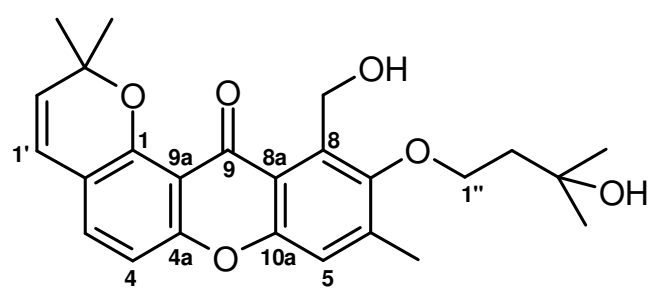

$\mathbf{C}_{25} \mathbf{H}_{28} \mathbf{O}_{6} \quad$ (424.20).

$\mathbf{R}_{\mathbf{f}}$-Wert: $0.60\left(\mathrm{KG}, \mathrm{CHCl}_{3} / \mathrm{MeOH} 91\right) ; 0.31\left(\mathrm{RP}, \mathrm{MeOH} / \mathrm{H}_{2} \mathrm{O} 91\right)$.

Anfärbeverhalten: blau (Anisaldeyd/Schwefelsäure).

MS (EI, 70 eV): m/z (\%) = 424 (25) [M] $]^{+}, 377$ (14), 337 (100), 305 (14), 284 (17), 84 (26), 66 (29), 57 (20), 43 (18).

MS (ESI): $m / z(\%)=425[\mathrm{M}+\mathrm{H}]^{+}, 447[\mathrm{M}+\mathrm{Na}]+, 849[2 \mathrm{M}+\mathrm{H}]^{+}, 871[2 \mathrm{M}+\mathrm{Na}]^{+}$.

HR-ESI-MS: $m / \mathrm{z}(\%)=$ ber.: $m / z=425.1958651[\mathrm{M}+\mathrm{H}]^{+}$

$$
\text { gef.: } m / z=425.1958510[\mathrm{M}+\mathrm{H}]^{+} \text {. }
$$

UV (MeOH): $\lambda_{\max }(\lg \varepsilon)=213 \mathrm{~nm}$ (3.4982), 225 (3.4466), 237 (3.4993), 254 (3.4082), 280 (3.6153), 350 (2.86), 376 (2.9503); $(\mathrm{MeOH}, \mathrm{HCl}): \lambda_{\max }(\lg \varepsilon)=237 \mathrm{~nm}$ (3.3941), 253 (3.3023), 280 (3.5574), 350 (2.4382), 377 (2.6623); (MeOH, NaOH): $\lambda_{\max }(\lg \varepsilon)=201 \mathrm{~nm}$ (2.0837), 202 (2.4663), 213 (3.4635), 223 (3.4056), 257 (3.3754), 280 (3.5845).

IR $(\mathrm{KBr}): \widetilde{v}\left(\mathrm{~cm}^{-1}\right)=3430,2926,1682,1641,1608,1460,1431,1383,1214,1126,1068$, 814.

${ }^{1} \mathbf{H}-\mathbf{N M R}\left(600 \mathrm{MHz}, \mathrm{CDCl}_{3}\right): \delta=1.33$ (s, $\left.6 \mathrm{H}, 4 "-\mathrm{H}_{3}, 5^{\prime \prime}-\mathrm{H}_{3}\right), 1.54$ (s, $\left.6 \mathrm{H}, 4^{\prime}-\mathrm{H}_{3}, 5^{\prime}-\mathrm{H}_{3}\right), 2.07$ (t, $\left.J=6.0 \mathrm{~Hz}, 2 \mathrm{H}, 2^{\prime \prime}-\mathrm{H}_{2}\right), 2.41\left(\mathrm{~s}, 3 \mathrm{H}, 6-\mathrm{CH}_{3}\right), 3.70\left(\mathrm{~s}_{\mathrm{br}}, 1 \mathrm{H}, 8-\mathrm{CH}_{2} \underline{\mathrm{OH}}\right), 4.10$ (t, $J=6.0 \mathrm{~Hz}$, $\left.2 \mathrm{H}, 1 "-\mathrm{H}_{2}\right), 5.01\left(\mathrm{~s}_{\mathrm{br}}, 2 \mathrm{H}, 8-\underline{\mathrm{C}}_{2} \mathrm{OH}\right), 5.61\left(\mathrm{~d}, J=10.0 \mathrm{~Hz}, 1 \mathrm{H}, 2^{\prime}-\mathrm{H}\right), 6.30(\mathrm{~d}, J=10.0 \mathrm{~Hz}$, 
$1 \mathrm{H}, 1$ '-H), $6.84(\mathrm{~d}, J=8.5 \mathrm{~Hz}, 1 \mathrm{H}, 4-\mathrm{H}), 7.18(\mathrm{~s}, 1 \mathrm{H}, 5-\mathrm{H}), 7.23(\mathrm{~d}, J=8.5 \mathrm{~Hz}, 1 \mathrm{H}, 3-\mathrm{H})$ ppm.

${ }^{1} \mathbf{H}-\mathbf{N M R}\left(600 \mathrm{MHz}, \mathrm{DMSO}-\mathrm{d}_{6}\right): \delta=1.18\left(\mathrm{~s}, 6 \mathrm{H}, 4\right.$ "- $\left.\mathrm{H}_{3}, 5^{\prime \prime}-\mathrm{H}_{3}\right), 1.47$ (s, $\left.6 \mathrm{H}, 4^{\prime}-\mathrm{H}_{3}, 5^{\prime}-\mathrm{H}_{3}\right)$, $1.95\left(\mathrm{t}, J=7.2 \mathrm{~Hz}, 2 \mathrm{H}, 2^{\prime}-\mathrm{H}_{2}\right), 2.38$ (s, $\left.3 \mathrm{H}, 6-\mathrm{CH}_{3}\right), 3.94\left(7, J=7.2 \mathrm{~Hz}, 2 \mathrm{H}, 1 "-\mathrm{H}_{2}\right), 4.88$ $\left(\mathrm{s}_{\mathrm{br}}, 2 \mathrm{H}, 8-\mathrm{C}_{2} \mathrm{OH}\right), 5.76\left(\mathrm{~d}, J=10.0 \mathrm{~Hz}, 1 \mathrm{H}, 2^{\prime}-\mathrm{H}\right), 6.46$ (d, J=10.0 Hz, $\left.1 \mathrm{H}, 1^{\prime}-\mathrm{H}\right), 6.97$ (d, $J=8.5 \mathrm{~Hz}, 1 \mathrm{H}, 4-\mathrm{H}), 7.39(\mathrm{~s} \mathrm{br}, 1 \mathrm{H}, 5-\mathrm{H}), 7.46(\mathrm{~d}, J=8.5 \mathrm{~Hz}, 1 \mathrm{H}, 3-\mathrm{H}) \mathrm{ppm}$.

${ }^{13}$ C-NMR (150 MHz, $\left.\mathrm{CDCl}_{3}\right): \delta=17.5\left(6-\mathrm{CH}_{3}\right), 27.9$ (C-4', C-5'), 29.7 (C-4", C-5"), 42.5 (C-2"), $57.0\left(8-{ }_{\mathrm{C}} \mathrm{H}_{2} \mathrm{OH}\right), 70.3(\mathrm{C}-3 "), 72.7$ (C-1"), 77.9 (C-3'), 108.4 (C-4), 112.7 (C-9a), 117.0 (C-2), 119.1 (C-5), 120.7 (C-8a), 121.5 (C-1'), 129.5 (C-2'), 131.9 (C-3), 134.1 (C-8), 140.1 (C-6), 152.4 (C-7), 152.9 (C-10a), 154.3 (C-1), 156.3 (C-4a), 179.1 (C-9) ppm.

${ }^{13}$ C-NMR (150 MHz, DMSO-d 6 ): $\delta=16.7\left(6-\mathrm{CH}_{3}\right), 27.7$ (C-4', C-5'), 29.6 (C-4", C-5"), 42.9 (C-2"), 55.3 (8- $\left.\mathrm{CH}_{2} \mathrm{OH}\right), 67.7$ (C-3"), 71.9 (C-1"), 77.5 (C-3'), 108.1 (C-4), 111.8 (C-9a), 116.4 (C-2), 118.7 (C-5), 119.6 (C-8a), 121.1 (C-1'), 129.2 (C-2'), 132.2 (C-3), 133.8 (C-8), 140.0 (C-6), 152.4 (C-7), 151.9 (C-10a), 153.3 (C-1), 155.5 (C-4a), 177.3 (C-9) ppm.

\section{Emerin (159)}

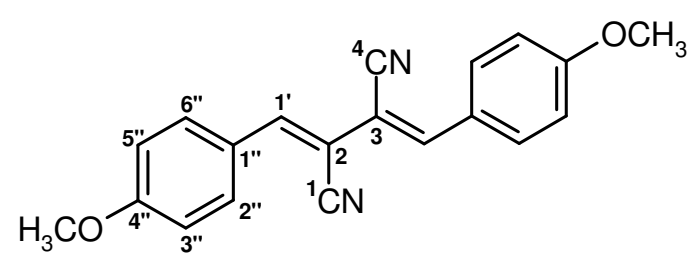

$\mathbf{C}_{20} \mathbf{H}_{16} \mathbf{N}_{2} \mathbf{O}_{2}$ (316.36).

MS (EI, $70 \mathrm{eV}): m / z(\%)=316(100)\left[\mathrm{M}^{+}, 108(20), 158\right.$ (8), 209 (20), 239 (8), 285 (10).

MS (ESI): $m / z(\%)=317(90)[\mathrm{M}+\mathrm{H}]^{+}, 339(70)[\mathrm{M}+\mathrm{Na}]^{+}, 355(50)[\mathrm{M}+\mathrm{K}]^{+}$.

IR $(\mathrm{KBr}): \widetilde{v}\left(\mathrm{~cm}^{-1}\right)=3431,2925,2222,1602,1508,1384,1263,1178,1024,828$.

${ }^{1} \mathbf{H}-\mathbf{N M R}\left(600 \mathrm{MHz}, \mathrm{CDCl}_{3}\right): \delta=3.86\left(\mathrm{~s}, 2 \times 3 \mathrm{H}, 2 \times 4 "-\mathrm{OCH}_{3}\right), 6.97(\mathrm{~d}, J=9.0 \mathrm{~Hz}$, $\left.2 \times 2 \mathrm{H}, 2 \times 3 "-\mathrm{H}, 2 \times 5^{\prime \prime}-\mathrm{H}\right), 7.54\left(\mathrm{~s}, 2 \times 1 \mathrm{H}, 2 \times 1^{\prime}-\mathrm{H}\right), 7.86(\mathrm{~d}, J=9.0 \mathrm{~Hz}, 2 \times 2 \mathrm{H}$, $2 \times 2 "-\mathrm{H}, 2 \times 6 "-\mathrm{H}) \mathrm{ppm}$.

${ }^{13} \mathrm{C}-\mathrm{NMR}\left(125 \mathrm{MHz}, \mathrm{CDCl}_{3}\right): \delta=55.6\left(2 \times 44^{\prime}-\mathrm{OCH}_{3}\right), 105.2(2 \times \mathrm{C}-1 "), 106.1(\mathrm{C}-2, \mathrm{C}-3)$, 114.6 ( $2 \times \mathrm{C}-3$ ", $2 \times \mathrm{C}-5 "), 131.6$ (C-1, C-4), 131.8 ( $2 \times \mathrm{C}-2$ ", $2 \times \mathrm{C}-6 "), 143.1\left(2 \times \mathrm{Cv1} 1^{\prime}\right)$ ppm. 


\section{Demethylsterigmatocystin (160)}

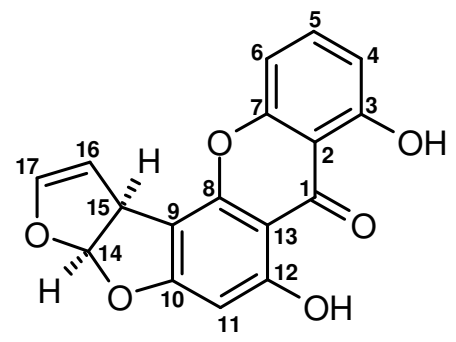

\section{$\mathbf{C}_{17} \mathbf{H}_{10} \mathbf{O}_{6} \quad(310.27)$.}

MS (EI, $70 \mathrm{eV}): m / z(\%)=310.2$.

HR-EI-MS: $m / z(\%)=:$ ber.: $m / z=310.0477[\mathrm{M}]^{+}$

$$
\text { gef.: } m / z=310.0474[\mathrm{M}]^{+} \text {. }
$$

${ }^{1} \mathbf{H}-\mathbf{N M R}\left(600 \mathrm{MHz}, \mathrm{CDCl}_{3}\right): \delta=4.68(\mathrm{dd}, J=2.3,7.0 \mathrm{~Hz}, 1 \mathrm{H}, 15-\mathrm{H}), 5.43(\mathrm{~d}, J=2.3 \mathrm{~Hz}$, $1 \mathrm{H}, 16-\mathrm{H}), 6.45\left(\mathrm{~d}_{\mathrm{br}}, J=2.3 \mathrm{~Hz}, 2 \mathrm{H}, 11-\mathrm{H}, 17-\mathrm{H}\right), 6.76(\mathrm{~d}, J=8.0 \mathrm{~Hz}, 1 \mathrm{H}, 4-\mathrm{H}), 6.78(\mathrm{~d}$, $J=6.5 \mathrm{~Hz}, 1 \mathrm{H}, 14-\mathrm{H}), 6.86(\mathrm{~d}, J=8.0 \mathrm{~Hz}, 1 \mathrm{H}, 6-\mathrm{H}), 7.54(\mathrm{t}, J=8.0 \mathrm{~Hz}, 1 \mathrm{H}, 5-\mathrm{H}), 11.9$ (s, $1 \mathrm{H}, 12-\mathrm{OH}), 12.1$ (s, $1 \mathrm{H}, 3-\mathrm{OH}) \mathrm{ppm}$.

${ }^{13}$ C-NMR (125 MHz, $\mathrm{CDCl}_{3}$ ): $\delta=47.4$ (C-15), 90.3 (C-11), 102.6 (C-916, 103.3 (C-9), 107.4 (C-2), 109.5 (C-13), 107.0 (C-6), 110.9 (C-4), 113.1 (C-14), 136.7 (C-5), 144.9 (C-17), 156.0 (C-7), 157.1 (C-8), 161.1 (C-3), 144.9 (C-17), 158.1 (C-12), 165.6 (C-10), 184.7 (C-1) ppm.

\section{Averufin (161)}

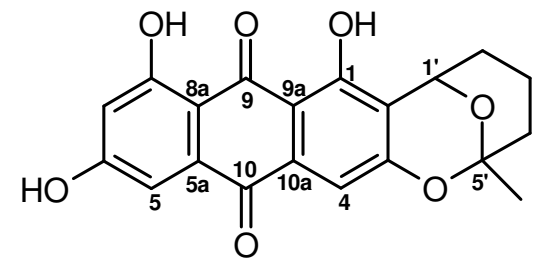

\section{$\mathbf{C}_{20} \mathrm{H}_{16} \mathrm{O}_{7}$}

MS (ESI): $m / z(\%)=391[\mathrm{M}+\mathrm{Na}]^{+}, 759[2 \mathrm{M}+\mathrm{Na}]^{+}, 367[\mathrm{M}-\mathrm{H}]^{-}, 757[2 \mathrm{M}-2 \mathrm{H}+\mathrm{Na}]^{-}$.

HR-ESI-MS: $m / z(\%)=$ ber.: $m / z=367.0823[\mathrm{M}-\mathrm{H}]^{-}$

$$
\text { gef.: } m / z=367.0823[\mathrm{M}-\mathrm{H}]^{-} \text {. }
$$

${ }^{1}$ H-NMR (600 MHz, DMSO-d 6 ): $\delta=1.44\left(\mathrm{~m}, 1 \mathrm{H}, 3^{\prime}-\mathrm{H}_{\mathrm{A}}\right), 1.53\left(\mathrm{~s}, 3 \mathrm{H}, 66^{\prime}-\mathrm{H}_{3}\right), 1.64(\mathrm{~m}, 1 \mathrm{H}$, $\left.3^{\prime}-\mathrm{H}_{\mathrm{B}}\right), 1.74\left(\mathrm{~d}, J=13.0 \mathrm{~Hz}, 1 \mathrm{H}, 4^{\prime}-\mathrm{H}_{\mathrm{A}}\right), 1.85\left(\mathrm{dt}, J=5.0,8.0 \mathrm{~Hz}, 1 \mathrm{H}, 2^{\prime} \mathrm{H}_{\mathrm{A}}\right), 1.99(\mathrm{~m}, 1 \mathrm{H}$, 
3'- $\left.\mathrm{H}_{\mathrm{B}}\right), 2.02\left(\mathrm{~m}, 1 \mathrm{H}, 4^{\prime}-\mathrm{H}_{\mathrm{B}}\right), 5.28\left(\mathrm{~m}, 1 \mathrm{H}, 1^{\prime}-\mathrm{H}\right), 6.47$ (s, $\left.1 \mathrm{H}, 5-\mathrm{H}\right), 7.04$ (s, $\left.1 \mathrm{H}, 4-\mathrm{H}\right), 7.06$

(s, $1 \mathrm{H}, 7-\mathrm{H}), 12.1$ ( $\left.\mathrm{s}_{\mathrm{br},} 1 \mathrm{H}, \mathrm{OH}\right), 12.6\left(\mathrm{~s}_{\mathrm{br}}, 1 \mathrm{H}, \mathrm{OH}\right) \mathrm{ppm}$.

${ }^{13}$ C-NMR (125 MHz, DMSO-d 6 ): $\delta=15.3\left(\mathrm{C}-3^{\prime}\right), 26.9\left(\mathrm{C}-2^{\prime}\right), 27.4\left(6^{\prime}-\mathrm{CH}_{3}\right), 35.2\left(\mathrm{C}^{\prime} 4^{\prime}\right)$, 66.0 (C-1'), 100.9 (C-6), 106.7 (C-4, C-5), 107.9 (C-9a), 108.6 (C-7), 115.8 (C-2), 129.4 (C-10a), 133.0 (C-5a), 134.6 (C-8a), 157.9 (C-1), 159.3 (C-3), 164.3 (C-6, C-8), 181.1 (C-10), 187.6 (C-9) ppm.

\subsection{Verifizierung des neuen Cycloisoemericellinols (156)}

\subsubsection{Variation der Aufarbeitung}

Zur Untersuchung des Metabolitenspektrums vom Pilz Aspergillus nidulans auf Mykotoxine wurden Festphasenkultivierungen und Isolierungsarbeiten von $C$. Handrich (AK Müller, Arbeitsmedizin Göttingen) durchgeführt. Zur Aufarbeitung wurden die Festphasenkulturen (60-70 Agarplatten, YES-Agar) zerkleinert und mit $\left(\mathrm{CH}_{2} \mathrm{Cl}_{2} / \mathrm{MeOH} 2: 1\right.$, Zusatz von $150 \mu \mathrm{L}$ Ameisensäure auf $30 \mathrm{~mL}$ Lösungsmittel) extrahiert, das Lösungsmittel i. Vak. entfernt. Das Rohprodukt wurde in DMSO aufgenommen und mittels präperativer HPLC (Eurospher 100-7 C18, $250 \mathrm{~mm} \times 8$ mm I.D., (Knauer); Lösungsmittel A: $\mathrm{H}_{2} \mathrm{O}$ plus $0.05 \%$ TFA, Lösungsmittel B: AcCN plus $0.05 \%$ TFA, Gradient: $90 \%$ A, in 30 min auf $50 \%$ A, in 10 min auf $10 \%$ A, $10.5 \mathrm{~min}$ bei $10 \% \mathrm{~A}$, in $7.5 \mathrm{~min}$ auf $90 \% \mathrm{~A}$, in $5.5 \mathrm{~min}$ auf $92 \% \mathrm{~A}$; Flussrate $2.5 \mathrm{~mL} / \mathrm{min}$ ) in 5 min-Fraktionen fraktioniert. Die jeweiligen Fraktionen wurden auf Mutagenität und Cytotoxizität untersucht und aktive Fraktionen dann mittels präperativer HPLC (ODS-AQ, $250 \mathrm{~mm} \times 10 \mathrm{~mm}$ I.D., S-5 $\mu \mathrm{m}, 12 \mathrm{~nm}$ (YMC); Lösungsmittel A: $\mathrm{H}_{2} \mathrm{O}$ plus $0.05 \%$ TFA, Lösungsmittel B: AcCN plus $0.05 \%$ TFA, Gradient: $75 \%$ A, in 16 min auf $69 \%$ A, in 1 min auf $29 \% \mathrm{~A}$, in $13 \mathrm{~min}$ auf $5 \% \mathrm{~A}, 11 \mathrm{~min}$ bei $5 \% \mathrm{~A}$, in 3 min auf $90 \% \mathrm{~A}, 6 \mathrm{~min}$ bei $90 \% \mathrm{~A}$; Flussrate $3.0 \mathrm{~mL} / \mathrm{min}$ ) weiter aufgereinigt. ${ }^{194}$

Um zu untersuchen, ob das aus Aspergillus nidulans isolierte Cycloisoemericellinol (156) zum Metabolitenspektrum des Pilzes gehört, oder diese Verbindung erst bei der Aufarbeitung durch Zugabe der Ameisensäure zum Extraktionslösungsmittel aus Cycloisoemericellin (157) gebildet wird, wurde die Aufarbeitung variiert. Hierzu wurde zu Festphasenkulturen (3 Agarplatten) als Extraktionslösungsmittel $\mathrm{CH}_{2} \mathrm{Cl}_{2} / \mathrm{MeOH}$ 2:1 ohne Zusatz von Säure gegeben und mittels Ultra Turrax ${ }^{\circledR}$ zerkleinert, filtriert und die Phasen getrennt. Die wässrige Phase wurde noch einmal mit $\mathrm{CH}_{2} \mathrm{Cl}_{2}$ extrahiert, die organischen Phasen vereinigt und das Lösungsmittel bis zur Trockne entfernt. 


\subsubsection{HPLC-ESI-MS-Analytik}

Für die vergleichende HPLC-ESI-MS-Analyse wurden die Rohextrakte der jeweiligen Aufarbeitungen mit und ohne Säure sowie die Reinsubstanz $156 \mathrm{im}$ positiven und negativen Mode gemessen (HPLC D, Säule A: Grom Superspher 100, RP-18, Programm B: $\mathrm{MeOH} / \mathrm{H}_{2} \mathrm{O}$, jeweils mit $0.05 \%$ Ameisensäure, Gradient; s. 1.2 ). Hierfür wurden die Rohextrakte in einer Konzentration von $c=5.0 \mathrm{mg} / \mathrm{mL}$ in $\mathrm{MeOH}$ aufgenommen, die Reinsubstanz 156 in einer Konzentration von $c=1.0 \mathrm{mg} / \mathrm{mL}$ in $\mathrm{MeOH}$ gelöst, alle Proben zentrifugiert und analysiert. 



\section{ANHANG}

\section{Literatur}

${ }^{1}$ F. V. Nussbaum, M. Brands, B. Hinzen, S. Weigand, D. Häbich, Angew. Chem. 2006, 118, 5194-5254; Angew. Chem. Int. Ed. 2006, 45, 5072-5129.

2 a) World Health Organisation (WHO) Geneva, World-Health-Report-2002. b) C. Nathan, Nature 2004, 431, 899-902.

${ }^{3}$ a) B. M. Kuehn, JAMA J. Am Med. Assoc. 2007, 298, 1389; b) J. F. Barrett, Expert Opin. Ther. Targets 2004, 8, 515-519.

${ }^{4}$ D. Häbich, F. v. Nussbaum, Angew. Chem. 2009, 121, 3447-3451; Angew. Chem. Int. Ed. 2009, 48, 3397-3400.

${ }^{5}$ World Health Organisation (WHO) Geneva, World-Health-Report-2008.

${ }^{6}$ G. D. Wright, Chem. Biol. 2000, 7, R127-R132.

${ }^{7}$ C. Hertweck, T. Spellig, „Krank? Schwamm drüber!“ in „Biotechnologie 2020“, 2005, Dechema e.V.

${ }^{8}$ M. R. Barbachyn, C. W. Ford, Angew. Chem. 2003, 115, 2056-2144; Angew. Chem Int. Ed. 2003, 42, 2010-2023.

9 a) A. Raja, J. LaBonte, J. Lebbos, P. Kirkpatrick, Nat. Rev. Drug Discovery 2003, 2, $943-$ 944; b) J. D. Alder, Drug Discovery Today 2005, 41, 81-90.

10 J. Wang, S. M. Soisson, K. Young, W. Shoop, S. Kodali, A. Galgoci, R. Painter, G. Parthasarathy, Y. S. Tang, R. Cummings, S. Ha. K. Dorso, M. Motyl, H. Jayasuirya, J. Ondeyka, K. Herath, C. Zhang, L. Hernandez, J. Allocco, Á. Basilio, J. R. Torno, O. Genilloud, F. Vicente, F. Pelaez, L. Colwell, S. H. Lee, B. Michael, T. Felcetto, C. Gill, L. L. Silver, J. D. Hermes, K. Bartizal, J. Barret, D. Schmatz, J. W. Becker, D. Cully, S. B. Singh, Nature 2006, 441, 358-361.

${ }^{11}$ J. Zhou, D. K. Thompson, Y. Xu, J. M. Tiedje, Microbial Functional Genomics, 1. Auflage, John Wiley \& Sons, 2004.

${ }^{12}$ D. Häbich, F. v. Nussbaum, ChemMedChem 2006, 1, 951-954.

${ }^{13}$ J. Wang, S. Kodali, S. H. Lee, A. Galgoci, R. Painter, K. Dorso, F. Racine, M. Motyl, L. Hernandez, E. Tinney, S. L. Colletti, K. Herath, R. Cummings, O. Salazar, I. González, A. Basilio, F. Vicente, O. Genilloud, F. Pelaez, H. Jayasuriya, K. Young, D. F. Cully, S. B. Singh, Proc. Natl. Acad. Sci. 2007, 104, 7612-7616. 
${ }^{14}$ U. Holzgrabe, Pharm. Unserer Zeit 2007, 36, 418-419.

15 a) H. Irschik, H. Augustiniak, K. Gerth, G. Höfle, H. Reichenbach, J. Antibiot. 1985, 38, 145-152; b) H. Augustiniak, H. Reichenbach, G. Höfle, Liebigs Ann. Chem. 1985, 822-836.

16 a) H. Irschik, H. Augustiniak, K. Gerth, G. Höfle, H. Reichenbach, J. Antibiot. 1995, 48, 787-792; b) H. Augustiniak, H. Reichenbach, G. Höfle, Liebigs Ann. 1996, 1657-1663.

${ }^{17}$ D. Newmann, G. Cragg, K. Snader, J. Nat. Prod. 2003, 66, 1022-1037.

${ }^{18}$ H. B. Bode, R. Müller, Angew. Chem. 2005, 117, 6988-7007; Angew. Chem. Int. Ed. 2005, $6828-6846$.

${ }^{19}$ A. Zeeck, G. Bach, H. Terlau, Der Internist 2001, 1422-1427.

${ }^{20}$ E. Leistner, Pharm. Unserer Zeit 2005, 34, 98-103.

${ }^{21}$ D. Hoffmeister, A. Bechthold, S. Pelzer, W. Wohlleben, BIOspektrum 2002, 8, 508-511.

22 a) X. Ruan, A. Perada, D. L. Stassi, D. Zeidner, R. G. Summers, M. Jackson, A. Shivakumar, S. Kakavas, M. J. Staver, S. Donadio, L. Katz, J. Bacteriol. 1997, 179, 64166425.

${ }^{23}$ R. L. Arslanian, L. Tang, S. Blough, W. Ma, R. G. Qiu, L. Katz, J. R. Carney, J. Nat. Prod. 2002, 65, 1061-1064.

${ }^{24}$ P. Proksch, R. A. Edrada, R. Ebel, Appl. Microbiol. Biotechnol. 2002, 159, 125-134.

${ }^{25}$ P. Proksch, R. A. Edrada-Ebel, R. Ebel, Biol. Unserer Zeit 2006, 36, 150-159.

${ }^{26}$ C. Schmeisser, H. Steele, W. R. Streit, Appl. Microbiol. Biotechnol. 2007, 75, 955-962.

${ }^{27}$ U. Hentschel, J. Piel, „Die Zukunft hat schon begonnen - Sind wir dabei?“ in „Vorbild Natur“" 2007, Dechema e.V..

${ }^{28}$ T. Schuhmann, Dissertation, Universität Göttingen, 2004.

${ }^{29}$ M. Quitschau, Diplomarbeit 2006, Universität Göttingen.

${ }^{30}$ M. Scheuermayer, Dissertation, Universität Würzburg, 2006.

${ }^{31}$ H.-C. Flemming, J. Wingender, Biol. Unserer Zeit 2001, 31, 169-180.

${ }^{32}$ C. A. Fux, J. W. Costerton, Trends in Microbiol. 2005, 13, 34-40.

${ }^{33}$ C. U. Schwermer, G. Lavik, R. M. M. Abed, B. Dunsmore, T. G. Ferdelman, P. Stoodley, A. Gieske, D. de Beer, Appl. Environ. Microbiol. 2008, 74, 2841-2851.

${ }^{34}$ C. M. Waters, B. L. Bassler, Annu. Rev. Cell. Dev. Biol. 2005, 21, 319-346.

${ }^{35}$ K. H. Nealson, T. Platt, J. W. Hastings, J. Bacteriol. 1970, 104, 313-322.

${ }^{36}$ L. Eberl, Syst. Appl. Microbiol. 1999, 22, 493-506.

${ }^{37}$ R. J. Redfield, Trends Microbiol. 2002, 10, 365-370. 
${ }^{38}$ B. A. Hense, C. Kuttler, J. Müller, M. Rothballer, A. Hartmann, J.-U. Kreft, Nature Rev. Microbiol. 2007, 5, 230-239.

${ }^{39}$ S. Uroz, Y. Dessaux, P. Oger, ChemBioChem 2009, 10, 205-216. ${ }^{40}$ T. B. Rasmussen, M. Givskov, Microbiol. 2006, 152, 895-904.

${ }^{41}$ T. Defoirdt, C. M. Miyamoto, T. K. Wood, E. A. Meighen, P. Sorgeloos, W. Verstraete, P. Bossier, Environ. Microbiol. 2007, 9, 2486-2495.

${ }^{42}$ T. B. Rasmussen, M. Givskov, Microbiology, 2006, 152, 895-904.

${ }^{43}$ T. Defoirdt, N. Boon, P. Sorgeloos, W. Verstraete, P. Bossier, The ISME Journal, 2008, 2 , 19-26.

${ }^{44}$ M. Timmen, B. L. Bassler, K. Jung, J. Biol. Chem. 2006, 281, 24398-24404.

45 A. Eberhard, A. L. Burlingame, C. Eberhard, G. L. Kenyon, K. H. Nealson. N. J. Oppenheimer, Biochemistry, 1981, 20, 2444-2449.

${ }^{46}$ S. R. Chhabra, B. Philipp, L. Eberl, M. Givskov, P. Williams, M. Cámara, Topics in Curr. Chem. 2005, 240, 279-315.

${ }^{47}$ J.-G. Cao, E. A. Meighen, J. Bacteriol. 1993, 175, 3856-3862.

${ }^{48}$ T. J. Tavender, N. M. Halliday, K. R. Hardie, K. Winzer, BMC Microbiology 2008, 8:98.

${ }^{49}$ K. R. Hardie, K. Heurlier, Nature Rev. Microbiol. 2008, 6, 635-643.

${ }^{50}$ S. T. Miller, K. B. Xavier, S. R. Campagna, M. E. Taga, M. F. Semmelhack, B. L. Bassler, F. M. Hughson, Molecular Cell 2004, 15, 677-687.

${ }^{51}$ M. F. Semmelhack, S. R. Campagna, M. J. Federle, B. L. Bassler, Org. Lett. 2005, 7, 569572.

${ }^{52}$ K. Winzer, K. R. Hardie, N. Burgess, N. Doherty, D. Kirke, M. T. G. Holden, R. Linforth, K. A. Cornell, A. J. Taylor, P. J. Hill, P. Williams, Microbiology, 2002, 148, 909-922.

${ }^{53}$ A. Eberhard, C. A. Widrig, P. McBath, J. B. Schineller, Arch. Micrbiol. 1986, 146, 35-40.

${ }^{54}$ U. Schmidt, M. Kroner, H. Griesser, Synthesis, 1991, 294-300.

${ }^{55}$ F. Major, Dissertation, Universität Göttingen, 2006.

${ }^{56}$ U. D. Lengweiler, M. G. Fritz, D. Seebach, Helv. Chim. Acta. 1996, 79, 670-701.

${ }^{57}$ M. F. Semmelhack, S. R. Campagna, C. Hwa, M. J. Federle, B. L. Bassler, Org. Lett. 2004, 6, 2635-2637.

${ }^{58}$ F. Surup, O. Wagner, J. v. Frieling, M. Schleicher, S. Oess, P. Müller, S. Grond, J. Org. Chem. 2007, 72, 5085-5090.

${ }^{59}$ M. J. Bibb, Curr. Opin. Microbiol. 2005, 8, 208-215. 
${ }^{60}$ V. D. Gruzina, E. V. Gorbatyuk, O. V. Efremenkova, S. N. Filippova, G. I. El'-Registan, Y. V. Dudnik, Microbiol. 2003, 72, 682-685.

${ }^{61}$ T. Beppu, Gene, 1992, 115, 159-165.

${ }^{62}$ C. Schipper, C. Hornung, P. Bijtenhoorn, M. Quitschau, S. Grond, W. R. Streit, Appl. Environ. Microbiol. 2009, 75, 224-233.

${ }^{63}$ S. Uroz, Y. Dessaux, P. Oger, ChemBioChem. 2009, 10, 205-216.

${ }^{64}$ Y. H. Dong, L. H. Wang, J. L. Xu, H. B. Zhang, X. F. Zhang, L. H. Zhang, Nature 2001, $411,813-817$.

${ }^{65}$ E. A. Ozer, A. Pezzulo, D. M. Shih, C. Hun, C. Furling, A. J. Lusis, E. P. Greenberg, J. Zabner, FEMS Microbiol. Lett. 2005, 253, 29-37.

${ }^{66}$ S. Uroz, S. R. Chhabra, M. Camara, P. Williams, P. Oger, Y. Dessaux, Microbiology 2005, $151,3313-3322$.

${ }^{67}$ F. Xu, T. Byun, H. J. Deussen, K. R. Duke, J. Biotechnol. 2003, 101, 89-96.

${ }^{68}$ T. B. Rasmussen, T. Bjarnsholt, M. E. Skindersoe, M. Hentzer, P. Kristoffersen, M. Köte, J. Nielsen, L. Eberl, M. Givskov, J. Bacteriol. 2005, 187, 1799-1814.

${ }^{69}$ a) A. F. Gonzáles Barrios, R. Zuo, Y. Hasimoto, L. Yang, W. E. Bentley, T. K. Wood, J. Bacteriol. 2006, 188, 305-316; b) M. Herzberg, I. K. Kaye, W. Peti, T. K. Wood, J. Bacteriol. 2006, 188, 587-598.

${ }^{70}$ N. Weiland, Dissertation Universität Kiel, geplant 2009.

${ }^{71}$ P. Huŝek, J. Chromatogr. B 1998, 717, 57-91.

${ }^{72}$ D. J. Newmann, G. M. Cragg, J. Nat. Prod. 2007, 70, 461-477.

73 a) P. Proksch, R. A. Edrada, R. Ebel, Appl. Microbiol. Biotechnol. 2002, 159, 125-134; b) J. Piel, J. Nat. Prod. Rep. 2004, 21, 519-538.

${ }^{74}$ G. Schwartsmann, A. B. da Rocha, J. Mattei, R. M. Lopes, Expert Opin. Invets. Drugs 2003, 12, 1367-1383.

${ }^{75}$ Y. Ikeda, H. Matsuki, T. Ogawa, T. Munakata, J. Antibiot. 1983, 36, 1284-1289.

${ }^{76}$ C. Cuevas, M. Pérez, M. J. Martin, J. L. Chicharro, C. Fernández-Rivas, M. Flores, A. Francesch, P. Gallego, M. Zarzuelo, F. de la Celle, J. Garcia, C. Polanco, I. Rodriguez, I. Manzanares, Org. Lett. 2000, 2, 2545-2548.

77 a) J. Piel, Proc. Natl. Acad. Int. 2002, 99, 14002-14007.

78 a) L. Fieseler, U. Hentschel, L. Grozdanov, A. Schirmer, G. Wen, M. Platzer, S. Hrvatin, D. Butzke, K. Zimmermann, J. Piel, Appl. Environ. Microbiol. 2007, 73, 2144-2155; b) T. L. 
Simmons, R. C. Coates, B. R. Clark, N. Engene, D. Gonzalez, E. Esquenazi, P. C. Dorrestein, W. H. Gerwick, Proc. Natl. Acad. Sci. 2008, 105, 4587-4594.

79 a) H. Kang, P. R. Jensen, W. Fenical, J. Org. Chem. 1996, 61, 1543-1546; b) N. Miyari, H. I. Sakai, T. Konomi, H. Imanaka, J. Antibiot. 1976, 29, 227-235.

${ }^{80}$ C. Moss, D. H. Green, B. Pérez, A. Velasco, R. Henríquez, J. D. McKenzie, Marine Biology 2003, 143, 99110.

${ }^{81}$ H. B. Bode, B. Bethe, R. Höfs, A. Zeeck, ChemBioChem 2002, 3, 619-627.

${ }^{82}$ N. Czempinski, Diplomarbeit, Universität Göttingen, 2003.

${ }^{83}$ Organikum, 21. Aufl., H. G. O. Becker, R. Beckert, G. Domschke, E. Fanghänel, W. D. Habicher, P. Metz, D. Pavel, K. Schwetlick, Wiley-VCH, Berlin 2001.

${ }^{84}$ N. K. Hamer, R. D. Tack, J. Chem. Soc., Perkin Trans 2 1974, 1184-1187.

${ }^{85}$ R. Tacke, M. Strecker, R. Niedner, Liebigs Ann. Chem. 1981, 387-395.

${ }^{86}$ H. Quast, M. Heuschmann, M. O. Abdel-Rahman, Liebigs. Ann. Chem. 1981, 943-966.

${ }^{87}$ A. B. Fosters, W. G. Overend, M. Stacey, J. Chem. Soc. 1951, 980-985.

${ }^{88}$ Y. Kobayashi, T. Koizumi, E. Yoshi, Chem. Pharm. Bull. 1979, 27, 1641-1650.

${ }^{89}$ M. Quitschau, T. Schuhmann, J. Piel, P. v. Zezschwitz, S. Grond, Eur. J. Org. Chem. 2008, $5117-5124$.

${ }^{90}$ a) C. McGuigan, D. Cahard, H. M. Sheeka, E. De Clercq, J. Balzarini, Bioorg. Med. Chem. Lett. 1996, 6, 1183-1186; b) D. Saboulard, L. Naesens, D. Cahard, A. Salgado, R.

Pathirana,S. Velazquez, C. McGuigan, E. De Clercq, J. Balzarini, J. Mol. Pharmacol. 1999, 56, 693-704.

91 a) P. Perrone, G. M. Luoni, M. R. Kelleher, F. Daverio, A. Angell, S. Mulready, C. Congiatu, S. Rajyaguru, J. A. Martin, V. Levêque, S. LePogam, I. Najera, K. Klumpp, D. B. Smith, C. McGuigan, J. Med. Chem. 2007, 50, 1840-1849; b) P. Perrone, F. Daverio, R. Valente, S. Rajyaguru, J. A. Martin, V. Levêque, S. LePogam, I. Najera, K. Klumpp, D. B. Smith, C. McGuigan, J. Med. Chem. 2007, 50, 5463-5470.

92 a) B. G. Davis, V. Boyer, Nat. Prod. Rep. 2001, 18, 618-640; b) P. G. Hultin, F.-J. Mueseler, J. B. Jones, J. Org. Chem. 1991, 56, 5375-5380; c) B. M. Trost, Y. Li, J. Am. Chem. Soc. 1996, 118, 6625-6633.

\footnotetext{
${ }^{93}$ A. N. Serreqi, R. J. Kazlauskas, J. Org. Chem. 1994, 59, 7609-7615.

${ }^{94}$ E. Narisano, R. Riva, Tetrahedron: Asymmetry 1999, 10, 1223-1242.

${ }^{95}$ P. Wipf, Y. Uto, S. Yoshimura, Chem. Eur. J. 2002, 8, 1670-1681.
} 
${ }^{96}$ H. Laatsch, Antibase - a database for the identification of natural products, Chemical Concepts, Weinheim, 2006.

${ }^{97}$ Dictionary of Natural Products on CD-Rom, Vol. 15:2; Autorenkollektiv, Chapman \& Hall / CRC, Boca Raton (FL), 2007.

${ }^{98}$ M. Matsumoto, Y. Kawamura, Y. Yoshimura, Y. Terui, H. Nakai, T. Yoshida, J. Shoji, J. Antibiot. 1990, 43, 739-747.

${ }^{99}$ W. Klyne, Biochem.J. 1950, 47, xli-xlii.

100 a) C. S. Hudson, J. Chem. Am. Soc. 1909, 31, 66-86; b) C. S. Hudson, Adv. Carbohydr. Chem. 1048, 3, 15.

${ }^{101}$ E. Schöttner, K. Simon, M. Friedel, P. G. Jones, T. Lindel, Tetrahedron Lett. 2008, 49, $5580-5582$.

${ }^{102}$ Wir danken Herrn Prof. L. F. Tietze und C. Raith für die Nutzung der HPLC-Anlage und die außerordentlich freundliche Betreuung.

${ }^{103}$ W. Keller-Schierlein, R. Muntwyler, W. Pache, H. Zähner, Helv. Chim. Acta. 1969, 52, 127-142.

${ }^{104}$ M. Rohmer, M. Knani, P. Simonin, B. Setter, H. Sahm, Biochem. J. 1993, 295, 517-524.

${ }^{105}$ W. Eisenreich, M. Schwarz, A. Cartayrade, D. Arigoni, M. H. Zenk, A. Bacher, Chem. Biol. 1998, 5, R221-R233.

106 a) H. Seto, H. Watanabe, K. Furihata, Tetrahedron Lett. 1996, 37, 7979-7982; b) H. Seto, N. Orihara, K. Furihata, Tetrahedron Lett. 1998, 39, 9497-9500.

${ }^{107}$ F. Tomita, T. Tamaoki, K. Shirahata, M. Kasai, M. Morimoto, S. Ohcubo, K. Meneura, S. Ishii, J. Antibiot. 1980, 33, 950-946.

108 J. A. Waltz, A. C. Horan, M. Kalyanour, B. K. Lee, D. Lohenberg, J. A. Marquez, G. Miller, M. Patel, J. Antibiot. 1981, 34, 1101-1106.

${ }^{109}$ R. Holzbach, H. Pape, D. Hook, E. F. Kreutzer, C.-J. Chang, H. G. Floss, Biochemistry 1978, $17,556-560$.

110 a) O. A. Mascaretti, C.-J. Chang, D. Hook, H. Otsuka, E. F. Kreutzer, H. G. Floss, Biochemistry 1981, 20, 919-924; b) J. J. Lee, J. P. Lee, P. J. Keller, V. Cottrell, C.-J. Chang, H. Zähner, H. G. Floss, J. Antibiot. 1986, 39, 1123-1134.

111 T. Tamaoki, F. Tomita, J. Antibiot. 1983, 36, 595-598.

${ }^{112}$ X.-Y. Jia, Z.-H. Tian, L. Shao, X.-D. Qu, Q.-F. Zhao, J. Tang, G.-L. Tang, W. Liu, Chem. Biol. 2006, 13 575-585. 
${ }^{113}$ H. Zhang, J. A. White-Phillip, C. E. Melancon, III, H.-J. Kwon, W.-I. Yu, H.-w. Liu, J. Am. Chem. Soc. 2007, 129, 14670-14683.

114 J. Fang, Y. Zhang, L. Huang, X. Jia, Q. Zhang, X. Zhang, G. Tang. W. Liu, J. Bacteriol. 2008, 190, 6014-6025.

${ }^{115}$ M. Hildebrand, L. E. Waggoner, H. Liu, S. Sudek, S. Allen, C. Anderson, D. H. Sherman, M. Haygood, Chem. Biol. 2004, 11, 1543-1552.

${ }^{116}$ T. Schuhmann, D. Vollmar, S. Grond, J. Antibiot. 2007, 60, 52-60.

${ }^{117}$ Biochemical Pathways, Spektrum Akademischer Verlag, Heidelberg, Berlin, 1999.

118 a) Y. Sun, H. Hong, F. Gillies, J. B. Spencer, P. F. Leadlay, ChemBioChem 2008, 9, 150156; b) Y. Demydchuk, Y. Sun, H. Hong, J. Staunton, J. B. Spencer, P. F. Leadlay, ChemBioChem 2008, 9, 1136-1145.

${ }^{119}$ T. Schuhmann, S. Grond, J. Antibiot. 2004, 60, 655-661.

${ }^{120}$ S. Kornfeld, L. Glaser, Biochim. Biophys. Acta. 1960, 42, 548-550.

${ }^{121}$ S.-W. Yang, G. A. Cordell, J. Nat. Prod. 1996, 59, 828-833.

${ }^{122}$ W. Knöss, Pharamzie in unserer Zeit 1999, 28, 247-254.

123 S. L. Spuregon, J. W. Porter in Biosynthesis of Isoprenoid Compounds, (Hrsg.: S. L. Spuregon, J. W. Porter, John Wiles and Sons), Vol. 1, New York, 1981.

${ }^{124}$ M. Rohmer, Nat. Prod. Rep. 1999, 6, 565-574.

${ }^{125}$ F. Lütke-Brinkhaus, H. Kleinig, Plant 1987, 170, 401-406. ${ }^{126}$ G. Flesch, M. Rohmer, Eur. J. Biochem. 1988, 175, 405-411.

${ }^{127}$ T. Kuzuyama, H. Seto, Nat. Prod. Rep. 2003, 20, 171-183.

128 a) W. Eisenreich, A. Bacher, D. Arigoni, F. Rohdich, Cell. Mo. Life Sci. 2004, 61, 14011426; b) W. N. Hunter, J. Biol. Chem. 2007, 27, 21573-21577.

129 a) C. Hertweck, B. S. Moore, Tetrahedron 2000, 56, 9115-9120; b) K. Yazaki, L. Heide, M. Tabata, Phytochemistry 1991, 30, 2233-2236. ${ }^{130}$ P. M. Dewick, Medicinal Natural Products 2. Aufl., Wiley-VCH Verlag GmbH Weinheim, 2002.

${ }^{131}$ H. Lüllmann, K. Mohr, L. Hein, Pharmakologie und Toxikologie, 16. Aufl., Georg Thieme Verlag Stuttgart, 2006.

${ }^{132}$ B. Antonijevic, M. P. Stojiljkovic, Clin. Med. Res. 2007, 5, 71-82.

${ }^{133}$ U. Holzgrabe, P. Kapková. V. Apltüzün, J. Sceiber, E. Kugelmann, Expert Opin. Ther. Targets 2007, 11, 161-179.

${ }^{134}$ Wir danken Frau Prof. U. Holzgrabe und E. Kugelmann (Universität Würzburg) für die Durchführung der Cholinesterase-Inhibierungs-Tests. 
${ }^{135}$ G. L. Ellmann, D. K. Courtney, V. Andreas, R. M. Featherstone, Biochem. Pharmacol. 1961, 7, 88-95.

${ }^{136}$ Wir danken Herrn Prof. C. Meier und N. Gisch für die Durchführung der CholinesteraseInhibierungs-Tests.

${ }^{137}$ F. Duspiva, Angew. Chem. 1954, 66, 541-551.

${ }^{138}$ L. F. Tietze, F. Major, I. Schuberth, Angew. Chem. 2006, 118, 6724-6727; Angew. Chem. Int. Ed. 2006, 45, 6574-6577.

139 Wir danken Herrn Prof. W. Beil für die Durchführung der cytostatischen und cytotoxischen Untersuchungen mit verschiedenen Tumorzelllinien.

${ }^{140}$ Wir danken Herrn M. Kaiser (Schweizer Tropeninstitut, Basel) für die Durchführung der in vitro-Tests.

${ }^{141}$ Pressemitteilung, MPI für biophysikalische Chemie Göttingen, 2000.

$142 \mathrm{http} / / / \mathrm{www} . w h o . i n t / l e i s h m a n i a s i s / d i s e a s e \_$_epidemiology/en/html.

143 a) F. Tomita, T. Tamaoki, S. Shirahata, M. Kasai, M. Morimoto, S. Ohkubo, K. Mineura, S. Ishii, J. Antibiot. 1980, 33, 668-670; b) F. Tomita, T. Tamaoki, J. Antibiot. 1980, 33, 940945.

${ }^{144}$ A. Kawashima, Y. Nakamura, Y. Ohta, T. Akama, V. Yamagishi, K. Hanada, J. Antibiot. 1992, 44, 207-212.

145 V. A. Bykov, G. G. Zapesochnaya, V. A. Kurkin, Khim. Farm. Zhurn. 1999, 33, 28-39; Pharm. Chem. J. 1999, 33, 29-40.

146 T. Takeuchi, M. Hamada, H. Naganawa, Y. Takahashi, S. Ryuichi, Tetromycin C1, C2, C3, C4 and C5, their manufacture with Streptomyces species, and their use as bactericides, in Japan Patent, Application: JP96-216484 19960816, Jpn. Kokai Tokkyo Koho, 1998.

147 A. Hornung, M. Bertazzo, A. Dziarnowski, K. Schneider, K. Welzel, S.-E. Wolert, M. Holzenkämpfer, G. J. Nicholson, A. Bechthold, R. D. Süssmuth, A. Vente, S. Pelzer, ChemBioChem 2007, 8, 757-766.

${ }^{148}$ G. W. Gribble, J. Chem. Educ. 2004, 81, 1441-1449.

149 a) M. Sancelme, S. Fabre, M. Prudhomme, J. Antibiot. 1994, 47, 792-798; b) L. Sun, A. C. Lindbeck, A. M. Nilius, T. B. Towne, C. C. Zhou, T. J. Paulus, J. Antibiot. 2004, 57, 691694.

${ }^{150}$ M. H. McCormick, W. M. Stark, G. E. Pittenger, R. C. Pittenger, J. M. McGuire, Antibiot. Аппи. 1955-56, 606-611.

${ }^{151}$ Glycopeptide Antibiotics (Hrsg.: R. Nagarajan), M. Dekker, New York, 1994. 
152 a) D. H. Williams, B. Bardsley, Angew. Chem. 1999, 111, 1264-1286, Angew. Chem. Int. Ed. 1999, 38, 1172-1193; b) B. K. Hubbard, C. T. Walsh, Angew. Chem. 2003, 115, 752-789; Angew. Chem. Int. Ed. 2003, 42, 730-765.

153 a) J. Recktenwald, R. Shawky, O. Puk, F. Pfennig, U. Keller, W. Wohlleben, S. Pelzer, Microbiol. 2002, 148, 1105-1118; b) E. M. Nolan, C. T. Walsh, ChemBioChem 2009, 10, 34 53.

154 a) D. Bischoff, B. Bister, M. Bertazzo, V. Pfeifer, E. Stegmann, G. L. Nicholson, S. Keller, S. Pelzer, W. Wohlleben, R. D. Süssmuth, ChemBioChem, 2005, 6, 267-272; b) E. Stegmann, S. Pelzer, D. Bischoff, O. Puk, S. Stockert, D. Butz, K. Zerbe, J. Robinson, R. D. Süssmuth, W. Wohlleben, J. Biotechnol. 2006, 124, 640-653.

155 A. N. Holding, J. B. Spencer, ChemBioChem 2008, 9, 2209-2214.

156 S. Pelzer, R. D. Süssmuth, D. Heckmann, J. Recktenwald, P. Huber, G. Jung, W. Wohlleben, Antimicrob. Agents. Chemother. 1999, 43, 1565-1573.

${ }^{157}$ S. J. Hammond, M. P. Williamson, D. H. Williams, L. D. Boeck, G. G. Marconi, J. Chem. Soc. Chem. Commun. 1982, 344-346.

158 a) V. Pfeifer, G. J. Nicholson, J. Ries, J. Recktenwald, A. B. Schefer, R. M. Shawky, J. Schrüder, W. Wohlleben, S. Pelzer, J. Biol. Chem. 2001, 276, 38370-38377; b) H. Chen, C. C. Tseng, B. K. Hubbard, C. T. Walsh, Proc. Natl. Acad. Sci. USA 2001, 98 14901-14906. 159 a) L. D. Boeck, F. P. Mertz, J. Antibiot. 1986, 39, 1533-1540; b) M. J. Zmijewski, B. Briggs, R. Logan, L. D. Boeck, Antimicrob. Agents. Chemother. 1987, 31, 1497-1501; c) S. D. Lamb, T. Patel, K. P. Koteva, G. D. Wright, Chemistry \& Biology 2006, 13, 171-181. ${ }^{160}$ N. J. Skelton, D. H. Williams, M. J. Rance, J. C. Ruddock, J. Am. Chem. Soc. 1991, 113, 3757-3765.

${ }^{161}$ N. J. Skelton, D. H. Williams, J. Org. Chem. 1990, 55, 3718-3723.

${ }^{162}$ K. C. Nicolaou, C. N. C. Boddy, S. Bräse, N. Winssinger, Angew. Chem. 1999, 111, 22312287, Angew. Chem. Int. Ed. 1999, 38, 2096-2152.

${ }^{163}$ L. Vértesy, H.-W. Fehlhaber, H. Kogler, M. Limbert, J. Antibiot. 1996, 49, 115-118.

${ }^{164}$ M. Westermann, Staatsexamensarbeit, 2007, Universität Göttingen.

165 J. Diana, D. Visky, J. Hoogmartens, A. V. Schepdael, E. Adams, Rapid Commun. Mass. Spectrom. 2006, 20, 685-693.

166 Wir danken Herrn Dr. D. Wunderlich und Herrn Dr. J. Fuchser für die Durchführung dieser Experimente. 
${ }^{167}$ H.-M. Jung, S.-Y. Kim, H.-J. Moon, D.-K. Oh, J.-K- Lee, Appl.Microbiol. Biotechnol. 2007, 77, 789-795.

${ }^{168}$ B, Geers, Dissertation, 1998, Universität Göttingen.

169 a) O. Isler, G. Brubacher, S. Ghisla, B. Kräutler, Vitamine II, Georg Thieme Verlag, Stuttgart, New York, 1988; b) R. Banerjee, Chem. Biol. 1997, 4, 175-186.

${ }^{170}$ G. Chen, G. Y. Wang, X. Li, B. Waters, J. Davies, J. Antibiot. 2000, 53, 1145-1153.

${ }^{171}$ Wir danken dem Arbeitskreis Prof. G. Sheldrick und A. Thorn für die Bemühungen zur Kristallstrukturanalyse.

${ }^{172}$ S. Bergmann, J. Schümann, K. Scherlach, C. Lange, A. A. Brakhage, C. Hertweck, Nat. Chem. Biol. 2007, 3, 213-217.

${ }^{173}$ D. M. Kuhn, M. A. Ghannoum, Clin. Microbiol. Rev. 2003, 16, 144-172.

174 J. Bünger, G. Westphal, A. Mönnich, B. Hinnendahl, E. Hallier, M. Müller, Toxicology 2004, 202, 199-211.

175 a) N. Kawahara, K. Nozawa, S. Nakajima, K.-I. Kawai, J. Chem. Soc. Perkin Trans I 1988, 907-911; b) G. Bringmann, G. Lang, S. Steffens, E. Günther, K. Schaumann, Phytochemistry 2003, 63, 437-443.

${ }^{176}$ K. K. Chexal, J. S. E. Holker, T. J. Simpson, K. Young, J. Chem. Soc. Perkin Trans I 1975, 543-548.

177 a) M. Ispida, T. Hamasaki, Y. Hatsuda, Agr. Biol. Chem 1975, 39, 2181-2184; b) K. Tatsuta, T. Yamaguchi, Tetrahedron Lett. 2005, 46, 5017-5020.

${ }^{178}$ P. S. Steyn, Pure \& Appl. Chem. 1979, 52, 189-204.

${ }^{179}$ C. M. H. Watanabe, C. A. Townsend, J. Am. Chem. Soc. 1998, 120, 6231-6239.

${ }^{180}$ B. F. Nesbitt, J. O’Kelly, K. Sargeant, A. Sheridan, Nature, 1962, 195, 1062-1063.

${ }^{181}$ Mündliche Mitteilung, Claudia Handrich (AK Müller, Arbeitsmedizin Göttingen).

${ }^{182}$ H. B. Bode, B. Bethe, R. Höfs, A. Zeeck, ChemBioChem 2002, 3, 619-627.

183 Merck, Anfärbereagenzien für Dünnschicht- und Papierchromatographie, E. Merck, Darmstadt, 1998.

${ }^{184}$ W. C. Still, M. Kahn, A. Mitra, J. Org. Chem. 1978, 43, 2923-2925.

185 a) D. D. Perrin, W. L. F. Armarego, Purification of Laboratory Chemicals, Pergamon Press, New York 1987; b) Organikum, 16. Aufl., VEB Dt. Verlag der Wissenschaften, Berlin 1986; c) L. F. Tietze, T. Eicher, Reaktionen und Synthesen, 2. Aufl., Thieme Verlag, Stuttgart, 1992.

${ }^{186}$ C. B. Ziegler, R. F. Heck, J. Org. Chem. 1978, 43, 2941-2946. 
${ }^{187}$ H. Quast, M. Heuschmann, M. O. Abdel-Rahman, Liebigs Ann. Chem. 1981, 943-966.

${ }^{188}$ Schlegel, H. G. Allgemeine Mikrobiologie; Georg Thieme Verlag: Stuttgart, 1992.

${ }^{189}$ I. Scott, C. A. Townsend, K. Okada, M. Kajiwara, R. J. Cushley, P. J. Whitman, J. Am. Chem. Soc. 1974, 96, 8069-8080.

${ }^{190}$ G. L. Peterson, Anal. Biochem. 1977, 83, 346-356.

${ }^{191}$ Schriftliche Mitteilung, Claudia Anetzberger (Kooperationspartner Jung, München).

${ }^{192}$ M. F. Semmelhack, S. R. Campagna, C. Hwa, M. J. Federle, B. L. Bassler, Org. Lett. 2004, 6, 2635-2637.

${ }^{193}$ Schriftliche Mitteilung, Nancy Weiland (Kooperationspartner Schmitz-Streit, Kiel).

194 Mündliche Mitteilung, Claudia Handrich (AK Müller, Arbeits- und Sozialmedizin, Göttingen). 


\section{Veröffentlichungen und Posterpräsentationen}

\subsection{Publikationen}

M. Quitschau, T. Schuhmann, J. Piel*, S. Grond* (2009). Tunicate-associated Streptomyces sp. JP90: A Source of Structural and Biogenetic Diversity (in preparation with cooperation partner).

C. Schipper, C. Hornung, P. Bijtenhoorn, N. Weiland, M. Quitschau, S. Grond, W. R. Streit* (2009). BpiB05, a novel $\mathrm{Ca}^{2+}$-dependent and metagenome-derived $N$-acylhomoserine lactone ( $N$-AHL) lactonase (in revision).

C. Schipper, C. Hornung, P. Bijtenhoorn, M. Quitschau, S. Grond, W. R. Streit* (2009). Metagenome-derived clones encoding for two novel lactonase family proteins involved in biofilm inhibition in P. aeruginosa, Appl. Environ. Microbiol. 2009, 75, 224-233.

M. Quitschau, T. Schuhmann, J. Piel, P. v. Zezschwitz*, S. Grond* (2008). The New Metabolite (S)-Cinnamoylphosphoramide from Streptomyces sp. and its Total Synthesis. Eur. J. Org. Chem., 5117-5124.

\subsection{Posterpräsentationen}

M. Quitschau, T. Schuhmann, J. Piel, P. von Zezschwitz, , S. Grond (2008). Poster: Associated Bacteria from Aplidium lenticulum: The Talented Producer Strain Streptomyces sp. JP90; European Bioperspectives Hannover, Dechema e.V. (07.-09.10.2008).

M. Quitschau, T. Schuhmann, J. Piel , P. von Zezschwitz, S. Grond (2008). Poster: Endosymbionten aus Aplidium lenticulum: Der begabte Produzent Streptomyces sp. JP90; 20. Irseer Naturstofftage der Dechema e.V. (20.-22.2.2008).

M. Quitschau, S. Grond (2007). Poster: Novel anti-biofilm strategies from metagenomes: Synthesis and chemical analysis of novel biofilm inhibitors; Tagung, Prokagen 2007, Göttingen.

M. Quitschau, T. Schuhmann, J. Piel, P. von Zezschwitz, S. Grond (2007). Poster: Characterization and Total Synthesis and Derivatization of Cinnamoylphosphoramide, an Unusual Metabolite from Streptomyces sp.; 1. Fakultätstag der Chemie 2007

M. Quitschau, T. Schuhmann, J. Piel, P. von Zezschwitz, S. Grond (2006). Poster: Characterization and Total Synthesis of Cinnamoylphosphoramide, an Unusual Metabolite from Streptomyces sp.; $1^{\text {st }}$ European Chemistry Congress, Budapest 2006. 



\section{DANKSAGUNG}

An dieser Stelle möchte ich zunächst allen Mitarbeitern des Instituts danken ohne deren Mitwirken diese Arbeit nicht möglich gewesen wäre. Ich danke ganz herzlich unserem NMRTeam, Herrn Dipl.-Chem. Machinek, Herrn Martin Weitemeyer, Herrn Ullrich Leohnhardt, Frau Carola Zolke und Frau Christiane Siebert, nicht nur für das Messen vieler NMRSpektren, sondern insbesondere für die Einarbeitung zum Grondschen NMR-Operator, für die vielen Tipps, jegliche Hilfe beim Ausschreiben der NMR-Daten und natürlich für die vielen netten Gespräche!

In der Massenspektrometrie möchte ich mich bei Herrn Dr. Holm Frauendorf, Frau György Udvarnoki, Frau Gabriele Krökel sowie Herrn Frank Hambloch für die Aufnahme der Massenspektren und die Hilfe bei jeglichen Problemen und Fragestellungen rund um die Massenspektrometrie bedanken. Des Weiteren danke ich Herrn Olaf Senge für die analytischen Messungen des Rosiridols an chiraler stationärer Phase.

Den Hausmeistern Wolfram Matthies und Frank Peters danke ich für ihre schnelle Hilfe bei Problemen jeder Art und das Überbringen von Probenzusendungen. Holger Tucholla und Rupert Schrommeck, den Herren der Chemikalienver- und entsorgung möchte ich hierfür danken sowie für die Versorgung der vielen Probenzusendungen. Und natürlich danke ich auch den Werkstätten des Hauses für ihre Arbeiten.

Unserer Institutsverwaltung, Frau Dr. Corinna Meyer, Frau Karin Peinemann und Frau Erika Schmalstieg danke ich für das Verrichten aller bürokratischen Arbeiten und die nette Hilfsbereitschaft.

Ein weiterer besonderer Dank gilt Herrn Hans-Jörg Langer, der mich insbesondere in der letzten Laborzeit auf der Suche nach dem „rosa Spot“ tatkräftig unterstützt hat, viele IR- und UV-Spektren aufgenommen sowie Drehwerte bestimmt hat und mir immer hilfsbereit mit Rat und Tat zur Seite stand. Vielen Dank auch für die vielen netten Unterhaltungen!

Für die $\mathrm{N}_{2}$-Einlagerungen zur Stammhaltung bedanke ich mich bei Frau Michaela Klingebiel und Frau Verena Brandenburg, der ich auch für die Aufnahme von CD-Spektren danken möchte. Ebenso danke ich Herrn Hans-Peter Kroll für all seine Hilfe und Tipps! Euch drei an dieser Stelle ein herzlicher Dank für die Hilfsbereitschaft, die Kaffeepausen und die Mittagessen bis zum Ende meiner Unizeit!

Frau Jutta Gerber-Nolte danke ich für das Herstellen unzähliger Testplatten und ihre Bereitschaft hierzu bis zum Umzug der Abteilung Grond nach Tübingen. 
Dr. Inken Plitzko und Dr. Sandra Lösgen danke ich für die finale Einarbeitung zum NMROperator und für das Messen meiner Spektren am Wochenende vor meiner Zeit als solcher.

Ein herzliches Dankeschön an Dr. Nadine Czempinski und Dr. Daniel Vollmar für die unzähligen LC-MS-Messungen inklusive vieler Auswertungen sowie Eure Hilfe beim Selbstauswerten. An dieser Stelle auch ein Dankeschön an Dr. Adriana Textor, nun Irmer, für die vielen hilfreichen Tipps bei der Datenbearbeitung.

Ein dickes Dankeschön an alle Computeradministratoren für ihre stete Hilfsbereitschaft und Unterstützung bei allen Problemen und Fragen rund um Computer und Drucker: Dr. Marko Gentzsch, Dr. Philip Kössler, Dr. Daniel Vollmar, Torben Hofeditz und Jan-Niklas Fricke.

Dr. Nadine Czempinski, Dr. Adriana Irmer, Dr. Christian Raith, Torben Hofeditz und JanNiklas Fricke danke ich ganz herzlich für das schnelle und kurzfristige Korrekturlesen meiner Arbeit - vielen Dank - ohne Euch wäre die Arbeit nicht so wie sie ist!

Dem Arbeitskreis v. Zezschwitz danke ich für das nette Arbeitsklima und die Hilfsbereitschaft während meiner synthetischen Arbeiten zum Cinnamoylphosphoramid.

Allen Mitgliedern der Arbeitsgruppe Grond/Zeeck sowie Bioviotica ein besonders großes Dankeschön für die Hilfsbereitschaft, das nette Arbeitsklima - insbesondere in Z6, die schönen Stunden im Kaffeeraum und die vielen Mittage in der Mensa - es war eine schöne und unvergessliche Zeit!

Vielen Dank natürlich auch an Frau Gisela Gastrock und Frau Marianne Wagener für ihre Unterstützung im „Hintergrund“, die schöne Zusammenarbeit bei den Medizinern und die vielen Pläuschchen!

Zum Schluss möchte ich mich bei meiner Familie von Herzen bedanken, die mich in jeder Hinsicht unterstützt hat und an mich glaubt. Mein ganz besonderer Dank gilt allerdings meinem Christian für seinen Rückhalt und für seine Liebe.

Vielen Dank.

Meine akademischen Lehrer waren u.a. die folgenden Professoren und Dozenten:

G. Beuermann, P. Botschwina, J. Brockmöller, A. de Meijere, U. Diederichsen, W. Hack, W. Felsch, L. Fitjer, S. Grond, U. Klingebiel, H. Laatsch, J. Magull, F. Meyer, H. W. Roesky, J. Schroeder, G. M. Sheldrick, M. Suhm, L. F. Tietze, J. Troe, S. Tsogoeva, A. Zeeck, und P. v. Zezschwitz. 



\section{E Curriculum VitaE}

\section{Persönliche Daten}

Name:

Geburtsdatum:

Geburtsort:

Familienstand:

Nationalität:

\section{Schulausbildung}

1986 - 1990

1990 - 1999

06. 1999

\section{Studium}

seit 04. 2001

10. 2003

06. $2005-02.2006$

05. 2006

seit 11.2006
Melanie Quitschau

12. September 1979

Bad Segeberg

ledig

deutsch

Grundschule Warderfelde

Städtisches Gymnasium, Bad Segeberg

Allgemeine Hochschulreife

Studium der Chemie an der Georg-August-Universität, Göttingen

Diplomvorprüfung

Diplomarbeit am Institut für Organische und Biomolekulare

Chemie, Göttingen unter der Leitung von

Prof. Dr. A. de Meijere und Prof. Dr. A. Zeeck

"Das Cinnamoylphosphoramid aus Actinomyces sp. JP90:

Totalsynthese und Biotransformationsexperimente"

Diplom

Dissertation am Institut für Organische und Biomolekulare Chemie, Göttingen unter der Leitung von Prof. Dr. A. Zeeck und Prof. Dr. S. Grond

„Neue Biofilminhibitoren mittels Metagenom-Strategie und marine Streptomyceten, neue Naturstoffe, Synthesen und Biosynthesen "

23.10.2009

Disputation

Göttingen, den 22. September 2009 